\title{
The Mixtec Pictorial Manuscripts
}




\title{
The Early Americas: History and Culture
}

\author{
General Editor \\ Alexander Geurds, Leiden University
}

\author{
Editorial Board \\ Nikolai Grube, Bonn University \\ John Hoopes, University of Kansas \\ Maarten Jansen, Leiden University \\ Arthur Joyce, University of Colorado \\ Michael Smith, Arizona State University \\ Eric Taladoire, Sorbonne \\ Laura Van Broekhoven, National Museum of Ethnology, Leiden
}

VOLUME 1 


\title{
The Mixtec Pictorial Manuscripts
}

Time, Agency and Memory in Ancient Mexico

\author{
By \\ Maarten E.R.G.N. Jansen \\ Gabina Aurora Pérez Jiménez
}

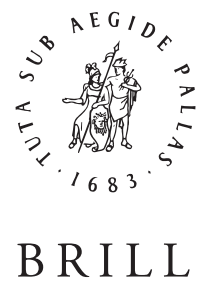

LEIDEN • BOSTON

2011 

are credited.

On the cover: Monument to ancient Mixtec rulers in Yanhuitlan (Oaxaca, Mexico), inspired by a scene in Codex Añute.

This book is printed on acid-free paper.

Library of Congress Cataloging-in-Publication Data

Jansen, Maarten E. R. G. N. (Maarten Evert Reinoud Gerard Nicolaas), 1952-

The Mixtec pictorial manuscripts : time, agency, and memory in ancient Mexico /

by Maarten E.R.G.N. Jansen and Gabina Aurora Perez Jimenez.

p. cm. - (The early Americas : history and culture, ISSN 1875-3264 ; v. 1)

Includes bibliographical references and index.

ISBN 978-90-04-18752-8 (hardback : alk. paper)

1. Manuscripts, Mixtec. 2. Picture-writing-Mexico. 3. Mixtec language-Writing.

4. Mixtec Indians-History. 5. Mexico-History-To 1519. I. Pérez Jiménez,

Gabina Aurora. II. Title. III. Series.

F1219.54.M59J37 2010

$972.7401-\mathrm{dc} 22$

2010030391

ISSN $1875-3264$

ISBN 9789004187528

Copyright 2011 by Koninklijke Brill NV, Leiden, The Netherlands.

Koninklijke Brill NV incorporates the imprints Brill, Hotei Publishing,

IDC Publishers, Martinus Nijhoff Publishers and VSP.

All rights reserved. No part of this publication may be reproduced, translated, stored in a retrieval system, or transmitted in any form or by any means, electronic, mechanical, photocopying, recording or otherwise, without prior written permission from the publisher.

Authorization to photocopy items for internal or personal use is granted by Koninklijke Brill NV provided that the appropriate fees are paid directly to The Copyright Clearance Center, 222 Rosewood Drive, Suite 910, Danvers, MA 01923, USA.

Fees are subject to change. 
To the memory of Luis Reyes García, tlacuilo, tlamatini 
Maarten Jansen and Gabina Aurora Pérez Jiménez - 978-90-04-19358-1 Downloaded from Brill.com@4/26/2023 11:36:13AM 


\section{CONTENTS}

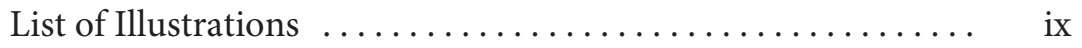

Preface $\ldots \ldots \ldots \ldots \ldots \ldots \ldots \ldots \ldots \ldots \ldots \ldots \ldots \ldots \ldots \ldots \ldots \ldots \ldots$

\section{PART ONE}

NEE NUUHU SANAHA: THE ANCIENT BOOKS

I. Introduction to Mixtec Pictography $\ldots \ldots \ldots \ldots \ldots \ldots$

II. Treasures from Ancient Libraries . . . . . . . . . . . . 42

III. Rediscovery and Decipherment $\ldots \ldots \ldots \ldots \ldots \ldots . \ldots 9$

IV. Contemporary Studies and Discussions . . . . . . . 127

PART TWO

TNUNI TANIÑO: SIGNS AND SYMBOLS

V. Post Colonial Hermeneutics ................. 181

VI. Acts and Visions ................... 217

VII. Memory Landscape $\ldots \ldots \ldots \ldots \ldots \ldots \ldots \ldots \ldots \ldots 271$

\section{PART THREE}

YAA TNUHU: DYNASTIC HISTORY

VIII. Foundation Narratives $\ldots \ldots \ldots \ldots \ldots \ldots \ldots \ldots$

IX. The Noble Houses . . . . . . . . . . . . . . . . . . . . 407

X. Colonial Transformation .................. 462 
viii

CONTENTS

CONCLUSION

NUU TAYU: THE SOVEREIGN COMMUNITY

XI. Political and Ideological Dynamics $\ldots \ldots \ldots \ldots \ldots \ldots . . \ldots 03$

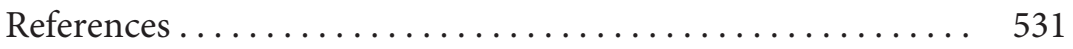

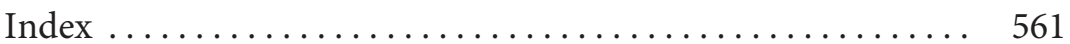




\section{LIST OF ILLUSTRATIONS}

1.1. Late Preclassic-Early Classic calendar sign on carved stone found in the Agencia Guadalupe Victoria, San Miguel el Grande,

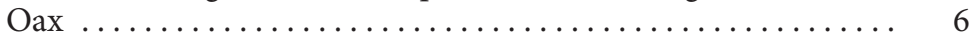

1.2. Map of the Mixtec region $\ldots \ldots \ldots \ldots \ldots \ldots \ldots \ldots \ldots$

1.3. The ruined Dominican convent at San Miguel Achiutla ...... 9

1.4. Yuq yuq or Boustrophedon patterns ................. 13

1.5. The early colonial palace (Casa de la Cacica) in Yucu Ndaa

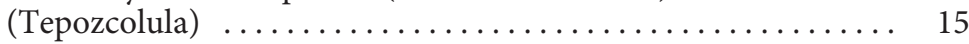

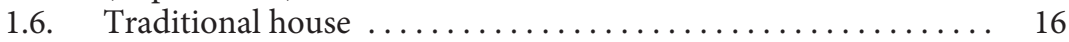

1.7. Codex Mendoza, p. 43: places from the Mixteca Alta and their tributes ............................... 19

1.8. Codex Yuta Tnoho, pp. 11-12: siqui or 'wards' .......... 21

1.9. Codex Yuta Tnoho, p. 45-IV: Ñuu Dzaui ............... 22

1.10. The twenty day signs of the Mexica and Nuu Dzaui calendar . . 23

1.11. The Mixtec year sign (cuiya) with the four 'Year-bearers' ..... 28

1.12. Day of the Dead: sharing a meal in the cemetery ........... 29

1.13. The mayordomo carrying his chest ............... 30

1.14. Cutting the fire wood for the fiesta ............... 30

1.15. Codex Añute, p. 8-IV: Lord 4 Wind 'Fire Serpent' (Yahui) and Lady 10 Flower 'Spiderweb of Rain' (Dzinduhua Dzavui) are seated on the marriage mat, and rule the Town of Flints (Nuu

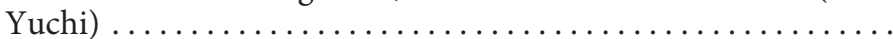

1.16. Codex Tonindeye, p. 26-III (Top to Bottom): in the year 13 Reed [AD 1103], on the day 13 Serpent, Lord 8 Deer 'Jaguar Claw' marries Lady 13 Serpent [here erroneously written as 12 Serpent]. In the year 7 Rabbit [AD 1110] their first son, Lord 4 Dog 'Coyote Catcher' is born. In the year 9 Flint [AD 1112] Lord 4 Alligator 'Sacred Serpent' is born ............... 33

1.17. Examples of the quechquemitl (dzico) in Codex Yuta Tnoho . . 35

1.18. Priests holding xicolli tunics (dzico) in Codex Tonindeye ..... 36

1.19. Codex Tonindeye, p. 50: a priest dressed as 'Fire Serpent'

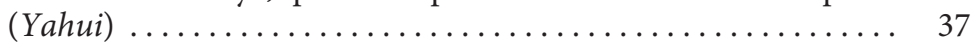

1.20. Codex Tonindeye, p. 32-II: Lord 2 Water and his 'burning foot' 39

2.1a. Map of Chiyo Cahnu (Teozacualco), left half ............ 44

2.1b. Map of Chiyo Cahnu (Teozacualco), right half .......... 45

2.2a: Codex Yecu showing the four directions: North and West (left

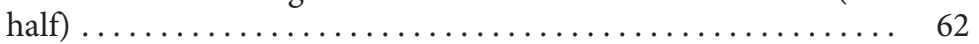

2.2b. Codex Yecu showing the four directions: East and South (right

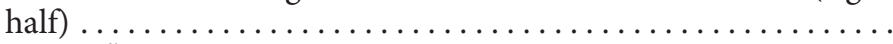

2.3. Codex Nuu Tnoo-Ndisi Nuu, p. 20-II: Lord 8 Grass (Malinaltzin) 'Rain Sun' and his wife Lady 9 Deer 'Flower Ornament', rulers of

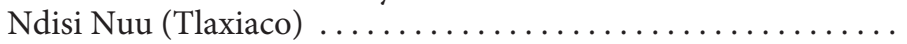

2

(1)

(1)

30

37
39
44
45
62


2.4. Codex Tonindeye, p. 33: Lord 5 Flower of the Xipe Dynasty marries Lady 4 Rabbit 'Quetzal' (from Chiyo Cahnu) ........

2.5. Lord 8 Deer (left) and Lady 6 Monkey (right) in Codex Ñu Tnoo-Ndisi Nuu and Codex Añute, respectively .......... 75

2.6. Codex Iya Nacuaa II (Becker I), p. 8-I: funerary orchestra . . . . 75

2.7. Final pages of the Codex Añute (or Codex Selden) ......... 81

2.8. Coat of Arms of Saha Yucu (Cuilapan), copy preserved in the collection of unpublished works of Manuel Martínez Gracida

2.9. Codex Iya Cochi (Becker II), p. 3 (Left to Right): intermarriages between the local ruling lineage and the dynasties of other towns. Lord 5 Rain 'Coyote Sun' marries Lady? Monkey 'Jewel Arrow’ from Black Frieze, i.e. Ñuu Tnoo (Tilantongo). Their first daughter marries the ruler of Town of the Warband (possibly Nuu Yecu, Yauhtepec in the State of Guerrero), while the second marries Lord 3 Monkey, the ruler of Plain of the Eagle, i.e. Yodzo Yaha (Tecomaxtlahuaca). Their son, Lord 11 Flint 'Eagle of Precious Feathers', inherits the kingdom and marries Lady 13 Reed 'Garland of Flowers' from Altar of the Rosette. Their daughter, Lady 7 House, marries Lord 2 Rabbit, ruler of 'Plain of the Year Sign, i.e. Yodzo Cuiya (Juxtlahuaca) .......

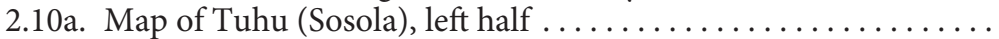

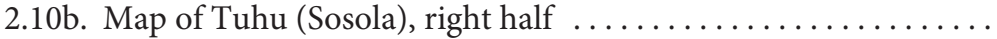

3.1. Anders' comparison of spirit figures with roots in the Codex Yuta Tnoho to the contemporary papercuttings from San Pablito ...

4.1. Kaua Kandiui, the Mountain of Heaven, East of Yutsa Tohon

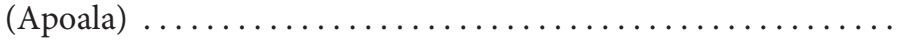

4.2. Codex Yuta Tnoho, p. 35 (Lower Right to Lower Left, boustrophedon): Invocation of the Nuhu. The elderly couple Lord 1 Flower and Lady 13 Flower have a daughter, Lady 9 Alligator. The father speaks to Lord 9 Wind, who acts as a 'marriage ambassador' and visits Lord 5 Rain in the Place of Heaven. As a consequence of his mediation, Lord 5 Rain weds Lady 9 Alligator in River of the Hand Holding Feathers, i.e. Yuta Tnoho (Apoala)

4.3. Carved stone, representing a Nuhu, set in the wall of the church of San Martín Huamelulpan .................... 131

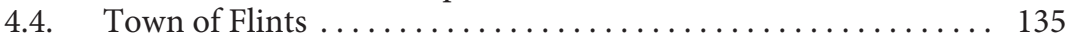

4.5. Codex Añute, p. 8-IV: the birth of Lord 4 Wind 'Fire Serpent' in year 2 Flint $[$ AD 1092] . . . . . . . . . . . . . . . . 136

4.6. Codex Nuu Tnoo-Ndisi Nuu, p. 7-III: Lord 5 Alligator 'Rain Sun' .................................. 137

4.7. The Council of Four Priests in Nuu Tnoo (Tilantongo) . . . . . . 139

4.8. Codex Añute, p. 7-III : Two priests ('Long Hairs') of Tocuisi (Zaachila) shout 'knife, knife' (yuchi yuchi) to Lady 6 Monkey, who is carried by two officials in the marriage procession ...... 144

4.9. Stone of Red and White Bundle (left) and Town of Red and White Bundle (right) ........................ 155 


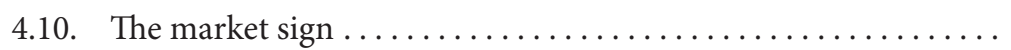

4.11. Codex Yuta Tnoho, p. 24 (Lower Right to Lower Left, boustrophedon). Conversations of the Nuhu in Yuta Tnoho (Apoala), conversations of Lord 9 Wind and Lord 2 Dog. Lord 9 Wind brings the Mushroom Ladies 4 Lizard and 11 Lizard. Rituals for the Dead, for Rain and Maize. Visionary ritual: Lord 9 Wind sings and produces funerary music with bones and skull. Eight Primordial Lords and Ladies consume pairs of (hallucinogenic) mushrooms. Their vision deals with the cradle and the town (the foundation of settlements), the mat and the throne (the city-states). After that, a priest enters the river or a cave in Yuta Tnoho (Apoala), to which the 'market' sign is added. Two Primordial Lords participate in the same ritual and receive the branch that the priest brought back from his visionary voyage..

6.1. Codex Nuu Tnoo-Ndisi Nuu, p. 6-I: The ruler of Place of the River at the Foot of Curved Jaguar Mountain and Black Mountain (possibly Ayuta near Tilantongo), Lord 13 Dog 'White Eagle', marries Lady 1 Vulture 'Rain Skirt' (Huatu Dzavui, 'Glory of the Rain God'). They have a son: Lord 5 Alligator 'Rain Sun' ......

6.2. Codex Tonindeye, p. 5: the marriage of Lord 8 Wind 'Eagle' (elsewhere: 'Twenty Eagles') and Lady 10 Deer 'Jaguar Quechquemitl' (Dzico Naña, i.e. 'Virtue or Power of a jaguar'). In the year 2 Rabbit their son Lord 13 Grass is born .................

6.3. Tira of Yodzo Yaha: the first ruling couple arranging the tribute

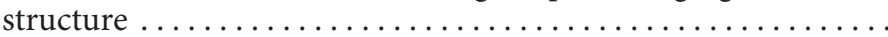

6.4a. Gestures: (a) one arm across chest $=$ acting with respect, (b) both arms across chest = showing respect and obedience, (c) finger downward = ordering, (d) finger upward = telling what to do, (e) pointing finger and stretched-out hand = to order and accept, (f) two fingers upward = alliance, $(\mathrm{g})$ two fingers forward = ordering to marry or to make an alliance, (h) open hands up and down = venerating, (i) hand against forehead = lamenting

6.4b. Acts of war: (j) Lady 9 Grass standing with spear and shield on the war band (yecu) in Place of Death and of the Deer Hoof = being a brave and successful warrior, $(\mathrm{k})$ an arrow perforating a place sign $=$ conquest, $(\mathrm{l})$ grabbing a person by the hair and wounding him $=$ winning the war and making a captive $\ldots . .$.

6.5. Codex Tonindeye, p.16-I (Top to Bottom): Preparation of the sweatbath by two priests. In the year 3 Flint Lady 3 Flint 'Shell Quechquemitl - Plumed Serpent' (i.e. 'Strength and Virtue of the Plumed Serpent'), gives birth to a daughter, Lady 3 Flint 'Jade Quechquemitl' (i.e. 'Beauty of Jade'). Afterward the mother enters a cave and transforms into a river $\ldots \ldots \ldots \ldots \ldots \ldots$

6.6. Traditional kitchen, San Pablo Tijaltepec ..............

6.7. Codex Tonindeye, p. 25-III: the death priest Lord 5 Alligator draws blood from his ear with a bone perforator and offers it to the Sacred Bundle in the Temple of Heaven .............. 
6.8. Codex Ñuu Tnoo-Ndisi nuu, p. 7-II (Right to Left): Lord 5 Alligator passing through successive ranks of priesthood ..... 251

6.9. A large boulder in Yutsa Tohon (Apoala) is a manifestation of the Nuhu, 'Divine Owner of the Land' ............... 253

6.10. Codex Añute, p. 1-I: Deities Lord 1 Death (Sun) and Lord 1 Movement (Venus) ........................ 258

6.11. Codex Yuta Tnoho, p. 48: Lord 9 Wind 'Quetzalcoatl', the Whirlwind, coming down from the Place of Heaven ........ 259

6.12. Codex Yuta Tnoho, p. 25: Lord 7 Rain, drinking pulque ... . . . 260

6.13. Codex Yuta Tnoho, p. 5: Deities Lord 7 Serpent and Lord 4 Serpent, presiding over the ritual foundation of towns ...... 262

6.14. Codex Tonindeye, p. 51: Deity Lady 9 Reed 'Power and Glory of Knives' (Dzico Yuchi Huatu Yuchi) on the Mountain of Town of Blood, Nuu Niñe (Tonalá) .......................

6.15. Codex Yuta Tnoho, p. 25-III: the Divine Grandmother Lady 1

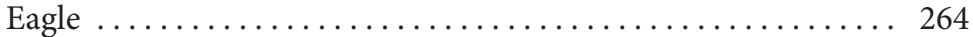

6.16. Codex Añute, p. 6-IV: Lady 9 Grass in the Temple of Death . . . 266

6.17. Sculpture of a Death Deity, set in the wall of the church of San Martin Huamalulpan ............................ 268

7.1. Codex Yuta Tnoho page 47: Lord 9 Wind brings the water of Heaven to the mountain of the People of the Rain, i.e. Nuu Dzaui, and the surrounding landscape (including the two oceans

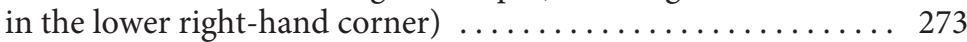

7.2. Codex Yuta Tnoho, p. 50: the Sacred Tree ................ 275

7.3. Codex Tonindeye, p. 1: origin and rituals of Lord 8 Wind .... 278

7.4. Codex Tonindeye, p. 2: enthronement ritual of Lord 8 Wind in the ceremonial center of Yucuñudahui .............. 279

7.5. Codex Tonindeye, p. 15 (Right to Left, boustrophedon): ritual acts performed by Lady 3 Flint and Lord 5 Flower ......... 281

7.6. Codex Yuta Tnoho, p. 42: Nuu Tnoo (Tilantongo) .......... 284

7.7. Codex Tonindeye, p. 22: the ancient landscape of Nuu Tnoo

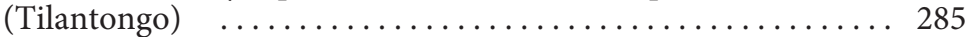

7.8. Codex Nuu Tnoo-Ndisi Nuu, p. 15-III: Chiyo Cahnu (Teozacualco) with the names of its rulers Lord 12 House 'Fire Serpent that flies through Heaven' and Lady 10 [elsewhere: 11] Alligator 'Quetzal Spiderweb.' .......................... 287

7.9. Codex Tonindeye, p. 36: the Valley of Yuta Tnoho (Apoala) . . 290

7.10. The Valley of Yuta Tnoho (Apoala) .................... 290

7.11. The waterfall at the end of the Valley of Yutsa Tohon (Apoala) 291

7.12. Codex Yuta Tnoho, p.1: Añute (Jaltepec) . . . . . . . . . . . . . . . 292

7.13. Codex Añute, p.2-II: In the year 10 Reed (AD 931), on the day 4 Deer, the founders of the Añute dynasty, Lord 2 Grass 'Dead Ancestor Plumed Serpent' and Lady 8 Rabbit 'Sun Head', marry at the Yoco (Spirit) Temple of Altar of the Spiderweb

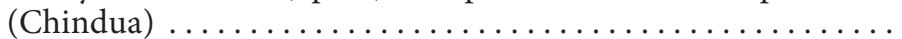

7.14. Codex Yuta Tnoho p. 42 (Lower Right to Lower Left, boustrophedon): list of place names and connected dates ......... 294 
7.15. The carved stone found in Mogote del Cacique (Nuu Yuchi): the year 13 Owl (corresponding to 13 House, likely AD 1129), the day 4 Vulture, ordered and observed the entrance of the yaha yahui priest [likely Lord 4 Wind] in a cave in the Mountain of Flints, where he stayed in a trance for four times twenty days ..

7.16. Lienzo of Tlapiltepec (E 37) Lord 2 Flower visits Town of Flints and converses with its ruler, Lord 4 [Wind] ........... 295

7.17. Codex Yuta Tnoho, p. 43-IV: Cut Town .............. 296

7.18. Codex Tonindeye, p. 23: Cut Mountain with Town, representing Ñuu Nañu (Tamazola), with the founders of its dynasty: Lord 2 Grass and Lady 13 Grass ..................

7.19. Codex Nuu Tnoo-Ndisi Nuu, p.6-V: Chiyo Yuhu with the name of its queen, Lady 10 Deer 'Jaguar Quechquemitl' (Dzico $\tilde{N} a \tilde{n} a)$

7.20. Codex Ñuu Tnoo-Ndisi Nuu, p. 19-III: Lord 8 Death 'Jaguar - Fire Serpent (Yahui Ñaña)' and Lady 1 Flower 'Jaguar Quechquemitl (Dzico Ñaña)', rulers of Yanhuitlan ......... 298

7.21. Genealogy of Tixii: the sign of Tepozcolula (Yucu Ndaa) . . . 300

7.22. Lienzo of Tlapiltepec: the sign of Tepozcolula (Yucu Ndaa) . . 301

7.23a. Codex Nuu Tnoo-Ndisi Nuu, p. 15-V: Temple of the Crossed Beams and Eye (Ndisi Nuu) .................. 303

7.23b. Codex Nuu Tnoo-Ndisi Nuu, p. 15-II: Town of the Crossed Legs, Crossed Beams and Eye (Ndisi Nuu) ............ 303

7.24. Codex Añute, p, 2-I: the landscape of Ñuu Ndecu (Achiutla) 304

7.25. Codex Añute, p. 6-II: Lord 2 Rain 'Twenty Jaguars (Ocoñaña)' consults with the Heart of the Mixtec People in a cave ......

7.26. Codex Yuta Tnoho, p. 49-I: divine founding couple seated at Town of Jade and Turquoise, and other primordial places . . . . 306

7.27. Codex Yuta Tnoho, p. 13. Heaven, representing the East . . . 309

7.28. Codex Yuta Tnoho, p. 21: New Fire ceremony and ceremonial cleansing of the landscape of the North ........... 310

7.29. Codex Yuta Tnoho, p. 16: the Grandmother of the River, Lady

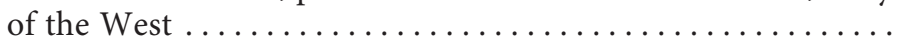

7.30. Codex Yuta Tnoho, p. 15: the Death Temple (Huahi Cahi) in

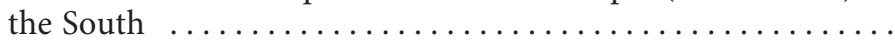

7.31. Codex Yuta Tnoho, p. 14: New Fire ceremony and ritual cleans-

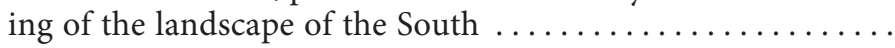

7.32. Codex Añute, p. 7-IV (Right to Left): Lady 6 Monkey consults with Lady 9 Grass, Patron of the Huahi Cahi (Vehe Kihin) and commander of the warriors from Death Town (Nuu Ndaya) and Mountain of the Deer (Cerro de los Cervatillos) ........

7.33. Codex Yuta Tnoho, p. 12: the Maize Ladies in Heart of the Alligator, i.e. the Center . . . . . . . . . . . . . . .

7.34. Codex Nuu Tnoo-Ndisi Nuu, p. 18- I: Lord 4 Flower 'Pheasant' marries Lady 7 Vulture 'Quetzal Fan', daughter of [Lord] 10 Water 'Rain Knife' and [Lady] 11 Lizard 'Butterfly, Fire Serpent', rulers of Ñu Nduchi (Etla) ............. 
7.35. Codex Yuta Tnoho, p. 1: Mountain that is Opened - Insect

7.36. Codex Tonindeye, p. 19: the birth of Lady 1 Death in Place of the Reeds, Mountain of the Insect, Altar of the Rain Vessel ..

7.37. Codex Yuta Tnoho Reverse, p. II-3: Lord 10 Movement visits lady 1 Death, ruler of Mountain that is Opened - Altar -

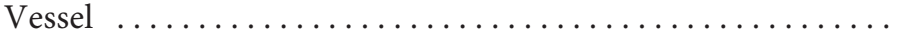

7.38. The 1619 version of the Map of Xoxocotlan, showing the slopes of Monte Albán: second and third from the right are Mountain of the Insect and Mountain of Reeds

[For the color reproduction, see Ruiz Cervantes \& Sánchez Silva

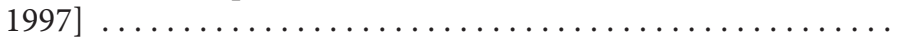

7.39. Codex Tonindeye, p.33: the capital of the 'Xipe Dynasty', i.e. Zaachila, at the foot of the Big Mountain, on the bank of the

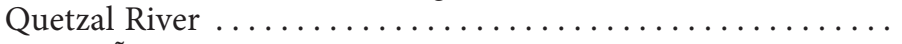

7.40. Codex Nuu Tnoo-Ndisi Nuu, p. 24-III: Plain of the Carrying Frame, Tocuisi (Zaachila) .................... 327

7.41. Codex Yuta Tnoho, p. 44: Places in the Mixteca Baja ...... 328

7.42. Codex Tonindeye, p. 3 (Lower Right to Upper Left, boustrophedon): war against the Stone Men .............. 329

7.43. Codex Yuta Tnoho, p. 4-II: Yucu Yusi (Acatlan) . . . . . . . 330

7.44. Codex Yuta Tnoho, p. 3-II: Nuu Niñe (Tonala) and Ñu Nduyu (Silacayoapan) .................... 332

7.45. Codex Nuu Tnoo-Ndisi Nuu, p.11: Red Sweatbath, likely Ñu Niñe (Tonalá) ........................... 333

7.46. Temazcal (sweatbath) in the Mixteca Alta ............. 333

7.47. Codex Yuta Tnoho, p. 3-II: Ballcourt of Gravel, Yuhua Cuchi

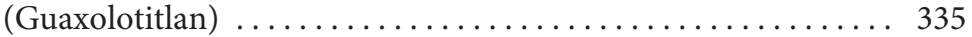

7.48. Codex Yuta Tnoho, p. 3-I: Stone Circle, Ñuu Dzai (Huajuapan) 338

7.49. Codex Yuta Tnoho, p. 43-I: River of the Cradle (dzoco) of the Nuhu, i.e. a Sanctuary, and River of the Seated Lord ....... . 339

7.50. Codex Yuta Tnoho, p. 3-I: Rock of the Eagle, identified as Toavui (Chilac) ........................... 340

7.51. Codex Yuta Tnoho, p. 43-I/II (Lower Right to Lower Left, boustrophedon): the area of Piaztla, Tuzantla, and Tonalá ........ 341

7.52. Lienzo Coixtlahuaca II (Seler II): the kingdom of Serpent Valley, i. e. Coixtlahuaca, including Mountain of Blood .......... 341

7.53. Codex Yuta Tnoho, p. 1-II: the Mountain of Pulque ......... 343

7.54. Lienzo of Otla: the place sign of otlato[n]go, i.e. San Jerónimo

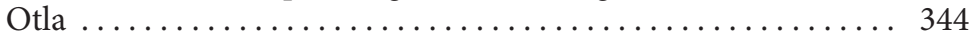

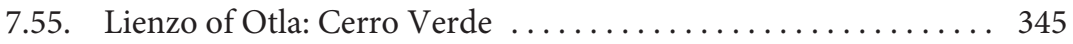

7.56. Lienzo of Yucu Satuta: the central Mountain of 7 Water (Yucu Satuta) guarded by a double-headed eagle ............ 345

7.57. Lienzo of Yucu Satuta: Mountain of the Moon and the FireWood (Nuu Yoo, Yucu Iti) and the Town of Death, i.e. Nuu Ndaya (Chalcatongo) ...................... 346 
7.58. Codex Iya Nacuaa I, p. 5: Yucu Dzaa (Tututepec) and Nuu

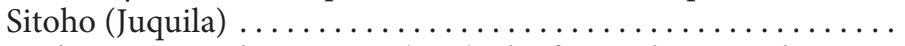

7.59. Codex Yuta Tnoho page 39 (I+II): the four volcanoes, the Cave of Origin and the Place of the Tule Reeds (Cholula) ......... 348

7.60. The Toltec nose-piercing ceremony in Codex Iya Nacuaa (top) and Codex Nuu Tnoo-Ndisi Nuu (bottom) . . . . . . . . . . . . . .

7.61. Lienzo of Tlapiltepec: the final phase of the campaign from the Coixtlahuaca area to the North. From left to right we recognize Tepeji (Split Hill), Cuauhtinchan (House of the Eagle), Tecalli (Wall, i.e. House of Stone), Oztoticpac (Head of the Stone, i.e. Above the Cave), Tepeaca (Mountain of the Face), Ichcaquiztla (Altar of Cotton), Quecholac (Mountain of the River), and Techamachalco (Altar with the Tree and Hut). [after Johnson 1997] ....................................... 351

8.1. Codex Yuta Tnoho, p. 49-IV: the birth of Lord 9 Wind ... . 358

8.2. Codex Yuta Tnoho, p. 48-II: Lord 9 Wind as Giver of divine inspiration and Primordial Instructor in Painting Codices ...

8.3. Codex Yuta Tnoho, p. 48-III: Lord 9 Wind receives instructions from the Ancient Ones in the Place of Heaven and comes down as nahual to the communities (water and mountain) on

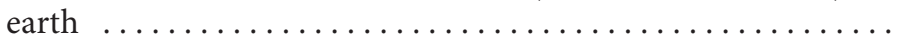

8.4. Codex Yuta Tnoho, p. 37: after a statement referring to the Mixtec world as 'the green and precious valleys', as 'what has Heaven as its roof" and 'what is grounded in earth', Lord 9 Wind is shown speaking to the Spirits (Nuhu) of Rocks and

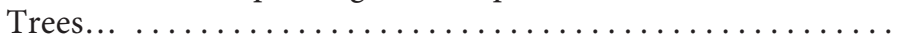

8.5. Codex Yuta Tnoho, p. 36: the Priests / Spirits of the Days 7 Rain and 7 Eagle decorate and open the Mother Tree in the Sacred

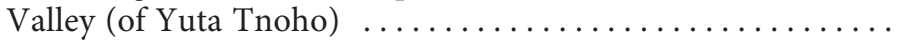

8.6. Codex Añute, p. 2: two ancient priests making offerings to the Mother Tree at the bank of the primordial lake in the Valley

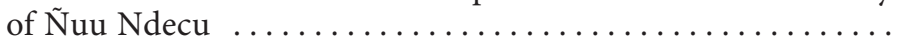

8.7. Codex Yuta Tnoho, p. 23: Lord Sun, the Warrior, rose in a stream of light above the Altar of Songs (the famous place); the sun rose from the darkness above the mountains, the valleys

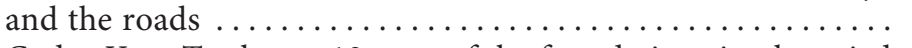

8.8. Codex Yuta Tnoho, p. 13: part of the foundation ritual carried out in the East (Place of Heaven) $\ldots \ldots \ldots \ldots \ldots \ldots \ldots \ldots$

8.9. Codex Yuta Tnoho, p. 22: the foundation ritual carried out in the North ............................ 366

8.10 Scraping the maguey for making pulque, Nuu Ndeya (Chal-

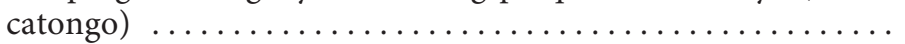

8.11. Codex Yuta Tnoho Reverse, p. I-3: Lord 4 Alligator, from the Region of the Rain (Nuu Dzaui) marries Lady 1 Death ......

8.12. Codex Nuu Tnoo-Ndisi Nuu, p. 1-V: the birth of Lady 1 Death from the Sacred Tree 
8.13. Codex Nuu Tnoo-Ndisi Nuu, p. 4-V: the marriage of Lord 9 Wind 'Stone Skull' and Lady 5 Reed 'Dzico Dzavui.' ..........

8.14. Codex Añute, pp.5-6 (Bottom to Top, boustrophedon): Lady 9 Wind making offerings for the Sacred Bundle in the temple of Añute, i.e. taking possession of the kingdom. Her marriage, three sons and one daughter, Lady 6 Monkey ............

8.15. Codex Nuu Tnoo-Ndisi Nuu, p. 9-V: young Lord 8 Deer finds a

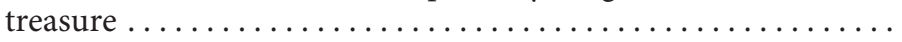

8.16. Codex Tonindeye, p. 44: Lady 6 Monkey and Lord 8 Deer, guided by the nahual priest Lord 3 Lizard, visit the Vehe Kihin

8.17. Codex Añute, p. 8-I/III (Lower Left to Upper Right): Lady 6 Monkey attacks the two priests ('Long Hairs') of Tocuisi (Zaachila) who had shouted 'knife, knife' to her, burns their place of residence (Monte Albán), sacrifices one in Añute and takes the other to the town of her husband to have him executed there. After undergoing a ceremonial cleansing, she marries Lord 11 Wind in Town of the Xipe Bundle ..............

8.18. Codex Nuu Tnoo-Ndisi Nuu, p. 10-III: Lord 8 Deer receives the four Toltec ambassadors sent by Lord 4 Jaguar of Tula-Cholula

8.19. Codex Iya Nacuaa I, p. 14 (Lower Left to Upper Left, boustrophedon): Lord 8 Deer travels in procession toward TulaCholula, passing several sacred mountains, among them a

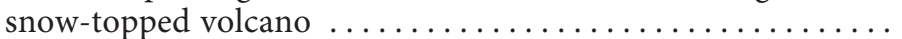

8.20. Codex Iya Nacuaa I, p. 13: Nose piercing in the ceremonial center of Place of the Cattail Reeds (Tula-Cholula), situated in a large valley $\ldots \ldots \ldots \ldots \ldots \ldots \ldots \ldots \ldots \ldots \ldots \ldots \ldots \ldots \ldots \ldots$

8.21. Lienzo of Tlapiltepec: Warrior Lord 4 Jaguar participates in the enthronement of Lord 7 Water (Atonal), founder of the Coixtlahuaca dynasty $\ldots \ldots \ldots \ldots \ldots \ldots \ldots \ldots \ldots \ldots$

8.22. Codex Tonindeye, p. 75: Lord 8 Deer and Lord 4 Jaguar, crossing a tropical lagoon and conquering an island ..........

8.23. Codex Nuu Tnoo-Ndisi Nuu, p. 11-II/III (Upper Right to Lower Left, boustrophedon): Lord 8 Deer and Lady 13 Serpent visit a temple to meet a Vision Serpent. The following year their first son, Lord $4 \mathrm{Dog}$, is born $\ldots \ldots \ldots \ldots \ldots \ldots \ldots \ldots$

8.24. Codex Yuta Tnoho Reverse page VIII (Upper Right to Lower Left, boustrophedon): 1) the marriage of Lord 8 Deer and Lady 13 Serpent, followed by their son, Lord 4 Dog and four other children, 2) the marriage of Lord 8 Deer and Lady 6 Eagle, 3) followed by their son, Lord 6 House; the marriage of Lord 8 Deer and Lady 11 Serpent, followed by a son and a daughter

8.25. Codex Nuu Tnoo-Ndisi Nuu, p. 11-IV/V (Upper Right to Lower Left, boustrophedon): Lord 8 Deer marries Lady 11 Serpent, daughter of the royal couple of Totomihuacan (?) and of Toltec descent (ultimately coming from Temazcal, i.e. Tonalá) .......

8.26. Codex Ñuu Tnoo-Ndisi Nuu, p. 14-V/IV (Lower Left to Upper Left, boustrophedon): the Death of Lord 8 Deer ........... 386 
8.27. Codex Yuta Tnoho Reverse Page IX (Lower Right to Upper Left, boustrophedon): 3) Lord 8 Deer marries Lady 10 Vulture, two children are born; Lord 8 Deer marries Lady 6 Wind. 2) In the year 12 Reed, day 1 Grass, Lord 8 Deer dies. H son, Lord 6 House, marries Lady 9 Movement. They have a son, Lord 5 Water, who marries Lady 10 Reed. 1) The children of this couple are: a) Lord 8 Reed, b) Lady 5 Rabbit (who marry), c) Lord 11 [likely an error for 10] Rabbit, who marries Lady 10 Vulture, and

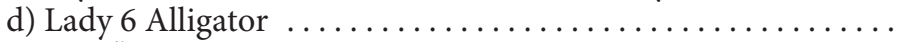

8.28. Codex Ñu Tnoo-Ndisi Nuu, p. 11-III: the daughter of Lord 8 Deer, Lady 10 Flower 'Spiderweb of Rain' (Dzinduhua Dzavui), who had been born in the year 8 Reed, marries Lord 4 Wind; they rule the kingdom of Flint Town (Nuu Yuchi) . . ........

8.29a. Codex Tonindeye, p. 27 (Left half, connecting with p. 28 on the left: reading from Right to Left). In the center: Lord 4 Dog ....

8.29b. Codex Tonindeye page 28 (connected on the right to p. 27: reading from Right to Left, boustrophedon, following the guide lines). Marriage of Lord 4 Dog to Lady 4 Death, the birth of their son Lord 13 Dog, his marriage and sons, Lord 7 Water and Lord 3 Wind. The marriage of Lord 7 Water and the birth of his son,

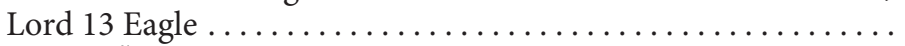

8.30. Codex Nuu Tnoo-Ndisi Nuu, p. 28-II: the death of Lord 4

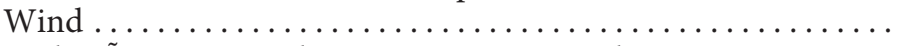

8.31. Codex Nuu Tnoo-Ndisi Nuu, p. 28-III: Lord 13 Serpent marries Lady 6 Alligator, daughter of Lord 5 Water and Lady 10 Reed, rulers of Nuu Tnoo .........................

8.32. Codex Ñu Tnoo-Ndisi Nuu, p. 28-V: discussions about the succession in Nuu Yuchi .....................

8.33. Codex Nuu Tnoo-Ndisi Nuu, p. 28-III: negotiations with other

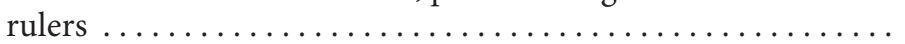

8.34. Codex Tonindeye, p. 30 (Lower Right to Lower Left, boustro-

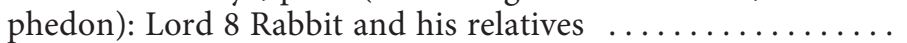

9.1. Codex Ñuu Tnoo-Ndisi Nuu, p. 14-II (Right to Left): Lord 8 Reed and Lady 5 Rabbit, of the Nuu Tnoo dynasty, marry and have a son, Lord 2 Movement, who married Lady 4 Eagle from

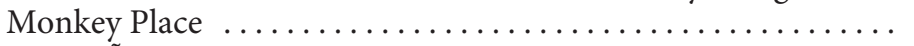

9.2. Codex Nuu Tnoo-Ndisi Nuu, p. 14-I (Left to Right): the conflict between Lord 1 Lizard and Lord 8 Grass ............. 410

9.3. Codex Nuu Tnoo-Ndisi Nuu, p. 16-II: Lord 12 Reed and Lady 3 Jaguar, ruling Nuu Tnoo . . . . . . . . . . . . . . . 410

9.4. Codex Ñuu Naha, p. 2: Lady 4 [6] Grass and Lord 8 Rabbit ruling Chiyo Yuhu $\ldots \ldots \ldots \ldots \ldots \ldots \ldots \ldots \ldots \ldots \ldots \ldots \ldots \ldots$

9.5. Codex Tonindeye, p. 31 (Lower Right to Upper Left, boustrophedon): the birth of Lord 12 House, his brothers and sisters,

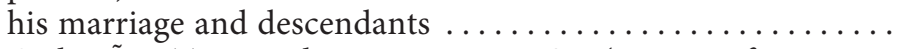

9.6. Codex Nuu Tnoo-Ndisi Nuu, p. 16-III/IV (Upper Left to Lower Left, boustrophedon): Lord 4 Water and his sisters ....... 415 
9.7. Codex Nuu Tnoo-Ndisi Nuu, p.25-I (Right to Left): Lord 7 Serpent defending Serpent Mountain ..................

9.8. Codex Nuu Tnoo-Ndisi Nuu, p. 25-II (Right to Left): Lord 3 Dog, his marriage and pilgrimage $\ldots \ldots \ldots \ldots \ldots \ldots \ldots \ldots$

9.9. Codex Nuu Tnoo-Ndisi Nuu, p. 24-II (Right to Left): Lord 3 Dog hunting a deer, while his wife carries the Bundle of Lady

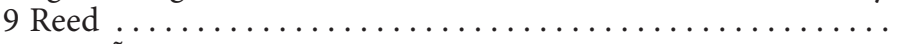

9.10. Codex Nuu Tnoo-Ndisi Nuu, p. 23-II (Right to Left): Lord 3

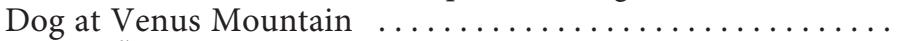

9.11. Codex Nuu Tnoo-Ndisi Nuu, p. 25-III/IV (Upper Right to Lower Right, boustrophedon): the two marriages of Lord 12

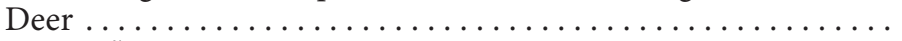

9.12. Codex Ñuu Tnoo-Ndisi Nuu, p. 25-IV: Lord 6 Death and Lady

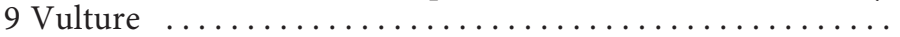

9.13. Codex Nuu Tnoo-Ndisi Nuu, p.22-I (Right to Left): Lord 3 Dog arrives at Mountain of the Mask; Lord 9 House attacks

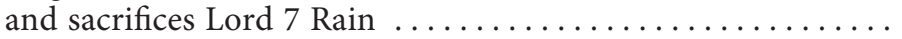

9.14. Codex Yuta Tnoho Reverse. p. XII (Upper Right to Lower Left, boustrophedon): 1) Lady 6 Reed [here erroneously called: 6 Flower] 'Plumed Serpent' and two other sisters of Lord 4 Water, the marriage of Lord 4 Water and Lady 6 Water; 2) their children, the second marriage of Lady 6 Water to Lord 4 Death and their children, the first-born being Lady 3 Rabbit, 3) sisters of Lady 3 Rabbit, her marriage to Lord 9 House, and the birth of their son, Lord 2 Water, in the year 7 House ....

9.15. Codex Nuu Tnoo-Ndisi Nuu, p. 15-V (Left to Right): the marriage of Lady 6 Water and Lord 4 Death from Ndisi Nuu, son of Lord 10 Rabbit and Lady 11 Rabbit .................

9.16. Codex Añute, p. 11-III / p. 12-III (Lower Right to Upper Right, boustrophedon): the expedition to Cuauhtinchan ...........

9.17. Codex Tonindeye, p. 32 (Upper Right to Lower Left, boustrophedon): Lord 2 Dog and Lady 6 Reed with their descendants until Lord 5 Reed Ocoñaña ........................

9.18. Codex Nuu Tnoo-Ndisi Nuu, p. 23-V (Right to Left): the marriage of Lord 11 Wind and Lady 4 Grass from Nuu Ndecu; the birth of their son, Lord 1 Monkey $\ldots \ldots \ldots \ldots \ldots \ldots \ldots \ldots$

9.19. Codex Nuu Tnoo-Ndisi Nuu, p. 24-IV/III (Lower Left to Upper Left, boustrophedon): marriage of Lord 1 Monkey and Lady 5 Flint; birth of their son, Lord 13 Eagle ................

9.20. Codex Ñuu Tnoo-Ndisi Nuu, p. 24-III (Right to Left): the marriage of Lady 1 Reed and Lord 6 Water ................

9.21. Codex Nuu Tnoo-Ndisi Nuu, p. 17-IV (Right to Left): the marriage of Lord 2 Water and Lady 3 Alligator; birth of their son Lord 5 Reed Ocoñaña .........................

9.22. Codex Nuu Tnoo-Ndisi Nuu, p. 17-II (Right to Left): Lady 5 Serpent married Lord 3 Monkey from Andua and Lady 2 Flower married Lord 6 Death from Nuu Naha ................ 
9.23. Codex Nuu Tnoo-Ndisi Nuu, p. 17-I (Left to Right): the marriage of Lord 6 Deer and the birth of Lord 5 [elsewhere: 4]

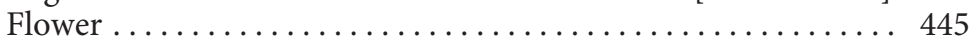

9.24. Codex Nuu Tnoo-Ndisi Nuu, p. 18-I: the birth of Lord 10 Rain 446

9.25. Codex Nuu Tnoo-Ndisi Nuu, p. 23-III : the marriage of Lady 5 Flower and Lord 5 Rain . ..................... 450

9.26. Codex Ñuu Tnoo-Ndisi Nuu, p. 21-IV: Lord 8 Grass (Malinaltzin) and his wife Lady 9 Deer ................. 452

9.27. Codex Añute, p. 16-III: Lord 3 Monkey attacks Añute in the year 8 House ............................. 455

9.28. Codex Nuu Naha, p. 6: Lord 6 Death marries Lady 2 Flower from Chiyo Yuhu. They have a son: Lord 3 Dog . . . . . . . . 457

9.29. Codex Nuu Tnoo-Ndisi Nuu, p. 19-III: Lord 4 Deer 'Ndisi Nuu Eagle' marries Lady 11 Serpent ............... 460

10.1. Codex Yodzo Cahi: Assembly in front of the palace (JM: II) 468

10.2. Codex Yodzo Cahi: encomendero y cacique (SH: VII) . . . . . 472

10.3. Codex Yodzo Cahi: Tlacaxipehualiztli (SH: X) . . . . . . . . 474

10.4. Codex Yodzo Cahi: Etzalcualiztli and Ochpaniztli (SH: IX) . . 475

10.5. Codex Yodzo Cahi: Panquetzaliztli (SH: XI) . . . . . . . . 475

10.6. Codex Yodzo Cahi: feather crown ( MG: V-62) . . . . . . . 477

10.7. Codex Yodzo Cahi: Cutting wood as 'tribute' (JM: XXI) . . . 477

10.8. Codex Yodzo Cahi: two flutes (MG: V-29) . . . . . . . . . . 478

10.9. Codex Yodzo Cahi: the cacique (Don Diego Nuqh) and the colonial town $(\mathrm{SH}: \mathrm{XV}) \ldots \ldots \ldots \ldots \ldots \ldots \ldots \ldots \ldots$

10.10. Codex Yodzo Cahi: Golden shield as special gift (MG: V-27) 480

10.11. Codex Yodzo Cahi: two spear-throwers, identified by Martínez Gracida as 'scepters' (MG: V-27) . ................ 481

10.12. Codex Yodzo Cahi: the two encomenderos (SH: XVII) . . . . 482

10.13. Codex Yodzo Cahi: the bishop and the Dominican provincial

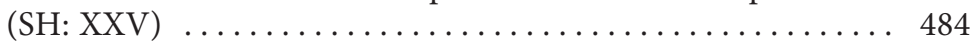

10.14. Codex Yodzo Cahi: the cacique (Don Domingo de Guzmán), a gobernador, and the land between two rivers (MG: V-40). Martínez Gracida identifies the scene erroneously as the foun-

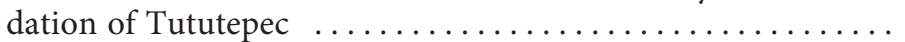

10.15. Codex Yodzo Cahi: four settlements, producing silk and weat

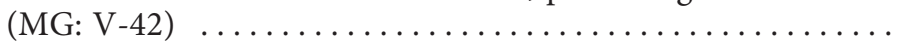

10.16. Codex Yodzo Cahi: the encomendero teaches the Mixtec caciques (Don Gabriel and Don Domingo) to pray the rosary (JM:

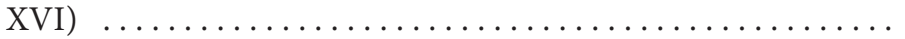

10.17. Codex Yodzo Cahi: the Christian town of Yanhuitlan (JM:

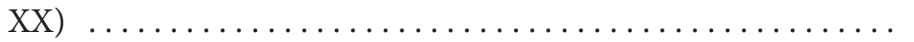


Maarten Jansen and Gabina Aurora Pérez Jiménez - 978-90-04-19358-1 Downloaded from Brill.com@4/26/2023 11:36:13AM 


\section{PREFACE}

Ñuu Dzaui, today often pronounced Ñu Savi or Nuu Davi, meaning 'Nation of the Rain', the Mixtec land and people in southern Mexico, developed its own beautiful writing tradition long before the Spanish conquest (1521). Screenfold books made of deerskin and large pieces of cloth were covered with bright and polychrome paintings, telling specific stories through pictures. Only a few examples of such pictorial manuscripts have survived colonial destruction: the codices Yuta Tnoho (Vindobonensis), Iya Nacuaa (Colombino-Becker), Tonindeye (Nuttall), Nuu Tnoo-Ndisi Nuu (Bodley), Añute (Selden), Ñuu Ñaña (Egerton), Nuu Naha (Muro), the Map of Chiyo Cahnu (Teozacualco), and several other minor documents register the history of various dynasties governing the sovereign communities, often called 'citystates', which made up the geo-political map of the Mixtec Highlands during more than six centuries before the colonial invasion, spanning the so-called Postclassic Period ( \pm AD 900-1521).

This book is a guide to the scholarly interpretation of those pictorial chronicles, to 'read' the images and to understand their cultural and political background. Different themes appear prominently in these pre-conquest records. On the one hand there is the genealogical register of rulers, on the other, there are more dramatic accounts of their acts in war and ritual. Each codex offers its own specific selection of historical data, in accordance with the viewpoints of its community of origin and the interests of the dynasty that ruled there. We started out writing a commentary on the so-called 'Codex Bodley', as a logical sequel to our earlier work on other pictorial manuscripts. The main result is the brief explanatory text that accompanies the photographic edition of that manuscript by the Bodleian Library (Jansen \& Pérez Jiménez 2005). The foundation for this was the work done during a sabbatical year (1997-1998), financed by the Netherlands Organization for Scientific Research (NWO). The complex and comprehensive character of Codex Bodley made it necessary, however, to follow up on the many cross-references that connect it to other Nuu Dzaui sources and to reconstruct the dynamics of the ancient Nuu Dzaui polities. The NWO-financed research project 'Mixtec city-states' (2001-2008) enabled us to explore these aspects further, while Laura 
van Broekhoven and Alex Geurds investigated the archeology and the economy of the region, and Gilda Hernández Sánchez made important breakthroughs in the interpretation of the codex-style decorations on Mixteca-Puebla style ceramics. The Royal Netherlands Academy of Arts and Sciences (KNAW) gave us important additional support.

For a second NWO-financed project we focused on the Mixtec language itself, together with linguist Michael Swanton and Ph.D. candidates Ubaldo López García and Juan Julián Caballero. This effort resulted not only in a coursebook and in the conversion of the monumental Spanish-Mixtec dictionary of Friar Francisco de Alvarado (1593) into a Mixtec-Spanish one, but also in a much better understanding of the relationship between pictorial writing and the spoken language.

In this context we started working on an overall reconstruction and analysis of Nuu Dzaui Postclassic history. The first result was a detailed reading of the formative story of the Nuu Dzaui communities, focusing on the creation of the polities in the Early Postclassic and on the saga of Lord 8 Deer and Lady 6 Monkey, with an interpretation of the ritual and religious aspects of power in precolonial Mesoamerica: Encounter with the Plumed Serpent (Jansen \& Pérez Jiménez 2007a).

A third NWO-grant for a research program concerning time and identity in Mesoamerica allowed us to produce the present synthesis as a sequel and complement to that specific study. It is meant to be a handbook, which not only offers an overview of the whole of Postclassic Nuu Dzaui dynastic history, from the Primordial Founders to the early colonial caciques (indigenous rulers), but also provides a discussion of the pictorial sources themselves and the problems of decipherment, reviewing the impressive amount of earlier research and indicating the main empirical foundations and methodological tools. This ambition calls for detailed and technical discussions, with up-todate references to the most relevant publications. Our reading of Codex Bodley, that backbone of Mixtec memory, is incorporated here as a leading thread, but embedded in, and connected to, the full corpus of the Mixtec pictorial manuscripts, ranging in contents from the sacred origins of the Postclassic dynasties (codices Vindobonensis and Nuttall) to the colonial transformation of indigenous society (Codex Yanhuitlan). We hope that this comprehensive presentation may serve as a companion to the study of individual manuscripts and as an 
introduction to the profound meanings and themes of Mesoamerican historiography.

Therefore we wanted to include the - often fragmentary and dispersed - data and complex considerations that are the indispensable background and basis for future research, as well as give an adequate idea of the present state of decipherment and understanding of the nucleus of the - mostly precolonial - pictographic chronicles from the Mixtec Highlands. These sources are in themselves important as works of art and examples of an original form of historiography, worthy of attention, but they are also a relevant case for more general theoretical reflections on the relations between writing, ritual performance, and memory. The ancient manuscripts were not meant to be read in silence, but were the scores for oral literature (story-telling or dramatic performances) in the context of important social events. In this way they were cornerstones of the development of mnemonic communities and their cultural memory. ${ }^{1}$

Historiography looks back at the passage of time, manifest in human actions, and in doing so it imposes on those actions a narrative structure. Here we refer to the fundamental insights of the French hermeneutic philosopher Paul Ricoeur, who in his famous Time and Narrative (1984-1988) explains:

By means of the plot, goals, causes and chance are brought together within the temporal unity of a whole and complete action...

The plot of a narrative ... grasps together and integrates into one whole and complete story multiple and scattered events, thereby schematizing the intelligible signification attached to the narrative taken as a whole. (op. cit.: ix, $\mathrm{x}$ )

... what is ultimately at stake in the case of the structural identity of the narrative function as well as in that of the truth claim of every narrative work, is the temporal character of human experience. The world unfolded by every narrative work is always a temporal world. Or, as will often be repeated in the course of this study: time becomes human time to the extent that it is organized after the manner of a narrative; narrative in turn, is meaningful to the extent that it portrays the features of temporal experience. (op. cit.: 3 )

The humanized time of historiography, structured as a set of narratives, integrated through its underlying human and divine inten-

\footnotetext{
${ }^{1}$ For a discussion and exemplification of the applicability of the concept 'cultural memory' (J. Assmann 1992 and A. Assmann 2007) to Mesoamerica, and in particular to Mesoamerican writing, see Graña-Behrens 2009.
} 
tions and causalities, becomes social and cultural memory, while also transmitting ethical and ideological messages, especially concerning the legitimacy of power structures, in particular the positions and acts of the rulers, who supervise the very way these stories are told. The veneration of the ancestors (persons of divine origin and status), the attendance of ritual obligations, but also the relations of kinship (genealogy), the conquests of places and the consequent accumulation of tribute rights, in this manner become interwoven in a single pattern, producing the narrative identity of a people. This narrative identity is a prime mover of cultural memory. In the case of Mesoamerica, the 16th century colonization meant a painful and traumatic interruption, drastic reorientation and partial overwriting of the indigenous identity and memory, to the extent that contemporary indigenous peoples have been excluded from their own history and literature, and consequently they have been made 'strangers in their own land'. This background lends dramatic social relevance to what otherwise might seem a simple iconographical and philological exercise.

Our book is divided into three parts. Focusing on the primary data and pre-understandings of this research, the first part contains an introduction to the conventions of pictorial writing (chapter 1), a presentation of the corpus of codices in question (chapter 2), a sketch of the fundamental decipherment during the first three quarters of the 20 th century (chapter 3 ), and an overview of advances and issues of scholarly debate during the past decades (chapter 4).

The second part lays the general foundation for our own reading of this ancient historiography, it introduces the basic elements of ethnoiconological theory and method (chapter 5), continues with analyzing the depiction of the protagonists and their actions (chapter 6), and sketches the geographical dimension through the identification of place signs (chapter 7).

The third part contains a discussion of the contents of the corpus in historical order. Chapter 8 tells the story of the origin of the dynasties, connected to the formative process of the Mixtec city-state culture during what archeologists call the Early Postclassic Period ( \pm AD 900-1200). Chapter 9 presents in detail the genealogies and their alliance policies, i.e. the structure of peer polity interaction in the later part of the Postclassic, and chapter 10 illustrates the transformations and local developments after the Spanish colonial invasion of 1521 by commenting on the Codex of Yanhuitlan. The conclusion (chapter 11) 
gives a synthetic view of the way in which the Mixtec political landscape has developed over time.

We pay special attention to the relationship between the ancient images and the spoken language, both in the identification of toponymic signs and in the reading of scenes. Another important aspect is the clarification of the genealogical relationships within and among the different royal families, and, in relation to those, the correlation of the Mixtec dates, which has obvious implications for archeological research in the region and for Mesoamerican chronology in general. These are intricate and specialist issues, which, however, are of utmost importance for reconstructing the spatial and temporal dimensions of ancient historiography. This leads us to organize the data in a coherent sequence and in the wider context of a reflection on city-state culture and ideology, which permits explanations in terms of causality, political purpose, and narrative structure. Taken as a whole, the resulting (re)construction is necessarily subjective and speculative, but may serve as an explicit reference point, and, hopefully, a stimulus, for further study of the historical processes that affected Nuu Dzaui and of the religious concepts that determined most of the rulers' actions, while sustaining the social ethos and sovereignty of the communities.

Over the past decades we have had the privilege of being able to dedicate ourselves to this study, analyzing the pictorial scenes, trying to read them in Dzaha Dzaui (Sahin Sau), the Mixtec language, and visiting many places where the historical events took place. More than an intellectual exercise, it has become a personal quest, together with family members and many good friends in Nuu Dzaui, who, with great hospitality and patience, shared their knowledge of traditions with us and helped us in innumerable ways. We honor especially the memory of the late Doña Crescencia Jiménez Quiroz and the late curandera María Jiménez Quiroz, who were crucial in shaping our understanding of the Nuu Dzaui world.

Ferdinand Anders and Nancy Troike taught us how to read the codices, while Emily Rabin clarified the chronology problem and Ronald Spores introduced us to Nuu Dzaui colonial history. Over the years they and other teachers, friends and colleagues, such as Willem Adelaar, Juan José Batalla Rosado, Antonella Cammarota, Nikolai Grube, Benedikt Hartmann, Arthur Joyce, Iván Rivera Guzmán, Gaspar Rivera Salgado, Victor Hugo Ruiz Ortiz, Mary Elizabeth Smith, Kevin Terraciano and Javier Urcid, have shared their data and knowl- 
edge with us. In Oaxaca, the cooperation of Enrique Fernández Dávila, director of the regional center of the Instituto Nacional de Antropología e Historia, and his staff of experts, has been crucial. Similarly we thank Nelly Robles for the invitations to participate in the Monte Albán round table conferences and other meetings, and Andrés Webster Henestrosa for his help and orientation. The staff of the Sala de Estudios Oaxaqueños of the Biblioteca Pública Central in Oaxaca, Mrs. Itandehui Gutiérrez Yañiz and Javier Rodríguez, helped us in a kind and professional manner with the study of the unpublished works of Manuel Martínez Gracida (which, among many other treasures, include copies of several pictorial manuscripts).

We thank the Bodleian Library, particularly Bruce Barker-Benfield and Samuel Fanous, for letting us study the original of the Codex Nuu Tnoo-Ndisi Nuu (Bodley) and putting at our disposal excellent new photographs of that manuscript and of Codex Añute (Selden).

Furthermore it has been a great stimulus to work with (international) students, Ph.D. candidates and post-doctoral researchers within the institutional framework of Leiden University, specifically the Faculty of Archaeology and the CNWS Research School of Asian, African and Amerindian Studies. Several draughtsmen contributed to our project. Long ago Jorge Pérez Morales traced Codex Yuta Tnoho. Later Frans Schoonens drew Codex Tonindeye and the Map of Chiyo Cahnu, while Peter Deunhouwer drew large parts of Codex Ñuu Tnoo-Ndisi Nuu. Ferdinand Anders provided drawings of the Codex Añute and Mary Elizabeth Smith gave us photos and drawings of Codex Nuu Naha and other documents. All of them made keen and valuable observations about the style and composition of the scenes. Aileen Bintliff, Arie Kattenberg and other students helped us in the correction, preparation and illustration of the manuscript.

In the first phase of this work, we received the sad notice of the passing away of our friend and maestro Luis Reyes García. We remember his great erudition and strong idealism, his orientations and good company, the hospitality of his home between the volcanoes, the pleasure of working together in Oaxaca, Leiden and Rome. By insisting on reading the sources in terms of their own culture, he has shown the way to the decolonization of Mesoamerican studies. He was an inspiring force in the project Códices Mexicanos, a great linguist, historian, and humanist, looking to the past and to the future. 


\section{PART ONE}

NEE ÑUHU SANAHA:

THE ANCIENT BOOKS 
Maarten Jansen and Gabina Aurora Pérez Jiménez - 978-90-04-19358-1 Downloaded from Brill.com@4/26/2023 11:36:13AM 


\section{CHAPTER ONE}

\section{INTRODUCTION TO MIXTEC PICTOGRAPHY}

Today we use the term 'Mesoamerica' for the millenarian, original and sophisticated cultural tradition that has developed in the huge region that stretches from the northern deserts of Mexico to the tropical mountain ranges of Nicaragua and Costa Rica. ${ }^{1}$ This region is famous for its impressive archeological sites, its pyramids and artistic monuments, situated in landscapes of great beauty, as well as for its colorful folklore and rich panorama of languages and oral literatures that characterize the descendant communities. Having come to flourish without strong influences from the outside world, this civilization is a truly original contribution to world heritage. Studying it offers fascinating insights into the commonalities and variations of human creativity, community building and religious experience. On the other hand the Spanish colonial invasion (1521) initiated a prolonged period of cultural interaction between Mesoamerica and Europe, a violent and painful experience, from which, however, a lot may be learned.

Several Mesoamerican peoples had invented writing systems, which took several forms, but which all consisted of combinations of figurative scenes with hieroglyphic (phonetic) elements, in varying proportions. Inscriptions and pictorial manuscripts registered information about history, religion, astronomy and many other aspects of the ancient society and way of life. ${ }^{2}$ Mesoamerican pictorial writing, as in

\footnotetext{
${ }^{1}$ Although there are many interesting local variations, the native civilizations of this huge region are to be seen as one single cultural continuum or co-tradition. Paul Kirchhoff coined the concept 'Mesoamerica' in the early 1940s. A critical analysis of several theoretical preconceptions and connotations of those days (e.g. diffusionism) has been presented by Vázquez León (1996). The concept has developed with time, however, in accordance with successive currents of archeological thought, and has proved to be of great theoretical and practical value (see the comment by Gordon Willey 1981: 4). There are numerous introductions to this culture area, e.g. Carmack \& Gasco \& Gossen 1996, Smith \& Berdan 2003, Evans 2004, Hendon \& Joyce 2004.

${ }^{2}$ See the Guide to Ethnohistorical Sources, in vols. 12-15 of the Handbook of Middle American Indians for an overview of the pictographic and other historical sources for Mesoamerica. Anders (1999) provides an extensive and detailed update. Several major works, such as Martin \& Grube 2000 and Houston \& Stuart \& Taube 2006, offer an inspiring synthesis of the decipherment of the Maya hieroglyphic inscriptions, with an analysis of the political history and related worldview of the
} 
use shortly before and after the Spanish invasion, particularly in the Nuu Dzaui (Mixtec) region, is the subject matter of this book.

The ancient Mexica or Aztecs, the dominant people and empire at the time of the Spanish invasion, defined their own culture as part of the Toltecayotl, 'the legacy of those who inhabited the Place of Reeds'. Indeed, several successive imperial and cultural capitals, all designated as Tollan, 'Place of Reeds', mark the progress of this civilization: Teotihuacan, Cholula and the Aztec capital Mexico-Tenochtitlan. These Central Mexican sites are now impressive ruins, admired by thousands of tourists from all over the world.

In $\mathrm{AD} 1521$ the conquistadors took over the Mexica (Aztec) agrarian tribute-state, which had been created in a mere hundred years of military and commercial expansion, and dominated large parts of the area at the time. Many smaller polities had been subdued and/or incorporated by the Mexica realm, others had preserved their independence. The Spanish siege of the Mexica capital Mexico-Tenochtitlan, followed by the colonization of the whole Mesoamerican world, interrupted the further autonomous development of this civilization in a brutal manner. It was a major blow, a watershed, which still has a traumatic and determining influence on present-day reality. Much knowledge and many artistic products were destroyed or lost.

During the remainder of the 16th century, Spanish took the place of Nahuatl, the language of the Mexica, as the lingua franca in New Spain and became the metalanguage for the research and discourses on the Native American world. Spanish conquerors and monks, such as Hernán Cortés himself, the Franciscan Friars Toribio de Benavente Motolinia, Bernardino de Sahagún and Juan de Torquemada, or the Dominican Friar Diego Durán, produced important chronicles, describing the native civilization of Central Mexico with a wealth of details, but their vision was often distorted, or at least strongly influenced, by European bias and value-judgements. ${ }^{3}$ The same is true for documents such as the Relaciones Geográficas, descriptions of the dif-

Classic Maya city-states. The Beni Zaa (Zapotec) inscriptions of Monte Albán have been analyzed by Urcid 2001.

${ }^{3}$ There is abundant literature about the European view of America, see Nowotny 1960, Keen 1971, Kohl 1982, Wolf 1982, Anders 1975, Lemaire 1986, Mason 1990, Ordahl Kupperman 1995, Churchill 1998 etc. The abuses, racial prejudices, discrimination and ethnocide against the Native Americans in successive periods have been discussed already by Paulat Legorreta 1972, Lipschutz 1975, Jaulin 1976 and 1979, Graham 1994 and many other authors. For the general framework of postcolonial 
ferent villages of what was then known as 'New Spain', written around 1580 in response to a questionnaire: basically they tried to accumulate data as a guide for Spanish governmental administration and economic exploitation. The surviving examples of the historiography and literary heritage of the Native American peoples themselves, therefore, constitute a crucial primary source of inside information, which no study of the Americas can ignore.

Writing had started in Mesoamerica more than 2000 years before the Spanish conquest. Its roots are found already in the formative period, generally designated as 'the Preclassic' by archeologists, concretely in the so-called Olmec 'mother culture' ( \pm 1200 till $\pm 600 \mathrm{BC}$ ). Later, the civilization of Teotihuacan in the first half of the Classic Period ( \pm 200-650) used in its frescoes - and presumably also in pictorial manuscripts, which did not survive - a fully developed system of pictorial writing, pictography. ${ }^{4}$ During the second half of the Postclassic ( $\pm 1250-1521)$, in the centuries immediately preceding the Spanish invasion, different peoples in Central and southern Mexico, such as the Mexica (Aztec) and the Nuu Dzaui (Mixtec), used it in screenfold books (codices), made of deerskin or bark paper, on large pieces of cloth (lienzos), as well as on carved stones, frescoes, painted ceramics and other decorated artefacts. The scenes are painted in polychrome and figurative style, according to a specific system of pictographic signs and conventions. ${ }^{5}$

When colonization interrupted the ancient pictographic tradition, it also severed the link between the Native American peoples and their literary heritage. The few codices and lienzos that have survived became riddles of the past. Their interpretation today is a special form of iconological and contextual analysis. Those not familiar with this

theory, see e.g. Bhabha 1994, Loomba 1998 and Smith 1999; for a contemporary perspective focusing on Oaxaca: Maldonado Alvarado 2002 and Van Broekhoven 2006.

4 The works edited by Berrin (1988), Fuente (1995), and Ruiz Gallut (2002) summarize the long tradition of research on the Teotihuacan sign system. The volume edited by Jansen and Van Broekhoven (2008) offers an overview of the succesive phases of the Nuu Dzaui (Mixtec) writing system. See also the volume edited by Van Doesburg (2008) on the development of writing in Oaxaca. Riese discusses the different genres of Mesoamerican books in his contribution to the volume edited by GrañaBehrens (2009).

${ }^{5}$ For the Mixteca-Puebla style ceramics, see for example Smith \& Smith 1980, Lind 1987, Hernández Sánchez 2005 and Pohl 2005, 2007. The work of Kowalewski et al. 2009 offers a timely overview of the ceramic chronology in the Mixteca Alta. Postclassic carved stones from the Mixtec region have been studied by Blomster (Blomster 2008: ch. 9). 


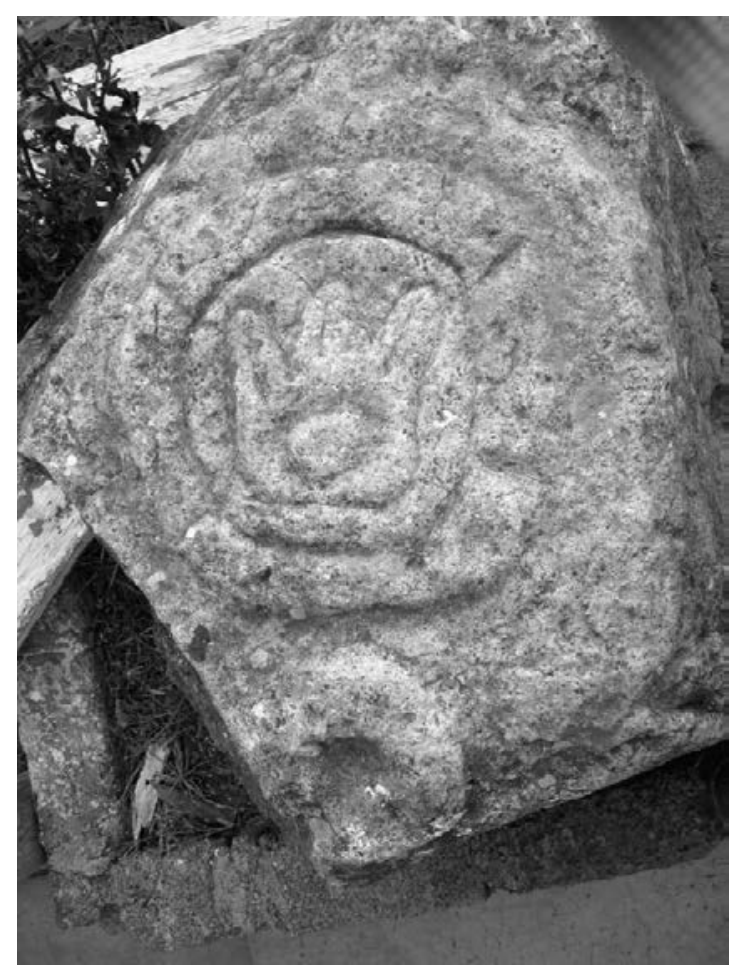

1.1. Late Preclassic-Early Classic calendar sign on carved stone found in the Agencia Guadalupe Victoria, San Miguel el Grande, Oax.

matter often wonder how we can know what certain images mean and consider the modern 'readings' as mere hypotheses, comparable with the speculations about the possible meanings of prehistoric rock art, for example. Fortunately this is not the case. There are various 'bilingual' keys to the system in the form of colonial codices in precolonial style but adequately explained through added comments written in Spanish or an Amerindian language (in alphabetic notation) under the images, a famous example being the Codex Mendoza and the Matrícula de Tributos (Clark 1938; Reyes García 1997). Often these glosses or annotations come directly from those who were intimately familiar with both the pictographic forms and the cultural contents. In the same way, the Spanish monks, in their zeal for recognizing paganism with the intention to exterminate it, have left us paintings and descriptions of the Gods and the major rituals, sometimes with very precise 
lists of attributes, sacred objects and temples (e.g. Codex Magliabechi). Other sources expand and clarify these data. Especially valuable are the chronicles in Nahuatl and other Mesoamerican languages written with the Spanish alphabet (e.g. the Historia Tolteca Chichimeca or the chronicle of Tezozomoc). Thus, careful screening of the annotated pictograms, in terms of consistency, clarity and probable correctness, provides us with a 'pictographic dictionary' (cf. Nowotny 1959b), which permits us to recognize the basic elements and the conventions of pictorial representation.

Furthermore, the Mesoamerican culture, although affected and transformed by centuries of external and internal colonialism, is not dead. Today scores of Native American peoples in Mexico, Guatemala, Belize and Honduras manifest a distinct linguistic-cultural identity and preserve many precolonial traditions. The ancient scriptures document their history and memory, their worldview and rituals, their social and religious ethics, as well as their political strategies and ideology.

\section{Nuu Dzaui: Land and Language}

A unique precolonial literary heritage of codices and lienzos belongs to Nuu Dzaui or Ñu Savi, the 'Nation of the Rain God', living in the heart of Mesoamerica, in the southern part of Mexico (the States of Oaxaca, Puebla and Guerrero). They are generally known as the 'Mixtecs', from their name in Nahuatl, mixtecâ, which means 'inhabitants of the land of the clouds'. Their land, also called Nuu Dzaui, is therefore referred to in Spanish as 'la Mixteca'. Many places are now known by their Nahuatl names or were rebaptized in Spanish. Nowadays several hundreds of thousands of people speak different dialects of the Mixtec language or Dzaha Dzaui.

The northern and central part of the region (in the State of Oaxaca) is the Mixteca Alta, a high mountainous area more than 2000 meters above sea level. Originally the people named it with special respect $\tilde{N} u u$ Dzaui Ñuhu or 'Ñuu Dzaui of the Gods'. Other names were Ñuu Nino, 'the Highlands' and Dzini Ñuu Dzaui, 'the Head of Nuu Dzaui'. Of central importance here is the large Valley of Yodzo Cahi and Atoco, villages now known by their Nahuatl names Yanhuitlan and Nochistlan.

To the West, in Oaxaca and the neighboring states of Puebla and Guerrero, lies a somewhat lower mountainous area, hot and eroded, 


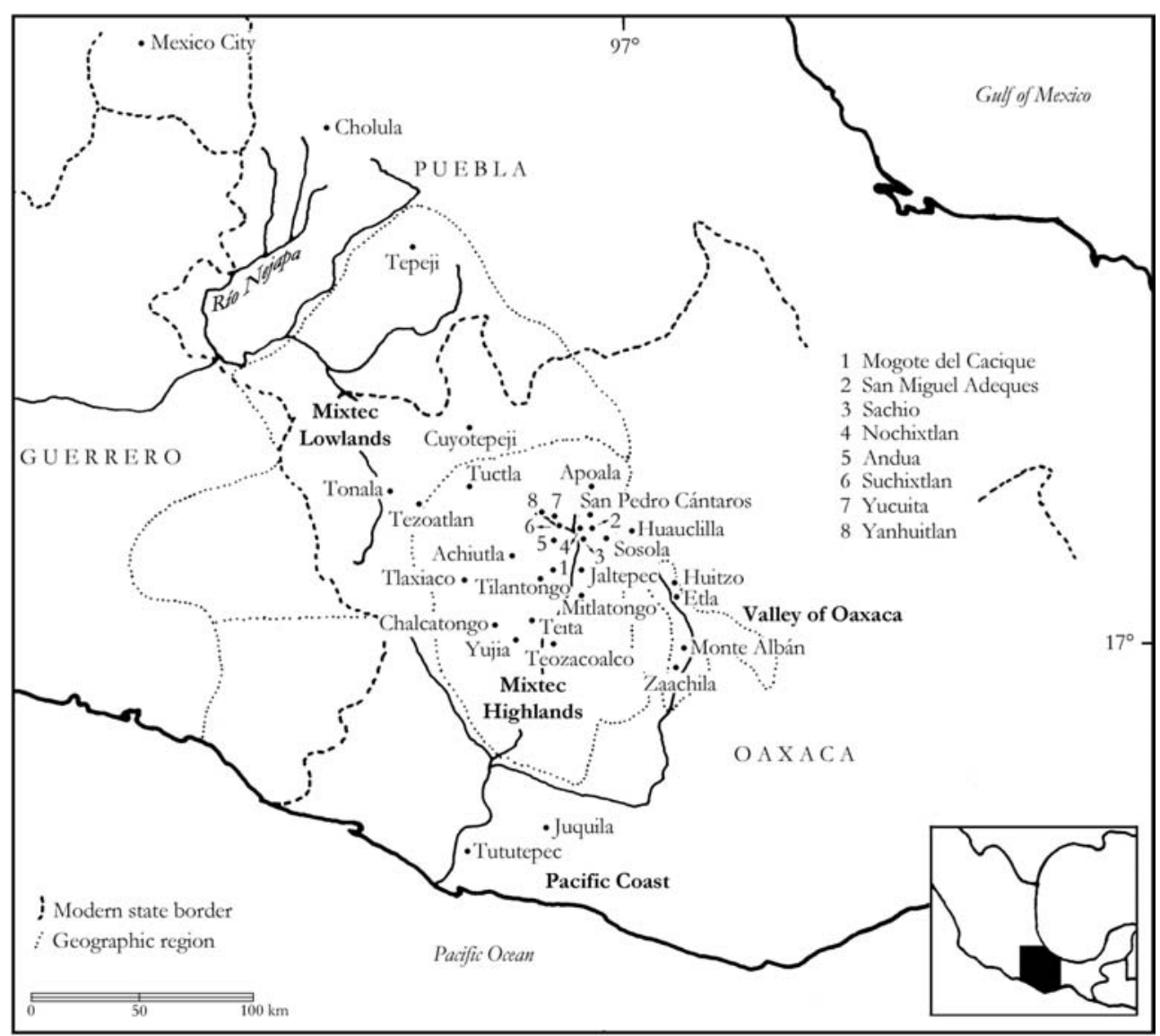

1.2. Map of the Mixtec region.

the Mixteca Baja, called Ñuu Dzaui Nino, 'Ñuu Dzaui of Above (i.e. toward the North)' or Nuu Niñe, 'Hot Land', which was also the name of the major town in this area (now known as Tonalá).

The third subdivision consists of the humid tropical lowlands along the Pacific Coast of Oaxaca and Guerrero, the Mixteca de la Costa, where Yucu Dzaa (Tututepec) was the major precolonial polity. There were several names in Dzaha Dzaui for this area, such as Nuu Ndaa, 'Flat Land' or Nuundevui, 'Land of the Sky', after the word for horizon, saha andevui, 'at the foot of Heaven' (Reyes 1976: i-ii). 


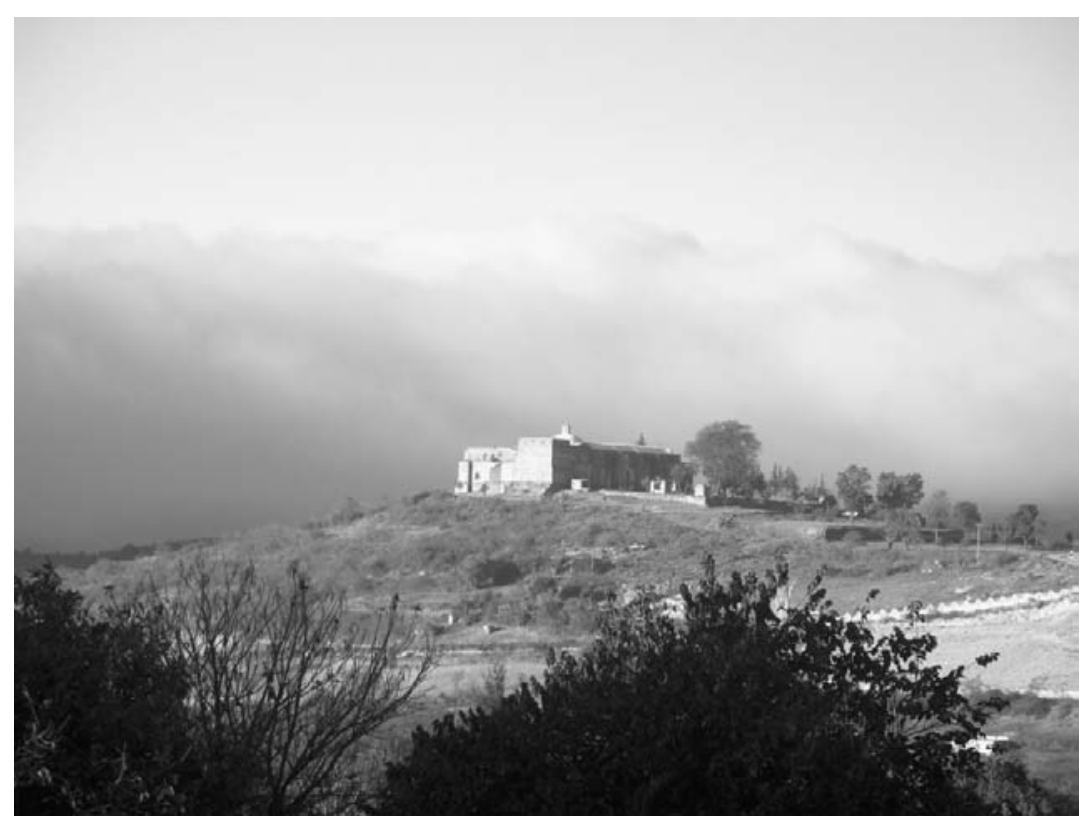

1.3. The ruined Dominican convent at San Miguel Achiutla.

There are far fewer colonial accounts of this people than of the Mexica (Aztecs) of Central Mexico. Fortunately several Relaciones Geográficas from the area have been preserved. From others, now lost, the Spanish official historian Antonio de Herrera collected data and included them in his major work. The Dominican Friar Gregorio García (1607) preserved a translation of the Mixtec creation story. Our main source is the 17 th century chronicle of the Dominican missions, written by Friar Francisco de Burgoa, which includes valuable references to the native culture, history and religion.

During the 16th century the dialect of Yucu Ndaa (Tepozcolula) in the central area was used as a lingua franca. We still use it in this way in historical studies (also in the present book). For evangelization purposes the Dominican monks made an effort to document it. In 1593 a grammar was published by Friar Antonio de los Reyes, together with the impressive vocabulary edited by Friar Francisco de Alvarado. Many colonial documents were written in Dzaha Dzaui with the European alphabet in essentially the same way. The Dominican orthography, used as a standard in historical studies, remains close to the Spanish 
writing conventions. The same is true for the way collaborators of the Summer Institute of Linguistics use it in their Bible translations, linguistic studies and texts in different modern dialects. Several contemporary Nuu Dzaui authors prefer a less hispanized form of the alphabet, using /s/ and / $/ \mathrm{k}$ instead of $/ \mathrm{c} /$ and $/ \mathrm{qu} /, / \mathrm{sh} /$ instead of $/ \mathrm{x} /$.

Let us briefly review the main characteristics of Dzaha Dzaui, or in Alvarado's orthography, Dzaha Dzavui. Vowels can be short or long: in the latter case they are written double (/a/ vs. /aa/ etc.). They are often nasalized, which is today indicated by writing an $/ \mathrm{n} /$ after the vowel. In the dialect of Nuu Ndeya and several others there is a sixth vowel, close to the /e/ in English 'father', generally written as/it. This vowel is not represented in colonial texts, which use only /e/ or /i/.

Words are determined and do not change in the plural. Thus huahi means '(the) house', ee huahi, 'a house' or 'one house', and oco huahi, '(the) twenty houses'. All this in the orthography of Alvarado; today the word is vehe. Nouns may be followed by an adjective or second substantive. This construction we usually find in toponyms. Nuu Tnoo, the Dzaha Dzaui name of the town now known as Santiago Tilantongo, is composed of $\tilde{n} u$ (town) and tnoo (black), meaning 'Black Town'. In the same way Yucu Ita is composed of yucu (mountain) and ita (flower), meaning 'Mountain of Flowers'. An important literary device is the hendiadys or difrasismo: one (often abstract) concept is expressed through the pairing of two (often concrete) terms in a couplet. Generally, therefore, such pairs have a metaphorical meaning. For example yuvui tayu, 'the mat, the throne', stands for 'authority', 'rulership', 'nation', while ñene ini, 'the blood, the heart' is used to refer to a son or daughter. In accordance with this device, parallellism is often employed in constructing the sentences of a literary or otherwise special text.

The pronouns are expressed through suffixes, added to the nouns (in possessive forms) or the verbal stems (in verbs). The suffix of the first person ('I'), speaking with respect, is - nadza, and without respect: $-n d i$. The suffix of the second person ('you'), speaking with respect, is $-n i$, and in an equal relationship: $-n d o$. When the subject is known, it is not necessary to indicate the third person ('he'/'she') explicitly; otherwise a series of different suffixes may be used, according to the category of that subject: - ta (man), - ña (woman), -to (person of respect), $-y a$ (divine person), -te (animal). In the different dialectal variants of today these suffixes have often suffered major modifications, but the principle remains the same. 
The present tense of the verb is indicated by the prefix yo-, which nowadays has generally disappeared. The past tense is expressed by the prefix $n i$-. These prefixes are located before other prefixes that may be added to the verbal stem. In a significant number of cases the future tense uses a modified form of the stem, for example 'I look' is yo-sito$n d i$, but for the future the stem coto is used, instead of sito. Logically the causative prefix $d z a$ - and the intentional prefix na- are always combined with the future stem.

In possessive constructions a suffix -si may be added before the pronominal suffix: huahi-si-ta, 'his house'. When a person is the object of the action, this may be indicated by adding the suffix of the object after that of the subject, e.g. yo-sini-mani-ndi-ndo, 'I love you' (the verbal stem being composed of sini, 'to feel' and mani, 'love, affection, care, respect, compassion'). A general indication of the person as object is the suffix - naha, added to the stem, before the pronominal suffix: yo-sini-mani-ñaha-ndi, 'I feel compassion for someone'.

Like all languages, Dzaha Dzaui is divided into a number of dialects, distinguished by phonetic changes. The /dz/ of Yucu Ndaa is generally /d/ in the northern part of the Mixteca Alta, but/s/ and sometimes / $\mathrm{sh} /$ in the southern part. The final syllable hui / vui may be pronounced $w i / v i$ or shortened to $/ \mathrm{w} /$ or $/ \mathrm{u} /$. As a consequence the word dzavui, 'rain', is today written davi, daui, dau, savi, saui or sau in the different parts of the region. For reasons of uniformity we write this as $d z a u i$ in words referring to the people, the region or the language. Another major dialectical change is the /s/ of Yucu Ndaa, which corresponds to / $\mathrm{j} /$ (Spanish jota) in the southern Mixteca Alta and to /ts/ on the coast, while the /t/ usually becomes /ch/ and /ty/ respectively. Some vocal changes occur in fixed patterns: huahi has become vehe in most of the region, and tnoo is often pronounced tuun.

In this publication we will use the 'classic Mixtec' (Dzaha Dzaui) of 16th century Yucu Ndaa (Tepozcolula) as standard, referring to terms and expressions in the vocabulary of Friar Francisco de Alvarado, but including explicit or implicit comparisons with cognates in contemporary variants, especially the living dialectal variant of Nuu Ndeya (Chalcatongo) in the south-western Mixteca Alta (Sahin Sau), of which we have an active knowledge (cf. Pérez Jiménez 2008). ${ }^{6}$

\footnotetext{
${ }^{6}$ For an overview of dialect variability see the dissertation of Kathryn Josserand (1983). Terraciano (2001) devotes his chapters 2 and 3 to a detailed discussion of writing, literacy, figurative speech and language change in the early colonial period. A first attempt to reverse the Spanish-Dzaha Dzaui vocabulary of Alvarado into a Dzaha
} 
We also take into account other dialectal variants, such as that of contemporary Yutsa Tohon (Apoala), especially its flowery discourse and pictorial language (cf. López García 2007). As indicated above, the many variants of Mixtec may at first sight seem very different, but a closer inspection shows that they actually follow very regular patterns of phonetic changes, so that, on a higher level of abstraction, they are very similar and easy to relate one to another (as long as we are very precise in identifying the variant that we are using). Mixtec language is clearly one.

\section{Ñu Dzaui Historiography}

The surviving Mixtec pictorial manuscripts were painted in the Postclassic Era and the early colonial period. In Dzaha Dzaui a 'codex' is called tacu, 'painting' and ñee ñuhu, 'sacred skin'. The first seems to be a general term for a pictographic manuscript; the second refers specifically to the books on deerskin. ${ }^{7}$ Indeed these were often considered to be 'sacred'. This is obvious in the case of religious books, which contained images of the Gods and were objects of ceremonial respect. The historical codices, however, must have been seen in a similar light: their protagonists were generally rulers who had passed away, designated as $\tilde{N} u h u$, 'deities'.

Dzaui-Spanish wordlist has been published by Arana and Swadesh (1965), but is incomplete and suffers from various deficiencies. We have tried to make a more complete version (Jansen \& Pérez Jiménez 2003, 2009a). It is wise to always check with Alvarado's original and to compare the terms with their cognates in present-day forms of the language. An important dictionary for the dialectal variant of the southwestern Mixteca Alta has been elaborated by Dyk \& Stoudt (1973). Grammatical and syntactical analysis of modern dialectical variants are to be found in Alexander 1980, Bradley \& Hollenbach 1988-1992, and Macaulay 1996.

7 Smith (1973ab), König (1998) and Boone (2000) give general descriptions of the Nuu Dzaui writing system. Maldonado Alvarado \& Maldonado Alvarado (2004) and Maldonado Alvarado (2009) explain the preparation of the deerskin, while Lenz (1948) and Vander Meeren (1997) describe the making of amate paper. Weitlaner Johnson (1966) has made a technical analysis of a Mixtec lienzo. Arellano Hoffmann (1998) describes the painting techniques, while Laurencich Minelli (1999) reports on her microscopic observations on Codex Tlamanalli (Cospi). New non-destructive analyzes will certainly enhance our understanding of the colors and the physical composition (see Zetina et al. 2009).

${ }^{8}$ See the comment by Friar Antonio de los Reyes (1976: 19) on how the term $\tilde{n} u h u$ is used (cf. Jansen 1982b: ch. V $\$$ ). The veneration of ancient pictorial documents in present-day communities in Guerrero has been documented by Jiménez \& Villela (1998: 67 ff.). 

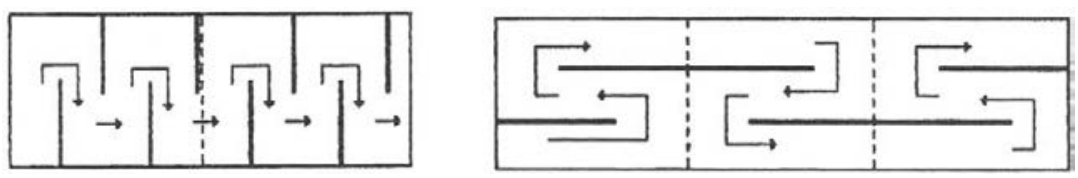

1.4. Yuq yuq or Boustrophedon patterns.

Alvarado distinguishes three general categories of writing material ('paper on which the ancient Indians wrote'): ñee, 'skin, leather', tutu, 'paper', i.e. the native bark paper or amate, and dzoo, 'cloth' i.e. a lienzo. Furthermore he translates tutu nuhu as 'brown/rough paper or local paper' (papel de estraza o de la tierra), clearly referring to amate. The term tutu appears in the context of other categories, which are clearly geographically specified: tutu Ñu Dzuma, 'paper of the Colhua', i.e. Mexica and tutu Nuu Dzaui, 'paper of the Mixtec'.

In colonial times ñee ñuhu was replaced by ñee cuisi, 'white leather', i.e. parchment. Other colonial terms betray precolonial uses: the pluma (a 'feather' used for writing in Europe) is yeque taa tutu, 'bone to write on paper'; the inkpot is a tiyaha tnoo, 'a gourd bowl of black ink'. The translation for 'line of writing' is $y u q$, literally 'furrow' or 'row'. In Dzaha Dzaui we might call the boustrophedon pattern yuq $y u q$, 'following the furrow'.

As far as the concept and contents of Mixtec historiography are concerned, the terms for 'history' given by Alvarado are illustrative. The first is an image, clearly recognizable to anyone familiar with codex painting: nduvua iya, 'arrows of the lords', i.e. conquests, represented as darts thrown by the protagonists into the place-name signs. The other expressions are forms of tnuhu, 'word, discourse, account', e.g. tnuhu sanaha, tnuhu nicuvui or tnuhu yata, 'discourse about the past' and tnuhu niquidza iya, 'telling the deeds of the lords'.

In the same dictionary we find several terms for 'historian'. Two refer to a 'man who writes the account of what has been in the past' (tay taa tnuhu sa yyo, tay taa tnuhu nicuvui sanaha). The verb 'writing' is in the present tense, suggesting that the author of the 1593 dictionary is thinking in these cases of contemporaneous, i.e. early colonial, historians. In two other terms the same word occurs but in the past tense, suggesting that these are the terms for the precolonial historians: tay ninataa ñee ñuhu, 'the man who wrote (on) the sacred skin', and tay ninataa tonindeye, 'the man who wrote the lineage history'. 
Friar Francisco de Burgoa was personally acquainted with a Nuu Dzaui historian and portrayed him as a venerable elder who was very knowledgeable about the ancient history of his noble lineage, sharply distinguishing the falsehood, which he detested, from the truth, and who was widely respected because of his authority (Burgoa 1934b, I: 320 ).

In the terms for 'chronicler' we find more interesting references to the concept of history: tay taa tacu tnuhu yaa, 'the man who writes and paints the words and songs', i.e. the lineages, tay taa tutu quevui cuiya, 'the man who writes the paper of the days and years', tay taa tnuni nandehe sa nicuvui, 'the man who writes the signs of all that was'. In all terms the author is male (tay). One could argue, however, that this is because these terms are given as translations of the Spanish 'historiador'. The little we know about precolonial historians generally pictures them as men, but, again, this may be due to the biased and incomplete character of the historical record. At least one exception is known from the Mexica world: the wife of the Aztec ruler Huitzilihuitl who was called the 'painter', i.e. scribe ('la pintora' represented in Codex Telleriano-Remensis, f 30). ${ }^{9}$ Today, women are excellent artists and artisans, play an important role in transmitting oral traditions, act prominently as midwives and healers (curanderas) and, where the ancient calendar is still in use, as day-keepers. It is quite likely, therefore, that in ancient times they also participated in the production of the codices and lienzos.

The main topic of the ancient Nuu Dzaui manuscripts is the history of the noble houses that ruled the different sovereign communities in the region. The narrative usually starts with a scene in which the place sign - the emblem of the community - is combined with a sacred foundation date and a primordial ruling couple, the Mother-Father (dzehe dzutu) of the dynasty and of the people. Land and people are one ( $\tilde{n} u u)$. The community was defined in terms of its ecological niche and described as yucu nduta, 'mountain and water' (Nahuatl: in atl in tepetl), a difrasismo which identified it with the landscape. A similar expression, yuvui tayu, 'mat and throne' (Nahuatl: petlatl icpalli), denoted the political unit, i.e. the realm of a noble house. The whole region was subdivided into a series of such sovereign towns or 'city-

\footnotetext{
9 See Boone's essay on 'In Tlamatinime, the wise men and women of Aztec Mexico', a contribution to the volume in honor of Mary Elizabeth Smith (Boone 2005: 9-25).
} 


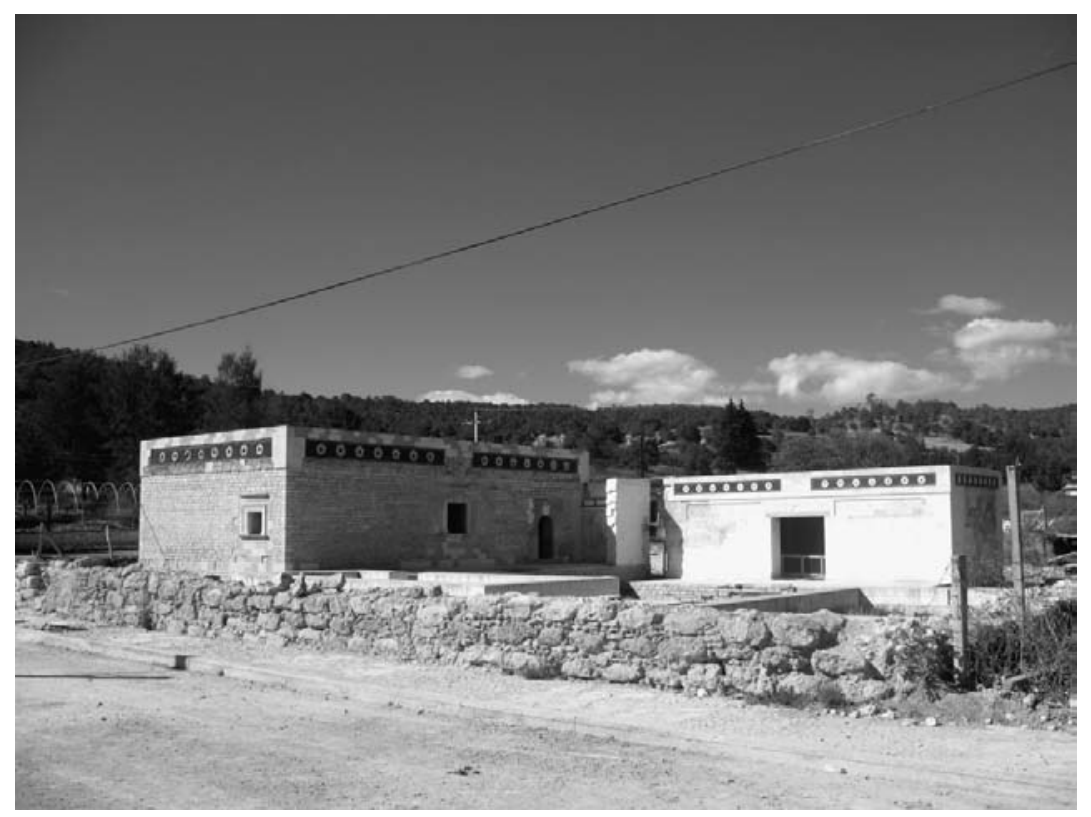

1.5. The early colonial palace (Casa de la Cacica) in Yucu Ndaa (Tepozcolula).

states', each with its own royal dynasty. These may be described as 'peer polities', but we should keep in mind that there were significant differences among them. The seat of government was the dzini $\tilde{n} u u$, 'head of the town', i.e. a civic-ceremonial center (Spanish: cabecera), with its temples, palaces, ballcourts and administrative buildings, the locale of public cult and politics. Around it the people lived as farmers in a dispersed settlement pattern of houses among the fields. It is customary to use the term 'city-state', although 'village-state' or 'sovereign community' would probably be a closer fit for Postclassic Nuu Dzaui reality just as for the early Greek polis. ${ }^{10}$ Needless to say, this

10 Cf. Kirsten's classic concept Dorfstaat, discussed and applied by Bintliff 2002. The yuvui tayu organization has been described in detail by Spores 1967, 2007 and Terraciano 2001, chapters 4 and 6. The same hendiadys is already represented in Classic Maya inscriptions: the superfix of the so-called Emblem Glyph. Renfrew and Cherry 1986 have elaborated the 'peer polity' concept, while Hansen (2000) describes the ordered continuum of these polities as a 'city-state culture', offering a worldwide comparative perspective. The latter book also contains an important overview article on the Nuu Dzaui case by Lind. For a discussion of the applicability of this concept in Mixtec archeology, see the volume by Kowalewski et al. (2009: ch. 11), which concludes: "Our claim is that Mixteca Alta urbanism was fundamentally agrarian and that 


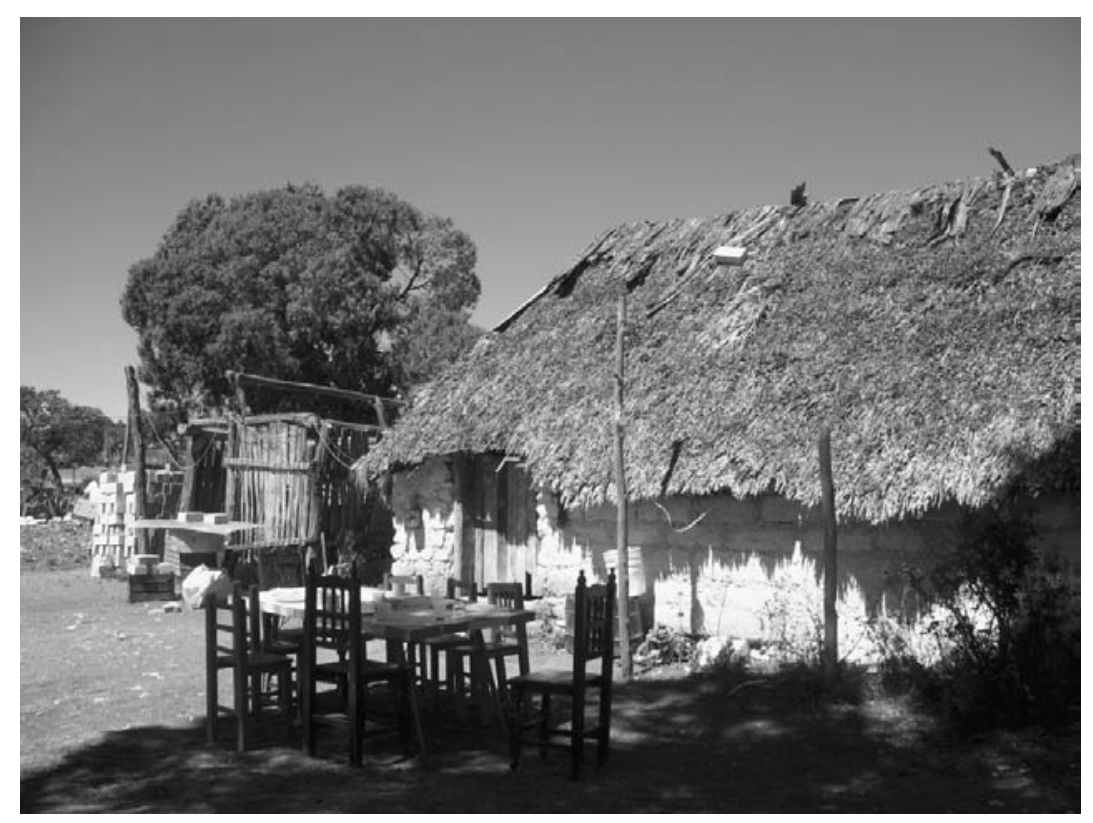

1.6. Traditional house.

term should not be taken to imply a lack of social complexity or cultural sophistication.

In accordance with these conceptions, the codices represent the communities literally as the base of rulership, the place signs on top of which the royal couple are seated. The rulers change but the place remains the same. Often a jaguar cushion or seat (both tayu in Dzaha Dzaui) is added as an emblem of the ruler's power. The mat (yuvui) is an index of both rulership and marriage: the concept yuvui tayu, 'mat and throne' designates the polity, while the marriage of two people of royal blood is called huico yuvui, 'ceremony of the mat'.

In modern Nuu Dzaui usage women normally sit on a mat (yuvui) and men on a chair (tayu), therefore the term yuvui tayu refers to the seating place of both women and men, connoting the concept of a noble house in which both maternal and paternal descent are important. Sometimes a house, or rather a palace, is added: the aniñe or 'place of rulership'.

cities performed the central place functions necessary to integrate an intensive agricultural economy" (op. cit.: 348 ). 


\section{Mexica and Mixtec Place Signs}

Although pictography communicates information directly through the painted images, its interpretation does have an important linguistic component. In general a first-hand knowledge of the cultural concepts and pictorial expressions, the etymologies, narrative conventions, style figures, and metaphors, is essential for bringing the iconographical analysis to the level of a 'reading' of the pictorial scenes in terms of the culture to which they belong. This is particularly evident in the study of phonetic elements in the pictorial record, such as names of places and persons.

Toponymic 'hieroglyphs' are a crucial category both for the understanding of pictography and for the connection of the contents of a document to reality. Such signs have a long tradition: in the Oaxaca area they already occur in Late Formative and Early Classic inscriptions, such as the carved stones set in the walls of Mound J in Monte Albán. The conventions are well-known because of the enormous number of such signs in Mexica pictographic lists of conquered towns that rendered tribute to their empire. A key example is Codex Mendoza, painted after the Spanish invasion, still during the first half of the 16th century. It contains a short history of the foundation of Mexico-Tenochtitlan, a list of the Mexica rulers and their conquests, as well as a description of education and daily life. The pictorial scenes are accompanied by Spanish explanations and glosses. The placename signs are identified by their Nahuatl names written with the Latin alphabet, which are relatively easy to translate.

Since Samuel Purchas published drawings of the Codex Mendoza in 1625 , this document has become one of the most important foundations for iconological studies and for research on the Mexica world in general. In his monumental edition of Codex Mendoza, James Cooper Clark (1938) included a comprehensive analysis of the place signs, their glosses in Nahuatl and their etymologies. Later Karl Anton Nowotny (1959b, 1967) made an index of this list and categorized the different signs. Following this method in his commentary on the Matrícula de Huexotzingo, Prem (1974) has added a substantial set of onomastic signs to the corpus. These works, together with similar studies by several other authors (e.g. Reyes García 1993, 1997), contain a Nahuatl 'pictographic dictionary' that is fundamental for reading the codices. 
Toponyms and place signs are formed by the combination of a geographical category (mountain, river, rock, etc.) with a specifying adjective (e.g. a color) or second noun. Most nouns in place names are rendered as icons (figurative representations, in the form of stylized drawings, mostly in profile). Where words could not be rendered iconically, special conventions or signs of an arbitrary nature ('ideograms') had to be invented. An example is the X-shaped sign for 'earthquake' (ollin). Sometimes the painters chose to depict a homonym. Such cases are classified as 'phonetic writing': only the phonetic value of the sign is used, not its semantic value.

In order to understand the etymology of a toponym and its relationship with the place sign, we need to have at least a basic knowledge of the relevant Mesoamerican languages. Most research has focused on Nahuatl, but the conclusions about the pictorial conventions are generally also valid for documents painted by speakers of other languages. Let us illustrate this with some representative examples from Codex Mendoza, p. 43 (corresponding to f 12r of the Matrícula de Tributos), which shows the tributes of towns in the Mixteca Alta.

- A bell-shaped form is the schematic rendering of a mountain (tepetl in Nahuatl). A filling of black dots on a white background represents 'sand' (xalli). Together they read Xal-tepe-c, 'On the Mountain of Sand'.

- The sign of Coixtlahuaca, 'Valley of the Serpents', consists of an iconic rendering of a serpent (coatl) on top of a rectangle filled with dots and hooks, which is a conventional sign for earth (tlalli), a field (milli) or a plain (ixtlahuacan). Eyes (ix-tli) are added to the rectangle as a phonetic complement to guarantee the reading ixtlahuacan.

- Yanhuitlan, 'New Place', is painted in the form of a white blanket, a convention to indicate the quality 'new' (yancuic), in combination with a tooth (tlan-tli), a near homonym for the place name suffix -tlan, which in itself is difficult to depict.

- In order to represent Mic-tlan, the Place of Death, two indexical references to death (miquiztli) are used: a skull and a mummy bundle, both depicted iconically in profile. In this case the locative suffix -tlan is simply not specified. 

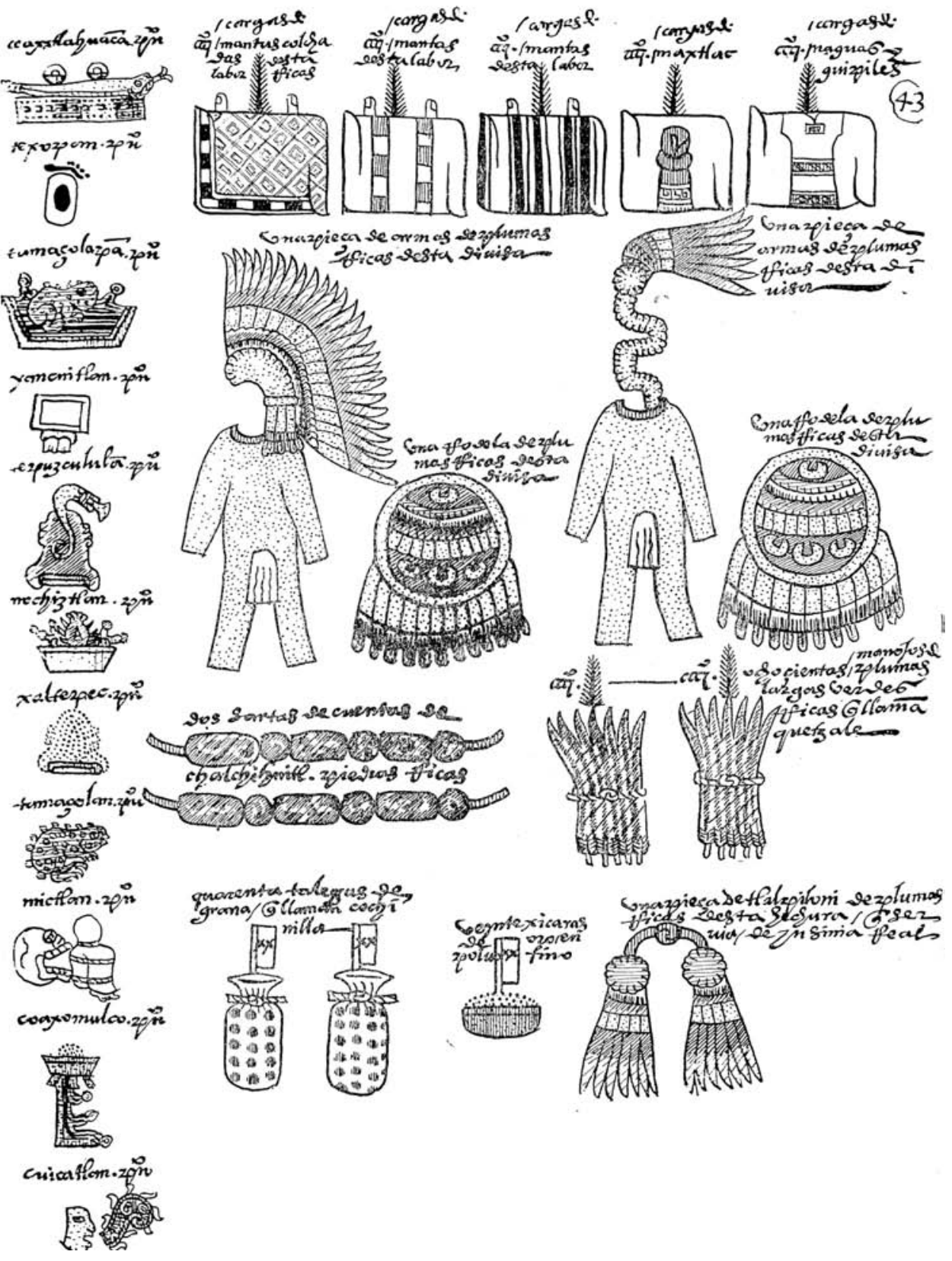

1.7. Codex Mendoza, p. 43: places from the Mixteca Alta and their tributes. 
There are also cases in which only the semantic value counts, without reference to the phonetics, e.g. the addition of a mountain or house for the general notion 'place'.

- The toponym Tepozcolula probably means 'Place (-lan) of the Copper (tepoz-tli)-colored Terraces (colol-li)', but is analyzed as 'Place (-lan) of the Curved (coltic) Axe (tepoz-tli)'. Consequently an axe with a curved helve is drawn on top of a mountain, which functions here as a semantic determinative.

The analysis of the place signs, identified with their Nahuatl names in Codex Mendoza, is the point of departure for studying the conventions in the representation of toponyms in other areas. Glosses in a number of early colonial manuscripts from the Nuu Dzaui region produce a pictographic dictionary of much smaller dimensions, but essentially similar to the one that has been elaborated on the basis of Nahuatl manuscripts. ${ }^{11}$ This is enough, however, to demonstrate that Nuu Dzaui pictography operates in the same way as that of the Mexica. In the concrete case of the toponyms the structuring principles are identical, but the character of both languages is quite different. While Nahuatl is polysynthetic and not tonal, Dzaha Dzaui is a tonal language, which means that words pronounced with different tones have radically distinct meanings. For example, in Sahin Sau, the modern dialect of the area of Nuu Ndeya (Chalcatongo) and Nuu Kahnu (San Miguel el Grande), with which we are most familiar, yukù (with midlow tones) means 'herb', but yuku (mid-mid) 'mountain', and ñuhù (mid-low) is 'fire', but ñuhu (mid-mid) 'earth, land'. ${ }^{12}$

Due to the different structure of both languages, the elements in the toponym are in opposite order. For example 'Black Mountain' in Nahuatl is Tliltepec (from tlilli, 'black', tepetl, 'mountain' and the locative suffix -c), but in Dzaha Dzaui Yucu Tnoo (from yucu, 'mountain' and tnoo, 'black'). Both pictographic systems represent it as a bellshaped drawing (mountain) painted black.

${ }^{11}$ Mary Elizabeth Smith has laid the foundations for the systematic analysis of Nuu Dzaui place signs in a classic monograph (1973a) and deciphered several other important signs in her study of the relationship between signs and language (1973b). A fundamental compendium of the sources about the ancient towns is Gerhard 1972. Examples of new decipherments of place signs in specific historical contexts are: Roskamp 1999, Asselbergs 2004, Castañeda de la Paz 2006, and Gutiérrez Mendoza \& Medina Lima 2008.

${ }_{12}$ See Dyk \& Stoudt 1973, Macaulay 1996, and Pérez Jiménez 2008. 

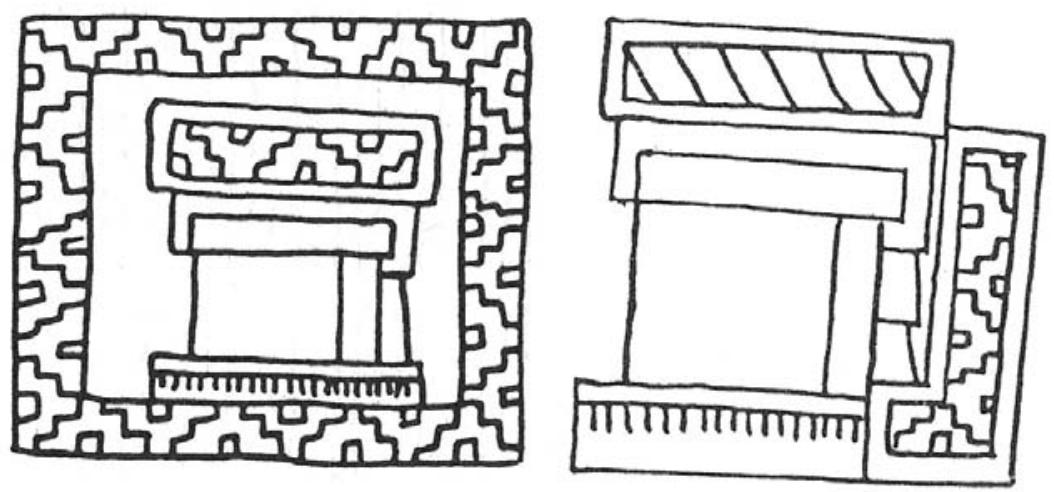

1.8. Codex Yuta Tnoho, pp. 11-12: siqui or 'wards'.

Where Nahuatl uses a large number of locative suffixes (-tlan, -co, -c, etc.), Dzaha Dzaui has a specific noun for 'town', 'village' or 'peo-

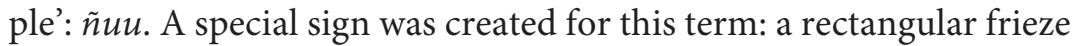
with a step-fret motif. Thus the Nahuatl Mictlan corresponds to Nuu Ndaya, 'Town of Death', in Dzaha Dzaui, which may be painted as a frieze with a skull. The step-fret motive ( $\tilde{n} u u$ sign) already occurs in the Classic Period (the so-called Nuiñe style) and seems to be derived from Teotihuacan.

The $\tilde{n} u u$, 'town', was divided in siqui, 'wards' (barrio in Spanish). This term can also mean 'corner', thus it was painted as a frieze formed as an angle or square (Codex Yuta Tnoho, pp. 12-11).

Another special Mixtec sign is the feather carpet representing 'plain', a convention derived from the fact that the words 'large feather' and 'plain' are both yodzo in Dzaha Dzaui. The locative prefix $a$ - is painted as an open mouth and chin $(d z a a)$. Thus Xaltepec (presentday Magdalena Jaltepec) in Dzaha Dzaui is called A-ñute, 'Place of Sand', which may appear as a mouth $(a-)$ that seems to spit out a white volute with black dots ( $\tilde{n} u t e$, 'sand').

Further categorical elements are identical to those in Mexica pictography, for example: river (yuta; Nahuatl: -apan), house (huahi; Nahuatl: calli, -calco) or altar base (chiyo; Nahuatl: teocalli, teopan), all represented conventionally in a cross-section. A typical Mesoamerican structure is the ballcourt (yuhua; Nahuatl: tlachco), repre- 


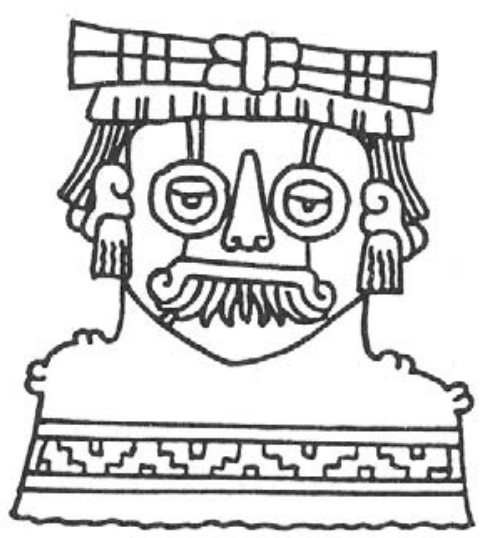

1.9. Codex Yuta Tnoho, p. 45-IV: Ñuu Dzaui.

sented as seen from above, in the shape of a double T. The cliff (cavua) or rock (toto) is a mountain, painted in colored bands, indicating the different geological layers. The same pattern in a round or oval cartouche represents 'stone' (yuu; Nahuatl: tetl).

The name of Nuu Dzaui itself is represented as the combination of a frieze ( $\tilde{n} u u)$ with the head or mask of the Rain God (Dzaui, in historical orthography: Dzavui; Nahuatl: Tlaloc). The latter is characterized by a face or mask with 'goggle eyes' and large teeth. ${ }^{13}$

\section{Days and Years}

The historical character of the story told in the codices is made explicit by the fact that events are dated. A hendiadys (difrasismo) expresses the concept of time in Dzaha Dzaui: quevui cuiya, 'days and years', while the term huico means 'period, feast'. The main ordering principle in the pictorial manuscripts, either historical or religious in nature, is the Mesoamerican calendar, based on a sequence of twenty signs. This is a logical unit in the vigesimal counting system, which is characteristic of the different Mesoamerican languages and comes from the corporal device of counting with fingers and toes. The names and function of the Postclassic standard sequence are well defined by

13 See for example the central sign on page 47 of Codex Yuta Tnoho. The Nuu Dzaui sign also appears in the given names of several historical personages. 

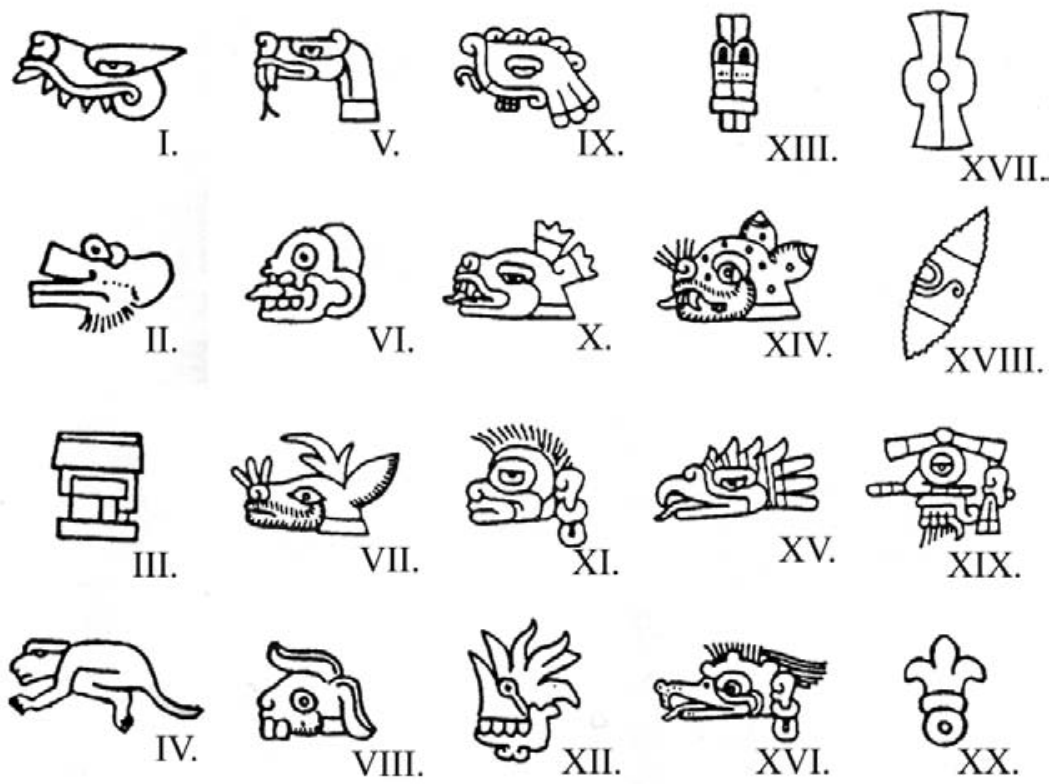

1.10. The twenty day signs of the Mexica and Nuu Dzaui calendar.

many Central Mexican sources. The terms in Nahuatl are words of daily usage for the elements depicted, but in Dzaha Dzaui a special calendrical vocabulary was used, quite distinct from the normal terms.

I. Alligator (cipactli in Nahuatl): a profile view of the head of the animal in question, with its characteristic jaw and row of sharp teeth. The special term in Dzaha Dzaui is: quevui, which is the normal word for 'day'.

II. Wind (ehecatl): the beaked head of the Wind God. The special term in Dzaha Dzaui is: chi, which seems to be a shortened form of the normal word for 'wind', tachi.

III. House (calli): a profile representation of a house, with a flat or a thatched roof. The special term in Dzaha Dzaui is: cuau, maa. These are probably archaic words that refer to darkness.

Simaa is one of the words for 'owl', maa means 'deep inside' and the verbal root cuaa refers to the 'falling of the night'. In the Classic Period we also find the frontal representation of an owl's head. 
IV. Lizard (cuetzpallin): the full figure representation or only the head of a lizard. The special term in Dzaha Dzaui is: q, que, which is actually closer to the term for 'bee', tequee, than to that for 'lizard', tiyechi.

V. Serpent (coatl): the full figure representation or only the head of a snake. The special term in Dzaha Dzaui is: yo, sounding like a shortened version of yoo ('moon', 'reed', 'jar', 'crest') or yoho ('cord'). The normal word for snake is coo.

VI. Death (miquiztli): a skull. The special term in Dzaha Dzaui is: mahu or maha. Maybe this term is related to tamaa, 'hunger'.

VII. Deer (mazatl): the head of the deer, often but not always with antlers; generally the teeth in the lower jaw are shown. The special term in Dzaha Dzaui is: cuaa. Normally this is the word for 'yellow'; in some places it is still known as an archaic reference to 'deer'. In daily usage the word for 'deer' is idzu.

VIII. Rabbit (tochtli): the head (often with teeth in the upper jaw) or the full figure of a rabbit. The special term in Dzaha Dzaui is: sayu, quite distinct from the normal word idzo.

IX. Water $(a t l)$ : a cut-through profile of a container with blue liquid, often with foam or brilliant disks on the surface. The special term in Dzaha Dzaui is: tuta. This is probably an archaic version of nduta, 'water'. According to Alvarado nduta caya and tuta caya ('bebida de maíz morada') are synonymous.

Today tuta (in Nuu Ndeya: tucha) is known as a special souplike dish, locally known as chiliatole.

X. Dog (itzcuintli): the head of a dog, with a characteristically cut (bitten) ear. The special term in Dzaha Dzaui is: hua.

This may be a shortened version of the word for 'coyote': ehu$a h u$ or a onomatopoeic reference to the barking of the dog.

XI. Monkey (ozomatli): again the head of the animal. The special term in Dzaha Dzaui is: $\tilde{n} u u$. In daily usage this word has many meanings, including 'palm tree', 'willow', 'drum', 'town', 'people' and 'night', while ñuu cuii is a species of mountain cat or fox.

XII. Grass (malinalli): a lower jaw of a human skull in combination with green leaves (or feathers) and sometimes with an eye. The special term in Dzaha Dzaui is: cuañe. This is the normal term for 'adverse, difficult' and close to the word for 'squirrel' (сuaño). It is interesting to note that cañe noho means 'gnashing of teeth' (noho being 'tooth') while yocuañe is a verb for having an aching stomach or feeling the pains of labor. 
XIII. Reed (acatl): a bamboo reed, often taking the shape of an arrow, decorated with small feathers. The special term in Dzaha Dzaui is: huiyo. Actually this is the word for 'sprouting milpa' (cf. yoo, 'Reed').

XIV. Jaguar (ocelotl): the head of the animal in profile, with its characteristic pointeourd ear. The special term in Dzaha Dzaui is: huidzu. Alvarado mentions ñaña idzo as the name of a species of mountain cat; huidzo signifies 'the word of the ruler', 'law'.

XV. Eagle (cuauhtli): the head of the bird in profile, with white and black feathers falling back behind it. The special term in Dzaha Dzaui is: sa. Probably this is an shortening of sasa, 'falcon'.

XVI. Vulture (cozcacauhtli): the bald head of this bird, often decorated with an earring. The special term in Dzaha Dzaui is: cuii. Possibly this is an archaic version of the word for 'vulture': sii, which also can mean 'grandfather' and 'pearl'. Today cuii is 'green' and 'clear'.

XVII. Movement (ollin): an ideogram in the form of an X. The special term in Dzaha Dzaui is: qhi. We suspect a relationship with cahi, which means 'agitate', but also 'abundant, wide, many' and 'patio'. We might also think of a shortened form of siqui, 'quadrant', 'corner', 'ward', 'fist' and 'wave'.

XVIII. Flint (tecpatl): a pointed flint knife in red and white. The special term in Dzaha Dzaui is: cusi. The reference is probably to the verbal stem cusi, 'cutting'. The normal word for 'flint' and 'knife' is yuchi.

XIX. Rain (quiahuitl): the mask of the Rain God with jade rings around the eyes and large teeth. The special term in Dzaha Dzaui is: co. This recalls the normal word for 'serpent' (coo), maybe as an abreviation of coo dzaui, 'Rain Serpent', a term for the cloud formations that announce storm and rain.

XX. Flower (xochitl): the profile of a stylized yellow flower. The special term in Dzaha Dzaui is: huaco. This is the normal word for a climber plant, but also the root of tehuaco, 'guacamaya'.

The day signs are mostly derived from Nature. The first, Alligator, is a metaphor for the Earth itself. We find references to elements like Wind, Water, Rain, Flint, Movement (or Earthquake) and Death. A few plants appear: Grass, Reed, Flower, as well as a relatively large number of animals, some in significant combinations: Lizard and 
Serpent, Deer and Rabbit, Dog, Monkey, Jaguar and Eagle, Vulture. The only sign that refers to a human artefact is House, but that seems to be a later introduction: its earlier form was Owl.

These twenty signs are combined with numbers from 1 to 13 . The numbers were indicated by prefixes, which in Dzaha Dzaui again differ notably from the normal numerals (given here between brackets):

$$
\begin{aligned}
& 1=c a, c o[e e] \\
& 2=c a, c o[u v u i] \\
& 3=c o[u n i] \\
& 4=q h, q u i[q m i] \\
& 5=q, q h u[o h o] \\
& 6=\tilde{n} u[i \tilde{n} o] \\
& 7=s a[u s a] \\
& 8=n a[u n a] \\
& 9=q, q h u[e e] \\
& 10=s i[u s i] \\
& 11=s i, \text { sii }[\text { usi ee }] \\
& 12=c a[\text { usi uvui] } \\
& 13=s i[\text { usi uni] }
\end{aligned}
$$

In some cases these prefixes seem to be shortened forms of the normal terms for the numbers: $q h$ corresponds to $q m i(4), \tilde{n} u$ to $i \tilde{n} o$ (6), sa to usa (7), na to una (8) and si to usi (10). The other terms clearly have a different, probably very archaic, origin.

The combination of number (1-13) and sign (I-XX) results in a basic cycle of 260 days $(13 \times 20)$, which is called tonalpoalli, 'day count', in Nahuatl. The first day is 1 Alligator, then follows 2 Wind, 3 House and so on until 13 Reed, which ends the first thirteen-day period (Spanish: trecena). The next thirteen-day period starts with 1 Jaguar and continues to 13 Grass, and so on, until the twentieth period of thirteen days, which brings us to the last day of the tonalpoalli: 13 Flower. The origin of the 260 -day count is probably related to divinatory, mantic, purposes. Traditional day-keepers, interviewed in recent times, have explained that the 260 days represent the period of human pregnancy. ${ }^{14}$ In it the basic sequence of 20 signs is repeated

${ }^{14}$ For information provided by K'iché day-keepers, see Schultze Jena 1933-38, vol. I. The symbolic implications of the Mesoamerican calendar are discussed by Anders \& Jansen (1993) and Anders \& Jansen \& Loo (1994). 
13 times. This produces an ideal equivalence in mantic terms between the moment of conception and the moment of birth. The number 20 is diagnostic for the human being (ten fingers and ten toes). The fact that this unit of 20 (the human being) has to be counted (in pregnancy) 13 times before the conceived child is born, qualifies the 13 as a number of completeness. This becomes the point of departure for more symbolic associations. By using the axes produced by the sun's movement, the earth plain is divided into four parts with a center (yielding $4+1=5$ ). The same quadripartite division is applied to the Underworld, resulting in a total number of $9(=4+4+1)$, which indeed is the symbolic number of death. Adding the four parts of Heaven $(4+4+4+1)$, we arrive at 13 , as the sum of cosmic divisions.

Each sign and each combination of sign and number has its symbolic associations and divinatory value for actions undertaken and those born on the day in question. People are identified by their day of birth, which accompanies them through life as a 'calendar name', and expresses their connection to the symbolic order of time, space and divine power: it contains esoteric information about the possibilities, the character and destiny of the individual. Each day is guarded and guided by a series of different Patron Deities: the God of the day sign (cycle of 20), the God of the night (cycle of 9), the God of the number (cycle of 13), as well as the Gods that governed certain periods such as the units of thirteen days. To the educated readers (priests) these associations provide a symbolic dimension, which may invite specific reflections or emotions.

For agriculture and later for the keeping of historical accounts, periods of 365 days, i.e. 'solar years' (xihuitl in Nahuatl), were delineated within the continuum of 260-day cycles. Each solar year was named after a specific day, the 'year-bearer'. It was marked by a special sign, which resembles a bound or chained ray of the sun, but historically seems to stem from a diadem-like headdress. ${ }^{15}$ This 'A-O sign' as it is often called in the literature, is a characteristic feature of manuscripts from the Nuu Dzaui area. ${ }^{16}$ In Dzaha Dzaui it is read cuiya, 'year'. The

15 In the Classic inscriptions of Monte Albán the year-bearers are clearly 'crowned days'. An interesting intermediate form is found on a carved stone from Mogote del Cacique (Jansen \& Winter 1980). The future stem cuiya also appears in verbs given by Alvarado as 'to put a garland on the head' and 'to arrange the hair in the form of a crown'.

${ }^{16}$ In the Codex of Tejupan (Sierra) it is combined with a leaf, producing a bilingual reading of year in Dzaha Dzaui and Nahuatl: cuiya and xihuitl ('year', 'leaf') respectively. 


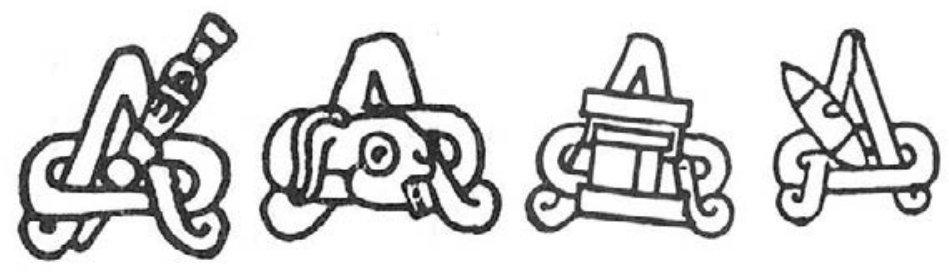

1.11. The Mixtec year sign (cuiya) with the four 'Year-bearers'.

A-O sign may be accompanied by an eye (nuu), suggesting the reading nuu cuiya, 'in the year ...'.

As year-bearers are 365 days apart, mathematics dictates that only four of the twenty day signs can occupy this position. These were: Reed (XIII), Flint (XVIII), House (III) and Rabbit (VIII), in this sequence. Because of the same mathematics the number associated with the yearbearer sign progresses one unit per year, resulting in the year-bearer sequence: 1 Reed, 2 Flint, 3 House, 4 Rabbit, 5 Reed, 6 Flint, and so on until 13 Rabbit, after which the year-bearer 1 Reed returns and a new year cycle begins. As each of the four year-bearer signs appears in combination with each of the 13 numbers, the cycle consists of 52 years. This cycle was called a xiuhmolpilli 'binding of years' in Nahuatl. Friar Francisco de Alvarado registers different Dzaha Dzaui terms for it: dziya, which, we suspect, is a specific technical term for this period, or dzini toto 'head, rock', which we interpret as a hendiadys (difrasismo) for 'unit', as the same expression is used for 'degree of kinship'.

Full dates consist of a day in the 260-day cycle and of a year-bearer. Thus, events are dated in cycles of 52 years. Often the sequence is clear, as birth, marriage, and death of an individual have to occur in that order; but if the record is incomplete it becomes a problem to correlate dates in the cyclical Nuu Dzaui historiography with the linear yearcount of the Christian calendar.

Dates are not only markers of a chronological sequence, but also indicators of rituals and commemoration events, which are important moments for shaping a community's identity. Today the public life of a Mixtec village is structured around such fiestas. Some are intimate and clear refigurations of precolonial religion: the Days of the Dead (October 31-November 2), and the Holy Cross (May 3). Others are the public festivities of the Catholic liturgy, such as the celebration of the Patron Saint, Lent, Semana Santa (Easter), which may also contain 


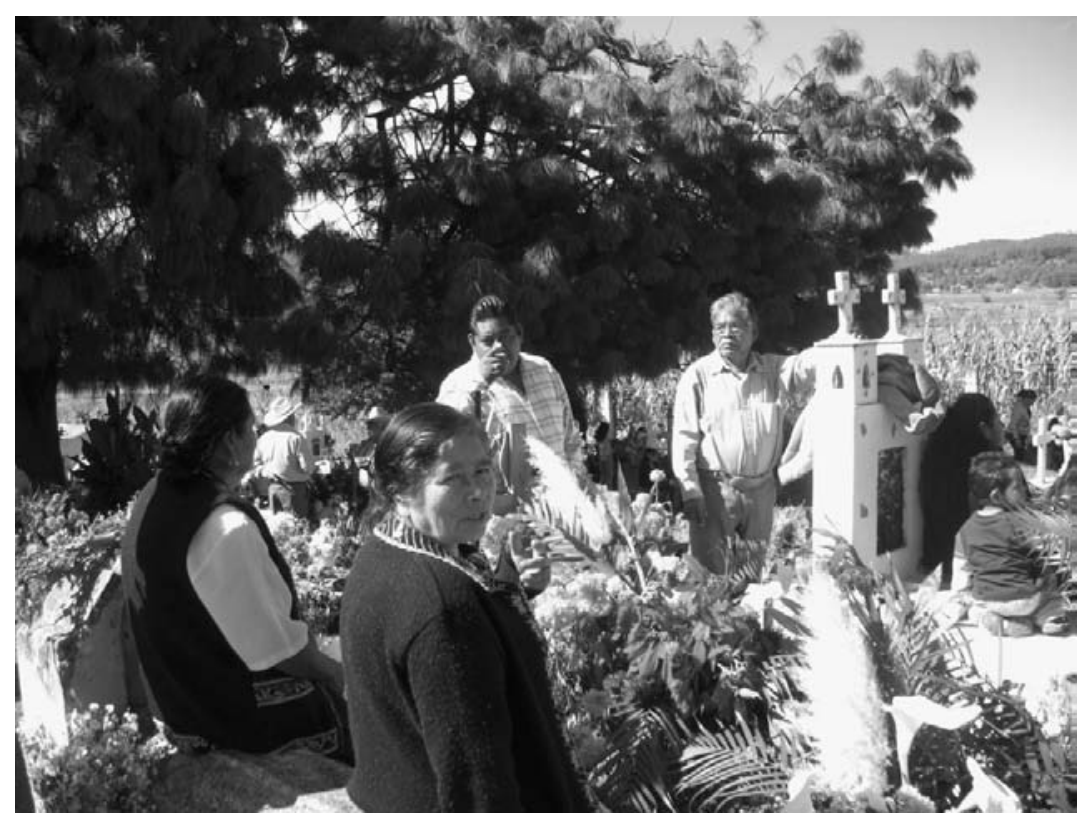

1.12. Day of the Dead: sharing a meal in the cemetery.

implicit references to ancient festivals. The latter rites are carried out by groups of citizens as mayordomos, novenarios and madrinas, who by this ritual performance become connected as 'compadres' and 'commadres', respecting one another as ritual kin. The participation in organizing such a fiesta implies many (costly) activities, such as the making of candles, the cutting of wood, the preparation of meals for family, friends, and neighbors, the regular cleaning and decoration of the church, etc. The offerings of incense in the traditional tripod vessels, the carrying of the mayordomo's chest as if it were a Sacred Bundle, the reciprocity and piety involved, are all elements that recall - and continue - ancient customs and ideas.

\section{Kings and Queens}

The pictorial manuscripts depict human and divine personages involved in specific actions, within a temporal and spatial dimension. They are conventionally represented as figures in profile, not as individual portraits, but as pictographic elements. Men are character- 


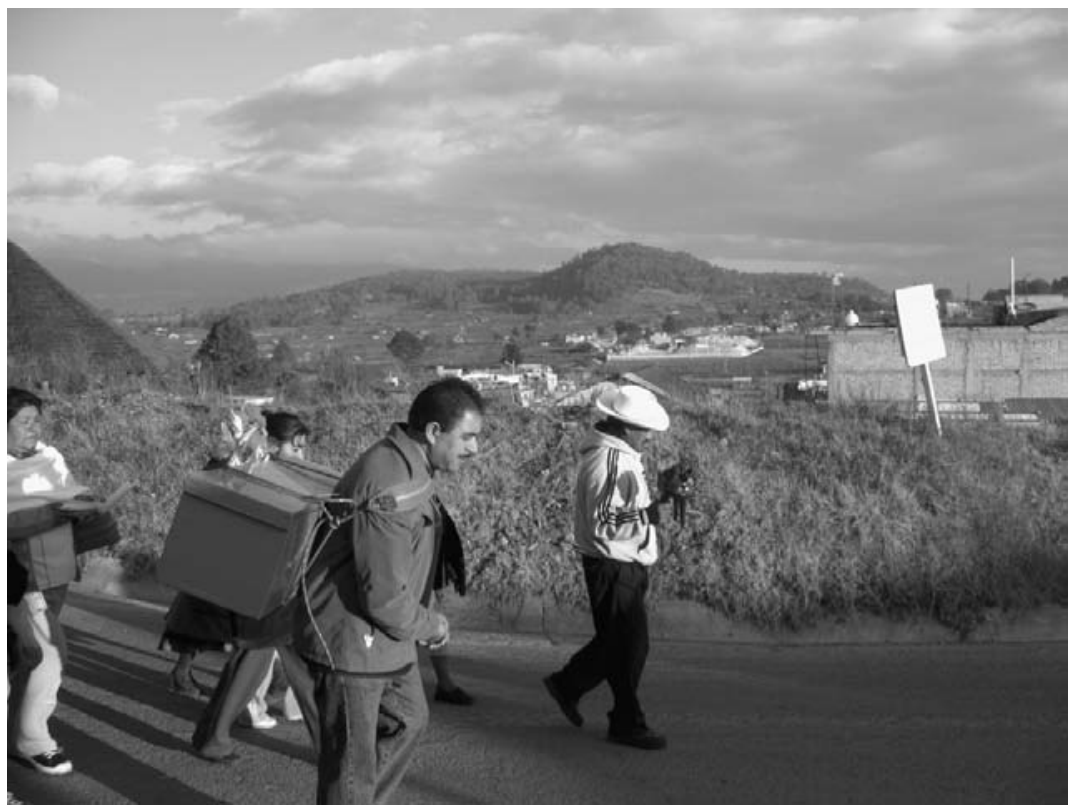

1.13. The mayordomo carrying his chest.

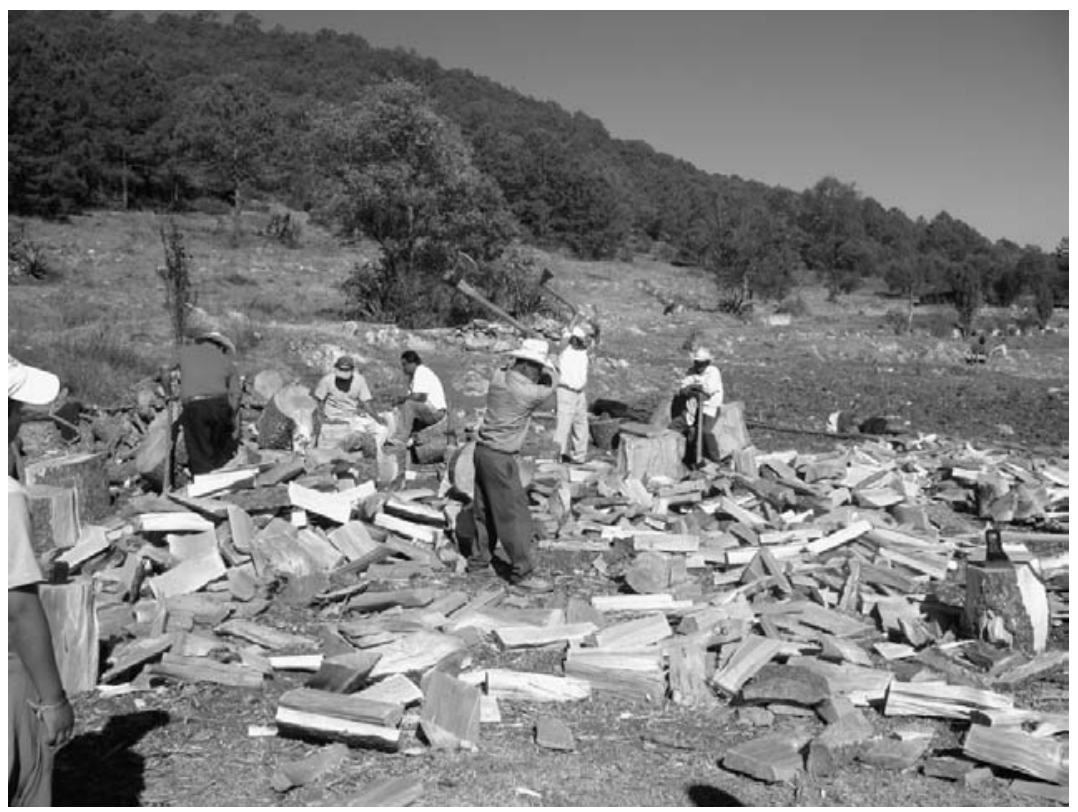

1.14. Cutting the fire wood for the fiesta. 
ized by their short haircut, and loincloth or tunic (xicolli in Nahuatl), women by their braids, and long dress (huipil) with upper garment (quechquemitl). Their actions are qualified through conventional positions and specific attributes or objects. A seated couple on a mat represents a marriage, a man with black ointment with an incense burner in his hand is a priest, a man armed with shield and club or dart-thrower is a warrior, while a place sign perforated by a dart or a toppled temple in flames indicates a conquest.

Generally the protagonists belong to the dynasties that ruled the communities in the region. Their Dzaha Dzaui titles iya, 'Lord', and iyadzehe, 'Lady', connote a special sacred status. Consequently they were addressed with great respect, in a special reverential language, full of elegant expressions, metaphors and archaisms. Early colonial sources, such as Herrera, describe these Lords and Ladies as elegant in appearance, dressed in white cotton clothes, embroidered with colorful motifs, such as flowers and birds. They wore sandals and jewelry such as rings, necklaces, and nose-, ear- and lip-plugs of gold, crystal and precious stones. Their palaces, furnished with woven reed mats and cushions of jaguar- and puma- hides, were surrounded by beautiful gardens. They governed a complex society of counsellors, merchants, priests, teachers, healers, ambassadors, warlords, warriors, and, of course, peasants. Between the tributary farmers and the central authority, there was an important group of intermediate, lower nobility, often called the principales (toho), whom the ruler used to consult for major decisions. ${ }^{17}$

A roof decorated with stone mosaics, especially a frieze with disks or circles, distinguishes the palace (aniñe in Dzaha Dzaui; tecpan in Nahuatl) both in pictorial representations and in reality - a beautiful example of such a building is the Casa de la Cacica in Yucu Ndaa (Tepozcolula). It is both an iconic representation of the rulers' home and a symbolical representation of their lineage. ${ }^{18}$ As an alternative the

${ }^{17}$ Herrera decade III, book III, ch. 12; cf. the Relación Geográfica of Chila, Acuña 1984-85, II: 44. The position of the early colonial caciques of Nuu Dzaui has been clarified by Spores (1967, 2007) and Terraciano (2001). Friar Antonio de los Reyes includes a brief vocabulary of the reverential 'lordly' language (1976: 74-81); see also Jansen 1985.

18 See Batalla Rosado's brilliant iconographical analysis of the tecpan in Jansen \& Reyes 1997. The Mapa Quinatzin offers a detailed graphic representation of its layout and use (e.g. Offner 1983: ch. 2 and Corona Sánchez 2002). The reading aniñe in Dzaha Dzaui is documented by glosses in the Codex of Yodzo Cahi (Yanhuitlan). For historical comments on the Casa de la Cacica, see Kiracofe 1995 and Terraciano 2001: 


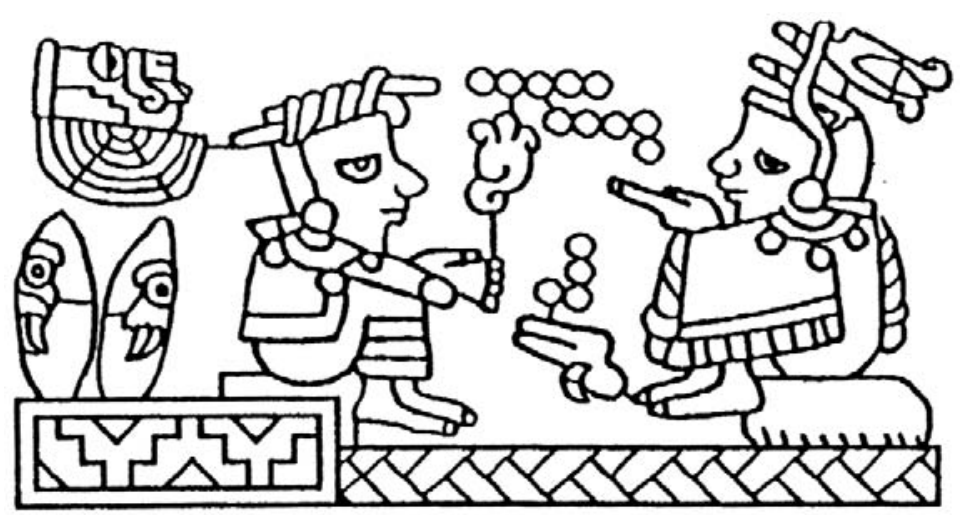

1.15. Codex Añute, p. 8-IV: Lord 4 Wind 'Fire Serpent' (Yahui) and Lady 10 Flower 'Spiderweb of Rain' (Dzinduhua Dzavui) are seated on the marriage mat, and rule the Town of Flints (Nuu Yuchi).

rectangular frieze with a step-fret motif could be painted in the roof, indicating that this was the house of the village-state $(\tilde{n} u u)$. We find the antecedent of these conventions already in the visual art of Teotihuacan: the frescoes of Tetitla, for example, show a path going to a house the roof of which is decorated with disks and the $\tilde{n} u u$ frieze, while an added mat motif characterizes it as the seat of rulership (Fuente 1995: 308).

Sometimes such a palace appears in the Nuu Dzaui codices surrounded by small lines or marks (Codex Yuta Tnoho, p. 11). The latter sign, we propose, represents tnuni, 'line, signal, symbol', which - often coupled with the term tniño, 'work, task' - occurs in expressions for 'law', 'to judge', 'to order' and 'to rule'. The combined configuration then may be read as aniñe iya, huahi tasi tnuni tniño, 'the palace of the Lord, the house where orders are given and judgments are pronounced'.

Two types of name are used to identify the protagonists of Nuu Dzaui history. First there is the calendar name, which is the day on which the person was born, such as 8 Deer or 6 Monkey. This naming practice has survived until today in the guise of giving a child the name of the

$160 \mathrm{ff}$. Garza Tarazona 1978 gives an overview of the architectural representations in the codices. 


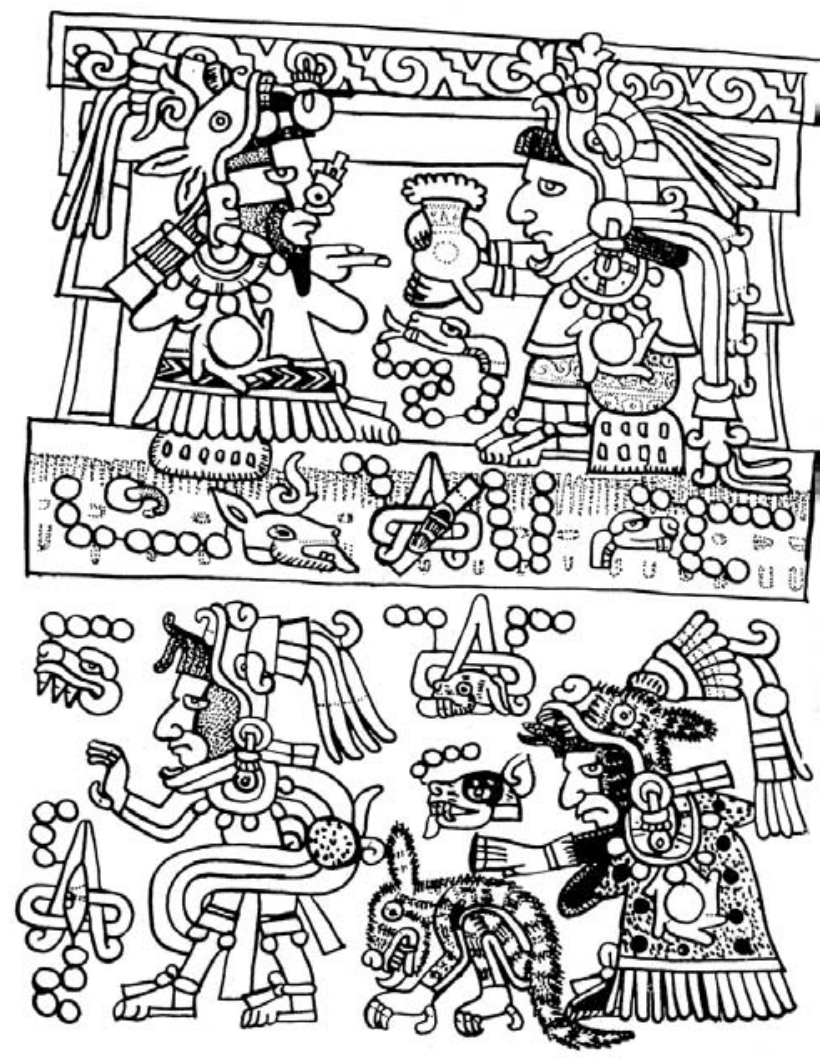

1.16. Codex Tonindeye, p.26-III (Top to Bottom): in the year 13 Reed [AD 1103], on the day 13 Serpent, Lord 8 Deer 'Jaguar Claw' marries Lady 13 Serpent [here erroneously written as 12 Serpent]. In the year 7 Rabbit [AD 1110] their first son, Lord 4 Dog 'Coyote Catcher' is born. In the year 9 Flint [AD 1112] Lord 4 Alligator 'Sacred Serpent' is born.

Patron Saint of its birthday. Such a name is called dzevui. In addition Alvarado registers the term dzeque, a word that can also mean 'jewel' and 'head'. We find it in the 'name taken from a forefather': dzeque iya nisanu ninaquaiya, literally 'the name that an old Lord left'. It is likely that this term referred to the ancient 'given name', which each individual carried in addition to the calendar name. In pictography this given name is often put as a separate sign close to or on top of a person's head. 
The Ladies have given names that refer to flowers (ita), jewels (dzeque, yusi) and other beautiful aspects of nature, for example Nduvua Dzisi Andevui, 'Spiderweb that Filters the Sky', meaning 'Transparent Spiderweb', Yusi Ticuvua Tiyoo, 'Jewel, Butterfly, Tortoise', and Tedzaa Ndodzo Cuisi, 'White Quetzal Bird'. The sun with a heart or spirit face in it is read as Tacu Ndicandii, 'Living Sun'. ${ }^{19}$

A special case is that of the woman's upper garment being used as a basic element for female names. One might think that it is a metonym for 'lady', but we propose to read it in a phonetic way. In Nahuatl it has a characteristic triangular shape and is called quechquemitl, a word also used in the descriptive studies of Nuu Dzaui pictography. Actually in Nuu Dzaui codices this upper garment often seems to be a short dress or huipil, combined with a skirt. Alvarado's dictionary does not give a Dzaha Dzaui term for the garment known as quechquemitl in Nahuatl, but the 'shirt worn by the native women, called huipil' is: $d z i c o .{ }^{20}$ Indeed, in the coastal region the corresponding word shiku refers both to the huipil (gown) and to a piece of cloth that is folded in a triangular shape and worn as an upper garment.

The word dzico is important: it not only designates that type of dress, but also the abstract concepts of 'nobility', 'beauty', 'honor', 'bravery' 'fame', 'virtue' and 'authority'. Thus, combinations such as 'Star Quechquemitl' or 'Jade Quechquemitl' may actually have been read as references to the beauty of stars and jewels respectively, while 'Jaguar Quechquemitl' may be understood as 'Brave as a Jaguar', and 'Blood Quechquemitl” as 'Of Noble Blood'. The combination of a quechquemitl with a plumed serpent (which occurs in the given name of the famous Lady 6 Monkey) may be read as 'Dzico Coo Yodzo' or

${ }_{19}$ Nduvua Dzisi Andevui is mentioned in Codex Nuu Naha, p. 3; Yusi Ticuvua Tiyoo in Codex Ñu Ñaña, p. 15; Tedzaa Ndodzo Cuisi in Codex Nuu Ñaña, p. 21; Tacu Ndicandii in Codex Nuu Naña, p. 16. See also the studies of the personal names in the Nuu Dzaui codices by Smith (1973b) and Hermann Lejarazu (in: Van Doesburg 2008: 197-213).

20 'Camisa que usan las indias, que llaman huipil'. The same term is given by the Relación Geográfica of Yodzo Cuiya or Juxtlahuaca (Acuña 1984, I: 287). Studying the given name 'Sun above Quechquemitl', read as Tnono Yucu Dzini (Nuu Naha, p. 7), Smith (1973b) explored the possibility of 'quechquemitl' being any of those three words. We think that Tnono Yucu Dzini means 'Arch (tnono) of the Pleyades (yucu dzini)' and suspect that the quechquemitl-like object is actually an inverted arch, while the half sun disk may be a somewhat misleading rendering of what should have been a big star sign. 


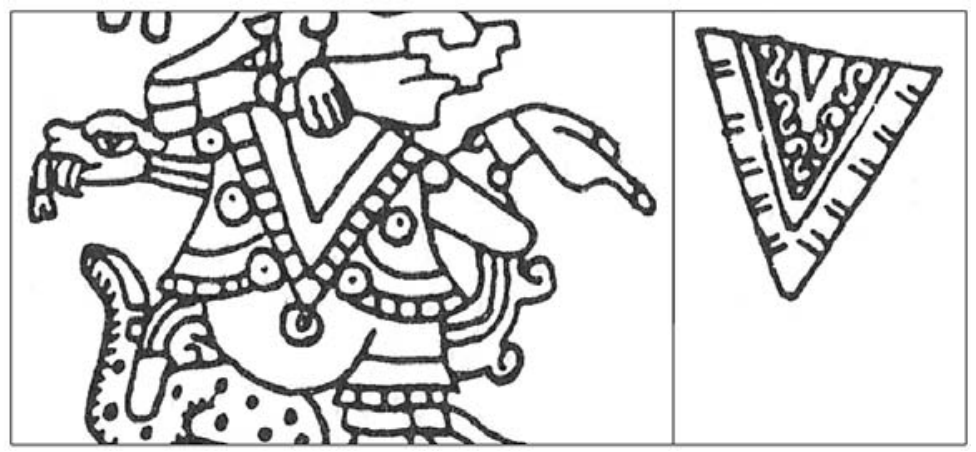

1.17. Examples of the quechquemitl (dzico) in Codex Yuta Tnoho.

'Dzico Coo Ndodzo', 'Virtue of the Plumed Serpent'. ${ }^{21}$ We also find a combination of the Plumed Serpent with a quechquemitl that contains a conch shell (Lady 3 Flint in Codex Tonindeye, p. 14 ff.). The conch shell is yee in Dzaha Dzaui and may have been used as a phonetic writing of the abstract quality 'strength' (yee). As the conch shell (yee) is painted inside ( $\mathrm{ini}$ ) the quechquemitl it is even possible to read it as yee ini, 'magnanimous'. In present day Nuu Ndeya (Chalcatongo) the concept referred to is tiyii, 'strong (not only physically, but also mentally)', 'brave' or 'capable'. The name of the 'Shell (yee) Quechquemitl (dzico)', then, is probably to be read as the paired qualities of 'strength' (yee) and 'virtue' (dzico) of the Plumed Serpent.

When the concept of 'fame', 'nobility' or 'virtue' (dzico) occurs in the name of a man, it is represented by the xicolli-tunic, which is also called dzico in Dzaha Dzaui.

Another female name sign contains the drawing of a skirt. We find, for example, a Lady named 'Skirt of Rain'. The position of the determining sign on the skirt suggests that more precisely the border or fringe of the skirt is the main element. That part of the garment is called huatu in Dzaha Dzaui, a homonym of a term that means 'nice', 'happy', 'content' and 'grace'. 22 Thus 'Skirt of Rain' may be understood as 'Pleasant Rain' and even as 'Grace or Glory of Nuu Dzaui'. The same

\footnotetext{
${ }^{21}$ Dzico coo also means 'serpent's venom'. For the use of dzico, 'virtue' in the disfrasismos of contemporary ceremonial speech, see López García 2007.

${ }^{22}$ Cf. sa huatu: 'linda cosa'; caa huatu: 'gentil hombre o hermosa mujer'; yoquidza huatundi inita: 'agradar a otro'.
} 


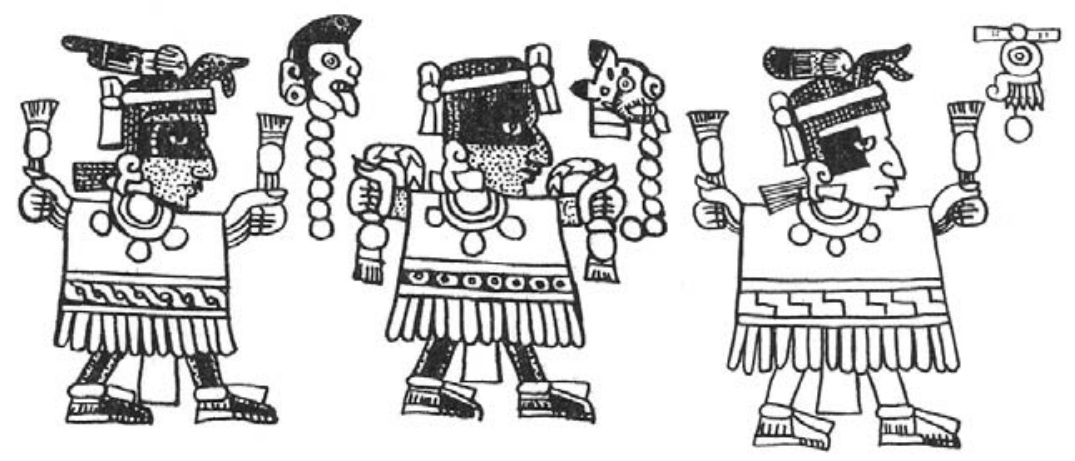

1.18. Priests holding xicolli tunics (dzico) in Codex Tonindeye.

word may be depicted as a woman's braids (also huatu in Dzaha Dzaui). ${ }^{23}$ Clearly huatu and dzico are parallel concepts, and often appear combined.

The given names of the Lords often include animals that function as symbols of strength and courage, such as jaguars (cuiñe, ñaña) and eagles (yaha), but also divine powers such as sun (Ndicandii) and rain (Dzavui / Dzaui). An important underlying idea is the still widespread dream-experience of having an 'animal companion' or 'alter ego' in nature, the nahual or tonal (tona, tono). This hidden potential of becoming a being in nature is related to the concept of power, conceived as a cooperation with the deities in their creation and maintenance of the natural cycle of life, and as a post of protecting the community, its frontiers, harvest and well-being (see for example López Austin 1980 and Navarrete Linares 2000). The term, and the underlying vision or dream-experience, was distorted as 'magic', 'witchcraft' or 'nigromancy' in the vocabulary of the Spanish inquisitors. Anthropologists have theorized about it as a form of worldview ('nahualism'), often equated with 'shamanism', a problematic term in itself (cf. Klein et al. 2002). Here we limit ourselves to noticing that several names of individuals in the codices express the strength of

${ }^{23}$ An example of a name that includes the skirt (huatu) is that of Lady 1 Vulture in the codices Tonindeye, p. 25-II, Nuu Tnoo-Ndisi Nuu, p. 7-I and Yuta Tnoho Reverse, p. V-1. Braids occur in the name of Lady 5 Wind (Nuu Tnoo-Ndisi Nuu, p. 29-II/III). In the latter case we find a clear parallel between her given name, 'Braids Vapour', and that of her brother, 'Xicolli Vapour'. As vapour can be read yoco, 'spirit', we may understand these two names as Huatu Yoco and Dzico Yoco, 'Graceful Spirit' and 'Noble Spirit' respectively. 


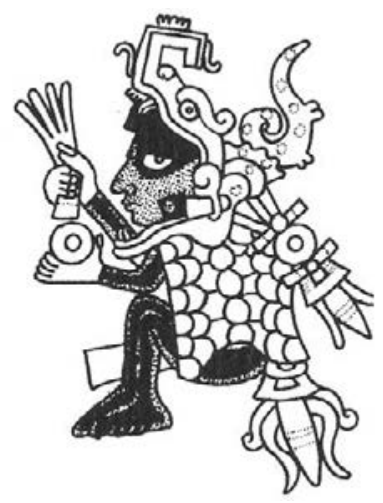

1.19. Codex Tonindeye, p. 50: a priest dressed as 'Fire Serpent' (Yahui).

animals or beings that may have been the nahual or alter ego of those persons. We find combinations such as Dzavui Ndicandii ('Rain Sun'), Dzavui Yuchi ('Rain, Flint Knife'), Nuu Coo ('Serpent's Eye'), Yaha Tnii Neñe ('Bloody Eagle Claw'), Yaha Yuhua ('Eagle of the Ballcourt'), Cuiñe Ndicandii ('Jaguar Sun'). ${ }^{24}$ A very powerful nahual is the yahui, a ball of lightning which flies through the air and is able to perforate the rocks. It is painted as a 'fire serpent', i.e. a red serpent with an up curled snout, a tortoise shell covering its body and a tail of pointed scales. ${ }^{25}$ It appears alone or in combinations such as Yahui Tnoo Yecu ('Fire Serpent that Lightens the War'), and occurs as a special outfit during sacrifices and visionary rituals.

${ }^{24}$ Dzavui Ndicandii is mentioned in Codex Nuu Naha, p. 6 and Codex Nuu Naña, p. 20, Dzavui Yuchi in Codex Nuu Ñaña, p. 23, Nuu Coo in Codex Ñuu Ñaña, p. 11, Yaha Tnii Neñe in Codex Ñuu Ñaña, p. 25, Yaha Yuhua in Codex Ñuu Ñaña, p. 29, Yahui Tnoo Yecu in Codex Ñuu Naha, p. 5, and Cuiñe Ndicandii in Codex Ñuu Ñaña, p. 30.

${ }^{25}$ The reading of the fire serpent as yahui is based on glosses (Smith 1973b). In some cases we find an onomastic sign consisting of a yahui entering heaven (Tonindeye, p. 31). A play on words is probably underlying that image: the reading andevui, 'heaven', is phonetically supported by a reference to ndevui, 'to enter'. See also Jansen 1982b: 149 and Jansen 2002. On a Postclassic shield from Acapulco we see a human being transformed in the fire serpent: the tortoise shell is replaced by the sun disk, which reinforces the interpretation of this nahual as a ball of light (Cabrera Guerrero 2008). Interestingly, a shield in the form of a fire serpent with a sun disk replacing the head appears in a drawing in the work of Martínez Gracida (1986: 28, corresponding to vol. V: 64), supposedly reproducing an early colonial painting of the first ruler of Zaachila. The combination of yahui and sun disk (ndicandii) may also represent a personal name (Codex Yuta Tnoho, p. 30; Codex Ñuu Naha, p. 8). 
In complex combinations of signs we are not sure about the reading sequence of the elements nor about the way in which words belong together. A given name represented as a jaguar that plunges a sacrificial knife into the sky, is glossed as Cuiñe Nisani Devi (= Cuiñe Nisani Andevui), 'Jaguar that Sacrificed Heaven', which can also - and more likely - be interpreted as 'Jaguar that Made a Sacrifice in or to Heaven' or 'Sacrificing Jaguar from Heaven' (Codex Ñuu Naha, p. 3).

The visual representation of the names may be based on punning with homonyms or words that only differ in tones. For example $n d u-$ $v u a$ is normally 'arrow' but in the elegant language of the Nuu Dzaui nobility it also means 'foot of the Lord', so we find the name Nduvua represented as arrows placed on the feet. The foot can then be associated with the chevron band that is read yecu, 'war', to express nduvua yecu, meaning really 'War Arrow'. ${ }^{26}$ Because of the same wordplay, the hendiadys (difrasismo) for war itself, nduvua ñuhu, 'arrows and fire', may be represented in two ways: a flaming arrow or a burning foot. ${ }^{27}$

We have already seen that nduvua with still another tone can mean 'Spiderweb' and as such occur in Ladies' names. Nuhu with other tones can mean 'earth' and 'deity'. These near homonyms lend themselves to a further play upon words. So we find a Lady 3 Rabbit Nduvua $\tilde{N} u h u$, 'Divine Spiderweb', whose son, Lord 2 Water, is also named Nduvua Nuhu, but with the more masculine meaning 'War', represented as a burning foot (pictorially to be understood as 'he who walks in war', 'warlord'). ${ }^{28}$

The names of ladies and lords alike may contain references to places that were of specific significance to them. The beloved land of origin itself appears in names such as Huichi Ñu Dzavui, 'Fan of Nuu Dzaui' or Cuiñe Ñuu Dzavui, 'Jaguar of Ñuu Dzaui'. ${ }^{29}$ In the dynasty of Ndisi Nuu (Tlaxiaco) we find given names such as Cuiñe Ndisi Nuu, 'Sharp Eyed Jaguar', and Yaha Ndisi Nuu, 'Sharp Eyed Eagle', which may also be understood as 'Jaguar of Ndisi Nuu', 'Eagle of Ndisi Nuu'. The expression sahmi nuu (mostly written as sami nuu) refers to the Nahuatl speakers (Toltecs, Mexica) and is represented as burnt eye sockets or as a combination of flames (sahmi) with an eye or a forehead (nuu). Cases such as Cuiñe Sahmi Nuu, 'Jaguar of the Mexicans',

\footnotetext{
${ }^{26}$ Codex Ñuu Tnoo-Ndisi Nuu, p. 4-I, and p. 2-III.

${ }^{27}$ Codex Tonindeye, p. 24, and Codex Nuu Tnoo-Ndisi Nuu, p. 9-I.

${ }_{28}$ Codex Nuu Tnoo-Ndisi Nuu, p. 18-V, and Codex Tonindeye, p. 32-II.

29 Codex Nuu Tnoo-Ndisi Nuu, p. 17-V, and Codex Añute, p. 19-III.
} 


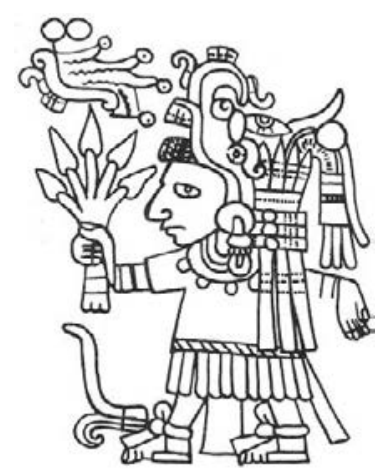

1.20. Codex Tonindeye, p. 32-II: Lord 2 Water and his 'burning foot'.

are probably to be understood as triumphant names similar to Germanicus, Brittanicus or Gothicus among the Romans, and may refer to battles with the people in question. ${ }^{30}$

To designate the different kinds of rulers they came across in the New World, and to avoid the equivalence (and possible confusion) with the title 'king' (rey) of their own monarch, the Spanish conquistadors used the word cacique, a term for 'chief they picked up from an Amerindian language in the Caribbean. ${ }^{31}$ The 'mat and throne' became a cacicazgo. This term came to be used to characterize both the pre-Columbian chiefdoms of the Greater Antilles and the ancient city-states of Mesoamerica. Now the word cacicazgo is helpful precisely because of its ambiguity: in practice the difference between these forms of social organization, chiefdom and state, was often not so clear as theoretical definitions would suggest. In their discussion of 'the cacicazgo, an indigenous design', archeologists Elsa Redmond and Charles Spencer

30 Cf. Smith 1973: 209 and Jansen 1989. The clearest example is Lord 3 Monkey from Andua, mentioned by Herrera as king Tres Micos of Yodzo Cahi (Yanhuitlan), who fought against the invading Mexica. His given name was Cuiñe Sahmi Nuu (codices Nuu Tnoo-Ndisi Nuu, p. 17-II, and Añute, p. 16-II).

31 The Spanish perception of the Native American socio-political organizations seems to reflect, at least in part, the political developments in Spain itself. The Caribbean peoples were presented as 'wild men', in a clear opposition with the Mediaeval European urban citizenry (Mason 1990). The Mexica realm is portrayed as a feudal, rather loosely structured empire, much like Spain or the Holy Roman Empire in the 15 th and early 16th century. The later conquered Tahuantinsuyu of the Incas, however, is described in terms of an absolutist monarchy, according to the political ideals that became dominant as the reign of Charles $\mathrm{V}$ proceeded. 
compare the cases of Hispaniola and the Cuicatec Cañada (Oaxaca, Mexico) and observe considerable differences in territorial extent but nevertheless several basic similarities in political structure and ideology:

They both had clearly defined two-level regional administrative hierarchies controlled by regional paramount caciques and local village caciques... there was minimal internal differentiation or specialization of administrative roles on either the community or regional levels...

Local allegiance to the paramount caciques was sustained by actual (or fictive) kinship ties with village caciques... Some of the larger supraregional confederacies were probably crafted by ambitious caciques for the purpose of alliance, exchange, and warfare. Important as such external alliances may have been for sustaining the member caciques' authority at home, they were susceptible to the oscillating political fortunes of individual rulers, and therefore, usually fluid and shortlived... In spite of differences in their size and political might, the native rulers of all these cacicazgos actively pursued interpolity marriage alliances, which helped to enhance their higher social status and legitimize their rule at the same time that they had the potential to enlarge and consolidate their territories... Exchange and warfare also served these cacicazgos as important mechanisms for their political legitimacy and growth...

We conclude that the cacicazgo was a highly successful political strategy that was pursued by a great number of pre-Columbian societies under a variety of sociopolitical and environmental conditions. The centralized but generalized rule by hereditary caciques served to administer supra-village polities of considerable range of sizes, and a variety of external relations reinforced the cacique's authority (in Marcus \& Zeitlin 1994: $218-221) .{ }^{32}$

We have quoted this synthesis in full because it provides an adequate concise portrait and a workable definition. In the Americas the main difference between these social forms - 'chiefdom' and 'citystate' - is found not so much in their internal organization, but in their scale, especially in the degree of sedentary life and urbanization. Characteristic elements, such as shamanism, kinship and reciprocity, are important in both. The cacicazgo is not a mere transitory phase in the evolution between egalitarian and strongly ranked societies, but an autonomous, stable form of political organization, which escapes

${ }^{32}$ The article by Redmond and Spencer is an appropriate contribution to a volume in honor of Ronald Spores (Marcus \& Zeitlin 1994), who has done fundamental ethnohistorical and archeological research on Nuu Dzaui cacicazgos (recent synthesis: Spores 2007). 
the theoretical distinction between large tribes, chiefdoms and early states. $^{33}$

With these general concepts and basic elements, which introduce us to the representation of time, space and acting individuals, we can start to discuss in more detail the corpus of Nuu Dzaui pictorial chronicles and the problems of their interpretation.

${ }^{33}$ See also Curet 1992: 18. An early but still inspiring monograph on social evolution is that by Sanders \& Price (1968), who applied the fundamental theoretical insights of Elman Service and Morton Fried to the archeology of Mesoamerica. Monjarás-Ruiz 1980 and Van Zantwijk 1985 have examined the social structure of the Mexica society, while Carrasco \& Broda 1976 and Chase \& Chase 1992 deal with different areas within Mesoamerica. In her study of the role of lineages and ancestor veneration in the Maya cacicazgo, Patricia McAnany 1995 shows the complexity of its internal structure and the worldview behind it. Examples of in-depth studies on chiefdoms and early states are the works edited by Earle 1991, Brumfiel \& Fox 1994 and Redmond 1998, while the review article by Smith and Schreiber 2006 offers an analytic synthesis and discussion of important themes. Modern demographic-environmentalpolitical explanatory models in retrospect often include the somewhat misleading notion of a 'logical evolution' aimed at reaching the state level (see also Blanton et al. 1996). A better way to understand the process of state formation is the 'Complex Interaction Model', elaborated by Claessen and Van de Velde (see e.g. Claessen 1991). Wolf 1999 discusses the conceptualization and function of power in depth. For power symbols in the Ñu Dzaui codices, see Jansen 1997a, 2004, and Jansen \& Pérez Jiménez 2007ab, as well as Hermann Lejarazu 2007b. Rivera Guzmán (2000, 2002, 2004) has interpreted similar elements in Classic Mixtec iconography. Olko's dissertation (2005) is an excellent study of Mexica insignia of power, while Olivier 2008 offers a rich panorama of essays on the symbols of power in different parts of Mesoamerica. 
At the time of the Spanish invasion, the Nuu Dzaui sovereign communities had been struggling for some decades against the military expansion of the Mexica empire. One of them had a special, superior status: the yuvui tayu of Nuu Tnoo, 'Black Town' (Tilantongo). According to Friar Antonio de los Reyes its royal dynasty was held in high esteem, because it went back to the time in which the different realms or village-states had been founded. Like other ancient lineages, it descended from the First Lords who had been born from a huge tree in the town of Yuta Tnoho (Apoala). One of these primordial Lords had gone to Nuu Tnoo and there, according to a story registered by the Dominican chronicler Friar Francisco de Burgoa, he fought a battle with the Sun God and won.

In an early colonial lawsuit about succession in the cacicazgo of Yucu Ndaa (Tepozcolula), the dynasty of Nuu Tnoo even claimed that if in a specific town the ruler died without offspring, it had the right to appoint one of its own ranks as the successor. This was because a prince of Nuu Tnoo had founded those local dynasties, long ago. Actually these statements seem to refer to the exploits and power of the great historical warlord and king of Nuu Tnoo, Lord 8 Deer 'Jaguar Claw' (1063-1115), who ruled large parts of Ñu Dzaui. By the 16th century his life had become shrouded in legends.

The 1580 Relación Geográfica of Nuu Tnoo (Tilantongo) informs us that in the early 16th century the ruler of this village-state was a Lord (iya), known as Qhcuaa, '4 Deer'. As this Lord 4 Deer died shortly after the conquest, at least before the Dominicans started their missionary efforts around 1530, he was not baptized. He descended in a direct line from the first ruler, named Iya Qhquehui Yaha Neñe, 'Lord 4 Alligator Blood Eagle', who had been born from the Earth itself, on the mountain where Nuu Tnoo is situated.

They said that the first ruler that they had known, was named Iya $\mathrm{Qh}$ Quehui Yaha Neñe, which in Nahuatl corresponds to Nahui Cipactli and in Spanish means 'Lord 4 Alligator Eagle of Blood'. This lord, they say, was born from a mountain called Tilantongo. They say that he was born 
from the earth itself. A direct descendant of his ruled the place when Cortés came to conquer New Spain: his name was Iya Qh Cuaa, which corresponds to Nahui Mazatzin in Nahuatl and which means 'Lord 4 Deer' in Spanish. This Lord was not baptized as he died shortly after the conquest. (Acuña 1984, II: 231-232).

This last precolonial king of Nuu Tnoo, Lord 4 Deer, can be identified in the pictorial manuscripts. We take him as a point of departure to discuss briefly the main sources, their relationships and early history.

\section{The Map of Chiyo Cahnu (Teozacualco)}

A detailed pictorial account of the genealogy of the Nuu Tnoo rulers is given by an early colonial Map, a polychrome painting on European paper, added to the 1580 Relación Geográfica of Chiyo Cahnu (Teozacualco), a southern neighbor of Nuu Tnoo. Its dimensions $(176 \times 138 \mathrm{~cm})$ and composition suggest that it may have been a copy of a lienzo. Teozacualco is a Nahuatl toponym, like so many in Mexico, due to the Mexica expansion and to the spread of Nahuatl as a lingua franca in the contact between the Spaniards and the indigenous peoples during the early colonial period. The original name of the town in Dzaha Dzaui is Chiyo Cahnu, 'Large Altar or Pyramid'. Its painting contains a geographical and a historical section. The first is a round map, which gives the spatial extension and the boundaries of the cacicazgo in a mixed Nuu Dzaui-European style, registering rivers, mountain ridges and roads as well as place signs for the names of the boundary points. The historical part consists of 'columns' of successive ruling couples, one representing the dynasty of Nuu Tnoo and another that of Chiyo Cahnu. The personages are painted in a schematic way according to the conventions of Mesoamerican pictography, and identified through signs that represent their given names. A gloss in Spanish explains that they belonged to the dynasty that originally ruled Nuu Tnoo; from there a prince departed to govern Chiyo Cahnu and so founded the second lineage (column).

These are the nobles and lords that in ancient times came from the town of Tilantongo to this (town) of Teozacualco and those who descended from them and are alive today: Don Felipe de Santiago and Don Francisco de Mendoza, his son. 


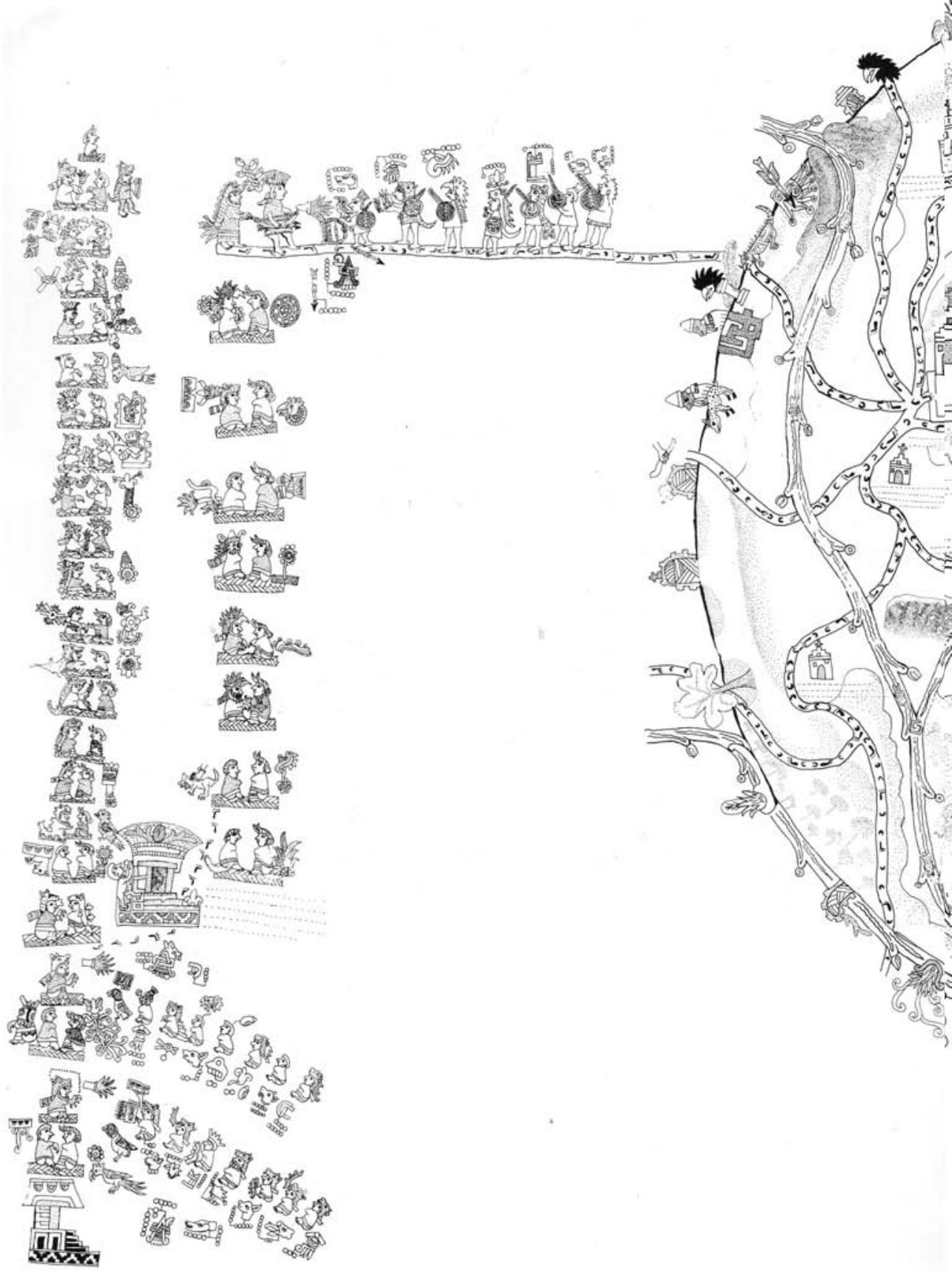

2.1a. Map of Chiyo Cahnu (Teozacualco), left half. 


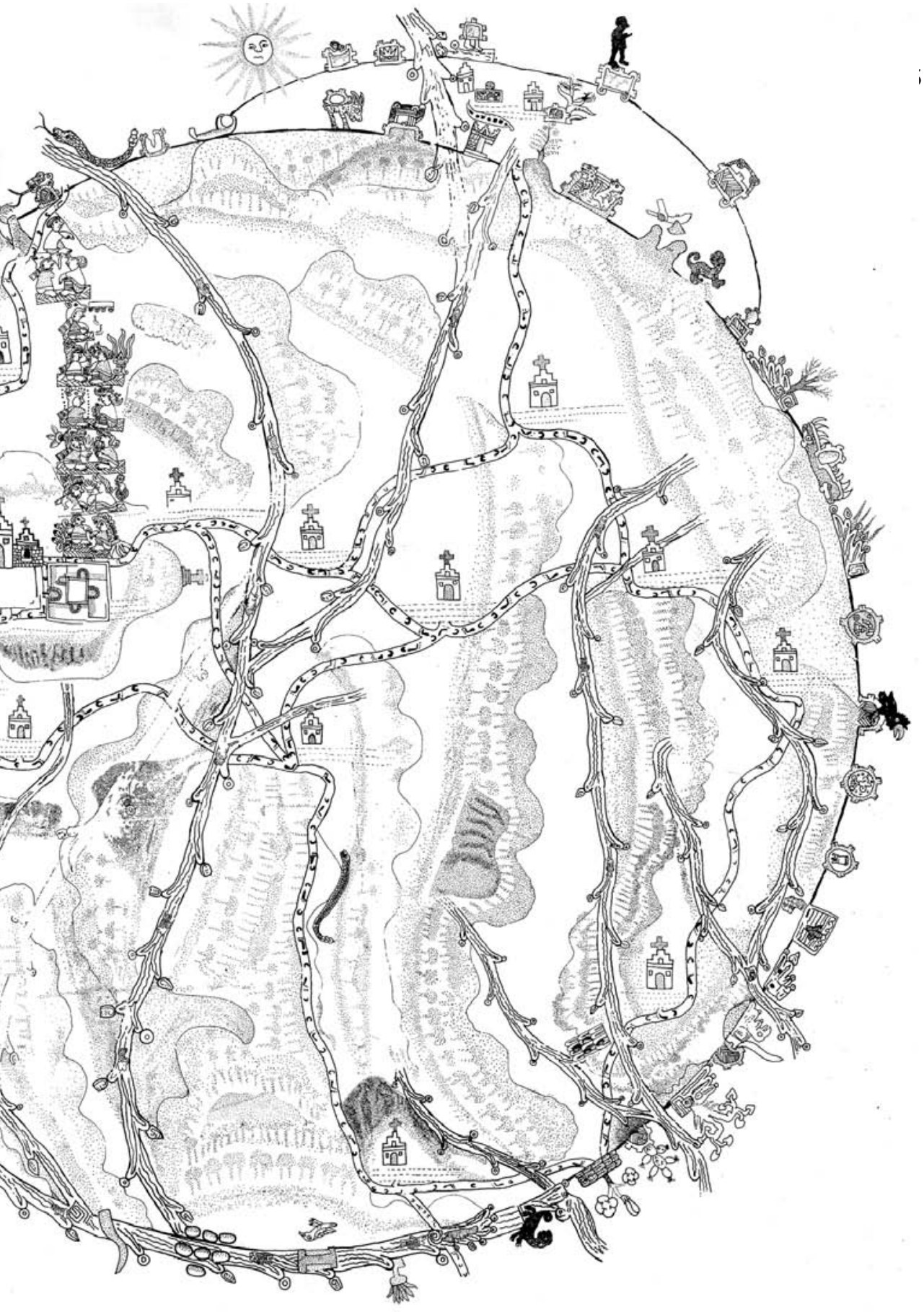

2.1b. Map of Chiyo Cahnu (Teozacualco), right half. 
Don Felipe de Santiago, also known as Don Felipe de Austria, then, was the ruling lord in the second half of the 16th century under whose supervision the Map was painted. Another gloss identifies his palace in the center of the main town, next to the church, painted as a building of four rooms around a patio. The genealogical columns represent his background. The present-day association between church and municipal palace is prefigured here: each column starts with a temple and a place sign. The sovereign community, the temple and the dynasty appear as a unit, expressing the same ideological message as the real temple that dominates the civic-ceremonial center and usually contains the tomb of the deified Founding Ancestor.

The place associated with the first column (along the left-hand border of the Map) is Black Frieze. The rectangular frieze with step-fret motif is to be read as $\tilde{n} u u$, 'town, place, people'. In combination with the black color (tnoo) of the step-fret motif it represents Nuu Tnoo, 'Black Town', the Dzaha Dzaui name for the place called Tilantongo in Nahuatl. On top of this place sign we see a temple (huahi) decorated with eyes on a blue background, representing the heavens (andevui). The 1580 Relación Geográfica of Nuu Tnoo (Tilantongo) gives as the complete name of the hill on which the town, or rather the ceremonial center, was situated: Nuu Tnoo Huahi Andevui, 'Black Town, Temple of Heaven'. The second lineage, derived from that of Nuu Tnoo in early times, is connected with a frieze bent by a small man. This sign represents the Dzaha Dzaui toponym Chiyo Cahnu, 'Big Altar, Big Pyramid'. As the abstract notion of 'big' is difficult to represent pictorially, the painter used a homonym with another tone: cahnu, 'to bend, to break'. The anonymous small man, painted black, is just an actor who represents the verb.

It was the Mexican archeologist Alfonso Caso (1949) who made a first analysis of this crucial document, using it as a Rosetta Stone to decipher the Nuu Dzaui codices. He observed that the seated men and women in the two columns are the same as those mentioned in a whole group of screenfold books, in which they are identified not only by the hieroglyphs of their given names but also by their calendar names. Consequently the Map demonstrates that that group of codices comes from the Nuu Dzaui Nuhu (Mixteca Alta) region and that it is historical in content. 
The main part of the Map is a stylized representation of the geographical dimension of the cacicazgo, with rivers, mountains, settlements and a borderline, marked with place signs. ${ }^{1}$

A detailed comparison with the actual situation as well as with local archival documents and modern maps, made it possible to identify enough names of boundary marks (mojoneros) to reconstruct the kingdoms' territorial extension. In reality it does not have the form of a circle: this configuration is clearly inspired by the European concept of the mapa mundi. ${ }^{2}$

Drawing a map with the contour line of 2000 meters altitude, one sees immediately that the cacicazgo occupies the basin or drainage system of several joining rivers (from left to right, i.e. North to South: Río Hondo, Río de Nochistlan, Río Peñoles or Río Minas and Río Grande). The Map is quite correct in representing the most characteristic features of the landscape. The mountains surrounding the town of Chiyo Cahnu (San Pedro Teozacualco) are - in clockwise order the Yucu Cahno, the small Yucu Daa (Spanish: 'Cerro del Pajarito'), the Yucu Nama with its important archeological remains, while in front of the church we see the extension of the Cahua Cuehe ('Peña Colorada'). Behind the latter lies the subject settlement of San Mateo Sindihui; from a spring here, a river takes its rise and, cascading over the nearby cliff, flows toward the river coming from Nochistlan. At the lower (western) side of the Map it is easy to identify the confluence of the different rivers. Where the river coming from San Francisco Cahua Cuaha (the village in the center of the Map) joins the others the boundary sign consists of seven stones, referring to the settlement Yuu Usha (today written as Yujia), belonging to Nuu Ndeya (Chalcatongo). Near this same point lies the impressive archeological site of El Mogote (part of the present-day municipality of Santa Cruz Tacahua), with several pyramids, plazas, tombs and a ballcourt overlooking the turquoise river. Between here and Cahua Cuaha we recognize the Mountain of the Serpent as 'Cerro del Culebrón'. The historical iden-

\footnotetext{
${ }^{1}$ For a detailed discussion of the geography of the Chiyo Cahnu Map, see Anders \& Jansen 1988 and Anders \& Jansen \& Pérez Jiménez 1992b (the conclusions of which are partially reproduced by Mundy 1996: 117). In the cacicazgo of Coixtlahuaca a similar geographical order is found (Parmenter 1982: $3 \mathrm{ff}$.). An archeological survey of Teozacualco has been conducted by Stephen Whittington and others (for reports see the website www.famsi.org).

${ }^{2}$ König discusses the Mapa Mundi form in her contribution to the volume edited by Van Doesburg (2008: 215-232), while Mundy (in Boone 2005: 363-381) defines the Map-Genealogy as a specific genre.
} 
tification of the precise spatial extension of the Chiyo Cahnu kingdom, in combination with the description of the area given by its Relación Geográfica, makes it possible to analyze its catchment area, i.e. the environmental base of its economy. The rivers form impressive gorges, which have a hot, tropical climate within the cold and high Mixteca Alta, creating magnificent possibilities for a 'vertical economy'. Different roads connect the conceptual central place, Chiyo Cahnu, with its dependencies and with neighboring Nuu Dzaui towns. Interestingly no road is shown crossing the border with the region of the Beni Zaa (Zapotecs) - a clear orientation point being the Rock of the Crow: 'Cerro del Cacalote' to the East of Santo Domingo Yahui Nuhu (Teojomulco).

At the top of the Map we see the rising sun, which may have a double meaning. In the geographical context, it provides the orientation of the Map, marking the East - a convention shared by European maps and Mesoamerican iconography. On the level of sacred history the sunrise marks the beginning of human time and defines the ruling lineages as living 'after the First Sunrise', i.e. in history as we know it. An anomalous and therefore special feature is the presence of two frontier lines in the upper right hand corner. The main place sign in the middle of the two frontiers is Rock of the Maize Cob, identified by a gloss as Elotepec ('Yucu Ndedzi' in Dzaha Dzaui). The gloss further states that this place was originally a subject town of Chiyo Cahnu, but its name does not figure among the estancias of Chiyo Cahnu mentioned in the Suma de Visitas, a list of the main towns in New Spain from around the middle of the 16th century. A document in the municipal archive explains that the frontier in this area was changed in 1574. The Map documents both the old and the new frontier between Chiyo Cahnu and Yucu Ndedzi (Elotepec), i.e. not the actual independence of the latter town but its taking control of an extension of lands (including the estancia Exotepec), which, at least according to this Map, originally belonged to Chiyo Cahnu.

By comparing the representation of the lineages in the Map to other codices, it becomes clear that the given name of Lord 4 Deer, the last precolonial ruler of Nuu Tnoo was represented as 'Eagle - Crossed Beams - Eye'. In Dzaha Dzaui the combination of the crossed beams (ndisi, 'to put crosswise') and the eye (nuu) reads: ndisi nuu, an expression that means 'good view' or 'clear sight'. This is also the Dzaha Dzaui name of the town of Tlaxiaco, locally pronounced as Ndijin Nuu. The 
given name of Lord 4 Deer, therefore, was Yaha Ndisi Nuu, which means both 'Sharp-eyed Eagle' and 'Eagle of Tlaxiaco'. In the Map of Chiyo Cahnu we find him seated in the third to last couple of the Nuu Tnoo dynastic column. His successor was his eldest son, who, according to the Relación Geográfica of Ñuu Tnoo (Tilantongo), was baptized as Don Juan de Mendoza. A document in the Archivo General de la Nación (AGN: Ramo de Tierras 24, exp. 6) tells us that this Don Juan de Mendoza married Doña María de Estrada. In the Map of Chiyo Cahnu the original Dzaha Dzaui names of this couple are given as Lord 'Faces of the Rain God' and Lady 'White Quechquemitl'.

In baptism the indigenous rulers had to adopt Christian, i.e. Spanish, names. Generally they chose those of the Spanish officials or nobles of their own rank, like the viceroy or the local Spanish encomenderos. This also happened here. Mendoza is, of course, the family name of the Spanish viceroy Antonio de Mendoza, who ruled New Spain from 1535 till 1550. The name Estrada probably comes from Alonso de Estrada, encomendero of Nuu Tnoo. ${ }^{3}$

Following the Map of Chiyo Cahnu we see that Lord 'Faces of the Rain God' and Lady 'White Quechquemitl' had a son, 'Jaguar with Torch' (probably 'Jaguar that Lightens the War'), who married an unnamed lady. This couple, in turn, had an unnamed daughter, shown seated on the mat in Nuu Tnoo. At the same level as this couple we see a Lord 'Coyote with Staff', going away in the direction of Chiyo Cahnu. We find him back in the Chiyo Cahnu dynastic column, as the man in the last ruling couple, which produced an unnamed son. Thinking of the quoted gloss in the Map about the contemporary rulers of Chiyo Cahnu, we identify Lord 'Coyote with Staff' as Don Felipe de Santiago and his son as Don Francisco de Mendoza. It is important to notice that Don Felipe the Santiago went to rule in Chiyo Cahnu, but originally belonged to the Nuu Tnoo dynasty.

This representation corresponds to the political situation described in archival sources: a Don Francisco de Mendoza, whom we will call 'the Elder', had been ruler in Nuu Tnoo and was succeeded by his daughter, Doña Francisca de Mendoza, who died without having children. Therefore Don Felipe de Santiago, the younger brother of Don

\footnotetext{
3 See Spores 1992: 4. On the encomenderos see Himmerich \& Valencia 1991. Rabin 2004 includes a full diagram of the genealogies in the Map of Chiyo Cahnu.
} 
Francisco de Mendoza, demanded to be recognized as the legitimate cacique of Nuu Tnoo in $1576 .{ }^{4}$

It follows that 'Jaguar with Torch' on the Map of Chiyo Cahnu is Don Francisco de Mendoza 'the Elder', the successor of Don Juan de Mendoza. The boy 'Coyote with Staff' departing for Chiyo Cahnu is Don Francisco's younger brother, Don Felipe de Santiago. ${ }^{5}$ The son of Don Felipe de Santiago was also named Don Francisco de Mendoza; we will call him 'the Younger' to distinguish him from his paternal uncle. ${ }^{6}$

In the Map of Chiyo Cahnu the last person in the Nuu Tnoo column is Don Francisco's daughter: Doña Francisca de Mendoza. As she died without having children, her father's brother, Don Felipe de Santiago, became her successor as cacique of Nuu Tnoo in $1576 .^{7}$ This, however, had not yet happened at the time the Map was painted otherwise Don Felipe 'Coyote with Staff' would certainly have been shown as ruler of Nuu Tnoo, which he was in 1580, when the Relación Geográfica was written. On the other hand, the Map was clearly composed after the boundary-correction with Yucu Ndedzi (Elotepec), which took place in 1574. This narrows down the date for the making of the Chiyo Cahnu Map to between 1574 and 1576. So it was not painted as an appendix of the Relación Geográfica (1580), but several years earlier, for another occasion. When the questionnaire for the Relación Geográfica arrived, the Map was already present in the town and just handed over as a convenient illustration or copied for that purpose.

Looking again at its contents, we see that its most peculiar feature is precisely the boundary correction. We therefore suppose that the Map was originally drawn to document the agreement about the new frontier with the neighboring village. We also understand that it represents the viewpoint of the ruler, Don Felipe de Santiago. In 1574 he

\footnotetext{
${ }^{4}$ See the document published by Spores 1967: 226. A colonial Mixtec pictorial document with Nahuatl text, published by Oudijk and Van Doesburg (2007), mentions the intervention of the cacique of Tilantongo, Don Francisco de Mendoza (i.e. 'the Elder'), together with a gobernador of the same town, Don Domingo de Guzmán, in settling a land dispute between two men of Totomachapa in 1555, and clarifies that their calendar names were Lord 11 Reed and Lord 9 Rabbit respectively.

${ }^{5}$ Both brothers are mentioned in a document in the Archivo General de la Nación (AGN): Ramo Civil 516 (Paillés Hernández 1993b: 19).

${ }^{6}$ See also Acuña 1984, II: 138, who corrects Caso's identification of 'Jaguar with Torch' as Don Felipe de Santiago.

7 See the document published by Spores 1992: 57.
} 
redefined his 'mat and throne' as an idealized unit, to be inherited by his son. He also indicated that he himself originally came from Nuu Tnoo and that on several earlier occasions the Lord of Chiyo Cahnu had also come from that place: Nuu Tnoo is presented as the 'mother dynasty'.

Don Felipe de Santiago is also known as Don Felipe de Austria. The colonial chronicler Friar Francisco de Burgoa tells us how when baptized he consciously chose this name as the reproduction of that of the Spanish king, his equal:

The first king of Tilantongo to be baptized, asked, before receiving the sacrament, what the name was of the king, our lord, to whom he was pledging obedience. And the conquistadores told him that our lord king was named Don Felipe de Austria. Then he said: 'Well that same name and lineage I choose, and I want to be called that same way'. Thus he received his name; and his eldest son and heir he called Don Francisco Pimentel, the second Don Juan de Aguilar, to whom he entrusted the land of Tezoatlan... (Burgoa 1934 b, I: 371).

The original Felipe de Austria, better known as Philip II, was the king of Spain, who acceded to the throne in 1555. That year, therefore, is the terminus post quem for the referred baptism. Our Don Felipe was not the first Nuu Tnoo ruler to undergo this ritual of becoming Christian, as Burgoa suggests. His father, Don Juan de Mendoza, had already been baptized - his choice of family name indicates that that had happened during viceroy Mendoza's reign.

As we have seen, Don Felipe de Austria/Santiago was a prince of the house of Nuu Tnoo, but became ruler of Chiyo Cahnu after the foregoing cacique of that town, Lord 'Coyote that came down from Heaven', died without offspring. Colonial documents inform us that in 1542 there had not been a cacique in Chiyo Cahnu for three years. This situation had caused conflicts and disorders, so under supervision of the Spanish corregidor of Itzcuintepec an 'indio principal', named Don Luís, was elected as gobernador. It seems that he was not of the royal lineage, so he is probably not represented in the Map of Chiyo Cahnu. ${ }^{8}$ This suggests that the last dynastic ruler had been Lord 'Coyote that came down from Heaven', who had died in 1539. He had been the successor of Lord 'Jaguar that Lightens the War', who in turn had succeeded Lord Ocoñaña ('Twenty Jaguars'), who was mentioned in the Relación Geográfica of Chiyo Cahnu (Teozacualco) and, accord-

\footnotetext{
8 See Spores 1992: 3-4, and Spores 1967: 143.
} 
ing to precolonial codices, was born in 1397. Don Felipe de Austria/ Santiago may have been installed as cacique in Chiyo Cahnu because of the prestige of the Nuu Tnoo dynasty, which moreover was related to the ruling family of Chiyo Cahnu by frequent intermarriage.

From colonial documents we know that Don Felipe de Austria/ Santiago was married to a lady baptized as Doña Inés de Zárate, daughter of the indigenous caciques of Yucu Ndaa (Tepozcolula), who had been baptized as Don Pedro Osorio and Doña María de Zárate. In 1563, therefore, Don Felipe was declared cacique of Yucu Ndaa, but at the same time he remained in control of Chiyo Cahnu. In 1566 Doña Catalina de Peralta challenged his authority over Yucu Ndaa, claiming descent, through her mother (Doña María) from the precolonial rulers Lord Flint (Tecpateuctli in Nahuatl) and Lady Monkey (Ozumasuchitl). This was the lawsuit in which Don Felipe claimed that Ñuu Tnoo had an ancient right to appoint rulers in places where the local dynasty had died out. Don Felipe lost the case. In 1569 Doña Catalina and her husband, Don Diego de Mendoza, cacique of Tequevui (Tamazulapan), took possession of the cacicazgo of Yucu Ndaa and established themselves in the palace (aniñe), still known locally as the 'Casa de la Cacica'. '

During the following years (1572-74), Don Felipe de Austria tried to gain control of the cacicazgo of Nuu Ndaa (Tejupan), with similar claims and with a similar frustrating outcome. But, finally, he did succeed in expanding his realm, by becoming cacique of Nuu Tnoo in 1576. Another case in which, at last, the ideological claim of Don Felipe de Austria seems to have had the desired effect, was that of his younger son, Don Juan de Aguilar, whom he was able to appoint cacique of Tezoatlan when the ruler of that town died without children.

The eldest son of Don Felipe de Austria was Don Francisco de Mendoza, 'the Younger' (not to be confused with Don Felipe's older brother). We saw that he appears in the Chiyo Cahnu Map as the son of 'Coyote with Staff'. In 1574 he was still an unmarried boy. This Don Francisco de Mendoza 'the Younger', called Don Francisco de Pimentel by Burgoa, married Doña Inés de Guzmán, the daughter of Don Gabriel de Guzmán, cacique of Yodzo Cahi (Yanhuitlan), who ruled from 1558 till 1591, and Doña Isabel de Rojas, who, in turn was a daughter of the caciques of Nuu Ndecu (Achiutla) and Ndisi Nuu

\footnotetext{
9 See Archivo General de la Nación Mercedes 6, exp. 402 (Spores 1992: 31) and Tierras 24, exp. 6 (cf. Jansen 1994 and Terraciano 2001).
} 
(Tlaxiaco). ${ }^{10}$ Doña Inés de Guzmán was the richest and most powerful lady in the region at that moment. The wedding was one of the major society events in Nuu Dzaui early colonial history, bringing together more than 2000 nobles from the whole region for a huge gala of banquets and dances - a display of wealth and elegance, and show of power (Burgoa 1934, I: 371).

This linking of the two most influential dynasties of the Mixteca Alta must have been particularly satisfying to Don Felipe de Austria/ Santiago. For those familiar with the codices, this marriage was a symbolic reference to the primordial marital alliance between Nuu Tnoo and the antecedent of Yodzo Cahi (Yanhuitlan), 'Altar of the White Flowers' or 'Chiyo Yuhu' (Suchixtlan), which, as we shall see, had a determinant effect on the course of Nuu Dzaui Postclassic history. Maybe the wedding of Don Francisco de Mendoza/Pimentel to Doña Inés de Guzmán was seen at the time as the starting point of a new period of glory for the Nuu Dzaui dynasties. But that was not to be.

\section{Codex Yuta Tnoho (Codex Vindobonensis Mexicanus 1), Reverse and Obverse}

Two of the surviving precolonial codices can be traced back to the town of Nuu Tnoo. As they deal with topics of its dynastic history, we may safely assume that they were once part of the archives or library under control of its precolonial ruler Iya Qhcuaa, Lord 4 Deer. The first is a pictorial manuscript preserved in the Österreichische Nationalbibliothek in Vienna. As the Latin name for Vienna is Vindobona, the book is officially designated 'Codex Vindobonensis Mexicanus 1', shortened to 'Vindobonensis' or 'Vienna'. ${ }^{11}$ It is painted on both sides. We will first consider the Reverse side or verso.

10 Doña Isabel de Rojas was the sister of Don Felipe de Saavedra, cacique of Nuu Ndecu (Achiutla) and Ndisi Nuu (Tlaxiaco), who had arranged in his testament (1573) that his cacicazgo would pass on to his daughter, Doña María de Saavedra, on the condition that she would marry a son of his sister, Doña Isabel (Spores 1967: 222-223). Indeed, Doña María married Don Miguel de Guzmán, a son of Doña Isabel and Don Gabriel de Guzmán of Yodzo Cahi (Yanhuitlan). See also the genealogical tree published by Caso (in Paddock 1966: 333).

11 See the edition and commentary by Anders, Jansen and Pérez Jiménez (1992a). The breakthrough in deciphering the Reverse was made by Caso (1950); the Obverse has been studied in depth by Furst (1978) and Jansen (1982b). In their introduction to the magnificent edition of 1929 Lehmann \& Smital clarified most of the European history of the manuscript. This information was reproduced and elaborated upon by 
Only 13 pages of this reverse side contain paintings; they are now numbered I to XIII. The overall reading order is from right to left. Each page $(26 \times 22 \mathrm{~cm})$ is divided by red guiding lines in three horizontal bands, now designated as 1 to 3 from top to bottom. These bands are read in a yuq yuq (boustrophedon) pattern. They contain an incomplete genealogy of the Nuu Tnoo ruling family starting with the marriage of Lord 4 Alligator 'Blood Eagle' (Iya Qh Quehui 'Yaha Neñe'), mentioned as the founder of the dynasty in the Relación Geográfica of Ñuu Tnoo. In an earlier publication we therefore called this side 'Codex Ñuu Tnoo', after its contents and place of origin. Actually the place sign of Nuu Tnoo is not present. Instead we find several references to its ceremonial center, the Huahi Andevui, 'Temple of Heaven'. In order to avoid confusion with the other more important manuscript coming from Nuu Tnoo, the so-called Codex Bodley, we might call it: Codex Huahi Andevui. On the other hand it is preferable to keep one name for the whole document and distinguish the two sides as 'Reverse' and 'Obverse'.

The painting of the Reverse is done in a rather sloppy style, with an abundance of errors, indicative of a copy. It is striking that the information was increasingly abbreviated toward the end: apparently the painter was in a great hurry and not able to finish his task. Several fascinating conclusions may be drawn from this internal evidence:

1) the painter was not a well-trained professional, at least not in the Nuu Dzaui style,

2) he did not know the history of Nuu Tnoo well himself, but was copying an original which (maybe because it was old and damaged, and/or in an unfamiliar style), he did not always understand,

3 ) as the painter had no opportunity to compare it with other versions, he was probably not working in Nuu Tnoo,

4) he painted under pressure and with increasing haste.

In order to reconstruct a possible scenario of how the Reverse was made, we first have to concentrate on the Codex Vindobonensis

\footnotetext{
Adelhofer (1963). Toorians, following a suggestion made by Jansen (1982b) on the base of Simons (1963), was able to complete the story $(1983,1984)$. Nielsen (2009) examines an early copy (preserved in Copenhagen) of page XII of the Reverse, and its importance for the history of this codex. It is interesting to note that early reproductions of this codex had already led to falsifications around the turn of the 19th/20th century: see Guzmán 1937 and Batalla Rosado 1994.
} 
Obverse, which is a completely different manuscript. Where the Reverse is imperfect and sloppy, the Obverse is thoroughly composed, polished and flawless. With its symbolic number of 52 pages, its flowery text deals with the sacred story of creation. The first clearly identified individuals, Lady 1 Deer and Lord 1 Deer (pp. 51-I), appear also as the Primordial Couple in an ancient sacred text of Nuu Dzaui, an abbreviated Spanish translation of which was included by Friar Gregorio García in his work on the origins of the Native American peoples (originally published in 1607). According to that text, Lord 1 Deer and Lady 1 Deer dwelt in the 'Place where the Heaven was' on a mountain near the town of Yuta Tnoho, today locally pronounced as Yutsa Tohon, and placed on the map as Santiago Apoala. The mountain with the 'Place of Heaven' clearly corresponds to the Kaua Kaandiui (Cavua Caa Andevui in Alvarado's orthography), immediately East of the small valley in which the town of Apoala is located. Codex Tonindeye (Nuttall), which has close connections to Codex Yuta Tnoho, contains a large painting of this valley (p. 36): the landscape features in that representation correspond entirely to the geographical reality of the site.

Codex Yuta Tnoho Obverse further tells how many primordial elements and spirits came into being and how the Patron or Culture Hero, Lord 9 Wind 'Quetzalcoatl', was born and 'set the time' for the main sites in the region. Then a series of individuals proceeded from a Great Mother Tree in a Sacred Valley. After the First Sunrise, they participated in the ritual founding of polities in the four directions, represented by specific landscapes. This coincides with the information provided by Friar Antonio de los Reyes in his grammar and by the chronicler Friar Francisco de Burgoa that the first Lords and Ladies of Nuu Dzaui had been born from trees in the Valley of Yuta Tnoho (Apoala) and had then divided themselves to take possession of the Nuu Dzaui region. On the basis of all this information Alfonso Caso could identify the most important place of origin for the Nuu Tnoo dynasty, represented as 'River with a Hand Holding Feathers', prominent in this codex and in other manuscripts as well, as Yuta Tnoho. ${ }^{12}$ Because of the prominence of the Yuta Tnoho origin story in the

${ }^{12}$ Smith (1973a: 75) discusses the place sign. It is the focal point of the opening scenes of Codex Tonindeye (p. 1), Codex Ñuu Tnoo-Ndisi Nuu Reverse (p. 40-III), and the Lienzo of Yucu Nama / Amoltepec (called Yolotepec by Caso 1957). Furthermore the River of the Hand Holding Feathers is a central place in Codex Yuta Tnoho, which deals precisely with the origin of the Nuu Dzaui dynasties. Codex Tonindeye, 
contents of the manuscript in Vienna, we prefer to rename the Codex Vindobonensis as 'Codex Yuta Tnoho'. According to the local dialect one might also pronounce this as Yutsa Tohon.

The obverse side is completely painted, and it is here that we appreciate the full dimension of the screenfold book: it consists of a strip of 15 segments of deerskin, glued together, and folded into 52 pages of ca. $26 \times 22 \mathrm{~cm}$. each, protected by wooden covers. The pages were numbered 1-52 in a European manner (from left to right) at a time when the reading order was not yet understood. Now we know that the pages are to be read from right to left, so the codex starts on p. 52 and ends on p. 1. Here too are red guidelines, but they are vertical, dividing the pages into columns (designated with roman numerals according to the reading order), again in a yuq yuq (boustrophedon) pattern.

Although the pictorial text presents itself as a work of great importance for the whole of Nuu Dzaui, with emphasis on the landscapes in the four directions, the singular protagonism of Nuu Tnoo (Tilantongo) is highlighted in several scenes. Its place sign, Black Frieze, is the first toponym on the first page of the story (p. 52) and the place where the protagonist, the Culture Hero 9 Wind 'Quetzalcoatl' first arrives (p. 48). From other sources (Codex Tonindeye or Nuttall, pp. 22 and 42) we know that the Holy Bundle of that Culture Hero, probably containing the Flint from which he was born, was venerated in the main sanctuary of Nuu Tnoo, the 'Temple of Heaven'. The Patron Deities of Nuu Tnoo, mentioned in the Relación Geográfica (Acuña 1984, II: 232), Qhyo Sayo, Lord 4 Serpent and Lord 7 Serpent, appear as two of the main divine personages, mentioned among the first created beings (p. 51) and in a crucial role as leaders of an important reunion at Yuta Tnoho (p. 33). In combination with the genealogy of the noble house on the Reverse, these references suggest that Nuu Tnoo was the place of origin of the codex.

The central theme is the origin of this dynasty in Yuta Tnoho, a sacred place, where the Culture Hero Lord 9 Wind came down from the Place of Heaven and where the Sacred Mother Tree gave birth to the Founding Fathers and Mothers. Lord 9 Wind instructed the people in many aspects of culture and religion. He also acted as the 'marriage ambassador' for an important primordial marriage.

p. 36, situates this place sign in a landscape, which actually can be identified around the town of Yuta Tnoho (Apoala): see Jansen 1982b. 
The many parallelisms (difrasismos) in the pictorial text indicate that the Obverse served as the basis for a flowery discourse or 'parangón' $(s a h u)$, to be pronounced on very special occasions. The theme divine origins and cosmic order - suggests that the occasion of reciting this manuscript was a ritual of extraordinary proportions, in which the kindling of the New Fire and the ceremonial cleansing of the landscape played a central role, together with recalling the sacred origin of the dynasties that ruled the region. The enumeration of so many places suggests an 'international' event. Thinking further about the fascinating blend of historical-ideological and ritual references in this codex, we might speculate that it may have served (and have been prepared for) the enthronement ritual of a Nuu Tnoo ruler, probably Lord 4 Deer himself. If so, the text was constructed to emphasize the relevance of this occasion for the whole region, while at the same time embedding it in an explicit recognition of the many autonomous communities, dynasties and sacred dates that constituted the 'city-state culture' of the late Postclassic Nuu Dzaui world.

Among the many dates mentioned in the pictorial text, the sacred date of Nuu Tnoo - Year 7 Flint, day 7 Flint (p. 42-II) - does not receive special attention. The most emphasized date is Year 13 Rabbit, day 2 Deer. This follows one day after the name day of the Sun God, Lord 1 Death, and seems to connote the original couple, which consists of First Father and First Mother, Lord 1 Deer and Lady 1 Deer. As a year, it precedes the symbolic date of 'beginning', Year 1 Reed, day 1 Alligator. If Year 13 Rabbit, day 2 Deer, was chosen for the ritual to be celebrated with reciting this sacred book, it would have been 1506 (or, less likely, one or two 52 year cycles earlier).

How did this very important document leave the library of the ruler or his priestly staff? The Latin text written on the back of the codex by Johann Albrecht Widmanstetter (1506-1557) informs us that the first European owner was King Manuel of Portugal, who died in December 1521. Such an early presence in Europe can only be accounted for if the codex formed part of the first or second shipment of Mexican treasures sent to Charles V by Hernán Cortés. The inventory of the first shipment mentions two books ('más dos libros'), but Petrus Martyr, who saw them in Spain, described the material as amate paper and the writing as a series of figurative drawings of animals and humans (mainly kings) with rows of abstract signs similar to the Egyptian hieroglyphs. A similar testimony comes from Giovanni 
Ruffo de Forli, Bishop of Bertinoro who described the codices of the first shipment as he saw them exposed in Valladolid. He also noted the 'figures with signs in the form of Arabic or Egyptian characters'. ${ }^{13}$ Because of these contemporary descriptions we can be sure that these two books sent as part of the first shipment were Maya hieroglyphic books, not one of the known Nuu Dzaui pictographic manuscripts on deerskin. That leaves the second shipment as the means by which the codex came to Europe. It accompanied the second carta-relación (dated October 30, 1520, but sent later). We are not well informed about what it contained, how it arrived and what happened to the cargo. The codex must have ended up in the possession of King Manuel of Portugal, who died in December 1521. From there on its wanderings are relatively well documented: via Pope Clement VII and his bastard son, Cardinal Ippolito dei Medici, it came into the hands of the Cardinal of Capua, Nikolaus von Schömberg. After the cardinal's death in 1537 his German secretary, Johann Albrecht Widmanstetter, took the codex to Bavaria. There Duke Albert V bought it together with other books from Widmanstetter's estate. When Munich was plundered in 1632 during the Thirty Years' War, the codex ended up in the hands of Duke Wilhelm IV of Sachsen-Weimar, whose son presented it to the Emperor Leopold I in 1677. Since then it has been in the imperial library, now the Austrian National Library in Vienna.

As to the way in which the codex was transferred from Lord 4 Deer to Cortés, the rather unusual circumstances under which the Reverse was painted suggest the following reconstruction. During the process of conquest, Cortés had several meetings with rulers and ambassadors from Nuu Dzaui; the best documented one taking place in Izucar. There he received ambassadors from different sovereign communities in the region of Coixtlahuaca, i.e. a major part of the Mixteca Alta, who were enemies of the Mexica and came to explore the possibility of an alliance with the conquistadors. ${ }^{14}$ We might speculate, then, that during this or a similar occasion, Lord 4 Deer, in order to clarify for the 'new Quetzalcoatl', the divine order of the Nuu Dzaui realms, wanted to present the codex used at his own inauguration to Cortés: it explained how the power of the Nuu Dzaui rulers was derived from the primordial instructions of Lord 9 Wind Quetzalcoatl himself and

${ }_{13}$ Conquistador Anónimo 1986: 167-168; cf. Anders \& Jansen \& Pérez Jiménez 1992b: 19.

${ }^{14}$ Cortés 1963: 111-112. The Mexica tribute province of Coixtlahuaca is represented in Codex Mendoza, p. 43. 
how this Founder was still held in great respect and veneration. Moreover, we suggest, this book was not just a register of past events, it was a ritual element, meant to be opened and recited in public. Sending it to the conquistadors, Lord 4 Deer invited them to participate in the ritual, and, thereby, to recognize the legitimacy of his position. In our view the handing over of the codex would have been similar to the famous 'gifts' sent by Moctezuma to Cortés, which were clearly ritual garments. For the interpretation of such gifts it is important to remember that the performance of a ritual generally implies the public acceptance of a moral obligation. In these cases the intention of the senders was obviously to obtain recognition of their power (based on ideology and rituals) from the divine power they were addressing. ${ }^{15}$

Continuing this hypothetical reconstruction of events, we suspect that when the first reaction of the Spaniards demonstrated total lack of comprehension, Lord 4 Deer's ambassadors decided to add the genealogical tree of their ruler on the back of the manuscript. This task had to be carried out in great haste - probably because Cortés was in a hurry to move on - and without access to the 'royal library' or knowledgeable people. The painter may have been a local tlacuilo, not versed in the interpretation of Nuu Dzaui pictography, or a member of the ambassador's party, without a thorough experience in codex painting. He only had a single other document before him to copy, probably a somewhat deteriorated painting, which was not always clear to him.

\section{Codex Yecu (Fonds Mexicain 20/21) and the Books of Wisdom}

This is a single painting on deerskin $(91 \times 51 \mathrm{~cm})$, which in the first half of the 18th century came into the hands of the Italian collector and historian Lorenzo Boturini and later, with many other items of his collection, ended up in the Bibliothèque Nationale de France in Paris. There it is known as manuscript 20 of the Fonds Mexicain. Number 21 of the same fonds is a colonial copy. Both documents are generally considered together, as the original (number 20) is severely damaged, so many details are only preserved in the copy (number 21). On the

${ }^{15}$ Anders \& Jansen et al. (1996: 44) discuss the 'gifts' of Moctezuma to Cortés. See Rappaport (1999: $117 \mathrm{ff}$.) for an analysis of ritual as public manifestation of moral commitments. 
basis of an earlier interpretation, the manuscript is also referred to as 'Culte rendue au soleil'.

Several elements in the painting suggest that it is a Nuu Dzaui document. It shows the same landscapes of the four directions and the center, which are so important in the Codex Yuta Tnoho (and also occur in several other manuscripts). A chevron band, to be read as yecu, 'war', connects these landscapes. As this is the central element in the representation, we propose to rename the document 'Codex Yecu'. In each of the four directions and in the center a couple are standing. The male holds weapons and is represented as one of the deities known in Nahuatl as Macuiltonalleque, 'They of the calendar sign 5', i.e. as one of the deified Warriors who died in battle. The female is one of the Cihuateteo, the deified Women who died in childbirth. These five couples have specific calendar names which structure the sacred 260day count in five segments of 52 days each, represented by dots around the scenes. We read the pictorial text as the score for a ritual chant by a shaman or 'mother-father', an invocation of the primordial role models as Father and Mother, to provide power to win the war and to confront the struggles of life. ${ }^{16}$ Codex Yecu demonstrates the religious and ritual implications of the directional symbolism used in Codex Yuta Tnoho.

The couples and the symbolic interaction of time and space connect the Codex Yecu to a cluster of other pictorial manuscripts, in which the same deities and principles are referred to. That cluster is generally named after its major member 'the Codex Borgia Group'. ${ }^{17}$ Its contents are religious, presenting the symbolic associations between segments of time and the power of specific deities, as a basis for divination and ritual. It would be more in accordance with indigenous terminology to call these the 'Books of Wisdom'. Very few examples have survived the persecution campaigns of the Spanish missionaries. In the

${ }^{16}$ For a colour reproduction and a more detailed interpretation see Jansen 1998c, as well as Simonin 1998.

${ }^{17}$ Ground breaking work on this group has been done by Eduard Seler in a series of detailed commentaries (e.g. 1904-09), which, however, were heavily influenced by the astralistic interpretations of religion, fashionable in his day. Nowotny (1961a) corrected this viewpoint and brought about a fundamental change in paradigm, still valid today (see the annotated English translation of his work published in 2005). Nowotny's work was the point of departure for the interpretive commentaries on different members of this group by Anders, Jansen and others in the series Códices Mexicanos of the Fondo de Cultura Económica (see below). Boone 2007 offers a synthesis of these earlier studies. 
process, information about their provenience was lost. Today they are known by the names of collectors or libraries. More appropriate names could be derived from special features or diagnostic aspects of their contents. To establish a way of citation that would be the same in different languages we might use terms in Nahuatl, as most information on Mesoamerican religion was documented in it. Although it is by no means certain that the painters of these manuscripts were speakers of Nahuatl - in fact the Codex Yecu shows that manuscripts of this kind were also known and used by the Nuu Dzaui -, they are certainly part of the Toltec tradition. The Nahuatl term for this genre is teoamoxtli, 'book of the Gods' or 'sacred book'. We might use it to designate the whole group.

- Codex Borgia (Vatican) contains a special section on rituals in a ceremonial center dominated by a Temple of Heaven and a Temple of Darkness. Priests in trance transform into serpentine figures with bodies of darkness and masks of the Wind God, a reference to the metaphor for mysterious divine power: yoalli ehecatl, 'night and wind' in Nahuatl. Therefore it would be appropriate to rename this most important precolonial religious manuscript as the 'Book of Night and Wind' or Codex Yoalli Ehecatl. ${ }^{18}$

- Codex Vaticanus B (Vatican) is the 'pocket' manual of a day-keeper. We would therefore call it 'Book of the Diviner' or Codex Tonalpouhqui. ${ }^{19}$

- Codex Cospi (Bologna) contains a calendar, several divinatory scenes and a large section on offerings of counted bundles of leaves or similar materials. We propose the designation as 'Book of Offerings' or Codex Tlamanalli. ${ }^{20}$

- Codex Fejérvàry-Mayer (Liverpool) gives prominence on its first and last page to the deity of the Smoking Mirror as Lord of the days and thirteen-day periods. This provides the name 'Book of the Smoking Mirror' or Codex Tezcatlipoca. ${ }^{21}$

18 Facsimile editions and commentaries: Nowotny 1976; Anders \& Jansen \& Reyes García 1993. Obviously there are abundant other interpretive studies and several other complete or partial reproductions. We limit ourselves to mentioning the recent editions and commentaries of the Códices Mexicanos program, which include wide ranging bibliographic references and are the outcome of a coherent research project.

${ }_{19}$ Facsimile edition and commentary: Anders \& Jansen 1993.

${ }^{20}$ Facsimile edition and commentary: Anders \& Jansen \& Van der Loo 1994.

${ }^{21}$ Facsimile edition and commentary: Anders \& Jansen \& Pérez Jiménez 1994. 


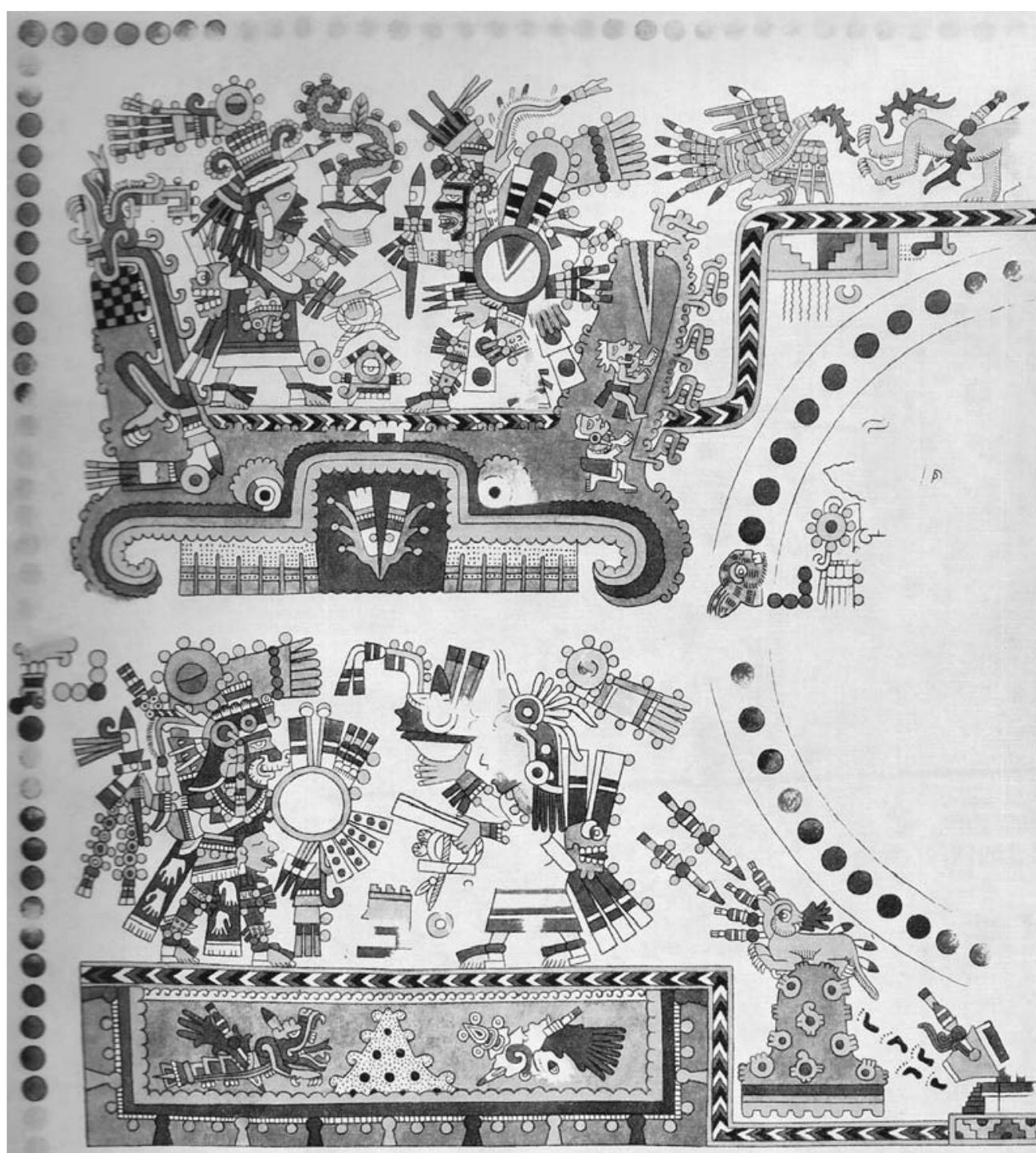

an 0000000030000

2.2a. Codex Yecu showing the four directions: North and West (left half). 
- Codex Laud (Oxford) contains a section that refers to special influences of the Death Deities, a reason to call it the 'Book of Death' or Codex Mictlan. ${ }^{22}$

- Codex Yauhtepec (San Bartolo Yauhtepec, Oaxaca): two pages of a divinatory precolonial manuscript with polychrome paintings in magnificent style but rather damaged condition, preserved in the inside of a leather cover of a colonial book with Gregorian chants. ${ }^{23}$

- A manuscript from Yan Yada or Tututepetongo in the Cuicatec Cañada (State of Oaxaca), combines a historical account of the village-state with a chapter that forms part of the 'Teoamoxtli Group'. In order to please the Mexican president it was called Codex Porfirio Díaz. It is now preserved in the Biblioteca Nacional de Antropología, Mexico City. Since the name of the place of origin is now well-known, we use the original Cuicatec toponym to refer to this book as Codex Yada. It contains a - possibly precolonial - divinatory section (in black and white drawings), which was discontinued and then seems to have been used as 'waste book' for drafting a more extensive historical section dealing with the foundation of the Postclassic Cuicatec political order (in polychrome paintings). ${ }^{24}$

- A Mexica manuscript clearly related to this group is the Codex Borbonicus (Paris), which in its series of year-feasts gives prominence to the role of the high priest and to the sanctuary of his divine Patron, the Goddess Cihuacoatl. It was sent by Mexica nobles to the Spanish king and is mentioned among the possessions of Phillip II. The document probably comes from Xochimilco, but in order to underline its religious character we prefer to call it Codex Cihuacoatl. ${ }^{25}$

The names we propose for these important religious manuscripts are, of course, also arbitrary to some extent. Deities such as Tezcatlipoca or Cihuacoatl are not limited to the manuscripts that we propose to name

${ }^{22}$ Facsimile edition and commentary: Anders \& Jansen 1994.

${ }^{23}$ The manuscript has been known locally for some time. We were shown this fascinating find in February 2008 in the Biblioteca Burgoa (Oaxaca City), where it was being restored.

${ }^{24}$ Photographic edition and commentary on the historical section: Van Doesburg 2001. Commentary on the religious section is included in Anders \& Jansen 1994.

${ }^{25}$ Facsimile edition and commentary: Anders \& Jansen \& Reyes García 1991 (cf. Jansen 2002). A similar but shorter Mexica work just covers the 20 thirteen-day periods with their respective divinatory images. Because of the French scholar-collector who took it out of Mexico it is called Tonalamatl Aubin. We prefer to shorten this to Codex Tonalamatl. 
after them, nor are the references to offerings or death. And in fact, all these codices were in the possession of diviners or tonalpouhque. On the other hand we feel it is imperative to start using names that conform more closely with the character of these documents and bring us closer to crucial aspects of the Mesoamerican worldview.

Although the Teoamoxtli Group constitutes an important chapter of its own in Mesoamerica's ancient literature, there are many - often still unexplored - links between the symbolism contained in their pages and the Mixtec historical narratives. We have found it very inspiring to study both corpora simultaneously.

\section{Codex Nuu Tnoo-Ndisi Nuu (Bodley Ms. Mex.d. $1 /$ arch. Bodl. A. 75 / Bodley 2858)}

A direct parallel to the obverse side of Codex Yuta Tnoho Reverse and the Map of Chiyo Cahnu is a codex that also comes from Nuu Tnoo and is considered the 'backbone' of Nuu Dzaui Postclassic history. It is preserved in the Bodleian Library, Oxford as MS. Mex. d. 1 and has become known in the literature as Codex Bodley 2858, shortened among students of ancient Mesoamerica to 'Bodley'. ${ }^{26}$ It is a screenfold consisting of strips of leather (presumably deerskin), glued together and folded into 23 pages of $26 \times 29 \mathrm{~cm}$. Twenty of these are painted on both sides, resulting in a pictorial text of 40 numbered pages (20 on the Obverse, 20 on the Reverse of the codex). The pages are subdivided into four or five horizontal bands by red guidelines, which create a yuq yuq (boustrophedon) reading pattern over two pages, in upward or downward sequences. For reference purposes, these bands are designated by roman numerals top down, so the upper band is I and the lower band is either IV or V. The pages have been numbered with Arabic numerals on both sides from left to right, following the European convention. In reality, however, the overall sequence of the pages is only from left to right on the Obverse (pp. 1-20), but goes from right to left on the Reverse (pp. 40-21).

In some spots we can still see some traces of the preparation of the deer hide: small holes were covered with pieces of leather and painted over (p. 16-I/II, p. 17-V). After the polychrome painting was finished,

${ }^{26}$ See the edition and commentary by Caso 1960, and the photographic reproduction (based on new scans from the Bodleian library) with introduction and reading by Jansen \& Pérez Jiménez 2005. 
the text seems to have been corrected: in a few places emendments and additions in black paint have been added.

The obverse side tells the genealogical history of the dynasty of Nuu Tnoo, from its sacred origins (the Tree of Yuta Tnoho, the birth of Lord 4 Alligator) right up to the birth and marriage of Lord 4 Deer shortly before the Spanish invasion. The emphasis is on marital alliances and descent, but specific attention is given to the life of the great king Lord 8 Deer 'Jaguar Claw' (1063-1115 AD).

The Reverse also starts with the story of Yuta Tnoho (Apoala), but then follows another line, ending with the dynasty of Ndisi Nuu (Tlaxiaco). Its last precolonial ruler, Lord 8 Grass, is the one called 'Malinaltzin' in Central Mexican sources. ${ }^{27} \mathrm{He}$ defended his yuvui tayu against the Mexica imperial expansion, but in the end was captured and sacrificed. His first wife, Lady 9 Deer, was the youngest sister of the father of Lord 4 Deer of Nuu Tnoo. Here both lineages and both sides of the codex are connected: the same marriage is represented toward the end of the Reverse (p. 21-IV) and the end of the Obverse (p. 20-II).

Like the obverse, the reverse side emphasizes the male line of descent, but frequently indicates the names of the parents of the brides, which often makes it possible to reconstruct female lines as well. It does not give much attention to Lord 8 Deer, but instead contains a relatively long chapter on his successor, Lord 4 Wind, who seems to have been instrumental in the founding of the Ndisi Nuu village-state. The opening scenes deal with the way in which Lord 4 Wind's ancestry was connected to Yuta Tnoho.

The codex gives the impression of being a finished document, but, at the same time, leaves ample space at the end of both sides, to continue the historical register (presumably that of the descendants of Lord 4 Deer and Lord 8 Grass respectively), thereby presenting the ruling couples of Nuu Tnoo and Ndisi Nuu not as 'the end of history', but as having a - still undefined - future, as links in the chain of time. The emphasis on genealogy in its contents suggests that this codex was intended as a compendium to be consulted whenever disputes over succession and tribute rights arose. The logical moment to paint such a book would be a dynastic marriage or the official appointment of 1978).

27 This crucial identification was made by Jiménez Moreno (in: Gaxiola \& Jansen 


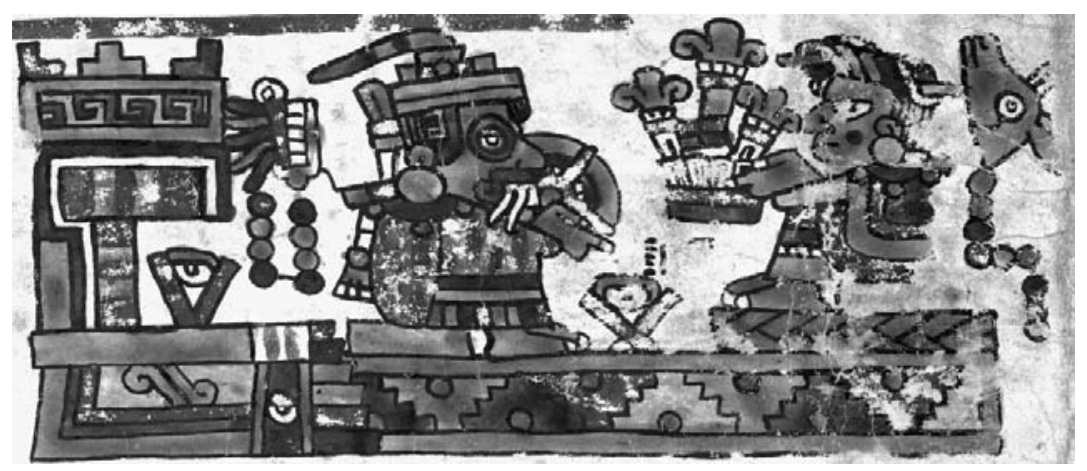

2.3. Codex Ñuu Tnoo-Ndisi Nuu, p. 20-II: Lord 8 Grass (Malinaltzin) 'Rain Sun' and his wife Lady 9 Deer 'Flower Ornament', rulers of Ndisi Nuu (Tlaxiaco).

an heir. In the composition of the Obverse - which seems to be the principal side - but also in the chronological sequence, the last scene is the marriage of Lord 4 Deer and Lady 11 Serpent: maybe the codex was made for that occasion. ${ }^{28}$

The particular combination of the two lineage histories seems to have been drafted for the earlier marriage between Lord 8 Grass and Lady 9 Deer. We hypothesize that there was an earlier codex, which ended with that marriage and which some years later was copied and brought up to date for the marriage of Lord 4 Deer. In an earlier publication we proposed that if this book should be called after its first known owner, its proper designation would be 'the codex of Lord 4 Deer', i.e. Codex Iya Qhcuaa. In view of the fact that it is not about this ruler alone, but about the houses of Nuu Tnoo and Ndisi Nuu, we will refer to it here as 'Codex Nuu Tnoo-Ndisi Nuu', using the standard orthography of Alvarado. Taking into account modern dialect variations, one might pronounce this as 'Nuu Toon and Ndijin Nuu'. Our reasoning parallels that of Brotherston, who has proposed the name of 'Tilantongo Annals'.

How this manuscript left the 'royal library' at Nuu Tnoo is a matter of pure conjecture. Probably it did not leave together with the Codex Yuta Tnoho - otherwise the inclusion of the genealogy on the Reverse of that codex would not have made any sense. The next thing we know

${ }^{28}$ The fact that the genealogical background and provenience of the bride was not given suggests that a child was not yet born. Moreover it seems that Lord 4 Deer remarried shortly after: he appears with another wife in Codex Añute, p. 18. 
is that it became part of the library formed by Sir Thomas Bodley (1545-1613).

Given the political situation of Nuu Tnoo during the 16th century, it is possible that the codex was presented as evidence in one of the numerous lawsuits of Don Felipe de Austria/Santiago. This was a common custom. In the 1582 lawsuit of Nuu Tiyaha (Tecomatlan) against Yodzo Cahi (Yanhuitlan), for example, several references are made to such historical 'pinturas' - Yodzo Cahi itself had one that covered 24 generations and 500 years. A principal or noble from Nuu Tnoo, Domingo Hernández, testified that they coincided with similar books in his own town. ${ }^{29}$ The testimonies also document that the foundation and the history of the 'mat and throne' were registered in paintings, which were kept in special 'archives' and 'public places'. ${ }^{30}$ We suppose that these were the libraries of palaces and temples, from where the books were taken on certain occasions for public display and declamation. Domingo Hernández further stated that the rulers of Yodzo Cahi and Nuu Tnoo were 'cousins' (primos hermanos). Actually Don Felipe de Austria/Santiago of Nuu Tnoo and Don Gabriel de Guzmán of Yodzo Cahi (Yanhuitlan) were second cousins: their grandfathers Iya Qhcuaa (Lord 4 Deer) and Iya Namahu (Lord 8 Death) had been brothers - that is precisely one of the last statements in Codex Nuu Tnoo-Ndisi Nuu Obverse (p. 19-II/III). In the Dzaha Dzaui terminology both rulers were ñani, a term equally applied to brothers, cousins and second cousins.

It is tempting to interpret this testimony as a possible reference to the Codex Nuu Tnoo-Ndisi Nuu, but we know that it was by no means the only book of this kind in Nuu Tnoo. Given the numerous lawsuits in which Don Felipe was involved, the codex may have been taken out of the ancient royal library and presented to the Spanish authorities as a demonstration of the historical predominance of the Nuu Tnoo dynasty (Don Felipe's central theme). It would then have been added to the lawsuit documents, from which it was later separated. Maybe it was already taken out in Mexico by an interested collector of such 'curiosities', who may then have brought or sent it to Europe. But in view of the administrative importance of such documents, it is more probable that the whole dossier was sent to Spain for inspection by the higher authorities.

\footnotetext{
29 AGI, Escribanía de Cámara 162 f 166v; Spores 1967: 217; cf. Smith 1994: 130.

30 AGN Tierras 24, exp. 6, cf. Jansen 1994: 16.
} 
There are many possible ways in which it could then have migrated to England. It is important to keep in mind that Sir Thomas Bodley was an active collector of books and manuscripts, committed to restoring and expanding the earlier library that had existed in Oxford. ${ }^{31}$ Bodley himself had studied in Oxford. Proficient in Italian, French, and Spanish, he had traveled through Europe on various diplomatic missions for Queen Elizabeth. In 1597 he retired from the court. Having married a rich widow, Ann Ball, he was well to do. The couple did not have any children, and Bodley now dedicated himself fully to his project, outlined in a letter of 1598 to the vice chancellor:

Where there hath bin heretofore a publike library in Oxford: which you know is apparant, by the rome it self remayning, and by your statute records I will take the charge and cost upon me, to reduce it again to his former use: and to make it fitte, and handsome with seates, and shelfes, and Deskes, and all that may be needfull, to stirre up other mens benevolence, to helpe to furnishe it with bookes. (Myers 1951: 9).

Personally selecting the most valuable items, Bodley spent his money buying books in London, and sent agents around Europe and as far as Syria. Moreover the library received numerous donations, and in 1602, when 2000 books had been brought together, it was opened to the public. A first catalog was printed in 1605. In 1610 the number of books had become so large that a considerable extension had to be constructed. When the first librarian, Thomas James, retired in 1620, there were already 16,000 books. The codex seems to have become part of the library between 1603 and $1605 .^{32}$ It is mentioned in the 1605 catalog, without any reference to an earlier owner: this may indicate that Sir Thomas Bodley himself donated it. How he would have obtained it is a matter of speculation.

Sir Eric Thompson has suggested that Bodley received the Codex Nuu Tnoo-Ndisi Nuu in 1600 from his friend the Earl of Essex, who had sacked Bishop Mascarenhas of Faro from the library in $1596 .{ }^{33}$ In that case, however, one would expect to find a more precise reference.

${ }^{31}$ The original library had been formed in the first half of the 14th century in the Old Congregation House adjoining the Church of St. Mary the Virgin. It had been expanded in the 15th century thanks to the interest and support of Humfrey, Duke of Gloucester. This second library was housed on the upper floor of Divinity School. By the middle of the 16th century it had become dispersed.

${ }^{32}$ Caso 1960: 11, citing the Summary Catalogue by Hunt \& Madan \& Craster, vol I: 30 and vol II: 542 .

${ }_{33}$ This 'collection' numbered 252 volumes and was an important starting point for Bodley's library. See Caso 1960: 11. Philip dryly observes: "The seizure of the Portu- 
The fact that the codex was identified in the 1605 catalog as a 'Mexican manuscript' (Liber lingua mexicana scriptus) suggests that it had followed a relatively short and direct route, during which a general knowledge about its provenience remained intact. It should be remembered that Bodley got many of his books through specific agents. One of these was the London bookseller John Bill, who in 1604 traveled to Spain, where he even visited Seville, the entrance port for goods and documents from the 'New World' ((Philip 1984: 9). Bill came back with a considerable number of Spanish books and he just may have bought this codex there too, as a curious example of an unknown writing system.

\section{Codex Tonindeye (Codex Zouche / Codex Nuttall)}

Let us now look at other codices, related to the Nuu Tnoo historiography, but clearly coming from other places. One screenfold is today a treasure of the British Museum (dept. of Ethnography) in London. It came to the Museum as an item from the collection of Robert Curzon, Lord Zouche (1810-1873). In 1902 Zelia Nuttall edited a lithographic facsimile with a first commentary. The codex is consequently now known as 'Zouche-Nuttall' or simply 'Nuttall'. Lord Zouche had received it in 1859 from his friend John Temple Leader, who, in his own words "by dint of diplomacy and gold obtained it from the Library of the Dominican Convent of San Marco in Florence". Its route from Mexico to Italy is not yet clear. Leader synthesizes what may have been a local oral tradition:

It is written on the skin of some animal - and it is evidently the record of embassies, wars etc.... It was probably brought to Italy by some padre Domenicano, and left in the Library of their Convent di Sn Marco at Florence. (in Troike 1987: 19).

Maybe the Dominican monk who played an intermediary role in bringing the codex from Mexico to Italy, was Friar Antonio de la Serna, who had been very active as a missionary in the Nuu Dzaui region and died in 1604 on his way to Rome in the Dominican convent of Santa Maria Novella in Florence. When the archives and library of

guese bishop's library was a not untypical piece of Elizabethan book-collecting... (1984: 10). See also Rogers 1991: 29. 
this convent were dispersed at the end of the 18th century, part of the collection of books indeed went to the convent of San Marco. ${ }^{34}$

The codex consists of 16 segments of deerskin, which were glued together and folded to form 47 pages on each side, approximately 24.5 $\times 18.5 \mathrm{~cm}$. Both sides have been painted. Zelia Nuttall established the numbering of the pages in the edition of 1902. The overall reading order is from right to left, following the vertical red guidelines in a yuq yuq (boustrophedon) pattern. Internal evidence suggests that the codex, although painted in a magnificent flamboyant style, was not a finished work, but an incomplete recompilation of segments copied from different sources. This, by the way, does not make it a less important document, but on the contrary offers us valuable insights into the processes of the native painters and historians. Because of this composite character we call this pictorial manuscript 'Codex Tonindeye'. The Dzaha Dzaui term tonindeye appears in Alvarado's dictionary as the translation of 'lineage history'; probably it is a contraction of toniñe ndeye, 'deceased kings'.

It is important to note that the Reverse of this codex was painted before the Obverse, and that the physical dimensions and contents of the Reverse coincide conspicuously with those of the codex now known as 'Colombino-Becker I' or 'Caso', which we refer to as Codex Iya Nacuaa. ${ }^{35}$ Both manuscripts contain the elaboration of a specific chapter of Ñuu Tnoo dynastic history: the life of Lord 8 Deer 'Jaguar Claw' (1063-1115 AD). Although differing in details, style and graphic composition, the two books clearly stem from the same historiographic tradition.

Referring to the coincidence in format, Nancy Troike has suggested that both may have been created as two stages of the same project, two drafts of the same story, done in the same format, because the deerskins were already prepared. The main problem in this reasoning is the unlikelihood that precisely these two codices (Tonindeye and Iya Nacuaa), originally painted in the same place as successive stages of the same project but separated afterward, would have been preserved in the very limited sample of codices that survived the colonial destruction. The coincidence is too nice to be convincing without further evidence. On the other hand Troike's idea does offer an inter-

34 Burgoa (1934a) gives a biographical sketch of Friar Antonio de la Serna. For references to the history of the Santa Maria Novella collection, see Orlandi 1952.

35 See the careful codicological studies by Nancy Troike (1974a, 1974b, 1987). 
esting model for speculation on the origin and possible relationships of the documents that have come down to us.

As Codex Tonindeye Reverse was not finished, it seems to represent a first effort to paint Lord 8 Deer's biography. We can see that the painter struggled with the precise sequence and the organization of his data, which resulted in several corrections. He may have been copying from one or more other codices, or even from a lienzo: in such a painting on cloth the narrative sequence is not usually presented in a linear format, but appears situated at different places in a landscape. Having advanced quite a lot with his story, the painter gave up his work. Later the back - which we now call 'Obverse' - of the screenfold was used as a notebook to copy different segments of Mixtec history, without an effort to integrate them into a new coherent whole. The same painter probably did this; one or more pupils may have assisted him. ${ }^{36}$

After several episodes of the primordial times, the story line follows the early dynasty of Nuu Tnoo and then presents the lineage of the rulers of Chiyo Cahnu (Teozacualco), easily identifiable because the same individuals appear on the Map of Chiyo Cahnu. For this reason Brotherston (1995) proposed changing the name of Codex Nuttall to 'Teozacoalco Annals'. A chapter of special interest is that of the socalled 'Xipe dynasty'. The rulers of this royal house wear a specific outfit in red and white colors, associated with the attributes of the Flayed God known as Xipe in Nahuatl. The same outfit is characteristic of the two men who appear on the stucco reliefs in Tomb I of Zaachila (presumably representing the lords buried there). The signs in the calendar names of the rulers of this dynasty correspond to those that identify the rulers of Zaachila in the Beni Zaa lienzos of Guevea and Petapa. We therefore identify this dynasty as that of the Beni Zaa city-state Zaachila, which dominated the Valley of Oaxaca during the Late Postclassic. It was the eastern neighbor of Chiyo Cahnu, of course, and its Dzaha Dzaui name was Tocuisi, '(Place of the) White Lord(s)'.

The different segments of Codex Tonindeye Obverse can be recognized easily because they reproduce the pictographic conventions of the originals they were copied from, and, as a result, differ slightly from one another, in particular when it comes to the representation of marriages. The basic convention is that of a seated man and woman,

${ }^{36}$ There is some stylistic difference to the Reverse: the painter used other colours (a more stable green, that did not fade into a yellowish brown) and made his figures generally smaller than on the reverse side (Smith 1973a: 12; cf. Robertson 1982). 


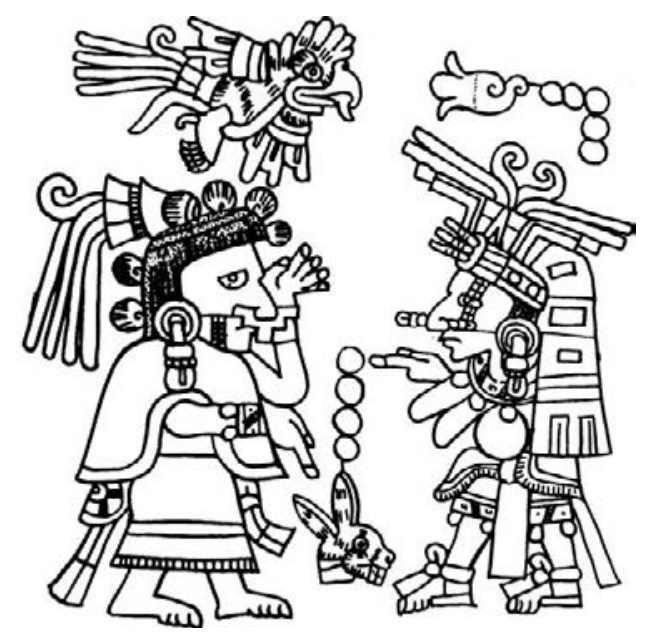

2.4. Codex Tonindeye, p. 33: Lord 5 Flower of the Xipe Dynasty marries Lady 4 Rabbit 'Quetzal' (from Chiyo Cahnu).

facing each other. In several genealogies (pp. 10-13) they are simply seated without any sign under or around them, but in the dynasty of Ñuu Tnoo (pp. 14-27) they are seated in a palace, and in that of Chiyo Cahnu (pp. 27-33) they are seated on a yellow band, i.e. a stylized reed mat. The separate account of the dynasty of Zaachila (pp. 33-35) follows the same convention as that of Chiyo Cahnu, but the final dynasty, associated with an unknown place (p. 41), again presents the couples within palaces.

The focus on the dynasty of Chiyo Cahnu in the Mixteca Alta (pp. 27-33) and on the related dynasty of its neighbor, Zaachila in the Valley of Oaxaca (pp. 33-35), suggests that the Obverse was painted in close connection with the royal library of Chiyo Cahnu. The original composition may be dated as several years after the birth of Lord 4 Reed 'Ocoñaña' in the year 8 House (1397), but seems to have preceded his marriage and enthronement (Codex Tonindeye, p. 32; Codex Nuu Tnoo-Ndisi Nuu, p. 17-IV). Several sources indicate that the interaction (alliance and conflict) between the Alta and the Valley was a crucial political issue during most of the 15 th century. It was in this context that the Obverse was painted. 


\section{Codex Iya Nacuaa (Codices Colombino \& Becker I)}

It is tempting to follow Troike's suggestion that after the Tonindeye painter interrupted his work on the biography of Lord 8 Deer, other painters set themselves to the same task, continuing to use the deerskin already prepared and creating as the integral and final version the screenfold 'Colombino-Becker I' ${ }^{37}$ Because this is the finished story of the life of that renowned warrior and king, we prefer to call it 'Codex Iya Nacuaa', or in abbreviated form 'Nacuaa' after Lord 8 Deer's calendar name in Dzaha Dzaui.

Although in fragmentary and bad condition this codex is very impressive. It tells the story of Lord 8 Deer in a much more dramatic way than any of the other manuscripts. One of the central dramatic lines is the relationship between Lord 8 Deer and the young princess of Añute, Lady 6 Monkey. They start off as a daring couple, going together to pact with the dark powers of the Cave of Death, then are separated and have different careers. Lady 6 Monkey marries someone else. When they meet again, Lord 8 Deer - still a bachelor - has become her enemy: he kills Lady 6 Monkey and her husband. Other codices also contain references to this story but do not connect them in such a dramatic way. Both the Codex Tonindeye and the Codex Nuu TnooNdisi Nuu leave out the violent and tragic death of Lady 6 Monkey altogether. Codex Nuu Tnoo-Ndisi Nuu tells us that Lady 6 Monkey's husband had already died - apparently of natural causes - several years before Lord 8 Deer attacked her. In adding his death to the killings by Lord 8 Deer, Codex Iya Nacuaa clearly creates a more sensational image (cf. Jansen \& Pérez Jiménez 2007a). The narrative structure but also the vivid and colorful representations of actions and the presence of 'special effects' such as an orchestra, all indicate that this codex was indeed related to a dramatic performance of great impact.

${ }^{37}$ See Troike 1974b, 1980, 1982a. The 'Becker I' fragment was published by Nowotny (1961b), the 'Colombino' by Caso (1966a). In her dissertation (1974b), Troike has made a detailed study of the contents and composition of both. The combined version was called 'Códice Caso' by León-Portilla (1996) to honor that great scholar on the first centenary of his birth year. Brotherston (1995) has proposed to call it 'Tututepec Annals', which is somewhat misleading as the codex does not deal specifically with the Tututepec dynasty. In Encounter with the Plumed Serpent (Jansen \& Pérez Jiménez 2007a) we offer a synthetic commentary. 


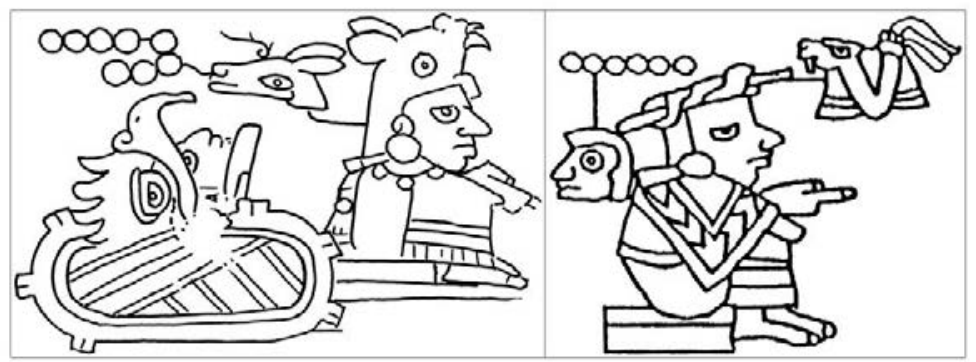

2.5. Lord 8 Deer (left) and Lady 6 Monkey (right) in Codex Ñuu Tnoo-Ndisi Nuu and Codex Añute, respectively.

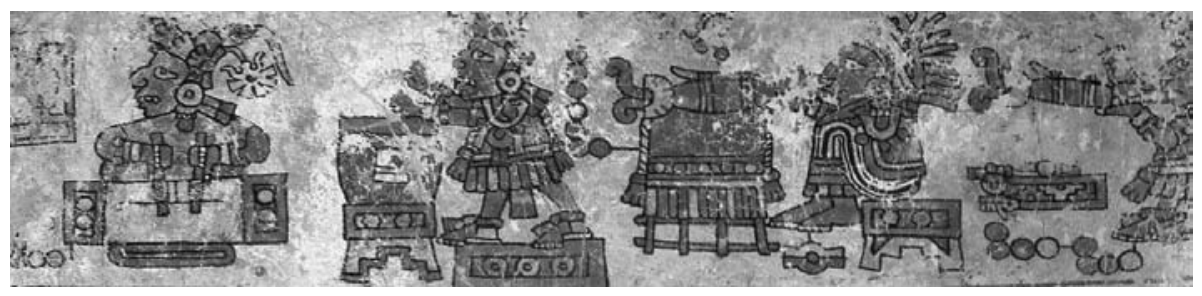

2.6. Codex Iya Nacuaa II (Becker I), p. 8-I: funerary orchestra.

The glosses in alphabetic script in this manuscript refer to the boundaries of Yucu Dzaa (Tututepec) on the Mixtec Coast and at least the first fragment (Colombino) was still there in 1717 when it was presented in a lawsuit. ${ }^{38}$ The place sign of Yucu Dzaa is prominently painted on page 5. We may assume, therefore, that Codex Iya Nacuaa was painted (or rather copied) on the orders of a king of Yucu Dzaa (Tututepec), near the end of the Postclassic Era, as a literary work to commemorate his illustrious predecessor. Again, the most probable occasion for presenting a declamation or performance of such a work would be an heir-appointment ceremony or a similar ritual of the royal house.

The last precolonial ruler of Tututepec was called Coaquitecuhtli or Coaxintecuhtli in Nahuatl, i.e. either a given name such as Coaxiuhtecuhtli, 'Lord Turquoise Serpent' or the calendar name Coatzintecuhtli, 'Noble Lord Serpent'. It is likely that he was the precolonial owner of the codex, and he may even have commissioned it. His son was bap1966a).

${ }^{38}$ Mary Elizabeth Smith has analyzed the glosses and the related lawsuits (in: Caso 
tized as Pedro de Alvarado and died in 1547. It may have been during his lifetime that the alphabetic glosses were added. ${ }^{39}$

If Nancy Troike's hypothetical reconstruction of the events (1974a) is right, the Reverse of Codex Tonindeye would have been an earlier, unfinished version of the same work, it would consequently follow that that part of Codex Tonindeye was also painted in Yucu Dzaa and then taken to Chiyo Cahnu where, as we saw, the painter used the back side for copying parts of other codices. This is plausible but impossible to prove. Lord 8 Deer's story clearly had significance for the coastal kingdom, as this was the area in which he had ruled first and probably founded the dynasty. On the other hand, the story itself focuses on the Mixteca Alta, and seems to have originated there. In fact, as the main towns in the Mixteca Alta played a role in the drama, their local and partial perspective tended to influence the tradition and even to distort it in the production and copying of their codices. It is our impression that Yucu Dzaa, geographically removed from those interests, preserved a rather pure version of the original composition, which must have come into the possession of its dynasty at a relatively early date.

Codex Iya Nacuaa, then, would be a copy or new version of an earlier manuscript in that tradition. After the Spanish conquest it stayed in the coastal region and was transformed into a título or land document. Later, when the meaning of its contents was largely forgotten or at least considered irrelevant, it was cut up into different parts, which were apparently given to different people. This segmentation was probably related to the division of lands and privileges among different heirs.

Two portions or fragments, which we will call Codex Iya Nacuaa I (= Colombino) and Codex Iya Nacuaa II (= Becker I), have survived. Codex Iya Nacuaa I remained in Yucu Dzaa until at least the 18th century, and was heavily annotated with the names of the boundaries of the cacicazgo in alphabetic script. In the case of Codex Iya Nacuaa II there was apparently no reason to transform it into a 'written map' of the cacicazgo or community land.

The portions I and II ended up in the hands of lawyers in Puebla Manuel Cardoso and Pascual Almazán respectively - around the middle of the 19th century. This may have had something to do with

${ }^{39}$ See Smith in Caso 1966a, Smith 1973a: 88, and Troike 1974b. Rosanna Woensdregt (Leiden University) is carrying out a detailed study of archival materials related to the colonial history of the cacicazgo of Tututepec. 
the process of dissolution of the cacicazgos and the selling off or giving away of cacique lands. ${ }^{40}$ Fragment I was deposited in the Museo Nacional de Antropología in Mexico City.

Fragment II was obtained by Phillip J. Becker, whose collection, after his death, became part of what is now the Museum für Völkerkunde in Vienna. Its first editor, the Swiss naturalist Henri de Saussure (1891) tells us that in 1852 a descendant of caciques from the Mixteca region (presumably the Villagómez family) gave it to Pascal Almazán as documentation for a lawsuit. According to tradition this document contained the history of a rich and mighty cacique of the Mixtec region, Sar-Ho and his wife Con-Huyo, who were living in Tindu.

Curiously enough the mentioned personages (Sayo 'Lord 7 Serpent' or Saco, 'Lord 7 Rain', and Cohuiyo, 'Lady 2 or 3 Reed') are not mentioned in this fragment of Codex Iya Nacuaa. Also their residence, Santa María Tindú in the Mixteca Baja, seems foreign to the story told in the codex. So, maybe this historical tradition conserves instead the names of those who once owned the manuscript.

Nancy Troike (1974b) has reconstructed the original sequence of the pages. On the basis of her work we offer the following concordance in five columns. The first column gives the sequence number of the existing pages, as established by Troike. The second column lists the position of that page in a specific section, indicated by letters of the alphabet, again based on the work by Troike. The third column contains the reference to the two surviving parts as we now know them: Codex Iya Nacuaa I or the Yucu Dzaa fragment (= Colombino) and Codex Iya Nacuaa II or the Tindu fragment (= Becker I). The fourth column indicates if it is a left hand (l) or a right hand page (r). The fifth column gives the position of the page in the publication of the two parts under the name of 'Codex Caso' by León-Portilla (1996) - the latter author followed an early study by Caso himself, which still contained some significant errors.

${ }^{40}$ For the description of this process see Van Doesburg 1996 and Monaghan 1997, as well as Monaghan's article 'Mixtec Codices and the Transition from Noble Estates to Corporate Communities in the Nineteenth Century', a contribution to the volume in honor of Mary Elizabeth Smith (Boone 2005: 415-426). Cf. Chance 2008. 


\begin{tabular}{lllll}
\hline 1 & 2 & 3 & 4 & 5 \\
\hline
\end{tabular}

- A Missing [?? pp.]

1. B 1. Nacuaa I (Colombino), p. 1

(1.) Caso, p. 1

2. B 2. Nacuaa I (Colombino), p. 2

(r.) Caso, p. 2

3. B 3. Nacuaa I (Colombino), p. 3

(1.) Caso, p. 3

4. B 4. Nacuaa I (Colombino), p. 4

(r.) Caso, p. 4

5. B 5. Nacuaa I (Colombino), p. 5

(1.) Caso, p. 5

6. B 6. Nacuaa I (Colombino), p. 6

(r.) Caso, p. 6

7. B 7. Nacuaa I (Colombino), p. 7

(1.) Caso, p. 7

8. B 8. Nacuaa I (Colombino), p. 8

(r.) Caso, p. 8

9. B 9. Nacuaa I (Colombino), p. 9

(1.) Caso, p. 9

10. B 10. Nacuaa I (Colombino), p. 10

(r.) Caso, p. 10

11. B 11. Nacuaa I (Colombino), p. 11

(1.) Caso, p. 11

12. B 12. Nacuaa I (Colombino), p. 12

(r.) Caso, p. 12

13. B 13. Nacuaa I (Colombino), p. 13

(l.) Caso, p. 13

14. B 14. Nacuaa I (Colombino), p. 14

(r.) Caso, p. 14

15. B 15. Nacuaa I (Colombino), p. 15

(1.) Caso, p. 15

16. C 1. Nacuaa I (Colombino), p. 17

(r.) Caso, p. 16

17. C 2. Nacuaa I (Colombino), p. 18

(1.) Caso, p. 17

18. C 3. Nacuaa I (Colombino), p. 19

(r.) Caso, p. 18

D Missing [2+?pp.]

19. E 1. Nacuaa I (Colombino), p. 20

(1.) Caso, p. 21

20. E 2. Nacuaa I (Colombino), p. 21

- F Missing [?? pp.]

21. G 1. Nacuaa I (Colombino), p. 22

(r.) Caso, p. 22

22. G 2. Nacuaa I (Colombino), p. 23

(1.) Caso, p. 27

23. G 3. Nacuaa I (Colombino), p. 24

(r.) Caso, p. 28

(1.) Caso, p. 29

$(+30=$ missing p. $)$

24. H 1. Nacuaa II (Becker I), p. 1

(r.) Caso, p. 23

25. H 2. Nacuaa II (Becker I), p. 2

(1.) Caso, p. 24

26. H 3. Nacuaa II (Becker I), p. 3

(r.) Caso, p. 25

27. H 4. Nacuaa II (Becker I), p. 4

(1.) Caso, p. 26

- $\quad$ I Missing $[1+$ ? p.] 
$\begin{array}{lll}1 & 2 & 3\end{array}$

$4 \quad 5$

28. J 1. Nacuaa II (Becker I), p. 5

(r.) Caso, p. 31

29. J 2. Nacuaa II (Becker I), p. 6

(1.) Caso, p. 32

30. J 3. Nacuaa II (Becker I), p. 7

(r.) Caso, p. 33

31. J 4. Nacuaa II (Becker I), p. 8

(1.) Caso, p. 34

32. J 5. Nacuaa II (Becker I), p. 9

(r.) Caso, p. 35

33. J 6. Nacuaa II (Becker I), p. 10

(1.) Caso, p. 36

34. J 7. Nacuaa II (Becker I), p. 11

(r.) Caso, p. 37

35. J 8. Nacuaa II (Becker I), p. 12

(1.) Caso, p. 38

36. J 9. Nacuaa II (Becker I), p. 13

(r.) Caso, p. 39

37. J 10. Nacuaa II (Becker I), p. 14

(1.) Caso, p. 40 $(+41=$ missing p. $)$

38. K 1. Nacuaa I (Colombino), p.16

(r.) Caso, p. 44

39. L 2. Nacuaa II (Becker I), p. 15

(1.) Caso, p. 42

40. L 3. Nacuaa II (Becker I), p. 16

(r.) Caso, p. 43

- M Missing [?? pp.]

The dimensions of the pages are approximately $25 \times 18.5 \mathrm{~cm}$ on average. The overall reading order is from left to right and follows the guidelines, which generally divide the pages in three bands, to be read in a yuq yuq (boustrophedon) pattern.

A modern technical analysis of the material of Codex Iya Nacuaa I (Colombino) suggests that the pictorial manuscript was composed in one continuous creative effort:

From our UV-IR imaging and XRF measurements we may conclude that the composition of the Colombine codex is very homogeneous. Colorants were applied on a gypsum ground layer and carbon inks were used. Blue color was prepared by colorant fixed to clay, while green may be made from blue and yellow superposition. (Zetina et al. 2009: 5).

\section{Codex Añute (Ms. Arch. Selden A.2 / Codex Selden 3135)}

The last document to be discussed refers the history of the ruling family of a place represented as a Mountain of Sand or as a Mountain with a Mouth (a-) that Spits Sand ( $\tilde{n} u t e)$, nicknamed 'Belching Mountain'. 
The sign is mentioned in close connection with the place sign of Nuu Tnoo and has therefore been identified by Mary Elizabeth Smith as Añute, i.e. Magdalena Jaltepec, the direct neighbor of Nuu Tnoo in the Mixteca Alta. ${ }^{41}$ Brotherston (1995), therefore, has proposed to call it 'Xaltepec Annals'.

The manuscript is preserved in the Bodleian library, Oxford, and known as Codex Selden 3135 after the English scholar who is its first known European owner. ${ }^{42}$ The way in which it was transferred from Mexico to England is not clear. The manuscript contains the genealogical history of the Añute dynasty. The last ruler is Lord 10 Grass: Iya Sicuañe. As he was the one who ordered the document to be painted, we might call it 'Codex Sicuañe' (cf. Jansen \& Pérez Jiménez 2000), but as the manuscript actually contains the dynastic history of its community, we prefer naming it 'Codex Añute'.

Its style and conventions are completely precolonial, very similar to those of Codex Nuu Tnoo-Ndisi Nuu (that belonged, as we saw, to the neighboring town Nuu Tnoo). On the other hand the last dates given in the pictorial text are already part of early colonial history. From the conservative style, we conclude that the painter must have been trained in the precolonial era, and, therefore, was already somewhat advanced in age ( \pm 60 years old?) when he composed the Codex Añute. This circumstance might explain why the drawings are often executed with an unsteady hand.

The codex itself is largely a palimpsest: pp. 1-15 originally contained another pictographic text, painted on both sides of the screenfold. The little that may be distinguished today shows that that codex also had a genealogical historical character. The strip was cleared and prepared for reuse. Two hides were added for new pages (pp. 16-20) - a process that may indicate that by that time it had become difficult to obtain new good strips of deerskin, which was considered the necessary material for this purpose.

${ }^{41}$ Codex Yuta Tnoho, p. 42; cf. Codex Mendoza, p. 43. See Smith 1983 and 1994.

${ }^{42}$ See the edition and commentary by Caso (1964a), as well as the studies by Mary Elizabeth Smith $(1983,1994)$ and Jansen \& Pérez Jiménez $(2000)$. The latter work was followed to a large extent by Cecilia Rossell in the updated version of her study of female protagonists in the Nuu Dzaui codices (Rossell \& Ojeda Díaz 2003: ch. 1). In 2007 a second edition of our 2000 commentary was published with some corrections in Oaxaca, including a new facsimile edition based on scans taken from the original (Jansen \& Pérez Jiménez 2007b). 

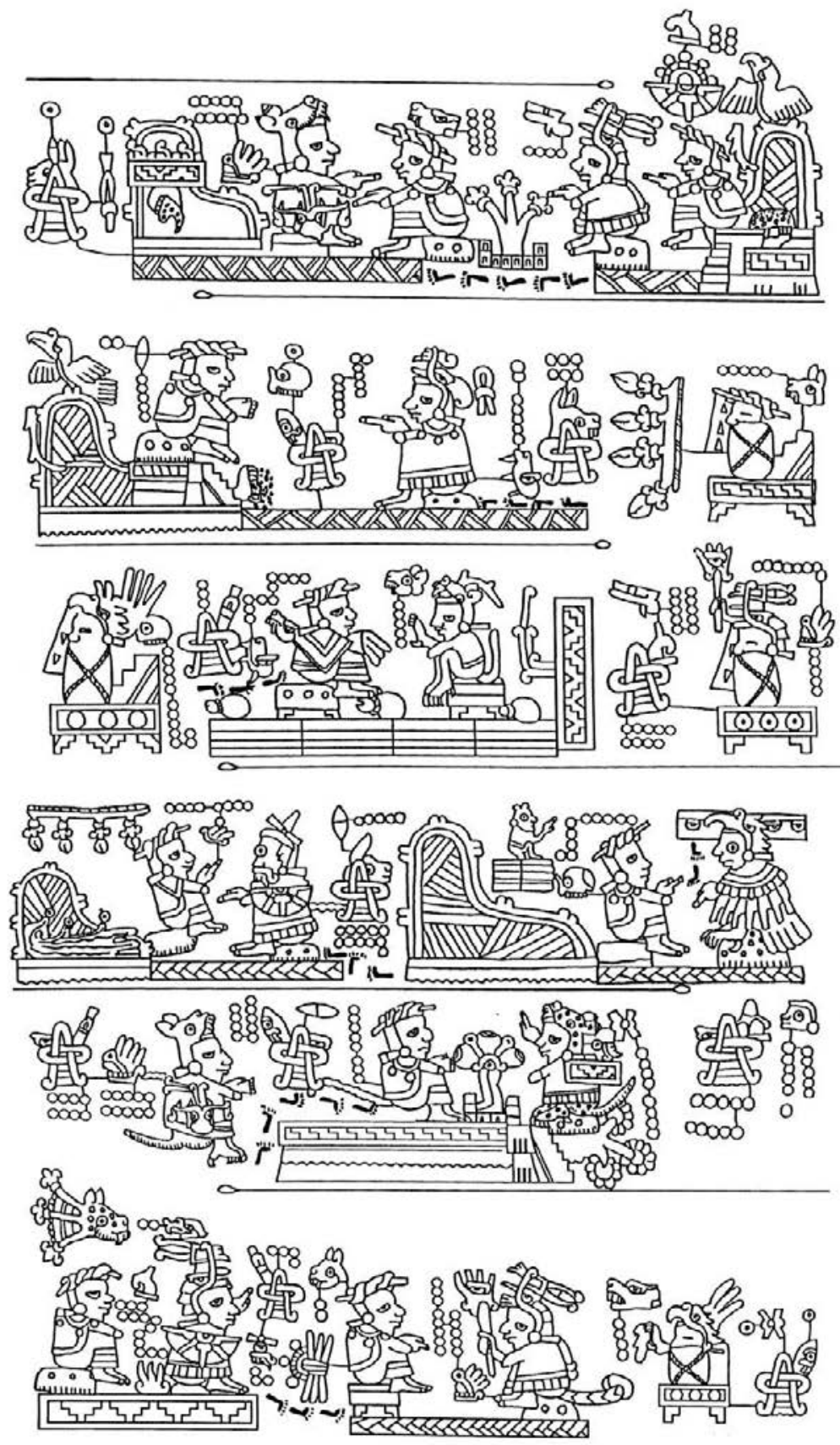

2.7. Final pages of the Codex Añute (or Codex Selden). 
Mary Elizabeth Smith (1994) has observed that at the end of the genealogical register the death of several protagonists is explicitly mentioned. She sees an interesting parallel with the historical expositions in early colonial lawsuits, whose primary aim was to clarify which members of the noble house were still alive and which not, in order to claim inheritance or other rights. On the other hand references to legitimacy of indigenous rulership in colonial terms are conspicuously lacking: the last caciques do not wear Spanish clothes, are not sitting on a Spanish chair, nor do they appear saluting the Marqués, i.e. Hernán Cortés. There is no reference to a church or to Christian rituals (such as baptism).

In fact, the emphasis on how the prehispanic ancestors of the ruler had been engaging in the veneration of the Sacred Bundle could have become a liability if presented before a Spanish court. Only a few years earlier the cacique and nobles of Yodzo Cahi (Yanhuitlan) had been thrown in prison and narrowly escaped burning at the stake, precisely because of such acts. ${ }^{43}$

The codex further contains an important fragment of the great saga of Lord 8 Deer, namely the part played by Lady 6 Monkey of Añute. Because of what the other codices tell us, we know that this part ended in a very tragic way, but the painter of Codex Añute selected only the triumphant moments of this story and simply left the rest untold, thereby creating an exclusively self-glorifying text. Leaving out all references to the successive Mexica and Spanish invasions reinforces the same effect. The conflicts mentioned are only those between the local cacicazgos.

These details suggest that Codex Añute was not so much prepared for presentation in a colonial court, but for an 'internal affair', an occasion where traditional rights of the noble house had to be affirmed in traditional forms. On the last page we see two marriages between princes of Añute and princesses from a place represented as 'Altar with Claw that throws Gravel, at the foot of Mountain of Bird and Blood'. The two princes are brothers and their wives may have been sisters. The oldest brother is the one who inherits the cacicazgo and

${ }^{43}$ The acts of this inquisitorial process were partially published and analyzed by Jiménez Moreno \& Mateos Higuera (1940). For a recent edition see Sepúlveda y Herrera 1999. The contents have been discussed by Greenleaf (1978), Jansen \& Pérez Jiménez (2000 / 2007b: ch. IV) and Pérez Ortiz (2003). Further background information on the role of the inquisition in Oaxaca is given by Jiménez Muñoz \& González Medina 2009. 
continues the line: Lord 10 Grass, 'Jaguar, Breath of the Earth'. In accordance with the conventions of Nuu Dzaui pictography, first his birth is given (Añte, p. 19-III) in the year 8 Reed (1527), then the birth of his brothers and sisters, who are shown with their respective wives and husbands. The father of all these children, Lord 13 Grass, died on the day 10 Wind in the Year 9 House (June 6, 1541).

The youngest brother, Lord 7 Alligator, whose birth in 1538 is given as an afterthought, is shown marrying Lady 7 Flint, on the day 1 Death, in the year 11 Flint (May 22, 1556). Then the narrative sequence returns to the first-born and his marriage to Lady 10 Serpent. This marriage is painted as the last in the sequence since it is that of the first-born prince who continues the genealogical story. Actually the ceremony had taken place earlier than that of the younger brother, on the day 1 Reed of the year 1 Rabbit (May 22, 1546). We suppose that Lord 10 Grass is identical to Don Carlos de Villafañe, mentioned in colonial documents as cacique of Añute in this period. ${ }^{44}$

It is interesting to notice that these early colonial marriage dates differ from the traditional custom. The precolonial Lords and Ladies preferred to marry on a day Eagle or Deer, as those were days of the West, dedicated to the Patron of the West, the Grandmother of the River, the Goddess of human reproduction and fertility. In the early colonial period the princes of Anute chose other symbolic days: 1 Reed, associated with the beginning of the year counts, and 1 Death, the ancient day of the Sun God. Interestingly both correspond to the 22nd of May in their respective years in the Christian calendar. So, clearly, the younger brother arranged for his marriage, which reconfirmed the marital alliance between Añte and Altar with Claw that throws Gravel at the foot of Mountain of Bird and Blood, to take place on the same day in the Christian calendar as the marriage of his older brother, exactly ten years earlier. Interesting enough the chosen date fell one week after May 15, the fiesta of San Isidro Labrador that replaced the precolonial veneration of the Rain God on the mountain of Añute. ${ }^{45}$

This marriage of the younger brother in 1556 is the terminus post quem for the painting. Possibly Codex Añute was made for some form of commemoration of these marriages. Now, as both the principal cacique and his younger brother had chosen a bride from the same

44 See Spores 1992: 36, 37.

45 Cf. Jansen \& Pérez Jiménez 2000: 10, 93. 
town, an arrangement had to be made as to how the traditional privileges (succession, tribute rights) in these cacicazgos would be distributed among the children of these two couples - the last mentioned marriages in the codex. To this effect the centuries long dynastic history was an essential point of reference.

The first page (cover) of the codex contains the date Year 2 Flint, day 5 Reed: maybe this is the date for which the codex was prepared - it would be the 8th of May of 1560, two weeks before the fourth anniversary of the last marriage.

In the late 1560's his son, Don Angel de Villafañe, who must have been a teenage boy in 1560, succeeded Don Carlos de Villafañe as cacique of Añute. We speculate that the codex was prepared for the ceremony in which he would be designated as heir and successor.

Analyzing its contents we conclude that this book was a strong statement by the conservative faction in native society. The pictorial text reminds the future cacique of his glorious past, the divine origins of the dynasty, and the rituals which his ancestors had always piously celebrated for the Sacred Bundle of the Nuhu (deity) in the temple on top of the mountain of Añute. The tragic irony of the case is that in 1568, when he had become cacique, Don Angel sent a letter to the Viceroy to ask for priests, who then actively christianized the population. The small provisional church that had been built on the ancient acropolis was deserted and replaced by a big building in the center of the colonial town. In this new context the traditionalist codex lost most of its original meaning.

It is interesting to note that Friar Francisco de Burgoa in the 17th century still knew that 'paintings and characters' with historical contents had existed in Añute (1934b, I: ch. 34). But in the latter part of the 16th century or the beginning of the 17th century the Codex Añte must have left the town, maybe as an appendix to some official document (possibly in the context of a lawsuit) or as a collector's item.

\section{Related Pictorial Manuscripts from Early Colonial Times}

The demonstratively Christian behavior of Don Angel in Jaltepec corresponded to a general trend among the colonial caciques, after an insecure period, in which many doubted whether they should take the side of the cruel conquistadors, greedy encomenderos and demanding Spanish administration, or, defiant and rebellious, stick to the order 
of the ancient Gods and traditions. For some time many seem to have led a double life, combining the two lifestyles and the two religions. They were 'in-between', nepantla, as the Nahuas of the 16th century themselves formulated it. ${ }^{46}$

In this nepantla period, having genealogical records in ancient style was still important for most caciques so as to show their rights to certain privileges. At the same time new necessities arose. Colonialism meant that land became a commodity, and as a consequence the painters of the pictorial documents struggled to adapt to this circumscription and enclosure of space. The proof of the possession of a cacicazgo had to include the fixing of its territorial extension. Large paintings on cloth (lienzos) and maps therefore registered the names of the boundaries, either in the ancient pictographic tradition, or just in words, as 'written maps'. These border toponyms do not refer to fortified frontier settlements or otherwise inhabited areas but to demarcation points in the landscape ( $d z a \tilde{n} u$ in Dzaha Dzaui, mojoneras in Spanish) to anchor a boundary line (lindero). Generally the connecting line separates the uninhabited communal lands of both towns; the points themselves are marked with piles of stone and crosses, to avoid easy removal.

We mention here the most important examples of the early colonial pictorial manuscripts from the Nuu Dzaui area.

The Codex of Yodzo Cahi (Yanhuitlan) is in a fragmentary condition. Parts are preserved in the Academia de Bellas Artes, Puebla, in the Archivo General de la Nación, Mexico City, and in the collection of unpublished works of Manuel Martínez Gracida in the Oaxaca Public Library. ${ }^{47}$ The opening scene depicts an assembly before the palace (aniñe) of Yodzo Cahi, likely an investiture ceremony of the ruler Lord 9 House, on a sacred date, which corresponds to the beginning of the Mixtec year in 1520. A scene from the conquest of Tenochtitlan -

${ }^{46}$ Durán 1967, I: 237. For an in-depth study of how the early colonial pictorial manuscripts from Nuu Dzaui reflect the mentality and social dynamics of this period, see Terraciano 2001. On colonialism and cultural resistance, see Bartolomé 2008: $55-79$.

${ }^{47}$ For a color reproduction and explanation, see Sepúlveda y Herrera 1994, complemented by Martínez Gracida 1986. The pioneering study by Jiménez Moreno y Mateos Higuera 1940 is still of great value, offering important insights and documentation. Below, in chapter 10, we offer a more detailed discussion of the contents and historical context, with a new reconstruction of the sequence of pages. 
a battle between Aztec warriors in canoes and Spanish conquistadors - is followed by a series of scenes showing that a new cacique (Lord 8 Death from Nuu Tnoo) took over power and became an ally of the Spaniards. The codex lists the tributary towns, gifts, contributions and services he was still entitled to in this subdued condition, mentioning the feasts on which the tributes were due. References to the line of caciques are mixed with those to other protagonists of colonial society: the Spanish encomendero, the bishop and the Dominican monks. Access to traditional power, 'the mat and the throne' became conditioned by the observation of Catholic cult, manifest in the Rosary and in the newly constructed colonial churches (huahi ñuhu). The drawing style is a fascinating innovative blend of Mesoamerican and European artistic elements.

The Codex of San Pedro Cántaros in the Mixteca Alta, now in the Biblioteca Nacional de Antropología in Mexico City, where it has become known as 'Códice Muro'. ${ }^{8}$ The pictorial representation of the main town in the manuscript - Mountain of Head (dzeque) with Open Mouth (a-) - may actually represent San Pedro Cántaros' neighbor San Miguel Adeques ( $A$-dzeque), as argued by Mary Elizabeth Smith (2000). This could mean that originally this sovereign community had a double capital. We will refer to the manuscript by the name its glosses assign to its community of origin: 'Codex Nuu Naha'. It contains the list of ruling couples of this small village-state ( $\tilde{n} u u)$ and is of particular interest as its pictographic scenes are explained or rather 'read' in an alphabetic text in Dzaha Dzaui. These glosses confirm the identifications of several toponymic signs, such as Black Frieze representing Nuu Tnoo (Tilantongo) and Broken Frieze representing Chiyo Cahnu (Teozacualco), but also make possible new identifications, e.g. Altar of The Flowering Tree being Chiyo Yuhu (Suchixtlan). The basic format of Nuu Dzaui dynastic historiography - the statement of a marriage, indicating the places of origin of the people involved - was still in use in the latter part of the 17 th century:

do ju.o mexia nidesiya adutu niduvi sihi doña cristina maldonado nidesi ñudodzo yya adutu de 1680 años

48 This 'black-and-white codex' has been reproduced and interpreted by Smith (1973b, 2000), López García (1993), Jansen (1994) and Hermann Lejarazu (2003). See also Smith's final study of this codex as a land document (in Boone 2005: 382-414). 


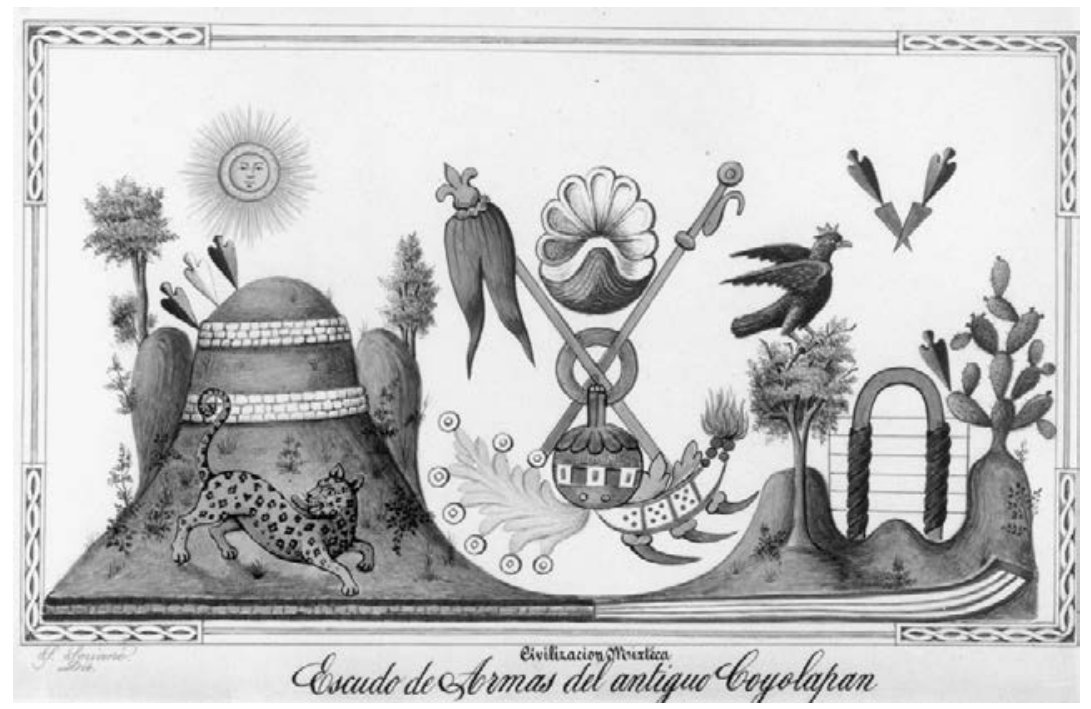

2.8. Coat of Arms of Saha Yucu (Cuilapan), copy preserved in the collection of unpublished works of Manuel Martínez Gracida.

Don Juan Mexía came from Andutu (Amatlan), married Doña Cristina Maldonado, who came from Nuu Ndodzo (Huitzo). They were caciques of Andutu (Amatlan) in 1680.

The Coat of Arms of Saha Yucu (Cuilapan) has been preserved in two drawings in the unpublished papers of Manuel Martínez Gracida, one clearly being a well done and colored redrawing of the other. The location of the original is unknown. Cuilapan, or rather Coyolapan, the Nahuatl name of Saha Yucu, is represented as a bell (coyolli) above a stream of water (apan), which combines with flames into the sign 'water and fire', i.e. war. A lance and a spear-thrower that flank the toponym as heraldic symbols further express the bravery of the town. Between them a shell, as used in baptism, indicates that the community has become Christian. The configuration is put next to a Jaguar Mountain with walls and arrowheads, probably Monte Albán. On the other side we find references to the successive powers in the area: the carrying frame that represents Zaachila, the cactus of Tenochtitlan and the royal eagle of the Spaniards. ${ }^{49}$

${ }^{49}$ A photo of the colored drawing was published in a selection of illustrations from Martínez Gracida's unpublished work (1986). For the identification of Monte Albán and a more detailed interpretation, see Jansen's chapter 'Monte Albán y Zaachila en 
The names and hieroglyphs for the different slopes of Monte Albán are registered on another important colonial document: the Map of Xoxocotlan, of which several copies have been preserved (Smith 1973a: appendix F; Ruiz Cervantes \& Sánchez Silva 1997).

The Lienzo of Yucu Nama (Amoltepec) is now in the American Museum of Natural History, New York. It was originally identified as 'el mapa del pueblo de Amoltepec, del Distrito de Juquila', but then attributed by Caso (1957) to the nearby town of Yolotepec. His argument was the fact that the central element in the main toponymic glyph looks like a heart (yollotl in Nahuatl). But, as that sign is indeed also used to represent the root of the soap plant (amolli), which gave its name to Yucu Nama (Amoltepec), we have to abandon Caso's theory. We find the same sign in the pictorial manuscript (black drawing on amate paper) of another town with a similar name, San Pedro Yucu Nama (Jansen 1994). The Yucu Nama (Amoltepec) close to Juquila must be the southern neighbor of Chiyo Cahnu (Teozacualco), from which a Relación Geográfica with an important pictorial map has survived (Acuña 1984, II: 147-151).

The Lienzo of Yucu Satuta (Zacatepec) is now in the Museo Nacional de Antropología, Mexico City. ${ }^{50}$ It shows the boundaries of this sovereign community in the coastal area, but also its main neighbors and a sequence of rulers. The upper part shows Lord 11 Jaguar 'Fire of Nuu Dzaui' (iya Sihuidzu 'Ñuhu Ñu Dzaui), honoring Lord 4 Wind 'Fire Serpent' and his wife Lady 10 Flower 'Rain Spiderweb' at the moment of their enthronement as supreme rulers in Nuu Yuchi (Mogote del Cacique) and Ndisi Nuu (Tlaxiaco) in the year 4 Flint (1120) and receiving instructions from them. After having been in charge of several towns in the realm of Lord 4 Wind (among which the Mountain of the Moon and the Fire-Wood: Nuu Yoo and Yucu Iti), Lord 11 Jaguar enters the territory of Yucu Satuta and establishes his residence at the site of Seven Pines. His son moves the throne to the town of Yucu Satuta (Zacatepec) itself. An interesting detail is the presence of the Sacred Bundles of two Founding Ancestors, Lord 7 Deer and Lord 9 Movement, in the main temples. The lienzo includes the toponymic hieroglyphs of the boundary markers of Yucu Satuta's territory and of

los Códices Mixtecos' in Jansen \& Kröfges \& Oudijk 1998: 67-122. For colonial documentation on the villages concerned, see Méndez Martínez \& Méndez Torres 2007a.

${ }^{50}$ A photographic reproduction with commentary is included in Smith 1973a. 
the neighboring towns, among them in the top segment the Town of Death, Nuu Andaya (now: Nuu Ndeya), Chalcatongo.

The Tira or Codex of Yodzo Yaha (Tecomaxtlahuaca), now in the Archivo General de la Nación in Mexico City (AGN: Ramo de Tierras 2692, exp. 16), is a vertical strip of amate paper and contains a list of rulers and the tributes given to them. The town's name, 'Plain of Eagles', is represented as the feather (yodzo, homonymous with the word for 'plain') of an eagle (yaha); it was, however, also understood as 'Plain (yodzo) of the Tecomates', i.e. 'Gourds (tiyaha)' and translated as such into Nahuatl: tecoma-ixtlahuacan. The manuscript was painted in 1578 on the instructions of Don Francisco de Arellano, the native cacique of Yodzo Yaha in the Mixteca Baja, to be presented to the corregidor Diego de Terrazas. ${ }^{51}$ Its purpose was to clarify the historical background of the existing tribute structure and to avoid excessive payments to the Spanish colonial authorities.

Codex Sánchez Solís or Egerton 2895 is now in the British Museum, London, but originally belonged to the dynasty of Nuu Naña (Cuyotepeji) in the Mixteca Baja. ${ }^{52}$ We therefore call it 'Codex Nuu Ñañ'. The individuals on the last page (p. 31), representing the last rulers, are scratched out. Only the town of the person allied by marriage to the successor to the throne is still visible: Mountain of War, glossed Nuu Yecu. ${ }^{53}$ Another gloss next to it reads tnoho gui biyo, lineage of 4 Reed'. From other documents we know that Lord 4 Reed (Nahui Acatl in Nahuatl) was the ruler of Nuu Naña (Cuyotepeji) at the time of the conquest and was baptized as Don Francisco de Mendoza. He married two different wives, one (Ozomatzin from Camotlan) according to the ancient native law and one (Doña Catalina Cuetzpalin) according to the newly introduced Christian ritual. As was often the case, this provoked a lawsuit between the descendants of these two marriages as to who was the legitimate successor. ${ }^{54}$ According to the different testimonies Lord 4 Reed belonged to the line of rulers of Nuu Naña.

\footnotetext{
${ }^{51}$ See Spores 1976, Smith \& Parmenter 1991: 92-94, and Jansen 1994: 31-45.

52 Facsimile edition by the Akademische Druck-und Verlagsanstalt, Graz: Burland 1965 and Jansen 1994.

${ }_{53}$ There are several candidates for this toponym. König (1979) suggests Yautepec, Morelos. The glyph also includes the element 'night', which points towards a Nahuatl place name, in which yaotl ('war') could alternate with yoalli, 'night'.

${ }^{54}$ Archivo General de la Nación (AGN), Ramo Civil 679, exp.1 (Paillés Hernández 1993b).
} 


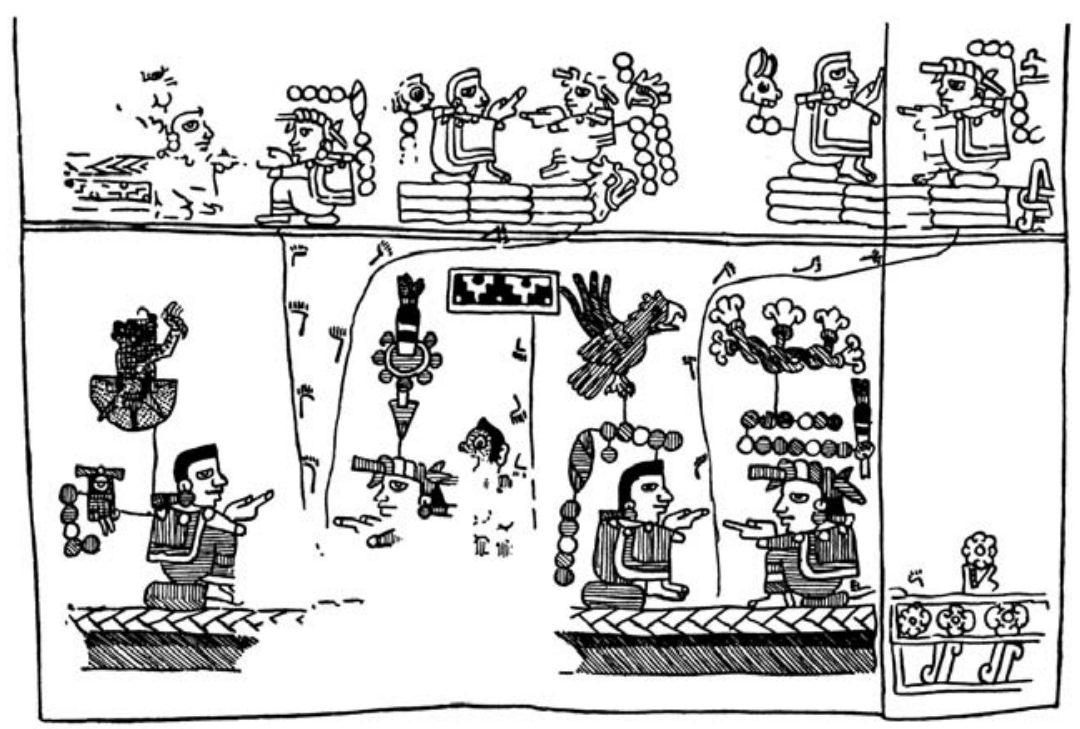

2.9. Codex Iya Cochi (Becker II), p. 3 (Left to Right): intermarriages between the local ruling lineage and the dynasties of other towns. Lord 5 Rain 'Coyote Sun' marries Lady? Monkey 'Jewel Arrow' from Black Frieze, i.e. Nuu Tnoo (Tilantongo). Their first daughter marries the ruler of Town of the Warband (possibly Nuu Yecu, Yauhtepec in the State of Guerrero), while the second marries Lord 3 Monkey, the ruler of Plain of the Eagle, i.e. Yodzo Yaha (Tecomaxtlahuaca). Their son, Lord 11 Flint 'Eagle of Precious Feathers', inherits the kingdom and marries Lady 13 Reed 'Garland of Flowers' from Altar of the Rosette. Their daughter, Lady 7 House, marries Lord 2 Rabbit, ruler of Plain of the Year Sign, i.e. Yodzo Cuiya (Juxtlahuaca).

His parents were Iya Quisayo (Lord 4 Rabbit) and Yacatli, which may be an error for Iya Cachi (Lady 1, 2 or 12 Wind). This couple may have been the one originally represented on the last page of the codex.

The manuscript is of particular interest because it contains a brief alphabetic transcription of the names of protagonists and their places of origin in Dzaha Dzaui, which makes it a valuable source for identifying a number of toponymic signs, among them: Huahi Andevui, the Heaven Temple, as a sign for Nuu Tnoo (Tilantongo), Place of Herbs as Ñuu Yucu (San Miguel Cuevas), Place of Plants as Nuu Ndaya (San Martín Duraznos), Place of Red Dots as Nuu Ndoco (Zapotitlan), Sweatbath as Nuu Niñe (Tonalá), Mountain of the Jewel as Yucu Yusi (Acatlan) and Mountain of the Standing Conch Shell as Yucu Ndaa Yee (San Pedro, San Pablo Tequixtepec). 
Codex Becker II, now in the Museum für Völkerkunde in Vienna (like the Becker I fragment of Codex Iya Nacuaa), is also from the Mixteca Baja. We will call it 'Codex Iya Cochi' after the last depicted ruler: Lord (Iya) 3 Wind (Co-chi). It is a fragment of a larger manuscript, the beginning of which is probably the 'Nochistlan Fragment', now in the Museum für Völkerkunde, Hamburg. ${ }^{55}$ A red line divides the pages into two horizontal bands. In the last pages the lower band contains the genealogical register of rulers of an unidentified villagestate and references to the origin of their wives, while the upper band shows the out-going marriages of some of the female descendants. Among the places to which these daughters go to are Valley of the Eagle, i.e. Yodzo Yaha (Tecomaxtlahuaca), and Valley of the Year Sign, i.e. Yodzo Cuiya (Juxtlahuaca), both major towns in the southern Mixteca Baja. The ruler of Yodzo Yaha is Lord 3 Monkey (p. 3), who appears as Ozomatzin ('Lord Monkey') in the Codex of Yodzo Yaha, one generation before the Spanish conquest. Among the places of origin of the dynasty is a mountain and town with a checkerboard motif (naa, 'dark'), to be read as Yucu Naa or Nuu Naa. The first of these is documented as the emblematic place of the North, but there is also a community called Santos Reyes Yucuná in the Mixteca Baja.

The Codex Tulane is actually a roll. Extracted from the town of Yucu Nindavua (San Martín Huamelulpan) in the Mixteca Alta, and for some time in the possession of the family Daza (Tlaxiaco, Chalcatongo), it fell into the hands of the merchant Felix Muro (Oaxaca), who sold it to a person who took it to the U.S., where it ended up in the Latin American Library of Tulane University, New Orleans. As Mary Elizabeth Smith has demonstrated, it contains the ruling lineages of two of the main polities of the Mixteca Baja. ${ }^{56}$ The most important toponym is painted as a mountain with a sign for a jade or jewel inside. The place is identified by an alphabetic gloss in the Codex Nuu Naña as Yucu Yusi, 'Mountain of the Jewel', the Dzaha Dzaui name of Acatlan (which means 'Place of Reeds' in Nahuatl). The other town is represented as River of the Seated Lord and the Eagle. Smith has convincingly argued that this is the sign of Toavui (Chila). We therefore

55 Nowotny 1961b, 1975; Smith 1979; Jansen 1994.

56 Facsimile edition (ADEVA Graz) with commentary: Smith \& Parmenter 1991. In this commentary Smith includes an overview and summary discussion of the other pictorial manuscripts from the Mixteca Baja. Rodríguez Cano $(2006,2007)$ provides a valuable update. Van Doesburg (2008ab) presents several new data. 


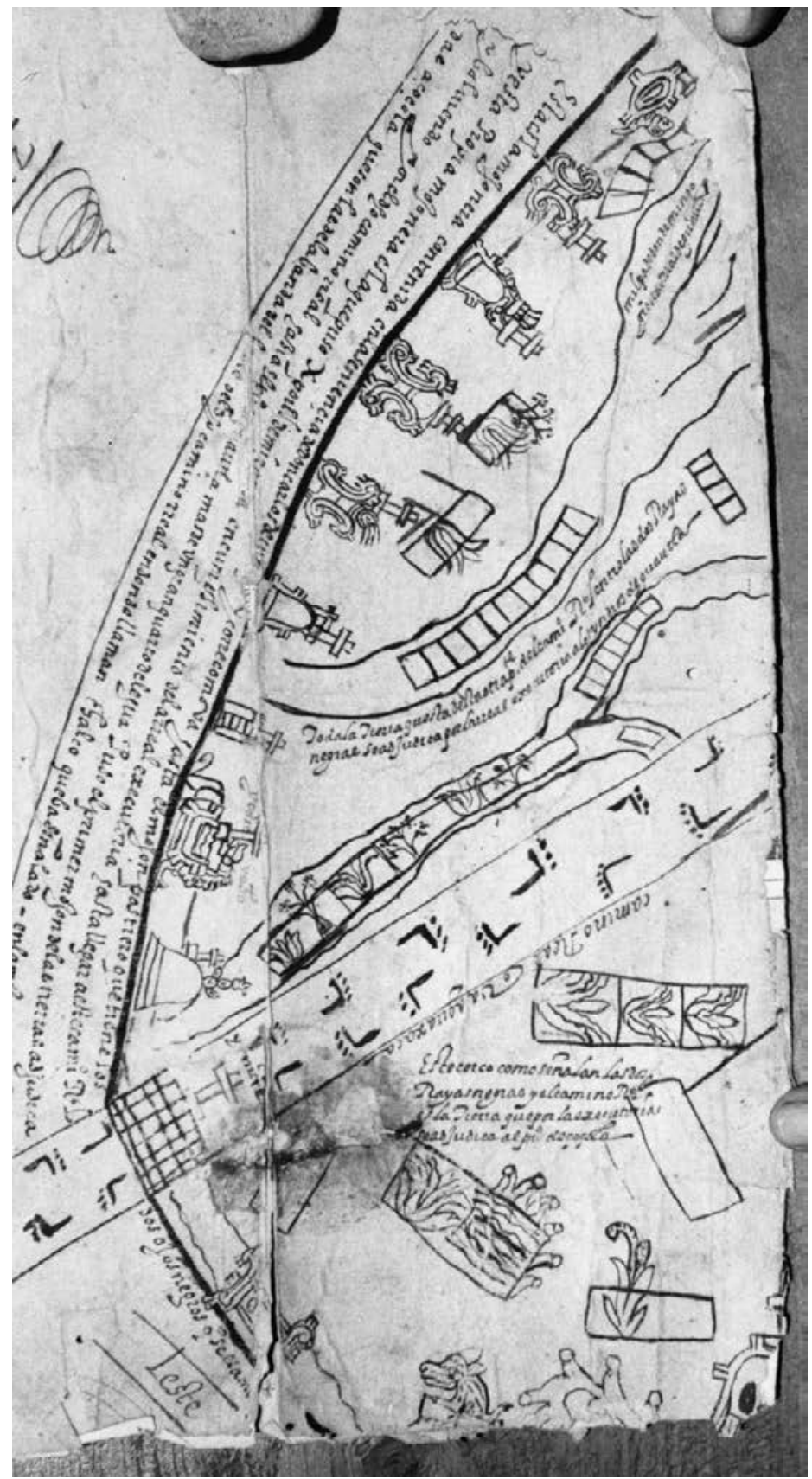

2.10a. Map of Tuhu (Sosola), left half. 


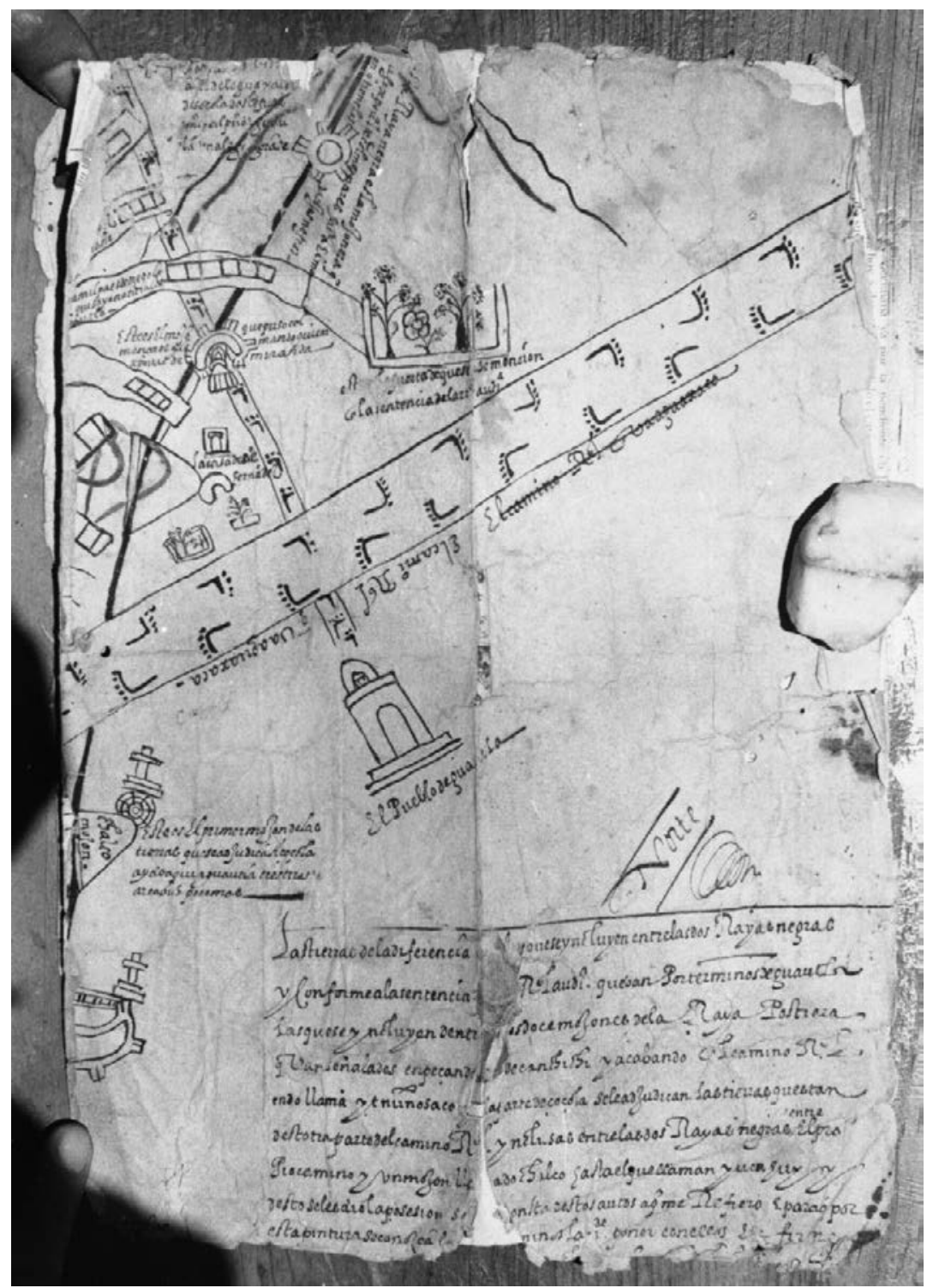

2.10b. Map of Tuhu (Sosola), right half. 
might refer to it as the 'Roll from Yucu Nindavua' or the 'Roll of Toavui-Yucu Yusi'.

There are more Early-colonial Mixtec lienzos and maps, such as the Genealogy of Tixii or San Agustín Tlacotepec (in the literature referred to as Tlazultepec), ${ }^{57}$ the Map of Tuhu (San Juan Sosola), ${ }^{58}$ the Lienzo of Ocotepec, ${ }^{59}$ the Lienzo of San Esteban Atatlauhca, ${ }^{60}$ the Lienzo of Philadelphia, ${ }^{61}$ the Map of Xochitepec ${ }^{62}$, the Map of San Vicente Palmar and the Codex Mixteco Postcortesiano No. 36, ${ }^{63}$ as well as the maps of the Relaciones Geográficas. ${ }^{64}$ Most of these deal with the territorial extension of a specific community and/or the rights of the ruling cacique. They may contain place signs with glosses that are a valuable addition to our 'pictographic dictionary', as well as other detailed data that are in some way connected to the main narrative of Nuu Dzaui history.

A related corpus is that of the Lienzos of the Coixtlahuaca Valley. Especially relevant are those known as the Lienzo of Tlapiltepec (formerly referred to as Lienzo Antonio de León), the Lienzo of Ihuitlan, the Lienzo of Coixtlahuaca I and the Lienzo of Coixtlahuaca II (also known as Lienzo Seler II), the two Lienzos of Tequixtepec, the Lienzo of Tulancingo, the Lienzo of Nativitas and the Lienzo of Otla. The socalled Selden Roll also belongs to this group: it contains data similar to the Codex Yuta Tnoho. As its central theme is the ritual for the

57 Spores 1964; Smith 1973a: 237; Smith 1998: 172-179; Pérez Reyes 2008.

58 Jansen \& Pérez Jiménez 2000 and 2007b, ch. 2.

59 Caso 1966b; Weitlaner Johnson 1966; Heijmerink 1973; Smith 1998: 151-155.

${ }^{60}$ Smith 1998: 155-164.

${ }^{61}$ Parmenter 1966; Caso 1964b; Smith 1998: 165-172.

${ }^{62}$ Caso 1958; Rodríguez Cano 2008.

${ }^{63}$ Smith 1973a: 194-201, 230; Rodríguez Cano 2008; Van Doesburg 2008ab. Particularly interesting is the relationship Van Doesburg discovered between the Genealogía de Igualtepec (Biblioteca Lafragua, Puebla), the Mapa de Santa Vicente el Palmar (village), and the Códice Mixteco Postcortesiano No. 36 (Biblioteca de Antropología, Mexico City), related to the area of San Juan Ihualtepec/Yoaltepec and San Pedro Atoyac: the last two documents refer explicitly to the process of salt making. The publication by Gutiérrez Mendoza \& Medina Lima (2008) offers an analytical overview of the signs that represent places in the Western frontier area of Oaxaca and the neighboring State of Guerrero; see also the study of Mixteca Baja toponyms by Acevedo Conde 2009.

${ }^{64}$ Acuña 1984, 1984-85; Mundy 1996. 
foundation or inauguration of a dynasty, we refer to it as the 'Roll of the New Fire' (Spanish: Rollo del Fuego Nuevo). ${ }^{65}$

With the passing away of ancient society and art, pictography became superfluous and out-dated, its techniques and symbols becoming forgotten. The old documents lost their significance as historical texts and became mere symbolic objects, as foundation charters or títulos. ${ }^{66}$ Those that had left the country were even more disconnected from their origin: generally their provenience was not considered a matter of importance and, consequently, was not even registered. The European collectors took only a vague and passing interest in them as curious 'barbaric' examples of a totally different type of manuscript or hieroglyphic writing. The whole Oaxacan region, once a cradle of writing, a center of painted and sculpted literature, entered a dark age.

${ }^{65}$ In this region Ngigua (Chocho) was the dominant language, though Mixtec was spoken in several places as well. Fundamental studies of this Coixtlahuaca corpus are: Burland \& Kutscher 1955; Caso 1961; Smith 1973a: 182-184; Parmenter 1982, 1993, 1997; König 1984; Van Doesburg \& van Buren 1997, Van Doesburg 2000, 2001, 2003; Boone 2000: ch. 6. The Ph.D. thesis of Rincón Mautner (1999) offers an overview. There are important differences between the interpretations of Rincón Mautner and those of Van Doesburg, but this is not the place to discuss them. Jansen 1992 comments on the cartographic aspect of the Lienzo of Tlapiltepec and the Mixtec expedition towards Cuauhtinchan (also mentioned in the Historia Tolteca Chichimeca and related documents). The commentary on the Lienzo of Otla by Ruiz Ortiz \& Jansen (2009) is also a general introduction to the Coixtlahuaca corpus.

${ }^{66}$ For more details on the colonial transformation process, see e.g. Carmagnani 1988, Ouweneel \& Miller 1990, Harvey 1991, Lockhart 1992, Romero Frizzi 1996, Terraciano 2001. The consequences of these social and mental changes for the production of pictorial manuscripts, chronicles and literary works have been investigated in depth by Gruzinski (1988), Florescano (1999, 2002), Wood (2003) and other scholars. Important case studies are presented in the dissertations of Van Doesburg (1996), Roskamp (1999), Oudijk (2000) and Asselbergs (2004). See also the volume edited by Levin and Navarrete (2007). Our chapter 10 builds on this scholarship. 


\section{REDISCOVERY AND DECIPHERMENT}

As the ancient, precolonial world faded out of sight, an antiquarian interest in that world started to arise. This was especially the case among those of Spanish descent born in New Spain, the criollos, who were looking for hallmarks of their identity in an incipient form of nationalism. The first noticeable scholar is the late 17th century savant Carlos de Sigüenza y Góngora. The following century saw the important collecting enterprise of the Italian Lorenzo Boturini. Inspired by his compatriot, the philosopher Giambattista Vico, he tried to create a systematic overview of the historical sources by ordering their data in a tripartite scheme of cultural and political evolution. Civilization like human life - was thought to proceed from a period of youth and formation to one of maturity and apogee, followed by decay and death. Such a view, although not completely unknown in Mesoamerica itself, was projected onto the archeological and historical analysis because of observations made in Europe. ${ }^{1}$ Today most archeologists still use the sequence of a Formative or Preclassic Period ( \pm 1500 вС - \pm 250 AD), a Classic Period ( $\pm 250- \pm 900 \mathrm{AD}$ ), and a Postclassic Period $( \pm 900-1521 \mathrm{AD})$ for easy reference, but without attaching any specific value judgement to these terms. Boturini's work led to the first monumental synthesis of precolonial history by the exiled Jesuit Francisco Xavier Clavigero, as well as to the first effort to interpret a precolonial religious codex by another Jesuit, José Lino Fábrega. ${ }^{2}$ After these isolated, though important, scholarly contributions of the 18th century, it was the renowned and widely read scholar Alexander von Humboldt who promoted interest in the codices, kept as unfamiliar treasures in different European collections. His own opinion about their contents was colored by prejudices stemming from a Eurocentric perspective:

${ }^{1}$ In Codex Vaticanus A (f 61v) the stages of human life are compared to climbing and descending a mountain (Anders \& Jansen 1996: 279-281). For a summary of the ideas of Boturini and Vico, see Matute 1976.

${ }^{2}$ See the introductory chapters of the commentaries on Codex Yoalli Ehecatl or Borgia (Anders \& Jansen \& Reyes García 1993) and Codex Tezcatlipoca or FejérvàryMayer (Anders \& Jansen \& Pérez Jiménez 1994). 
he concluded that little would be lost for Science if the books of such a primitive people were never deciphered.

Some decades later, between 1831 and 1848, Lord Kingsborough, arguing that the Native American peoples had originated from the ten 'lost tribes' of Israel, published a series of the most spectacular manuscripts, though without a scholarly commentary. Among them were the codices Yuta Tnoho (Vindobonensis) Obverse and Reverse, Nuu Tnoo-Ndisi Nuu (Bodley), and Añute (Selden).

At that time most of their contents had become inaccessible. When the Codex Tonindeye was still in the Convent of San Marco in Florence, for example, the monks could not make any sense of it:

They had already sent it to be examined by a member of the institution known as the Propaganda Fide in Rome. His reply had been 'that the document was probably intended for the amusement of children, but was so foolish that it could only bore them'. (Nuttall 1902: 2).

\section{First Historical Research in the Region}

It was not until the second half of the 19th century that progress was made in the understanding of these pictorial texts. Precisely at the time when the ancient royal dynasties themselves had disappeared completely, local historians started to take an interest in their legacy, to the extent that this tradition was not only salvaged, but reinvented. This emerging interest was inspired by the surge of romantic nationalism. The complex and poorly known history of the Nuu Dzaui, Beni Zaa and the other peoples of Oaxaca - the State of the first Native American president of Mexico, Benito Juárez - had been extracted from its fragmentary Viceroyal sources by local historians such as Juan B. Carriedo and José Antonio Gay. At the end of the 19th and beginning of the 20th centuries it was Manuel Martínez Gracida (1847-1923), Mariano López Ruiz (1872-1931) and Abraham Castellanos (1868-1918) who undertook to enrich these insufficient data with wider inquiries.

They were in several ways authors of a renaissance movement. In the course of the 19th century most of the former cacique families saw their privileges and possessions drastically reduced and their position taken by newcomers. Martínez Gracida knew several of the last descendants personally and tried to obtain information from them about earlier times. 
In his monumental Cuadros sinópticos (1883), Martínez Gracida published a detailed geographical description of all the settlements in the state. During the following years he pursued his interests and collected many historical notes and observations on the Native American cultural heritage, including drawings and original descriptions of archeological sites, oral traditions, toponyms and their etymologies in the native languages. He also saw and studied a number of original codices and other antiquities, several of which he acquired for public institutions. In this enormous project, which was to produce his magnum opus Los Indios Oaxaqueños y sus monumentos arqueológicos, long unpublished, he made use of a network of contacts in many places in the State of Oaxaca, who supplied him with information.

One of Martínez Gracida's most important collaborators was Mariano López Ruiz (1872-1931). Being a native of the Mixtec region himself - he lived and worked most of his life in Atoco (Nochistlan) - he was responsible for many descriptions of Nuu Dzaui sites and antiquities in Martínez Gracida's work. Following up the fragmentary clues left in the historical sources, López Ruiz visited the places that played an important role in history and legend. His knowledge of Dzaha Dzaui allowed him to collect and analyze toponyms, as well as native botanical terms. In 1887, following earlier explorations by the local priest Juan Tomás Palacios in 1882, López Ruiz even conducted excavations in the ceremonial center of Nuu Tnoo, where he discovered "aqueducts, fragments of fountains, concave slabs, mutilated pieces of columns, fragments of the façades of buildings, and several triangular stones, all of solid cantera, rose-colored marble with beautiful red veins, many with incrustations - apparently of gold - others with hardly recognizable figures of animals and plants, showing decorations and hieroglyphic inscriptions." (Martínez Gracida, Obra Inédita, vol. 4). Moreover López Ruiz was keen to register toponyms and local lore connected with such ancient structures.

López Ruiz was a poet and co-authored with Martínez Gracida the novel Ita Andehui. The sentimental story, somewhat reminiscent of that of Pyramus and Thisbe, was published in Spanish, but López Ruiz also prepared a version in Dzaha Dzaui (preserved in Martínez Gracida, Obra Inédita vol. 45). The text contains many descriptions of Nuu Dzaui customs, clearly based on first-hand knowledge of the traditional culture, and reproduces the atmosphere of local legends.

López Ruiz's most intriguing work is the interpretation of a now lost Nuu Dzaui pictorial manuscript, probably a lienzo, containing a 
number of Mixtec glosses. He sent the text as a 'surprise' to his friend. Probably Martínez Gracida sent it right away to the Sociedad Científica 'Antonio Alzate', which published the document the same year (1898) in its Memorias. Curiously enough the text is presented as a 'chronological study' and - in the article - as a 'tradition', but it is apparently an effort to read a codex (Smith 1998). This, however, is not stated explicitly and no reference is given to the place where the document was consulted. As in those years the scholarly understanding of pictographic conventions was still in its infancy and as a survey of all the relevant sources was impossible because of their dispersion and the lack of editions, an interpretation of the painted scenes was difficult. Even though this reading by López Ruiz contains a great number of inconsistencies and confusions, it was an important venture at the time, showing that such pictorial manuscripts could actually be read as historical narratives.

In their ambitious project to reconstruct the precolonial past of the Oaxacan peoples, these authors had to resort to intuition and imagination. They produced evocative accounts of dynasties, rulers, battles, speeches, heroism and love. Knowing that the Nuu Tnoo dynasty played a central role in Nuu Dzaui history, Martínez Gracida reconstructed the genealogical tree of Ocoñaña, which, following López Ruiz's information about local lore, he saw as an early colonial ruler of that village-state, identical to Don Felipe de Austria. Interpreting the name Ocoñaña ('20 jaguars') as León XX, he postulated that this lord was the son of León XIX (Sahoqmiñaña), the grandson of León XVIII (Sahouniñaña) and so on. Though this reconstruction had no historical basis, Martínez Gracida was completely right about the overall picture: Ñu Dzaui ancient history (at least as it has come down to us) pivots on the genealogy of the rulers of Nuu Tnoo.

This is an example of how these authors, confronted with the fascinating but confusing and fragmentary world of legends, mysterious ruins and inaccessible manuscripts, tried to supply with their own imagination what was lacking in the sources. It should be emphasized that they did not present these reconstructions as scientific studies but rather as novelistic 'legends' and 'traditions'. The principal aim of their work was educational, trying to raise the historical and cultural consciousness, the patriotic pride and idealism of their contemporaries. The amount of data they saved from oblivion still remains an impressive and lasting contribution. 
The third figure of importance to the early history of Nuu Dzaui codex interpretation was the well-known teacher Abraham Castellanos, also from Nochistlan (Ramírez Zarza 2004; Magallón Anaya 2006). Also writing from an educational and emancipatory perspective, in a lyrical, poetic style, he recreated the past, connecting its fragmentary remnants with his personal identification with Nuu Dzaui tradition. One of his books (1910) he dedicated to his sister, remembering her on the Day of the Dead. In another (1914) he begins his text invoking his grandmother with great love and respect. It was personal experiences such as the participation in daily life, the markets, the ceremonies, or the 'pelota mixteca' games, that enabled Abraham Castellanos to evoke and revive the past in an almost visionary way. The ruins, palpable testimonies of a by then unknown and mysterious past, triggered the imagination and curiosity of these Nuu Dzaui historians, as well as a deep romantic sense of belonging. It was in these places, which had become the abode of ghosts and nahuales, that the mind inquired into the meaning of human existence, confronted the mysterious designs of higher powers and lamented the lost greatness of the past.

We have to recall the context of these works. The fourth centennial commemoration of the voyage of Columbus (1492) had been celebrated with virtually no critical debate or opposition to Eurocentric terms such as the 'Discovery of America' or 'the Great Discoverer, Columbus'. On the 12th of October 1892 the president Porfirio Díaz, amidst numerous laudatory speeches by several high officials and leading intellectuals, unveiled a statue of Columbus. This same president created a commission to prepare and organize a presentation of Mexican culture for the exposition in Madrid. The aim of this 'Junta Colombina' was to commemorate and celebrate the 400 years of the 'Discovery of America' and to pay homage to the 'discoverer' Christopher Columbus. Interestingly enough the exposition had at the same time a nationalistic character: it should give an idea of the Native American civilizations of Mexico (only superficially known at that time), the beauty of their art and the advanced level of technical skill and science, especially astronomy, in order to impress the public. Among the numerous activities of the Junta Colombina was the edition of a number of ancient Mexican pictorial manuscripts, one of which was a fragment of the Codex Iya Nacuaa, called 'Códice Colombino' in honor of the occasion. 
Nearly two decades later Abraham Castellanos published his interpretation of this manuscript. He was able to identify the language of the glosses as Dzaha Dzaui, and motivated by this initial success, he tried to translate them as a text. Today we know that those glosses actually register the names of boundaries. But Castellanos thought they explained and complemented the pictorial scenes, which he interpreted as more than a historical account, rather as the myth of a wandering king, representing the cyclical struggle of the Nuu Dzaui. Thus, reading the toponymic glosses as narrative texts and connecting them with an intuitive approach to the ancient paintings, he created a literary work, the legend of Iukano, a mystical manifesto directly related to the social reality of 1910, on the eve of the Mexican Revolution. Focusing on Quetzalcoatl, identified with the Evening and Morning Star, as a religious ideal - the good God, Time itself, who teaches patience, faith and strength, as well as the struggle against ignorance - Castellanos' work becomes an authentic example of Nuu Dzaui resistance literature.

Even though the techniques of interpreting the pictographic details and scenes have evolved considerably since then, and few of the specific readings by Martínez Gracida, López Ruiz and Castellanos would be regarded as valid today, we have to give them full credit for being the first scholars to interpret Nuu Dzaui codices as such and to recognize their historical contents, Nuu Dzaui concepts, literary style and educational value. In doing so they were guided by an extensive knowledge of the geography and traditional culture of the region, and their intuition was reinforced by direct collaboration and personal identification with the people concerned. When we compare their works with modern analytical studies, it strikes us that although they contain a substantial element of fiction, they are closer to the Nuu Dzaui culture and mentality in many respects. Where, for lack of data, they were not capable of making acceptable decipherments, they do capture the spirit behind the images and offer a way to relate to these codices on an experiential level.

Their defense of the native cultural tradition was in marked contrast with the dominant views of that time. The successive governments of the Mexican republic were strongly inspired by nationalist sentiment. With a centralist and hegemonic (top-down) perspective, the authorities tried to homogenize the country and to hispanize the population. Several governmental ideologists openly indicated that the Native American peoples should disappear as distinct entities, in the interest 
of national unity, always conceived as 'Western' in character. One of the main features of their 'educational policy' was the campaign to prohibit and eradicate the use of the Amerindian languages. These languages were labeled as 'primitive dialects', which could not be written and lacked grammar and literature. Nowadays the official discourse has become much more subtle, but many still think in their hearts like the famous secretary of education Justo Sierra, who declared in 1902 that Mexico's multilingual reality was in his view an obstacle to national development (Heath 1986: 124).

This is 'the Janus face of nationalism': the state presents its bureaucratic principles of law and order in terms of an impartial and universalistic ideology, considering ethnic particularism either as irrelevant or as a possible threat. Ethnic-cultural homogenization is an inherent element of nationalism, which has been defined as "a theory of political legitimacy, which requires that ethnic boundaries should not cross across political ones..." (Gelner 1983: 1). It was born as a reaction to the social upheaval caused by the industrial revolution and the (re) creation of power structures: the new nation-states needed to indoctrinate their peoples with a new feeling of loyalty to the elites. ${ }^{3}$ Mexico is one of the countries in which "the nationalist ideology of a hegemonic group will be perceived as a particularist ideology rather than a universalist one, where the mechanisms of exclusion and ethnic discrimination are more obvious than the mechanisms of inclusion and formal justice" (Eriksen 1993: 119).

\section{Astronomy or History?}

The dominant paradigm of today is the fruit of the institutional development of archeology and Americanist studies toward the end of the 19 th century. Inquiries were normally done within the framework of positivism. This form of scholarship evolved outside the Nuu Dzaui region and made the concerns and contributions of local authors such as Mariano López Ruiz or Abraham Castellanos fall into oblivion. Its

${ }^{3}$ Cf. Eriksen 1993: $104 \mathrm{ff}$. The immediate antecedent of Justo Sierra's viewpoint is to be found in the work of Francisco Pimentel (cf. Villoro 1979: 175 ff.). For an explanation of the simultaneous development of anthropology as a science of colonial control and its invention of the 'primitive', see for example Leclerq n.d., Fabian 1983 and Kuper 1988. 
focus of interest was the manuscripts preserved as treasures in different libraries and museums throughout Europe, the U.S.A. and Mexico. Basically it was an investigation of ancient Native American culture as a dead object. Indigenous peoples themselves were considered 'primitive' and not fit to participate in this humanistic enterprise of the Western elites. Although they participated in the War of Independence at the beginning of the 19th century and in the Revolution for 'land and freedom' at the beginning of the 20th century, they remained marginalized and oppressed, so that they have become invisible, without influence and voice in the shaping of their own society and future. The colonization of their communities only became more intense and acute with the advances of communication and national control (the 'second conquest').

Meanwhile the study of Native American cultures and history became more and more institutionalized. Various scholars, standing in the long tradition of the collection and antiquarian study of curiosities, took interest in the codices and undertook the difficult work of editing them with explanatory notes. In 1902 Zelia Nuttall published the Codex Tonindeye that since then has carried her name. In a pioneering introduction she analyzed the document as being historical in contents; she did not relate it, however, to the Nuu Dzaui, but rather to the Mexica. She clarified the naming pattern:

A striking feature of the present Codex, and one which opens fresh lines of research, is the prevalent association of individuals with day-symbols. In a limited number of cases the personages depicted are also accompanied by a composite sign which expresses a name or title in picturewriting. (Nuttall 1902: 19).

Consequently Zelia Nuttall could identify one of the protagonists of the history told by the Codex as 'the conqueror named Eight-Deer, also Tiger's Claw', engaged in priestly and military actions. After a first global description of the different scenes, she concluded:

There seems to me to be no doubt that the Ancient Mexican reader of the present Codex recited in beautiful language, and metrical verse, composed by himself or acquired by oral transmission, the history of the native heroes whose deeds are pictured, accompanied by hieroglyphs recording the names of persons or of localities only. By this time those who have followed my outline sketch of the history of Eight-Deer will have realized that the Codex does not contain what might be termed a consecutive written text, but merely consists of pictorial representation of events, accompanied by such hieroglyphic names which were 
necessary in order to preserve them exactly and fix them in the memories of the native bards, who would constantly derive inspiration from the painted pages. (Nuttall 1902: 25).

Quite contrary to the views expressed by Nuttall was the interpretation put forward by her contemporary, the German scholar Eduard Seler, who may be called the founder of the scientific study of ancient Mexican iconography. ${ }^{4}$ Seler saw connections between different documents, which he called the 'Vindobonensis Group'. He established correctly that the two fragments 'Colombino' and 'Becker I' belonged together and that the language of the glosses was Dzaha Dzaui (Gesammelte Abhandlungen I: 155), but he did not reach the conclusion that the group as a whole dealt with Nuu Dzaui history. Although he had crossed the Mixteca Alta on horseback and had visited Monte Albán in the company of Martínez Gracida, Abraham Castellanos and other passionate scholars of Oaxaca, he never made the connection. On the contrary he considered these codices as religious documents similar to the Books of Wisdom ('Borgia Group'). Furthermore, conforming to the general views held at the time, he analyzed sacred accounts and religious iconography as the symbolic representations of the movements of sun and moon, planets and stars. So the contents of the codices, in his view, were essentially about Gods, i.e. astral phenomena. This paradigm, known by the German term Astraldeutung, limited him enormously in drawing conclusions from his otherwise sharp observations on these documents. The chronological sequences of what we now know as historical codices were interpreted by Seler as complex devices for the calculation of large astronomical periods:

In the Tonalamatl system, which is the base for all this, the same combinations of year- and day-names always repeat themselves after 52 years. This is indeed a very imperfect way of calculating time. The remedy seems to have been found in indicating intermediate dates ( $\mathrm{Zwi}$ schendaten), which supposedly do not exceed the period of 52 years. The central issue here seems to be that only the result of the calculation was to be registered by means of these dates, without presenting the actual calculation itself to the beholder. That has made it extraordinarily difficult to follow and reconstruct the calculations. And I admit openly that

\footnotetext{
${ }^{4}$ Anders includes a biography of this great scholar in the index volume that he prepared for the Graz edition of Seler's Gesammelte Abhandlungen. For further indepth studies of the life and work of Eduard Seler and his wife Caecilie Seler-Sachs, see the volume edited by Von Hanffstengel \& Tercero Vasconcelos 2003.
} 
my investigations in this field have not yet progressed very much. (Seler, Gesammelte Abhandlungen III: 204).

Several German-speaking investigators, such as Damian Kreichgauer (1915-1916, 1917), Walter Lehmann (1929) and Fritz Röck (1935, 1937) elaborated upon Seler's astralistic interpretation. Kreichgauer read both Codex Yuta Ynoho (Vindobonensis) and Codex Tonindeye (Nuttall) as astronomical manuals, containing large calculations for the orbits of Sun, Moon, Venus, Jupiter, etc. What was painted next to the dates he saw as 'mythological images' which were used to indicate necessary corrections, and further to cover up the true content of the books to the uninitiated eye, in other words to mislead profane readers. For example the unit of twenty black dots that appears in some personal names (such as 'Twenty Eagles') or toponymic signs, he read as 'subtract twenty days here'. This 'decoding' of the text was not even always consequent, but in fact quite arbitrary. We should be aware that once the contents of a manuscript are reduced to numbers, all kinds of manipulation become possible. It becomes very easy to 'identify' structures as the mind of the beholder organizes the data immediately in accordance with its own preconceptions and the units it is looking for.

Walter Lehmann, Seler's principal student, who was working in Berlin until the Nazis took power, criticized the arbitrary and unfounded character of several of Kreichgauer's speculations about signs meaning addition or subtraction. Although his own commentary on Codex Yuta Tnoho (Vindobonensis) still uses the ideas and vocabulary of the Astraldeutung (lunar houses, eclipse tables, corrections of the length of years, compatibility between synodical and diaconitical months, etc), he included a detailed descriptive analysis of the pictorial scenes.

Röck, professor in Vienna, added a number of highly intuitive readings in his comments on Codex Yuta Tnoho. The large scene on p. 37, where people are born from a tree, for example, he glossed as "The miracle tree, which always grows up again. It is the precious tree of the East, the tree of numbers and of the calendar, at the same time the tree of life. The image indicates the death of the descending Moon Lady and the birth of the young Sun God." (Röck 1937: 201).

In the English speaking world, on the other hand, Zelia Nuttall had her own followers: James Cooper Clark, Richard Long and Herbert 
Spinden explored clusters of scenes that made sense as historical narratives. The work of James Cooper Clark is particularly relevant for us. He wrote a short biography of Lord 8 Deer, using parallel scenes from different codices:

After having made a special study of the contents of the Codex Colombino, I am now able to demonstrate that it tells us the history of an individual called Eight Deer or Ocelot's Claw, also that many incidents in his life are to be found in the following codices: The Bodleian No. 2858, the Vienna, the Selden No. 3135, the Becker, and of course, the most important of all, the Zouche. In the last mentioned Codex Mrs Zelia Nuttall was the first to identify and interpret this Warrior Chief. The clue which suggested the comparing of the Codex Colombino with the Zouche Codex was the figure of the Ocelot Claw on Page II of the former, and it was at the suggestion of Dr. Seler of Berlin that I compared it with the Becker Codex. (Cooper Clark 1912: 7).

A crucial question is the time to which these codices refer. For Martínez Gracida and López Ruiz the beginning of the Nuu Tnoo dynasty was related to the Toltec era. With this intuitive notion they were ahead of their time. Zelia Nuttall thought that 'her' codex dealt only with a period shortly before the Spanish invasion. Following in Nuttall's footsteps, James Cooper Clark observed that the name 8 Deer also occurs on a relief in Monte Albán, so he identified his protagonist and the codices that describe his life - as Zapotec. Furthermore he observed that Lord 8 Deer was born in the year 12 Reed. Going back in the precolonial period, this would have been 1491. But, as his biography in the codices made no reference at all to the Spanish conquest, James Cooper Clark suggested that it had to be one cycle of 52 years earlier: 1439 AD.

The historical depth of these codices became a question intimately related to the overall interpretation of the genealogies and events. Richard Long made the first thorough computation of a sequence of dates in 'Codex Nuttall'. His basic assumption is still valid:

Now, as the dates in the Codex are given by the calendar-round method, a year of the same name, such as 7 Acatl, will recur every 52 years. When such a date is followed by another, such as 10 Acatl, we know that it must either be 16 years (plus any number of calendar rounds) after 7 Acatl, or 36 years (plus any number of calendar rounds) before it, and if we merely had the dates without any context we would get no further. But the Codex treats for many consecutive pages at the time of the history of particular individuals, such as Eight Ehecatl [8 Wind] or Eight Mazatl [8 Deer]. This at once gives the check that in no case where events 
in the life of the same person are shown can more than one calendar round be interpolated, as otherwise the life would be over a century long, while generally there could not be any calendar round intervening, and it gives the further check that while in most cases the count is forward from the last date, yet sometimes it must be backwards, when a forward count would give an unreasonably long distance. (Long 1926: 240).

Taking the whole codex as a true historical record, Long calculated that it encompassed 478 years. Adding time for five undated generations, he arrived at a total of at least 610 years of precolonial history.

Herbert Spinden (1935) gave a further impulse to the 'historical interpretation' of these codices by demonstrating that a long sequence of images in the Codex Añute (Selden) could be read as the biography of a princess of a specific town (Lady 6 Monkey). Regarding the provenience of this group of manuscripts, there still existed a lot of uncertainty, but Spinden noticed connections between certain personages and rulers of the Nuu Dzaui polities mentioned in colonial sources. As for the chronology, Spinden corrected Long, proposing that Codex Tonindeye (Nuttall) spanned 374 years, starting in 1220. In another study (1940) Spinden tried to interpret the dates in Codex Yuta Tnoho (Vindobonensis) as related to the orbit of Venus in the 15th century, showing to what extent even he was influenced by the astralistic theories.

\section{The Religious Dimension}

It was the Austrian scholar Karl Anton Nowotny who demonstrated in his groundbreaking works $(1948,1961 \mathrm{a})$ that the astralistic interpretations of the Mexican codices had become obsolete. As a student in Vienna he wrote his thesis on the interpretation of Codex Mictlan (Laud), finished in 1939. His supervisor, professor Fritz Röck, was a strong advocate of decoding Mexican codices in terms of the Astraldeutung (enriched with such esoteric terms as Tarnkunst and Ortungskunde), which he had applied to the main manuscript in Vienna, Codex Yuta Tnoho (Vindobonensis). Under Röck's influence, Nowotny's thesis still remained largely in the astralistic method and idiom. ${ }^{5}$ After the war, however, Nowotny took up the study of codices

\footnotetext{
5 This episode is told with some more detail in the commentary on Codex Mictlan (Laud) by Anders \& Jansen (1994). For a general review of the genesis and decline of
} 
again, with a fresh perspective and a wide-ranging scholarly erudition. From his preparation in the astralistic method he took the systematic analysis of the calendrical structure, but connected this with a profound study of Mesoamerican symbolism as reported in the precolonial and colonial sources. In 1948 he analyzed the internal structure of Codex Yuta Tnoho and situated the document in the Mixtec region. No references to astral orbits, only sacred history and rituals were to be found in its painted scenes. Nowotny pointed out the links with the colonial chronicle of Friar Francisco de Burgoa, and particularly with the Mixtec creation story summarized by Friar Gregorio García. Connecting his work with the decipherments made by Alfonso Caso (see below), Nowotny showed in a later article (1959c) the connections of the subject matter of Codex Yuta Tnoho with other manuscripts such as the Roll of the New Fire (Selden Roll), the Lienzo of Tlapiltepec (Antonio de León), Codex Yada (Porfirio Díaz), and Codex Yecu (Fonds Mexicain 20).

At the same time he derived a summary but immensely useful pictographic dictionary of signs and their readings in Nahuatl (Nowotny 1959b, 1967) from the Codex Mendoza tribute list (Clark 1938).

Nowotny's major synthesis, Tlacuilolli (1961a) is more than a compendium or manual; it is a paradigmatic change with respect to Seler. This becomes evident when we compare the commentaries of both scholars on the major precolonial source of Mesoamerican religion, Codex Yoalli Ehecatl/Borgia (Seler 1904-1909 and 1963; Nowotny 1976). Both are monumental works, classics in our field. The difference between them illustrates the progress of thought within the discipline. Seler's work has eventually been translated into Spanish and English, and is therefore still of tremendous influence. Until its recent translation into English (2005), Tlacuilolli was only accessible in German: consequently the investigators unfamiliar with that language have had difficulty in getting an adequate perception of his expert and profound contributions.

Founded on long research of cognitive systems of Mediaeval Europe and of other civilizations, within a broad cultural-philosophical perspective, Nowotny's studies exposed the divinatory ('mantic') and ritual character of the religious codices. Nowotny ordered the contents

astralistic interpretations, see the commentary on Codex Tezcatlipoca (FejérváryMayer) by Anders \& Jansen \& Pérez Jiménez (1994). Still, there are on-going intents to interpret Mixtec codices in an astralistic manner (see for example the work of Séjourné 1987) or as mathematic manuals (e.g. Agustín Aquino 2007). 
of the codices by taking the structure of the Mesoamerican calendar as his criterion for organizing the pictorial sequences. His lapidary formulations on the value of the pictorial manuscripts and the problems of interpretation are still indispensable guidelines for all investigations in this field. He first stressed the unique importance of the pictorial manuscripts in a broad cultural-historical perspective. Methodologically he identified a number of pitfalls and criticized particularly those who wanted to rush to premature, fanciful speculations. Instead, he emphasized, the cultural continuity in Mesoamerica is a crucial clue for understanding the ancient images. As parallels in Europe he mentioned the research on toponyms and legends (Flurnamenforschung, Sagenforschung) in connection with a general documentation and study of lore and oral tradition (Heimatkunde). Although all modern research on codices should build on Nowotny's work, this proves to be not so easy, as he wrote in an aphoristic style. In order to understand his contribution one really needs concentration, discipline and patience, which in the end are rewarded with critical insights. ${ }^{6}$

A key example of his method is his explanation of a chapter in the Books of Wisdom ('Borgia Group'), consisting of a series of scenes which show numbers, represented by combinations of bars and dots (the bar meaning 5 and the dot meaning 1), under the image of a deity. Adherents of the Astraldeutung had tried to relate these numbers to the movements of planets and stars, but without success. Basing himself on the important work of Schultze Jena, who in his search to understand the Popol Vuh, documented oral traditions among different Mesoamerican peoples in the 1930s, Nowotny was able to demonstrate the similarity of the arrangements of numbers under a deity in the codices to arrangements of carefully counted bundles (of fir-needles, grass, leaves or flowers) offered on the altars (mesas) to different Gods, by medicine men (curanderos) in the Tlapanec area. ${ }^{7}$ These rituals continue to exist today in Native American communities and

\footnotetext{
${ }^{6}$ Nowotny's Tlacuilolli is often seen as a collection of interpretations instead of the methodological manual it really is. Especially interesting in this respect are Nowotny's programatic articles 1959a, 1976 and 1980. For a short biography and a bibliography of his works, see Köhler 1979.

7 Nowotny's methodological reference to the work of Schultze Jena (1933-38) became the point of departure for the Ph.D. dissertation of Peter van der Loo (1987) and for Anders \& Jansen's general introduction to the Mexican codices (1988). For a recent study of Tlapanec rituals see the work of Dehouve (2007).
} 
can be connected with those of the past, helping us with the interpretation of iconography and with the reconstruction of human activities in ceremonial centers such as the Mexica Templo Mayor. With this example, Nowotny made it clear that the codices and lienzos should be interpreted through a combination of iconographical analysis, investigation of historical sources and ethnographic fieldwork in contemporary Native American communities.

The leading thread of his lasting contribution may be illustrated by a set of quotes from the late master's complex work, in which he formulated, in his peculiar concise style, a set of fundamental insights and guiding principles for codex research.

1) The pictorial manuscripts are of huge historical, archeological and ethnographical importance, our main source for the intellectual history of ancient Mexico.

Die Bilderhandschriften enthalten aber einen großen Schatz von historisch, archäologisch und etnografisch belangreichen Dingen, die bisher nicht gehoben werden konnte. (1961a: 198).

Die heute archäologisch so ergiebigen Bilder der Codices waren für den Zeitgenossen eine Selbstverständlichkeit, ein bloßes Ausdrucksmittel. Die Bilderhandschriften haben immer einen konkreten Inhalt und sind nicht Kompendien des Wissens ihrer Zeit. (1961a: 198).

Die Codices berichten entweder Geschichte oder sind Denkmäler der Geistesgeschichte, wenn sie andere Bildungsgüter enthalten... Soweit sich ihr Inhalt und ihr historisches Verhältnis zu einander noch aufhellen läßt, kann auch die Geistesgeschichte des alten Mexiko aufgehellt werden. (1961a: 199).

2 ) Studies of this material must proceed in a careful manner, considering and ordering all relevant data. One should not rush to premature interpretations, which only silence the sources.

Die Inhalt der Bilderhandschriften ist nur zum kleineren Teil bekannt. Der Weg zu neuen Ergebnissen ist zeitraubend und verlangt vor allem die Absage an alle Deutungen. Das ist nicht immer leicht. Viele Deutungen drängen sich geradezu auf... Wo der zu einer Bilderhandschrift gehörige mündliche Kommentar fehlt, kann man nur durch Sammlung und Ordnung aller in Betracht kommenden Quellen unter günstigen Umständen die Ergänzung finden. (1961a: 199).

Die Arbeit ist mit der Ordnung des Materials nicht abgeschlossen, sondern erst begonnen. Nur ein kleiner Bruchteil des Inhaltes der Bilder- 
handschriften ist derzeit klar verständlich. Bei richtiger Befragung wird dieses Material immer wieder Neues ergeben; auf die Folter der Deutungen und Theorien gespannt, wird es wie bisher verstummen. (1961a: 7).

3) These ancient writings are potentially much more informative than even sensational excavations, but at the same time they are very complex in their contents, connecting social order with the religious worldview. This calls for a holistic approach, paying attention to myth, ritual and divinatory symbolism. Who does not take this into account is led astray.

Da die originalen Bilderhandschriften in ihrem Bereich weit reichere Auskünfte bieten als etwa Grabungen mit noch so sensationellem Erfolg, haben sie auch in ausweglose Labyrinthe geführt. (1976: 18).

Mit der vom Menschen errichteten Welt, mit dem Bau des Weltbildes ist die reale sinnenfältige Welt schicksalhaft verbunden und wird nicht als etwas von diesem geistigen Bau Verschiedenes empfunden... Die soziale Gliederung ist dem Weltbild angepaßt. Das Weltbild inspiriert die Kunst... Einer systematischen Untersuchung ist die übliche Parzellierung des Stoffes nicht günstig. Die Verbindung aller Lebensbereiche mit Riten wird so undeutlich gemacht. Das Verhältnis von Mythos, Kult, Mantik bleibt im Dunkeln. (1980: 118-119).

4) New breakthroughs depend on the study of contemporary oral tradition (including toponyms, narratives and customs). Although the conventions of pictorial writing itself have not been preserved in the cultural memory, the knowledge and concepts of the indigenous communities are an important key to understanding the ancient texts, as demonstrated by the work of Schultze Jena.

Bezüglich der Möglichkeiten für eine Weiterarbeit ist folgendes zu sagen. In der volkstümlichen Überlieferung der Gegenwart spielt die Bilderschrift naturgemäß keine Rolle mehr. Es sind in diesen Überlieferungen aber Elemente erhalten, die ganze große Teile der alten Codices erklären können. (1961a: 199).

Es haben sich in Europa mehrere historische Wissenschaften entwickelt dei auf Mexiko und das Mayagebiet noch kaum angewendet worden sind. dazu gehören vor allem die Flurnamenforschung und die Sagenforschung... Die Verbindung dieser Wissenschaften mit der 'Heimatkunde' führt ihnen eine Armee von Mitarbeitern zu... Sicherlich gibt es in Mexiko und im Mayagebiet Fakten, für die keine andere Quelle mehr existiert, als in der Erinnerung des bäuerlichen Volkes festgehaltene Namen und Sagen. (1959a: 119) 
Obwohl die Kenntnis der Bilderschrift verloren ist, besitzen die Indianer Mexikos Überlieferungen die zum Verständnis der Bilderhandschriften in ungeahntem Maß beitragen können. Das von Schultze Jena gesammelte Material ist ja von diesem Blickpunkt aus zusammengetragen. Für die große Bedeutung, die der Kontinuität der Überlieferung in Mexiko für die vorspanische Welt zukommt, kann auf die Einleitungen von Schultze Jena zu den drei Bänden der Indiana $(1933,1935,1938)$ verwiesen werden. (1961a: 272).

\section{The Map of Teozacualco as a Rosetta Stone}

Meanwhile in post-revolutionary Mexico a new generation of scholars had been formed: anthropologists, archeologists and historians, committed to (re)discovering, cultivating and interpreting the national patrimony. One of the most prominent was Alfonso Caso, on whom Spinden's analysis had a decisive impact. ${ }^{8}$ Having worked as an archeologist in Monte Albán, Caso became increasingly involved in the study of the codices during the 1930s. He was convinced that these painted manuscripts were products of the Nuu Dzaui civilization because of their stylistic similarity with the late ceramics of that site. Since his discovery of the famous 'Tomb 7', which contained a whole treasure of objects in this 'Mixtec style', such as bones incised with pictographic scenes, Caso started to work with his archeology students at the Universidad Nacional on the elaboration of a catalog of all the persons in these manuscripts. ${ }^{9}$

At the same time the great Mexican historian Wigberto Jiménez Moreno and his associate Salvador Mateos Higuera published an extensive commentary on the colonial Codex of Yanhuitlan (1940), bringing together crucial materials on the 16th century history of Nuu Dzaui. One of the important contributions of this classic monograph was that it clarified the Nuu Dzaui calendar system: it was the same as that of the Mexica, but signaled another day of the year as 'year-bearer' (the day that gives its name to the year). Consequently the Nuu Dzaui year count differed from the Mexica in having one unit less in its day number: the Nuu Dzaui year 1 Reed roughly corresponds to the Mexica year 2 Reed.

\footnotetext{
${ }^{8}$ For an overview of Caso's life and scholarly work, see: León-Portilla 1973.

9 This catalog was published posthumously as the second volume of Reyes $y$ Reinos de la Mixteca (Caso 1977-79, II).
} 
In 1944 during a history congress held in Guadalajara, the Dirección de Estudios Geográficos of the Secretaría de Agricultura displayed a series of maps, including the Map of Teozacualco, thought to have come from Teozacualco, Jalisco. Jiménez Moreno, who attended the congress, saw the document, realized its importance and called Caso's attention to it. Caso recognized the Map as pertaining originally to the Relación Geográfica of Teozacualco (also written as Teozacoalco), Oaxaca, which he had edited some years earlier. In a detailed analysis of its contents, Caso showed that the Teozacualco Map contained representations of individuals that also appeared in the group of codices he had been studying. The glosses that accompanied these individuals on the Map established beyond doubt that they were the rulers of the Nuu Dzaui communities Chiyo Cahnu (Teozacualco) and Nuu Tnoo (Tilantongo) in the State of Oaxaca. It followed that the other manuscripts in which they appeared were historical documents of the same region. This was the foundation for his successive commentaries on Codex Yuta Tnoho (Vindobonensis) Reverse, Nuu Tnoo-Ndisi Nuu (Bodley), Añute (Selden) and Codex Iya Nacuaa I (Colombino).

Analyzing the complex set of genealogies and dates, Caso offered explanations of many pictographic scenes and proposed a coherent overall correlation of the Nuu Dzaui historical chronology with the Christian calendar. According to his calculations, the history treated in the codices started as far back as the end of the 7th century AD. These calculations were based on the fact that some of the last generations of the Mixtec precolonial dynasties depicted in the codices are also mentioned in early colonial Spanish sources. We have already seen that Lord 4 Deer of Ñuu Tnoo is documented as having lived at the time of the Spanish invasion and having died shortly after. According to the Codex Nuu Tnoo-Ndisi Nuu, this Lord 4 Deer was born after his sister, Lady 5 Monkey, who was born in the Year 12 Rabbit. That year must be in the cycle that preceded the Conquest, so it has to be equivalent to AD 1466. Dating Lord 4 Deer's sister's birth 52 years earlier or later would contradict the statement of the Relación Geográfica.

Lord 4 Deer's aunt, Lady 9 Deer, married Lord 8 Grass of Ndisi Nuu (Tlaxiaco), called 'Malinaltzin' in Central Mexican sources, who was born in the Year 7 Reed (Codex Nuu Tnoo-Ndisi Nuu p. 21-III). As this ruler fought the Aztecs, his birth year has to be 1435. Again, in principle it could also be 52 years later or earlier, but the context will only permit the correlation of AD 1435. 
Starting from 1466 Caso calculated back into the past, counting the cycles of 52 years until he arrived at the marriage of Lord 4 Alligator 'Blood Eagle', mentioned in the Relación Geográfica as the founder of the Nuu Tnoo (Tilantongo) dynasty. In Codex Yuta Tnoho Reverse this marriage of Lord 4 Alligator to Lady 1 Death is dated in the year 6 Flint. According to Caso's calculation this would be 732 AD. The earliest dated event in these codices, according to Caso, was the birth of Lord 4 Alligator's mother from Earth in the year 5 Flint, 692 AD. Major problems remain, however. Caso himself had already stated explicitly that his correlation was by no means indisputable, especially regarding those early dates (1977-1979, I: 39).

The progress made by Jiménez Moreno and Caso, had been followed closely by Philip Dark. In 1958 he published an attempt to found the genealogical analysis on a systematic notation. This was even before Caso brought out his more detailed commentaries on codices Nuu Tnoo-Ndisi Nuu (Bodley) and Añute (Selden) in 1960 and 1964 respectively. Noticing several problems in earlier chronological and iconographical analyzes, Dark stated critically:

Interpretations of the meaning of these pictographs will, however, be largely based on what the observer can read into them, tempered of course, by what knowledge can be brought to bear in the process of inference. This knowledge has very little empirical basis, so that scholars in this field often find themselves altering their opinion as to the meaning of the codices as they discover new complexes that suggest a new pattern of meaning, thus causing a shift in the patterns of interpretation integrating previous thinking about content. (Dark 1958: 14-15).

Basically trying to eliminate subjective and intuitive factors in the interpretation process, he proposed a thorough schematization of the contents of the manuscripts:

In any reconstruction of prehistoric materials the maximum attainable degree of certainty is required. Such a requirement must, perforce, subtend a high degree of objectivity in both observation and procedure, which should be heightened, though never confused, by perceptual experience of an aesthetic nature. Frequently an intuition may point the way to the linking up of one group of kin with another. Such a linkage must be demonstrated by other means as well or intuition will only lead to a picturesque tree of descent lines, genealogically subtending all sorts of people clinging to its branches in fanciful and colourful patterns. Such a tree might delight the aesthete but not the social scientist. 
In order to obtain the maximum degree of objectivity possible it was felt that two requirements must be met: (a) the phenomena observed must be reduced to symbols that could be more easily handled, and (b) all elements must be controlled so that hypotheses as to meaning could be applied consistently not only for a codex, but cross-codically as well. Previous approaches do not seem to have attempted a symbolic analysis to seek meaning in terms of pattern, nor do they appear to have maintained consistently hypotheses as to meaning in the course of analysis of the codices." (Dark 1958: 21-22).

Clearly annoyed by statements such as this one, Caso immediately published a critical review of Dark's book:

After a scrupulous examination of the genealogies, using the author's systematic and objective method, I have discovered 39 errors in [Dark's treatment of] the Bodley and 21 in the Selden. This is due to a number of causes. The first is that the author did not compare all of the known Mixtec genealogical manuscripts, nor did he previously compile a catalogue of the personages mentioned in them. Second, he did not understand the general sense of what the genealogical codices tell us. In each case, these codices deal with the genealogy of a place, and all the personages mentioned therein are related in one way or another to this genealogy. This is more important than noting whether a man is looking to the right or to the left. In the third place, he did not realize that the Mixtec scribes had different ways of saying the same thing, and that they used this diversity of expression in the same manuscript and at times on the same page. In the fourth place, his method is excessively rigid and does not perceive the contingency and variation inevitable in historical material....

In short, Dark's book places us on guard against a danger. We should not impose upon the authors of codices a rigid system of how they should have written what they had to tell us, but rather, with a certain humility, study how they wished to write it. I do not know if someone may feel more at ease handling Dark's glyphs instead of the Mixtec glyphs. I, for my part, prefer the latter." (Caso 1959: 150-151).

We have quoted these interactions because they provide valuable insights into the quest for method at that early stage of the interpretations. The debate had a clear winner: Caso, but his work was not without errors either, and the difficult reconciliation of intuition and analysis in the study of ancient art is still a problem today. 


\section{Elaboration and New Perspectives}

Nowotny's publications, together with those of Caso, formulated a new paradigm for codex research, which is still essentially valid today. We should mention here another great scholar of that time: Donald Robertson, professor of Mesoamerican art at Tulane University. His major opus (1959) focused on the Central Mexican codices, providing a methodological framework in which codicology and art history are combined with historical analysis. Enthusiastic about Caso's discoveries, Robertson compared the Books of Wisdom ('Borgia Group') with the historical codices of Nuu Dzaui and called them 'Mixtec religious manuscripts' (in: Paddock 1966). This lead to an intensive academic debate on the problem of provenience of the religious codices, particularly the main member of the group, the Codex Yoalli Ehecatl (Borgia) itself: some scholars (e.g. Donald Robertson) defending that it was Mixtec, others (e.g. H.B. Nicholson) pointing toward Cholula as the most likely place of origin. Later, as consciousness grew among scholars that the Nuu Dzaui codices did not stand alone but were part of a much larger universe of stylistic and iconographical conventions, Robertson (1970) widened the term 'Mixtec style' to the more fortunate 'international style of the Postclassic' ${ }^{10}$

The decades after World War II saw a decisive increase in both the quantity of publications on ancient Mexico and in the professionalism of this discipline. The works of Angel María Garibay and his pupil, Miguel León-Portilla, as well as the sharp analyzes by Paul Kirchhoff, Robert Barlow, Thelma Sullivan, Fernando Horcasitas, and several others, laid the foundation for an impressive tradition of philological, literary, historical and religious studies of early colonial Nahuatl texts, generally referred to as 'ethno-history'. Motivated by the wish to reconstruct for ancient Mexico an equivalent of Platonic philosophy, León-Portilla (1974) analyzed a set of symbolic terms and difrasismos in Nahuatl poetry and 'flowery discourse' as the conceptual building blocks of a profound Aztec theoretical and ethical worldview. In accordance with French structuralism which was popular in those days, León-Portilla defined the binary opposition as the basic principle of that worldview, and considered it to be deified as Ometeotl, 'God of the Duality'. Later studies suggest that these claims are slightly off the

10 Anders \& Jansen \& Loo (1994) provide a synthesis of the debate and an evaluation of the problem as it stands today; see also Boone (2007). 
mark. Binary oppositions are such a fundamental characteristic of human reasoning, that most of the time we cannot be sure whether such symbolic structures are really relevant and explicitly referred to in the native texts, or if they are imposed and projected into the ancient mind by modern scholars. The fact that many Mesoamerican stories refer to a divine founding couple, consisting of a primordial Lord and Lady, is no good evidence for the existence of a deified concept of duality. In fact, the Nahuatl term Ome-teotl ('two-God') does not seem to have an equivalent among other Mesoamerican peoples, and may well be a form of Omi-teotl, the God of Bones, i.e. of Death and the Ancestors. Translations using the term 'duality' may have been inspired by the concept of the Trinity, introduced by the Spaniards. ${ }^{11}$ But León-Portilla's publications have been essential in drawing attention to the fascinating worldview contained in Nahuatl literature, popularizing a more positive, intellectual and poetic view of Aztec civilization, and in attracting many students to this discipline.

In subsequent years a vast array of authors from different countries have dealt not only with documents written in Nahuatl but also with related pictorial manuscripts, such as Luis Reyes García, Pedro Carrasco, Joaquín Galarza, Johanna Broda, Alfredo López Austin, Jacqueline de Durand-Forest, Rudolf van Zantwijk, José Alcina Franch, Richard Townsend, Xavier Noguez, Michel Graulich, Marc Thouvenot, Keiko Yoneda, Juan José Batalla Rosado, Patrick Johansson, Luz María Mohar Betancourt, Guilhem Olivier, Justyna Olko and Katarzyna Mikulska-Dąbrowska, to name just a few. The series Estudios de Cultura Náhuatl (published by the Universidad Nacional Autónoma de México) gives a good idea of their contributions. The studies of Nahuatl pictorial writing by Reyes García (1993), Johansson (2007) and Mikulska-Dąbrowska (2008) are particularly relevant. In the United States this tradition led in the last decades of the 20th century to an important 'school' focusing on texts written in Native American languages during the colonial period: the so-called 'New Philology' with prominent authors such as James Lockhart and Stephanie Wood (see Restall 2003).

As for research specifically concerning the Nuu Dzaui history and culture, Barbro Dahlgren published an early and now classic synthesis of

${ }^{11}$ See the seminal paper by Haly (1992) and the exhaustive, intelligent discussion by Mikulska-Dąbrowska (2008: 237 ff). 
historical data (from chronicles and Relaciones Geográficas) in 1954. This work was continued and brought to a higher level by Ronald Spores, who, on the basis of an original analysis of many archival documents, especially those dealing with the cacicazgo of Yanhuitlan, formulated new insights on the early colonial political structure in the Mixteca Alta. Later Spores undertook archeological fieldwork in the same area, surveying numerous sites, identifying the ceramic sequence and major processes in the development of precolonial settlements. Different survey and excavation projects in the Nuu Dzaui region continue to this day and involve a growing number of archeologists from different countries. ${ }^{12}$

Information on the Mixtec language, especially in its ancient form, became very necessary. Wigberto Jiménez Moreno supplied the growing field of interest in Mixtec codices, history and archeology with the facsimile edition (1962) of the early colonial Spanish-Mixtec vocubulary, which was the result of the work of the Dominican missionaries, brought together and edited by Friar Francisco de Alvarado (1593). Following up on his earlier commentary on the Codex of Yodzo Cahi (Yanhuitlan), Jiménez Moreno added a seminal introduction about the early colonial Dominican activities in the region. A few years later the linguists Evangelina Arana and Mauricio Swadesh published a Mixtec-Spanish root dictionary (1965) extracted from Alvarado's monumental work. In 1976 on the instigation of Ronald Spores a reedition of Friar Antonio de los Reyes' Mixtec grammar appeared in the Vanderbildt University Publications in Anthropology series. These have been most valuable tools for codex researchers; it turned out to be difficult, however, to situate these colonial works in the context of a good knowledge of the living Mixtec language and use them accord-

12 The archeology of Oaxaca had been studied from the 1930s onwards by Alfonso Caso, Ignacio Bernal and John Paddock (publishing in the 1950s and 1960s). With the publication of his survey results, Spores (1972) initiated the important series of Vanderbilt University Publications in Anthropology (VUPA) and established a framework, based on ceramic chronology. The Instituto Nacional de Antropología e Historia's regional center in Oaxaca has carried out continuous research projects and salvage work: archeologists such as Marcus Winter, Margarita Gaxiola, Nelly Robles García, Raúl Matadamas Díaz and others have made substantial contributions to Oaxacan archeology. Robles García \& Juárez Osnaya (2004) provide a historical overview of Oaxacan archeology, and Balkansky (1998) evaluates the progress in the last decades of the 20th century. The recent volumes by Kowalewski et al. (2009) and A. Joyce (2010) offer a synthesis of the latest archeological surveys and related investigations, tracing the development of settlements in the Mixteca Alta (and their regional patterns) from archaic to Postclassic times. 
ingly. Given the large number of homonyms and words distinguished only by tones, in connection with a complex dialectical variability, it is easy to make errors in the etymology of Mixtec terms. ${ }^{13}$

Crucial for further interpretation of the pictorial manuscripts has been the publication of the sources themselves. Facsimiles of the codices Ñuu Tnoo-Ndisi Nuu (Bodley), Añute (Selden) and Nacuaa I (Colombino) were brought out by the Sociedad Mexicana de Antropología with the classic commentaries by Alfonso Caso (1960, 1964a, 1966a). A government re-edition of the pictorial manuscripts reproduced by Lord Kingsborough, contained among others color photographs of the codices Nuu Tnoo-Ndisi Nuu (Bodley), Añute (Selden), and Yuta Tnoho (Vindobonensis), with commentaries by Corona Nuñez (1964-67), based on Caso and Seler. An inexpensive and popular re-edition of Zelia Nuttall's Codex Tonindeye (Miller 1975) contributed enormously in creating broad interest in this particular group of pictorial manuscripts.

The most important and qualitatively superior project in this respect, however, was that of the Austrian editorial office Akademische Druck- und Verlagsanstalt (ADEVA) in Graz, which since the beginning of the 1960s specialized in the professional facsimile edition of Mexican codices, as part of its larger enterprise to publish facsimile editions of ancient manuscripts and books, especially from Europe. To date it has published some twenty of the most important Mexican screenfolds, in high quality color photographs, mounted like the original, in a limited edition of several hundred copies. Among these publications are the facsimiles of the Books of Wisdom or Teoamoxtli Group, and of the Nuu Dzaui (Mixtec) codices Yuta Tnoho (Vindobonensis), Tonindeye (Nuttall), Nacuaa II (Becker I) and Ñuu Ñaña (Egerton).

The intellectual force behind this series was Ferdinand Anders (Institut für Völkerkunde, Vienna University), who worked in close collaboration with Hanns Biedermann at the editorial office in Graz. Anders, a leading authority on Mesoamerican iconography and religion, as demonstrated by his monumental Das Pantheon der Maya

${ }^{13}$ It is most unfortunate that the new Diccionario del Idioma Mixteco, brought out by the Universidad Tecnológica de la Mixteca (Caballero Morales 2008) mixes terms from different dialects, without distinction and without identifying the specific origin of each term. Uneducated use of this dictionary, therefore, is bound to produce enormous mistakes. 
(1963), carried on the research line started by Nowotny. Where Nowotny himself had never been able to do fieldwork in Mexico, Anders put his principle of studying cultural continuity into practice, focusing on the traditional production of amate-paper and related cosmovision in the Ñahñu (Otomí) hamlet San Pablito near Pahuatlan (Puebla). This enabled him, for example, to compare the tree spirits in Codex Yuta Tnoho (Vindobonensis) with the San Pablito figures of amate-paper, representing 'Dueños de las Semillas'. Maarten Jansen, originally a student of Leiden University, followed the classes of Ferdinand Anders in Vienna and was instructed by him in the codicological and iconographical analysis of the Mexican manuscripts, and also in its ethnographic dimensions. ${ }^{14}$ Logically he was introduced to living Mesoamerican culture during a visit to San Pablito (1974), where he interviewed two Nahñu curanderos, who cut figures of amate-paper figures and used them in rituals for healing and planting. ${ }^{15}$ These experiences lent further support to Nowotny's insight that new breakthroughs in understanding the ancient pictorial texts and their symbolism had to come from listening to the indigenous experts themselves.

Alfonso Caso died in 1970. Although he did not create a school of followers in Mexico, his fundamental contributions, which showed that the ancient codices told their own story, and the splendid new editions of the manuscripts themselves have triggered a lot of interna-

${ }^{14}$ Maarten's choice for this specialization in Vienna was largely inspired by his Dutch mentor in the Americanist field, Mrs. Guda E.G. van Giffen-Duyvis, who had been the collaborator of Walter Lehmann in the 1920s, and by Benedikt Hartmann, a Swiss Professor of History of Religions at Leiden University, who during an intensive seminar on the Popol Vuh had made him familiar with the phenomenological analysis of religious texts. The research of Ted Leyenaar, curator of the Middle and South American department of the Museum of Ethnology in Leiden showed the importance of documenting cultural continuity for understanding the precolonial ball game ulama (cf. Leyenaar 1978). In addition the teachings of the Professor of Classical Archeology in Leiden, Frédéric Bastet, who at the time was advancing new interpretations of Roman wall-paintings, as well as the discussions with his fellow student Frank Müller, working on a similar topic (cf. Müller 1994abc), had demonstrated to him the potential of the iconographical method. It should be mentioned that in those days a group of scholars and students at Leiden University was carrying out a major project of indexing iconographical themes in Western art, called 'iconclass' (nowadays continued and accessible through the internet).

15 See Jansen \& Leyenaar 1975 and, for an overview report, Anders \& Jansen 1986. See also Anders 1999 for a review of studies and editions of the Mexican pictorial manuscripts. Another student at Vienna University, Regina Fitl, followed up on Anders' research in San Pablito and wrote a dissertation on this topic (Die 'Muñecos' von San Pablito, Vienna 1975); for a later study, see Sandstrom 1991. 
tional interest in the last thirty years of the 20th century. Different investigators have dedicated themselves to elucidating specific aspects of Mesoamerican iconography. In the context of the long-term project Handbook of Middle American Studies (under the editorship of Robert Wauchope) John Glass and Donald Robertson (1975) published a census of all pictorial manuscripts from precolonial and early colonial Mexico. This remains an extremely important tool for studies, including basic codicological data such as the different names used for documents and the place where the original is preserved, as well as bibliographic references to editions and commentaries.

Another contribution to the Handbook was less fortunate. Robert Chadwick (1971) undertook the task of connecting Nuu Dzaui historiography with the chronicles about Central Mexico. In a way this approach had been stimulated by Caso's identification of the toponym 'Town of the Cattail Reeds' in the Nuu Dzaui codices as the famous Tollan in Aztec annals. Comparing loose elements of both sets of sources, Chadwick went much further and postulated far-reaching identifications between personages and places in the two areas. In retrospect we see it as a bold but premature intention, done in an unsystematic, intuitive, and speculative way, the outcome of which remained unconvincing. That his work was published as an article in the prestigious Handbook had a traumatic effect: for a long time serious researchers abstained from further comparisons in this direction and focused on the specific Nuu Dzaui character and context of the sources.

A new impulse was Mary Elizabeth Smith's Ph.D. dissertation, a thorough study of Ñuu Dzaui place signs. ${ }^{16}$ In this classic monograph (1973a), accompanied by an important large article (1973b), she analyzed toponymic and onomastic glyphs in a systematic way, using archival documents and such key manuscripts as the Codex Nuu Naña (Egerton), Codex Nuu Naha (Muro), the Lienzo of Yucu Satuta (Zacatepec) and the Lienzo of Nuu Sii Cuaha (Jicayán). On the one hand she established that the people with black or red markings around their eyes, who appear associated with the Town of the Cattail Reeds, were tay sami nuu, 'men with burned eyes', a Mixtec designation of speakers of Nahuatl, i.e. probably Toltecs. On the other she

${ }^{16}$ For a portrait of this important scholar, who passed away in December 2004, an overview of her publications and an idea of her impact, see the volume in her honor, edited by Boone (2005). 


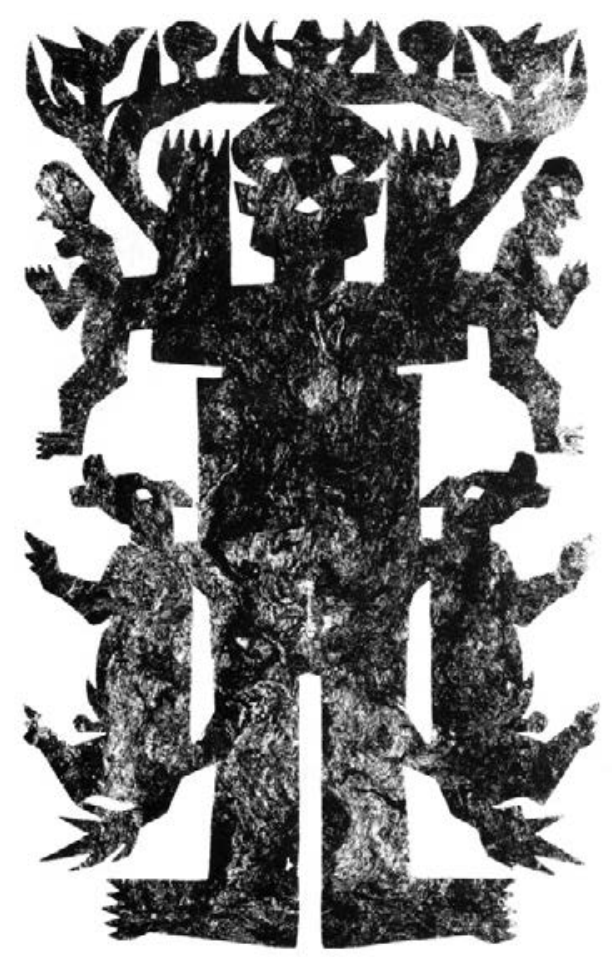

24

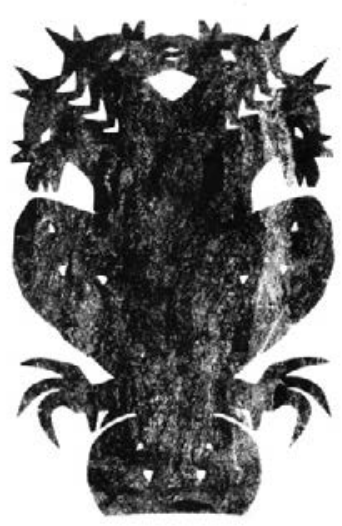

Der Herr des Berges (,.Señor del Monte") mit seinen Begleitern. Vier Köpfe weisen den „Bergvogel“ oder "Vierkopfigen Adler" (Pajaro del Monte, Aguila con cuatro cabezas) als besonders mächtig aus. Fs gibt auch solehe Vögel mit zwei Köpfen, die aber nichts mit dem habsburgischen Doppeladler zu tun haben.

\subsection{Anders' comparison of spirit figures with roots in the Codex Yuta Tnoho} to the contemporary papercuttings from San Pablito

proposed to identify the toponym itself not as Tollan but as Tulancingo, a rancho of Jicayán on the Mixtec Coast.

Another hallmark was the doctoral dissertation of Nancy Troike on the Codex Iya Nacuaa (Colombino-Becker), presented at London University in 1974. This detailed and thorough work, although unpublished and circulating only in photocopied form, has set the standard for precision in the analysis of style and pictographic conventions. Troike not only reconstructed parts of the lost texts, but also discovered a dramatic structure underlying the narrative, one comparable to that of a Shakespearean tragedy, such as Richard III.

In that same year (1974) Troike organized a symposium on these codices as part of the International Congress of Americanists in 

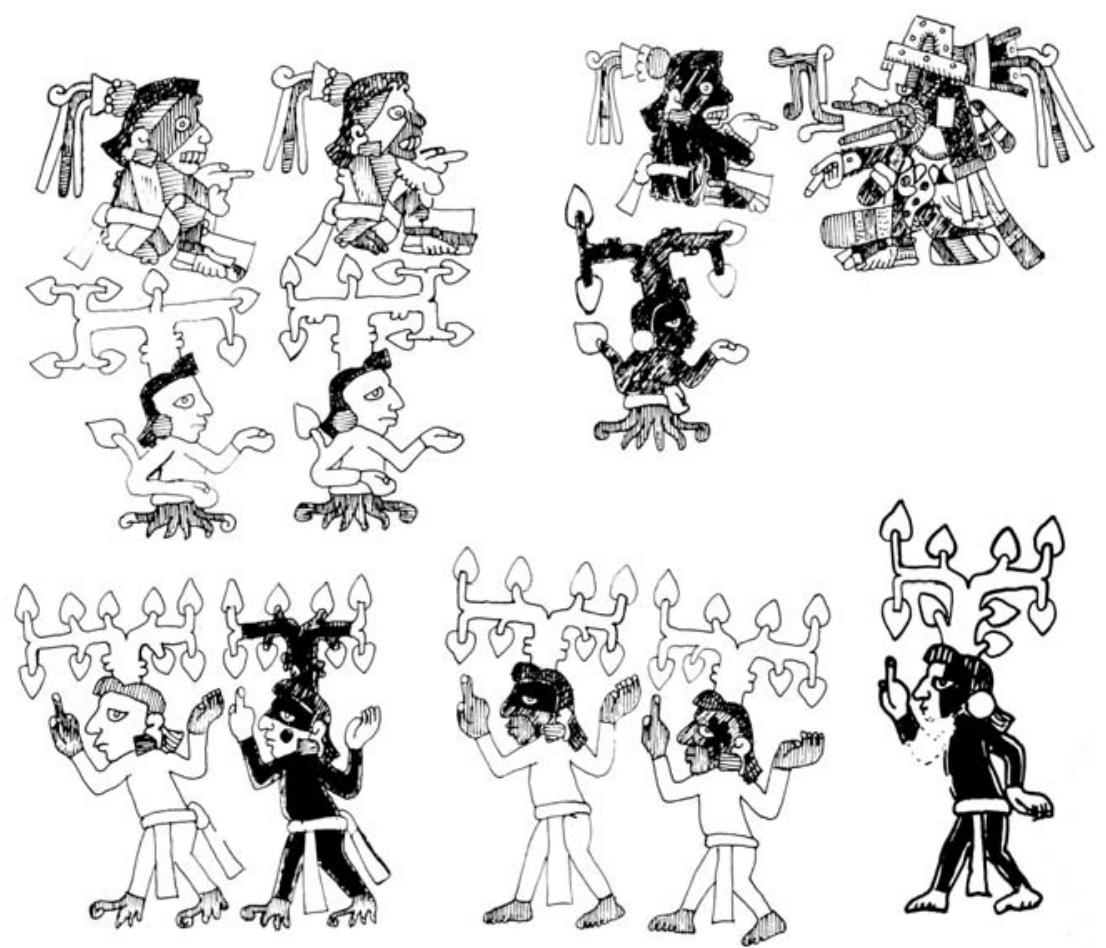

Wie tief verwurzelt die in San Pablito noch lebendigen Traditionen waren, zeigt eine Passage des aus dem mixtekischen Raum (heute Oaxaca) stammenden Codex Vindobonensis Mexic. 1, welche Quetzalcoatl im Gespräch mit den Wesen der Umwelt zeigt: dunkle Steingeister des Obsidian, bunte Steingeister und Pflanzengeister. Bemerkenswert ist die gleiche Form der Wiedergabe der Pflanzenelemente in Gestalt der personifizierten Pflanzen- oder Baumstämme und der Wurzeln an den Füßen.

Codex Vindobonensis Mexic. 1, Österr. Nationalbibliothek, Wien. S. 37/38, 50 und 51.

\subsection{Continued.}

Mexico. Here Mary Elizabeth Smith proposed the identification of 'Belching Mountain', the main toponym of Codex Añute (Selden) as Añute (Jaltepec). At the same symposium Emily Rabin presented a first critical revision of Caso's chronology. Having already heard several preliminary objections against any critical review of Caso's ideas, she made her position very clear in the opening phrases of her paper:

The pioneering work of Alfonso Caso and his mastery of the nature, conventions, and decipherment of the Mixtec historical manuscripts leave us a vast legacy of historical and genealogical studies. With this foundation we have the opportunity to bring about a still broader understanding of this history, and surely the most appropriate tribute to Caso's work is to carry it forward. 
Using biological criteria such as generation length as well as menarche, puberty and menopause as age limitations for childbearing, Rabin showed that there were inconsistencies and errors in Caso's reconstruction. A quote from her original paper illustrates her reasoning:

Going back to the beginning of the sequence we see that five women play key roles. They represent three direct line generations: a mother, Lady 1-Death; her daughter, Lady 1-Vulture (Eagle); and her three granddaughters, Lady 5-Reed, Lady 10 or 11 Alligator, and Lady 4- or 5-Tiger.... If the marriage of Lady 1-Death to Lord 4-Alligator occurs in 732 and their granddaughter, Lady 5 Reed, marries in 886, the number of years encompassing these two events amounts to 154. If we take the general average of 31 years for a generation (....), three full generations would amount to 93 years. If, however, all girls are married at 14 and have their first child at 15 , three generations might be - as is not uncommon in fact - as short as 45 years. But there is an upper limit too. If each mother here concerned bore the daughter who interests us at age 45, the three generations would (in this case) span 135 years....

Despite this extremely brief analysis, it becomes readily apparent that the dates proposed by Caso for this section of the sequence are biologically impossible. Therefore, I am forced to put forward the hypothesis that the marriage date for Lady 1-Death and Lord 4-Alligator should be advanced by 156 years or three 52 -year cycles.

Re-examining the scenes, Rabin proposed alternative interpretations and elaborated a new correlation $(1981,2004)$. We accept her comprehensive analysis and corrections. For the period between Lord 8 Deer and the Spanish conquest, Caso's analysis follows the dates given in the codices and as such is most of the time impeccable. There are, however, some problems regarding the dates themselves. The years given for the father and grandfather of Lord 4 Deer, the last precolonial ruler of Nuu Tnoo, mark unusually long generation spans in the Nuu Tnoo dynasty (of 42 and 38 years respectively). Here Rabin proposes to shorten the chronological sequence elaborated by Caso with one cycle of 52 years. Consequently Rabin dates the lifespan of Lord 8 Deer from 1063 till 1115 AD, while Caso put him one 52-year cycle earlier, i.e. between 1011 and 1063 .

These matters and their consequences are still being debated. The groundbreaking symposium in Mexico (1974) had its sequel at the International Congress of Americanists in Paris (1976) and a number of other meetings in the U.S.A. and Mexico. First attention focused on aspects and manuscripts that Caso had left untouched, or specific problem areas in his work. One of the main discussion points was the 
status of the early part of the story told in the Nuu Dzaui manuscripts. Leaving the Astraldeutung behind us, there was still a noticeable difference to be accounted for between the clear-cut genealogical history (on which Caso had mainly concentrated) and what was now called the 'mythological section', dealing with creation and rituals, mainly present in Codex Yuta Tnoho (Vindobonensis). Were the protagonists to be addressed as 'Deities' or 'humans'? For a long time it was usual to refer to them as 'personages', as it was to use the symbols of 'Male' and 'Female' for all Lords and Ladies in the codices. Although Troike insisted on the need to approach Mixtec codices from a Mixtec perspective and to avoid Nahuatl terms and preconceived notions imported from the Mexica world, as had been the general custom so far, an interesting first paper on this subject, presented at Troike's symposium in Paris, came from an expert on the Aztec world: Henry B. Nicholson's serious and valuable analysis of the protagonist of Codex Yuta Tnoho, Lord 9 Wind, as a form of 'Ehecatl-Quetzalcoatl' (published in 1978).

Caso had not written a commentary on Codex Yuta Tnoho. Jill Furst chose this impressive manuscript as the topic for her Ph.D. thesis (published in 1978, and complemented by several articles, such as Furst 1978b). Although not including ethnographic field experience nor linguistic studies, this work provided a good ordering of the data and a detailed discussion of the problems and the relevant sources. Inspired by the wide knowledge of her husband, Peter Furst, an expert on Native American shamanism, Jill Furst stressed the sacred, symbolic and ritual aspects of the story, and made important observations about the possible metaphorical meanings of some of the dates. She further pointed out that skeletal features in the codices seem to have symbolic value related to fertility and life (cf. Furst 1982). Similar observations have been made about death imagery in Maya art (e.g. McAnany 1995, Houston \& Stuart \& Taube 2006), which suggest that images of skulls and bones should not be taken as products of a macabre fascination with death, but rather as references to the Ancestors.

Shortly afterward, John Pohl in his doctoral dissertation also dealt with the religious ideas underlying the pictorial narratives, but, informed by his work for the Disney Film Studios, he added a specific emphasis on the visual and performative aspects of story-telling. In fact he drew the attention of colleagues to this point by showing at several congresses his short movie in which the codex pictures were animated and told the story in a cartoon-like manner. 
Equally in the 1980s research in neighboring disciplines created a better context for Mixtec codex studies. The historians Rodolfo Pastor and Angeles Romero shed light on the economic and social dynamics of the Nuu Dzaui region during the colonial period, while Kathryn Josserand made an important and timely contribution to the understanding of the distribution and historical relationships of the different dialects of Dzaha Dzaui. Most of the information on the different dialects of Dzaha Dzaui at the time came from the protestant Summer Institute of Linguistics: for example the collection of tales by Dyk (1959), the dictionary by Dyk \& Stoudt (1973), and the grammar by Alexander (1980). ${ }^{17}$

The frequent interaction and correspondence between investigators, mainly stimulated and organized by Nancy Troike (working at the University of Texas in Austin), triggered a period of lively discussions and fruitful contributions. ${ }^{18}$ We remember vividly the debates in hotel rooms under her enthusiastic direction, with codices unfolded all over the place, wild guesses, detailed analysis, good humor and scholarly dedication. At the same time we noted with increasing frustration the continuous absence of Nuu Dzaui participants in all these scholarly meetings and activities, developed far from the region, language and culture that were the center of fascination.

In 1978 Troike published a first review of the reorientation and changes in the study of Nuu Dzaui codices in the journal American Antiquity, warning that "almost everything now in print concerning the Mixtec codices is out-of-date or inaccurate". In a programatic tone she stated:

The field of Mixtec codex interpretation is now a separate and firmly established area of specialization within Mesoamerican scholarship. The centuries of historical events, wars, alliances, genealogies, and mythologies that these manuscripts depict can no longer be interpreted in fanciful ways by persons having neither the background in nor a knowledge of the Mixtec data. The Mixtec codex field demands of its participants a thorough grounding in the literature and in the culture and language of the Mixtecs. (Troike 1978: 566).

\footnotetext{
${ }_{17}$ See also Bradley \& Hollenbach's recompilation of diverse grammatical studies (1988-1992).

${ }^{18}$ Gutiérrez Solana (1987) summarizes the research on Nuu Dzaui codices in the period 1973-1984.
} 


\section{CONTEMPORARY STUDIES AND DISCUSSIONS}

Our own work started in the aftermath of the International Congress of Americanists in Mexico (1974). We met in 1974 in Ñu Ndeya (Chalcatongo) by mere chance (if there is such a thing), during Aurora's rescheduled vacation to attend the Patron Feast of September 8 and Maarten's first (and unplanned) trip to the Mixteca Alta. Born in the Mixtec traditional community of Yuku Shoo, belonging to Nuu Ndeya, Aurora had learned her first Spanish when she entered the local primary school at the age of eleven. After finishing at that school, she worked as a domestic servant in Mexico City and then for two years as a migrant in the United States, where she learned English. Coming back to Mexico she worked as a hotel-receptionist and tour guide in Oaxaca, and then for seven years as an international telephone operator in Mexico City, during which time she made her first trip to Europe. Meanwhile Maarten had combined the study of GrecoRoman philology and archeology (B.A.) with minors in Nahuatl and Quechua at Leiden University, and had started the M.A. specialization in ancient American civilizations with Professor Ferdinand Anders at the Institut für Völkerkunde, Vienna University. As part of his long-term research, Anders was directing a major project of facsimile editions of ancient Mexican codices at the Akademische Druck-und Verlagsanstalt (ADEVA) in Graz, Austria. Becoming involved in this project, Maarten tried to apply his Leiden training in iconographical and philological methods to these manuscripts.

Forming a team we chose to combine our diverse interests and early expertises by focusing on the history and language of Nuu Dzaui, in particular on the interpretation of the Mixtec pictorial manuscripts. Our first aim was to relate the contents of Codex Yuta Tnoho (Vindobonensis) to Nuu Dzaui geography and religious worldview. The geographical dimensions of this manuscript had often been discussed in class by Anders, who in those years had just prepared a new facsimile edition of the manuscript (Adelhofer 1974). The first impressions of the Mixteca Alta inspired Maarten Jansen to try to locate some of the impressive mountain ranges that fill its pages. The point of 
departure was, obviously, the breakthrough by Karl Anton Nowotny in the interpretation of this specific codex $(1948,1959 \mathrm{c})$, as well as his fundamental studies of the composition of the pictographic signs (1959b) and of the world of the ancient Mexican religious pictorial manuscripts in general (1959a, 1961a, 1967). The new handbook on Mixtec place signs, just published by Smith (1973a) was an eye-opener. Aurora Pérez brought into this field her first-hand and active knowledge of Sahin Sau, the modern Mixtec language as spoken in Nuu Ndeya (Chalcatongo) and a personal understanding of customs and concepts of the cultural tradition.

Not really in opposition to Furst's art-historical study, but following another approach, we tried to situate the Vienna manuscript within the total corpus of both the Books of Wisdom and the other Nuu Dzaui codices, published and interpreted by Alfonso Caso, and to connect the contents with the landscape, concepts and customs of Nuu Dzaui itself. Starting to work in the region together, we went to Yuta Tnoho (Santiago Apoala), a truly magical place. Here, according to the story of creation registered by Friar Gregorio García, the primordial couple Lady 1 Deer and Lord 1 Deer had lived on the Mountain of Heaven. The same couple appears associated with Heaven in the first pages of Codex Yuta Tnoho. A large painting on page 36 of Codex Tonindeye situated the place sign of Yuta Tnoho, 'River that pulls out' (Río que Arranca) or 'Story-Telling River' in an impressive landscape.

On the truck that took us from Nochistlan to Apoala, Don Raúl García Alvarado had already expressed to us his profound interest in the village's past: from the stories told by the elderly he knew that Yutsa Tohon was a community of historical importance, he was convinced that there must be an ancient manuscript or códice somewhere that would confirm and clarify the local legends, he had been looking for such a document himself.... With his help and that of other inhabitants the representation of the town in the codices was soon identified. To the East rises the peak of the Mountain on which the Heaven rests, Kaua Kaandiui (Cavua Caa Andevui in Alvarado's orthography). The Story-Telling River, the Cave of the Serpent, the Waterfall, the place where the Sacred Mother Tree (Tinuu) had once stood, were all there.

Nancy Troike, following all this from a distance, immediately invited us to communicate these findings at a symposium of the annual congress of the Society of American Archaeology, in spring 1976, in St. Louis Missouri. Later Maarten presented a more formal 


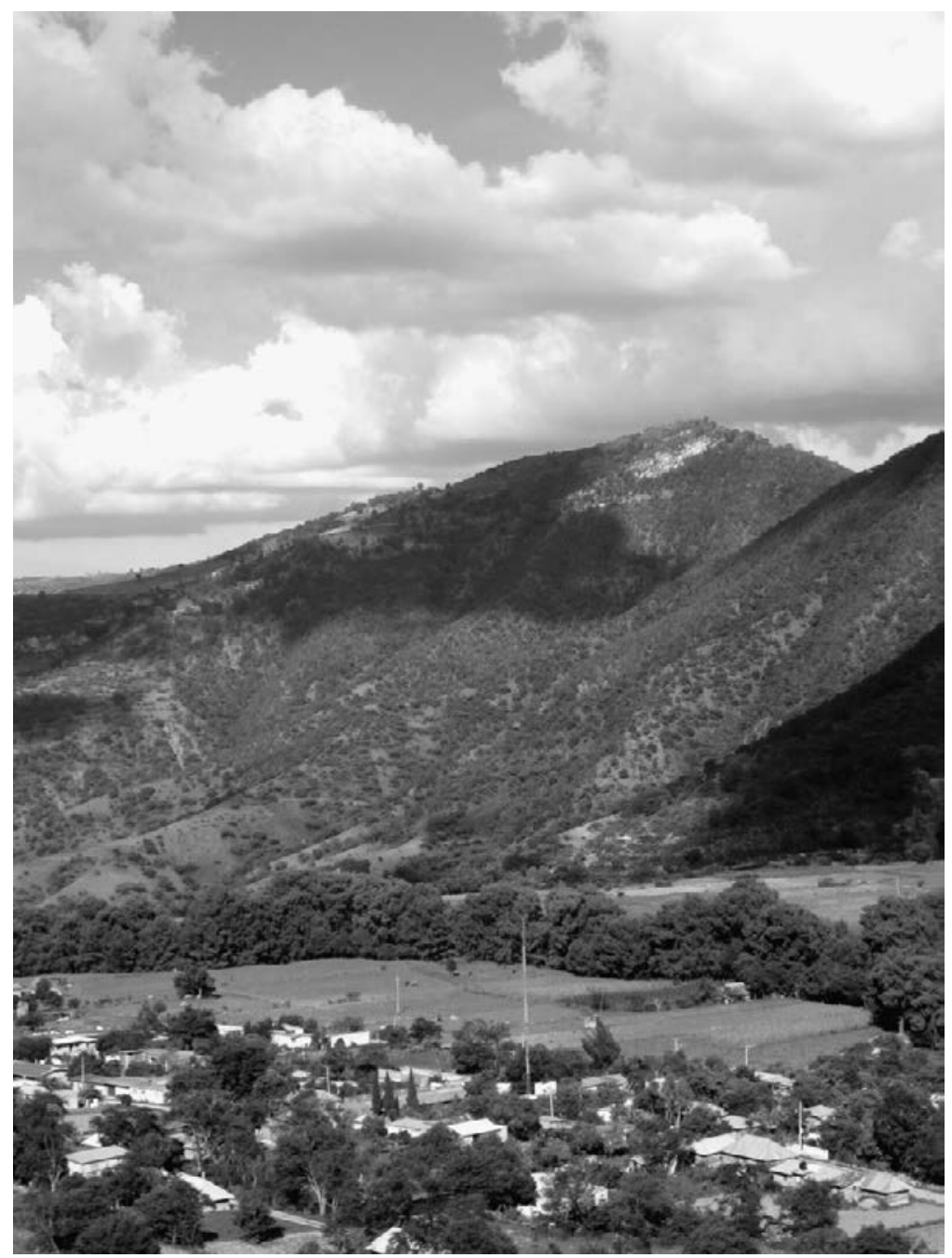

4.1. Kaua Kandiui, the Mountain of Heaven, East of Yutsa Tohon (Apoala).

paper to the session organized by Troike during the International Congress of Americanists in Paris (1976, published 1979), followed by his Master's thesis 'El Lugar donde estaba el Cielo' (Leiden 1976), supervised by Ferdinand Anders. The discussion of the main results with Karl Anton Nowotny, living his final years in Cologne, was very inspiring and made a lasting impression. 


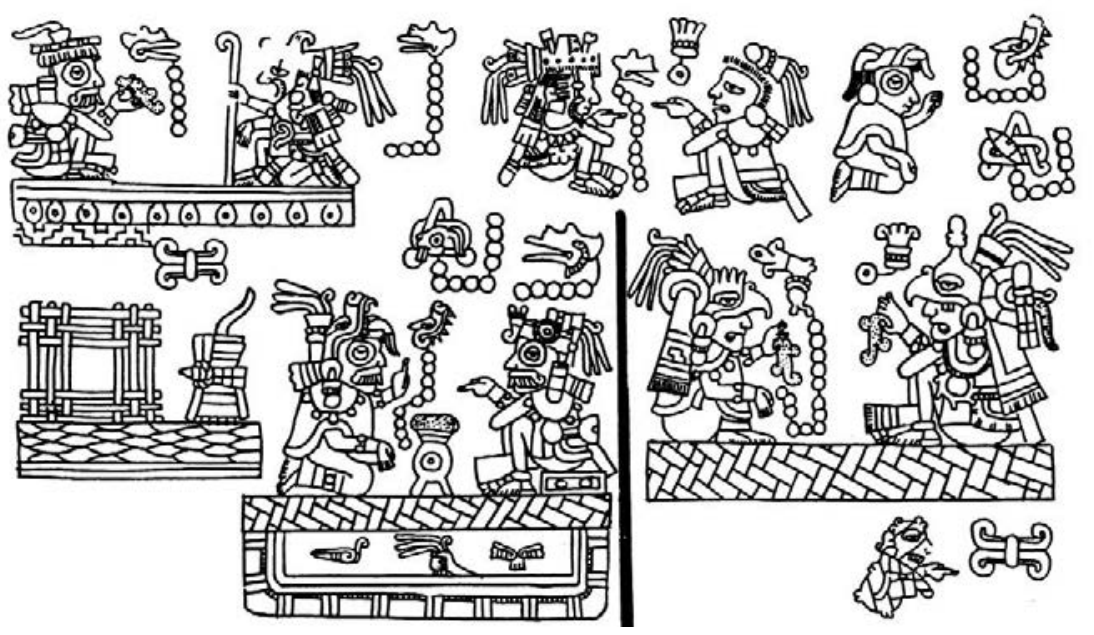

4.2. Codex Yuta Tnoho, p. 35 (Lower Right to Lower Left, boustrophedon): Invocation of the Nuhu. The elderly couple Lord 1 Flower and Lady 13 Flower have a daughter, Lady 9 Alligator. The father speaks to Lord 9 Wind, who acts as a 'marriage ambassador' and visits Lord 5 Rain in the Place of Heaven. As a consequence of his mediation, Lord 5 Rain weds Lady 9 Alligator in River of the Hand Holding Feathers, i.e.

Yuta Tnoho (Apoala).

In the framework of a position at Leiden University, which Maarten obtained for his Ph.D. research, we were able to continue the study of Codex Yuta Tnoho and related documents in more depth. Traveling through the region and talking to many people, mainly in Yutsa Tohon (Yuta Tnoho, Apoala) and Nuu Ndeya (Ñu Ndaya, Chalcatongo), but also visiting other important towns, such as Nuu Tnoo (Tilantongo) and Chiyo Cahnu (Teozacualco), we were able to identify more toponymic signs and specific acts. The supervisors of the thesis work, Benedikt Hartmann (originally a specialist in ancient Near Eastern religions) and Ferdinand Anders, did not just watch from afar, but actively participated in short fieldtrips to the Mixteca Alta, providing intellectual partnership over the years.

The analysis of the Codex Yuta Tnoho showed that the first Lords and Ladies, born out of the Tree in that Sacred Valley, performed a New Fire ceremony for a number of places, among which we found the emblematic glyphs of the four directions and the center. This was clearly in accordance with the testimonies of Friar Antonio de los Reyes and Friar Francisco de Burgoa about those Lords and Ladies of 


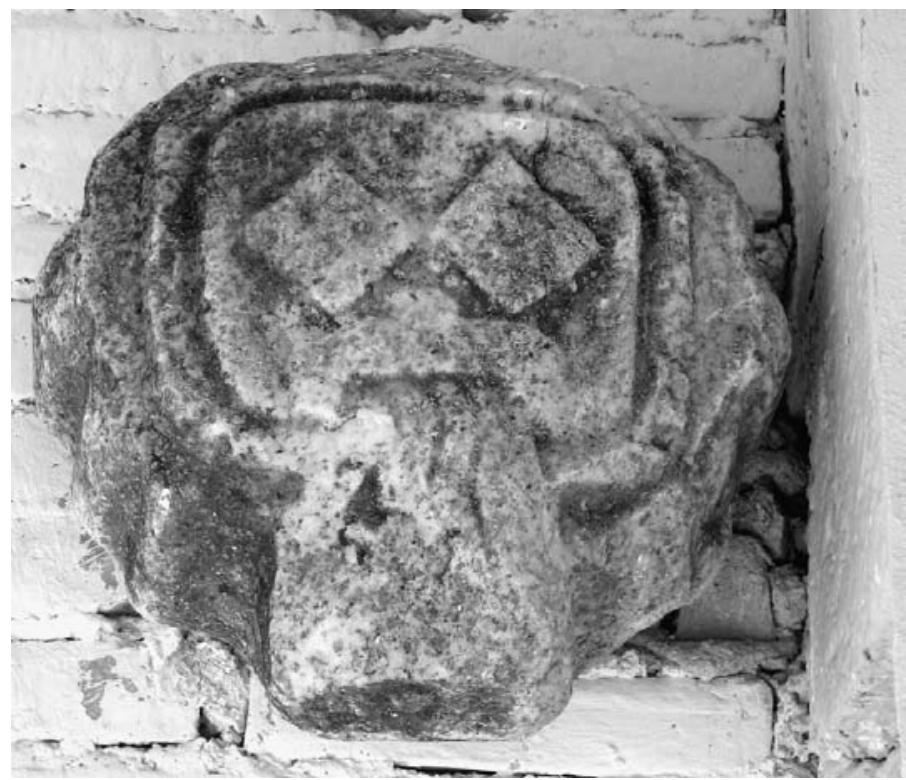

4.3. Carved stone, representing a Nuhu, set in the wall of the church of San Martín Huamelulpan.

Yuta Tnoho (Apoala) going to the four directions, taking possession of the land and founding the dynasties. The leader of the ceremony waves some branches over the landscape, an action that is clearly the same as the present day limpia or ceremonial cleansing. Following up the decipherments by Mary Elizabeth Smith, we could clarify concepts such as N $u h u$, 'deity' and iya, '(divine) Lord'. Their present-day usage made it clear to us that the old question of trying to define the protagonists of the foundation period in the codices using the dichotomy between 'Gods' or 'historical persons', simply made no sense in Dzaha Dzaui. The ancient rulers (iya) had religious importance and became deities ( $\tilde{N} u h u)$ after death (as indicated clearly in Reyes' grammar).

\section{Chronology Again}

On several occasions and in correspondence Maarten Jansen discussed extensively with Emily Rabin the possibility of shortening the time span between Lord 8 Deer and the Spanish invasion by 'taking out' a second 52-year cycle of the chronological sequence proposed by 
Caso. The main reason for this was the analysis of the opening scene and glosses of Codex Nuu Naha (p. 2): in the year 3 House three nobles from Nuu Naha arrived in Chiyo Cahnu in order to ask the local rulers, Lord 8 Rabbit and his wife, Lady 6 Grass, for their son, Lord 1 House, to become king in Nuu Naha. Amidst all kinds of annotations we find the statement ' 1300 años', i.e. 'the year $1300 \mathrm{AD}$ '. According to the conversion table the year 3 House could be 1301. This is a remarkably precise and explicit correlation. Because of the fact that Mesoamerican and Christian years are not completely identical a variation of one year is normal in such correlations. Furthermore the native historian who explained the pictorial scenes of Codex Nuu Naha seems to have been well informed. The date 1300 was not arrived at by the simple process of counting the years backward, because there are hardly any other dates in that codex. The equivalence must have been calculated on the basis of an oral tradition or another, more complete written source, which kept a record of the cycles of 52 (or 104) years that had passed.

According to Codex Tonindeye, p. 30, that very same Lord 8 Rabbit was born in the year 8 House. Following the gloss in Codex Nuu Naha that he was alive and father of an adult son in 1300, we must conclude that his birth year 8 House has to correlate with 1241 and not with 1189 , as would be the case in Rabin's synchronology. This would suggest that yet another cycle of 52 years has to be taken out of the time between Lord 8 Deer and the Spanish invasion. This is quite problematic, however, given the dates mentioned in the manuscripts. Lord 8 Rabbit's granddaughter, Lady 1 Eagle, marries in the year 5 House, which, according to Rabin, must correspond to 1277. The time elapsed between the birth of Lord 8 Rabbit and the marriage of his granddaughter, taking into account the sequence of generations and the genealogical relationships, has to be more than a mere 36 years. In other words, even if the year 5 House only refers to the ceremonial arrangement of Lady 1 Eagle's marriage, she being still a young child at the time, the period of 36 years is very short for what amounts to nearly three generations. Adding a full 52-year cycle, however, makes the sequence quite long.

This question has not been resolved to our satisfaction. We will follow the chronology as established by Rabin, but keep in mind that the dates before 1277 might have to be corrected with one cycle (according to the Nuu Naha correlation) and be 52 years later than we put them now. In other words, according to Emily Rabin, the dates for the life of Lord 8 Deer are 1063-1115 AD. Alfonso Caso dated him 1011- 
1063. The Nuu Naha correlation would situate him between 1115 and 1167.

The implications of these chronological discussions are important, as they affect the reconstruction of the Postclassic history of Central Mexico. Lord 8 Deer interacted with the Toltecs. Having a secure date for him, we would be able to create a good framework for resolving the many different and contradictory datings in Central Mexican sources.

The period preceding Lord 8 Deer includes that of the sacred origins. Here we find among the chronological dates also a number of dates in non-durational time, i.e. ceremonial founding dates associated with the place signs of the $\tilde{n} u$ (village-states). Caso had already discovered that year 1 Reed day 1 Alligator functioned as a general sign for 'beginning', but there are more dates that follow a similar pattern. Caso, however, calculated those other dates as chronological markers in the sequence of 52-year cycles. Consequently his correlation sequence became much too long here, containing a number of inconsistencies and biological impossibilities. In this part of the chronology Emily Rabin's revision of Caso's correlations is, therefore, much more extensive and completely changes the picture. Where Caso dated the first events in the Nuu Dzaui codices in the late 7th century AD (i.e. half way through the Classic Period), it can now be shown that they coincide with the beginning of the Postclassic Era around $900 \mathrm{AD}$.

The different ideas intended to carry on Caso's work were communicated freely in conversations and letters, which sometimes reached the length of true articles. We quote some fragments to give an impression of this fruitful period of exchange:

These problems affect to a degree the questionable year signs for Lord 6 Deer, Lord 4 Flower, and Lord 10 Rain at the end of Bodley Obverse. Trying to account for the various alternative sequences to cover the above interpretations results in the 'domino effect' whereby one change forces changes in other genealogies, etc. So depending on the alternative interpretation selected, it becomes necessary to revise the Chronological Charts, all of which require detailed explanations....

The other two year signs in the sequence, 8 House or 1241, for the birth of 8 Rabbit and 12 Rabbit or 1258, for 2 Motion's third marriage, could fit in your sequence [the shortened chronology, based on the gloss in Codex Nuu Naha]. But such a sequence, based on 7 generations at 14.0 years per generation, does not fit the general pattern for marriage 
and birth in the codices. Although there are some isolated instances of early marriage for both males and females based on year signs, I have not found any evidence to support successive generations at 14.0 years per generation....

Although the year signs for female birth and first marriage are meagre, those few indicate marriages which are very early between the ages of 8-10 and marriages at $13-14 \ldots$. Evidence of other early female marriages can be interpolated from the so-called uncle-niece marriages, brother-sister marriages, political marriages, etc.

With the uncle-niece marriages and in some cases with political marriages ( 1 Alligator and $4 \mathrm{Wind}$ ), the male has to wait for his future wife to reach the 'marriageable age' and then the nubile period has to be reached before she can become pregnant. In some of these cases the male is in his 20's or even 30's on his first marriage. As the first child would be born only after the nubile period has been reached, four or five years might elapse before the birth of the first child for very early marriages at $8-12$ could occur....

To conclude this section, I do not think a two 52-year cycle advance over Caso's sequence is valid for this section of the sequence. The time span for 7 successive generations is too short ( 7 generations in 99 years equals 14.0 years for each generation). One of your reasons for the two 52 -year cycle advance in this section is to place the birth of Lord 8 Rabbit at 1241 so that the Nunaha date of 1300 can be incorporated into the sequence for Lord 1 House. But a birthdate for Lord 8 Rabbit at 1241 can fit in a sequence with only one 52-year cycle advance over Caso's sequence. Such a sequence can also fit the general pattern of marriages, births, etc. in the codices. The birthdate of 8 Rabbit is not the problem - the problem is with the two generations that follow 8 Rabbit. They are too tight chronologically.

Before his birthdate can be resolved, the whole Teozacualco genealogy and Bodley Reverse (B 28-21) genealogies, etc. have to be fitted into the entire sequence. I have several alternative sequences to cover this period but to date I have not reached a definite solution....

Although there are some year signs which I really think are 'incorrect' for one reason or another, I try as many alternatives as possible to avoid changing year signs. Unless a change can be fully validated, I hesitate to make any changes based on my or Caso's interpretation. A case in point is 5 Alligator. Did he or did he not rule Tilantongo? By changing one year sign I could have accepted Caso's interpretation. This, however, is not to say that my present hypothesis stating that 5 Alligator did not rule Tilantongo is necessarily the correct one as there are still some problems which have to be resolved as you are well aware." (Rabin to Jansen, February 28, 1980).

And now something that might really interest you: the location of Flint City. According to Vindobonensis Obverse p. 42, Flint City, as well as Flint Mountain, are located between Tilantongo and Jaltepec. Recently 


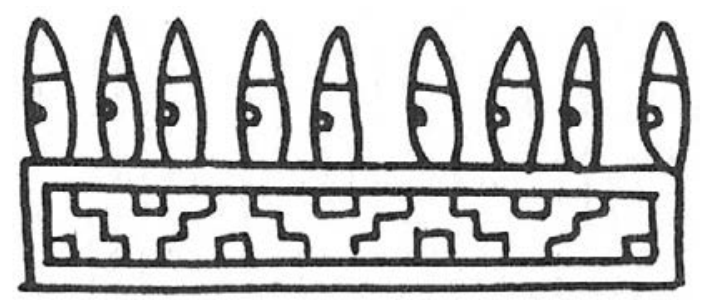

4.4. Town of Flints.

a relief with a Flint Mountain glyph was found on Mogote del Cacique in Tilantongo. The Mixtec name of Mogote del Cacique is Flint Town and this important archaeological zone is situated between Tilantongo and Jaltepec! I therefore think that Flint City is nowhere else than precisely Mogote del Cacique. This suggests even more that Lord 4 Wind tried to found a new capital, rather close to the traditional one of 8 Deer, but a little bit closer to Jaltepec, his place of origin through his mother. I discussed this just recently with Betsy [M.E. Smith] who now is in Oaxaca and she liked the idea very much. (Jansen to Rabin, March 13, 1980).

I have a xerox Emily sent me of what you and she have been arguing over. She has been working on the problem for the past 5 or 6 months, ever since you raised the possibility of taking out the 2 cycles; however, she just isn't convinced about the removal of the second cycle, and I am inclined to agree with her. The pattern that shows up in the codices is for females to be more than just at puberty when they marry. The modern pattern for youthful marriages is an outcome of the Conquest, no matter how traditional the town may be otherwise. So I would suggest you look for a cycle's error in the other material, not in the Mixtec codices. From my reading of the Historia Tolteca Chichimeca (Luis Reyes' edition), it is obvious that the Central Mexican manuscript people do not understand chronology problems, for there are obvious gaps in their chronology that they seem to be completely unaware of. They are much like Caso was in his early Mixtec studies, taking all dates literally and never noticing that some of the sequences of people don't fit together very well....

The idea that Mogote del Cacique could be 'Flint Place' is very interesting, and could help a lot in understanding the history that took place after 8 Deer was killed. Becker 13/14-III: 4 Wind is at 'Flint' when he plots the death of 8 Deer that occurs on Colombino 16-II.... 'Flint' is never of any importance in the codices, except when it is briefly associated with 4 Wind, and if he did try to move the capital from Tilantongo to 'Flint' / Mogote del Cacique, he did not succeed in making the new center an important place beyond his own lifetime. I'm not 
really so sure that 4 Wind was trying to set up a new capital but rather I think he may have been trying to compensate for the loss of Jaltepec (to his younger brother, Selden 9-I) and to get even with 8 Deer's importance by trying to set up a town that would also be of importance. Unfortunately for his dream, he apparently failed, in a great part perhaps because of bad luck with having children....

Biologically, considering the tangle that the genealogies get into after 8 Deer's time, it is a great wonder that the Bodley painter or anyone else can keep track of them. I don't think it means he is any less interested in Tilantongo, but does indicate that he cannot be sure of the dates or even who is ruling. There is very likely a big power vacuum after 8 Deer's death, and there are bound to be a lot of little squabbles and people trying to get to the top. It is difficult to keep good track of anything under those circumstances, because a lot of lying is being done. No strong power seems to emerge, however, and hence the period of instability lasts longer than normal. This might be due to outside pressures - like Toltecs? It might be good to think about what is going on elsewhere in Mesoamerica at the same time.... (Troike to Jansen, April 23, 1980).

To sum up briefly, the hypotheses included these matters: (1) That the 2 names for Tilantongo may refer to 2 different places, the 'House of Heaven' being a temple near Tilantongo town. (2) That 5 Alligator never had anything to do with Tilantongo town, but only the temple 'House of Heaven' near it. (3) That 5 Alligator is deeply involved with some kind of rites, possibly concerning Venus, at the temple 'House of

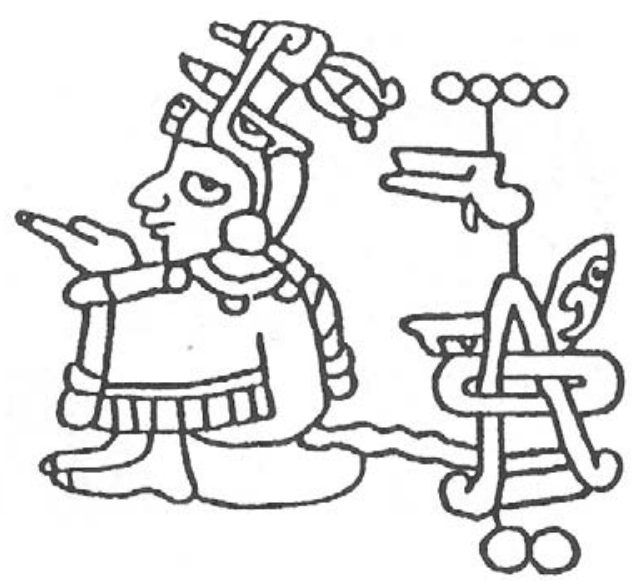

4.5. Codex Añute, p. 8-IV: the birth of Lord 4 Wind 'Fire Serpent' in year 2 Flint [AD 1092]. 
Heaven'. (4) That 2 Rain is killed in some kind of close association with Venus. (5) That the Venus associations of 2 Rain's death cause the Mixtec power structure to pick a new dynasty line descended from the person in their area most closely connected with Venus: 5 Alligator of the temple 'House of Heaven' (This is obviously a very controversial point.) (6) That since 5 Alligator is already dead, the choice falls upon his 2 sons from his 2 marriages, 12 Movement and 8 Deer, with the latter dominating.... (Troike to Jansen, April 25, 1980).

I really liked very much your detailed information about 4 Wind. I agree that he tried 'to get even with 8 Deer's importance by trying to set up a town that would also be of importance'. The interesting implication would be that Mogote del Cacique then should principally correspond to 4 Wind's lifetime. The only report on this zone that I know of is that by Ron Spores in Mixtec Kings, pp. 44-45. (Jansen to Troike, May 4, 1980).

Your ideas about Lord 5 Alligator's activities coincide very much with what I have been thinking since our great unión de mixtequistas in Austin. You are certainly right in defining his role as primarily religious and associated with the Temple of Heaven (huahi, modern vehe, is 'temple' as well as 'house') and I would think you may go even further. The Temple of Heaven may be the principal ceremonial center of Tilantongo - I guess the temple described in Papeles de la Nueva España IV, p. 74: Lord 5 Alligator's career corresponds quite clearly to what Herrera

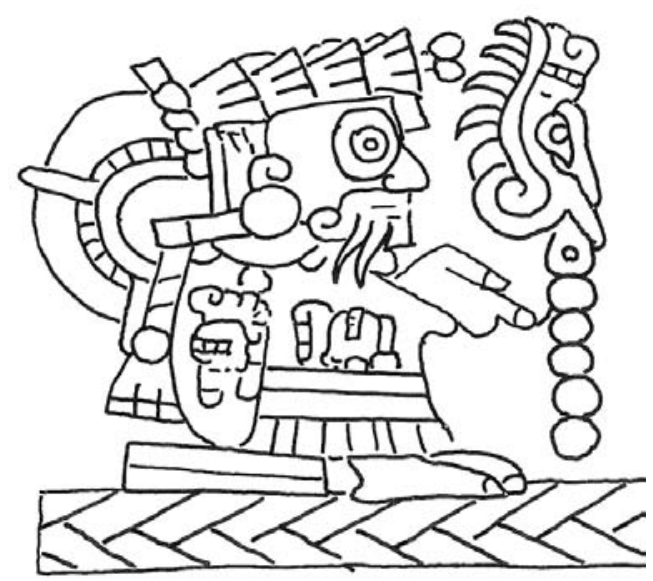

4.6. Codex Ñuu Tnoo-Ndisi Nuu, p. 7-III: Lord 5 Alligator 'Rain Sun'. 
describes: 'eran los oficios por cuatro años', 'En llegando al templo, le desnudaron y le ponían otra manta (!) diferente, y el Papa le daba un cañutillo de lancetas de pedernal (!!) etc. So there can be hardly any doubt that 5 Alligator was the most important high priest of Tilantongo, the one that was President of the Counsel of Four (Relación Geográfica de Tilantongo), and that decided peace or war etc. I think in Nuttall p. 25 we see him in discussion with the three other members of the Counsel. As the power of the more secular rulers in Tilantongo became weak, with 2 Rain very young, a former high priest and politically very influential figure like 5 Alligator, certainly could play a role like Richelieu!" (Jansen to Troike, May 9, 1980).

My whole idea is that if we can be sure of the artist's patterns of recording information, we won't misinterpret what he tells us.... I take up the problem of what I've called 'decorated bases', which are those basal place signs that really aren't place signs but just decorated things on which the marriage pair sits. Often such marriage pairs are without dates; perhaps even usually without dates is my impression, tho this is not something I've checked on (it would be worthwhile to do, \& if anybody wants me to do it I will). From the pattern of bases I saw in the codex [Bodley] I concluded that real place signs with marriages indicated both rulership \& legitimization of the children. From this pattern comes the proposal that some of the Tilantongo heirs never lived to rule but figured in the genealogical chain of descent, which contributes to the shortening of time needed for the whole sets of dynasties. This hypothesis has never been tested, to the best of my knowledge, however, \& I don't really know how it could be. It will ultimately stand or fall or be altered by the overall chronology solution....

Most people have no idea how a pictorial communication system actually functions: what its problems are, the nature of the ambiguities that will arise, the range of solutions that can be applied, and what the resulting information will actually look like on the painted page. I've been particularly interested in this problem, since the first step in any historical research is to create an authentic text. This is why I've undertaken the various 'stylistic' studies that I have done \& am continuing to do. The whole point is to recapture all the information the Mixtec scribes built into their manuscripts, \& to do so accurately. (Troike to Jansen and others, November 8, 1981).

Many thanks for sending me a copy of your doctoral dissertation.... You have utilized, in both a creative and thoughtful manner, the two-fold approach I have always advocated: a first-hand knowledge of the present-day Mixteca, and the analysis of unpublished and published documents from this region. (Smith to Jansen, November 22, 1982). 


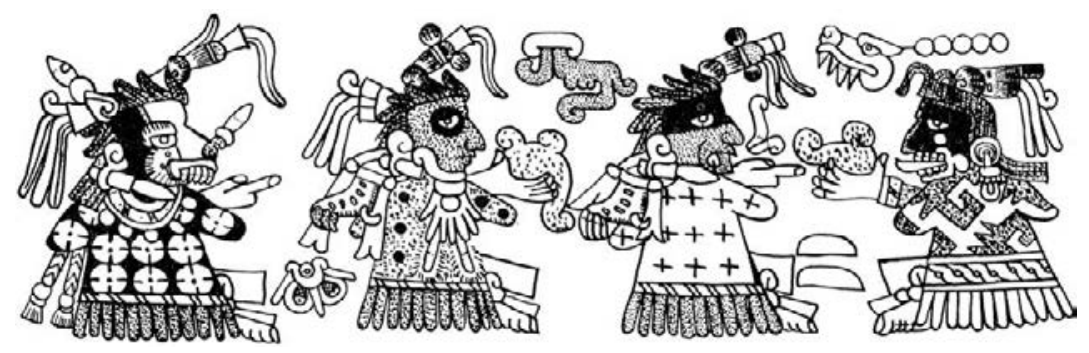

4.7. The Council of Four Priests in Nuu Tnoo (Tilantongo).

\section{Interregional Contacts}

The coming of age of Nuu Dzaui studies had pushed scholars in the direction of emphasizing the particularities of this culture and the need to see them in their own terms:

Mixtec codex specialists have now realized that many of the terms and concepts used in the older studies of these manuscripts actually reflect a Central Mexican, rather than Mixtec, point of view. Earlier scholars apparently absorbed this Central Mexican orientation because of the great amount of literature on that region and the almost total lack of corresponding Mixtec sources. Thus for many years Mixtec codex data have been viewed from this improper perspective and often imperceptibly, if unintentionally, distorted to conform to this alien pattern. This has obscured the real problems, confused the efforts to understand the meanings of the manuscript scenes, and delayed accurate interpretations. (Troike 1978: 553).

On the other hand, in the late 1970s Wigberto Jiménez Moreno explored again the possible relations with Central Mexican sources. He demonstrated that the last ruler mentioned on the reverse side of Codex Nuu Tnoo-Ndisi Nuu, Lord 8 Grass, appears in Torquemada's Monarquía Indiana as Malinalli, ruler of Tlaxiaco (Gaxiola \& Jansen 1978). This discovery confirmed Mary Elizabeth Smith's identification of the associated place (Crossed Beams with Eye) as Ndisi Nuu (Tlaxiaco). In conversations the maestro stimulated John Molloy and the present authors to rethink the role of the Toltecs. Molloy noted weaknesses in Smith's arguments for identifying Town of the Cattail Reeds as Tulancingo and proposed to return to Caso's original identification of that place as Tollan. This was an important contribution, but in his dissertation Molloy added several unconvincing specula- 
tions similar to those published earlier by Chadwick. Much later we were able to show that Town of the Cattail Reeds represents Tollan Cholollan, i.e. Cholula as capital of a late Toltec empire.

Another interesting connection between Ñuu Dzaui history and that of Central Mexico was found in the lienzos of the Coixtlahuaca Valley, a corpus closely related to that of the Nuu Dzaui codices. In retirement in Oaxaca, Ross Parmenter combined the study of these manuscripts with writing a voluminous biography of Zelia Nuttall. During visits to the communities he had become acquainted with lienzos unknown to the outside world (those of Tequixtepec and Tulancingo), and he made a series of crucial contributions to the interpretation of their contents. For example he demonstrated that part of the large Lienzo of Tlapiltepec (the upper half of the right-hand side) was actually a map of the Coixtlahuaca Valley, the place signs being distributed more or less according to their real spatial relations. Stimulated by this important discovery, Maarten Jansen went on to show that the continuation of this scene (i.e. the lower half of the right-hand side of the lienzo) had the same map-like characteristics and presented the account of an expedition toward the area of Cuauhtinchan and Tepeaca in the present-day State of Puebla. The same events were presented in sources such as the Historia Tolteca Chichimeca and the Mapa de Cuauhtinchan II, but also referred to in the Codex Añute (pp. 11-12). ${ }^{1}$

Several important manuscripts come from another intermediate region between the Mixteca Alta and Central Mexico: the Mixteca Baja. Over the years Mary Elizabeth Smith has focused on this region. Her classes at Hamburg University inspired a German student, Viola König, who in her thesis (1979) made great progress in explaining the contents of Codex Nuu Naña (Egerton) and in identifying its place signs. Smith's own edition and commentary of Codex Tulane (1991), the roll that had been robbed from Yucu Nindavua (Huamelulpan), was a masterpiece. While Ross Parmenter researched the history of the document, also known as Codex Daza, and could reconstruct in detail

${ }^{1}$ Parmenter and Jansen announced their discoveries at a congress in Oaxaca (Gaxiola \& Jansen 1978). Parmenter included his results in a book on the lienzos of the Coixtlahuaca Valley (1982), while Jansen presented a detailed but unpublished paper in 1983 under the title 'La Expedición hacia Cuauhtinchan: contactos entre mixtecos, chocho-popolocas y nahuas en la época postclásica' (used and quoted by Johnson 1997), reproducing the main contents later in Jansen 1992 and Jansen \& Pérez Jiménez 2000, 2007b. For a further elaboration, see Van Doesburg \& Van Buren 1997, and Ruiz Ortiz \& Jansen 2009. 
how it ended up in New Orleans, Smith deciphered the main place signs and established that the roll dealt with the dynasties of Toavui (Chila) and Yucu Yusi (Acatlan) in the State of Puebla.

Another interethnic contact exists between Ñu Dzaui and Beni Zaa (Mixtecs and Zapotecs) in the Valley of Oaxaca, and, consequently, there is a connection between the historical sources of both peoples. Alfonso Caso suggested that a place called Bent Rock with Tree on Quetzal River (Tonindeye, p. 33) represented Saha Yucu, i.e. Cuilapan, the major Nuu Dzaui village-state in the Valley of Oaxaca (Caso in Paddock 1966). He also pointed out that the dynasty of this town, characterized by attributes of the Aztec Flayed God, Xipe, was elsewhere connected with a place sign that consisted of a carrying frame (cacaxtli in Nahuatl). There was an archeological dimension to this as one of the early members of the Xipe dynasty, Lord 5 Flower, seems to have been one of the main individuals buried in Tomb I of Zaachila, the Beni Zaa capital in the Late Postclassic Era. Consequently the decipherment of the place signs became part of a complicated discussion about Nuu Dzaui presence in the Valley of Oaxaca. A Nahuatl gloss on the Map of Macuilxochitl, included in the 1580 Relaciones Geográficas, contains the word oconana. This is actually a form of the verb ana, 'to take', but reading it (mistakenly) as a reference to the Nuu Dzaui ruler Ocoñaña, a research group including John Paddock, Emily Rabin, Joseph Whitecotton and Judith Bradley Whitecotton was inspired to make a more detailed study of Beni Zaa pictorial manuscripts. ${ }^{2}$ At the same time Maarten Jansen discovered that the calendar names of the members of the Xipe dynasty coincided with those of the successive rulers of Zaachila in the Lienzo of Guevea, and concluded that Bent Rock with Tree on Quetzal River as well as Carrying Frame must represent that Beni Zaa capital: Zaachila, called Tocuisi in Dzaha Dzaui. ${ }^{3}$

\footnotetext{
2 See Whitecotton \& Whitecotton 1982, Whitecotton 1990, and for a critical analysis the contribution of Oudijk in Jansen \& Kröfges \& Oudijk 1998, as well as Oudijk's Ph.D. dissertation (2000). Other important studies on Beni Zaa lienzos have been published by König (1993), Cordero Avendaño (2004), De la Cruz (2008), and several contributors to the volume edited by Van Doesburg (2008). See also De la Cruz 2007 for an in-depth discussion of the Beni Zaa cosmovision.

${ }^{3}$ Although Jansen (1982a) had identified the Xipe dynasty as a list of rulers of Zaachila, Paddock, in his essay on these matters (1983: 56), quoted him - wrongly - as having suggested that the members of the Xipe dynasty, and also those buried in Tomb I in Zaachila, were Cuilapan lords. It was even more confusing to find that the place sign Carrying Frame was also represented on the Coat of Arms of Saha Yucu
} 
Conclusion: the Codex Tonindeye contained detailed information about the ruling lineage of Zaachila, information which was complemented by other codices. Consequently it becomes possible to investigate the links between the Nuu Dzaui (Mixtec) and Beni Zaa (Zapotec) dynasties, and to connect these data to Beni Zaa archeology (see the contribution by Oudijk in Blomster 2008).

Curiously enough, while Caso's intellectual legacy gave rise to all these new considerations, some other authors followed lines of research as if these breakthroughs had never happened. Luis Melgarejo Vivanco published commentaries on Codex Yuta Tnoho (Vindobonensis) and Codex Tonindeye (Nuttall) in 1980 and 1991 respectively, in which he ignored the fact that their Nuu Dzaui origin and contents had been firmly established by then. Suggesting that these manuscripts came from the State of Veracruz, he proposed to identify the toponymic signs as places in that region and adapted his reading of the contents accordingly, moving further and further away from Ñuu Dzaui reality. In the large section of Codex Yuta Tnoho (Vindobonensis), pp. 47-38, which consists of scores of place signs with dates, he read the dates consecutively as annals and the place signs as short indications of events. For example, the toponymic hieroglyph 'Mountain that is Opened - Insect' was to be decoded in his view as the phrase: 'at the same time campaigns were carried out against plagues that affected the agriculture' (1980: 135). He interpreted the contents of Codex Tonindeye (Nuttall) as referring to a people called the Pinome, especially their "insurrections against an impotent Totonac government, until the women, in a civil war, tried to restore the matriarchate ... but Mazatl VIII [= 8 Deer] finally imposed the centralized rule of his Pinome realm on the rebellious feudal lords." (Melgarejo Vivanco 1991: 23).

Without doubt Melgarejo Vivanco's theories were highly original, but as they simply did not take into account the state of the art in

(Cuilapan), a copy of which is found among the papers of Martínez Gracida. At first sight this suggested that Caso had been right after all (cf. Jansen 1992). Later Jansen clarified the situation, showing that Carrying Frame indeed represented Zaachila, also on the Coat of Arms of Saha Yucu (in: Jansen \& Kröfges \& Oudijk 1998). For a more detailed study of the Lienzo(s) of Guevea, see Oudijk \& Jansen 2000 and De la Cruz 2008, as well as the recent overview by Oudijk in Van Doesburg 2008. Historical documents from the colonial period have been published by Méndez Martínez \& Méndez Torres 2007a; while Zeitlin 2005 and Machuca Gallegos 2008 have analyzed the data from early colonial Tehuantepec. 
scholarly research, they did not include relevant argumentation and were not defendable vis-à-vis the more coherent position that specialists in the field had established by then.

\section{The 'Códices Mexicanos' Project}

As our work had started in the context of the editorial project of the Akademische Druck-und Verlagsanstalt (ADEVA) in Graz, we focused on the narrative, historical manuscripts (Aztec and Mixtec codices) as well as on the religious, mantic-ritual codices (the so-called 'Borgia Group'). It became clear to us that the different groups of pictorial books are connected in many ways: they belong to the same world and express the same worldview. This proved once more to us that those who study historiography, must also understand the worldview in which the sources are conceived, and equally that those who analyze religion, have to know the social and historical contexts of those ideas. Seeing the continuous presence of the language and many aspects of the ancient cultural tradition and mentality in the contemporary communities, we sought to combine archeological-iconographical analysis with the study of the present-day Mixtec culture and language. ${ }^{4}$ The area (and dialect) we are most familiar with is that of Nuu Ndeya (Chalcatongo), place of origin of Aurora Pérez; over the years we have paid shorter and longer visits to various other communities in the Mixteca Alta (such as Apoala and Tilantongo), as well as in the Mixteca Baja and Mixteca de la Costa areas. A very instructive and stimulating experience has been the realization of workshops about reading the codices with native speakers of the Mixtec language from different parts of the region.

Trying to read several scenes in Sahin Sau (Chalcatongo Mixtec), Aurora Pérez was the first to note the presence of specific cultural vocabulary and idiomatic expressions. A key moment was her decipherment of the scene in which two men interrupt the marriage pro-

${ }^{4}$ At the time most archeologists and art historians showed hardly any interest in the issue of cultural continuity in Mesoamerica, while otherwise important anthropological studies of the Nuu Dzaui (Ravicz 1961, Romney \& Romney 1966, Butterworth 1975, Flanet 1977) were equally unable to establish a link between present-day culture and the ancient documents or monuments. Only a few valuable examples of modern Dzaha Dzaui oral literature had been published by Schultze Jena (1933-38: vol. III) and Dyk (1959). 


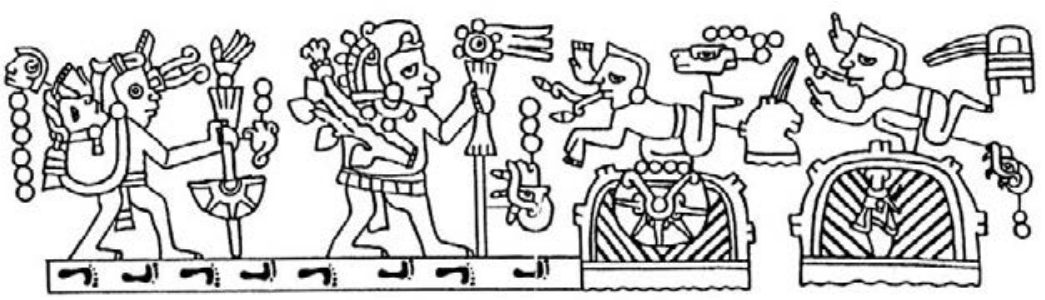

4.8. Codex Añute, p. 7-III : Two priests ('Long Hairs') of Tocuisi (Zaachila) shout 'knife, knife' (yuchi yuchi) to Lady 6 Monkey, who is carried by two officials in the marriage procession .

cession of Lady 6 Monkey (Codex Añute, p. 7-III). The speech scrolls coming from their mouths are topped with flint knives, a configuration read by Spinden (1935) as 'cutting words' because of the context, which suggests that the speakers were offending the princess. Aurora Pérez proposed to read them as the actual words with which they addressed her: yuchi yuchi, 'knife, knife', being a Mixtec expression meaning 'you will be killed by a knife'. In this context these words were indeed understood as an offense, or rather as a curse or a threat, by Lady 6 Monkey, who rapidly took her revenge, retaliated against the two men and had them sacrificed. The rest of the story, however, shows that she would indeed be killed by a knife, so that a second meaning of the phrase yuchi yuchi becomes evident: in retrospect the two men were warning her and she disregarded their foresight - a case of tragic irony. This and similar readings led us to consider the dramatic structure and performative aspect of the pictorial narratives (Jansen \& Pérez Jiménez 1986).

From here we became more and more interested in trying to read the pictorial manuscripts in the Mixtec language and in terms of the living oral literature, cultural landscapes and worldview of Ñuu Dzaui. This contextualization made us aware of the multiple references to ethnic identity in the codices and of the wider problem area of cultural property and development.

Living in Oaxaca between 1975 and 1980, we had the opportunity to discuss the actual predicament of indigenous peoples with the anthropologists Miguel Bartolomé and Alicia Barabas, members of the 'Group of Barbados', which had made a critical assessment of the ethnocide and oppression of indigenous peoples throughout the continent. We expressed our preoccupation with the double mentality that 
dominated Mexican society as well as the field of archeological, cultural and historical studies, i.e. to admire the treasures of the past as national patrimony and at the same time discriminate the present-day indigenous peoples as backward, primitive and inferior (Pérez Jiménez \& Jansen 1979). In those same years we witnessed the birth and growing presence of indigenous emancipatory movements (e.g. the Alianza de Profesionistas Indígenas Bilingües A.C.) and were inspired by the lucid writings and speeches of Nuu Dzaui sociologist Franco Gabriel Hernández (e.g. 1982).

Living most of the time since 1980 in the Netherlands, we had the opportunity to see the international dimension of this struggle and to participate in several sessions of the U.N. Working Group on Indigenous Peoples in Geneva (Pérez Jiménez 1984; Pérez Jiménez \& Jansen 2006). In 1988 we worked together with a number of enthusiastic volunteers in the organization of a week-long symposium in the framework of the XLVI International Congress of Americanists (Amsterdam), entitled 'La Visión India: tierra, cultura, lengua y derechos humanos'. The idea was to break with the tradition of those congresses to talk about indigenous peoples without any representative of these people being present. With the help of several Dutch non-governmental organizations it was possible to invite over twenty indigenous participants, experts in different aspects of socio-political and cultural reality - among them was also maestro Luis Reyes García, who formulated important principles for historical research (see Musiro 1989). The symposium led furthermore to a continued and inspiring collaboration with Antonella Cammarota at the University of Messina, Italy, and a solidarity group of sociologists, artists, teachers and philosophers in Sicily and southern Italy. Meetings were held on several occasions, which provided local information about the social reality of indigenous peoples in Mexico (Pérez Jiménez 1990, 1991, 1999), while the local NGO Centro Regionale d' Intervento per la Cooperazione (CRIC) supported school projects in Mexico.

This experience and the resulting combination of perspectives, which has remained a crucial source of inspiration, moved us first of all to rethink the emphasis on cultural continuity in the 'school' of Nowotny and Anders. The focus on the living community and its traditions is not simply a plea to involve 'indigenous informants' in an otherwise completely non-indigenous research design. It obliges us to rethink the 'scientific imperative' according to which cultures and peoples are objectified and dehumanized. It means that we have to 
approach and design this historical research together as a multicultural team, working from an intercultural perspective, for which the concepts and concerns of the inheritors of the culture in question are the first determinant.

These considerations were our point of departure when together with Ferdinand Anders we conceived the project of the series 'Códices Mexicanos', to be edited in the framework of the fifth centennial commemoration of 1492. Actually everything started with a critical remark by Aurora about publications of codices and interpretations of their contents not being accessible to the inheritors of the culture that produced these works. The idea arose to do something about this and at the same time to counteract the euphoric statements about the significance of Columbus's voyage. The Mesoamerican culture that suffered the impact of the colonial invasion, and its literary heritage, still little known in Mexico, were to be put in the foreground. Thus a facsimile edition of a group of the most important and aesthetically impressive pictorial manuscripts in Mexico was planned. Ferdinand Anders succeeded in convincing the Mexican publishing company Fondo the Cultura Económica (FCE) and the Austrian Akademische Druck- und Verlagsanstalt (ADEVA) to engage in a cooperative effort, which was a truly ambitious and major undertaking.

The codices in question had been published earlier by ADEVA in Graz. The fact that the photowork and further preparatory work had been done, made a relatively quick production process possible, but the new printing implied the need for a renewed quality control. As most accompanying introductions of the Graz editions had concentrated on the codicological aspects, and less on explanations, we had to bring out completely new commentaries in Spanish, which would present the actual state of knowledge (including the results of our own research) in such a way that these codices would be opened up to a relatively large public. At first this seemed a mountain too high to climb.

From his position in Vienna, Ferdinand Anders supervised the quality of the new facsimile editions (produced in Graz) and dedicated himself fully to the form and layout of the explanatory books (including tables, illustrations etc.), while Luis Reyes García (working at the Centro de Investigaciones y Estudios Superiores en Antropología Social, Mexico City) coordinated the work related to the editorial process in Mexico, assisting in the technical corrections (e.g. concerning the Nahuatl terms and sources), but first and foremost contributed 
with an overall guiding vision on the contents of the codices and the way in which we should comment on them. Working at Leiden University, we focused on the interpretive part of the project, systematically discussing the codex scenes together. Aurora Pérez's readings of passages in the Mixtec codices set the tone for the commentary style. Maarten Jansen wrote most of the explanatory texts, and incorporated and edited the contributions from other collaborators.

Less than five years $(1988-1992)$ were available for writing the new commentaries. Fortunately we had done a lot of research on precisely these codices since 1975. The discussion about the relations between historical and religious information in pictorial manuscripts such as Codex Yuta Tnoho had led us to make an in-depth study of the Books of Wisdom ('Borgia Group'), the first results of which were presented at a Summer Seminar at Dumbarton Oaks (1982) and in an exposition in the municipal museum of Linz, Austria (Anders \& Jansen 1986). The latter formed the base for overview and introduction to the highlights of the corpus of codices: Schrift und Buch im alten Mexiko (Anders \& Jansen 1988), published as an interpretive companion to the Graz series.

A period of concentrated additional research, writing under pressure, and intensive communications between Leiden, Vienna, and Mexico, during which Luis Reyes spent a sabbatical at Leiden University (1990) and the four of us explored libraries and archives in Rome together, resulted in a set of thirteen books with facsimile editions, published between 1991 and 1997. These included several important Mixtec pictorial manuscripts, as well as the religious codices of the Teoamoxtli (Borgia) group and some major early colonial codices dealing with Mexica history and religion.

The idealism and enthusiasm of all the people involved in the project together with support from the Sociedad del Quinto Centenario (Spain) made it possible to bring these books out at a considerably lower cost than the earlier Austrian editions. The technical and artistic (design) cooperation of the Fondo de Cultura Económica's staff was great, especially that of Guillermo Hagg, whose dedicated style correction brought our texts to an acceptable level of Spanish (a language of which none of us happens to be a native speaker). Working as such a close team had the advantage of creating a consistent form of interpretation for these different examples of ancient Mesoamerican literature, art and philosophy, and enabled us to produce concrete results at a rapid speed. Inevitably it also brought us criticism, obstruc- 
tion and negative propaganda from some colleagues, who, once the project was under way, felt offended that they had not been invited as its directors. Unfortunately this has limited somewhat the distribution and use of the editions. Nowadays most the commentaries are out of print but accessible through the internet (www.openaccess.leidenuniv .nl).

Given the intention to let the literary heritage speak for itself, as a protagonistic subject, our main concern in commenting on specific codices was to present a reading of the pictographic text, with the necessary explanatory notes, introduction, and bibliographical references. The formulation was not only based on iconological analysis, but also on the study of oral literature and of texts written in Mesoamerican languages during the colonial period. Aurora had already started in the 1980 's by reading pictorial scenes directly in Dzaha Dzaui. We were able to broaden this experience in two prolonged workshops in Oaxaca, aimed at the reading of Nuu Dzaui codices in the native language with the guidance of Luis Reyes García and with the participation of a group of Nuu Dzaui teachers (Centro de Investigaciones y Estudios Superiores en Antropología Social, 198990). As a participant in those workshops, Ubaldo López García made important contributions, indicating the correspondence between the style of pictorial narrative and the traditional formal discourse $(s a h u)$, a topic he later explored for his Ph.D. thesis (2007). Similarly, Alejandra Cruz Ortiz was able to turn the reading of some scenes into true poetry. ${ }^{5}$

For the commentaries on the Codex Yuta Tnoho and Codex Tonindeye, Aurora Pérez (1992ab) elaborated readings in Sahin Sau. The process of switching between the images and the original language in which they had been conceived proved to be very inspiring and illuminating. Of course, the technique of reading the pictorial images in terms of the living language and culture is primarily to be seen and used as a heuristic method. This approach is by no means easy, and calls for a careful and critical analysis. In the end, however, it may bring us closer to the original messages, and it may make those messages more relevant for our time.

\footnotetext{
${ }^{5}$ López García published several results of these workshops (1991, 1993; see also his contribution to the popular booklet of Hermann Lejarazu \& Libura 2007). His research in his own community Apoala $(1997,2001)$ resulted in an impressive Ph.D. dissertation (2007). Similarly Cruz Ortiz brought out a valuable collection of oral literature from the Mixteca de la Costa $(1998,2009)$.
} 
In addition we worked on a collection of smaller Nuu Dzaui pictorial manuscripts, such as the Tira of Yodzo Yaha, Codex Nuu Naha and Codex Ñuu Naña, combining the historical analysis with a translation and publication of an anthology of colonial documents written in Dzaha Dzaui with the Spanish alphabet (Jansen 1994). Later followed our commentaries on Codex Nuu Tnoo-Ndisi Nuu (2005) and Codex Añute (2000, 2007b), and a detailed study of early Mixtec history, in particular the life of Lord 8 Deer, as portrayed by Codex Iya Nacuaa and other codices (2007a).

We have been privileged to be able to carry out our investigations in the lively international environment of Leiden University, and in good continuous collaboration with the regional centers of the Instituto Nacional de Antropología e Historia (INAH) and of the Centro de Investigaciones y Estudios Superiores en Antropología Social (CIESAS) in Oaxaca. At Leiden University we taught not only regular introductory courses and advanced seminars on Mesoamerican iconography, but also a formal course on the modern Mixtec language, Sahin Sau (see Pérez Jiménez 2008). Needless to say that over the years the input and enthusiasm of students and colleagues has been very stimulating.

In the early 1980s, for example, Lauran Toorians was able to clarify the still obscure parts of the European history of Codex Yuta Tnoho (Vindobonensis), demonstrating that thorough library research can still lead to spectacular discoveries in this area. Peter Van der Loo wrote his Ph.D. dissertation with the programatic title Códices, Costumbres y Continuidad (1987), following up on the groundbreaking insights of Karl Anton Nowotny, and contributing to the interpretation of the religious codices in the framework of contemporary Mesoamerican religion, on the basis of his own fieldwork in the Tlapanec region (State of Guerrero).

The initial thrust of the Códices Mexicanos project led us to continue research on various other pictorial manuscripts and related texts as examples of the historiography of the Mesoamerican polities. We ourselves concentrated on the Nuu Dzaui codices, in connection with historical documents and contemporary culture. From the early 1990s to the present, several Ph.D. candidates and post-doctoral researchers have worked on related topics and similar sources. ${ }^{6}$

\footnotetext{
${ }^{6}$ These include topics such as Beni Zaa lienzos (Michel Oudijk), Cuicatec codices and the lienzos from the Coixtlahuaca area (Bas van Doesburg), Codex Azcatitlan and
} 
At the same time, our daughter Itandehui Jansen Pérez studied cinematography and literary criticism. Her professional comments and cooperation (involving the making of two documentary movies in and around Chalcatongo) opened our eyes to aspects of dramatic composition and other new dimensions of the research. ${ }^{7}$

The inclusion of Mixtec sociologist Gaspar Rivera-Salgado in the Dutch academic world (being awarded the prestigious 'Prince Claus chair in Development and Equity' at Utrecht University in 2005) contributed to a better perception of social issues affecting indigenous peoples, such as that of migration to the U.S.A. (cf. Fox \& Rivera 2004).

Parallel to all this we were also involved in the development of large-scale excavations and other archeological research in the Caribbean (the first campaign being in 1984 on St. Eustatius). Under the direction of former students and present-day colleagues Corinne Hofman and Menno Hoogland this long-term project has become an example of innovative modern archeology, exploring - through a lot of practical fieldwork, advanced analysis of material remains, and theoretical reflection - the formation of early villages as well as the mobility and interaction of the island populations. Serving as Director of Education and then as Dean of the Faculty of Archaeology (2000-

the Sigüenza Map as examples of Mexica historiography (María Castañeda), the Lienzo of Quauhquechollan, dealing with the Quauhquecholteca participation in the conquest of Guatemala (Florine Asselbergs), Mexica conceptualization and use of animals (Miguel Angel Nicolás Caretta), lienzos from Michoacan (Hans Roskamp), decorative motifs on Mixteca-Puebla ceramics as ritual texts (Gilda Hernández Sánchez), community archeology in the Mixteca Alta (Alex Geurds), landscape archeology of La Cañada (Raúl Matadamas Díaz), the early colonial history of Tututepec (Rosanna Woensdregt), the economy of Nuu Dzaui (Laura van Broekhoven), life-cycles in a present-day Nuu Dzaui community (Juan Julián Caballero), ceremonial discourses in Dzaha Dzaui (Ubaldo López García), colonial documents in Ngigua (Michael Swanton), Nahua oral tradition (Anuschka van't Hooft), Maya iconography and epigraphy (Roswitha Manning, Erik Boot), the ancient history and literature of the K'iché in connection with symbolic landscapes (Ruud van Akkeren), the history of the native peoples of Nicaragua (Laura van Broekhoven), colonialism and intercultural education in Oaxaca (Benjamín Maldonado Alvarado), Mixtec oral literature and religious syncretism (Hans-Jörg Witter), the symbolic meaning and social function of the contemporary Mesoamerican calendar among the Mixe and the Ixil (Araceli Rojas Martínez Gracida, Caroline Aretz, Søren Wichmann), and the principles of Mesoamerican civilization underlying the early colonial architecture in Nuu Dzaui (Victor Hugo Ruiz Ortíz). Similarly quite a few unpublished M.A. theses have focused on topics of Mesoamerican archeology, visual art and oral tradition.

7 The movies were included in the volume published by Jansen \& Van Broekhoven (2008). 
2006), Maarten Jansen furthermore became familiar with the wide spectrum of the Faculty's archeological research in Holland itself and in other parts of the world, especially Greece and Jordan. ${ }^{8}$

The immersion in these different projects has provided us with a comparative perspective and enriched our perception of the sovereign Ñuu Dzaui communities and their historiography in multiple ways.

\section{The Realm of Lord 8 Deer}

Today most studies of Nuu Dzaui pictorial manuscripts build on the foundation established by Caso, Smith, Troike and others, but from there take diverging routes. Authors may think differently about the temporal and spatial dimension of the events depicted in the codices. Some tend to avoid the technical problem of chronology altogether, and, hesitant to accept the corrections made by Rabin, prefer to stick to the dates established by Caso. Others have elaborated alternative correlations (e.g. Kelley 1992, Stokes 1997). It would go to far to discuss this technical matter in more detail here. We are satisfied by Rabin's arguments and find that the other correlations are generally inspired by a wish to make a particular interpretation of some special scenes and dates, but without an adequate grasp of the consequences of this for the whole complex sequence.

At the same time different identifications of certain crucial place signs have been proposed, which have implications for the interpretation of the scale of the events and the reconstruction of local perspectives.

Following Rabin's chronology, Bruce Byland and John Pohl published an original and provocative synthesis of Nuu Dzaui history in

8 The reports on Dutch contributions to Mexican studies by Fagel (2005) and Papousek (in Artís 2005: 229-242) are biased and incomplete. The mentioned investigations in Leiden are part of what has been called the 'Dutch school' or 'escuela holandesa' (Oudijk 2008; Batalla Rosado 2008). This term seems unfortunate to us, however, as this line of research started in Vienna, Austria (Ferdinand Anders), and was further developed at Leiden University in cooperation with colleagues from other institutions such as CIESAS in Mexico (Luis Reyes García), the Faculty of Political Sciences of the University in Messina, Italy (Antonella Cammarota), and the Institut für Altamerikanistik of Bonn University, Germany (Nikolai Grube). Consequently this 'school', or rather line of research, is not limited to the Dutch environment, nor are all of its practicioners Dutch. More principally, a specific scholarly perspective should not be identified with a nationality. A general designation as 'ethno-iconological method' (De la Cruz 2008: 20-21; cf. Jansen 1988a) or 'postcolonial hermeneutics' seems more fitting. 
1994. While Byland had trained as an archeologist, and had obtained a lot of field experience in Oaxaca, most codex interpretations in this work come from John Pohl, an expert in iconography, who published his views also in a separate book (Pohl 1994). Inspired by his work for Hollywood film studios, Pohl has put forward interesting insights into the performative aspect of pictography. His comparison of the ancient manuscripts with the story boards used in the making of modern movies may seem an anachronism, but reminds us of the fact that the reading of the paintings may have been accompanied by a theatrical act or ritual drama.

Both authors favor a very local interpretation of Nuu Dzaui history:

Others have made more radical proposals. Robert Chadwick (1971: 502-3) suggested that 8 Deer became the ruler of Teotihuacan, and Richard Adams (1977) (following David Kelley) proposed that 8 Deer's father, the Lord 5 Alligator, was involved in military exploits in the Petén rain forest of Guatemala.

While distant regions may well be portrayed in the codices, as in 8 Deer's residence at the lowland site of Tututepec (Smith 1973: 67-68), the frequency of repetitive marriage patterns and other interactions suggest a more localized form of elite interaction. It is unrealistic to believe that the relatively small communities of the Mixteca Alta had armies capable of marching throughout Mesoamerica conquering places from Teotihuacan to Tikal. It is much more reasonable to suggest that the place signs that appear most frequently are proximate to the known place signs of Tilantongo and Jaltepec. (Byland \& Pohl 1994: 41-42).

As an interdisciplinary team, Byland and Pohl have carried out an important archeological reconnaissance in the municipalities of Nuu Tnoo (Tilantongo) and Añute (Jaltepec), in the southern part of the Valley of Nochixtlan, in the heart of the Mixteca Alta. They confirmed the exact location of the Huahi Andevui, 'Temple of Heaven', near the church in the center of Santiago Tilantongo. Continuing the surveys initiated by Spores (1972), they provided a first inventory of settlements in this area, with an analysis of the ceramic sequence, and encountered impressive cult places still in use. Convinced that the main stories of the Nuu Dzaui codices took place in this nuclear area, they suggested identifications for a number of toponymic hieroglyphs as archeological sites in this relatively small region. Due to the difficulties inherent in the etymological understanding of words and toponyms in Dzaha Dzaui, some proposed place name identifications and some wider ranging hypotheses built on these, remain topics for further study and discussion. 
An example is the identification of a place depicted as a rectangular frieze (town) with a bundle of staffs, bound together with a white and red colored cloth, and therefore called 'Red and White Bundle' or, in iconographic jargon, 'Xipe Bundle'. Byland and Pohl (1994: 66-73, modified in Pohl and Byland 1996) consider this 'Town of the Red and White Bundle' to be the same as a somewhat similar toponymic sign, the 'Stone of the Red and White Bundle', and propose to identify both place signs as a site now known as Huachino in the general Nuu Tnoo area, more precisely in San Miguel, an agencia of Añute. The etymological analysis, as presented in their main book, is not convincing, however. In interpreting the first syllable of Huachino as short for huahi, 'house', they disregard that the latter word is now generally pronounced as vehe. The word chino does not occur in Arana and Swadesh' wordlist, so the authors took it to be identical to a similar word, chindo, translated into Spanish as tuerto. In the dialect as spoken in Nuyoo in the southern Mixteca Alta the /nd/ of Alvarado is indeed realized as $/ \mathrm{n} /$, but this phonetic transformation does not occur in the area of Nuu Tnoo itself. The equation of chino with chindo is therefore unacceptable. The term tuerto, as translation of chindo, refers to a one-eyed person (as is clear from Alvarado's tay nuu chindo, 'tuerto de un ojo'), but in the analysis it was confused with another, quite different meaning: 'twisted' (tuerto as an archaic equivalent of torcido).

The whole term then means 'house of the deformed, twisted, or injured one'. This meaning suggests a connection with the name of the cave located at the southern end of the ridge, called Cavua Cuee or Cave of Sickness. Sickness, injury, and deformity are all closely related conceptually, all referring to an undesirable deviation from normal states of being. (Byland and Pohl 1994: 68).

Byland and Pohl's analysis of the Red and White Bundle itself is very interesting. They suggest that this object may represent a set of bloodletting sticks, used in curing ceremonies, and describe impressive ceremonies still celebrated in the Cavua Cuee today. However important these latter observations are, the proposed etymology of Huachino remains incorrect. Consequently there is no real basis for the identification of the Town of the Red and White Bundle as that site. ${ }^{9}$

${ }^{9}$ Pohl has elaborated his ideas and given them more diffusion during annual workshops in Austin, Texas, and in the accompanying notebooks. Consequently several North-American authors, such as Williams (2009), build further on his work. For 
In another discussion, published one year later, Pohl and Byland did not repeat the etymological argument, but instead focused on a contextual analysis. Their point of departure is the representation of the landscape surrounding Monte Negro in Codex Tonindeye, p.22, which shows Stone of the Red and White Bundle. They then refer to Codex Yuta Tnoho, p. 42, showing the same place. We concur that the Stone of the Red and White Bundle seems to be in the vicinity of Nuu Tnoo and was likely once a subsidiary settlement of that capital. The Town of the Red and White Bundle, however, appears in the codices as a distinct sign. In principle, one might argue, yuu, 'stone' and $\tilde{n} u u$, 'town', are close in pronunciation and may have been used as substitutes on certain occasions, but the distribution of the Red and White Bundle place signs throughout the codices is quite distinctive. Citing a personal communication of Mary Elizabeth Smith to this effect, Pohl and Byland (1996: 9-11) recognize the problem, but point to one particular scene in which the 'stone' sign ( $y u$ / toto) seems to be substituted by a 'mountain' sign $(y u c u)$. This happens when Lord 8 Deer, after having received royal status, carries out rituals in several places in his newly obtained realm, accompanied by his half-brother and several priests. Codex Iya Nacuaa I, p. 19-III, shows Stone of the Red and White Bundle, but Codex Tonindeye, p. 68-III, depicts a mountain with the Red and White Bundle placed inside it. Pohl and Byland then mention some cases in which the Town of Red and White Bundle appears combined with a 'mountain' sign (Codex Tonindeye, p. 83, Codex Ñuu Tnoo-Ndisi Nuu, p. 37-V).

We have severe doubts here. The mountain with the Red and White Bundle in Codex Tonindeye, p. 68-III, contains neither a 'stone' nor a 'town' sign and is consequently more suggestive of a scene in which a ritual with a Red and White Bundle is celebrated on a non-specified mountain. Moreover the combinations of the Town of the Red and White Bundle with a mountain are due to its connection with yet another toponym, the Mountain of White Flowers and Blood. It is the Stone of the Red and White Bundle that is painted in close connection with Nuu Tnoo, but the Town of Red and White Bundle is clearly a

a detailed discussion of the Huachino identification see Jansen \& Kröfges \& Oudijk 1998. Both Pohl, in Latin American Antiquity 10: 3 (1999):317-318, cf. Pohl 2007, and Byland (in: Blomster 2008, and at the 73rd annual meeting of the Society for American Archeology, Austin 2007, shortly before his untimely death) have rejected our critique and alternative interpretations, insisting on the viewpoints they had expressed before. 

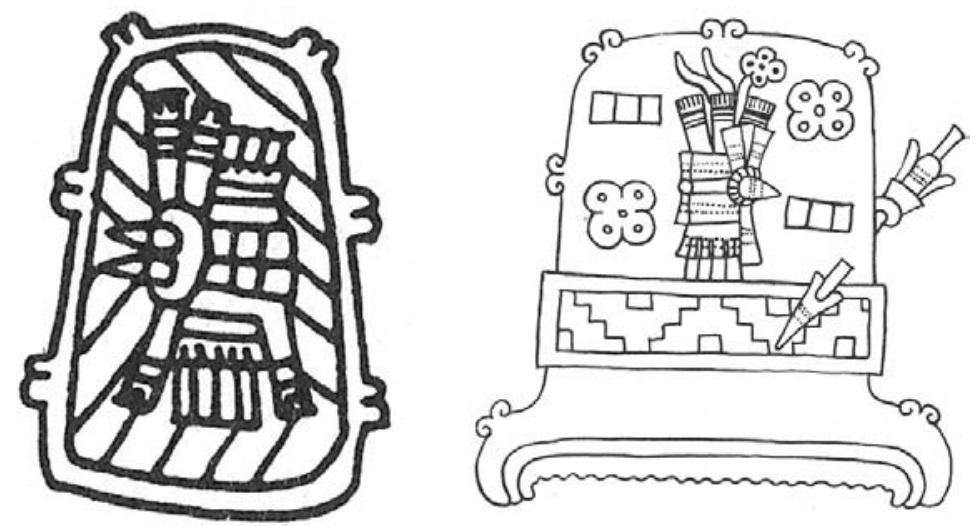

4.9. Stone of Red and White Bundle (left) and Town of Red and White Bundle (right).

different place, which does not appear to have been part of the Nuu Tnoo realm. Instead, it was an autonomous village-state with its own dynasty.

Without further coincidence of toponyms, Byland and Pohl's argument is basically reduced to the proposition 'Red and White Bundle must be an archeological site near Nuu Tnoo and Huachino is such a site'. If we distinguish sharply between the Town of the Red and White Bundle and the Stone of the Red and White Bundle, however, there is no evidence at all for proposing that Town of the Red and White Bundle is in the near vicinity of Nuu Tnoo.

Pohl and Byland (1996: 12 ff.) further argue that Town of the Red and White Bundle appears connected to a Bent Rock with a Cave of the Fire Serpent (Codex Iya Nacuaa II, p. 9-III). It is in this cave that Lord 4 Wind escapes the persecution by Lord 8 Deer (Codex Nuu Tnoo-Ndisi Nuu, p. 33-V). A similar place sign is present in the large landscape painting of Codex Tonindeye p. 19: we are not sure whether the same place is meant here or just another place with the same name. Pohl and Byland identify this Cave of the Fire Serpent (yahui) in both cases as the Cavua Cuee, a sacred cave in the gorge between the archeological site of Mogote del Cacique (Nuu Yuchi, 'Town of Flints', in San José Tres Lagunas, a hamlet or agencia of Nuu Tnoo) and the site now known as Huachino. Consequently they situate all related place signs in the codices nearby in that same area of Nuu Tnoo and Añute. They propose, for example, that the White Mountain of Flints 
(Codex Tonindeye, p. 19) is the combination of the site Nuu Yuchi, 'Town of Flints', and a nearby cliff Toto Cuisi, 'White Rock'. They identify the sweatbath where Lord 8 Deer's half-brother was murdered (Codex Tonindeye, p. 81) as a ruined structure in the vicinity, known today as Temascal. The Plain of the Flowering Maize, mentioned before the scene of this murder (Codex Iya Nacuaa II, p. 5) would then correspond to another ruined structure nearby, overlooking Cavua Cuee and named Yodoñuvio, 'Plain-Place of the Corn Field'. Then there is the Rock of the Jaguar near which Town of Red and White Bundle is located (Codex Yuta Tnoho, p. 41-I): this might be another ruined structure in the same area, called Yuu Naña, 'Stone of the Coyote or Feline'. The Mountain of Blood that also appears in combination with Town of Red and White Bundle would be another site nearby, Chindu niñe, 'Mound of Blood'.

At first sight this seems a quite convincing set of additional arguments, but on closer inspection we note several problems. The correspondence of signs and names is not always complete: in the White Mountain of Flints on p. 19 of Codex Tonindeye the 'town' sign (the frieze that reads $\tilde{n} u u$ ) is conspicuously lacking. Then, the relationship between these places in the codices is not clear at all. The sweatbath of the murder scene is a building where the event happened, not a place sign. The Plain of Flowering Maize depicted just before this scene is actually the last in a list of conquered towns; in other words it belongs to a preceding chapter and is not necessarily located in the vicinity of where the sweatbath stood. Furthermore the place names registered by Pohl and Byland refer mostly to specific spots. There is often no way of telling whether the ruined structures they refer to today were also so called in precolonial times and whether they played any role in the history that is told by the codices.

Thus, trying to construct and identify a whole cluster of place signs is in itself a sound method, but in this concrete case there are quite a number of assumptions and hypotheses involved and the identifications of the other related places are not without problems either. Consequently Pohl and Byland's proposed geographical identification of the total cluster remains speculative. Their work has demonstrated, however, the fascinating possibilities and far-reaching consequences of integrating data from the pictorial manuscripts with those from archeological surveys. 


\section{Different Ways of Reading}

Several general overviews have helped to embed the Nuu Dzaui manuscripts into the whole of Mesoamerican pictorial historiography. Joyce Marcus (1992) has established a thematic order in ancient Mesoamerican pictographic and hieroglyphic texts, which permits comparisons and theoretical analysis. Gordon Brotherston (1995) gave further attention to the question of precolonial and early colonial literary genres. The works of Enrique Florescano $(1999,2002)$ have focused on the general trends in Mesoamerican memory and historiography. A synthetic book by Elizabeth Hill Boone (2000) has compiled and ordered relevant data and ideas for a large audience, within a specific framework, in this case an art-historian's analysis of visual representation.

As the contextualization of the codices within their specific cultural landscape advances, the need to know the native language becomes increasingly obvious. Similarly a first-hand knowledge of present-day native culture and life-world is crucial for understanding the ancient sources. Landscape and worldview, customs and values, as well as specific forms of oral literature may be directly linked to codices. People in Yoso Nuu Viko (San Juan Mixtepec) tell about the birth of people from a tree in a way directly relevant for understanding the image of the Sacred Mother Tree in Codex Yuta Tnoho (Ibach 1980, Furst 1977). By transcribing and analyzing ritual texts in Dzaha Dzaui, anthropologist John Monaghan (1990ab) proved this point once more and made important contributions to the understanding of the reading and performative aspect of the ancient books (see also Hamann 2004). Nowadays many investigators recognize the need to use native terms and concepts as points of departure for their interpretations. A good example is the impressive opus of Kevin Terraciano (2001) on the dynamics of colonial Nuu Dzaui society. Working as a historian in the 'New Philology' tradition of James Lockhart, with a strong interest in colonial documents written in Mesoamerican languages, Terraciano has achieved a new high level of interpretation by the close-reading of historical reports in terms of the Nuu Dzaui culture itself.

In general, however, the knowledge of Dzaha Dzaui among those who set out to interpret its ancient pictorial texts, is still very limited. This unfortunate reality promotes the promulgation of misunder- 
standings and premature hypotheses, which the readers, due to their own unfamiliarity with Ñu Dzaui, its language and culture, in most cases cannot control. Particularly speculative is what we may call the 'anagrammatical method': essentially it pretends to uncover ciphered messages underneath the images. The work of Marc King $(1988,1990)$ is a case in point. Words of daily usage are dissected into syllables and then interpreted as abbreviated or garbled forms (anagrams or metaphoric associations) of quite different terms, supposedly 'hidden' under the surface. Thus King 'decodes' straightforward statements in pictorial texts as occult poetics with esoteric and sexual connotations. The resulting 'insights' are then fed back into anthropological works and projected into the Nuu Dzaui mind:

Candles, incense, pulque, liquor, flowers, and corn are the things Nuyootecos most commonly offer in sacrifice. Many of these items are marked as special substances by the incorporation of the morphological root ii (sacred, miraculous, delicate, fragile) into their names (King 1988: 134-9). Thus corn is itun, candles are itti, flowers are ita. (Monaghan 1995: 216).

This sounds like perfect 'Mesoamerican logic', but a quick look at other languages of the same culture area convinces us that this phonetic association cannot be construed as an explicit marker of a widely shared symbolism, but is a mere coincidence. In Nahuatl, for example, the referred words are centli, tlauilli (or: ocotl) and xochitl respectively. An additional, more technical problem would be that in Dzaha Dzaui the word $i i$ as an adjective would normally follow the noun instead of preceding it.

At first sight the language-based theories and etymologies seem very authoritative and sound fascinating, but in reality they often suffer from a high level of speculation. Outsider investigators, including linguists, may not have sufficient practical knowledge of Dzaha Dzaui. Even knowing the language does not guarantee sound etymologies or interpretations. Native speakers may be handicapped by insufficient training in historical, linguistic, philological, and other critical methods. Both outsider investigators and insider experts may lack an overview of dialect variability and historical development of the language and be unaware of specific literary expressions, metaphors and other relevant data. Similar problems may affect us when we try to reconstruct possible readings of the pictorial scenes. Indeed the ways and methods how to 'read' a codex are still a topic of debate. 
Recent publications by Miguel León-Portilla, prolific author on Mesoamerican literatures and historical sources, take us back to the paradigm developed by Alfonso Caso. Assigning the name 'Códice Alfonso Caso' to his own facsimile edition of Codex Colombino-Becker, LeónPortilla (1996) explicitly wanted to honor that great scholar on the first centenary of his birth year. The accompanying text includes a reproduction of Caso's commentary published thirty years earlier (1966a). In his own introductory note León-Portilla makes summary references to Troike's work, but dismisses her reconstruction of the order of the pages, invoking the authority of the master: nobody but Caso has made such a wide-ranging and profound study of so many codices, consequently he has been more than anybody in a position to establish the organization of the fragments (León-Portilla 1996: 37). Avoiding a critical discussion of Caso's chronology, León-Portilla keeps the dating problem open: tentatively we may say that Mixtec history, apart from a mythical prelude, begins at least as early as the 9th century (op. cit.: 29).

In 2003 León-Portilla published his 'Códices. Los antiguos libros del nuevo mundo', which gives an interesting historical overview of the studies of Mexican pictorial manuscripts with an extensive bibliography, but is somewhat unbalanced when it comes to evaluate the contemporary interpretations of Nuu Dzaui documents. Pointing to the interesting tree-birth story registered by Ibach (1980), León-Portilla suggests that pictography can be read as a text and that Mesoamerican discourse, written down during colonial times or preserved in oral tradition until today, may help to (re)construct such a reading. This insight is not new - exactly the same observation had already been made by Jill Furst (1977) - but it is nevertheless a valid point and important to insist upon for a larger audience.

Strangely enough León-Portilla is sweepingly critical of our own efforts in precisely this direction, and dismisses our readings as "lyrical inventions" of "supposed indigenous inspiration", which "do not elucidate the meaning of the scenes and are not based on any testimony". Unfortunately he pronounces this judgment ex cathedra, without more support than a set of rhetorical questions about our reading of one specific scene in Codex Yoalli Ehecatl (Borgia), p. 21. He asks, for example: "Why do the authors say that the Red Tezcatlipoca is the "numen of metal'?" Well, our libro explicativo quotes the early colonial treatise of Hernán Ruiz de Alarcón, which gives 'Red Tezcatlipoca' as the esoteric name of the copper axe. In this way León- 
Portilla's critical queries can easily be answered. ${ }^{10}$ To each serious reader of the Códices Mexicanos volumes it is evident that his negative qualifications do not do justice to the fact that the commentaries include extensive bibliography, notes and introductory chapters, which discuss sources and methods, present arguments and provide tools for constructing and controlling the proposed interpretations. In this way, well founded on the sources and present state of scholarship, our readings are to be considered as heuristic tools; at the same time they aim at reproducing the contents in their original genre and in an adequate form for interested contemporary readers, including the descendant communities.

Just like León-Portilla, María de los Ángeles Ojeda Díaz (2002) qualifies Caso's research as 'unsurpassable' and consequently feels free to ignore the existing scholarly literature on Nuu Dzaui pictography. ${ }^{11}$ In a similar vein, she begins her study of Codex Iya Nacuaa (Colombino) with dismissing our work right away as "based on a Western point of view, alien to the Mesoamerican culture". This is a curious comment to make for someone who is herself an outsider to the Mixtec world. Due to her lack of understanding of Dzaha Dzaui, Ojeda Díaz does not pay any attention to Perez Jiménez's effort to read codex scenes directly in Sahin Sau (contemporary Mixtec) nor to the fact that our interpretations are based on such exercises and on the interaction with many people in the Nuu Dzaui region.

The originality of her own interpretation, Ojeda Díaz claims, is her use of concepts from the history of religions (taken from somewhat older authors such as Van der Leeuw and Eliade) and her emphasis on

${ }^{10}$ León-Portilla had made exactly the same charge several years before (1997ab), which led Jansen to publish a detailed rebuttal ('Los fundamentos para una 'lectura lírica' de los codices') in Estudios de Cultura Nahuatl vol. 30 (1999), also included as an appendix in our commentary on Codex Añute (Jansen \& Pérez Jiménez 2000). In this new book León-Portilla reprints his earlier criticisms without further comment.

${ }^{11}$ Unfortunately Ojeda Díaz does not stand alone in this practice, which is unworthy of Caso's own high standards of scholarship. In the same series, published by the Universidad Tecnológica de la Mixteca (otherwise an excellent institution), for example, we find the articles by Méndez Martínez and Méndez Torres (2007b, 2008), affiliated with the Dirección de Arqueología of the Instituto Nacional de Antropología e Historia and with the Instituto de Investigaciones Antropológicas of the Universidad Nacional Autónoma de México respectively: these articles on Codex Selden, praised by the editors of the volumes, bluntly ignore or dismiss the contributions by 'some foreigners' and merely reproduce the comments published by Caso more than forty years earlier (1964), including his now obsolete chronology. 
the religious character of events and protagonists. Inspired by the important works of Alfredo López Austin $(1973,1980,1994)$ on Mesoamerican religion, she situates Lord 8 Deer as a Hombre-Dios ('ManGod') in an idealized worldview. Traveling through La Mixteca and working with several speakers of the language, Ojeda Díaz developed a valuable notion of sacred geography, but her text does not go into concrete native religious concepts and practices. Highly relevant Mixtec terms, such as iya and $\tilde{n} u h u$, do not play any role in her analysis. Several crucial problems, such as the chronology, are not identified, much less discussed.

Ojeda Díaz reconstructs Lord 8 Deer's Mixtec name as Una Yakuaa, from the words una, 'eight' (in the non-calendrical vocabulary), $y a$, 'lord' (Alvarado: iya), and kuaa, 'deer' (in the calendrical vocabulary). This disregards what we know about the conventions used in calendar names thanks to the studies by Jiménez Moreno, Caso and Smith. The title iya comes first, not in the middle of the name. The numeric indicator should be in the special calendrical vocabulary ( $n a$ instead of una), while one might deem it preferable to maintain the ancient spelling cuaa instead of using a modernized kuaa. The correct reading is therefore Iya Nacuaa instead of Una Yakuaa. Fortunately in a later publication (2005) Ojeda Díaz corrected her mistake and used for this ruler and for the other personages of Mixtec history, a correct transcription of the calendar names according to the reconstruction proposed by Mary Elizabeth Smith (1973a). ${ }^{12}$

In order to create a solid foundation for interpretations and to avoid subjective and intuitive speculations in iconological research, Joaquín Galarza has advocated a rigorous and very detailed descriptive analysis of the pictorial scenes. His teachings and publications (e.g. 1979, 1990, 1992), focusing on early-colonial pictorial manuscripts from the Nahuatl-speaking area, have been very influential, especially in Mexico itself. Treating pictographic scenes as written texts, his

${ }^{12}$ In a recent article Alvarado Bárcenas and Ojeda Díaz present unwarranted Mixtec translations of the names of Goddesses in the Teoamoxtli (Borgia) Group. For example, they translate Xochiquetzal as $\tilde{N} u$ Ita Tnumii, which, supposedly, they derive from the words for 'flower' (ita) and 'small feather' (tnumi, which is clearly distinct from the quetzal feather: yodzo) in combination with the general indicator of divine nature: the prefix $\tilde{n} u$ - from $\tilde{n} u h u$, 'deity'. The reconstructed name N $u$ Ita Tnumii does not appear in the sources. Their treatment of the Goddesses themselves is rather superficial; the profound work of Mikulska Dąbrowska (2008) provides a telling contrast. 
method ultimately aims at converting pictorial conventions directly into words, without intervening theories about meaning. The painted scene is deconstructed into its basic elements, which are organized in detailed card indexes and labeled with Nahuatl terms.

In his own work, Galarza, well acquainted with the context of the particular manuscripts he was analyzing, achieved notable progress, bringing us closer to the way in which the ancient painters constructed their pictorial texts. His method has had a notable appeal for quite a few students, who have continued his work by producing extremely useful inventories, making whole collections of codices accessible in a multiple, modern and systematical manner. ${ }^{13}$ An innate danger, however, is the tendency of some to apply this method as an automatism, just expressing in words what the eye sees. Such an easy and superficial procedure may result in the production of extensive catalogs of many pages about all elements in rather small (parts of) manuscripts, without really going into the question of meaning nor into that of social or historical context, and, consequently, without advancing toward a coherent overall picture of the themes and messages of these documents. Few theorists today would consider a 'pure reading without interpreting' methodologically possible, as it is generally understood that every beholder looks from a specific point of view, following or rejecting all kinds of established concepts, methods and pre-understandings. Moreover one might question the use of making card indexes of such details as eyes and toes of personages if there is not even the intention of employing them to solve interpretive problems.

To exemplify these and other problems that may occur in such unsound applications of a principally sound method we will briefly discuss the explicit 'Galarzian' reading of the Lienzo de Yucu Satuta (Zacatepec), presented by Fernández Gatica and Figueroa Silvestre (2002). The authors introduce their work as a contribution to the Movimiento Cultural Mexicayotl, committed to promoting the view of ancient Anahuac as an ideal 'socialist' federation of independent states. After a summary description and some photographs of the village of Yucu Satuta (Zacatepec), their short monograph continues with explaining and applying the principles of the método galarciano.

13 For a modern presentation of the method, its applicability and results, see Number 22 of the journal Desacatos (CIESAS, Mexico), in particular the introductory synthetic article by Mohar Betancourt and Fernández Diaz (2006). Compare, however, the criticisms voiced by Oudijk (2008), Batalla Rosado (2008), and MikulskaDąbrowska (2008: 25-26). 
Although this brings us a close-up view of the lienzo, the actual 'reading' suffers from several shortcomings. The authors use Nahuatl as the only language of reference, because nobody in their team knew Dzaha Dzaui (op. cit.: 43), and because of their ideological preference for "One single continent: the Aztec continent. One single race: the Aztec race. One single culture: the Aztec culture. One single idiom: the Aztec idiom" (op. cit.: 2). At times their Nahuatl is deficient, but, more importantly, the use of that language in this context has an alienating effect. The main protagonist of the lienzo, for example, is transcribed as Tlahtoani Matlactli ihuan ce Ocelotl Tlaloc-Tenamitl, 'gobernante 11 Tigre, Lluvia Amurrallada'. The number 11 in Nahuatl is actually matlactli once, and his given name makes more sense if we read the signs as 'Flame of Nuu Dzaui'.

Although Fernández Gatica and Figueroa Silvestre have been on the spot and mention interesting documents that contain names of the linderos (boundaries) of the municipality, they show little or no attempt to relate the pictorial signs to geographic reality and existing toponyms. All signs are 'translated' into Nahuatl, but the resulting names of places and individuals are nowhere documented. Moreover, the monograph does not contain any bibliography and does not use the relevant study of this same lienzo by Mary Elizabeth Smith (1973a). ${ }^{14}$ This disregard of the native language and of most of the scholarly literature produces quite a few unsatisfactory results. Thus the main building in the upper left-hand corner is called a huey tlahtocan, 'national palace', with the designation Ollinxayacac, 'Face and Movement', an astronomical observatory, while its ruler is referred to as Tlahtoani Nahui Ehecatl without further comment. In reality this is the well-known Lord 4 Wind, who succeeded Lord 8 Deer and is represented here as seated in front of the temple of Ndisi Nuu (Tlaxiaco). The given name of another, female protagonist in the lienzo consists of a $\tilde{n} u h u$ (deity figure) rising from pieces of jade. In Dzaha Dzaui the name can be reconstructed as Dzeque Nicana Nuhu, 'Jewel of the Rising Deity (East or Dawn)', part of which is still legible in the gloss. Within the limited Nahuatl frame of reference Fernández

${ }^{14}$ The study of the Lienzo of Yucu Sa Tuta by Ojeda Díaz (2005), in contrast, reproduces the earlier interpretations by Caso and Smith, but creates confusion where she introduces her own identifications of some place signs: Mountain of the Moon and Place of Death, identified by Ojeda Díaz as Acatlan and Mitlatongo, situated relatively far away, are most probably the neighboring towns Nuu Yoo and Nuu Ndaya (Chalcatongo). 
Gatica and Figueroa Silvestre read this sign as Tlacatl Nitla, "hombre en sancos", i.e. 'Man on Stilts'.

Although appreciative of the efforts made by these authors, we emphasize the need to refer explicitly to the contributions of earlier investigators, and, above all, to interpret the pictorial manuscripts within their appropriate context, landscape and language.

On the other hand, knowledge of the Mixtec language is in itself no guarantee for sound analysis. As we have seen above, a good understanding of Mixtec toponyms is crucial for the understanding of place signs in the codices. After an enormous initial thrust in the documentation and etimological analysis of these toponyms by Martínez Gracida and his co-worker Mariano López Ruiz (see Martínez Gracida's monumental publication of 1883, and his Obra Inédita), progress has been lacking. Raúl Alavez Chávez, a Mixtec researcher from Santa María Peñoles working with the Centro de Investigaciones y Estudios Superiores en Antropología Social (CIESAS) in Oaxaca, has produced two books on this topic $(1988,2006)$. These contain valuable data and local explanations, but are often lacking in depth and consistency, as popular etymologies and legends are mixed with interpretations in different dialect variants of Mixtec, without critical philological analysis, without knowledge of ancient Mixtec, without grasp of pictorial representations, and without regard to the logic of place names as such. For example, in the first book, Alavez Chávez proposed to translate Ndijin Nuu, the local Mixtec name of the town Tlaxiaco, as 'Tapando Bajando' (Covering, Descending), which clearly does not make sense as a place name. The name is locally understood as 'Buena Vista' (a place of good sight and visibility), which coincides with its hieroglyphic representation in the codices. In his second book, Alavez Chávez corrected his earlier mistake, but still includes several unconvincing etimologies, such as 'Se fue la mama' ('Mother went away') for Cuanana, or 'Hombre Colorado' ('Red Man') for Ticuá.

An exemplary detailed analysis of Codex Ñu Naha (Muro), based on toponymical research in its community of origin, San Pedro Cántaros, and on the study of important archival sources, was presented by Manuel Hermann Lejarazu, first as a thesis for the Escuela Nacional de Antropología e Historia in 1998, then updated and published with a good photographic reproduction of the manuscript (2003). After finishing his studies in Mexico, and an additonal year of advanced 
study at Leiden University, Hermann Lejarazu moved from here to the precolonial codices. He published new British Museum photographs of the two sides of Codex Tonindeye with accessible and didactically prepared commentaries in a widely distributed and economic form, as special editions of the popular journal Arqueología Mexicana (2006, 2008c). ${ }^{15}$ His text mainly follows and rephrases the results of the earlier investigations by Caso, Troike, Byland \& Pohl, and our own progressive understanding of this codex and Lord 8 Deer's biography, but also includes various discussions of problems and original interpretive suggestions. Going further along this path, Hermann Lejarazu also wrote articles on other ancient Mixtec topics such as the symbols of power, the Sacred Bundles, and the personal names of the ancient rulers. ${ }^{16}$

\section{Philological-Iconographical Analysis and Archeological Field-Research}

Nancy Troike has continued her efforts to bring experts and students interested in Mixtec codices, archeology, history, linguistics and anthropology together, as well as Mixtecs themselves (e.g. those living in the United States and working in translation services or other institutions dealing with the problems that the indigenous migrants face there). During the 1990s and the beginning of the 21st century she organised the annual Mixtec Gateway in a casino hotel in Las Vegas. Although this may seem a peculiar place to discuss and study the heritage of a marginalized and exploited people, the meetings provided many useful and inspiring contacts. Parallel to this, John Pohl organized an active and inspired study group on Mixtec codices in the context of the annual Maya Hieroglyphic Workshop in Austin. In the new millennium, Mexican archeologist Nelly Robles (I.N.A.H.) organized in Oaxaca the bi-annual 'Mesa Redonda de Monte Albán' conferences, interdisciplinary in character, dealing with the diverse aspects of Oaxacan cultural patrimony. These meetings, together with other symposia in Mexico, the United States and Europe, stimulated communication between the specialists, but also served to attract and form a new generation.

${ }^{15}$ Báez Pérez' interesting brief analysis of Lord 8 Deer's biography in terms of agency and structure (2008) is largely based on Hermann Lejarazu's publication in Arqueología Mexicana (2006).

${ }^{16}$ Hermann Lejarazu 2007b, 2008b, and his contribution in the volume edited by Van Doesburg 2008 (cf. Jansen 1989, 1997a). 
A new way of presenting the pictorial manuscripts and of expressing fascination with their contents and artistic aspects has been the Internet and CD-ROM projects. Many websites deal with themes such as these; some are very useful (e.g. the bibliography and reproduction of the sources and related studies by FAMSI, or the programs for using the Mesoamerican calendar), others are very speculative and even misleading. A beautiful and didactic analysis of Ñu Dzaui codices (with a full commentary on Codex Añu) is the CD-ROM 'Mesolore' coordinated by Liza Bakewell and Byron Hamann (Brown University, Providence 2000), which contextualizes the iconographical study of this corpus within the whole of Mesoamerican archeology and cultural history. It includes a new commentary on Codex Añute (Selden) and parts of Codex Tonindeye (Nuttall), as well as a reproduction of Alvarado's vocabulary, together with interviews with different experts, producing a series of important comments on Native American cultural heritage.

Following up on the work by Caso, Spores, Winter, and others, archeological research in the Mixtec region has intensified. The detailed investigations of the Valley of Oaxaca and the site of Monte Albán from the 1970s onward by Kent Flannery and Joyce Marcus (1983), Richard Blanton (1999) and others were important impulses to both practice and theory. Similarly, Caso's groundbreaking publication of Monte Albán's Tomb 7 (1969) has inspired in-depth studies of the Mixteca-Puebla art-style and of other aspects of precolonial art and iconography.

A special chapter is the significant progress in the study of Classic Nuu Dzaui iconography and writing, the Ñuine style, which precedes the pictographic manuscripts and is related to the epigraphy of Monte Albán (cf. Urcid Serrano 2001). Laura Rodríguez Cano produced a valuable index of all the carved stones in her thesis for the Escuela Nacional de Antropología e Historia (1996). Several studies are revealing more and more about the contents, style and iconography of these carved stones and figurative urns. ${ }^{17}$ Important wall paintings in this

17 E.g. Rodríguez Cano \& Rivera Guzmán \& Martínez Ramírez 1996-99; Rivera Guzmán 2000, 2002, 2004; Urcid Serrano 2004; Jansen 2004. Rivera Guzmán offers an overview of Classic Ñuu Dzaui inscriptions at a congress on Mixtec Writing and Society in Amsterdam, 2005 (edited by Jansen and Van Broekhoven 2008). 
style have been discovered in Tomb I of Jaltepetongo by Raúl Matadamas. ${ }^{18}$

Surveys of the Mixteca Alta region and a series of related archeological case studies (synthesized by Kowalewski et al. 2009) continue to clarify the precolonial settlement patterns, households, state formation process, and socio-economic situation in the Mixtec region. ${ }^{19}$ This is an important precondition for new developments and original approaches in the interpretation of ancient Nuu Dzaui culture.

Several recent archeological projects have made explicit connections to the world of the Postclassic pictorial manuscripts, for example the mapping and archeological landscape studies of Tilantongo and Apoala by a Leiden team (Van Broekhoven 2006; Geurds 2007), as well as the excavations at Tututepec and Yucu Ndaa (Tepozcolula), directed by Arthur Joyce and Ronald Spores \& Nelly Robles respectively. ${ }^{20}$

In this development interdisciplinarity and good intercultural communication are the ideal, but not always easy to achieve. The arguments become complex and the presence of speculative elements in one or more of the disciplines involved may make the overall result less convincing. The article by Pohl, Monaghan and Stiver (1997) combines archeological, iconographical, anthropological, and linguistic data as support for the original proposition that the boundary areas of the Nuu Dzaui city-states contained locales of economic exchange,

18 Matadamas 1997, 2001, 2005. Javier Urcid Serrano has analyzed these wall paintings in terms of Mesoamerican rituals and cosmogony (in: Jansen \& Van Broekhoven 2008). The work of de la Fuente and Fahmel Beyer (2005) offers a valuable overview of murals in Oaxacan tombs and palaces, while the paintings of the recently discovered tomb in Ixcaquixtla, Puebla, form a fascinating additional case (Rivera Guzmán 2008).

${ }_{19}$ See also Balkansky et al. 2000, Stiver 2001, King 2002, Pérez Rodríguez 2006, and Heredia Espinoza 2007, as well as A. Joyce (2010).

${ }^{20}$ See for example their reports in Jansen \& Van Broekhoven 2008. Arthur Joyce and his associates have made a consistent attempt to connect codices and archeology by focusing on Lord 8 Deer's rule in Yucu Dzaa; similarly, Raúl Matadamas has focused on both aspects in his interpretation of the village-state of Tutepetongo in the Cuicatec Cañada - see, for example, their contributions to the volume edited by Robles García (2004), as well as the synthesis published by A. Joyce (2010). In 2008 the journals Arqueología Mexicana (number 90) and Desacatos (number 27) each dedicated a whole issue to recent developments in Mixtec archeology and ancient history, while a bundle edited by Blomster brought together several archeological and historical perspectives on Postclassic Oaxaca as a whole, in particular concerning the transition from the Classic to the Postclassic. 
'border markets', which the authors connected to their specific reconstruction and interpretation of the ancient Nuu Dzaui political landscape.

The reason this trade would have occurred on the borders and not in the centers of adjacent polities as has so often be assumed, is also a function of the factionalized political environment of the Mixteca. Among many peoples in West Africa, where a similar situation prevailed, markets were held in open spaces away from settled areas." (op. cit.: 226).

And in an environment of intrinsic mistrust, border markets provided a solution to the problem of trading with potential enemies. In a border market, trade could occur without outsiders having to set foot on one's lands, where they might gather strategic intelligence. At the same time one could make exchanges without the risk of having to travel through hostile territories....

A program of survey and excavation would allow us not only to determine the precise location of these sites, and the way they correlate with political and ecological boundaries, but also to come to some conclusion about the times and periods of their use, and the kinds of material items transacted in them. (op. cit.: 227).

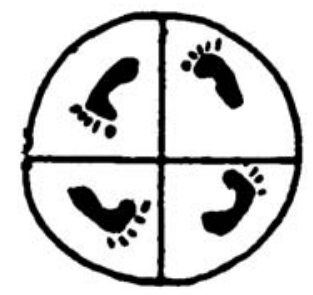

4.10. The market sign.

The concrete evidence that the authors present for this hypothesis is the fact that the sign for 'market' appears among the boundary markers of specific Mixtec polities in some early colonial pictorial documents. The sign in question consists of a circle containing footsteps. Actually it occurs as part of a boundary marker on Map No. 36, where it is glossed in Dzaha Dzaui as yahui, 'market', and on the Lienzo of Ocotepec, where is glossed in Nahuatl as tianquizco, 'market place'. ${ }^{21}$ In the first case it is combined with the head of a wolf, producing a

${ }^{21}$ Smith 1973a: 46, 199, 230, and 336-337. 
reading of the total toponymical sign as yahui yehe, 'market of wolves'. This suggests to us that a human market is not meant, but a place where there are many wolves, as if it were a 'wolves' market'. The second occurrence situates the market sign in a stony enclosure or rocky valley. This toponym may indeed indicate a place where a market was held, but might also simply signal a place which looks like a market.

It should be mentioned that the sign of the circle containing footsteps also occurs in Codex Yuta Tnoho (p. 24) in combination with the place sign of Yuta Tnoho (Apoala) in a ritual context that suggests a meaning other than just a market.

Pohl, Monaghan and Stiver recognize that the word yahui may also be translated in other ways, such as 'expensive', 'cost', 'investment', 'economic transaction', 'prize', 'gift', or 'property' (hacienda), but they do not consider the obvious conclusion: the occurrence of this word in a toponym does not necessarily indicate that market activity took place at the spot, but might just as well signal an expensive or valued property, perhaps obtained in a market or as a prize.

Pohl, Monaghan and Stiver mention furthermore the occurrence of the word yahui as a boundary marker in later colonial alphabetic texts, sometimes explicitly translated as 'market'. Here we are somewhat sceptical, because interferences with other words and meanings may have occurred. The vocabulary of Alvarado (1593) makes a distinction between hui (= 'vi, containing a glottal stop) and vui (= vi, without glottal stop), but other colonial alphabetic writings of Dzaha Dzaui are not that precise, for example Nuu Dzavui (Alvarado's term for the Mixtec region and people) is often written as Nudzahui. In colonial documents, therefore, a confusion may occur of yahui, 'market' (in modern Sahin Sau: yahu) with yavui, which, depending on the tone, means 'cave' or 'maguey' (yau in Sahin Sau), terms that, needless to say, are much more logical components of toponyms.

Yahui (with glottal stop) is also an ancient term for the ball of lightning that flies through the air and is considered a powerful nahual, but references to such a phenomenon would have sounded to Spanish ears as related to the practice of witchcraft, so that a translation as 'market' may have been a better option. The article we are reviewing here also mentions this alternative meaning, but presents it as a symbolic reinforcement, referring to an earlier theory of Pohl:

John Pohl has identified yahui priests as economic administrators and merchant princes charged with performing sacrificial rituals dedicated to the dead ancestors during religious festivals (Pohl, 1994: 42-68). Con- 


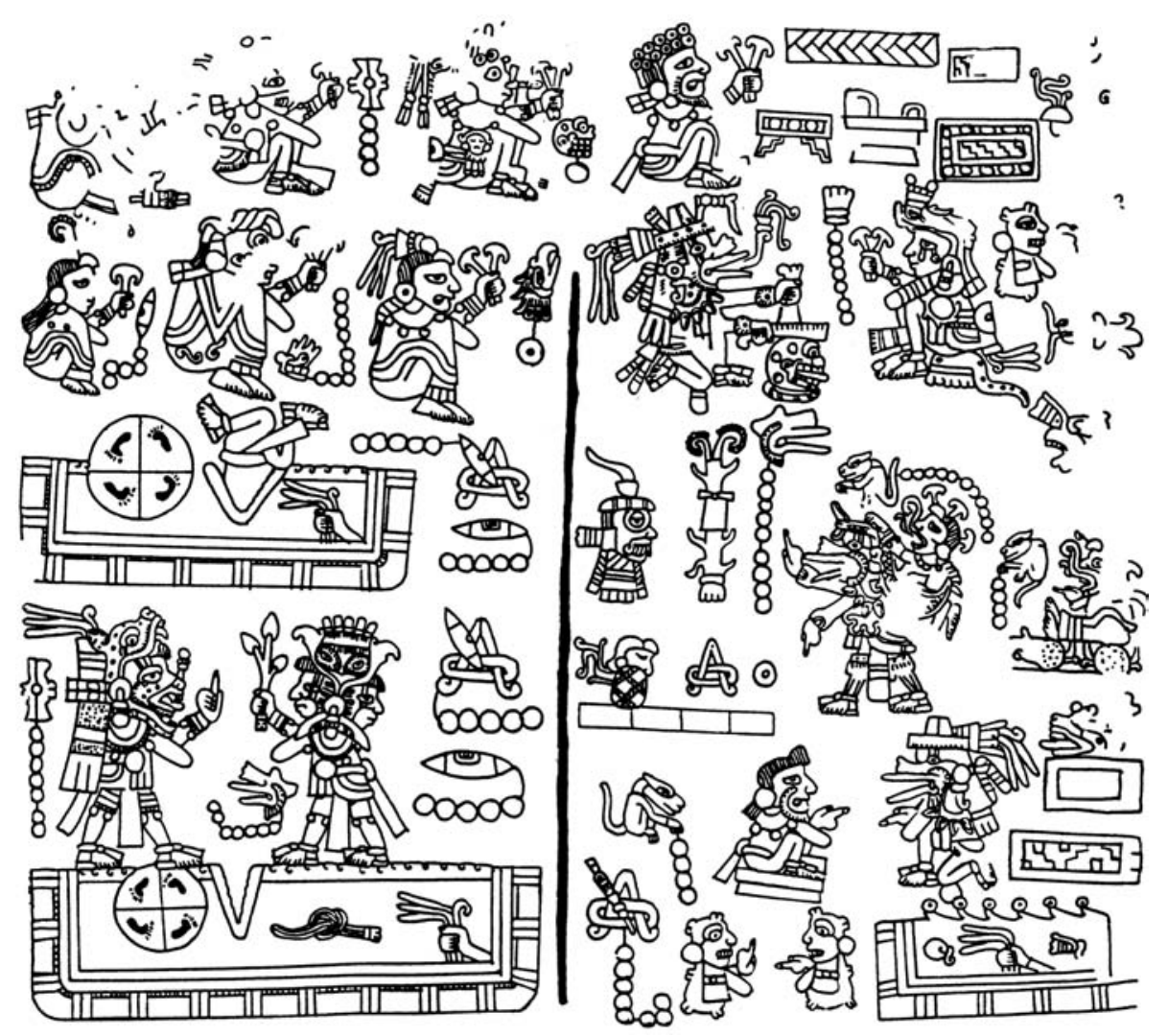

4.11. Codex Yuta Tnoho, p. 24 (Lower Right to Lower Left, boustrophedon). Conversations of the Nuhu in Yuta Tnoho (Apoala), conversations of Lord 9 Wind and Lord 2 Dog. Lord 9 Wind brings the Mushroom Ladies 4 Lizard and 11 Lizard. Rituals for the Dead, for Rain and Maize. Visionary ritual: Lord 9 Wind sings and produces funerary music with bones and skull. Eight Primordial Lords and Ladies consume pairs of (hallucinogenic) mushrooms. Their vision deals with the cradle and the town (the foundation of settlements), the mat and the throne (the city-states). After that, a priest enters the river or a cave in Yuta Tnoho (Apoala), to which the 'market' sign is added. Two Primordial Lords participate in the same ritual and receive the branch that the priest brought back from his visionary voyage.

sequently the appearance of the yahui figures in relation to caves may mark these locations as both sacred funerary shrines and trading stations, markets, storehouses or even mines. (op. cit.: 210).

This yahui is the one represented in the codices as a 'fire serpent', i.e. a red serpent with an up curled snout, a tortoise shell covering its body 
and a tail of pointed scales. We have pointed out that the difrasismo yaha yahui, 'eagle, fire serpent was translated by Antonio de los Reyes as nigromántico señor, i.e. 'nigromancer' or, in modern anthropological idiom, 'shaman' (Jansen 1982b: 149). In his argument, however, Pohl interprets this as 'a lord who divines with the death' (necromancer), specifically associated with the worship of death in caves (Pohl 1994: 46). We do agree that caves are very important in Nuu Dzaui religious life and worldview, as places of burial, oracle, mystery or as dwelling-places of the Gods (e.g. Lord Rain), but find Pohl's reconstruction based too much on a stack of hypotheses, rather free associations, inaccurate etymologies, and over-interpreted fragmentary data. On another occasion, Pohl notes the occurrence of the fire serpent as nahual in the attire of the Aztec God Tezcatlipoca in the representation of the 'month' Quecholli in Codex Cihuacoatl (Borbonicus), p. 33 and reads the Spanish gloss sacrificio de mercaderes, 'sacrifice of the merchants' (referring to a specific ritual taking place during this period), as 'sacrificer of the merchants' and a description of the Patron Deity (Pohl 1994: 17). This supposed link between the fire serpent and the merchants or market is then further elaborated. The term huahi yocuvui yahui, translated by Alvarado as 'shop' (tienda), is actually composed of huahi, 'house', and yocuvui yahui, a verb for the market activity (as is clear from expressions such as quevui yocuvui yahui, the market day' or modern Sahin Sau: kuu yahu, 'to sell'). But Pohl sees in this expression again a reference to the yahui (fire serpent) priest and concludes that such a person "held responsibility for the management of a royal economy and tribute collection" (Pohl 1994: 53). Observing that yaha can (with other tones) also mean 'chile' and yahui (as orthographic error for yavui without glottal stop) also 'maguey', Pohl suggests that the term yaha yahui also refers to 'elite food commodities', as a basis for stating: "How the yaha yahui may have functioned more specifically as economic administrators is not clear. Comparison with the roles of mayordomos would imply that they supervised tribute collection and served as institutionalized overseers of the stores." (Pohl 1994: 53). The alternative translation of yaha yahui as 'chile, maguey' could at best have been a tonal pun on the term for nigromántico señor, but it simply does not follow that his office and power was really seen as related to the food economy by the Nuu Dzaui people or associated with an office comparable to that of contemporary mayordomos. The details of the argument are not conclusive, which makes the result very shaky. In other words: because a chain is as weak as its weakest link, 
Pohl's composite hypothesis is not convincing and does not lend force to the theory about 'border markets'.

Such an etymological analysis may be deemed just hair-splitting, but the outcome is clear: these toponyms do not provide conclusive evidence for postulating the existence of 'border markets' in Nuu Dzaui culture and social organization. Consequently there is no justification for the proposed program of survey and excavation. Of course, the possibility cannot be totally ruled out that some places called yahui were indeed at a certain moment in time used for a longer or shorter period as a market, but the odds are that archeological research along these lines would not change the main outline of the picture.

When collecting toponyms that might be relevant in this respect, one should pay close attention to the word 'plaza', which in Spanish can mean both 'square' (plaza de armas) and 'market'. Visiting one of the archeological sites in Chalcatongo, Pohl (2007: 39) claims that the main plaza (as an archeological term) is called yahu, 'market', and uses this to bolster the above-mentioned theory, as the site is close to the boundary between Chalcatongo and its neighbor San Miguel el Grande (which, by the way, did not become separate independent villages until the second half of the colonial period). We are under the impression that this is a misunderstanding: the investigator may have asked something like ¿Cómo se dice la plaza aquí en mixteco?, "What is the plaza (square) here called in Mixtec', but his interlocutors apparently understood this question as 'What is the Mixtec word for market here' and answered: $y a h u$, not referring to the archeological plaza but to the plaza-as-market in the center of the modern town.

A special chapter in the field of combined archeological and iconographical studies was initiated by Sharisse McCafferty \& Geoffrey McCafferty (1994) in their analysis of the famous Tomb 7 of Monte Albán, originally excavated by Alfonso Caso in the 1930s. Observing that the iconography of the funerary gifts pointed toward the sphere of female activity, they suggested that the buried person was probably a woman, and that archeological/iconographical researchers should be aware of possible machismo biases in their presuppositions. Although several elements in this innovative article remain debatable, there is no doubt that gender issues, particularly female agency and presence, in the archeological/iconographical/historical record deserve much more attention. Later articles by Byron Hamann (1997) Sharisse McCafferty \& Geoffrey McCafferty (2006) have continued this approach with 
interesting results, pointing out, for example, the importance of spinning and weaving tools in the iconography of power, and the presence of weaving patterns in the painting of landscape features, suggesting an underlying conceptualization of the natural world as being 'woven'. Although they have so far not produced evidence for such a notion being part of ancient Nuu Dzaui worldview, there are suggestive parallels in northern Mexico (among the Huichol and Rarámuri). Some pointed objects interpreted as 'weaving picks' by Hamann (1997: 157159) are, in our opinion, actually bone and maguey-spine perforators for bloodletting rituals, but it is interesting to take into account such a possible connotation of other uses. ${ }^{22}$

Byron Hamann has made further original contributions to the analysis of Nuu Dzaui concepts and worldview, particularly of Mesoamerican ideas about primordial worlds preceding the rise of the present sun and of references to ancient buildings and ancestors in the Nuu Dzaui codices. ${ }^{23}$ As for the latter he has focused on the representation of the ceremonial platform or altar (cf. Smith 1973a: 45; Garza Tarazona 1978). The term for these structures in Dzaha Dzaui is chiyo, translated by Alvarado as 'altar', and in a general sense as foundation of a house (cimiento) or reference to family land (solar de casa or naturaleza, tierra de donde es alguno). Hamann observes that Alvarado translates the term chiyo yata as 'ancient place' (antiguo lugar) and proceeds to argue "that perhaps all of the platforms without buildings in the Nudzavui screenfolds are representations of ruins: that every codical image of a chiyo, a platform, is an image of a chiyo yata, an 'antiguo lugar' or ancient place" (in: Blomster 2008: 124) and that "the translation of chiyo as 'altar' would seem to be a colonial period innovation meant to distinguish Christian altars from their indigenous counterparts, and therefore we should not use 'altar' to translate representations of architectural platforms in Nudzavui pictorials" (ibid.: 136).

${ }^{22}$ Alvarado Bárcenas \& Ojeda Díaz (2009) similarly address the gender issue in the Mixtec codices, but ignore these and other studies on the topic. Although quite oldfashioned in its approach, their article does signal the 'archetypical' difference between young and elder goddesses in the Teoamoxtli (Borgia) Group, which is indeed important (as a reflection of social order) and has been commented upon before (e.g. Manning 1993).

${ }^{23}$ Hamann 2002 (cf. Jansen in Jansen \& Reyes 1997) and Hamann in Blomster 2008. 
We think this goes somewhat too far. Hamann is right in pointing out that the chiyo structures are different from sacrificial stones (yuu dzaa) and that Alvarado gives a special term for altar de demonios (tayu dzana, in which tayu means 'throne' or 'seat'), but it does not follow that chiyo exclusively means a Christian altar. And even if it did, it is not clear how a meaning of 'platform' could have shifted to that of 'Christian altar' if the term chiyo had not already had some religious association before. In the passages referring to the ritual foundation of the primordial polities, Codex Yuta Tnoho mentions the construction of chiyo buildings as a parallel to that of ndiyo buildings, i.e. 'staircases' (pyramids), which suggests an ancient parallelism chiyo, ndiyo for ceremonial architecture. Hamann's discussion contains many interesting observations, however, and we concur that many chiyo structures in the codices may indeed represent ancient (ceremonial) places, i.e. buildings from the Classic Period (cf. Geurds \& Jansen 2008). In fact we are under the impression that such ancient ceremonial places, even after being abandoned, were not considered 'ruins' in the modern Western usage of that term, but remained the dwelling place (and altars) of Gods and divine ancestors. The term used today in Sahin Sau for an earlier settlement (pueblo viejo) of a community would be referred to as ñuu yata, 'town of the past' or ñuu tuhu, 'old (in the sense of destroyed, ruined) town', while a precolonial ceremonial center is referred to as vehe ñuhu anaha (Alvarado: huahi ñuhu sanaha), 'house of God of the past', i.e. 'ancient temple' (Spanish: iglesia vieja, 'old church').

A similar interest in Mesoamerican (religious) concepts, terms and practices characterizes the groundbreaking work of Gilda Hernández Sánchez on Postclassic polychrome ceramics (from the MixtecaPuebla horizon style). In her comprehensive Ph.D. thesis (2005) and several related articles $(2004,2006,2007)$ she showed how decorative elements painted on the vessels, similar to signs in the codices, may actually be read as condensed references to ceremonial texts in the context of ritual feasting and ancestor veneration. Various frequent combinations of signs may be understood as parallel expressions or difrasismos, which also occur in the codices.

Particularly relevant in this respect are the continued studies of Ubaldo López García, who has elaborated on the presence of Yutsa Tohon (Yuta Tnoho), Apoala, in the codices, clarifying important elements of native symbolism, and has concentrated on documenting 
ceremonial discourses in Dzaha Dzaui, analyzing them in their context. ${ }^{24}$ Vicente Casiano Franco, in collaboration with Leiden students Chantal van Liere and Martijn Schuth, undertook a similar study of the special language used in prayers in the Mixtec part of the State of Guerrero. The same ceremonial language with its characteristic parallelisms and difrasismos is present in early colonial translations of Catholic texts into Dzaha Dzaui: the missionaries used the native art of oratory in order to give their message a more convincing literary force. As our understanding of the Mesoamerican literary forms and metaphors advances, a better fundament for a true reading of the ancient pictorial documents can be constructed.

\section{Outlook}

Ñuu Dzaui books contain ancient historiography in an aesthetic, 'literary' form, in accordance with native reality, language and mentality. Reading these works today demands the interaction of a thorough scholarly hermeneutic methodology and a profound personal acquaintance with that specific reality, language and mentality. In this chapter we have presented a brief and obviously very personal review of the main developments in the interpretation of the Nuu Dzaui codices. It cannot do justice to all the work that has been done, much less to the continuing production of congress papers and publications on the Mixtec world, but should suffice to point out the bases and main elements of present-day discussions about these manuscripts.

A detailed revision of the existing literature is necessary for a good evaluation of the advancements in the understanding of these sources. A first handicap, however, is the fact that several crucial insights have

${ }^{24}$ See López García 1997, 1998, 2001, 2007, as well as his papers in Romero Frizzi 2003a and in Robles García 2004. The Mixtec discourses, collected, transcribed, translated and analyzed by López García, as well as several ideas expressed in his unpubished M.A. thesis (1998), have been extensively used by Ignacio Ortiz Castro in his own doctoral dissertation (2006). Being from the Mixtec region but not a native speaker of the Mixtec language, the latter author based himself to a very large extent on Lopez García's fieldwork of many years in order to present a reconstruction of Mixtec philosophy and ethics, clearly inspired by León-Portilla's interpretation (1974) of Aztec thought as a kind of Platonic philosophy. Mikulska Dąbrowska (2008) also discusses the importance of difrasismos for interpreting the religious codices. In another study we analyze this element as part of the Mixtec literary style preserved in colonial documents (Jansen \& Pérez Jiménez 2009b). 
not been adequately published - not so much due to lack of efforts on the part of authors as to their lack of access to funds and good publication possibilities, or to lack of vision on the part of publishers. For instance, Troike's excellent dissertation on Codex Iya Nacuaa (Colombino-Becker) at the University of London (1974) has so far only circulated in photocopy. Rabin's crucial amendments of Caso's chronology were made in the 1970s but were only presented as papers to specialist symposia and her overview of the new chronology, although already presented in 1981, was not published until 2004 (and then only in abbreviated form).

Another problem is the lack of good and consistent referencing. Given the complexity of the sources and the abundance of studies in this field, it is often not possible to give complete and consistent credit to all the earlier works we build on, so it is comprehensible that contemporary authors make use of shortcuts in order to avoid burdening a text with extensive bibliographical references to the history of decipherment. In addition, monolingual students (in either English or Spanish) tend to consult and quote only the publications written in the language they know and consequently lack a good grasp of the international development of scholarship and the underlying ideas and debates. Whenever these factors affect a scholarly text, the nonspecialist readers are left in the dark as to who originally proposed a specific interpretation and on what grounds.

Evaluating the existing theories is also a delicate matter, as critical notes may be mistaken for (personal) attacks. Clearly, debates have to focus on the issues of interpretation themselves. In discussing several publications of our most prominent colleagues we felt obliged to indicate where there are differences of opinion, but this should not be construed as a lack of appreciation for the hard work and stimulating ideas that are also presented in their contributions. Disagreeing on scholarly matters, proposing alternatives or 'setting the record straight' is a normal function of progressing research, and does not mean that we would not have the highest regard for the personality, curriculum and sincere dedication of all the other members of this small community. It is through multiple conversations with these different experts and through examining their publications that we have learned much of what we know now, and we hope to continue learning.

We conclude by stressing the growing awareness about the social and cultural context of this academic endeavor, or, as we would like to call 
it, the unfolding of a postcolonial perspective. Looking to the future we expect to see an increasing involvement of indigenous experts, native speakers of Mesoamerican languages, in these types of studies, leading to what Michel Foucault has called "the insurrection of subjugated knowledge" (1980: 81 ff.). Empowering archeological and historical studies can and should be incentives in a society which is slowly but surely opening up to the concerns of peoples who have been colonized, marginalized and forgotten. The 'peoples without history', alienated and destroyed by the long and complex process of colonization (Wolf 1982), are now reclaiming their history.

Among the Nuu Dzaui people there is an increasing scholarly interest in tangible and intangible cultural heritage. Alavez Chávez (1997), Cruz Ortíz (1998, 2009), López García (1998, 2007), García Leyva (2005), Sánchez Sánchez (2007), and others have published relevant texts. More and more ethnographic and historical monographs of specific villages are being produced (e.g. Villavicencio Rojas \& Montesinos Maldonado 2004, Guzmán Flores 2005, and Santiago López 2006). ${ }^{25}$ Both the Academia de la Lengua Mixteca (Ve'e Tu'un Savi) and the Universidad Tecnológica de la Mixteca (Huajuapan) play an important role in the local diffusion of Nuu Dzaui cultural history.

Particularly impressive are the aesthetic creations and developmental projects designed by Ñu Dzaui architect Victor Hugo Ruiz Ortiz, including a monument for the ancient rulers of Cerro Jazmín (in the parador turístico of Yanhuitlan), an animated movie about the tragedy of Lord 8 Deer and Lady 6 Monkey, and an exposition in the Museo del Palacio, Oaxaca City, with the significant title 'Las historias inconclusas narradas en los códices merecen una continuación viva....'.

${ }^{25}$ For a contextualized overview of contemporanous writing in Dzaha Dzaui and the study of the language and its history by several native speakers, see the book edited by Romero Frizzi (2003a). For an analysis of the cultural and socio-economic contexts, see Julián Caballero 2009. 
Maarten Jansen and Gabina Aurora Pérez Jiménez - 978-90-04-19358-1 Downloaded from Brill.com@4/26/2023 11:36:13AM 
PART TWO

TNUNI TANIÑO:

SIGNS AND SYMBOLS 
Maarten Jansen and Gabina Aurora Pérez Jiménez - 978-90-04-19358-1 Downloaded from Brill.com@4/26/2023 11:36:13AM 


\section{POSTCOLONIAL HERMENEUTICS}

The study of sign systems, texts and visual art has become a vast and specialist area of critical thought. Interpreting the pictorial manuscripts from Mexico, as a culture-historical specialization, is a particularistic endeavor, which does not primarily aim at creating grand theories. On the contrary, those involved in such work generally use theoretical reflections in an eclectic way to elucidate or explain certain phenomena they observe in the record and to support their specific hypotheses. Therefore, most authors, we too, are looking for the practical hands-on guidance of general methodological works, trying to find simple or simplified procedures. There is no easy recipe, however. Interpretation is a personal quest and a dynamic process, evolving and changing over time as more and more implications are considered and new data and new theoretical perspectives come forward. Clearly, it is not the aim of this book to make a contribution to general theory, but the discussion of some methodical, theoretical and practical aspects, even in a superficial way, is necessary in order to evaluate how thinking about these matters has developed and to identify which challenges lie ahead.

\section{Interpretive Theory}

At present the knowledge of the ancient Mesoamerican pictographic conventions is quite advanced, but certainly not complete. The preserved manuscripts form an arbitrary sample of elements out of context, which may contain biases and ambiguities. The accompanying orally transmitted texts have gone. A basic method in interpreting pictorial scenes, such as these, is the classic iconological analysis, outlined by the art historian Erwin Panofsky. It distinguishes three levels or steps of inquiry, which may be characterized as description (analyzing the visual forms), interpretation (identifying the concepts and themes) and evaluation (exploring the intrinsic meanings). These correspond to the different layers of a work - codes, messages, and 
underlying ideas - each related to particular contexts. ${ }^{1}$ This model follows Hegel's classic distinction between the three moments of an artistic work: Gestalt (form) - Gehalt (contents) - Bedeutung (meaning). Since Panofsky a wealth of methodological and theoretical literature has been produced focusing on the status of signs and the act of interpretation. It has been emphasized that meaning is complex, layered, multiple, produced in the encounter of dynamic (and dramatic) subjects, and therefore changing and growing. Decipherment, therefore, is not the intellectual activity of an erudite subject observing static objects and signs, but a continuing process of active, participative and emotional engagements. Still, for a start we will follow Panofsky's classic tripartite scheme as a handy practical approach and a point of departure for discussing some crucial aspects of deciphering the Nuu Dzaui pictorial chronicles. In doing so, we situate ourselves, at least in the first instance, in a classic tradition of philological, literary, and art-historical interpretations. A famous philosophical current is that of 'hermeneutics'. '

Among other aspects, the hermeneutic approach is characterized by:

- a concentration on meaning, which transcends methods and theoretical frameworks, but is to be accessed through experience and insight,

- an attention to historical contexts and experiences, and the idea that meanings are time-bound and relative, change over time and thus accumulate,

- a conceptualization of meaning as a 'horizon' of a work, which expands and grows,

${ }^{1}$ See the collection of methodological essays published by Kaemmerling (1979). The application of the iconological method is well established in the study of GrecoRoman and later European art, generally combining a rigorous and methodical visual analysis with great literary erudition. As an example of the sensational results that may be obtained this way, we mention the trilogy of Frank Müller (1994abc), which has been particularly inspiring to us.

2 The term comes from the Greek verb hermeneuein, 'to interpret', connoting a reference to Hermes, the divine messenger of the Gods, and has become the name of a philosophical current, originally shaped by the German philosophers Friedrich Schleiermacher, Wilhelm Dilthey, Martin Heidegger, and Hans-Georg Gadamer. For an overview, see, for example, Palmer 1969 and Lawn 2006, while the volume edited by Udeani et al. (2008) deals specifically with the issue of intercultural hermeneutics. The insightful paper of Johnsen and Olsen (1992) already showed the importance of hermeneutics for contemporary archeological theory. 
- an analysis of pre-understandings of each interpreter, who has his/ her own interpretive 'horizon',

- a view of interpretation as fundamentally a process of encounter and dialog, and as a 'fusion of horizons' (of the work and the succession of interpreters),

- a notion of a ceaseless interaction between the parts and the whole of the work that we are interpreting (the 'hermeneutic circle').

The prominent French philosopher Paul Ricoeur developed these ideas further, for example in his illuminating essay Interpretation Theory (1976). Focusing on works as forms of 'discourse', Ricoeur conceives interpretation as a dialectical interaction of understanding and explaining, contextual empathy and logical analysis. Texts and works of art are fundamentally situated in a real world of human experience and responsibility. Through interpretation they point to another, possible world, and so aim at transforming the beholder. The successive interactions, 'dialogs', between works and their changing contexts and beholders create a lively historical development of interpretation, which in itself is related to, and illustrative of, cultural constructions and human experiences. Meaning is not a fixed unit but a dynamic process of communication and spiritual growth.

Signs are ultimately related to 'sense', to giving meaning to existence, reason for a sort of philosophical mysticism in the preoccupation with this topic. Interpretation is not a mere theory or method, but fundamentally a social, communicative, and creative event. All signs, events, encounters have also their emotional, affective, transformative, visionary and vital dimensions. The interplaying affects, differences, implications and explanations, are propelling forces in the philosophy of Gilles Deleuze:

The sign surges in a field of representation, i.e. of explicit significations or recognized objects, and implies what is heterogeneous or what escapes the right to representation. Therefore, in the first place, what is heterogeneous, or the other point of view, is implied (it cannot be object of an act of recognition). Therefore, in the second place, it may be said that the sense as expression or explanation consists in putting in communication two points of view, levels or heterogeneous dimensions. There is only sense in the interstitia of representation, in the hiatus of the points of view. Sense is divergence, dissonance, disjunction. Sense is problem: 'discordant agreement', unresolved dissonance. In the third and last place, the sense-sign affects a mutant subject, in becoming, dislocated between two individuations. (Zourabichvilli 2004: 53-54). 
Ultimately, trying to understand Mesoamerican art and texts, reading the codices, is an intercultural encounter, which brings us in an interstitial, interparadigmatic, liminal position, a difficult exercise, even disturbing to some, but certainly full of enriching potential. Interpretation, then, comes from the synergy of learning codes, processing data, discovering and attributing significance, guessing, fitting and translating. Practical experience and personal involvement are crucial for developing the necessary skills of communication and (inter)cultural understanding. This activity also produces a response, both in the interpreter and in his/her public.

Points of view, positions and focalizations are important here. One of the problems of analytical studies is that by taking the ancient images and texts as objects of inquiry, an overarching subject-object relationship is created, between the investigator and the investigated, the observer and the observed. ${ }^{3}$ The contribution of hermeneutics, conceived of as a "disciplined method for coming to terms with the 'strangeness' of literature, of the past or of peoples different from oneself", has been to show that all understanding is based on some form of pre-understanding and proceeds in a circular, dialogical mode, implying a dynamical interaction between investigator and investigated.

Instead of objectifying the phenomenon of one's attention (be it a manuscript, a building, a pottery sherd, or an indigenous ritual), one would concentrate on 'non-objectifying modes of disclosure'. Instead of an objectivist understanding of the ancient Maya born of self-conscious reflection on the world, Heidegger would argue for a relational understanding that involves direct engagement with the world. In this view, neither the twentieth-century interpreter nor the ancient Mesoamerican phenomenon under consideration (for instance, the Maya glyph, pyramid, pot, or whatever) is a discrete, independent entity; rather, in every instance of hermeneutical reflection, the human interpreter and the interpreted are subsumed by the relation in which they are involved. (Jones 1995: 188-189).

Contemporary studies of art and literature are inspired by the theoretical currents of our day: (de)constructivism, postmodernism and postcolonialism. They all contribute to a more profound and critical analysis of the interpretation process itself and emphasize that

\footnotetext{
${ }^{3}$ For a criticism of the way in which such 'visualism' has contributed to the reduction of the anthropological 'other' to a mere object, see Fabian 1983: ch.4; compare the observations of Mitchell 1994.
} 
the interpreter is not a passive, neutral beholder (as often implied in 'objective' science), nor otherwise innocent, but, on the contrary, an active participant in constructing significance. Inevitably everyone interprets from a specific perspective, determined by prejudices, by projects of an ideological nature and, as the work of Foucault has demonstrated, by omnipresent relationships of power and domination. The iconological and archeological interpretation itself produces and is produced by - narrative forms. The narrative of the interpreter enters into a dialectical relationship with the narrative of authors in the past, our intellectual ancestors. Respect is necessary here, and the will to listen. At the same time the very act of interpretation produces dialog, engagement and tension: what did the ancient story communicate in its own time, but also: what does it communicate to us?

In trying to elucidate how narrative structures work, one should focus on this aspect by analyzing critical questions such as: who is the narrator and how does he/she become manifest, who is speaking within the text, how is he/she embedded by the narrator, from whose point of view are things, emotions or events described (focalization), how and according to which criteria are images selected, which hierarchy can be distinguished in the process of signification, but also: what is the role and the perspective of the public/reader/audience and how does the text promote critical (self-)reflection in that public, in other words: which are the ideological and socio-political projects of the text (in its successive historical and social contexts) - and how do they relate to those of the public? $?^{4}$ This applies both to the analysis of the pictorial text of the past and to the interpretive text produced in the present.

\footnotetext{
${ }^{4}$ Especially in the field of literary criticism there is abundant methodological literature on these problems, provoked by the revolutionary work of authors such as Jacques Derrida and Edward Said. A practical guideline is the narratology elaborated by Mieke Bal 1997 - an example of how to apply these principles to the interpretation of pictorial manuscripts is the Ph.D. thesis of Florine Asselbergs (2004). Van Alphen (2005) offers an inspiring and (post)modern vision of the effects of visual art and representation, considering questions of subjectivity, embodiment, temporality, memory, and identity, which are crucial but so far receive little attention in the study of Mesoamerican iconography (with some important exceptions, such as Graña-Behrens 2009, Houston, Stuart \& Taube 2006, and Bartolomé 2008: 243-259). These foci coincide with the plea for developing a world perspective in art studies: Zijlmans and Van Damme 2008.
} 
The world is no mere passive matter awaiting interpretation or decoding by a scanning eye. It is no mere screen ground or surface but actor and agent, requiring interaction. (Braidotti 1994: 73).

Indeed, interpretation is not to be seen as the act of a 'supreme erudite subject' (the interpreter) who unveils and dissects an enigmatic object (the work and/or its author) but as an interaction, an encounter between subjects. In our quest to understand these figurative paintings, we ourselves enter into a special relationship with the ancient painters and, even more, with the original public or audience. We start by looking at their pictorial scenes as objects of inquiry and analysis, and are immediately confronted with the need to understand the central issues and values of Mesoamerican society and culture. As the interpretive process continues, we become more and more aware of the creative protagonists around us, not mere objects of our perspectives nor creations of our mind, but active thinkers and speakers in their own right, entering into dialog with the beholder, returning questions and making problematic (even suspicious) our very 'spectatorship'.

\section{A Practical Method: Three Steps}

All discussion presupposes a lot of information already present before we even start our research: our pre-understandings. In talking about Mesoamerican pictorial manuscripts, we presume a concept of Mesoamerica and a concrete corpus of data: sources have come down to us in specific ways, as well as the knowledge about them. It is important to make clear from the onset to others and to ourselves what these pre-understandings are.

From here we proceed with the first step of the iconographical study proper, which, following Panofsky, is a sound descriptive analysis of the signs and scenes. This is not a mere translation into words of what the eye sees, but a preliminary ordering and reading, based on what is known about the sources as well as the system and codes of representation. On this first level or in this sphere, the forms of the signs are the central concern, as well as the sources that contain these signs. We start this phase of the research, therefore, by focusing on the materiality, the physical dimension of the object that carries the signs. Thus we have to explore the form, origin, state and whereabouts of the sources and their history as items in diverse collections, which may have affected their state of preservation. In the case of the pictorial manu- 
scripts, this implies a thorough codicological study of the material base. $^{5}$

The physical composition of the register may condition the message or narrative. The properties and possibilities of a small scene painted on a ceramic vessel or incised on a bone are very different from the broad narrative spaces of codices and lienzos, the two major categories of ancient Mexican picture writing. Also between these two there are important differences as to organizational principles. A codex is composed on a continuous line: the bands in which the events are presented one after the other. Red lines define these bands, creating a yuq yuq (boustrophedon) pattern. This linear format is well suited for a sequential story with chronological order. The lienzo may include linear bands too, but its strongest point is, without doubt, the representation of space. It may be designed as a map, situating the toponymic signs in an open field, more or less according to their geographical distribution, so creating a 'spatial order of discourse'. ${ }^{6}$ The temporal or sequential order of the events is not always easy to determine: the connections between them may be indicated through a network of lines and/or footprints. Dynastic and chronological data may be painted next to the sign of the place they refer to. Often we find a combination of 'columns' of rulers (to be read from the bottom upward) with a series of places around them, as the scenery where specific events took place.

The use of certain materials and styles for expressing a particular message may be a matter of conscious choice. It is no casualty, for example, that the early colonial painter of the Codex Añute employed the traditional screenfold book of deerskin for his conservative and nostalgic view of the ancient realm and its values, while his contemporary, the painter of the Codex of Yodzo Cahi (Yanhuitlan), drew his figures on European paper, in a European-style book, blending Mesoamerican and European artistic conventions, in order to create a new form of text, apt to represent the worldview of the Christian Mixtec cacique.

${ }^{5}$ See the codicological introductions to the facsimile editions of the codices published by ADEVA, Graz (cf. Anders 1999), as well as the illustrative case studies and sound methodical observations of Batalla Rosado $(1999,2006,2008)$. If codicological studies are not connected with a study and experience of the living culture, language and landscape, however, they remain limited and sterile.

${ }^{6}$ In her interpretation of the Lienzos of Quauhquechollan, Asselbergs 2004 includes a detailed and methodical analysis of the lienzo genre. 
Composition, proportion, use of lines and colors, individual drawing styles ('handwriting') may reveal individual characteristics and personal circumstances of the production process and of the context in which the information was exchanged. The pictorial manuscripts that are preserved today are products of a long tradition and a quite complex formative process. Supposedly many manuscripts copy, at least in part, earlier works and/or integrate different pictorial and/or oral sources. This development is reflected in a number of internal problems, which sometimes permit us to discover traces of earlier stages within the document. In copying one or more codices into a new one, the main questions were what to include and how to connect data from different sources in one continuous text. Changing formats or categories while copying, e.g. putting the data of a lienzo in a codex or vice versa, was quite a challenge and must have caused the painterhistorian a good deal of worry and utmost exertion. The formal problem of mirroring the figures according to the changes of their positions in the yuq yuq (boustrophedon) pattern, must have been a technique that superior painters mastered through their training, but which kept causing trouble to many others in their compositions.

Originally the contents were mediated to the public not only by the images we still see, but also by an oral tradition and declamatory technique that accompanied it. History was cultivated by and for a specific public, i.e. preserved locally, in a dialectical process of loyalty to prescriptive tradition and continuous adaptation to the emotional involvement and 'taste' of specific audiences. As a new work copied or incorporated large parts of already existing books, it also added information and perhaps even personal interpretations of the events. These specific circumstances result in focusing on certain aspects of the story, selecting some elements for extra elaboration at the expense of others that become irrelevant and are left out. A careful, if necessarily speculative, reconstruction of this formation process may bring to light an 'internal stratification', which then in turn is to be contextualized in its proper cultural-historical moment.

Still on the first level of inquiry, we move from the analysis of the origin, materiality and state of the sources to the form and primary meaning of the signs themselves. The rise of semiotics, the study of signs in general, has deepened the way of looking at all kinds of representation, while focusing on the process of signification and communication itself (semiosis), as a fundamental characteristic of humanity. The relationships between signifier (s) and Signified (S) 
have themselves become a focus of attention. In Mesoamerican pictography the signs generally have a clear first referent: the depicted element. We may, however, distinguish different categories of (meanings of) signs, according to the way they are produced and signify. As we have seen above, Mesoamerican pictography uses both images, i.e. stylized representations of objects) and arbitrary signs (often called 'characters' or 'ideograms'). The insights of semiotics make us aware that both categories can signify in different ways:

a) icons refer to elements or terms in a direct way, generally as a stylized visual depiction of a specific object,

b) indexes refer to actions or notions associated with the depicted element or term (as metonyms),

c) symbols refer to abstract notions for which particular objects function as metaphors,

d) phonetic writings refer to the phonetic value (sound) of what is represented, especially in the names of places and persons. ${ }^{7}$

The meaning attributed to a sign depends on shared conventions and competences, ways of perception and conceptualization, often determined by the culture. The interpretation process tends to be continuous and ever more complex: first we try to define a denotational meaning (e.g. a sign referring to an object), which then, in turn, may become a sign for a second meaning. Such second meanings may be determined by the position, point of view and specific interests of the interpreter. ${ }^{8}$

With the help of our knowledge of Postclassic Mesoamerica's representational code or 'pictographic dictionary' (e.g. Nowotny 1959b; Prem 1974), it is relatively easy to make a descriptive analysis of the images in codices or lienzos, or for that matter on ceramics, painted walls and carved stones. Not all questions can be answered but it is safe to say that most remaining problems of interpretation do not occur on

7 This subdivision was elaborated in the fundamental work of Charles Peirce. A useful introductory overview is given by Hawkes 1977. See also the general monograph by Eco 1978 and the discussion of semiotics in archeology by Preucel (2006).

${ }^{8}$ See the lucid presentation by Mieke Bal (1994), who discusses the example of a footprint seen by Robinson Crusoe. It first indicated to him that there was another human being on the island, immediately followed by the thought: 'this is the end of my loneliness'. 
that first level of inquiry (identifying which object is represented by the image), but on the second level, that of the question: what do the scenes filled with such persons and objects mean?

Before we can try to produce an answer, we have to order and compare our data, first in form, then in contents. In between the first and second level of understanding, therefore, is an articulation, in which we have to take into account the genre of the message and the relevant sources, particularly the presence of different versions or other additional information. We have to ask ourselves: how have these images/ texts come down to us, and to which context do they refer? Analytically the manuscript has to be placed in a specific group. Are we dealing with a prescriptive (divinatory, ritual) text, with a descriptive (narrative) one or with a tribute list? Parallel sections have to be identified and the production of the pictorial manuscripts themselves examined. In some cases the reconstruction of lost parts is possible, as the existing painted texts often copy and/or synthesize one or more earlier paintings, prototypes, which are now lost. This insight also helps to explain several mistakes in the codices, but, even more importantly, it makes us aware of the fact that the manuscripts are produced over time (often reproducing the earlier versions in a process of specifically motivated selection and elaboration) and, accordingly, may contain different layers of signification.

We do not start from scratch: often there is abundant scholarly theorization about the contents of the sources, which, in turn, has to be put in a historical perspective. The process of colonization itself, the interaction between Native American and Spanish worldviews ('spiritual conquest', 'syncretism'), and the image that each party created about 'the other', form the context for understanding the (lack of) preservation of the originals, as well as the history of the collections and the development of studies of such sources and materials.

Proceeding from the first denotational meaning of the signs in the context of their genre, we come to the second level or sphere, that of the 'thematic meaning': what is being expressed by the combination of the depicted elements, what is the story told? Here we have to order the signs and scenes in coherent, meaningful topical clusters which Panofsky called "themes and motifs". These themes are not to be defined in an essentialist manner but as analytical units for practical use. The interpretation of such themes consists fundamentally of : 
1) analyzing the different scenes as expressions of a specific theme, comparing the different representations of that theme, and so getting a more complete perception of the extension and complexity of the theme itself, and

2) connecting the (reconstructed) theme to other relevant information outside of its pictorial representation - obviously, this implies a philological analysis of relevant text passages.

An often used example from Christian iconography clarifies the procedure: we may examine the different scenes of the theme of a young mother with child and so reconstruct a story line of birth, adoration by the three magi, etc., which we may then interpret by relating it to the biblical story of the Virgin Mary and Christ. ${ }^{9}$

We find such stories and other relevant data by resorting to a reference framework of cultural-historical knowledge. There we search for similar clusters of data that might correspond to the iconographical theme. This is not a tautological procedure, but a heuristic one. The interpretation moves forward by comparing and fitting the 'loose' parts from the first level (as examples of the general code of representation) with similar elements in structured wholes on the second level and vice versa (the hermeneutic circle). On the first level we search for the key to read the signs as 'morphemes' or words with their individual semantic/phonetic meanings. The second is about syntax and contents, the coherence of those morphemic terms as meaningful utterances or sentences. In other words, we search for the narrative/ poetic sense of a coherent image-text. Interpretations on the second level that are not supported by a descriptive analysis of components on the first level will be lacking in argument. On the other hand, the mere making of descriptive inventories (first level) without establishing thematic coherence and sense (second level) will remain unsatisfactory, void exercises.

In this exploration we should remember that the text surface is a historical product. In a concrete manuscript the themes, therefore, may be present in one or more successive 'strata', corresponding to

${ }^{9}$ Compare the classic study of Moche iconography by Donnan (1978: ch. VI). The dissertation of Loo (1987) is an example of the application of such a thematic approach to the Teoamoxtli (Borgia) Group. Mikulska-Dąbrowska (2008) offers important methodological notes and an exemplary iconographical-philological analysis of various themes and deities in these manuscripts, as well as general insights on the complex relationships between image and (metaphoric) language. 
successive drafts, compositions and uses. Such internal stratification of meaning, of course, has to be considered separately. Left to us are the fragments of a bigger, missing whole. From these fragments we may reconstruct the historical narratives by combining, comparing and connecting the data given in the different sources, by establishing a framework of chronological sequence and causality.

Narratology is an important method in understanding the composition, internal dynamics and communicative performance of narratives (Bal 1997). As for the topic becoming a narrative or message, we may distinguish between:

a) the 'pre-narrative moment', e.g. an experience, a feeling, a (perception of a) historical event, an element of the worldview, a fictional or poetic inspiration, produced in a specific context of events, protagonists and perceivers, creating a 'fabula',

b) the interlocutory, narrative act, produced in the (historical) interaction of a narrator and an audience, transforming the 'fabula' into a 'story', with its specific sequential or mosaic structure, plots, voids, and symbolic dimensions,

c) the narrative text/image, in which the story is presented according to specific focalizations (points of view), and codified, 'saved' as a new aesthetic (descriptive, argumentative, ideological) surface that starts interacting with changing audiences/beholders.

These three stages are linked to the threefold mimesis (narrative representation of human agency and its interpretation) distinguished by Paul Ricoeur in his monumental Time and Narrative (1984-1988), which opens up wide philosophical horizons:

- prefiguration (fundamental competences of identifying elements of action and meaning),

- configuration (narrative 'emplotment', generally from a specific perspective and with some form of temporal-logical structure),

- reconfiguration (the intersection of narrative/text with lived experiences of the reader).

The famous investigators of (folk) tales Propp and Greimas have shown that many narratives are constructed as a 'plot' in the classic sense, a general structure of personages and topics with a clear 'closure', which gives causality and meaning to the narrated events 
(cf. Hébert 2006). An example of such a very basic structure is Greimas's 'actantial model': a protagonist (hero) goes on a mission, overcoming obstacles and gaining victory over adversaries with the help of allies (alternation of conflict and contract), in order to finally achieve his objective. People may even see (select) parts of their own lives in such terms as well, delineating individual or collective 'narrative identities' as Ricoeur has pointed out. At the same time they (we) are also aware of the fact that such a life-narrative is only an arbitrary fragment of a larger whole, which in itself is without closure, and that the meaning/sense of real, experienced life is ultimately beyond the narrative expression. Furthermore, it should be stressed that narrative forms are diverse and not limited to such relatively simple emplotments, while goal-directedness itself (related to personal prestige, economic accumulation, amorous conquests etc.) is to a large extent culturally determined: societies differ in their internal organizations, thematic universes, codes, values, motivations and objectives. Still, such basic structures may help us to establish cohesion, to order artistic and narrative elements in themes as heuristic constructs, and to identify (with) the dramatis personae. In the story-line of the intertwined lives of Lord 8 Deer 'Jaguar Claw' and Lady 6 Monkey 'Power of the Plumed Serpent', for example, compositional techniques such as 'turning points' and 'tragic irony' are evident, as is the dramatic effect of the story, both on a modern Mixtec audience and on a general public. This suggests that we should indeed read this pictorial narrative text in the first place as a story, a literary elaboration on the base of some historical events, interpreted in a specific way to this effect, and possibly mixed with fictive elements (cf. Jansen \& Pérez Jiménez 2007ab). In contrast, such an analysis makes it clear that the Codex Yuta Tnoho is structured according to quite different principles. Although one might try to read the birth of the Founders of dynasties from a Mother Tree and their distribution over different places of Nuu Dzaui as some type of goal achievement, this is clearly not the dominant aspect of the story: the actions of Ancestors and other divine protagonists are largely ceremonial and subject to/expressions of a sacred temporal-spatial order; accordingly they are presented in a mosaic fashion, enumerated in the hieratic style of a ceremonial discourse, characterized by parallelisms.

From the second iconological level we proceed to a second articulation: the themes and motifs have to be considered as a discourse, the 
product of a specific historical, social and cultural context. In order to understand this context we have to understand the text itself as a historical product. How, for what purpose and in which different phases, was it designed and composed? What do internal strata of the text tell us about its successive uses and the related transformations of meaning?

First and foremost we ask: what did the themes mean to the original audience? Or, in other words, how do these themes reflect central concerns of society in that time?

Art is a laboratory where experiments are conducted that shape thought into visual and imaginative ways of framing the pain points of a culture.... Although the dominant commonsense notions of art are still the expressive and conceptual ones, the importance of art is also quite often seen in terms that assign a much more active function, that is, a performative one. Art is then conceived as the realm where ideas and values, the building stones of a culture, are actively created, constituted and mobilized. (Van Alphen 2005: xiii).

Here we come to the critical question, crucial in narratological analysis: who is speaking to whom and for what reason, with which motive? The process of identifying themes and understanding their messages should go hand in hand with acquiring enough contextual knowledge, so that we may come as close as possible to the original intended audiences and share their respective hermeneutic horizons. Tracing the relations between different corpora of sources and trying to accommodate them within a coherent structure, we may arrive at a better understanding of the position and ideology of the original authors/ commissioners of the narrative texts. An important step toward this is situating the sources within a specific community (people), its landscape and its topical universe. We have to ask ourselves how the given expressions and the mentioned characters and acts refer to social ethos and religious meanings, envisioned and embodied in a specific cultural-historical context.

In our case the identification of place signs is the beginning of a personal encounter with the Nuu Dzaui people and its cultural history. Studying published chronicles and reports about this part of Mesoamerica, such as Antonio de Herrera, Friar Francisco de Burgoa and the Relaciones Geográficas (Acuña 1984, 1984-1985), as well as archival documents, makes it possible to reconstruct the historical environment, the social organization and religious worldview in which the contents of the codices are to be contextualized. In many 
aspects the information from the early colonial period may be projected back into the past. Needless to say that knowledge of the language is crucial at this stage, not only of the cultural vocabulary, concepts and idiomatic expressions, but also of the root metaphors, symbolic meanings and ideological associations.

On this level it will become clear, for example, that the dramatic story of Lord 8 Deer and Lady 6 Monkey deals with power, ethics, and the human condition, in a way that remained relevant for many generations of rulers of the Nuu Dzaui village-states, right up to the Spanish invasion. As such this narrative is a crucial key to the precolonial political, intellectual and experiential world. As an overarching story that involves many places of the region, it also becomes an emblem of identification, a form of narrative identity, for the Nuu Dzaui people. In a different way, Codex Yuta Tnoho formulates a similar message: its presentation of a primordial, sacred temporalspatial order of the region stresses the underlying ideological unity of the political mosaic of diverse mats and thrones.

Personal work in the communities with which the studied manuscripts are connected, is needed both to register local information that may help the interpretation, and to develop a perspective on its social relevance. As cultural erosion is taking place on a huge scale, documenting the oral tradition is obviously also an aim in itself, as part of a strategy to support and revitalize the affected communities. Traditional knowledge is often expressed in texts of profound contents, dealing with age-old customs, social-political organization (e.g. the local hierarchy of offices or cargos, and the subdivision of the community in specific units, barrios) as well as sacred accounts and places, ceremonies and religious concepts. A better understanding of this lifeworld needs an (interparadigmatic) empathy with its values and a sharing of its emotional dimension.

We urge those with a specialist's interest in Nuu Dzaui culture and history to study and practice Dzaha Dzaui themselves in order to be able to grasp its semantics, concepts and metaphors, and to verify the arguments in the reconstruction of cultural history. Our own terminological and etymological analyses are generally based on comparing the terms given by Alvarado with their cognates in the variant spoken in Nuu Ndeya (Chalcatongo) today, a procedure that permits a philological interpretation within the context of a living language.

In studying the dialectical relationship with oral tradition and the internal stratification produced by copying and integrating other 
sources, we have to be aware of the fact that we are reading the manuscripts very differently from the way they were originally supposed to function. Codices and similar works were produced and performed in ceremonial contexts, on the instigation of the indigenous nobility; they express among other things the political preoccupation with the legitimacy of power, in this case achieved through references to the religious cosmos and to the historical world of the Ancestors. Our perspective is not determined by the aim to demonstrate the origin or legitimacy of a specific noble house and enhance its importance, but, instead, by the wish to construct an overview of ancient history, and, if possible, to understand some of the underlying motivating factors. We therefore often choose to re-accommodate the different data in a chronological framework, which would permit a clearer view of the sequence of events and their possible causal and dramatic relationships.

The third and last level of the interpretive process, then, involves us ourselves as active participants in dialogs with others. We evaluate the story, or rather the cultural interaction itself, in terms of our own experience, background and reflection. First we have to listen to the original statement, educating ourselves as much as possible in the ways of the public for which it was originally destined, by situating ourselves within the hermeneutic horizon of those days. Now, on this last, abstract level, we engage ourselves even more in this intersubjective communication and situate the work - and our response to it - in the whole of culture-history and society, exploring its messages for the present and for issues of our common world. We enter into a dialog with the past and so make it part of the present again. ${ }^{10} \mathrm{We}$ must do so critically, examining the particular relationships of the past to the present and vice versa, as well as our own involvement. Why are we doing this specific research? What is the concrete contribution of this research going to be? What are our aims? How do these aims interact with our investigations, motivations, methods and findings? These questions imply on the one hand taking some distance and on the other relating personally to the work or the message that we are

${ }_{10}$ The work of Rosemary Joyce et al. (2002) elaborates on the methodical and theoretical value of the Bakhtinian concept 'dialogue' in archeological studies. See also her contribution to the volume edited by Jansen and Van Broekhoven (2008). Important insights are gained by practical experiences in North America: see for example the work of Watkins (2000). 
trying to understand, often on an experiential level, e.g. in terms of aesthetic emotion and social engagement. For the encounter to be productive the investigator needs to go on a quest, to become aware of his/her own perspective and to question his/her own reality. Where the first and second levels are about codes and contents, the third level is about values, relationships and points of view, about the communication between minds, about experiential and spiritual growth, about philosophy, and about social and human solidarity.

Looking at the development of interpretation it is important to identify the areas of interest of all the participants: intellectual themes and the history of ideas, but also the needs, desires, traumas and social aspirations of the subjects involved, e.g. the issue of the recognition and defense of the human rights of indigenous peoples. It is here that we touch the cultural "pain points" Van Alphen was referring to, the pain points of Mesoamerica, but also the pain points of Europe or 'the West', and most of all, the pain points of the interactions between both. Are the indigenous peoples only objects embedded in the discourse of an outsider group that basically aims at confirming its own privileges? Or can the research be connected to the objectives and priorities of these peoples in a common struggle for social justice and emancipation? Here we enter a real-life world of contradictory experiences, complex memories and traumas, which are not just 'out there', but involve us directly (Estés 1992; A. Assmann 2007). This has led us to focus on the meaning of the ancient texts for the present-day Native American peoples in the light of the problematic power relationships that result from five centuries of colonialism.

The three levels of iconological analysis may be compared to the three orders of meaning, distinguished by Roy Rappaport in his magnificent study on ritual (1999). His 'low-order meaning' is the result of taxonomic distinctions - which correspond to the study of conventions on our first level of iconological interpretation. The 'middle-order meaning' becomes manifest through the discovery of similarities and metaphorical relationships - comparable to the status of the themes on the second level. The 'high-order meaning' is that of personal involvement, participation in an experience, which, indeed, belongs to our third level.

As far as the attitude of the interpreters is concerned, the three orders of meaning may be taken to represent a continuous path from objectivity via intersubjectivity to subjective experience and personal 
evaluation. This path is not a one-way street, obviously, but permits and stimulates the going to and fro, the dialectical interaction between the different levels, positions and points of view. In practice the levels and articulations of analysis interact continuously with one another. The subjectivity of the 'high order' should not be seen as something that makes communication and knowledge impossible, quite on the contrary. For 'low-order' and 'middle-order' meaning we have to study the categories of the culture. On the 'high-order' level deeper understanding is produced by human experience, concretely by fusing the other orders with empathy and the acceptance of other views as valid options, which deserve respect.

We should stress again that these different levels, spheres or orders are analytical tools. In practice the process of interpretation is a continuous interaction between all these aspects, a retro-alimenting and dynamic hermeneutic circle. Therefore, choices, positions and perspectives on the third level have their consequences for what happens on the first and the second.

Contexts and moods are also important here. Cultural studies do not take place in the sterile surroundings of a laboratory, but in specific social and emotional life spheres, which have consequences for the observations and understandings. Studying an ancient codex among erudite colleagues, with respected positions in Western academia discussing remote civilizations over sherry in the precious and comfortable surroundings of an elite institution, with access to a wealth of literature and other resources, is quite different from making such a study in a poverty-stricken village in direct contact with the cultural tradition the manuscript stems from and refers to, but at the same time immersed in an environment where pain, racism, discrimination and internalised colonialism determine the worldview and are still frustrating personal and collective development. ${ }^{11}$ Different are the challenges and questions, different the methods and possibilities, different the very natures and emotions of the research itself and different the resulting discourses. Hermeneutics would plead for an integration of such opposite approaches, and indeed the merging of such horizons would mean a lot to both communities involved, but the

${ }^{11}$ For an impression of the social reality in the Mixtec region, see for example Pérez Jiménez 1990, Fox \& Rivera Salgado 2004, and Reyes Hernández 2005. 
example also shows that bridging such differences is in itself quite a difficult and conflictive task.

\section{Intercultural Dialog}

In all its complexity, interpretation is a communicative and engaging process; it cannot be 'objective' because the reduction of the other to an object precludes any dialog.

At one time I maintained that the project of dismantling anthropology's intellectual imperialism must begin with alternatives to positivist conceptions of ethnography. I advocated a turn to language and a conception of ethnographic objectivity as communicative, intersubjective objectivity. Perhaps I failed to make it clear that I wanted language and communication to be understood as a kind of praxis in which the Knower cannot claim ascendancy over the Known (nor, for that matter, one Knower over another). As I see it now, the anthropologist and his interlocutors only 'know' when they meet each other in one and the same cotemporality. (Fabian 1983: 164).

Dialog has to be intersubjective, in this case between subjects from different cultures. It is not just between 'Western' scholars, who share the same mental framework, nor is it just between them and exotic authors of an imagined past or a 'folk' present, which both may be to a large extent constructions of the 'West'. In order to avoid being a monologue, the dialog has to engage the living descendants of the investigated past, the inheritors of that cultural tradition, not in an imposed passivity as 'informants', but as protagonists with their own ideas, aims and agency. Native American activists have to be the prime participants in the dialogs about their heritage. ${ }^{12}$

Obviously, such a dialog has to rely on equity, dignity and mutual respect, but this turns out not to be so easy in practice. The terms of the dialog are not equal nor mutual, as many definitions, concepts and values in the research come from the historically constituted 'Western' vocabulary and are unilaterally and uncritically applied to 'the others', i.e. 'Non-Western' societies. Among those there are quite a few terms which are only applied to others but never to 'self, and which connote

12 We agree completely with Artís (2005: 40-43) in her criticism of the term 'informant', but at the same time lament the absence of indigenous experts in her own edited volume. See also the criticism of anthropological practices by Pérez Jiménez $(1982,1989,1999)$ and the review of anthropology's relationship to colonialism by Pels (1997). 
self-serving ideas about 'Western superiority'. The lifestyle and values of Western Europe and the United States of America are often implicitly seen as the logical 'top' or end product of a 'natural evolution'. A deconstructive analysis of such misplaced self-satisfaction is a prerequisite for intercultural communication on an equal footing.

Although we may question the 'Westernness' of the so-called 'Western' culture and paradigm today (profoundly influenced and transformed as they are by centuries of cultural, political and philosophical-religious interaction with other parts of the world), there is no doubt that in practice the dominant mind-set of the North-Atlantic economic and political alliance holds a firm grip on intellectual projects and defines the world in its own, i.e. 'Western', terms. Behind those terms, the colonial structures inherited from the past are still lurking and determine, legitimize or reinforce the inequalities and injustices of the present. Representatives of indigenous peoples and decolonization theorists, such as Vine Deloria (1969), Ward Churchill (1998) and Linda Tuhiwai Smith (1999), have denounced this painful reality and raised some critical issues, which cannot be passed over in silence. The most pressing point for our consideration is the privileged and powerful position of 'Western' researchers (anthropologists, archeologists, linguists and others) vis-à-vis the indigenous peoples, which their very interest makes into mere 'objects' of study (and hence eventual manipulation). The dominant use of specific terminologies reflects this 'we-them' divide and continues, promotes the Western monologue on 'the (inferior) other'. In the 16th century the Spanish monks expressed themselves about Mesoamerican religion in terms of 'idolatry', 'witchcraft' and 'work of the devil', clearly distinct from their own 'true religion'. Later anthropologists coined the term 'myth' to refer to a story or account which is considered sacred by 'others' but not by the ('Western', rational) investigator, who sees it as a mere curiosity, maybe with interesting symbolic contents, but basically invalid. ${ }^{13}$ The Spaniards described native peoples as 'barbarians' (cruel, bloodthirsty, propelled by fears and other irrational emotions); later researchers invented terms such as 'primitive society' and 'pre-logical mentality', which basically convey the same picture. At present the

${ }^{13}$ Luis Reyes García, therefore, insisted on not using the designation 'myth' for Mesoamerican religious narratives, and suggested more dignifying terms, such as 'sacred history' or 'symbolic narrative'. We follow his example and are happy to see that several other scholars also start to feel the same way (e.g. Byland in Blomster 2008: 335; Brito Guadarrama \& Reyes Equiguas in Graña Behrens 2009: 248). 
contributions of 'Non-Western' civilizations to human knowledge are often distinguished by the prefix ethno-: 'ethnomedicine', 'ethnobotany', 'ethnolinguistics', etc. Originally such terms referred to the combination of the corresponding discipline with ethnography, but by now most of them have degenerated into an 'othering' label that distinguishes those activities as being done by persons of 'other' (inferior) cultures and therefore not of the same status and level as 'true (i.e. Western) science'. In this line of thinking, indigenous (i.e. internally colonized) peoples are no peoples (with rights and dignity) at all, but casual, disorganized 'ethnic groups'. This is not a politically neutral term, of course: indigenous social movements have been struggling for the past decades for the recognition of indigenous peoples as peoples (with the plural -s). Peoples have rights in international law and precisely the problem is that many nation-states do not want to recognize such rights, but prefer to maintain 'their' indigenous peoples in a permanent condition of internal colonialism. Consequently, there is a special term for the science that investigates them: anthropology, while the study of similar issues in 'Western' societies is not called that way, but qualified as 'cultural history'. The study of the history and music of the internally colonized peoples is set apart (and implicitly exposed to inferiorization) as 'ethno-history', 'ethno-musicology', and so on. When it concerns 'Others', many students of the social and cultural sciences become - from their early formation onward imbued with this paternalist vision (the superiority of the ego-group and the corresponding loyalty to the state), so that they, although often outspoken against social injustice, tend to reproduce it in their mental categories and in their way of thinking and acting.

This is just an example of the omnipresence and power of 'Western' terminologies and concepts, which are so engrained that questioning them may even provoke angry or disturbed reactions among students and colleagues. In a parallel way the speakers of Mesoamerican languages are totally surrounded by Spanish: most names of persons, places, streets, schools etc. are in Spanish and relate to national lifestyle and history; all schoolbooks, teaching programs and scholarly meetings are in Spanish, and it is in Spanish that their culture is being studied and their feelings are interpreted. What dialog? What intercultural hermeneutics? It is time for a postcolonial perspective and practice. 


\section{Ideology and Legitimation}

Scholarly perceptions and interpretations today are profoundly influenced by the developments and current themes in the study of ancient Mesoamerica themselves. A first important issue is the reconstruction of the ideology of the ancient rulers and their peoples. At the end of the 1970s Nancy Troike started organizing the successful series of workshops on Maya hieroglyphic writing at the University of Austin, given by the charismatic Linda Schele and a number of other scholars. The progress in that field had great influence on how specialists thought about Nuu Dzaui pictography. The new decipherments of Classic Maya inscriptions offered a wealth of fascinating data for understanding the ancient dynastic discourse, particularly the iconography of royal rituals and power symbolism. Studies such as that of accession expressions by Linda Schele and Jeffrey Miller, published under the title The Mirror, the Rabbit and the Bundle (1983), brought a new focus on the veneration of the Sacred Bundle, already highlighted by Karl Anton Nowotny and Werner Stenzel. The ecstatic aspects of this ceremonialism, symbolized by the 'Vision Serpent', became too obvious to ignore. The ongoing decipherments of Maya inscriptions and images brought back a consciousness of the strong common base of Mesoamerican concepts, connecting Maya, Mexica and Ñuu Dzaui discourses and works of art. This has inspired interdisciplinary investigations with a strong hermeneutic aspect.

The interest in religious thought, art, symbolism and poetic metaphors, is in accordance with the latest trends in archeology, which in part are a reaction to and, in part, a coming of age of the positivist, functional-processual 'New Archeology', and to some extent are inspired by Postmodernism. Actually we have 'cognitive-processual' and 'post-processual', 'contextual' or 'interpretive' archeologies, which show great interest in the meaning of archeological remains, in the continuity of cultural traditions, and, therefore, in the symbolism and ideology of ancient societies as well as in the presence of other, indigenous voices in the process of interpretation. ${ }^{14}$

In his introductory evaluation of archeological research, as presented in the first supplementary volume of the Handbook of Middle American Indians, Gordon Willey concluded:

${ }^{14}$ See for example Trigger 1995: ch.9; Hodder 1995; Renfrew \& Bahn 1996: ch. 12. A specific archeological application of cultural metaphors is offered by Tilley 1999. 
Archaeologists can only redouble their efforts in their application of scientific techniques and in the systematization of their own data to approach scientific standards and keep on trying. Whether these advances will lead to the explanation of cultural process is difficult to predict. There is, however, one encouraging aspect of Mesoamerican archaeology. This is its retention of its old, rich humanistic tradition. It is expressed in the way that the subject is embedded in a marvellous ethnographic and ethnohistoric context, and in some of the following chapters it can be seen how this tradition and these contexts have been further enriched and deepened by hieroglyphic and iconographic studies of the very recent years that help us tell the story of the past and, I think, better understand that story in direct, documented human behavioral terms. (Willey 1981: 27).

One would think that the positive value of striking a balance between those complementary approaches is obvious, but within the archeological discipline the quoted statement refers to an ongoing debate of theoretical self-reflection and self-definition in terms of 'history vs. science', 'materialism vs. idealism', 'hermeneutics vs. biological evolution', etc., with the all too real danger of creating a kind of archeological fundamentalism and, given the context of competition for shrinking funds, a senseless and fruitless polarization. The inspiring results of an inclusive approach, on the other hand, can be exemplified by impressive monographs such as that on The Cloud People, divergent evolution of the Zapotec and Mixtec Civilizations, for which the editors, Kent Flannery and Joyce Marcus, combined specialists from different trends and expertises:

We needed people who knew Oaxacan prehistory, and whose minds also would be open to an approach featuring divergent evolution or adaptive radiation. At the same time, we did not want our use of this explicitly ecological-evolutionary model to degenerate into the kind of monolithic cultural materialism that has characterized some archaeological theory in recent years. We did not want simply a description of how the Cloud People adapted their technology, farming, and economic networks to their respective valleys, or how they responded to demographic changes. We wanted people who were also willing to dig for the ancient cosmology, ethnoscience, ritual, religion, writing, and metaphysics of the Mixtec and Zapotec, regardless of the effort required." (Flannery \& Marcus 1983: xx).

At the same time there has been an increase in profound case studies of indigenous polities, which shows a growing interest in the ideologi- 
cal principles invoked in the discourse of the rulers. ${ }^{15}$ As to the concept of ideology in this context, we may distinguish between a 'holistic approach' in which ideology encompasses political organization and religion, and a 'more limited approach' in which ideology is equated with legitimacy. In a similar manner, Eagleton concludes his survey of the ways in which the concept 'ideology' has been used by different authors through time:

The term ideology has a wide range of historical meanings, all the way from the unworkably broad sense of the social determination of thought to the suspiciously narrow idea of the deployment of false ideas in the direct interests of a ruling class. Very often it refers to the ways in which signs, meanings and values help to reproduce a dominant social power, but it can also denote any significant conjuncture between discourse and political interests. (Eagleton 1991: 221).

The latter part of this definition (our italics), with its focus on the employment of sign systems, is of obvious relevance for iconological studies. Needless to say, it is important to interpret the ideological character of artefacts, images and signs as produced by and functioning in a historical and social context. Joyce Marcus sees Mesoamerican writing both as a product and a vehicle of the competition for prestige and leadership positions, i.e. as an arena of legitimation and propaganda in a specific sense:

Horizontal propaganda takes place within a group organized on the same level - for example within the ruling stratum of society rather then between the elite and the commoners. Such a group may have a set of beliefs, principles, myths, and ideology that defines it or sets it apart from other groups within society. Many Mixtec pictorial manuscripts, for example, contain information about the genealogies of ruling families; those documents were kept by priests so that it would always be clear who would be the appropriate successor to the throne. Such painted books were not intended to influence commoners, since the latter were not going to vote for the next ruler anyway. Rather, the books

15 The important role of ideology in the process of state formation and the ideological or even magical significance that writing itself can have in that context, have been the theme of many studies (e.g. the segment 'The rôle of writing and literacy in the development of social and political power' in Gledhill et al. 1988: $171 \mathrm{ff}$.). The ideological aspects of the native historiography of Mesoamerica have been analyzed by many authors - see for a synthesis: Demarest \& Conrad 1992 (cf. also Claessen \& Oosten 1996). A short history of ethnographic studies of Mesoamerican religion has been published by Medina Hernández (in Broda \& Báez-Jorge 2001); particularly relevant for the case of Oaxaca are the insightful books of Miguel Bartolomé (1997, 2008). 
were kept as a form of integration propaganda to settle disputes and keep all members of the elite aware of exactly where they stood in relation to the main line of royal succession. (Marcus 1992: 11-12).

This analysis has proven quite influential. On the other hand we should remember the small scale of Nuu Dzaui polities, which promoted strong interaction and shared social ethos between all segments of society. It is important to avoid modern 'Western' projections and to view ancient societies in their own terms (see Bartolomé 2008: 19-53). As Ian Hodder rightly argues, ideology is multiple and born in the interaction between the different parties:

I define ideology as the use of symbols in relation to interest. It is that component of symbol systems most closely involved in the negotiation of power from various points of interest within society... There is rather recognition that social groups are able to penetrate dominant ideologies and engage in resistance and social action in relation to different interests and ideologies. There is thus not one ideology but many, and there are many different types of power and prestige that are negotiated in relation to each other. (Hodder 1995: 208).

Ideologies are based in daily life, in cultural schemes that are taken for granted, in order to promote the notion of the 'normality' of certain social relationships (Hodder, op. cit.). In this way it is to be understood that the religious ideas about the order of the cosmos - often constructed precisely as a projection of the already existing social order - are continuously invoked as a paradigm for the order of society and the norm for human behavior. In this way politics, ethics and worldview are intimately connected:

Ideology certainly plays an important part in processes of legitimation, but its nature is more encompassing. It validates the order of the world in a much broader sense. It explains specific human relationships in terms of myths, it is expressed in rituals which maintain the order of the world and it is shaped by institutions which constitute the hierarchical order of the world. (Claessen \& Oosten 1996: 365 ff.).

Where ecological, economic and technological factors set the scene for the possible formation and growth of the $\tilde{n} u u$ (village-state), ideology had to provide the inspiration for the internal cohesion and identity of the community, the foundation for the legitimacy of the leadership and, often, the engine for expansion and development (cf. Conrad \& Demarest 1984). The concepts of order - both cosmic and social are reflected in the archeological record, most explicitly in historical 
monuments, iconography and texts. From an evolutionary perspective we can follow their use and development from the early Olmec chiefdoms, which show a strong emphasis on shamanic, nahual leadership, to the period of urbanization and early statehood with its elaborate court-life and ceremonial architecture. Ancient ideology is, therefore, quite an important topic in Mesoamerican archeology and history. The modern ideologies underlying these very studies, however, receive much less attention.

\section{Community and Continuity}

Another topic of debate in the studies of ancient America is the relationship between past and present, archeology and anthropology. To those who have spent some time in a contemporary Native American community, it is generally quite obvious that the knowledge and living traditions of the direct inheritors are a crucial source for understanding both the present culture and the past. But this observation has also provoked a stream of theoretical objections and methodological 'warnings'. A priori, it was claimed, the exploration of cultural continuity would make no sense, because of the phenomenon of disjunction: radical disruptions and transformations have severed modern Native American society from its past, broken the connection between form and content or even eliminated content altogether. The colonizers, it was further argued, did completely exterminate the native leadership and so effectively decapitated the culture created by that elite. Consequently the ancient culture is terminated and now can only be known through a kind of autopsy. While the image of a 'decapitated culture' was made popular by the work of the historian Arnold Toynbee, the term 'autopsy' was actually used by art-historian George Kubler (1961), a strong defender of the application of the notion of disjunction to Mesoamerica. ${ }^{16}$

Of course one should be aware of the possible pitfalls in using aspects of cultural continuity from precolonial times to the present, but this caveat should not be construed to ignore relevant elements. Implied in the 'decapitation' metaphor is the conviction that the 'head'

16 This notion was put forward by Panofsky himself in discussing (the quite different) phenomenon of the Renaissance's reuse of the motifs of ancient Greek and Roman art. For a discussion and refutation of Kubler's point of view, see Jansen 1982b, Loo 1987, Jansen 1988a, Anders \& Jansen 1988. Compare Hamann in Blomster 2008: $149 \mathrm{ff}$. 
(leadership) of the society is also the (exclusive) 'thinking part' of the population and the main creative force in the culture. This combination of intellectual, ruling and economic privileges into an upper class or 'elite' may sound logical from a modern perspective, according to which higher education is one of the keys to social mobility - as most authors working in academia are keenly aware - but cannot so easily be projected onto ancient civilizations. First of all the 'elite' of those days should not be judged only on its cultural creativity or philosophical abilities. Success in war was often a more important precondition for rulership. In using the vague notion of 'elite', we are actually dealing with a heterogeneous group of kings, queens, noblemen, priests, warriors, rich merchants and artists, who may have had quite different forms and degrees of education and intellectual capacity, but supposedly still shared one framework of reference, one sphere of communication. At the same time this sphere also included other segments of society, or at least communicated with those on several occasions. For the small village-states ( $\tilde{n} u u)$ of Classic and Postclassic Nuu Dzaui the concept of an 'elite' is problematic and, if used, needs clarification and contextualization.

Certainly there was social stratification that distinguished sharply between the tribute receivers (the rulers and priests: the iya and iyadzehe, 'divine lords and ladies' in Dzaha Dzaui) and the tribute givers (those who worked the fields: tay situ ndayu), but one should be careful not to project too rigid class divisions or to postulate a total divorce between the elite and the rest of the community. In the codices the members of the noble houses are distinguished by their turquoise necklaces, jewels, precious feathers and colorful clothing. These items are indicative of the tribute structure: those that were not locally produced signal the nobles' participation in networks of long-distance trade and 'international' exchange. On the local level such objects marked a social boundary, but since the polity was relatively small it is not to be expected that this status distinction took the form of a total barrier. Quite the contrary, the ruling families, and the artists working for them, conceived the public rituals and iconographical programs precisely in order to reaffirm their ideological position and to communicate messages about cosmic order as cultural value and social ethos to the people in general, referring to the worldview or 'cognitive map' shared by the whole community. ${ }^{17}$

17 See Renfrew \& Bahn 1996: 370. Particularly relevant in this respect is the concept of a 'theatre state' (cf. Demarest \& Conrad 1992: 149 ff.). The roles of elites and 
Across Mesoamerica, pyramids and plazas emphasized and made permanent the setting aside of sacred space for elite use and provided for public participation (at least as spectators) in rituals that constructed and reinforced societal conceptions on the nature of rulership. (Grove \& Gillespie in Demarest \& Conrad 1992: 35).

The expressions of ideology should be interpreted within that social context of communication. What the princes and priests were saying was meant to be understood and to be listened to by those who rendered them tribute. Seen in this light, history was part of ritual celebrations and commemorations that involved the whole of the community. Deeds and conflicts of the past became the subject matter of epic narratives and connected with a reiterated commitment to moral and religious values contributed to the construction narrative identity. Let us think about the city-states of Classical Greece: theatre and myth were not exclusive. Likewise, the social contexts of influential thinkers and religious leaders, such as Socrates or Jesus of Nazareth, show that neither they themselves nor their ideas can be easily defined as belonging to an 'elite'. Pervading society as a whole as a collective cultural memory, religious thought and experience may endure and survive critical historical transformations. That is one of the ideas behind the study of continuity.

On the other hand we agree that one should not simply project a present situation onto the past. We cannot stress enough the importance of recognizing that continuity implies change and on-going transformations. As the process of colonization and, more recently, industrialization has significantly transformed the indigenous cultures, the relationships of the present with the past must be analyzed carefully. Dramatic events, such as the Spanish conquest, and their consequences should be taken seriously and be investigated, but there is no justification for using them a priori as a theoretical impediment and for disregarding the traditions of the living Native American peoples altogether. Indigenous traditions have been seriously affected and changed by the process of colonization, but they have not been totally destroyed: many ancient customs and concepts (in the fields of technology, organization and religion) survive, be they connected or not

commoners (and their relation to 'high culture') in Oaxacan archeology is also discussed by Hamann and by Joyce in the volume edited by Blomster (2008). Particularly relevant is Bartolomé's critique (2008) of the dominance of 'Western' capitalist and individualist notions in modern archeological theory. 
with elements introduced from Europe. In the same way many indigenous languages continue to be spoken today.

The concept of continuity in Native American studies may be better understood if put in the context of the well-known theory of Fernand Braudel on the three modes or speeds of history: that of the events (histoire événementielle), that of the institutions (histoire conjoncturelle) and that of long duration processes (histoire structurale). Continuity refers especially to the latter and explores the presence of profound factors and values, not only in the landscape, but also in the language and the cultural tradition, which remain constant in spite of many rapid changes on the surface. These long-duration elements and structures, called the 'hard core' (núcleo duro) by Alfredo López Austin (1994), are especially well represented in the sphere of religion and social organization. ${ }^{18}$ When talking about long duration, Braudel was thinking of ecological processes. In applying this concept to culture, cognition and mentality we must not forget that history, as remembered by the people, has an accumulating and evaluating effect: collective memory stores the experiences of the past, draws conclusions and installs behavioral norms. In this way a cultural tradition can remain true to its 'core', its 'profound identity', in a subjective way, although over time its subsystems have suffered major transformations. The same happens with language: it changes over the course of the centuries, but, as this development is known, it is still felt and recognized to be the same language, even though ancient forms may have become unintelligible to a modern speaker. Specific forms and themes of literary expression become part of the tradition and may be in use for a long time. Speech acts of today, therefore, may open a window on the past.

On the first level, language proficiency is a key factor in identifying place signs, for example. On the second it is a conditio sine qua non for trying to understand the native worldview. On the third level we see it as an essential part of intercultural communication. The participation in a living language community is what distinguishes the insiders from the outsiders.

The awareness that thorough familiarity with the contemporary indigenous languages, societies and belief-systems is an important condition for a better understanding of the archeological data, as a

${ }^{18}$ See also Bartolomé 1997 and Broda \& Báez-Jorge 2001. For a panorama of modern, international and critical ethnographic studies in Mexico, see Artís 2005. 
complement to the historical research and as a heuristic tool, fits well into 'ethno-archeology', which in the 1970s became a recognized subdiscipline within the field of archeology. This time the prefix ethno-is still used in its original sense as expressing the need to combine archeology with ethnography, considering that ethnography can be done in all societies, also 'Western' ones. In principle, no exotizing nor inferiorizing implications are meant, nor does the term specifically refer to 'ethnic groups'. The main objective of the ethno-archeological method is the interpretation of the archeological record through a comparison with living cultures, whose customs are either historically related or only analogous to the archeological culture. Obviously, if the compared cultures are not historically related, the construction of an analogy must often remain a speculative hypothesis, and in that case ethno-archeology becomes part of a comparative anthropology. But the period of time that separates present-day Native American communities from their precolonial past is relatively short (at least in archeological terms) and well documented as to its social-cultural transformations. The comparison in this case is not a matter of analogy but of cultural continuity, and, therefore, an ideal ground for the application of the 'continuous model' or the 'direct historical approach' of ethno-archeology (as defined by Gould and Hodder respectively). In such cases the combination of archeology with the study of living traditions offers valuable possibilities for a better understanding of specific items of the past.

The concept of cultural continuity does not mean that we have to suppose an anachronistic fossilization of society, but, quite the contrary, implies a dynamic diachronic relationship of the present with the past, in which there are bound to be important changes and in which at the same time important traditional elements and structures may be preserved. In fact, the present-day traditions and concepts become a crucial point of departure for a better identification and understanding of the themes and motifs in ancient images and texts. There is a dynamic relationship between past and present, which is captured in the term 'cultural memory'. ${ }^{19}$

19 The concept of 'cultural memory' helps to overcome the dichotomy between cultural continuity and change and also to connect the spheres of cognition, experience and creativity (cf. J. Assmann 1992, A. Assmann 2007, Graña Behrens 2009). Similarly, Fischer (1999) connects the concept of cultural continuity with that of cultural logic. 
The logical consequence of the ethno-archeological approach in a continuous situation is the collaboration between the interested outsiders and the indigenous experts, a collaboration that implies a true partnership, no longer based on the classic 'participatory observation' in the interest of a dominant society, but on real participation with dialog, solidarity and a joint exploration of cultural values:

Although archaeologists working in our homeland have been able to identify a wide variety of artefacts through seasoned practice, it remains to be seen how much more could have been known or how much more refined their studies could have been if they had enlisted our elders to work side-by-side with them to challenge and share each other's perceptions. Both of us can only gain from this process, and I hope that, in the future, innovative programmes will be developed within the archaeological community to meet the needs of the Inuit and other aboriginal peoples of the world in preserving, interpreting and protecting yesterday for tomorrow. (Anawack in Preucel \& Hodder 1996: 650).

For Native Americans the cultural continuity is a connection with the roots, a legacy of the ancestors, which may be a source of consciousness, strength and spirituality. For those who try to listen to these voices and to understand the artistic expressions within the framework of this living cultural tradition, it is a beautiful experience to see and feel the interconnectedness between the past and the present. The great works of the precolonial times are not dead leftovers but strong messages, which may be understood in terms of the living culture. This perspective may radically change the attitude of the investigating outsiders:

As we began to research the themes we had chosen, to read the work of ethnographers, and most of all, to participate in modern Maya ritual, the book transformed itself before our eyes. It became a book on the continuity of Maya reality from the ancient past to the present. None of us will ever again be able to walk the streets of Yukatan, Chiapas or Guatemala and think of the Maya we meet as merely biological descendants of the ancients, cut off from their past by the trauma of the Conquest...

The ruins left by the ancient Maya, and the cultural legacy they represent, have been appropriated by the Ladinos and mestizos as the patrimony of modern nations, without reference to the Indian peoples who still live among them. We have learned a different way of understanding the modern Maya who have become our friends ... the history written and preserved in images on hundreds of stone monuments and clay vessels, the architecture of their Precolumbian cities and residences, the fossilized remains of rituals in temples and hamlets, all hold a vision for 
the modern Maya that reflects their heritage because it still makes sense in their languages and practices. The modern Maya can claim their past because it lives in their present. (Freidel \& Schele \& Parker 1993: 11, 13-14).

... those of us working in the Maya region need to move now toward ensuring greater participation of contemporary Maya in the research process and toward exhibiting greater sensitivity and professional responsibility toward Maya ancestral remains, which in some cases means reburial. Most of all, we must recognize, as I have tried to show throughout this book, that the ancestral presence gives power, economic clout, dignity, and social identity to descendants. (McAnany 1995: 168).

\section{The Aims and Ethics of Research}

In the past archeology has often been seen as the servant (Latin: ancilla) of history. For decades now, it has been an independent discipline with its own methodology and theoretical framework. Our insistence on the value of contemporary traditions and the need to become familiar with those, e.g. by doing ethnographic fieldwork, in order to elucidate archeological and historical questions should not be taken as a suggestion to now make ethnography the servant (ancilla) of archeology. On the contrary, we aim at integrating archeology, history and ethnography as parts of a common cultural history, in order to foster a postcolonial cultural and historical awareness among all people concerned.

Pictorial manuscripts are a characteristic example of cultural interaction: an interaction between individuals that uses cultural means, specifically symbolic systems, which are based on the social organization and communication (the spoken language) and ultimately on the organic life (embodiment) of the individuals. This cultural interaction, in turn, has a strong influence on social life and, transcending not only spatial but also temporal distances, creates, expresses and is informed and guided by cultural memory and identity (J. Assmann 1992; A. Assmann 2007). The relationship between cultural interaction, memory and identity is, therefore, dynamic and dialectical. The study of such ancient cultural interaction today produces in turn an interaction, an engagement, of the present with the past, as well as of the cultural environment of the researchers and that of the inheriting communities of the ancient civilization concerned. We are dealing with cultural memory not only in a retrospective sense, but also in a 
prospective and constructive manner, in a way that includes critical idealism and a postcolonial perspective (Bhabha 1992) as well as an awareness of social-psychological trauma and a search for emancipation and empowerment (Estés 1992). Past and present forms of colonialism still determine the existence, worldview and memory of those who suffer the consequences and of those who, in a general sense, benefitted from the resulting unequal structures of the world economy. Of course this is no reason for the peoples affected to fall into self-serving and laming 'victimism', taking the adverse historical reality as an excuse for not living up to their own responsibilities and possibilities of positive action. Recognition is due, however, that heritages have been damaged and dispersed, accesses have been hidden and limited, futures have been disfigured and lost, identities have been hurt and traumatized.

An emic hermeneutic and direct historical method with its narratological and postcolonial theoretical background, can and should serve the process of mutual understanding between cultures. As such, it can and should serve the cause of emancipation and reconciliation. In such cases we may speak of a 'postcolonial hermeneutics'. Intercultural dialog is not only a means in iconological or historical research, but also, first and foremost, an end in itself. This requires a (self-) critical analysis of intercultural relationships and neocolonial power structures, which impede mutual understanding and sincere cooperation. In other words: a conscious personal effort to link cultural historical study with an awareness of the developmental and educative perspectives of the present. Engaging cultural interaction means decolonizing memory and reintegrating identity. ${ }^{20}$

When we pass through the State of Oaxaca, Mexico, there is no attention whatsoever given to regional history in the (national) educational system, much less to the Mesoamerican languages and literatures. The same is true for many other indigenous regions. Unfortunately, ignorance, colonial mentality and racialized discourse still prevail.

Traditionally - and paradoxically - archeologists and historians are often fascinated by the power play in the past, but reluctant to take a critical stand against oppressive forces in the present and to connect

${ }^{20}$ Linda Tuhiwai Smith (1999) insisted already on decolonizing methodologies. The work edited by Denzin, Lincoln and Smith (2008) offers a broad perspective on this issue. 
with emancipatory movements. The interpretation of historical sources forms part of this socio-political reality, which implies the presence and the pressure of different political projects. It is important to recognize that until now the vast majority of modern ideas and judgements about the native cultures of the Americas have been fabricated by outsider intellectuals. Too often archeological, historical and anthropological studies have willingly or unwillingly, explicitly or implicitly, supported an ideology of domination. These disciplines tend to describe the formation of social hierarchies and states, of law and order, uncritically as a positive, logical and necessary evolution: history is conceived as the unquestionable 'progress' toward the military and economic powers of the present. Even the social scientists use conceptualizations and viewpoints from their own world, such as neoliberalism (focusing on economic development through 'modernization') or its opponent, the Marxist dependencia theory (focusing on 'national liberation' through class struggle and revolution), and, as a third party, the cultural relativism of anthropologists and, closely related to that, the romantic idealization of the 'Noble Savage' (focusing on ethnic and cultural identity).

Furthermore, some academic environments are under the banner of (and aligned with) established interest groups, which pay for their activities or hold some other form of influence over them. This, in combination with a burocratic culture of career-oriented rivalry and personal animosities, means that the movement toward a postcolonial perspective is easily distorted and made victim of politically motivated censorship, if not of institutional inquisition and marginalization. Indigenous people are admitted as long as they adapt themselves to the dominant structures and rules, but once they manifest themselves as subjects with their own opinions, they spoil the party and are no longer welcome. The independent voices of descendant communities make the investigators of their cultural history feel uncomfortable. Communicating an unpleasant truth, they are from the start considered problematic, dangerous and subversive. The offended adherents of petty nationalism or neocolonial worldview may engage actively in damaging campaigns to boycot and blacklist those who try to discuss these problems openly and to promote the participation of indigenous peoples on equal footing in research as well as in decision making.

Consequently a painful contrast still underlies the studies of the indigenous cultures: that between the abstract intellectual concerns of an academic enterprise, generally conceived from a privileged outside 
position, and the bitter reality of those whose life and past are investigated. This creates an ethical problem and at the same time may have a distorting effect on the research itself: inequality corrupts communication and promotes false images. Preying on a culture to build grand theories and foster personal careers, will only silence its voice. The result is not a dialog of true mutual interest, but a monologue, doomed to reproduce endlessly the outsider's ideas, without contradiction but also without feedback and without social relevance. All this is far removed from the reciprocity ethics of Native American cultures and from the challenges of our common social reality.

Since the late 1960s, however, the political pressure of the indigenous movements on the national and international level, in combination with the conscious criticisms of a growing number of solidary nonindigenous intellectuals (social scientists, politicians, lawyers, priests) has made the predicament of internally colonized peoples more visible and has created much more attention for their cause and space for their action. ${ }^{21}$

The expertise and experience of the native peoples, which the colonial discourse, continued in the 'Western' monopolization of science, has tried to disqualify and bury, now emerge again, with their tremendous memory of struggles and their age-old capacity for resistance and renewal. Especially strong manifestos, such as that of Vine Deloria (1969), and actions such as those of the American Indian Movement (e.g. the spectacular stand at Wounded Knee in 1973), forced the international community to break its silence and forgetfulness. It was thanks to this brave struggle that the doors of the Palais des Nations were opened: a truly historical moment. By 1982 the United Nations Organization had created a special Working Group on Indigenous Peoples to examine the situation and to work toward a standard setting Declaration of the Rights of Indigenous Peoples. Out of the U.N. Working Group grew a Permanent Forum. Indigenous representatives can participate in the discussions, but progress is not easy.

${ }^{21}$ The violence against indigenous peoples in Mexico in the past decades forms part of a generalized repression, already manifest in the massacre of Tlatelolco in 1968. Although denounced by defenders of human rights, this campaign was denied and covered up by the governments of those days with revolutionary rhetoric and progressive pretensions. Today it is recognized officially as a 'dirty war', similar to the dirty wars in other countries in Central and South America. 
Several indigenous organizations have concentrated already for decades on the question of education, demanding an end to ethnocidal policies ('castellanización') and the introduction of a true bilingualbicultural or intercultural curriculum. Conscious teachers have made admirable efforts in the defense and development of their language and cultural heritage. Among migrants a new consciousness about their roots is clearly growing; quite a lot of them struggle not only for the improvement of their situation and the defense of their rights, but also for the emancipation of their people back home. In Mexico, the Zapatista uprising of 1994 has underlined the presence of Mesoamerican peoples and has put their predicament high on the national agenda.

After many years of discussions in Geneva and elsewhere, in 1994 a final draft of the Declaration of the Rights of Indigenous Peoples was agreed upon by the indigenous peoples' representatives, but it took till 2007 for the General Assembly of the U.N. to adopt and proclaim a somewhat amended and adapted version:

Article 11.1. Indigenous peoples have the right to practise and revitalize their cultural traditions and customs. This includes the right to maintain, protect and develop the past, present and future manifestations of their cultures, such as archaeological and historical sites, artefacts, designs, ceremonies, technologies and visual and performing arts and literature.

Article 13.1. Indigenous peoples have the right to revitalize, use, develop and transmit to future generations their histories, languages, oral traditions, philosophies, writing systems and literatures, and to designate and retain their own names for communities, places and persons.

Article 15.1. Indigenous peoples have the right to the dignity and diversity of their cultures, traditions, histories and aspirations which shall be appropriately reflected in education and public information.

The years to come will show how its important statements and guidelines will gain general respect and enforcement in the countries concerned, as well as transform the concrete research aims and practices. 


\section{ACTS AND VISIONS}

The way in which writing was used and read in precolonial Mesoamerica differed considerably from modern practice. Pictography should not be seen as a register for silent, individual reading, but as part of a rich communicative tradition, which expressed itself in oral literature and in the plastic arts. Several sources state that the painted records accompanied memorized texts, described as 'songs' or 'flowery speech'. This does not reduce the codices or lienzos to a mnemonic device, however. The pictorial statements are independent communicating devices.

Several anomalies that occur in the sequences of images can be explained as errors in a complex process of copying. We deduce from them that the painters primarily looked at the pictographic source and did not always have the story itself in mind. Then, on public occasions, specially trained performing artists, storytellers or bards would present or 'read' the codex or lienzo aloud.

In the Oaxacan region the development of this pictorial writing system formed part of the expansion of the 'Mixteca-Puebla style' during the Early Postclassic. It replaced an older system, the hieroglyphs and iconography of Classic Monte Albán and the closely related Nuiñe style, so far mainly found in the Mixteca Baja, but by no means limited to that area. ${ }^{1}$

Pictography also has the advantage of being understood across linguistic boundaries. So it was particularly suited for multi-ethnic realms and interaction spheres. It has a special appeal for speakers of

\footnotetext{
1 About the Mixteca-Puebla style and the position of the pictorial manuscripts within this horizon there is abundant literature, summarized, for example, by Nicholson \& Quiñones Keber 1994, and Anders \& Jansen \& Loo 1994. See also the pioneering interpretive study by Smith \& Smith 1980. A fascinating analysis of the Classic epigraphy of Monte Albán is contained in the work of Urcid Serrano 2001, while Romero Frizzi 2003b contextualizes it in the history of Beni Zaa writing from the beginning until today. The Ñuiñe style was defined by Paddock (e.g. 1966), the term being derived from the Dzaha Dzaui name for the Mixteca Baja (Nuu Niñe in the orthography of Alvarado); after the groundbreaking work of Moser (1977), its iconography is now being studied in depth by Angel Ivan Rivera Guzmán, Laura Rodríguez Cano and Javier Urcid Serrano. For a historical overview of the development of Mixtec writing see also the volume edited by Jansen and Van Broekhoven (2008).
} 
tone languages, such as Dzaha Dzaui, because it avoids the whole problem of how to express tone differences and changing tone patterns (the linguistic phenomenon known as sandhi).

In this context the debate among contemporary scholars about the degree of literacy in precolonial times is somewhat artificial and off the mark. These documents were not part of a wide-spread reading and writing culture, but functioned as specific registers in a much wider context of oral communication. Specialists did their reading, or rather performance, with a special gift for the verbal art and with a special training in that respect. There were people of great memorizing capacities, who knew how to tell the stories. The Franciscan Friar Motolinia states in the foreword of his chronicle (1969:5) how he had consulted such a man, who explained to him the origin of the peoples according to the books and his own interpretation. The existence of specialists is well documented: writing and reading history was not a common capacity of all, but the work of special priests and maestros (Torquemada, book I: ch. 11). In ancient Oaxaca there were two categories of codex-painters: 'children of the Lords', i.e. children of noble birth, and 'those chosen for priesthood' (Burgoa 1934a: 210). This distinction probably paralleled the two main types of books we know: the historical narratives and the ritual-divinatory 'Books of Wisdom'. We should not deduce from this, however, that pictography was in itself unintelligible to the people. The paintings were displayed on the walls of the palaces of the rulers and read aloud, 'explained', on special occasions (Burgoa 1934a: 210).

\section{Literary Style}

It is crucial to keep in mind that the pictorial writing functioned in a context of oral performance, as an interface between a trained storyteller and an audience. Given the relatively small scale of the villagestate and the frequent interaction of the whole community in rituals, we should not think of that audience as limited to the royal family and the priests. The iconic character of codices and lienzos lends itself very well as a shared point of departure for the performer and his public: the main line of the story was clearly marked and could be followed. In more mundane circumstances, such as tribute collection, we may safely assume that not only the nobles but also the commoners recognized the stylized images and even specific elements like toponyms 
and day signs. On the other hand, the complex mantic symbolism of the Books of Wisdom was probably only understood by priests.

We get a glimpse of the terms used for the oral performance of the painted story from the translations of the Spanish 'comedia': yaa, 'song', yaa dzeque, 'song-jewel', yaa huaha, 'good song', yaa yodzo huidzo iya, 'song that praises the Lords/Ladies', yaa iya nindacu, 'song of the Lord's or Lady's descendance', yaa iya nicaha nduhua ñuhu, 'song of the Lords/Ladies who fought battles'. ${ }^{2}$

The ancient art of painting was called huisi tacu. Interestingly enough the verb tacu 'to paint', can also mean - probably with different tones - 'to understand' and 'to live'. An image, scene or figurative painting is naa; one that commemorates the past is naa ndeye, 'image of a dead person'. The painted sign is called taniño tacu. This taniño is also used for 'symbol'. Thus a 'map' is a 'taniño of the whole world'. In the terms for 'metaphor', ndudzu taniño or tnuhu taniño, it is combined with $n d u d z u$, 'voice, speech', or tnuhu, 'word'.

Directly related is the term tnuni, 'signal, sign, symbol', which occurs in the expression for 'it is written (on paper)', yodzo tnuni tutu, but also in 'to leave a memory of oneself, yocootasi tnuni taniño. The same word is used in expressions for the 'coat of arms' of a village-state (tnuni tayu, 'sign of the throne'), or a lineage (tnuni toho), for the insignia of honor (tnuni dzico), war (tnuni yecu), victory (tnuni $n d o d z o$, literally 'sign of the quetzal bird') and even dowry (tnuni siña, 'sign of reverence, office or court'). It is also used in expressions that deal with study and understanding ('seeing the tnuni'), as well as authority ('setting the tnuni') or law (tnuni yuvui tayu, 'signals of the mat and throne'). As the central element in 'thought', 'example', 'counsel', 'judgment', 'wise' and 'reason', it is what separates the considerate and discrete ('civilized') from the brute and the bestial people ('those without tnuni'). Cleverly the missionaries used it in the term for 'crossing oneself: yotaa tnuni tnaandi, literally 'making the sign on ones front'.

Another word designates the signs sent by the Gods for humans to interpret: ñena is the 'omen' or 'augurical sign'. The act of divination, is descibed as 'explaining' or 'clarifying' (yonatniño, yodzandaa, yod-

${ }^{2}$ Actually Alvarado registers iyo nicaha nduhua nuhu. As the series of terms starts with yaa, we have to supplement that word at the beginning. The term iyo means 'there is' and does not fit, so we take it to be a typographical error for iya, 'Lord'. 
zandacu) these ñena. This terminology was probably also applied to the reading of a divinatory manuscript.

The general term for reading is the verb yocahui, also used for 'to count'. In colonial Mixtec literature it became the technical term for 'saying (praying) the rosary'.

In view of these connotations it is safe to assume that the ancient Nuu Dzaui valued the reading of the scriptures as a civilized act par excellence.

The public narration of history, then, demanded a capacity for finding the right words and 'literary' terms, the elegant difrasismos, the digressions to show good taste and to construct suspense. This was the expertise of somebody whose mnemonic techniques included rhythm, alliteration, idiomatic formulas, redundancies and pleonasms. He was probably educated in a special school or workshop, where training must have included a differentiated program of recitation and drama, painting and other plastic arts, as well as general historical and philosophical reflection.

On the one hand, writing overcomes distances, stimulating canonization, on the other it permits the reader to take distance from the text (decanonization). ${ }^{3}$ We may suppose that in the case of the codices the texts were exposed to reinterpretation, embellishments and reformulation by different generations of performers, responding and reacting to different audiences. In the course of time, as the viewpoints and interests of audience and performers changed, stories could be manipulated to please the public or for the sake of comprehensibility. According to contexts and occasions, certain parts of the story could be emphasized and elaborated, others could be reduced or left out, which could lead to new drafts, i.e. new pictorial manuscripts that replaced the older versions. This produced a lot of variety but also confusion and contradiction in native historiography (cf. Torquemada, book I: ch. 11, and book III: ch. 9).

In accordance with the canonical status of writing, for the Nuu Dzaui historians the art of codex painting and story-telling was of divine origin. It was the primordial culture hero Lord 9 Wind 'Plumed Serpent' himself who had invented writing and songs. He spread his knowledge as he went around founding the sanctuaries, polities and

${ }^{3}$ See also the inspiring classic studies of Ong (1982) and Goody (2000) on writing and its effects. 
cultural institutions of Nuu Dzaui, leading his people into the light of history. Finding the right words to express beauty, suspense, glory or despair, was consequently a matter of divine inspiration, and the recording of the past was essentially passing on the ancient values to the coming generations.

As for the style and idiom used, we find a clear indication in what Friar Antonio de los Reyes describes as the "Language of the Lords". It was an elevated speech, consisting of "reverential names and verbs, which the natives use in talking to the great lords or in referring to them" (Reyes 1976: 74). This definition suggests that it was not exclusive, but known and used by the people at large. The friar included in his grammar a small dictionary of terms and expressions. Studying these, we confirm that this is not another language, but a special form of normal Dzaha Dzaui, full of metaphorical expressions and elegant, sometimes archaic, words. A characteristic is the special suffix (enclitic pronoun) for the third person $-y a$, instead of the normal $-t a$ and $-\tilde{n} a$ for men and women. Today the $-y a$ suffix is used for Saints and divine beings. They are referred to in a solemn metaphorical idiom: the feet of the Lord and Lady are nduvua, 'arrows', their stomach ñono, 'a carrying net', their back or shoulders yusa, 'a shield', their teeth yuchi, 'knives', their fingernails teyusi, 'small pearls or precious stones'. Sometimes we find traces of this reverential language in pictography. For example, in Codex Iya Nacuaa the claw in the given name of Lord 8 Deer, 'Jaguar Claw', is combined with a jewel sign (yusi), indicating that it should be read as teyusi, 'Lord's nail'. His full name may be reconstructed as Iya Nacuaa Teyusi Naña or Iya Nacuaa Teyusi Cuiñe.

Similar expressions are still used today in formal discourse (sahu), and in general on ceremonial occasions as well as in dealing with the authorities, or simply in situations where people want to express themselves with politeness and courtesy (cf. López García 2007). Among the terms Alvarado registers for 'speaking with reverence' we find yocaha quaindi, yocaha yehe ñuhu huijndi (kahan kee, kahan yiñuhu vii in present-day Ñuu Ndeya), literally 'speaking with honesty and humility, speaking with respect, eloquence and beauty'. Obviously such contexts preclude the use of coarse or foul language, or allusions in that direction.

The preserved corpus of texts written in Dzaha Dzaui during the colonial period is limited and consists mainly of legal documents (testa- 
ments, lawsuits) and missionary manuals (catechisms, sermons). ${ }^{4}$ An interesting example of the literary language is found in a manuscript in the library of the Sociedad Mexicana de Geografía y Estadística. Originally classified as a catechism, it turns out to be a translation into Dzaha Dzaui of a treatise on the miracles of the rosary by the Catalan Friar Jerónimo Taix. The first Mexican edition of the Spanish text had been printed in 1559. A later edition (1576) has been preserved in the library of the Santo Domingo convent in Oaxaca City, now incorporated into the Biblioteca Burgoa. The contents of Taix's book are partly philosophical-theological, partly narrative. A first analysis of some chapters of the Dzaha Dzaui text, finished in 1584, shows that it is not a literal translation, but rather a literary elaboration of the original. For example, in the Spanish text we read:

When the blessed father St. Dominicus, founder of the order of the preachers [ordo predicatorum, the Dominican order], was preaching in the town of Abi ... (Taix 1576, book 3: ch. 3).

But the Dzaha Dzaui version is much more elaborate and goes as follows:

Quihui nisiyo dzacuahañahaya sancto Domingo

yya yyondoo yyo yy

yya nicuhui nuu nidzacay saha

dzahuatnaha nidzacayya chiyo nisataya chiyo

nidzacayya yuhu saha

dzahuatnaha nisani nitasiya

taca nduhu dzayaya

quihui nisiyodzicaya ñuu ñayehui yaha

nidzacuahañahaya nicahandodzoya

ee ñuu nani Abi

tayu canu nicuhui ñuu yсa ....
The days that he lived teaching, St. Dominicus, the pure Lord, the delicate Lord, the Lord that was the first, who founded,

and put the fundament, made the foundation,

put in its place the foot-stone [corner stone],

and set forward, created

the whole trunk of his children,

when he lived in this world, taught, preached

in a town named $\mathrm{Abi}$,

a large throne [= capital] was that town ....

${ }^{4}$ A first index was published in 1984 (Josserand \& Jansen \& Romero). See the Ph.D. dissertation of Terraciano (1994, published by Stanford University Press 2001) as well as Jansen 1994 and Jansen \& Pérez Jiménez 2000-2007b). For the Mixtec 'Language of the Lords' see Jansen 1985, 1998a, as well as our monograph on this topic and other issues of Mixtec colonial literature (Jansen \& Pérez Jiménez 2009b). 
Thus the translation of Taix's book (called Dzeque Iyadzehe, 'the jewels or necklace of the Virgin') gives us a unique opportunity to study the Dzaha Dzaui narrative, literary forms and religious vocabulary. The ways in which Christian theological terms are translated offers interesting insights into the native concepts. In the narratives many speeches are made by high-status protagonists like kings and queens, Saints and the Virgin Mary. They all use, naturally, the elegant metaphors of the reverential 'Language of the Lords' mentioned by Friar Antonio de los Reyes. Even though the contents are purely Christian, these literary and metaphorical expressions are directly relevant for the interpretation and reading of the precolonial pictographic codices.

\section{Lordly Gestures}

One of the consequences of the codices being pictorial writing is the lack of portraits. If the pictorial manuscripts were indeed, as has been suggested by Pohl, Monaghan and Hamann, and as we too suppose, the scores and starting points (as necessary documentary 'proof) for an oral performance, a more detailed individual portrayal of the protagonists was superfluous. The standardized faces in profile and stylized bodies are sufficient to transmit the notion of 'Lord' (iya) or 'Lady' (iya dzehe), while the added name signs, special regalia and attributes define the individual and his or her titles and functions. Imaginary evocations of their looks and personality could be left to the art and acting of the story-teller. The images produce referents to the actors of the story in the third person (he, she, the Lord, the Lady). This is different from a frontal sculpted image in a ceremonial context which engages the beholder visually and may be addressed as 'thou'. The codex figures are first and foremost references to memorypersonages as subjects of specific actions. The precise, standardized, 'incrustated' style of the figures, in their regular boustrophedon ( $y u q$ $y u q$ ) patterns, suggest a general, sequential order, evoking in vision the equally strict and solemn auditive order of the ceremonial language $(s a h u)$.

For the same reason the images rarely show emotion. Only occasionally do we see an angry face or a tear as an expression of pain and sorrow. Still it is important to remember that behind these static and 'stoic' images there was a world of true life-experience, as well as a 
whole set of concepts about the body and its functions. ${ }^{5}$ The personhood of the rulers and other office-holders was constructed through prominent participations in ritual, public performance and multiple social interaction. ${ }^{6}$ Several details of their graphic representation may be interpreted as indexes that refer to those processes. It was their task to protect and defend the community, both in a governmental and military sense and in the religious sense of intervening before the Gods on behalf of their people. This dealing with power made them very special and worthy of respect, support, tribute and obedience as well as of special distinctions in terminology (the above-mentioned 'Language of the Lords') and outer appearance (regalia, jewelry, bodypaint).

Thanks to the in-depth studies by Alfonso Caso, Karl Anton Nowotny, Mara Elizabeth Smith, Nancy Troike and others we are now able to identify the meanings of different postures and scenes. The basic event of the history of the yuvui tayu, 'the mat and throne', is the marriage of the rulers, crucial in producing the dynastic chain and its alliances. Today the most common term for marrying is tnaha ndaha, 'to join hands', but the precolonial metaphor was 'the ceremony of the mat' (huico yuvui) or 'the Lord/Lady placed the vessel for a drink' (nisiñesahaya). The gifts of the groom were referred to as ino dzehua, 'tobacco and chocolate'. Consequently the couple is painted as seated on the marriage mat, often on top of the place sign, one partner offering to the other a precious polychrome vessel with chocolate. An illustrative detail: sometimes there is foam on the drink, topped with flowers, in accordance with the Dzaha Dzaui metaphor ita dzehua, 'flowers of the chocolate' meaning 'foam on the chocolate drink'.

As an alternative for the mat we find the house (huahi) as a symbol of married life, with the extended meaning of 'family' and 'dynasty'. In both cases the Lords and Ladies, seated as rulers of the sovereign communities, are shown as equals. This corresponds to their equal

${ }^{5}$ See for example the studies by López Austin 1980, Joyce 2000 and Mikulska Dąbrowska 2008 on the Nahuatl world and the equally inspiring work of Houston \& Stuart \& Taube 2006 on the Classic Maya.

${ }^{6}$ Cf. the comments by Bartolomé (1997: $\left.149 \mathrm{ff}\right)$ on Mauss' concept of the persona as constructed in social interaction. Julián Caballero (2009) describes the formation of the social persona in a contemporary Mixtec village (Huitepec). Fowler (2004) and Brück (2005) discuss the applications of the concept of personhood in modern archeology. 


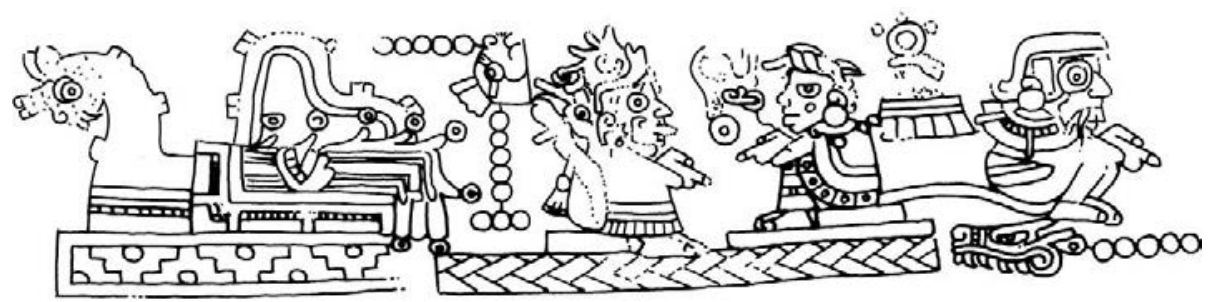

6.1. Codex Nuu Tnoo-Ndisi Nuu, p. 6-I: The ruler of Place of the River at the Foot of Curved Jaguar Mountain and Black Mountain (possibly Ayuta near Tilantongo), Lord 13 Dog 'White Eagle', sits on the mat, i.e. marries Lady 1 Vulture 'Rain Skirt' (Huatu Dzavui, 'Glory of the Rain God'). They have a son: Lord 5 Alligator 'Rain Sun'.

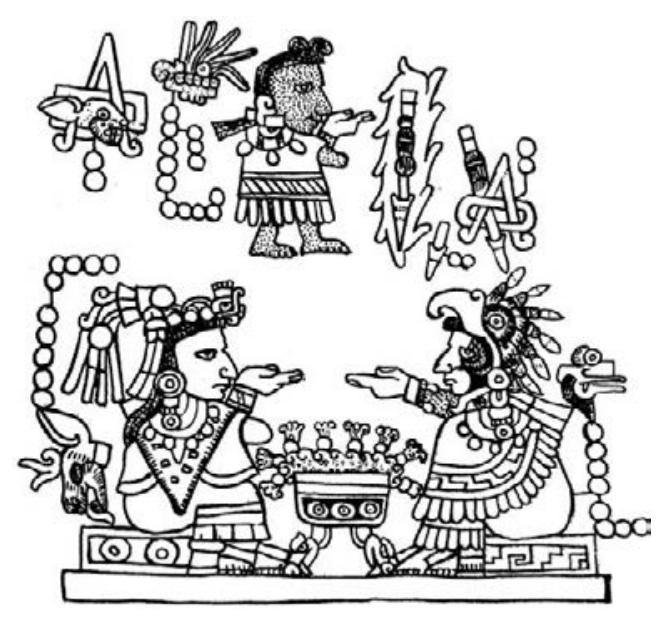

6.2. Codex Tonindeye, p. 5: Lord 8 Wind 'Eagle' (elsewhere: 'Twenty Eagles') and Lady 10 Deer 'Jaguar Quechquemitl' (Dzico Ñaña, i.e. 'Virtue or Power of a Jaguar') sit on a yellow band, which is an abbreviated version of the marriage mat. They drink chocolate. In the year 2 Rabbit their son Lord 13 Grass is born.

share in heritage and their equal importance for the legitimacy of their descendant. There were also differences, however. We have already seen that the naming pattern reflects an active role for men in war and a more passive role for women, being admired as beautiful and precious. Men and women alike may perform certain rituals, but the ceremonial recognition and greeting of the ruler at his enthronement is represented as an exclusively male affair. The comparison with the present-day situation, however, suggests that women, though less visible in public politics, may have played a pivotal role in the decision making process. 
A first, very basic, type of action is represented by a variety of hand gestures. In most cases these seem to be indicative of rulership. This is a logical association. In Dzaha Dzaui the expressions sa yondaa tnuni ndaha, 'the making of signals with the hand' or yotaa tnunindi and yosanindaa tnunindi, 'to signal', contain the same central term tnuni, 'signal', as the verb yotasi tnuni, 'to order' (e.g. a superior or judge), 'to draft and establish' (e.g. in legal matters, or when it comes to formulate a testament) and to 'leave a memory of oneself.

The seated rulers often have one arm bent across their chest or around their raised knees, the hand being invisible, and at the same time they point forward or slightly downward with the index finger of the other hand. Crossing both arms over the chest expresses veneration and subjugation. One bent arm in combination with another gesture, seems to be an abbreviated version of this sign, representing a general notion of respect and reverence. ${ }^{7}$

A good context for interpreting the pointing gesture is the opening scene of the Tira ('strip') of Yodzo Yaha (Tecomaxtlahuaca), in which the ruling couple are arranging the tribute structure. The Lord and the Lady are seated on the petate-throne in the palace (aniñe) of the town, signaling with their index fingers toward their tributaries. These answer by raising their hands. Both the lands of the town - a line framing the long feather (yodzo) of an eagle (yaha), to be read as Yodzo Yaha, 'Valley of the Eagles' - and the tribute goods are painted, as an explicit reference to the covenant: the rulers gave out the lands, over which they had special rights, being of divine origin, in exchange for tribute in both services and goods.

In this context the signaling index finger and the raised hand are clearly complementary gestures. As fixed combinations they may correspond to the normal Dzaha Dzaui expression for conversation, in which the speaking (yocachi) of one person is connected with listening and understanding (yosini) on the part of the other. Thus a phrase like 'she spoke to him' is formulated as 'she spoke, he listened'. ${ }^{8}$ The elegant

7 Sahagún, Book VI, ch. 1, plates 1 and 2. It may be significant that both in normal and in noble speech the upper arm is called chiyo, a word that also means 'altar' and thus may refer to the ancestral shrine.

${ }^{8}$ In her comparative analysis of the contexts in which these gestures occur, Nancy Troike (1982b) had already concluded that they represent 'request' and 'answer' or 'acceptance' respectively. We find similar gestures in the early colonial pictographic catechisms: the signaling index finger there stands for 'here is ...' or 'to make' (Anders \& Jansen et al. 1996: 82-86). 


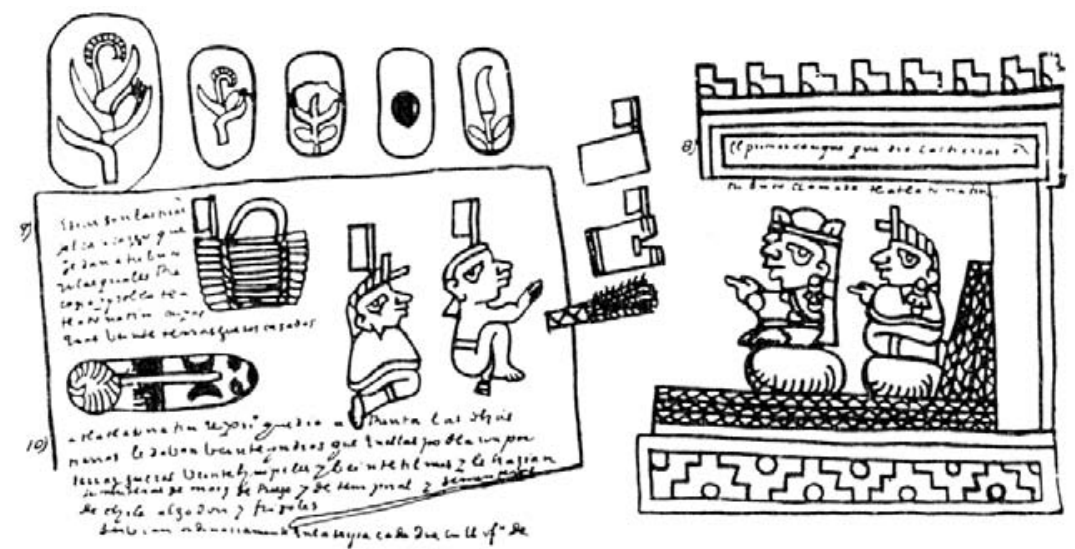

6.3. Tira of Yodzo Yaha: the first ruling couple arranging the tribute structure.

expression for speaking is yocana dzahaya, 'the Lord's doctrine comes forward'. In raising the hand, the answering person makes an allusion to the second meaning of 'hand' ( $n d a h a$ ), which is 'tribute'. The giving of tribute is yotniñondi ndaha, in which tniño is the verbal stem of 'putting' or 'pouring'. There is also a noun tniño, meaning 'work', used for a specific task or for the collective work for the community, the tequio. ${ }^{9}$ To obey in the sense of 'to receive (listen to) a task' is yosinindi tniño.

The signaling index finger then has to represent the giving of orders or instructions: yotasi tnunindi, 'to order, to judge, to legislate', or yotasindi tniño, 'to govern', literally 'to assign tasks'. To give out the tributes is yotasi tnuni cuitendi ndaha, and in the expression for distributing tequios yotaa tnunindi is a synonym for yosaha tniño ñahandi. The term tniño also occurs in the expression for 'authority': yonaindi tniño, 'to control the work'. According to Alvarado the index finger was named nuu ndaha yonaha tnuni, 'face of the hand (finger) that shows the signal', which again contains the word tnuni, in combination with the verb yonaha, 'to show'. The same word occurs in $s a$ yonaha tnuni, an expression for 'law', while tay naha is a 'civil person'.

So the signaling finger expresses one's will and power, while the raised hand becomes a statement like 'at your service'. The latter can

${ }^{9}$ On the use of ndaha ('tribute') and tniño ('communitarian work') in colonial Dzaha Dzaui documents, see Terraciano 2001: 41 and $191 \mathrm{ff}$. Cf. the contemporary customs described by Monaghan 1995, López García 2007, and Julián Caballero 2009. 
also occur in greetings. This combination of gestures is typical for two people conversing with each other or for one person giving instructions to the other. When both conversing persons make the same gesture, the implication would be that both are ruling, being of one opinion as to the measures that should be taken. At the same time they are leaving a memory of themselves.

As an example of what we have seen so far, we may interpret a scene in Codex Añute, p. 5-IV. Lady 9 Wind 'Power of Flints' (Iyadzehe Qchi 'Dzico Yuchi) is seated on the mat and the throne (yuvui tayu) of Añute, i.e. establishing her authority and founding her rule, while simultaneously (in one pictorial scene) having the feast of the mat (huico yuvui), i.e. contracting marriage, with Lord 10 Eagle 'Stone Jaguar', a prince from Ñuu Tnoo. She points her finger, while he stretches out his hand. Clearly she is the inheriting princess, holding the power, while her husband is the 'prince-consort', declaring himself at her service and accepting her instructions. Lord 10 Eagle's parents are seated on the sign of Nuu Tnoo, as rulers, with their arms crossed, i.e. expressing their respect for their daughter-in-law and their agreement with the marriage conditions.

An interesting variant is the pointing with two fingers, which seems to have a similar significance, but applied to two people together (tnaha). It may mean that by pointing two fingers an order for marriage is given. Such is clearly the case when Lady 9 Grass, the divine Guardian of the Temple of Death, instructs Lady 6 Monkey to marry Lord 11 Wind (Codex Añute, p. 6-IV). Tnaha is also a term for kinship and alliance. Raising a hand with two fingers seems to be a sign of offering alliance: Lord 8 Deer makes this gesture in front of the Toltec king Lord 4 Jaguar (Codex Tonindeye, p. 70).

A finger pointed upward may be read in a general way as the verb yonaha, 'to signal', which has the connotations of 'to know' and 'to give counsel'. The signaling gesture at the same time underlines the direction of the eyes, which implies the verb yonditondi, 'to see, to look after, to take care of in daily use, or its 'lordly' equivalent yotniño nanaya, 'the Lord moves his countenance toward it'. In the context of writing and reading we see a finger pointed downward, probably referring to the concentrated act of reading: yosito ndaa. ${ }^{10}$ An index finger pointing straight downward is often combined with the raised hand in contexts of greeting or conversation. Maybe the finger pointing

${ }^{10}$ See Codex Yuta Tnoho p. 48. 
downward is here again the indication for 'looking at the earth' in the sense of 'taking care' (sito ndaa ñuhu) or 'attending the Lord' (sito ñuhundi).

The extended hand with an object in it generally indicates the act of giving. Without an object it may mean 'giving' or 'receiving', with the connotation of giving permission, and allowing or accepting what somebody is saying or doing. Both hands extended, one upward and the other downward, represents the act of adoration. ${ }^{11}$

The extended hand may be combined with the gesture of an upward or downward pointing finger. Our impression is that the upward pointing finger may be read as a general sign of being alert and attentive, evoking expressions such as yonacahuindi nuuta ('to render an account to someone'), yonacahui inindi, yochihi tnunindi ('to count in oneself, 'to put signs' i.e. 'to think') and yonatuvui tnunindi ('to recognize a received benefit'). Going further on the level of symbolic associations, the raised finger might point toward Heaven, as a general call on the Sun as witness (in Spanish: 'Dios está viendo'), and the finger that points downward at earth may refer to the earth that gives us sustenance and is the stage on which our history in general is enacted. Sometimes an individual makes two gestures at the same time. The pointed finger may occur together with an extended hand. We find both combinations: finger pointed upward and extended hand directed downward or flat, and the finger pointed downward with the raised hand (as in the tribute gesture).

The meaning of other gestures is evident from their contexts: loosely hanging hands seem to express a passive attitude, while an inverted hand put against the forehead is a sign of lamentation. We find both in the representation of the men who are defeated by Lady 6 Monkey (Codex Añute, p. 8-I).

\section{War and Sacrifice}

Violence, cruelty and massacre are prominent aspects of Western culture, and consequently play a crucial part in the Western representation of 'the Other' in an unsettling blend of morbid fascination with bloodshed and the psychological need to inferiorize 'the Other' as irrational, barbarian and anti-human. Just as the Caribs were qualified

11 See Codex Iya Nacuaa I, p. 17-II and Codex Tezcatlipoca, p. 1. 


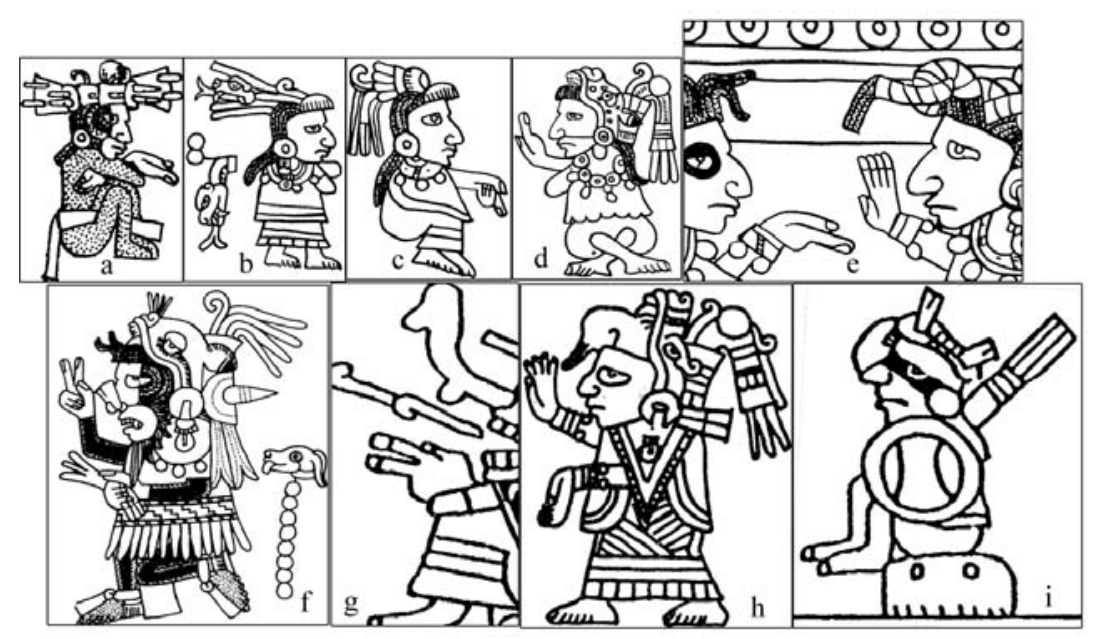

6.4a. Gestures: (a) one arm across chest $=$ acting with respect, (b) both arms across chest $=$ showing respect and obedience, $(c)$ finger downward $=$ ordering, $(d)$ finger upward = telling what to do, (e) pointing finger and stretched-out hand $=$ to order and accept, (f) two fingers upward = alliance, $(\mathrm{g})$ two fingers forward $=$ ordering to marry or to make an alliance, (h) open hands up and down = venerating, (i) hand against forehead $=$ lamenting.

as cannibals from the start of the colonial invasion, the Aztecs have become characterized as performers of human sacrifice. Although critical analyses of such representations have increased considerably since Edward Said's Orientalism (e.g. Lemaire 1986, Mason 1990), Mesoamerican war and sacrifice continue to be exploited in a scopofilic manner by Hollywood movies, and remain foci of adventurous or popular scientific literature.

This is not the place for a detailed discussion of this topic. A scholarly reading of the sources shows that human sacrifice represented a ritualized form of execution of enemies in a context of military conflict. Historical and archeological evidence clarifies that the practice certainly did exist, but that Spanish accounts were enormously exaggerated and generalized, out of a need to justify the colonizers' own brutal war of conquest.

The codices register a number of armed conflicts among ancient Ñuu Dzaui village-states. These scenes are easily recognizable. A person who carries lance and shield (ninihi tatnu ninihi yusa) by that very act represents the difrasismo (hendiadys) for 'brave warrior' (Spanish: 


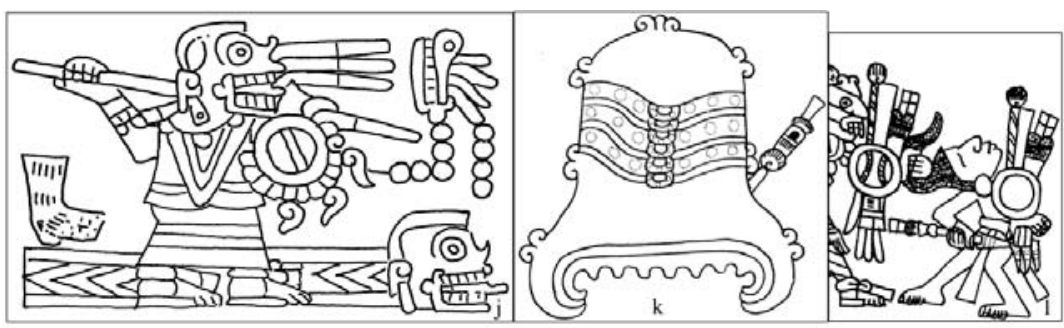

6.4b. Acts of war: (j) Lady 9 Grass standing with spear and shield on the war band $(y e c u)$ in Place of Death and of the Deer Hoof = being a brave and successful warrior, (k) an arrow perforating a place sign = conquest, (l) grabbing a person by the hair and wounding him $=$ winning the war and making a captive.

valiente señalado). There is a special ideogram for war: a chevron band (often referred to as 'warpath') and a band of wavy lines. Because of glosses we know that the chevron band represents the word yecu, 'war' or 'enemy'. ${ }^{12}$ The wavy lines, which are often combined with this sign, we read as tnañu, 'battle', a word probably derived from tnaa ñuhu, 'shaking earth'. The combination yecu tnañu is a difrasismo for 'war', equivalent of nduvua ñuhu, 'arrows and fire' or nduta ndecu, 'burning water'. The emblematic weapons are mentioned in the expression for sending in armed auxiliaries: yotasindi nduvua cusi yusa, 'I send the arrow, the atlatl (dart-thrower), the shield'. Conquests of other towns are indicated by an arrow or spear put in the place sign, an image conforming to the expression for conquest: yochihi nduvua ñuhu, 'to put an arrow in the land'.

The warrior who grabs his opponent by the hair, is the one who won the battle. The expression may be reconstructed as yotnee dzini, 'to grab the head'. An equivalent expression for dominance is 'carrying someone under the arm' (chisi dzahi) ${ }^{13}$ Making somebody a captive is yoquidza nduque or yoquidza dzaha (yoquidza = 'to make'). The

${ }_{12}$ Smith 1973b. The sign is already present in the visual art of Teotihuacan (see the contribution by Cabrera Castro to the volume edited by Ruiz Gallut (2002: 152). Herrera (decade XIII, book XIII: ch. 12) describes ancient warfare in Nuu Dzaui. Aztec warfare and related ideology have been the topic of many studies: see for example Hassig 1992 y Bueno Bravo 2007, while Duverger 1979 and Dehouve 2007 discuss sacrifice.

${ }^{13}$ Compare the present day Nuu Ndeya expressions tïn shini ñuu, 'grab the head of the town', i.e. control the municipal administration as authorities, and indee chii shrehe, 'be under the arm-pit', i.e. being dominated by someone. Both are represented visually in Codex Añute, p. 12-I. 
prisoner of war is executed ceremonially through human sacrifice, which is depicted by putting the victim face up over an altar (yuu neñe, 'stone of blood') and having his heart cut out. 'Head' (dzini) is the term to indicate the sacrificed captive, possibly referring to the exposition on the skull rack (Nahuatl: tzompantli). The victim is consecrated by pasting white paper or down balls on his head, painting a black band over his eyes and putting a white paper banner in his hand.

\section{Birth and Kinship}

The ruling couple is the starting point of historical events associated with the yuvui tayu and its dynasty. The offspring of the royal marriage is indicated as a list of children. The inheriting prince is the first child, generally shown alone, and followed by his brothers and/or sisters, all looking in the direction of the reading order. The brothers and sisters are often facing their respective wives and husbands. Umbilical cords or footsteps may make their position more explicit and emphasize their 'being born from' or 'descending from' relationship with their parents. The footsteps ('coming from') often seem to indicate that the person in question left his or her place of origin. The umbilical cord is more appropriate when it comes to stressing that someone is native of a specific place. In Alvarado we find the pairing of the verbs yocacu, yoquevui, 'to be born, to enter (life)' in the expression for 'generation'. As for the elegant metaphors: the noble woman does not simply conceive but 'catches a small deer' (yosidzo ñeniya), when nursing she spends honey ( $n d u d z i)$; at birth the child 'manifests its noble countenance' (yotuvui nanaya).

After the list of brothers and sisters, the first mentioned descendant is repeated with his/her partner, initiating a new generation. When given in its complete form, the system is quite clear and easy to understand. Sometimes, however, the representation is abbreviated, elliptic, and becomes difficult to interpret. When these events are accompanied by dates, it is usually no problem to follow the chronological sequence: the cycles of 52 years function adequately as a time frame for successive generations. Often, however, a consistent sequence of dates is lacking, making it uncertain how many years have passed between the events that are dated but are quite far apart. Possible errors and the presence of sacred dates without chronological function further hamper the chronological reconstructions. 


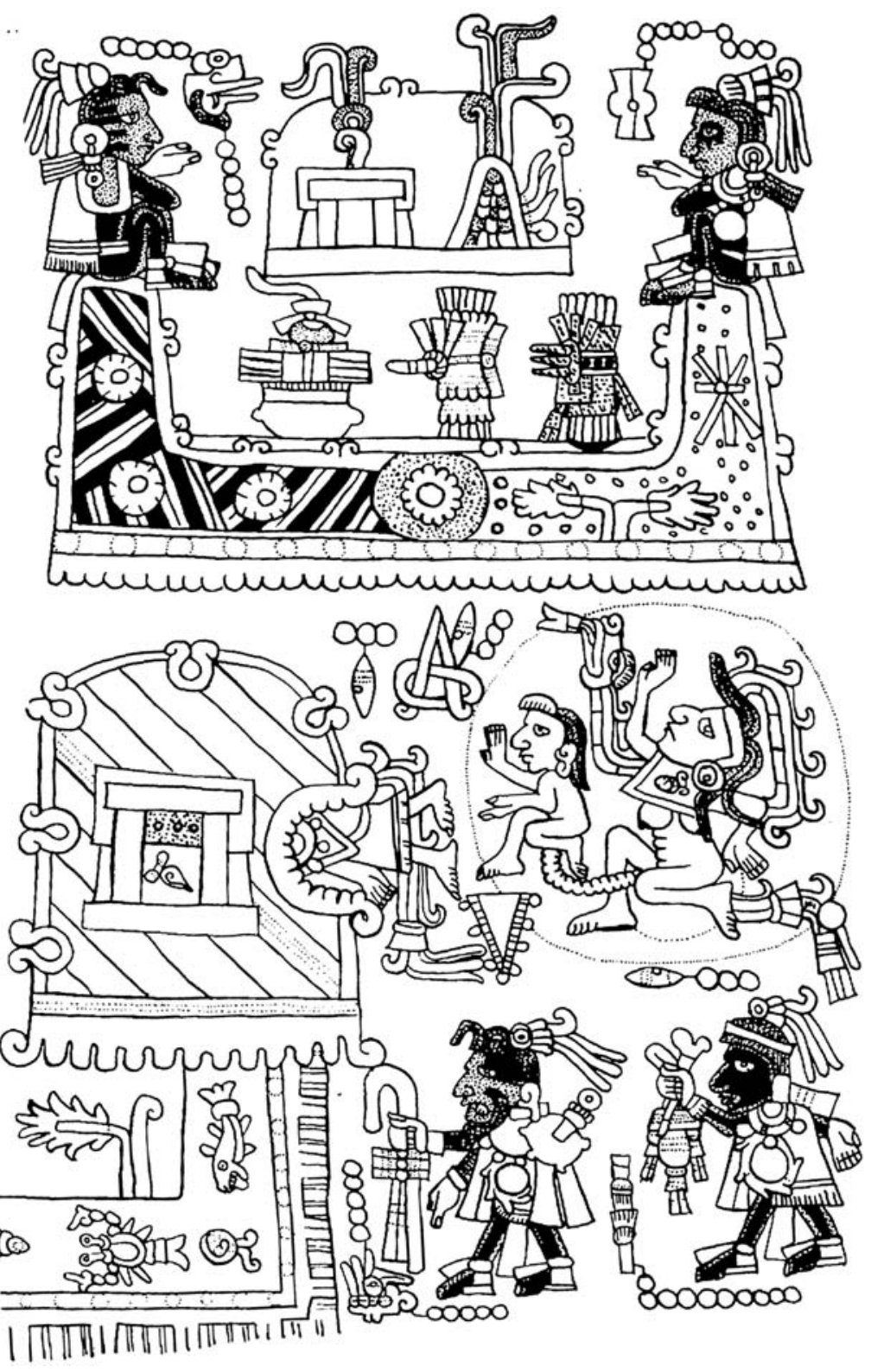

6.5. Codex Tonindeye, p.16-I (Top to Bottom): Preparation of the sweatbath by two priests. In the year 3 Flint Lady 3 Flint 'Shell Quechquemitl - Plumed Serpent' (i.e. 'Strength and Virtue of the Plumed Serpent'), gives birth to a daughter, Lady 3 Flint 'Jade Quechquemitl' (i.e. 'Beauty of Jade'). Afterward the mother enters a cave and transforms into a river. 
Genealogical relationships, therefore, have priority in the analysis. The Nuu Dzaui kinship terminology is well-known from the colonial dictionaries and texts, and also from present-day practice. Its basic principle is the distinction between generations (naa or dzehe, 'mother'; taa or dzutu, 'father'; dzaya, 'child') and the assimilation of relatives within the same generation, i.e. using the same terms for brothers and male cousins, and similarly for sisters and female cousins. ${ }^{14}$ Men and women use different terms for brothers and sisters; of these the same word is applied to a woman's brother and a man's sister. So ñani is a man's brother or male cousin, cuhui a woman's sister, cuhua a woman's brother or a man's sister.

The sex of the children may be distinguished by adding words for 'male' (yee) and 'female' (dzehe). The grandfather and grandmother are designated by special terms: sii and sitna (tatañuu and nanañuu in Nuu Ndeya). The grandchildren are dzaya ñani (sehe chani in Nuu Ndeya). Great-grandparents and great-grandchildren are distinguished by adding the term $d z u c u a$, while one generation more is called 'four units removed', e.g. sa qmi dzini siindi, sa qmi toto siindi, 'my grandfather of four heads, four rocks'.

Terms for 'aunt' ( $d z i d z i)$ and 'uncle' (dzito) are applied to the sisters and brothers of both father and mother. Also in the corresponding words for 'niece' ( $d z i c u)$ and 'nephew' ( $d z a s i)$ no difference is made between the paternal or maternal relatives.

The connection with other people, be it through kinship, friendship, companionship or another form of alliance is designated as tnaha, a word which expresses junction, the bringing together of two or more elements, e.g. yonutnaha tnaha yuta means 'the rivers join', and sa ñoho tnaha yeque is 'the joint of bones'. Consanguinity (Spanish: parentesco por sangre) is a special form: tnuhu tnaha, in which tnuhu is also translated as 'lineage'. Tnuhu basically means 'word', but in this context seems to refer to 'category', applied to 'sort of people' (ralea in Spanish); it may be combined with yaa (a word with meanings as

${ }^{14}$ In his grammar Friar Antonio de los Reyes already presented an overview of kinship terminology in Dzaha Dzaui (see also Spores 1967: 235-238). The family relations expressed in the Nuu Dzaui codices, as identified by Caso, have been analyzed by García Valencia 1989 and Lamas 1996, while Christensen 1998 discusses the aspect of inbreeding among the royal families. The contemporary situation of family and education is discussed by Julián Caballero 2002. For an in-depth analysis of the comparable Nahuatl kinship system, see Offner 1983, and for the historical contexts Van Zantwijk 1985 and Lockhart 1992. Bartolomé (2008: 187-241) discusses 'sistemas y lógicas parentales' among the indigenous peoples of Oaxaca. 
different as 'song' and 'ashes' depending on the tone) to yaa tnuhu, 'lineage, generation'. Being of the same yaa or tnuhu is synonymous with being of the same house (huahi) in the expression for the nuclear family. A blood relative is tnaha yaa tnuhundi. For becoming related as kin the verbal stem ndico/cuico is used, also meaning 'to rotate' or 'to take roots'. Thus alternative terms for 'my parent' are tnuhu yehe ndicondi and tnaha cuicondi. Both terms together, tnaha tnuhu, function as a difrasismo for kinship: the relationship between family relatives is tnuhu tnaha ndaa, 'true kinship', and not having a kinrelationship is simply the negation: huadzavui tnahandi, huadzavui tnuhundi.

A family relationship through marriage combines that difrasismo with the expression for marrying (yotnaha ndaha, 'to join hands') to tnuhu tnaha ndaha. The parentage through marriage is also designated with the term tnaha $d z i d z o$, either related to the verbal root chidzo, 'to add' or to the term $d z i d z o$, 'burden'. Brothers and sisters of the partner are $d z i d z o$. The parents of the partner are $d z u t u d z i d z o$ and dzehe $d z i d z o$, but spoken to as 'father' and 'mother'; their brothers and sisters are 'uncle' or 'aunt'. The parents of one's child's partner are tnaha nisanu, 'old relatives'.

Cadza appears in the terminology for a man with whom one has a relationship because he is married to a female relative, either (a) a sister or female cousin (cadza, 'brother-in-law'), (b) a daughter (dzaya $c a d z a$, 'son-in-law') or (c) a female $d z i d z o$ (tnaha cadza, 'husband of sister-in-law').

Sanu appears in the terminology for a woman with whom one has a relationship because she is married to a male relative, either (a) a brother or male cousin (sanu, 'sister-in-law'), (b) a son (dzaya sanu, 'daughter-in-law') or (c) a male dzidzo (tnaha sanu, 'wife of brotherin-law').

The family of the bride is referred to as tnuhu tnaha nahadzehe, 'kin of the woman'; that of the groom as tnuhu tnaha yee, 'kin of the man'.

Other connections through a ritual or symbolic act are designated in a similar way: tnaha sahu ñuhu, tnuhu sahu ñuhu, 'kinship through the word of God' is the colonial expression for the godparents' relationship because of baptism or confirmation. Today in Nuu Ndeya (Chalcatongo) we find compadrazgo, spiritual or ritual kinship, referred to as tahan vehe ñuhu, 'parentage through the house of God', as different from tahan vehe, 'parentage of the house' which refers to the nuclear family, and tahan ni $\tilde{n} \dot{i}$,'parentage through blood' or tahan 
tata, 'parentage through seed', which refer to the blood link. Where the relation is through baptism, water (nducha) takes the place of blood: child is sehe, but the godchild is sehe nducha, literally 'water child'.

The family as a living community is felt as the natural order and the basis of well-being. People who have lost their parents or partners are pitied: in the terms for orphan, widow or widower in Alvarado's dictionary we find the adjective cai ndahui, 'miserable, poor', a difrasismo also used for somebody who is ill.

The step-parent-step-child relationship is characterized by the allotment of yaha ñee, 'chile and salt', or yuvua huinda, 'greens and nopales', i.e. guaranteeing the minimal living conditions. The same difrasismos are used as expressions for poverty. The term for an adopted child is more neutral: a 'person that became a son' (tay nicuvui dzaya), a 'person taken in' (tay ninaquaca) or a 'person added to the altar' (tay nichidzo chiyo). In the latter expression the altar represents the family shrine and stands for the family as a cult community, unified by maintaining the ritual respect for the Founding Ancestors.

\section{Gender}

As the historiography of the sovereign communities or village-states ( $\tilde{n} u u)$ focuses on the ruling couples, women play a prominent part in the Nuu Dzaui codices. With good reason specific female protagonists such as Lady 3 Flint (in Codex Tonindeye) or Lady 6 Monkey (in Codex Añute) have received prominent attention in recent years. ${ }^{15}$ The precolonial documents treat the women (queens and princesses) in a very dignified manner. The married couple seated on the mat functions as the protagonist of genealogical history and the emblematic representation of the yuvui tayu. This suggests a relatively equal position of male and female members of the dynasty, and significant space for female agency in that segment of society. The royal Ladies (Iya dzehe)

${ }^{15}$ See the studies by Bellas 1999 and Furst 2002. Hartau, König and Löschner chose the couple Lord 12 Wind and Lady 3 Flint for the title of an exposition in Germany (2001), while Victor Hugo Ruiz Ortiz gave Lady 6 Monkey a prominent role in the animated movie 'La Epopeya de la Princesa Seis Mono y del Gran Guerrero Ocho Venado' as a central part of the exposition 'Las historias inconclusas narradas en los códices merecen una continuación viva....' (Museo del Palacio, Oaxaca, 2008-2009). 
clearly occupied an important role in politics. ${ }^{16}$ Women and Godesses participate in foundation rituals and New Fire ceremonies (Codex Yuta Tnoho), but not in the offering of royalty ceremonies, which suggests that they were visible in religious ritual and liturgic life, but less prominent in the public sphere of politics. We observe something similar today. We concur with the observations of Kevin Terraciano:

The yuhuitayu seems to offer an example of a political system in a 'complex' society that is based on 'egalitaran' concepts of gender. Evidence of gender equality within the yuhuitayu raises the question: did the same principles apply to gender relations beyond the high nobility? Scholars have linked the cultural practice of female succession to political office with the inheritance and possession of land and other forms of wealth. An examination of 128 testaments from the Mixteca Alta indicates that female testators owned as much land and property as male testators. Repeated examples of married couples who collaborated in the longdistance trade of cloth and other indigenous products suggest how members of a household allocated other forms of wealth... The general adherence to an even distribution of property between men and women, based on cultural expectations of reciprocal responsibilities and rights within the household and community implies a considerable degree of gender equality in Nudzahui society. On the other hand, patterns of male violence in disputes over accusations or incidences of adultery, and the justifications used by men to defend themselves before male authorities, undermine the ideal of gender equality within the huahi and nuu. (Terraciano 2001: 353-354).

At the same time we should point out that today's social reality is far removed from such a reconstruction. In a major anthropological work describing life in the present-day village of Nuu Yoo in the southern Mixteca Alta, focusing on the symbolic expressions of sociality, John Monaghan (1995) sketches a very negative picture of the social role of women. According to his analysis of fieldwork data, women are related to Tachi, the Wind (Spanish: aire), translated in Catholic terms as 'Devil' or 'Demon'. ${ }^{17}$ Consequently women are portrayed as having an envious and demonic nature, causing conflicts between households:

16 See Wood 1998 for a general discussion and compare Bellas 1999. Rosemary Joyce (2001) provides an in-depth discussion of idealized gender roles in Mesoamerican iconography, contrasting these with the much more heterogeneous and fluid image that may be (re)constructed from field archeology.

${ }_{17}$ On the role of 'aire' in traditional Spanish medicine, see Kuschick 1995: $15 \mathrm{ff}$., and compare the contextualization by López Austin 1980: 300 ff. 
The problematic relationships between households - at once reciprocal and conflictive - are reflected in the connections Nuyootecos make between women and Tachi... Women are the persons most likely to have yatuni [translated as 'envy'] for others ... women are 'miserly' (kuasunni).... women do not like to share, loan things, or offer hospitality... Women, like others who have inordinate amounts of yatuni, are associated with Tachi. For example, people say women are 'of the left'. The left hand, in turn is 'the hand of Tachi' and presenting something with the left communicates hostility and ill will. (Monaghan 1995:144). ${ }^{18}$

The problem here is how to distinguish between (a) what some people in a community say, (b) what the more general worldview and value system of that community is, and (c) what outsider observation and analysis suggests. The quoted statement gives us the impression that it reflects opinions expressed in an environment in which male chauvinism and alcohol played a dominant role. In view of what we ourselves have heard and seen in the same region, we feel that this image is not representative of Nuu Dzaui culture as such, but that it is indicative of machismo as a strong ingredient of contemporary social relations within the community, reinforced in the encounter between the male members of that community and a male Western anthropologist. Even though that anthropologist has no sympathy for machismo whatsoever, and certainly would not support any form of discrimination, a male perspective tends to become dominant in the analysis, especially when the perspective of the women themselves is left out. ${ }^{19}$

The association of women with the left, for example, is derived from the observation that the bride's family is sitting along the left side of the house in a marriage ceremony (op. cit.: 58). The association between 'right' and 'good', and between 'left' and 'bad', however, stems from a quite different context. Although the conclusion, that women are associated with the devil, may seem 'logical' in terms of structuralist analysis, we should be careful in supposing that such notions are really grounded in the Mixtec worldview.

18 The expression yatuni corresponds to jatu ini in Nuu Ndeya (Chalcatongo). It is not a substantive but a verb, meaning literally 'having pain in the heart', while kuasu ini means 'to feel envy'.

${ }_{19}$ Male prejudices are still innate within the theoretical framework and practical exercise of anthropology as a discipline. The same effect is present in archeology. Sharisse and Geoffrey McCafferty (1994) have discussed a case in point, showing that there is ample evidence to consider that the person buried in the famous Tomb 7 of Monte Albán may have been a woman. 
The same may be said about the anthropological analysis of a story of a man who had a dog, and at a certain moment that dog transformed into a woman:

This dog-woman proceeded to grind the corn, bake the tortillas, sweep the house and wash the clothes. (op. cit.: 145).

Nuyootecos also view dogs as dirty and disgusting animals. Dogs are filthy and full of fleas... People see nothing wrong with striking or kicking dogs... Women are like dogs in many ways ... (op. cit.: 146-147).

On the one hand this dog-woman story, interpreted as the expression of a Mixtec root metaphor, may indeed make us aware of a pervasive machismo mentality and discourse. On the other, it is difficult to derive general statements about social roles or symbolic association patterns from stories that people tell. We should be careful to use fairy tales about princes being transformed into frogs, for example, for reconstructing people's feelings about the monarchy.

The male gaze again comes to the foreground when the well-known anthropological interest in pollution (cf. Mary Douglas' classic monograph Purity and Danger) is applied to the Nuu Yoo worldview:

The association of women with the left and with untrustworthy outsiders is consistent with the idea that female sexuality is 'polluting' (te'en), something that male Nuyootecos link to promiscuity. Males value exclusive sexual access to females but feel that most women are incapable of being faithful ... The more women have sexual intercourse, the more polluted they are ... (op. cit.: 59)

The pollution that comes from female sex organs makes women inimical to corn, beans, squash, coffee and fruit trees ... The idea that women may harm corn and other seeds causes Nuyootecos to place restrictions on women's participation in agricultural production. A woman should not sow or weed cornfields because she may get sick, the field may die, or a wind may come and knock down the plants. Males also keep their implements away from women... (op. cit.: 59)

Nuyootecos also associate the snake, a child of Tachi, with women... Snakes, like a mature woman's sexual organs, are a source of pollution... In contrast to female sexual organs, male organs do not carry pollution. In fact, the penis - and things associated with it, such as the machete - can be used as a protection from Tachi... (op. cit.: 144-145)

Real, explicit evidence for the generalization that Nuu Dzaui culture considers women as polluted and polluting is, however, conspicu- 
ously lacking. A closer look demonstrates that the quoted social criticism only refers to some women, namely those who are considered to behave in an immoral way. Contrary to the suggestion of the text, women, as a rule, play a very active part in agricultural production, do sow and weed etc. Monaghan himself clarifies that:

Thus, when I asked one couple why both of them were weeding their cornfield (after they both told me that women are prohibited from doing agricultural work), they replied that it was all right if the woman is of the household; it is the women who come from outside the household who are dangerous. (op. cit.: 60)

As we understand it, the couple in question were explaining that normal women are virtuous (living a regular family life in the house), but that there are some 'out there' who are living a dissolute, bad life.

According to the (male) anthropological concept of the 'atom of kinship', (being the exchange of women between men), marriage is analyzed as a contract and a transfer:

Nuyootecos use the verb ke'e to describe a household's acquisition of a bride for one of its sons, the same verb they use for purchasing things in the market. Bilingual Nuyootecos will also translate the boy's father's activities in marriage as 'going to buy a woman' (va a comprar una mujer). (op. cit.: 65-66)

In connection with the above, this statement might cause the impression that women in Nuu Dzaui are bought and sold as sexual objects. That is far from being the case. The verbal stem ke'e, which corresponds to kihin in the dialectical variant of Nuu Ndeya, is actually a very general term for 'accepting', 'taking with you', 'receiving'. As such it can be used in the market, but it does not necessarily imply a financial transaction. In this context the Spanish verb comprar should not be taken literally. A similar idiomatic expression is used for getting pregnant: comprar un bebé, without implying the idea of going to a 'baby market'. The gifts exchanged during marriage ceremonies are not to be seen as some kind of payment for the bride, but as a normal token of mutual appreciation and support, customary in many cultures.

We read Monaghan's study as a testimony to the fact that in presentday indigenous communities a discriminatory and abusive attitude of men vis-à-vis women is very common, as are alcoholism and domestic violence. The protagonic role of (noble) women in the codices should 


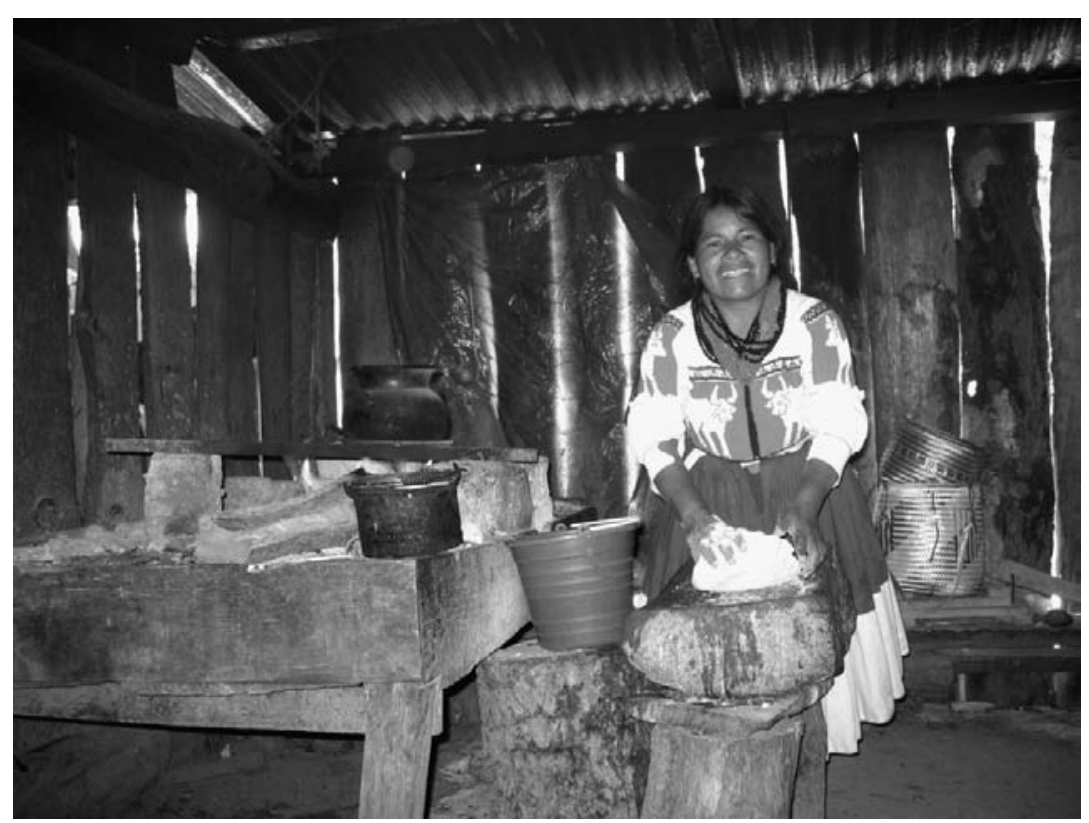

6.6. Traditional kitchen, San Pablo Tijaltepec.

not blind us to the machismo in Nuu Dzaui society, which has only increased from precolonial to colonial and modern times. For example, contemporary political traditionalism (as manifest in the widespread system of electing municipal authorities according to usos $y$ costumbres, i.e. in the communal assembly) tends to ignore women's rights altogether. Such practices must not be explained (and justified) by anthropological theories referring in a relativistic manner to indigenous terminology, root metaphors and symbolic worldview, as if they were the product of some underlying 'cultural logic'. ${ }^{20}$ On the contrary, by denouncing those scandalous realities cultural and historical research should contribute to critical awareness and emancipation.

\section{Inheritance and Tribute}

Royal kinship was called tnaha toniñe, or, more poetically, ndeye $d z o$ ee neñe ini, dzo ee yeque tuchi, 'fruits of one and the same blood and

${ }^{20}$ On the concept of 'cultural logic' see the contribution by Fischer (1999) and the following discussion in Current Anthropology 40 (4). 
heart, of one and the same bone and vein (or nerve)'. Alvarado registers similar metaphors for 'child': neñe ini, 'blood and heart', yeque tuchi, 'bone and vein (or nerve)', as well as ndeque tata, 'kernel and seed' or naa dzinañu, 'image and shadow'.

Members of the ruling family used to marry within their own social stratum. Their offspring was considered legitimate: dzaya cuite, 'true child'. Normally the first-born child, dzaya nuu (in which nuu means 'first, in front, most important') would inherit the yuvui tayu. Male children had preference, but if there were none, the daughter would inherit, and if a couple remained without children, the inhertance would go to their closest relatives. ${ }^{21}$

The parents of the prospective groom would call in a 'marriage ambassador' to arrange the marriage, who was generally an elder man (tay nisanu), with great ability to speak well, a tay sa nai ndudzu cano, dzahaya, 'man who carries important words, the instruction of the Lord'. He would make the negotiations with the parents of the bride. A favorable day had to be determined with the help of a divinatory codex.

In modern practice it is always the bride whose hand is asked for. In the codices, however, we find several instances in which an ambassador is sent to ask for the hand of the groom. Such a different practice makes sense in a situation in which rulers had to follow an active policy of forging marital alliances. ${ }^{22}$

The children of a second or third wife are dzaya nindendodzo, 'children that came extra'. A child of a Lord with a woman of common descent is a dzaya dzaca, 'a child of mixture', one from a relation with a woman of the lower nobility (toho dzehe, Spanish: principala) is a dzaya dzee dzitni, literally 'snotty nosed child'. These children generally did not inherit, as they were not considered part of the dynastic line.

${ }^{21}$ See the Relación Geográfica of Justlahuaca (Acuña 1984, I, p. 320, cf. Herrera, decade III, book III, ch. 12). Terraciano (2001, ch. 7) discusses in detail the Nuu Dzaui system of inheritance and land tenure in the colonial period. See also Oudijk 2002 on the rituals and ideology involved in taking possession of the realm.

${ }^{22}$ In Codex Nuu Tnoo-Ndisi Nuu, p. 39-II, we see such an ambassador offering to the parents of the groom a gold pectoral and a jade bead between powdered tobacco and a cacao bean - a combination we can now read as 'precious marriage gift'. The importance of marital alliances in Nuu Dzaui was already pointed out by Spores (1974). 
If there was more than one legitimate child, the heritage had to be divided. As the situation could become very complicated, depending also on what the man and the woman had brought into their marriage and how many children had been born, no fixed rules existed. In the case of a crown prince marrying an inheriting princess from another yuvui tayu, a special arrangement was made in advance.

A concrete example is the case of Doña María Coquahu (2 House), the eldest daughter of the precolonial queen of Yodzo Cahi (Yanhuitlan), Iyadzehe Cauaco (Lady 1 Flower), and her husband Iya Namahu (Lord 8 Death), who himself was the third son of the king of Ñuu Tnoo. Doña María inherited the cacicazgo of Yodzo Cahi and married Don Diego Nuqh (6 Movement), cacique of Yahua (Tamazola) and Yuta Nani (Chachuapa). They agreed that the first child would inherit the throne of the father and the second born would inherit the realm of the mother. ${ }^{23}$

The distribution of the possessions and tribute rights of the parents among the children was a potential threat to the unity of the yuvui tayu. Radical divisions could result in breaking up the territorial unit and in weakening the strength of its political organization and its defenses against hostile neighbors. This brought the ancient Nuu Dzaui ruling families to a policy of endogamy: the rulers arranged marriages between a son and a daughter (resulting in a brother-sister marriage), between a son and the daughter of another child (uncleniece), and between two grandchildren (cousins), in order to recover the divided heritage, if possible even before it was divided, i.e. while the rulers were still alive. If such an arrangement was not made, the ancient Mixtec heritage system was a likely source of conflicts. With the aim of recovering part of the realm of his parents, for example, a son would be tempted to disregard the rights of the children of his sister or younger brother and simply claim that their heritage had to revert to the main line. This was also the rationale behind the customary right claimed by the rulers of Nuu Tnoo to appoint rulers in places where the local had become extinct. ${ }^{24}$

In the discussion of the genealogical policies and histories, we often use (rather loosely) terms such as 'lineage' and 'dynasty'. Indeed tracing their descent to a common deified ancestor was crucial for the ruling family. These lineages were formed by a principle of 'double

${ }^{23}$ AGN Civil 516 (Paillés Hernández 1993b: 19. Cf. Spores 1967.

${ }^{24}$ Cf. AGN Tierras 24, exp. 6. 
descent', the dynasty of both the father and the mother being important, but generally with a 'patrilineal bias'. ${ }^{25}$ Most of the time the preserved codices focus on the male line, but there are some interesting exceptions. In creating and maintaining its power, the lineage had to keep its possessions and privileges in the family, conceived as a corporate entity. Several authors, therefore, have pointed out the applicability of the concept of a 'maison' or 'noble house', as defined by Lévi-Strauss:

a corporate body holding an estate made up of both material and immaterial wealth, which perpetuates itself through the transmission of its name, its goods, and its titles down a real or imaginary line, considered legitimate as long as this continuity can express itself in the language of kinship or of affinity and, most often, of both. (Lévi-Strauss 1982: 174). ${ }^{26}$

Studying the concrete case of Tecali in the State of Puebla, John Chance adds:

The house is best conceived, then, not as a kinship group per se, but rather as a named, corporate body with an estate that it seeks to preserve intact through various, often contradictory means.... The house in this sense can be fruitfully studied historically, as its strategies for maintaining its estate and reproducing its members are best understood over the course of multiple generations. (Chance 2000: 486).

The concept of the 'house' is not only close to the Dzaha Dzaui terminology for both the building and the family (huahi), but also reminds us of the fact that the estate at stake consisted mainly of tributary rights, or, rather, of a network of personal loyalties. The house stands for a collective identity, determined by mutual obligations, in which the rulers have an organizing and emblematic function. For them the community at large was just the extension (the tributary resources) of their 'house'.

The essence of rulership was, indeed, receiving and, in part, redistributing tribute. A number of sources inform us about this system. Codex Mendoza, based on an earlier manuscript known as the Matrícula de Tributos (Reyes García 1997) gives a detailed list of the tributes

\footnotetext{
${ }^{25}$ For an introduction to kinship terminology and analysis, see for example Stone 1997.

${ }^{26}$ Cf. Lamas 1996, Chance 2000, and the in-depth treatment by Joyce \& Gillespie 2000. In his contribution to the third Round Table of Monte Albán (Robles García 2004), Chance explicitly applied the concept of the 'noble house' to Nuu Dzaui.
} 
to the Triple Alliance of the Mexica empire. The Tira of Yodzo Yaha (Tecomaxtlahuaca) mentions the tributes given by the community to successive generations of rulers.

Essentially the tribute consisted of products (from agriculture, handicraft and commerce) and services (both on the lands and in the palace). The Codex Yodzo Cahi (Yanhuitlan) coincides with the Mexica sources in indicating four feasts of the solar year as the times for giving the tribute. We know only their Nahuatl names:

- Tlacaxipehualiztli, represented by the face of the Flayed God (Xipe),

- Etzalcualiztli, represented by the Rain God,

- Ochpaniztli, represented by the Mother Goddess (Tlazolteotl),

- Panquetzaliztli, represented by a solar disk with a divine face. ${ }^{27}$

These months were associated with major rituals celebrating the spring equinox (time of 'flaying', i.e. cleaning the fields in preparation for planting), the summer solstice (in the rainy season), the autumn equinox (associated with cleaning in preparation for the harvest), and the winter solstice (in the dry season).

Among the tributary activities is the cutting of trees and the delivery of hundreds of plates. A comparison with today's practices demonstrates that this is in preparation for a big feast: fire-wood is necessary for large-scale cooking, and the plates are to be used by the participants. Clearly this 'tribute' is the concrete assistance of the population to the ruler in his role as organizer of the public festivity that corresponded to the month, in a way very similar to the support (on a reciprocal basis) given to the contemporary mayordomos, the organizers of a religious communitarian feast.

Power had a strong religious component and was shared between the hereditary ruler and other nobles as well as priests. The chronicler Herrera (Decade III, Book 3: ch. 13) tells us that the priests were held in high esteem by the caciques: nothing was done without consulting them, they were considered sacred lords (clearly a reference to the Dzaha Dzaui term iya). In Nuu Tnoo (Tilantongo), according to the Relación Geográfica of this town, the king (señor natural) ruled the kingdom together with a Council of Four Officials (regidores), who intervened in matters of planning, administration, justice and liturgy.

${ }^{27}$ The Mexica twenty-day feasts are described in the commentary on Codex Cihuacoatl or Borbonicus (Anders \& Jansen \& Reyes García 1991). 
The wisest (más sabio) of these four officials was the head of this council or 'patriarch' and had a decisive voice in matters of war and peace. Elsewhere we have demonstrated that the codices contain clear references to such a Council of Four and even to a hierarchy of priestly functions (Jansen 1982b: 376-379). ${ }^{28}$

\section{Priests and Visions}

When the rulers or nobles die, they 'stop speaking' (yosiyo dzahaya) and 'become undone' or 'are extinguished' (yondahuaya). When killed in war, they 'leave the fortress or the ballcourt' (yosino yuhuaya). Generally the corpse was dried over a fire and prepared as a mummy bundle, which was wrapped in cotton blankets, decorated with a mask and jewelry of gold and precious stones, such as preserved in the famous Tomb 7 of Monte Albán. At midnight, after the appropriate rites, the mummy bundle was placed in a cave or tomb, a dzoco yeque, 'a pit or sanctuary for the bones', a dzoco ñuhu, a 'divine pit' or 'sanctuary' (cf. Herrera, decade XIII, book XIII: ch. 12). Prayers were said and offerings were made to the deceased, a ritual to be repeated on their name day (yodzacoondi quevui ndeye, 'to make offerings on the day of the dead').

The codices contain many references to the ancient rituals and religious festivities: the quevui cahnu, 'great day', quevui ii, 'sacred day' or huico, 'feast, ceremony'. Often, however, the signs do not give a full description of the action, but only mention some important objects that were prepared or offered. In preparation the floor or earth surface of the place was swept clean, and maybe covered with leaves or feather carpets, while the surroundings were decorated with flowers and paper ornaments. Given the considerable effort necessary to organize everything and the spiritual preparation in the form of fasting and vigil, the eve of the feast day (chisi quevui) was very important, and still is so today.

The participants would often prepare themselves by going into the steambath (ñehe in Dzaha Dzaui, temazcalli in Nahuatl). ${ }^{29}$ A limpia or

28 This identification was instrumental in clarifying the position of Lord 5 Alligator, the father of Lord 8 Deer, and consequently the relationship of Lord 8 Deer to the royal house of Nuu Tnoo. Byland and Pohl (1994: 132-133) follow our identification and take it as point of departure for their analysis of the Nuhu Bundle cult.

${ }^{29}$ For pictorial representations see the study by Krumbach (1982, as well as his contribution to Hochleitner et al. 1987). Katz 1996 discusses childbirth and temazcal 
ceremonial cleansing with special leaves and paper to brush off and absorb bad influences was often part of the ritual. Today the paper has been replaced by eggs. Generally the festivity implied the presentation of special newly woven clothes, such as the priestly tunic, dzico, known in Nahuatl as xicolli, as well as processions and dances, the drinking of alcoholic beverages (pulque), and the playing of ball games. ${ }^{30}$ Music bands included the standing drum ( $\tilde{n} u u$ ñee in Dzaha Dzaui, huehuetl in Nahuatl), the lying two-toned drum ( $q$ hu in Dzaha Dzaui, teponaztli in Nahuatl), flutes of bones (cutu yeque) and rattles (ndoco), as well as turtle shells to be hit with deer's antlers. Blowing on conchs (yee) announced the ritual, which would be initiated with praying to the four directions and invoking the divine Patrons of the occasion.

Fire $(\tilde{N} u h u)$ was and still is a crucial element: it is indicated by bundles of firewood placed on the ground or by torches that people carry in processions. The foundation of communities and dynasties was marked by making a New Fire, by drilling a round stick on top of a special plank. Ultimately the fire in each ritual referred back to that New Fire ceremony and thereby to the first rising of Lord Sun (Iya Ndicandii), the primordial light, which is the essence of human life. Today we find it represented in the candles and veladoras that accompany the prayers. It is accompanied by the burning of incense (copal, cutu in Dzaha Dzaui): for which the traditional tripod vessel is still used. The codices show priests swaying the ceramic spoon-shaped incense burners (cuu in Dzaha Dzaui, tlemaitl in Nahuatl). A related offering was the rubber ball, generally adorned with paper and a large feather. Just as today cigars serve to purify and establish contact with the divine powers; in the codices pulverized tobacco - supposedly the hallucinogenic variety, piciete (nicotiana rustica, yucu ino in Dzaha Dzaui) - is thrown in the air. 'To order tobacco for the ceremony', yotasindi ino huico, was the expression for organizing a feast. As an emblematic sacrifice a quail was decapitated and the blood sprinkled on a bed of leaves or feathers. Today the chicken has taken its place. People expressed their devotion through 'self-sacrifice': drawing blood from the upper part of the ear, the tongue or the penis, which were

use in the Mixtec region; the monograph by Alcina Franch (2000) provides an erudite overview.

${ }^{30}$ For a description and analysis of the ulama ball game, its rules and continuity, see Leyenaar 1978. In the Oaxaca region the 'pelota mixteca' has taken the place of such an older Mesoamerican form, incorporating European elements but preserving to a significant extent the social role of the game (Martin Berger, unpublished M.A. thesis, Leiden University 2009). 


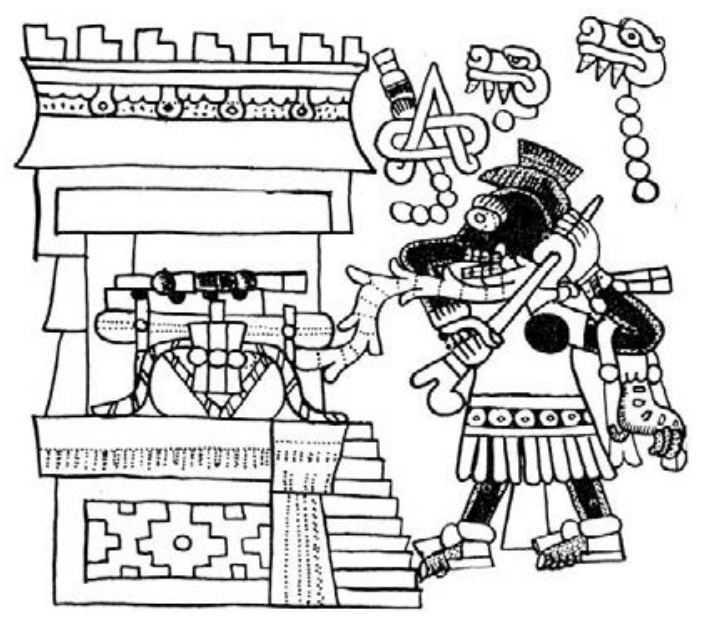

6.7. Codex Tonindeye, p. 25-III: the death priest Lord 5 Alligator draws blood from his ear with a bone perforator and offers it to the Sacred Bundle in the Temple of Heaven.

perforated with pointed bones or maguey spines, and letting it run on leaves, feathers, on paper or in bowls. The pain caused by this induced a special spiritual state or trance. Consuming psychotropic plants, e.g. wild tobacco (piciete), seeds of the ololiuhqui weed (Latin: rivea corymbosa), or pairs of hallucinogenic mushrooms, was another means of provoking visionary experiences. ${ }^{31}$

Trances are described with words for 'night' ( $\tilde{u} u)$ or 'darkness' (naa). Thus, 'darkness of the heart' (sa naa ini) refers to a miracle or a vision, while 'the dark, the obscure' (sa naa sa yavui) is a difrasismo for 'mystery'. The word for 'dark', naa, is also connoted in the verbal stem yonaa, 'to eclipse', 'to forget' and 'to lose consciousness'. The expression 'to have night inside or in the heart', yocoo ñuu ini, means: 'to enter in ecstasy'. The verbal form yocoo offers a play on words with coo, 'serpent'. We remember how Codex Yoalli Ehecatl (pp. 29. 36-38) depicts the trance as a serpent with a body of night and wind. These expressions make it possible to identify the painting of a house (huahi)

${ }^{31}$ See the representations of ritual in Codex Yuta Tnoho, passim. An 'orchestra' plays the different instruments in Codex Iya Nacuaa II, p. 8. For the acts of blowing and throwing piciete, see, for example, Codex Iya Nacuaa I, p. 2-III. This ritual practice is described in the story of creation, summarized by Friar Gregorio García. The importance of piciete is documented by, among others, Hernán Ruiz de Alarcón. The eating of mushrooms is depicted in Codex Yuta Tnoho, p. 24; compare Ravicz 1961. 
with clouds (huico) of darkness (sa naa) inside (ini) as a huahi huico sa naa ini, 'temple of visionary or mysterious rituals.' (Codex Yuta Tnoho, p. 17).

The Dzaha Dzaui translation of Friar Jerónimo Taix's treatise on the rosary, Dzeque Iyadzehe, gives interesting descriptions of visionary experiences, of course in a Christian context, but echoing the ancient terminology:

$\begin{array}{ll}\begin{array}{l}\text { nda ee quihui dzahua tnaha } \\ \text { niquidziya }\end{array} & \begin{array}{c}\text { And one day when the lady was } \\ \text { sleeping }\end{array} \\ \begin{array}{l}\text { dzahua tnaha ninaa nidzahui } \\ \text { nicuhui yniya }\end{array} & \text { had a vision (darkened her } \\ \text { nisiniya uni tayu toniñe } & \text { heart) } \\ \text { and saw three royal thrones } & \text { (towns) } \\ \text { ini andehue } & \text { in the Heaven. (Book III, ch. 51). } \\ \text { da nindoyo ñuhu sa naa yni yca } & \text { When that vision dissolved } \\ \text { da dzahua ñaha yca ninatacu yniña } & \begin{array}{l}\text { the woman regained conscious- } \\ \text { ness, }\end{array} \\ \text { anahua tnaha nindotona } & \text { and woke up. (Book III, ch.4). }\end{array}$

The precolonial priests lived in poverty, but were held in great esteem, as 'holy people'; they had a great influence on social life and politics. Normally they were vegetarians, subsisting on herbs and vegetables. Only on the occasion of sacrificial feasts did they receive meals cooked by women. During fasting they limited themselves to a diet of tortilla and juice of the maguey plant.

Boys who were to become priests were put in the temple's service at the age of seven. This explains the importance attributed locally today to the ceremony of evangelio, taking the child to the church for a blessing. There were several priestly ranks; it took four years to move from one to the next. After finishing this 'career', the priest could leave the service and marry. The codices mention the case of the High Priest of Nuu Tnoo (Lord 5 Alligator, father of Lord 8 Deer), who, after a first year of initiation, passed through four priestly ranks, each taking four years. The priestly status is indicated by black body paint: the hallucinogenic ointment that permitted the humans to speak to the Gods. ${ }^{32}$

32 For a precise description of the Central Mexican case see Durán, Ritos: ch. 5 (cf. Anders \& Jansen \& Reyes García 1993: 175 ss). The life of Ñuu Dzaui priests is commented upon by Herrera, decade XIII, book XIII: ch. 13. Bartolomé (1997) and 
The priest was 'the father who carried the God': dzutu sa ndidzo $\tilde{n} u h u$. The alternative title 'person of the ceremony', ña huico, was translated by Alvarado as 'yet another impostor' (embaidor otro) and 'the man who does or speaks the ceremony', tay yoquidza huico, tay yocaha huico, appears in his vocabulary as 'idólatra'. The designation of the present-day religious specialist (curandero, 'healer') has a medical connotation: tay tatna, literally 'medicine man'. The high priest had the title ñaha niñe, 'blood person', very close to that of the king (toniñe).

The ruler himself received a religious education. At the age of seven he was taken to the temple, accompanied by priests and nobles, with musicians blowing flutes and conches, beating drums and tortoise shells. Upon arrival at the temple he was dressed in a special tunic, covered with rubber sprinklings. Then the high priest put before him a basket with perforators made of flint for doing the bloodletting rituals. A ceremonial cleansing with piciete took place, and thus he stayed for one year in the temple, exercising obedience and abstinence, in vigils, fasting and offering his blood. Such ritual acts form an important part of the career of Lord 5 Alligator 'Rain Sun' (the father of the famous ruler Lord 8 Deer) as High Priest of Nuu Tnoo and are depicted in Codex Nuu Tnoo-Ndisi Nuu (pp. 7-8) and the Reverse of Codex Yuta Tnoho (p. VI).

It was in their condition of nahuales (i.e. in the dream-experience of becoming one's animal companion in Nature), that rulers or priests could interact with the Gods. Specific vision animals are the serpents: the plumed serpent (Quetzalcoatl in Nahuatl, Coo Dzavui in Dzaha Dzaui) and the fire serpent (xiuhcoatl in Nahuatl, yahui in Dzaha Dzaui) are the most prominent examples. An extremely important title, applied to both kings and priests, was that of yaha yahui, literally 'Eagle-Lightning Ball'. Both eagle and fire serpent are strong nahualanimals, capable of flying through the air, and as such they represent the powers of a shaman or nahual priest. Their combination is translated by Friar Antonio de los Reyes as a difrasismo for 'necromancer' (nigromántico señor). It is illuminating to read the original Spanish concepts that the monks of those days had in mind when they discussed certain Mesoamerican practices and ideas which we now

Barabas (2006) provide a description and anthropological analysis of religion in contemporary indigenous communities in the State of Oaxaca. 


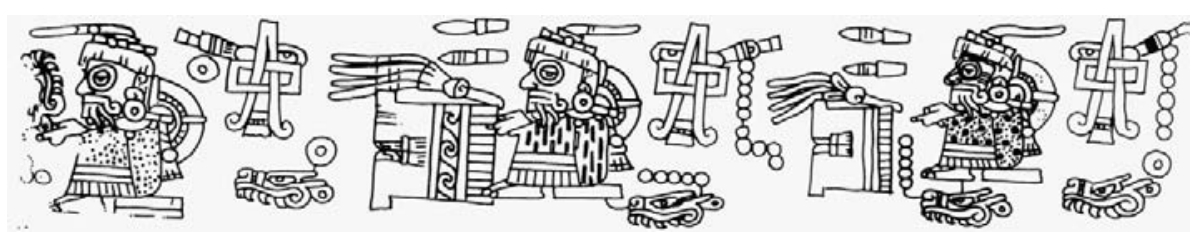

6.8. Codex Nuu Tnoo - Ndisi nuu, p. 7-II (Right to Left): Lord 5 Alligator passing through successive ranks of priesthood.

understand as a complex of ecstatic and visionary experiences, dubbed 'nahualism' in the literature. Their treatises describe necromancy as a pact between 'witches' and the devil. Special unctions created the ability to fly through the night to see and experience events in far-away places, while the body of the person remained in a state of sleep, cold as if it were dead (Ciruelo 1628). Here we find a coincidence in the strong shamanic roots, present both in Mesoamerica and in European societies of those days.

Friar Jerónimo Taix's treatise mentions a 'witch' (bruja), which is translated in Dzaha Dzaui as 'somebody who becomes [an animal] or transforms herself (ñaha sa nduhui):

nicachita ñaha sa nduhui nicuhuiña They said that she was a witch. yca saha nitnee ñaha justiçia

nisiyoña huay caa

Therefore the justice took her prisoner,

she was put in jail. (Book III, ch. 40)

The terminology and conceptualization from the time of the witchcraze and spiritual colonization is still among us and hampers a better understanding of 'nahualism' as a mental experience of relatedness with Nature, of encounters with the Divine Life Forces and Ancestors, as occult but strong potentialities for realizing oneself in the world as a helper of the Gods and a protector of the people.

\section{Divine Powers and Rituals}

For the Christian missionaries all native religion was, of course, the 'work of the devil'. The colonial chronicles use terms like 'idols', 'demons' 'witches' and 'witchcraft'. This terminology has also created confusion in the popular conceptions, so that designations like 'idols' for archeological statues or 'cave of the devil' for ancient ceremonial 
places are quite common. Even some modern anthropological texts repeat such designations uncritically and inaccurately. Mesoamerican religion has its harmful spirits and individuals (teñumi ñaha, 'owl persons') too, but those are far apart from the respected Powers of Nature and the Divine Ancestors. ${ }^{33}$ The colonial Christian doctrine condemned all of these equally as 'demons' and consequently promoted the vision that ancient religion was based on fear and lack of reason. Contemporary anthropological jargon has substituted positivism for Christianity, but that modern perspective often still sees 'the Other' as propelled by irrational motives, as someone who does not grasp 'reality' but believes in untrue stories (myths) and unscientific practices (magic, witchcraft).

Whereas an outsider talks about 'beliefs' and 'mythology', the insider or participant speaks of 'faith' and 'truth'. In Dzaha Dzaui 'faith' is sini ndisa, 'perceive, understand the truth'. Religion itself ( $s a$ $\tilde{n} u h u$ ) deals with the realm of the sacred and the divine powers. Different words are used for the deities. The categorical term is N $u h u$, used in contexts that suggest references to the internal power ('Owner', 'Inhabitant') of the elements. In the codices it is depicted as a stony, anthropomorphic, sexless being, generally colored red (i.e. 'hot'), consisting of a trunk and a head with round eyes and large teeth. That figure is identified explicitly as N $u h u$ by glosses in 16th century pictorial manuscripts. ${ }^{34}$ With other tones ñuhu means 'earth' and 'fire'. The very few colonial reports on Nuu Dzaui civilization are silent in this respect, but in present-day communities we find the Ñuhu is a wellknown concept, referring mainly to the Earth Spirit (christianized as San Cristobal, San Cristina, Santo Lugar), who is the real 'Owner of the Land', often visualized as a rock in the field, and who is invoked with prayer and food-offerings before planting and after harvesting.

The N $u h u$ figure also appears in combination with weapons (shields and lances), apparently representing the divine spirit of war and courage. In the codices, its head often characterizes a wrapped bundle of cloth as a Sacred Bundle, a crucial religious object and emblem for the Nuu Dzaui dynasties. This is the equivalent of the Tlaquimilolli carried by the teomama priests of the Mexica and of the Pizom Cacal,

\footnotetext{
${ }^{33}$ The Nahuatl concept of the tlacatecolotl, 'owl-man' has been studied by BáezJorge and Gómez Martínez (Broda \& Baez-Jorge 2001: 391 ff.).

${ }^{34}$ See Smith 1973b and Jansen 1982b: ch. V $\$ 4$. On the 'hot'-'cold' dichotomy of Mesoamerican medicine, see the classic monograph of López Austin 1980, and the more recent review by Chevalier \& Sánchez Bain 2003.
} 


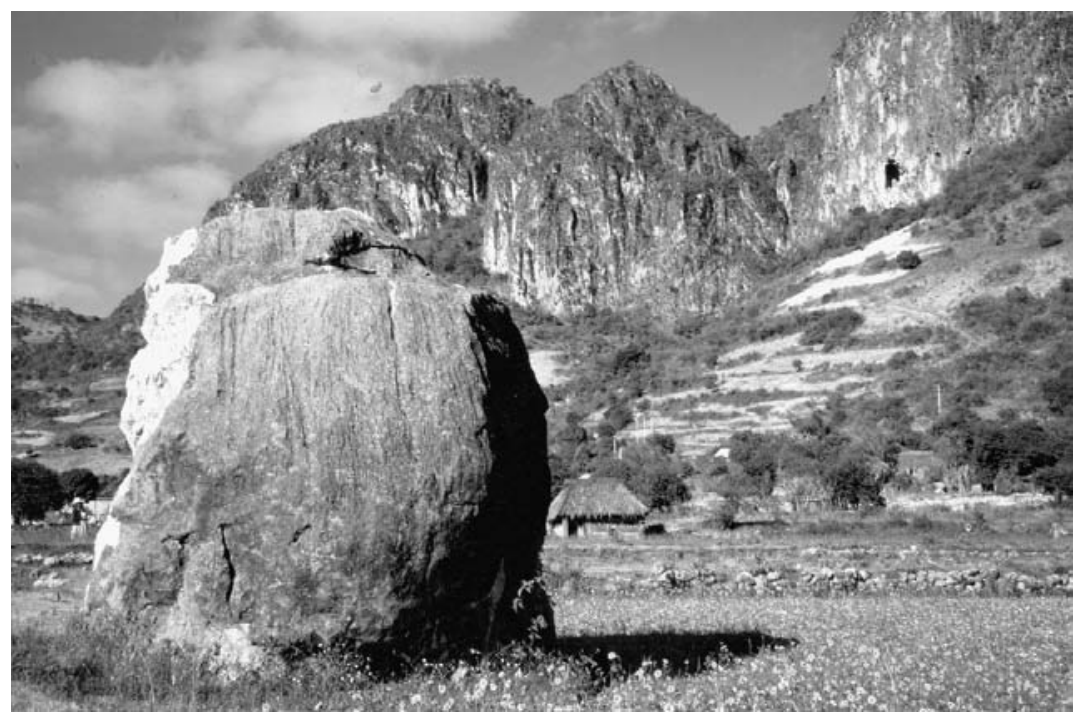

6.9. A large boulder in Yutsa Tohon (Apoala) is a manifestation of the $\tilde{N} u h u$, 'Divine Owner of the Land'.

'Shrouded Glory' in the Popol Vuh of the K'iché Maya people in Guatemala. Such a collective 'Medicine Bundle' was also known as 'Heart of the Community' (Nahuatl: altepetl iyollo). We do not know for sure the Dzaha Dzaui term for Sacred Bundle. Alvarado registers tnani for 'bundle of wrapped cloth' (Spanish: envoltorio de manta). Interestingly this word also means 'industrious, intelligent, creative' and appears in expressions for the supreme deity (Spanish: autor Dios creador de todas las cosas): iya ñuhu tnani huisi, ñuhu ninduyu nidzehua niquahaya, 'Lord God (who is) intelligent and capable, God (who) thought, created and constructed'. The first part ( $\tilde{n} u$ hu tnani huisi) is translated by the same author as 'Almighty God'. The term N $u h u$ and the bundle are general in character, but may, of course, refer to a multiplicity of divine forces.

An alternative title for deities is Yoco, which seems to convey the notion of 'spirit', as it is also used for 'breath, vapor'. A house with vapor may therefore refer to a Temple of the Yoco (cf. Codex Añute, p. 2-II). Onomastic signs with vapor in them may also be interpreted in this way. With other tones yoco means 'maize flower' and as such forms part of Sacred Bundles too. 
Cuacu is translated as 'ídol of the mountains'. In composite expressions (e.g. 'idolatrar') we find yuu сиаси, 'stone of the Cuacu', which seems to refer to the stone image of a deity. ${ }^{35}$

The temple is a huahi N $u h u$, 'house of the deity', a word still used for 'church' (vehe Nuhu in Nuu Ndeya) as well as for the ancient pyramids and the caves where Mesoamerican religious ceremonies are still practiced (vehe Ñuhu anahan). Its synonym, dzoco Ñuhu, 'sanctuary', is painted as a cradle (dzoco) with a deity figure (Nuhu) sitting or lying in it.

Often the Ñuhu bundle is combined, like a difrasismo, with another bundle, made up of sticks, put down vertically and wrapped in cloth, with clearly marked paper knots. Most of the time the colors of the cloth are red and white, which are diagnostic for the Flayed One, the God called Xipe in Nahuatl. The term used for this object in iconological studies is 'Xipe Bundle' or 'Red and White Bundle'. The Dzaha Dzaui name of the object is unknown. It seems to have had several connotations. Bundles of sticks, bound together with red or green thread, occur as offerings, related to the custom of offering counted bundles of grass, fir-needles or leaves. ${ }^{36}$ The red and white color scheme and the presence of special knots in the covering connect the object to the iconography of the Deity of Flaying (and Preparing the Fields), called Xipe in Nahuatl. The object also occurs as part of a staff of office (Codex Tonindeye, p. 1). Still today, such a staff (Spanish: bastón de mando) is an important symbol of authority in Mesoamerican communities (Cordero 1997) and logically it appears prominently in precolonial art (Olko 2005; Hermann Lejarazu 2007b). In the Mixteca Baja town Tezoatlan a bundle of sticks (Spanish: rollo de varas) is handed over by the mayor (presidente municipal) to the commander of police during the inauguration of the new municipal authority. Each individual stick (vara) stands for the authority of each policeman; the bundle represents the authority to distribute power to others. The same symbolism is found in the custom of Mexica merchants to venerate their staffs and bind them together (manojo de báculos) as a symbol of collective identity and strength. These staffs could also be sticks used for bloodletting (passing them through the tongue).

35 The same term is used in the Relación Geográfica of Atatlauhca (Acuña 1984, I: 50). See Terraciano 2001, ch. 8 , for a synthetic presentation of the colonial sources on the Nuu Dzaui religious tradition.

${ }^{36}$ Byland and Pohl (1994: 68) suggest that the sticks in the Red and White Bundle were those used in bloodletting. 
Similarly a bundle of sticks (manojo de ocote) would be clothed and venerated during the Mexica feast of Tititl, to honor the deceased Ancestors. $^{37}$

The general sign for 'ritual' consists of four speech scrolls, painted in the different directional colors (red-blue-yellow-green) and bound together. This sign probably refers to the invocation of the four directions, which is part of each ceremony. We often find it in combination with the Sacred Bundle and/or the Nuhu sign. Descriptions from other areas suggest that the Sacred Bundle contained relics of the Ancestors or Founding Deities, so the veneration of the Nuhu bundle in the main temple of the community probably referred to the Founding Ancestors. ${ }^{38}$ As a 'wrapped mystery', the Sacred Bundle is a source of power, which, when unveiled and released, provokes a moving visionary experience. An impressive pictorial representation is given in the central chapter of Codex Yoalli Ehecatl (Borgia), which deals with a series of rituals. We see priests, after preparing themselves by bloodletting, receive the Sacred Bundle in a temple, go through a ritual passage or pilgrimage and then open the Bundle. Out come the divine forces of 'night and wind' and a huge serpent, which swallows the priest: in ecstasy with closed eyes, swimming in the void, he travels through another state of being.

${ }^{37}$ We thank Mr. Jorge Cipriano Guzmán, presidente municipal of Tezoatlan, for his explanation. Derived authority is ndaha (literally 'hand') in Dzaha Dzaui, while the lineage of ancestors is $n d u h u$. For the offerings, see Anders, Jansen and Pérez Jiménez 1992a: 109, Loo 1987 and Oudijk 2000: 163-166. The merchants' staff bundle is described by Sahagún, Book IX, ch. 3 and 11. For the Mexica feasts see Codex Cihuacoatl, p. 36, and the Libro de la Vida or Codex Magliabechi, p. 44v).

${ }^{38}$ It was Karl Anton Nowotny who first called attention to the importance of the Sacred Bundle in Mesoamerica. Following in his footsteps, Werner Stenzel (1972) made a fundamental contribution, connecting it to the Medicine Bundle complex of North America. See also the interesting study by Eschmann (1976). More recently investigators of Maya iconography started to recognize the Sacred Bundle in the classic representations of ritual and visionary experiences. An illustrative example is the Pisom Cacal in the Popol Vuh, the Holy Book of the K'iché in Guatemala. Jansen (1982) and Pohl (1994) have commented extensively on its importance in Mixtec codices. Recent studies have shown that this religious object was already present in Preclassic iconography and central to the religious life of Teotihuacan (Headrick 2007). Barba (2002) examines its relationship with ancestor veneration, while Urueta Flores (2004) discusses its connection with the statuettes known as 'penates'. See Olivier 2007 for a contemporary assessment of the Sacred Bundle in Central and Southern Mexico, and Hermann Lejarazu (2008b) for a timely overview of its appearances in the Nuu Dzaui sources. 
The main deity of Nuu Dzaui is, of course, Dzaui (Dzavui, Sau), the Rain God, called Tlaloc in Nahuatl. He is represented in the same way as in the religious codices: a big Ñuhu with huge goggle eyes and long teeth. His name appears as synonymous with 'ídolo' in Alvarado's dictionary. He is still very much venerated today in the Nuu Dzaui villages, where he is said to live in specific caves or rocks, the vehe Sau or vehe Savi, 'houses of the rain'.

I came to place the gifts

in the House of the Great Rains, the House of the Rain Lords,

of the Four Lightnings and Thunder.

I came to you, Rain, who lives in the sanctuaries of the mountains.

A great day is today. I came today to call upon all the Rains,

all the Great Rains I came to call:

come and receive your gifts.

We offer them to you with our hands,

here is the mat, here is the throne,

our Father, our Mother.... (Schultze Jena 1933-1938, III: 86).

Generally the main Gods are also easily recognized, as their iconography is well-known from Central Mexican sources. It seems to have been Nuu Dzaui practice to designate them calendar names. As a consequence the divine Forces of Nature blend easily with primordial ancestors, as both categories are iya and iyadzehe, and both are identified through calendar names and given names that usually signal their specific powers.

In discussing the deities themselves we should transpose our minds to the polytheistic worldview and mentality, which is not dominated by theological dogmas but by a quotidian respect for Nature as an animated world of sacred places and a plurality of different forces superior to the human individual, as well as by a strong veneration of Ancestors. These Forces (Nuhu) are delicate, demand being remembered and taken into account, but also give us life, sustenance, comfort, hope and energy. The narratives that describe their doings contain root metaphors and archetypes both on a social and psychological level. The importance of such symbols for understanding mental processes, empowering the individual, and healing traumas, is exemplified in the inspiring work of Jungian psychologist Clarissa Pinkola Estés (1992). From a contemporary perspective the ancient messages of the codices have become part of the same symbolic universe: therein lies their power and inspiration. 
The Maize God in Mesoamerica is represented as a personified maize plant, generally a young Lord (e.g. Codex Yoalli Ehecatl, p. 14; Codex Tezcatlipoca, pp. 33-34), very similar to the iconography of the Espiritus de las Semillas in contemporary paper cuttings from the Sierra de Puebla (Jansen \& Leyenaar 1975; Anders \& Jansen 1986). In Codex Yuta Tnoho (pp, 12-11) we see a female version: the young Goddess of the Maize Flower (Yoco), associated with the Center of the Mixtec world. No doubt: maize is the axis of Mesoamerican life, thought, culture and community. At a symbolic and psychological level, we may interpret the maize deity as the archetypical young man or woman: life-force of germination and spiritual strength for working and building the future.

The Sun God (Iya Ndicandii) is depicted as a red colored warrior who carries a radiant golden disk. His calendar name is Lord 1 Death, which corresponds to the name iya caa maha or iya camaa, registered by Alvarado as "the sun, as the Indians called him in heathen times". Obviously it is derived from his position as the Patron of the thirteen-day period starting with 1 Death. ${ }^{39}$ As the divine principle of light and primordial dart-thrower, the Sun is also the symbol of understanding, justice and leadership, as well as the spiritual force for undertaking 'war', i.e. real armed conflicts but above all the struggles and tasks of life in general. The First Sunrise initiates human society and history, separating a cultural world from the primordial Creation, whose forces remain shrouded in darkness, i.e. mystery. The foundation ritual of a kingdom (mat and throne) involves the making of $\mathrm{New}$ Fire as a commemoration (a magical mimesis) of that decisive event.

The Sun's companion is often the Venus God, Lord 1 Movement (Iya Caqhi), who seems to have been a Patron of war. We recognize him because of the five white dots on his face (on forehead, nose and chin and on both cheeks); his head is often depicted with a fleshless jaw or completely as a skull. Codex Añute, p. 1, shows both Sun and

${ }^{39}$ Codex Yoalli Ehecatl (Borgia), p. 66 and p. 71. The word for 'sun', ndicandii, contains the verb $n d i i$, 'to radiate light' (equivalent of tona in Nahuatl). The first part, ndica, means 'breast', but could also be understood as a contraction of ndecaha, 'puma'. The Ñuu Dzaui codices mention as well a similar solar character: Lord 7 Flower, whose representation is comparable to that of the Mexica deities Piltzintecuhtli and Tonacatecuhtli: he appears associated with the Mountain of the Sun in Codex Yuta Tnoho and with the Mountain of the Turkey in Codex Nuu Tnoo-Ndisi Nuu (cf. Pohl 2005). 


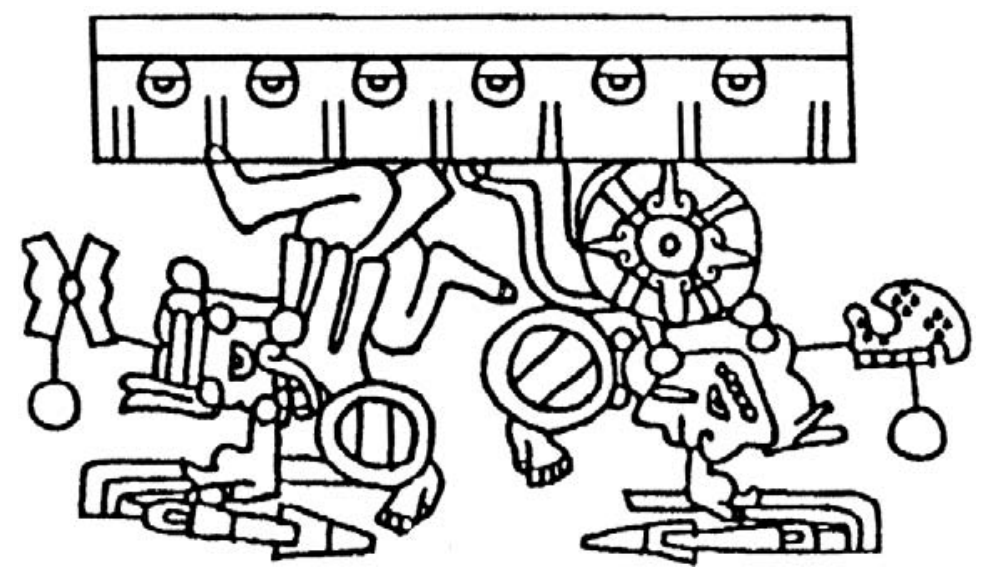

6.10. Codex Añute, p. 1-I: Deities Lord 1 Death (Sun) and Lord 1 Movement (Venus).

Venus as Creator Gods, throwing their darts, i.e. rays (nduvua) from Heaven: the Sun is seated on his high throne, while Venus is running through the sky as his messenger.

Alvarado mentions the calendar name of the Moon: iya caa huiyo, 'Lord 1 Reed'. In prayers of the ritual specialists (maestros cantores) in the State of Guerrero the Moon and the Sun are still invoked with these ancient calendar names, paired in a difrasismo: yoko kavi[yo], yoko kamao. ${ }^{40}$ In ancient tales, such as the Popol Vuh, Sun and Moon appear as brothers (twins), protagonists in the primordial time of darkness. A well-known Nuu Dzaui story explains how these two brothers were the children of the Grandmother, whom they tricked and enclosed in the steambath (Dyk 1959: $10 \mathrm{ff}$ ). We interpret this motif as another reference to the separation between the world of human understanding (light) and the world of the Grandmother (the Primordial Midwife), i.e. the mysterious creative and intuitive Forces of Nature.

The Wind God, the Feathered Serpent, known as Quetzalcoatl and Ehecatl in the Nahuatl sources, is Lord 9 Wind (Iya Qchi). As in

40 The names of these deities, together with several others, occur in prayer texts from Guerrero, which were registered by Chantal van Liere and Martijn Schuth, students of Leiden University, during the research for their M.A. thesis 


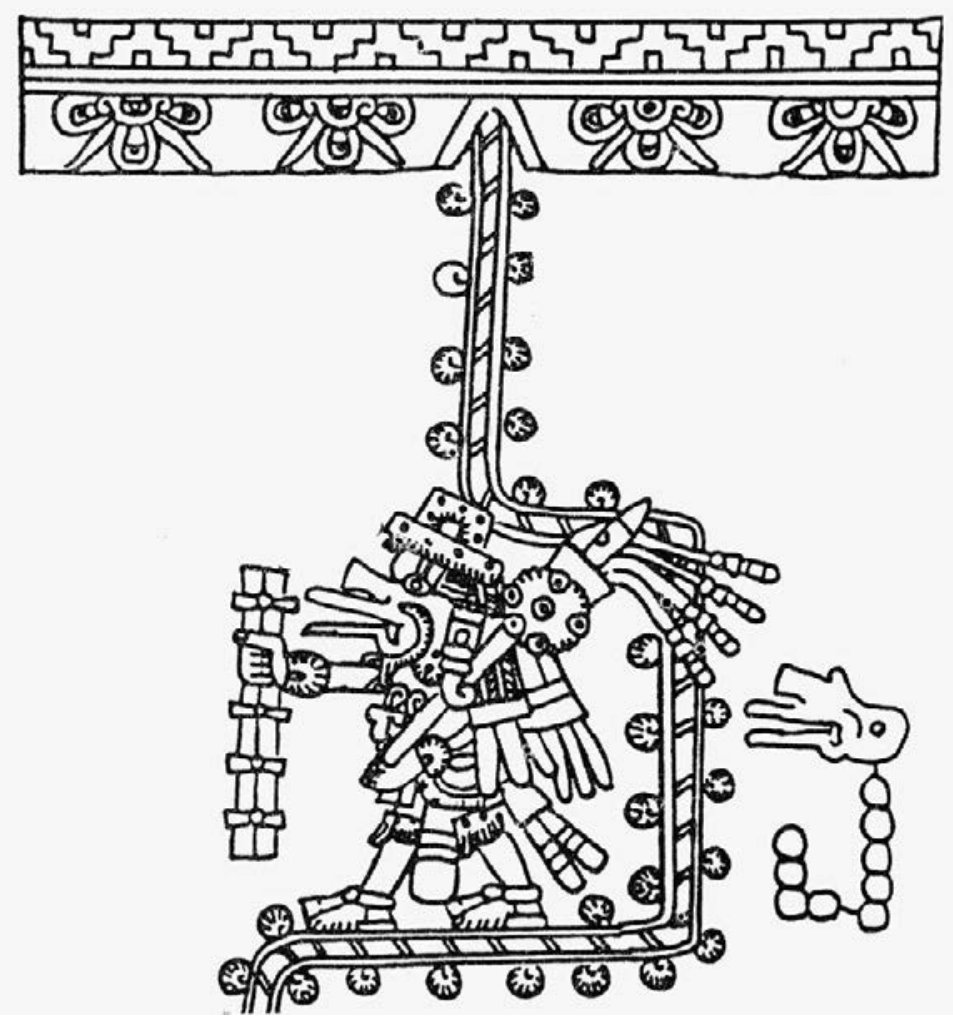

6.11: Codex Yuta Tnoho, p. 48: Lord 9 Wind 'Quetzalcoatl', the Whirlwind, coming down from the Place of Heaven.

Central Mexico, his distinguishing feature is the bucal mask of the Wind God. In present-day communities he is often referred to as the Rain Serpent (Coo Dzaui), the whirlwind. ${ }^{41}$ Symbolizing liminality, he enables the contact between humanity and the divine. He appears as the 'culture hero' (Codex Yuta Tnoho, p. 48-47), the primordial guiding priest and nahual, who taught how to speak well and paint codices, who brought the waters of Heaven, i.e. the forces of life, art

${ }^{41}$ Aurora Pérez identified the Quetzalcoatl figure of the codices as Koo Sau in present day Ñuu Ndeya or Chalcatongo (Jansen 1982b: 140 ss; Jansen \& Pérez Jiménez 1973a: ch. 2 \& 3). See also the story registered by Paulat Legorreta (1969), the description and visual representation in Nuu Yoo (Monaghan 1995: 108) and the analysis of Witter in his contribution to the volume edited by Jansen and Van Broekhoven (2008). 


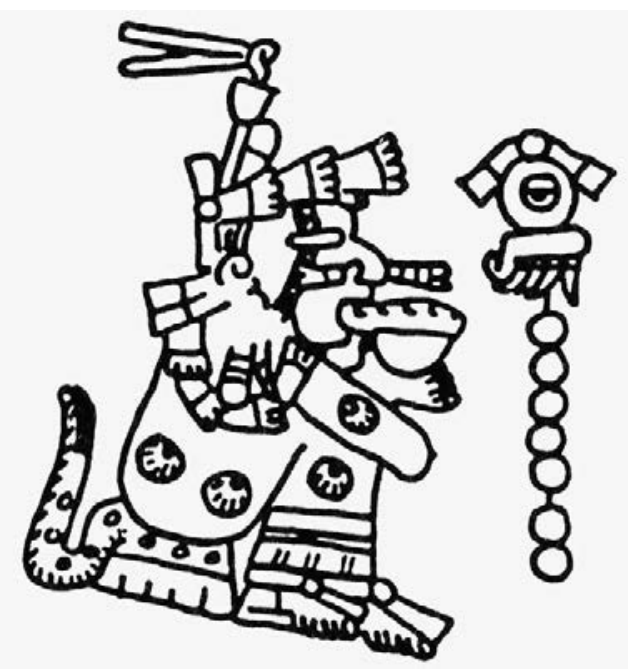

6.12. Codex Yuta Tnoho, p. 25: Lord 7 Rain, drinking pulque.

and faith, to the communities, integrating the world of Nuu Dzaui in sacred space and sacred time.

Lord 7 Rain (Iya Saco) is the Nuu Dzaui version of the Flayed God (Xipe in Nahuatl), who appears as the Patron of the Beni Zaa dynasty of Zaachila. We interpret flaying as a metaphor for clearing the fields and preparing them for a new agricultural season.

Lord 4 Serpent (Iya Qhyo) and Lord 7 Serpent (Iya Sayo) play an important part in the early history. They are depicted with knots (of paper) in their mouth, which qualify them as 'guardians of secrets' (yehe catnu yuhu). Together they are identified as Patron Deities of Nuu Tnoo, who were the focal point of a specific cult, directed by priests called tay saqui (Acuña 1984, II: 232-233). ${ }^{42}$ In Codex Yuta Tnoho, p. 33, they appear as presidents (and organizers) of a large reunion of the main protagonists of early Nuu Dzaui history, which

${ }^{42}$ Alvarado translates tay saqui as 'mandón como tequitlato'. Codex Yoalli Ehecatl (Borgia), p. 25, shows four war-gods, which we may relate to different peoples: Qhyo Sayo is the Patron of Nuu Tnoo, the Rain God the Patron of Nuu Dzaui in general, while Xipe is the Patron of the Beni Zaa, and Mixcoatl that of the Chichimecs or Tolteca Chichimeca. 
we interpret as a crisis cult community that brought about the social order of the Postclassic Era (Jansen \& Pérez Jiménez 2007a: ch. 3 \& 4).

Important among the divine personages in the Nuu Dzaui codices is Lady 9 Reed (Iyadzehe Qhuiyo). She is depicted with a quechquemitl and skirt bordered with flint knives, which we read as the title Dzico Yuchi, Huatu Yuchi, 'Power and Glory of Knives'. She seems to correspond to the Mexica Goddess Itzcueye, 'She with the Skirt of Obsidian Points or Knives', better known as Itzpapalotl, 'Obsidian Butterfly', which is the divine power of the obsidian arrowhead. ${ }^{43}$ As we saw above, the skirt is probably used in pictography to represent the Dzaha Dzaui term huatu, 'grace', 'glory'. The braids may allude to the same term. The hair of Lady 9 Reed is braided with intertwined serpents, indicating her dangerous character and possibly her being head of these animals as spiritual guardians and symbols of visionary power. In Yodzo Cahi (Yanhuitlan) she was venerated in a cave with sacrifices of birds (Jiménez Moreno \& Mateos Higuera, 1940: 40). In combination these elements portray her as a strong symbol of adult female agency, as well as of the power and vision to confront conflicts and struggles in a general sense. Her main sanctuary was situated on the mountain of Town of Blood, which we identify as the Boquerón Gorge in Nuu Niñe, 'Town of Blood', i.e. Tonalá in the Mixteca Baja (see next chapter).

Lady 1 Eagle (Iyadzehe Casa) is an elderly Lady, associated with the River of Ashes (Yaa Yuta), which symbolizes the West, and with the steambath (Codex Yuta Tnoho, pp. 16-15). We identify her as Yoco Sitna Yuta, the 'Spirit Grandmother of the River', the Patron of procreation, whose realm is the West. ${ }^{44}$ Her given name is painted as White Quechquemitl, Star Quechquemitl, the latter decorated with a plant motif, such as acxoyatl or zacate (Codex Yuta Tnoho, p. 28-III). The main part of the name may be translated as 'Virtuous and Pure, Beautiful as a Star' or as 'Virtue, Beauty and Power of the White Stars'. The stars may symbolize the realm from where the souls of children descend.

${ }^{43}$ Her distinguishing depiction is found in codices Yuta Tnoho (p. 28) and Tonindeye (p. 51), to be compared with Codex Yoalli Ehecatl (Borgia), p. 47. For the significance of Itzpapalotl, see Ruiz de Alarcón, Tratado II: ch. 9 (cf. Heyden 1974).

${ }^{44}$ See the Relación Geográfica of Yodzo Cuiya or Juxtlahuaca (Acuña 1984, I: 285), to be read together with Burgoa (1934b, I: 289). 


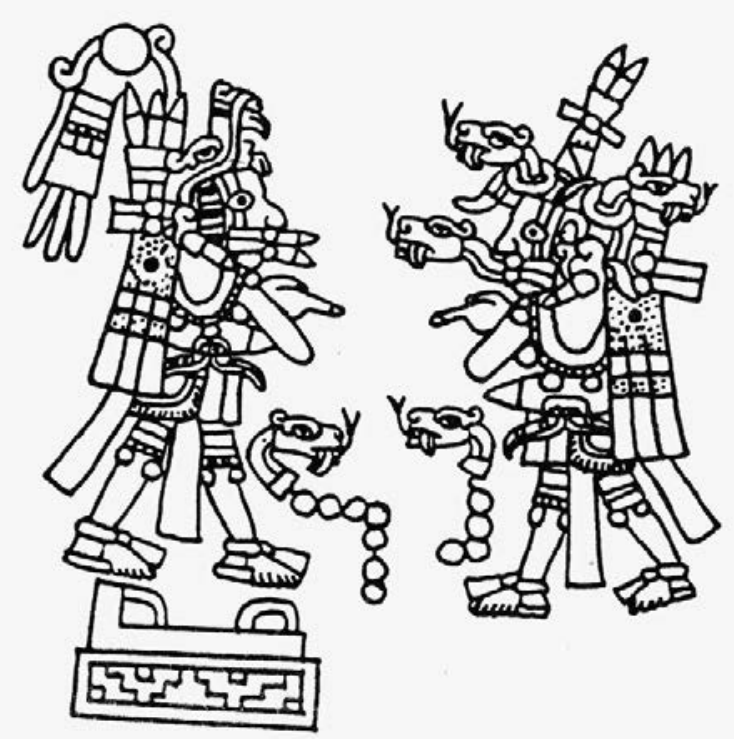

6.13. Codex Yuta Tnoho, p. 5: Deities Lord 7 Serpent and Lord 4 Serpent, presiding over the ritual foundation of towns.

Her elderly appearance and association with the steambath connects her with the 'Grandmother' who is still venerated today as the numen of the temazcal (steambath). Given the crucial role of the steambath in restoring strength and 'life heat' to young mothers after childbirth, we may interpret the Grandmother as the primordial midwife..$^{45}$ In traditional narratives she is the Grandmother of the two brothers, who later become Sun and Moon (Dyk 1959: $10 \mathrm{ff}$ ). She used to go regularly out into the mountains. One day the two boys follow her in secret and discover that she brings food to a deer, they kill the deer, flay it and fill the skin with bees and wasps. When the Grandmother comes again to see the deer it stands there without moving; she hits it on the back when it does not talk to her, the bees and wasps come out and sting her badly. She runs back to her house, where the two brothers have prepared the steambath. When she enters they close the temazcal behind her so that she remains in the bath forever as its numen. We have already said that this story strikes us as illustrating

45 Jansen \& Pérez Jiménez 1980 and Katz 1996 describe the present-day use of the temazcal in the Mixteca Alta, while Manning 1993 has discussed the archetype of the primordial midwife (Old Goddess) in Maya iconography. 


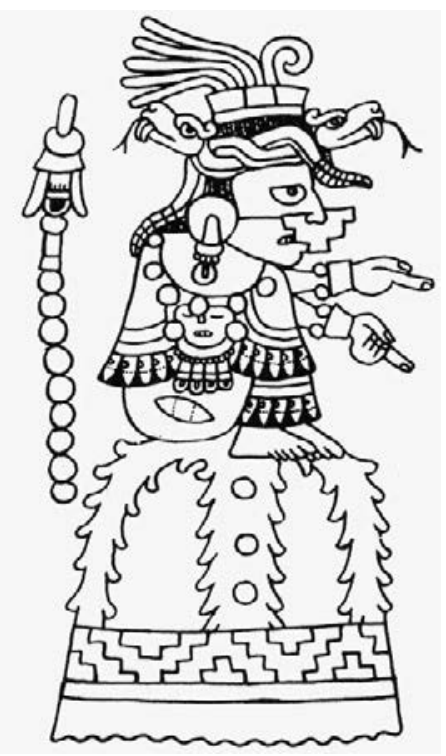

6.14. Codex Tonindeye, p. 51: Deity Lady 9 Reed 'Power and Glory of Knives' (Dzico Yuchi Huatu Yuchi) on the Mountain of Town of Blood, Nuu Niñe (Tonalá).

the separation of the world of men (consciousness and history, brought about by the light of Sun and Moon) from Nature (Deer and Grandmother), particularly the deep 'dark' mysteries of sexuality, child-bearing and raising, illness and health, in sum the cycle of lifedeath-life (in terms of Estés 1992). That separation was in itself an act of trickery and violence, leading to the suppression and imprisonment of ancestral female knowledge and intuitive forces (the Grandmother) within the confined dark space of the temazcal. The midwife, however, participates in the wisdom and protective force of the Grandmother, and becomes, like her, instrumental in continuing the line of human life on Earth.

As the Lady of the River Lady 1 Eagle may be compared with Chalchiuhtlicue, 'She with the Skirt of Jade', the Mexica Goddess of the rivers and lakes, who is, however, represented as a young woman, while as the Patron of the Temazcal, she is a cognate of Tlazolteotl, the Mexica 'Goddess of Filth', i.e. the Force of Cleansing, who has also a different iconography. The latter appears also with the title Teteo Innan ('Mother of the Gods'). Both these Goddesses are situated in the West, according to Codex Tezcatlipoca (Fejérváry-Mayer), p. 1. At the 


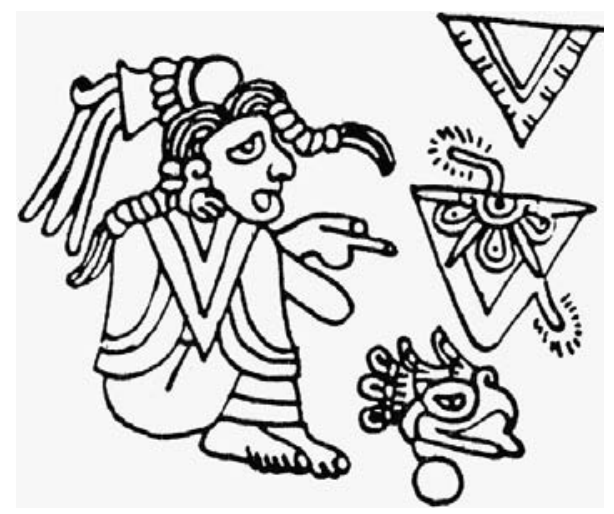

6.15. Codex Yuta Tnoho, p. 25-III: the Divine Grandmother Lady 1 Eagle.

same time Lady 1 Eagle seems to be the Mixtec equivalent of the Grandmother Ixmucané in the Popol Vuh and the primordial midwife Oxomoco of the Mexica. ${ }^{46}$

Especially awe-inspiring is Lady 9 Grass (Iyadzehe Qcuañe), a death deity who rules the Temple of Death (Huahi Cahi, Andaya), the emblem of the South, a place we have identified as the regionally important funerary cave in Nuu Ndaya, (Chalcatongo). In Codex Nuu Tnoo-Ndisi Nuu (p. 4-III) she appears with a deer's hoof, which has led Byland and Pohl to the following interpretation:

She is named with the hieroglyph of a deer leg referring to her title: Yan'si, a term today appied to her modern counterpart, the Virgin Mary (Monaghan, personal communication 1988). Yya is the title of royalty and Sii means 'grandmother' or 'leg of animal'; the deer leg thus forms a tonal pun meaning 'grandmother'. (Byland and Pohl 1994: 111).

This quote has its counterpart in the work of Monaghan:

Female $n u$ ñu'un are, like Catholic saints, yan si'i, which Nuyootecos translate as 'virgins'. Being a yan si'i, however, has nothing to do with virginity as we might define it, but instead indicates sacredness and feminity. Yan is the prefix for sacredness, and John Pohl points out that

${ }^{46}$ Oxomoco was the wife of Cipactonal, the primordial calendar priest. We suspect her name comes from otz-tzomocoa, referring to the efforts made by the pregnant woman in childbirth and the strength given to her by the midwife. See the commentary of Anders, Jansen \& Reyes García (1991) on the representation of Oxomoco in Codex Cihuacoatl (Borbonicus), p. 19. 
si'i might be related to the word for grandmother (John Pohl, personal communication, 1989). (Monaghan 1995: 101).

In reality the title yan si' $i$ in the dialect of the Mixtec language spoken in Nuu Yoo corresponds to what in Alvarado's orthography is yya dzehe, 'the Lady', a term used for the ancient queens as well as for female deities. Today it refers to 'the Virgin', i.e. Our Lady the Virgin Mary. The comment about "virginity as we might define it" is therefore out of place. As for the rest of the etymological theory, there is simply no basis for it. In Alvarado sii is 'grandfather' (not 'grandmother', which is sitna). One might argue that saha dzehe uvui, 'cleft hoof (Spanish: pata hendida), could in some way have been used to represent yya dzehe, 'Lady', but that is highly unlikely. All female protagonists in the codices were addressed with that title, so there was simply no need to express it in this specific case in such an uncommon and far-fetched way. The most plausible explanation of the deer hoof is that this attribute alludes to Lady 7 Grass's seat of power: the Huahi Cahi (Vehe Kihin) or cave where the Mixtec rulers were buried, on the Mountain of the Small Deer (Spanish: Cerro de Cervatillos) in the village-state of Nuu Ndaya (Chalcatongo).

Lady 9 Grass is comparable to the Cihuacoatl of the Mexica, who is the Spirit of the Hallucinogenic Tobacco (piciete) and the Lady of the Milky Way (cf. Codex Yoalli Ehecatl, p. 29). Supposedly she is the deity invoked in the Guerrero area as yi'ya si'i yichi, yi'ya si'i ñu (in Alvarado's orthography: iyadzehe ichi, iyadzehe ñuu), 'Lady of the Road, Lady of the Night', i.e. 'Lady of the Road of the Night Sky' or 'Lady Milky Way', known to be the 'Mother of Tobacco and Pulque'. ${ }^{47}$ The black quechquemitl (triangular female upper garment) decorated with white S-shaped motifs, which is part of her onomastic sign, may indicate this quality. In Nahuatl this form is known as xonecuilli and is used to indicate a type of tortillas specially made for rituals. The word also designates a particular constellation in the night sky. ${ }^{48}$ The

${ }^{47}$ Prayer texts from Guerrero, registered by Chantal van Liere and Martijn Schuth (M.A. thesis, Leiden University). The similarity of the onomastic sign with the Nahuatl title Citlalcueye, 'She with the Skirt of Stars', is obvious. We interpret ichi ñuu ('road of the night') as synonymous with sichi nuu ('furrow of the night') which is Alvarado's translation for the Milky Way ('Camino de Santiago'). Today in Nuu Ndeya the term for the Milky Way is ichi yuyu, 'road of dew'.

${ }^{48}$ See Codex Yuta Tnoho, p. 28-IV. The S-shaped tortillas are depicted in the Libro de la Vida (Codex Magliabechi), p. 81. The constellation is said to be 'las estrellas que están en la boca de la bocina' (Sahagún, book VII: ch. 4), and 'la encomienda de 


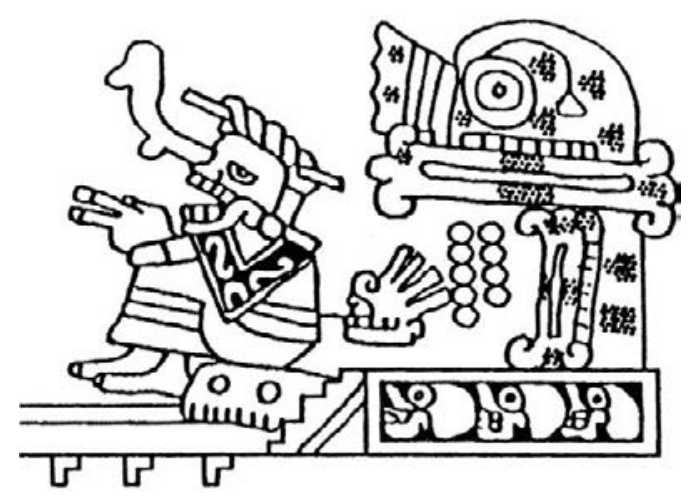

6.16. Codex Añute, p. 6-IV: Lady 9 Grass in the Temple of Death.

black and white combination is a reference to death. Her name is probably to be understood both as 'Lady of the Xonecuilli Constellation' and as 'Power of Death', which would make her a kind of Omiteotl (Nahuatl: 'Deity of the Bones').

In a legal document of 1596 from Nuu Ndaya we read about "the great lord called tani yoco, which means 'devil', who abides in the cave". The word Yoco means both 'spirit' and 'maize flower'. The word tani is difficult to interpret; it may come from a combination of taa, 'father' and nii/nee, 'whole' or ne(ñe), 'blood'.$^{49}$ If one would take tani to be the local variant of Alvarado's tnani (or tnahni) one might choose from meanings so distinct as 'Bundle (of cloth)', 'to incense', 'to smell', 'belt', 'lover', 'prudent' and 'industrious'. Referring to females, the term ñaha nee ñaha yoco means 'virgin'. The title taa, 'father', is adequate for the "great lord" mentioned in the text, apparently a male deity; in the case of a Goddess we would expect naa, 'mother' or sitna, 'grandmother'. A maize flower (yoco), drinking blood (neñe), indeed constitutes one of the names or titles of Lady 9 Grass. ${ }^{50}$

Just like Lady 1 Eagle, Lady 9 Grass is a Keeper of the secrets of lifedeath-life (in terms of Estés 1992), but where Lady 1 Eagle is the Grandmother and Primordial Midwife, Lady 9 Grass is the Knower of the deepest mystery, beyond death as a final frontier of the individual

Santiago, que es la que está por parte del Sur hácia las Indias y chinos' (Tezozomoc 1975: 574).

49 The document was published by Jansen 1982b, appendix 2 .

${ }^{50}$ See Codex Yuta Tnoho, p. 28-IV. 
life-span. She is the connection with the world of the Ancestors, with the numinous power that is the fundament of creature-feeling and ritual practice. We may compare her to the skeletal aspect of the primordial 'witch' Baba Yagá in Russian ancient narrative or with the Skeleton Woman of Inuit lore, so aptly analyzed by Clarissa Pikola Estés (1992: ch. 3, 4 and 5) as symbolic references to the cycle of lifedeath-life, to interior spiritual strength, to the psychic realm of inherited wisdom and natural intuition. In Western thought a dichotomy, or rather a rupture, was produced between Life and Death ('Halloween') as mutually exclusive and non-communicating realms, comparable to that between mind and matter, physics and metaphysics. Transcending this rupture, we can sense that Mesoamerican death imagery is not macabre or frightening, but rather an expression of reconnecting with origins, with the power, love and guidance of the Ancestors as an integral part of our existence.

Many deities known from the Nahuatl speaking world are also present in Nuu Dzaui documents. There are also some significant differences, however, in their attributes and fields of symbolic associations. Where we can make clear comparisons, the names of the deities often do not coincide in the two languages. Finally, it is interesting to see that several of the 'quechquemitl names' we found used by Nuu Dzaui queens were actually taken from the names of Goddesses.

In their book on women and female deities in the codices from Oaxaca, Cecilia Rossell and María de los Ángeles Ojeda Díaz (2003) propose a set of names for Nuu Dzaui deities, all directly translated from the Nahuatl into ancient and modern Dzaha Dzaui, with the help of Alvarado's vocabulary for the first and that of native speakers for the second. There is no problem at all, of course, with a case such as Dzaui, the Rain God, who is a direct equivalent to the Tlaloc of the Mexica. We may also suppose that in some other cases different Mesoamerican peoples were aware of alternative names or titles used by others, given the general symbolic idiom of the culture area. But in principle the simple translation of Mexica names into other languages (which recalls similar efforts by Martínez Gracida) is an unsound procedure. It may be interesting as a heuristic exercise, but a detailed iconographical analysis with well-documented philological or ethnographical evidence is necessary for establishing the original Dzaha Dzaui names, otherwise the results are misleading.

More importantly, we should learn that in dealing with these names, images and narratives, we enter a symbolic and emotional universe, which is still very much alive. In the Center we situate the Maize 


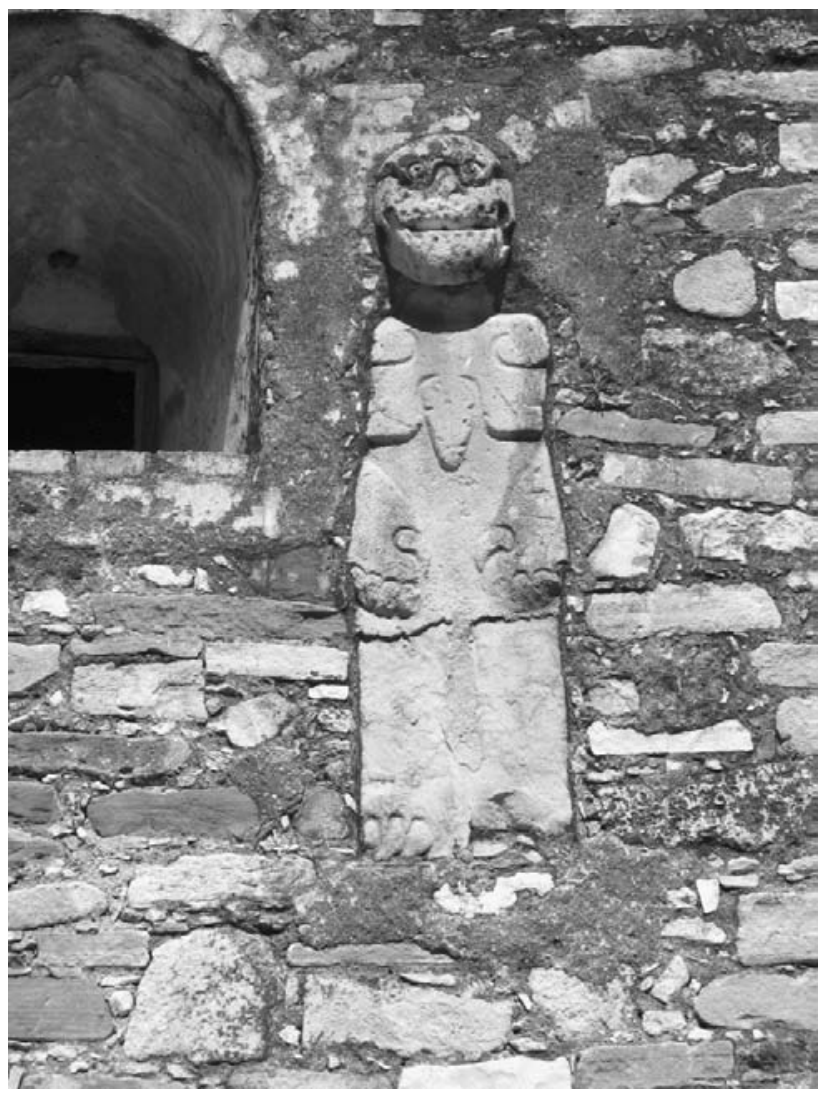

6.17. Sculpture of a Death Deity, set in the wall of the church of San Martin Huamalulpan.

Flower (Yoco) as symbol of (re)birth and of eternal germination and creativity. In the East we see the rise of light, reason and justice. When the Sun rises in the North-East the activities of the rainy season, the work in the fields, but also other struggles, occupy our attention. To the West is the realm of the midwife and the medicine woman (curandera), watching over childbirth with the wisdom of older age. The South is the house of Lady 9 Grass, where the soul passes through the realm of Death itself, understanding and transcending the example of the Ancestors, transforming the self and becoming a seed for a future phase of the cycle.

This empowering symbolic dimension may be sensed and grasped from within, with an emic understanding and a strong consciousness 
of cultural heritage, but is often not recognized when Western investigators are looking at another culture. Typically the academic discourse, when disconnected from the living human experience and interaction, tends to reduce 'the Other' to a void on which the 'inner demons' of Self may be projected.

\section{The Bias of Colonial Sources}

The Spanish missionaries saw and described Mesoamerican religion as an 'idolatrous' cult of 'demons', which they tried to combat in a holy crusade. In their zeal they often misrepresented and exaggerated the native ceremonial practices and convictions, playing on the macabre sensationalism of their European public. A well-known example is the enormous inflation of numbers of victims of human sacrifices. The practice existed but in a much more limited way and a much more rational context than the Spanish sources intend to make us believe: it was the ceremonial execution of enemy captains taken prisoner during battle, not unlike what was (is) common in other cultures. Still, that colonial propaganda haunts the modern popular representations of Mesoamerican civilization.

We find a subtle example of this same complex of ideas in the descriptions of the Mexica feast Cuauitleua by Friar Bernardino de Sahagún. In an early version of his work, known as the Primeros Memoriales we read that offerings were made to the Rain Gods:

the children died - they were called Tlacateteuhmê - there on the mountain tops. (Jiménez Moreno 1974: 19).

The Nahuatl word tlacateteuhmê, is the plural of tlaca-teteuitl, in which tlaca(tl) means 'man' or, in this adjective position, 'anthropomorphic', and teteuitl is the term for cut paper figures. Reading the whole text it becomes clear that the feast mainly dealt with the cutting of such paper figures, which were sprinkled with liquid rubber and carried around in processions. This practice is not only documented in precolonial iconography, but may also be observed today in the religious tradition of Nahua, Ñahñu and Tepehua communities: figures, known popularly as muñecos, are cut out of paper to represent different spirits and to be put on offering tables both during curing rituals and agricultural ceremonies (e.g. Sandstrom 1991: ch. 5). Observing the present, we understand that the historical text refers clearly to the 
ceremonial 'killing', i.e. the offering of precisely such paper figures, designated as 'children' in this context. ${ }^{51}$

The description of the Cuauitleua feast was elaborated, however, in a later version of Sahagún's work, the Florentine Codex. Here the ritual is presented as the actual killing of children:

In this month they slew many children; they sacrificed them in many places upon the mountain tops, tearing from them their hearts, in honor of the gods of water, so that these might give them water or rain. The children whom they slew they decked in rich finery to take them to be killed; and they carried them in litters upon their shoulders... When they took the children to be slain, if they wept and shed many tears, those who carried them rejoiced, for they took it as an omen that they would have much rain that year. (Sahagún, book II: ch.1, translation by Anderson and Dibble).

In this way the innocent solemnity of paying respect to the Rain Gods and invoking them with paper images, as it is still done today, was transformed by the hostile imagination of the missionary into an act of bloodthirsty sadism. The Franciscan friar - often hailed as 'the first ethnographer' - explicitly states his propagandistic objective in an introductory paragraph:

There is no need in this second Book to refute the idolatrous ceremonies described here, because they are of themselves so cruel and so inhuman that whoever hears them is filled with horror and fright. (Sahagún, book II: ch. 20).

In historical studies we should be continuously aware of such distortions and deconstruct the discourse of one culture about the other within its proper context and perspective, especially as misrepresentations are often used to justify and maintain situations of inequality and social injustice.

${ }^{51}$ The expression 'they died' is also used for the figures of tzoalli paste, representing the mountain deities (Tepictoton), which were beheaded during the feast of Atemoztli (Jiménez Moreno 1974: 58). In that case the ceremony was not reinterpreted as a form of human sacrifice, probably because of its superficial resemblance to the Eucharist. Compare the cutting and offering of paper figures by the merchants during their rituals (Sahagún, book IX: ch. 3). For a discussion of Sahagún's work and intellectual-historical postion, see for example Browne 2000. 


\section{CHAPTER SEVEN}

\section{MEMORY LANDSCAPE}

City-states or village-states do not exist in isolation, but function within an interactive network of relationships with others, manifest in alliances, conflicts, exchanges and other contacts. Each polity has its place within the geographical and historical consciousness of the 'city-state culture', the landscape of sovereign communities. ${ }^{1}$ The Homeric songs are a good example of such a shared landscape and memory, in which diverse communities, peoples and lineages could relate to a unifying grand narrative. A wealth of toponymic references to islands, regions and tribes, towns, mountains, rivers and springs, with their evocative epithets, anchor the story in space. The audience is thus situated in a world - be it real, fabulous or sacred - in which it can orient itself and with which it can identify. The rocky Skylla and the fatal whirl-pool of Charybdis, located at both sides of the northern end of the Straits of Messina, Italy, which separates Sicily from Calabria, become hallmarks of the Odyssey as a life-voyage, while the longed for island of Ithaka with its Cave of Nymphs and Fountain of Arethousa, just as the brilliant snow-capped Olympus, the oracle of Zeus at Dodona with its Sacred Oak, the fortified palace at Mycene, the city of Thebes with its seven gates, and so many others, all become places of significance, orientation and destiny in the Greek epic universe. The same may be said about sites such as Tintagel in Cornwall, England, with its ruined castle on top of a steep cliff overlooking the rocky ocean shore, beaten by waves of foam and thunder, with the cave of Merlin down below, echoing with the legends of King Arthur.

\section{Sacred Time, Sacred Space}

The ancient world of Nuu Dzaui held similar points of reference: sacred caves and mountain tops, lineage shrines of special prestige, towns that

\footnotetext{
${ }^{1}$ Hansen 2000 presents a comparative analysis, while, for example, Tilley 1994 and Ingold 2000 offer inspiring discussions of landscape and its conceptual-experiential value for archeology (see also Geurds 2007).
} 
had played their role in history or excelled because of wealth or prowess in war. The literary text, formal discourse or 'parangón' (sahu) painted in Codex Yuta Tnoho contains a long section of place signs and dates, which, as we saw above, has baffled many interpreters. It starts on p. 47 with an impressive image of Lord 9 Wind 'Quetzalcoatl', the divine Bringer of Culture, carrying the waters of Heaven to the mountainous world of Nuu Dzaui. We read it in Sahin Sau (the dialectal variant of Dzaha Dzaui in modern Nuu Ndeya, Chalcatongo) as follows:

Te iha ñahnu, iha Koo Sau nikuundiso andiu jiin nducha, te suan niskuun sau, niskuun viko nuu taka yuku, taka kava, taka yucha, taka yoso, nuu ndihi ñuu, ndihi teyu ja kayoo nuu Ñu Sau, te nijahaya kuia ii, kiu ii,

viko ñuu, nuu nikandukoo shranuu ñuu anahan, yuhu yucha kuka,

nuu nana chii ñuhu

taka ja kaichaku, ndenduu nducha kahnu, nuu kana tihiñu, nducha ñuhu, nuu yaa kiti nducha ja sihu,

kiti shraan ja janu vehe,

ja jahnu itu, ja jahni ndìy, yuku Ñu Sau, nuu ja kaa tiyuu vita nene,

sani kuu ishi nducha te sani kuu tuun, nuu yaa ñuhu ndehyu ini, mahñu ndekuun ichi andiu, Ndihi taka itu, yuku, yoso, ja juhni yoho, ja sa-unuu, ndihi ja indii chii andiu, sani kuu ndava veheyo, sihin veheyo,
And the Great Lord Plumed Serpent took charge of the heavenly waters and so caused the rain to fall, the seasons to come, for all the mountains, all the rocks all the rivers, all the plains all the towns and nations that constitute Nuu Dzaui; thus he established the holy years and days,

the feasts, for the towns founded in the beginning, in the past, for those on the banks of rivers full of gold,

where from the depth of the earth all living creatures sprouted, for both oceans, with waves covered with foam, for the sacred water (Pacific Ocean) where the horrific hurricane dwells,

the monster that demolishes the houses,

destroys the fields and kills the people, for the mountains of Nuu Dzaui, which form a circle around, in harmony, peaceful and soft as fur, as down-ball feathers, in the centre of which the Spirit lives, stretching towards the four directions, for all lands, mountains, plains bound together and unified, for all that rises and has Heaven as its roof beam 


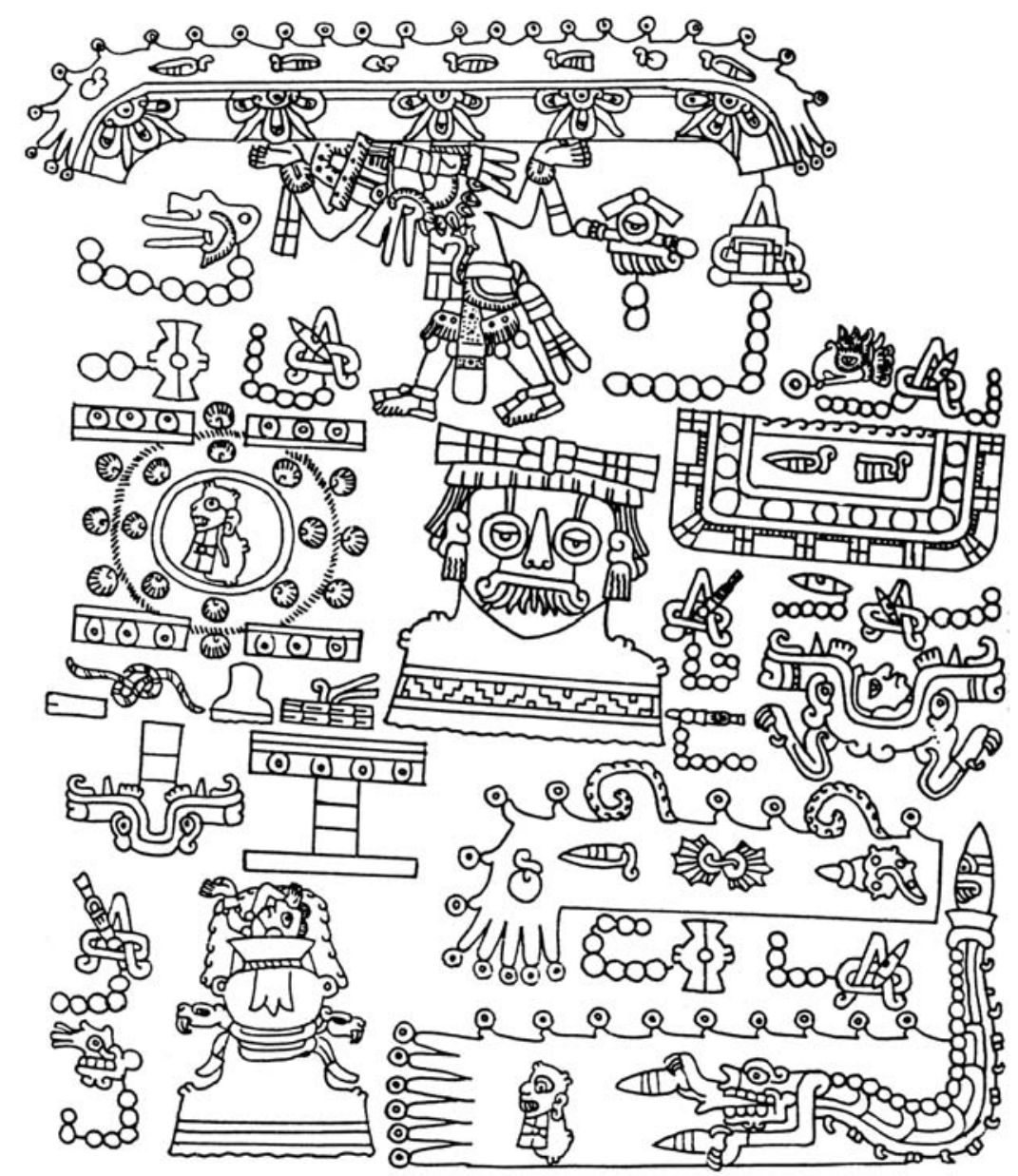

7.1. Codex Yuta Tnoho page 47: Lord 9 Wind brings the water of Heaven to the mountain of the People of the Rain, i.e. Nuu Dzaui, and the surrounding landscape (including the two oceans in the lower right-hand corner).

ndìì ja nana chii ñuhu, sani kuu jaha veheyo. for all that grows and has Earth as its fundament and origin.

The next nine pages (46-38) delineate the ancient world of Nuu Dzaui by listing the major primordial sites with specific dates. Many of them occur later during the ceremonies that mark the foundation of communities and dynasties through the kindling of New Fire and a cleansing ritual. These place-date combinations have baffled the interpreters 
for a long time. Adepts of the Astraldeutung (Kreichgauer, Lehmann) tried to decipher those pages as an esoteric table for astronomical calculations. ${ }^{2}$ Following the correct observation of Caso that the year 1 Reed day 1 Alligator indicates 'beginning', Jill Furst (1978a) proposed that the dates were metaphoric statements about the natural surroundings of the places. Examining the association patterns, she read the year 5 Flint day 5 Flint as a date for 'fertile earth', year 5 Flint day 8 Movement as a date for 'turbulent water', and the year 7 Reed day 7 Reed as a date for 'hill'. Diametrically opposite is the idea of Gordon Brotherston (inspired by the fanciful interpretations of Melgarejo Vivanco) that the only 'orthodox' reading of a long sequence of dates combined with place signs in Codex Yuta Tnoho would be to count them succesively as 'true annals', spanning several millenia (Brotherston 1983, 1985, 1995: 126-129, 2007: 220; for a critical discussion see Jansen 1988b).

Marc King (1990) attributes a phonetic value to the dates - that of the terms in the special calendrical vocabulary - and then reads them as short phrases or 'captions' in common Mixtec. This often means interpreting the calendric syllables as abbreviated or garbled forms (anagrams or metaphoric associations) of nouns and verbs of daily speech. Thus the pictorial text is 'decoded' in a way reminiscent of the Astraldeutung, but now as occult poetics with esoteric and sexual connotations. For example the year 13 Rabbit day 9 Reed, which accompanies the Sacred Tree of Origin (Codex Yuta Tnoho, p. 50), should be read as a verse. The name of the day 9 Reed in calendrical idiom, que-huiyo, permits various translations into common Mixtec, which King combines and reads together as a poetic phrase:

the body of the milpa,

the sown milpa,

the milpa that will ripen. (King 1990: 148).

The number 13 of the year date is composed of $5+5+3$ dots, which King decodes as separate verses dealing with sayu, the calendrical sign Rabbit, but a term meaning 'male genitals' in common Mixtec:

13-Rabbit: si-sayu, "male genitals are introduced/ingested"

5-Rabbit: cu-sayu, "male genitals descend" $(2 \times)$

3-Rabbit: co-sayu, "male genitals are seated in place"

${ }^{2}$ Séjourné 1987 and Hochleitner et al. 1987 are more recent examples of interpretations along astralistic lines. 


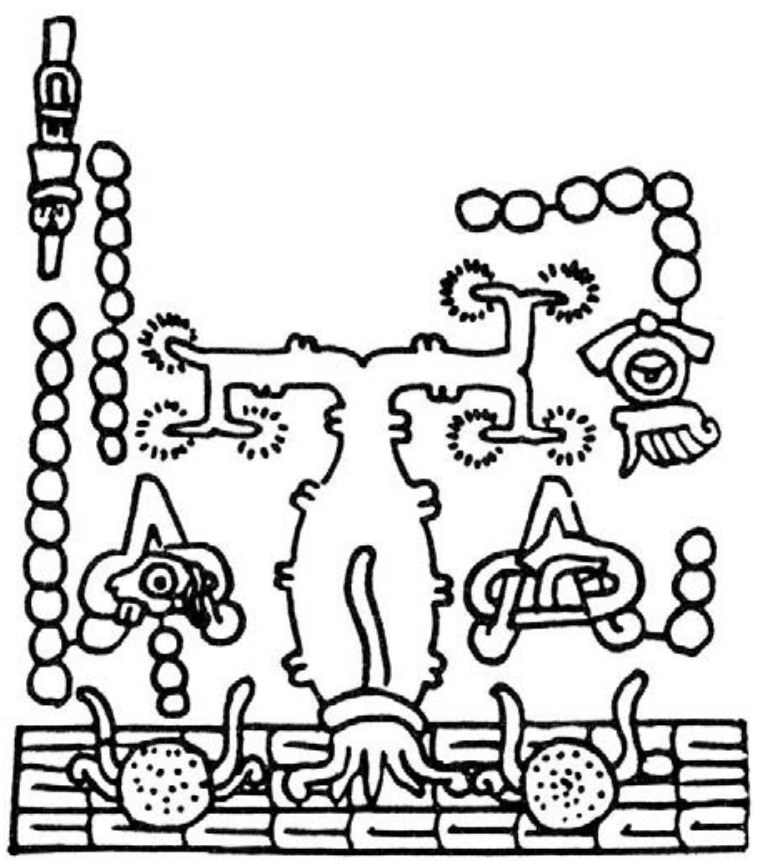

7.2. Codex Yuta Tnoho, p. 50: the Sacred Tree.

The general absence of explicit sexual references in ancient Ñuu Dzaui visual art suggests that sexuality was not a topic of public royal conversation. We therefore may already doubt the presence of such references in this highly normative genre of official historiography with its ritual dimension.

Byland and Pohl (1994: 115), however, quote King's reading with approval and add their own Freudian interpretation of the picture on page 37 of the codex:

Indeed the tree appears to be pregnant and the red mark on its trunk is suggestive of the labial opening of the vagina. ${ }^{3}$

The results of such 'decodings' sound fascinating, but the debatable character of the procedure immediately becomes clear when applied

3 Similarly, Alvarado Bárcenas and Ojeda Díaz (2009: 69), ignoring the work of Byland and Pohl, propose that the Sacred Tree represents the womb of Mother Earth. In contrast, another article in the same series, written by Agustín Aquino (2007), analyzes the image of the tree as the representation of a mathematical formula. 
in a well-known context. Let us take a modern example of a ritually important date: the 4th of July in the U.S.A.. King's method would result in decoding that celebrated day as the caption "the force (4th) of 'you lie' (July)", making the foundation date into a metaphor of deceitful imperialism. Such a reading would probably come as a shock to most American citizens, as, indeed, the way in which King proposes to read Codex Yuta Tnoho may confuse and offend speakers of Dzaha Dzaui.

A contextual analysis, on the contrary, shows that the day 9 Reed is the calendar name of a powerful female deity in the codices, while the year 13 Rabbit occurs frequently in the context of primordial events (such as the First Sunrise), probably because it antecedes the year 1 Reed, which marks the 'beginning' of the 52-year cycle. The tree itself is clearly a ceiba. On p. 37 a woman's head at the root qualifies it as animated and humanized: the Sacred Mother.

The place-date combinations are more likely explained as foundation statements: the date is the 'calendar name' of the community, a delicate and great day (quevui ii, quevui canu) in the dark and mysterious time of creation, which is to be commemorated and celebrated ritually (huico) on its regular reoccurrence. Although the precise principles that determine the order and association of places and dates still escape us, it is clear that a specific cognitive map underlies this presentation. In a similar way, the modern towns participate in a circuit of weekly market days and annual Patron feasts.

Thus a cultural landscape is constructed, which gives a people a sense of belonging and regional identity. The history of specific lineages and communities that then unfolds, is embedded in this landscape. The efforts to interpret the pictorial chronicles become a journey through both space and time.

\section{Landscape and Discourse}

Events literally 'take place': human actions are located in space as well as in time when they become the building blocks of narrative. Ordering them in a pictorial register often happened in accordance with the conventions of ceremonial speech. Many scenes contain parallel elements in structure and in detail, which provide a valuable key 
to the concepts and expressive creativity of the artist. As an example let us briefly review two passages from Codex Tonindeye.

On the first two pages of that manuscript we see four scenes, in which one individual, Lord 8 Wind 'Eagle', originates from different places and receives homage from a number of nobles (cf. Jansen \& Pérez Jiménez 2007a: ch. 5; cf. Williams 2009). First, in the lower right-hand corner, he is shown rising from an opening (mouth) of the Land of Death, i.e. an ancestral place. In front of him a stone-walled ballcourt and a Temple of Fire are indicated as the important ceremonial buildings.

The page is not subdivided by red guide-lines. Our eye is drawn to the scene immediately left of the first one as being the next, because we are accustomed to horizontal reading and because we can identify the place sign here, River with Hand Holding Feathers, as Apoala, the sacred town of origin mentioned in colonial sources. Indeed, it is plausible that a direct connection between these two scenes is meant. But if we apply a strictly formal analysis, we see that the reading order of the page follows a vertical boustrophedon pattern (as on p. 3 and following) suggesting that the second scene is actually the one above the first, i.e. the scene located in the upper right-hand corner. Here Lord 8 Wind 'Eagle' has proceeded from a red orifice in the Mountain of the Monkey and the Flower, where a stone-walled ballcourt and an altar for the Dead (Ancestors) are located. The first and the second scene have the same symbolic origin date of Year 1 Reed Day 1 Alligator. In both scenes the protagonist is accompanied by Lord 12 Alligator, who holds a staff. In the first scene this is the so-called 'Xipe Staff', because of being determined by a 'Xipe Bundle'; this object is decorated with quetzal feathers. Lord 12 Alligator also carries a large 'Xipe Bundle' on his back. In the second scene the staff he holds is the one often referred to in the literature as 'Venus Staff', but better identified as Tnu Cucua in accordance with a similar object in present-day Apoala (cf. López García 2007). We may call these two symbols of office the 'Staff of the Ancestor Cult' and the 'Staff of the Four Cardinal Points' respectively. On top a knife and a number of red feathers have been attached to it. These decorative elements may be read as the difrasismo yuu yuchi, yodzo cuii, 'precious stone, green feather', meaning 'very valuable'. In front of Lord 8 Wind: four approaching nobles, holding a quail and firewood (as offerings), lifting a red tunic as a gift (and sign of rulership), and crossing their arms in respect. 


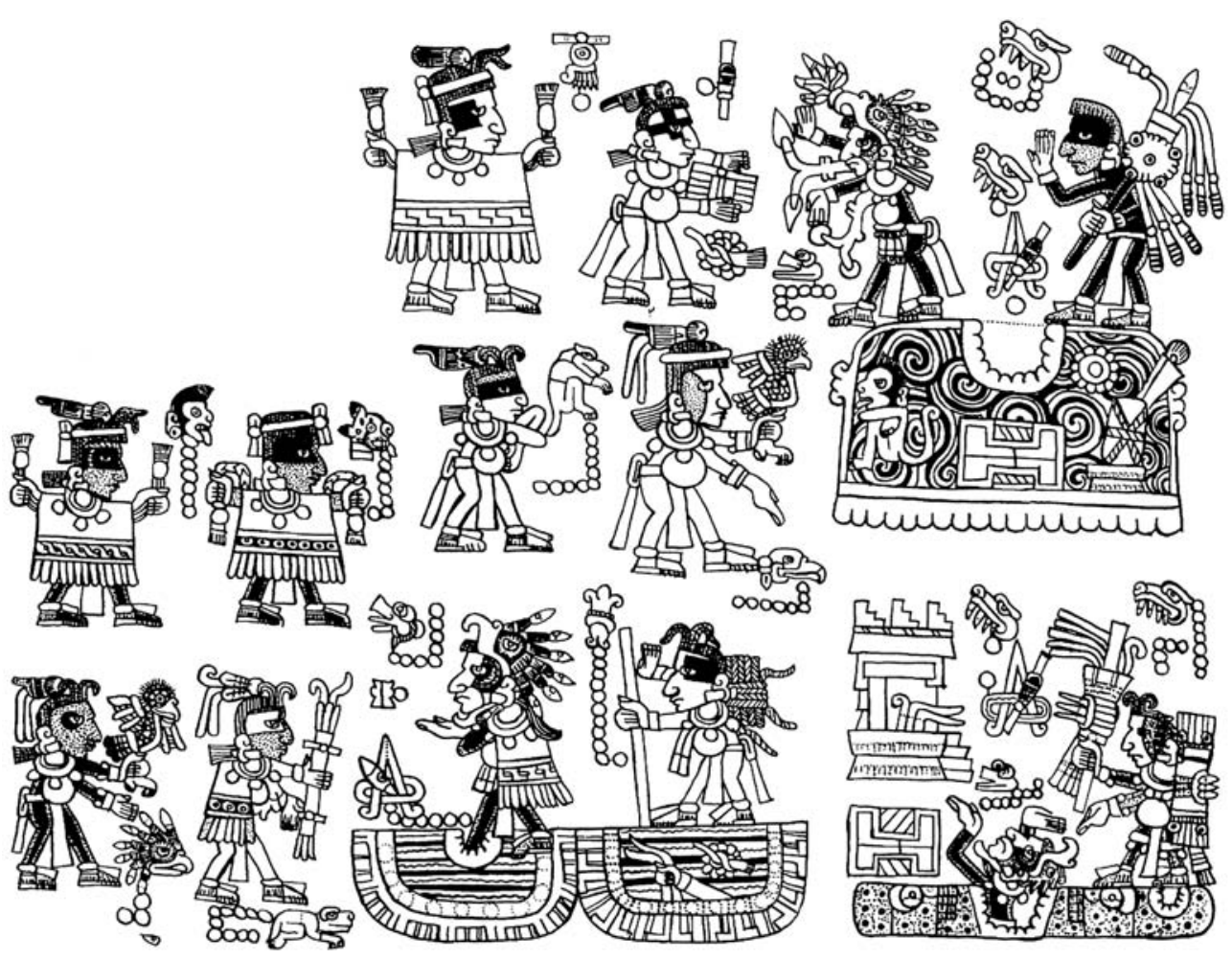

7.3. Codex Tonindeye, p. 1: origin and rituals of Lord 8 Wind.

The third scene, then, is taking place in Apoala. This time there is a different date: Year 7 Flint Day 1 Movement, and Lord 8 Wind is accompanied by another person: Lord 11 Flower (whose calendar name however is only one day before that of Lord 12 Alligator). The latter holds an undecorated staff and carries a bundle of cords on his back, possibly a reference to genealogy and family ties. In front again four priests, bringing fire, quail and two red tunics (with different fringe motifs). We notice that the last person in the group of scene two is the first person in the group of scene three. Apparently because of working in a format that differed from the original, the painter did not completely fill out the whole page but was left with an open space at the end of the group attendants in the third scene.

The fourth scene occupies the complete page 2 of the codex. Lord 8 Wind is shown as seated on top of Rain Mountain - Black Mountain, 


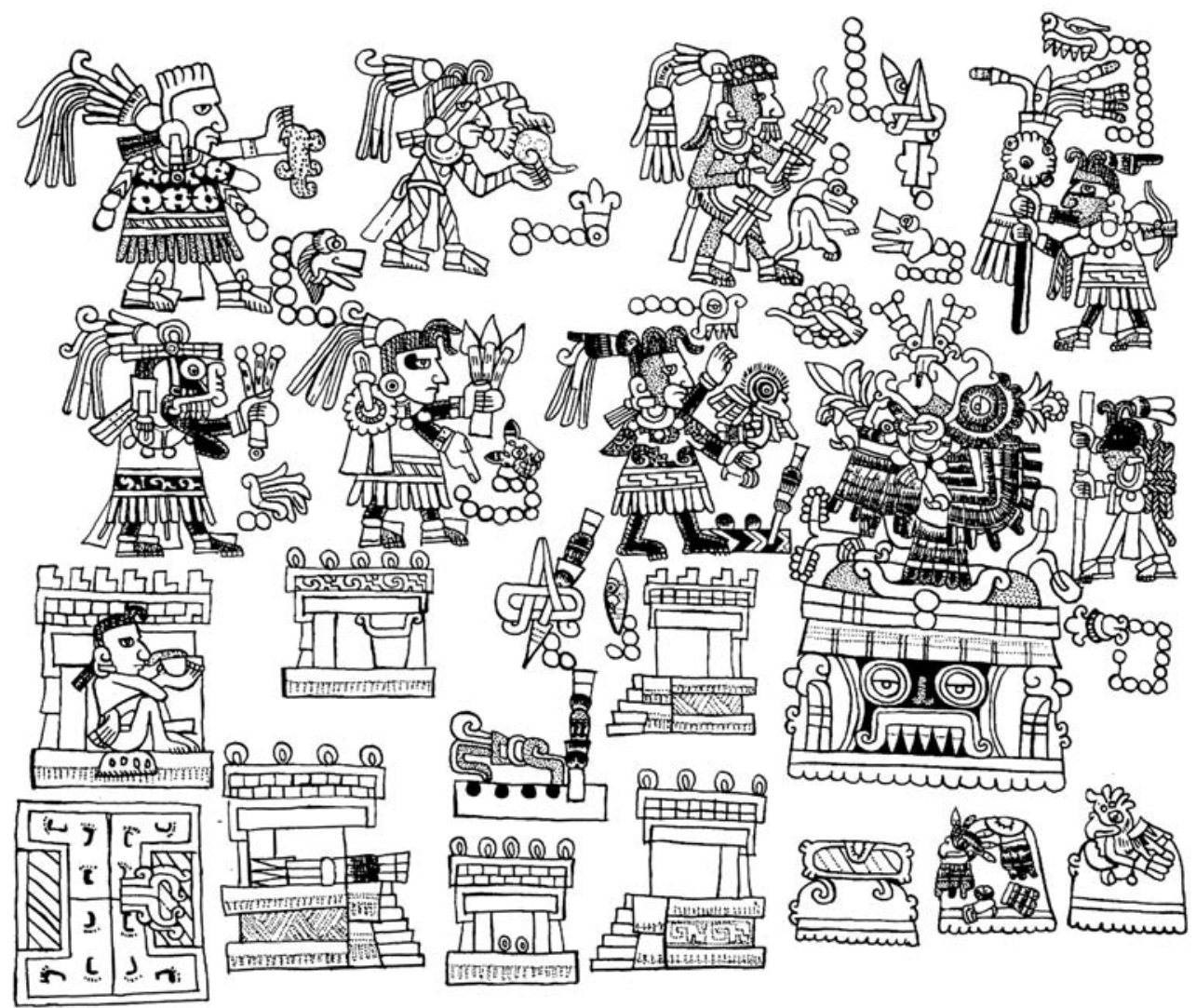

7.4. Codex Tonindeye, p. 2: enthronement ritual of Lord 8 Wind in the ceremonial center of Yucuñudahui.

receiving homage from a group of six attendants, who approach with the quail, the fire, blowing a conch, offering powdered tobacco and different leaves. The date of the third scene is repeated here, and the two people who accompanied him earlier are now mentioned together, with their different bundles and different staffs.

In sum, we see four scenes of basically the same protagonist involved in the same action, structured in the same way, but with a continuous variation in detail. Structure and variation produce a rhythm of parallels, very similar to what we may observe in the ceremonial speech $(s a h u)$. The successive toponyms refer to the Land of the Ancestors, the mountain of the specific kingdom (Flower and Monkey), the general place of origin of the Nuu Dzaui rulers (Apoala), and a special 
ceremonial center (Yucuñudahui, see below). As such the places clearly have an ideological value.

Our second example is a section of primordial history, that of Lady 3 Flint 'mother' and Lady 3 Flint 'daughter', on pages $14-16$ of Codex Tonindeye. ${ }^{4}$ The story opens (on p. 14) with locating a number of protagonists as pairs in a landscape. As pairs they are connected by specific gestures or attributes that generally occur as units. The first couple, shown as having come down from a Rock of Heaven with Seven Caves (clearly a primordial Place of Origin), are Lord 5 Flower and Lady 3 Flint. The day names are successive days (only separated by the day 4 Rain) and appear associated with one year-bearer: 7 Reed, which occurs often in sacred foundation dates. Lady 3 Flint has in her regalia attributes of different deities: in her hair the spindle of the Grandmother, as headdress a Plumed Serpent, the jade skirt of the Water Goddess, while Lord 5 Flower appears as the Young Prince, a manifestation of the Sun God.

On the next page (15) this couple then undertake a journey: Lord 5 Flower carrying a precious staff and a copal bag, referring to his official status and his priestly activities, Lady 3 Flint carrying a fan. They are followed by two pairs of two priests, all with calendar names starting with the number 10. The first duo, Lord 10 Reed and Lord 10 Vulture, carry Sacred Bundles on their backs and staffs in their hands, probably similar in function to the staffs of office (Spanish: bastón de mando) of contemporary authorities in the Nuu Dzaui region. The first priest holds the 'Venus Staff', the second one the so-called 'Xipe Staff' (which we already encountered as a pair on page 1 of this codex).

Behind them walks another pair of priests, now explicitely marked as elderly by the tooth in their mouth: Lord 10 Rain and Lord 10 Grass. They carry gourds encrusted with jade and hold in their hands bowls, which because of the blue painting, seem to have been decorated with turquoise mosaics. On top of these: wood and rubber represent the ritual burning of offerings.

This group, clearly structured in pairs, arrives at a ceremonial center, which has a fascinating parallel in the large temple scenes of Codex Yoalli Ehecatl (Borgia), pp. 29-38. We distinguish four main locales:

\footnotetext{
${ }^{4}$ For a basic outline of her biography, see Caso 1977-79, II: 398-399, and for a more detailed interpretive reconstruction: Jansen \& Pérez Jiménez 1992b, 2007a: ch. 4 (generally followed by Hermann Lejarazu 2008c).
} 


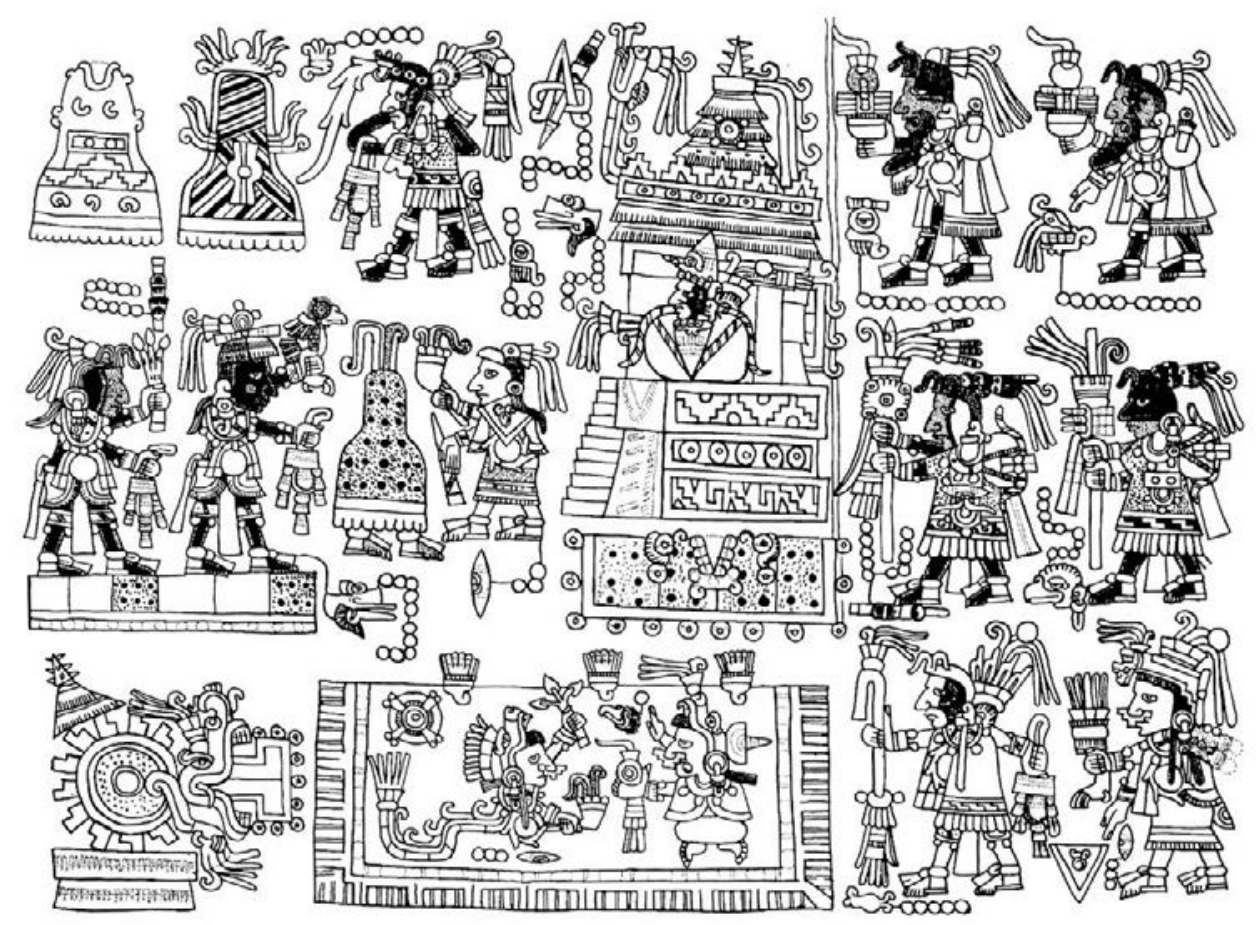

7.5. Codex Tonindeye, p. 15 (Right to Left, boustrophedon): ritual acts performed by Lady 3 Flint and Lord 5 Flower.

1) a river, with three ornaments consisting of jade, feathers and flowers, and a fourth element consisting of a sun disk combined with a red and white Xipe ornament (cf. Codex Yoalli Ehecatl, p. 38),

2) a round altar, decorated with the Fire Serpent (yahui), i.e. a place of nahual power, the altar stone being decorated with 'battlements' (tenamitl in Nahuatl) and located under a thatched roof - this ceremonial place is located 'at the mouth of, i.e. at the entrance of a ballcourt, where nocturnal rituals used to take place (cf. Codex Yoalli Ehecatl, pp. 35 and 38),

3) a dark opening in the Earth, associated with death, i.e. ancestor veneration (cf. Codex Yoalli Ehecatl, pp. 33-34 and 35),

4) a Temple of the Plumed Serpent, i.e. a sanctuary for visionary experiences, dedidated to the veneration of the Sacred Bundle of Lord 9 Wind 'Quetzalcoatl' (cf. Codex Yoalli Ehecatl, pp. 33-34 and 35). 
Lady 3 Flint transforms into her nahual (animal companion or alter ego), the Plumed Serpent, and in this state she enters the river, in order to honor (offering copal and leaves) the Grandmother Lady 1 Eagle. In a parallel fashion, she is then shown standing at the foot of Ash Mountain, offering copal and self-sacrifice, represented by a maguey spine. Apparently we are supposed to read the River and the Mountain together as 'Ash River', Yaa Yuta, the realm of the Sitna Yuta, the Grandmother of the River, Patron of the West. As this direction is associated with procreation and birth, we may understand the scene as that of a young woman directing herself to the archetypical Great Mother or Wise Grand Mother, who holds the power and knowledge about the continuation of life, in order to ask to become a mother herself. When Grandmother 1 Eagle answers her prayer with a precious gift (the difrasismo: jade, quetzal feathers), we understand that Lady 3 Flint has become pregnant.

While Lady 3 Flint holds the incense burner and the maguey spine, Lord 5 Flower holds the copal bag and draws blood with a bone perforator from (the top part of) his ear in front of two other mountains, that of Fire and Earthquake and that of Throne, Town and Speech. Husband and wife are involved in the same act, but that act is visually presented in a varied manner through complementary signs in parallel positions (such as spine and bone perforator, incense burner and copal bag). Two priests, Lord 10 Wind and Lord 10 Reed, are placed next to the Ash Mountain, carrying copal bags and assisting the protagonists with an offering of a quail and leaves.

All this action is situated in a ceremonial center dominated by a Temple of the Plumed Serpent, built above a cave or entrance to the Underworld. This sanctuary was dedicated to the visionary rituals for the Sacred Bundle, that shrouded the Flint from which the culture hero Lord 9 Wind 'Plumed Serpent' had been born. ${ }^{5}$

Structured in this way, the images evoke the solemn lordly language of parallelisms, appropriate for the occasion. In the next scene the fire of a sweatbath will be kindled, and Lady 3 Flint will give birth to a daughter. After that she will transform again into her nahual and

${ }^{5}$ Cf. Jansen \& Pérez Jiménez 2007a. As was already noticed by Eduard Seler (1904-09) and Karl Anton Nowotny (1961a), a similar ceremonial landscape appears as a stage for the rituals in the central chapter of Codex Yoalli Ehecatl (Borgia), p. 29 ff: see the detailed commentary by Anders \& Jansen \& Reyes García 1993, as well as the somewhat differently oriented comments by Byland \& Pohl (1994: $129 \mathrm{ff})$ and Boone (2006: ch. 7). 
become the numen of a river, springing from a rock and floating along trees. In human terms: the young mother dies after childbirth, but is remembered in the landscape. In the context of dramatic narrative this outcome suggests that she was willing to give up her own life for bearing her child.

Thus the scenes give us a glimpse of the embeddedness of ceremonial centers in the landscape (as we can still sense today) and even of the ritual aspect and nahual experience of that landscape, in the reverential language referring to the First Ancestors. This awe-inspiring memory is mobilized most intensely when we encounter concretely identifiable places.

\section{Bases for Deciphering the Place Signs}

At an early stage in the study of the codices Alfonso Caso (1949) identified several primary towns in Nuu Dzaui Nuhu, the Mixteca Alta. The most important one is Nuu Tnoo, 'Black Town' (Tilantongo). On the Map of Chiyo Cahnu (Teozacualco) it is rendered as a frieze $(\tilde{n} u u)$ in which the step-fret motif is colored black (tnoo). Additional evidence is provided by glosses in Codex Nuu Naha. Its ceremonial center, the Temple of Heaven (Huahi Andevui), mentioned in the Relación Geográfica de Tilantongo, is painted as a house (huahi) with a blue frieze with the 'star eye' motif, signifying 'Heaven' (andevui).

The Black Frieze is the first town mentioned in Codex Yuta Tnoho after the opening phrase that refers to the creation of time, the natural cycles and the landscape (p. 52). This corresponds to the fact that the reverse side of the same codex presents the genealogy of the royal dynasty of Nuu Tnoo (also identified by Alfonso Caso on the basis of the information in the Map of Chiyo Cahnu). As we mentioned earlier, Codex Yuta Tnoho contains a long list of toponyms: here we find the Black Frieze again, but now in combination with a Black Altar, a Rising Plumed Serpent and other elements (p. 42-II). The accompanying date is year 7 Flint day 7 Flint, which in Codex Nuu Tnoo-Ndisi $\mathrm{Nuu}$ (p. 1-II) is associated with the birth of the founder of the dynasty, Lord 4 Alligator 'Blood Eagle', from the Earth.

The same cluster of toponymic signs with this date are integrated in a large landscape painting in Codex Tonindeye (p. 22), which initiates the genealogical record of the dynasty of Nuu Tnoo (Tilantongo). This landscape in Codex Tonindeye is dominated by a Black Mountain, 


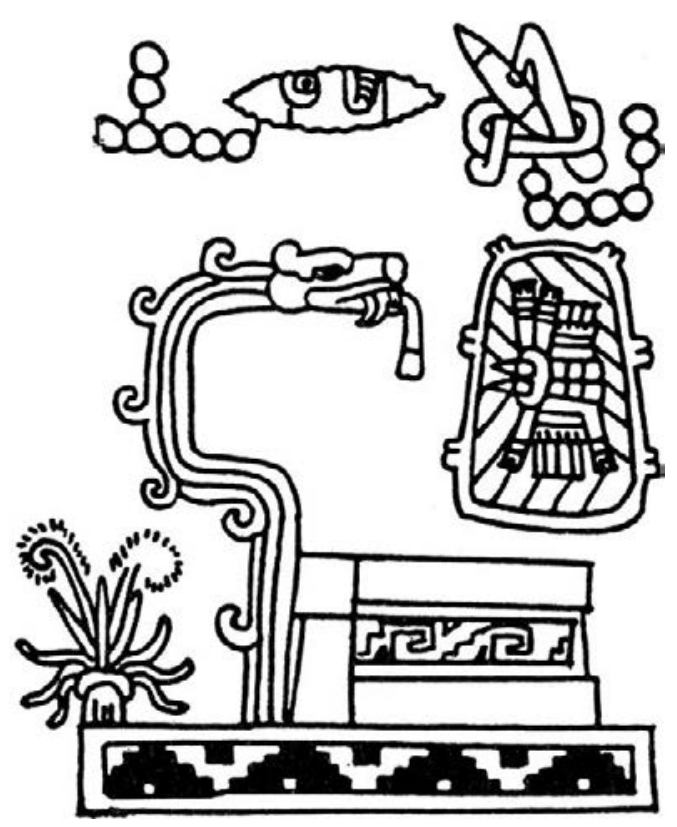

7.6. Codex Yuta Tnoho, p. 42: Ñuu Tnoo (Tilantongo).

most likely a representation of the impressive Yucu Tnoo or Monte Negro, the 'Black Mountain', which occupies the south-western horizon of present-day Tilantongo. The Rising Plumed Serpent corresponds to an important local spring: Ndute Coo, 'Water of the Serpent', while the Spring with a Tree may refer to the site of Río Tenuu ('River of the Tejocote'), an important Postclassic settlement. The Black Altar is part of a Ruined Temple on the Black Mountain, which may be read as huahi tuhu or chiyo tuhu' the old (worn) temple or altar'. Furthermore there are two altars (chiyo) on top of the Black Mountain, on which a founding couple are seated, making offerings to water between these two altars. Given the context, all these altars most likely represent the large Formative-Early Classic archeological site on top of the Monte Negro. ${ }^{6}$ This representation corresponds to

6 See Smith 1973a: 55-57. For an analysis of Codex Tonindeye, p. 22, as a reference to the site of Monte Negro, see Geurds \& Jansen 2008, in combination with Geurds' Ph.D. thesis (2007), which reports on the mapping of the archeological site and the surrounding sacred landscape, as well as on the local lore. Byland \& Pohl (1994) and Kowalewski et al. (2009) report on the archeological remains in the area. 


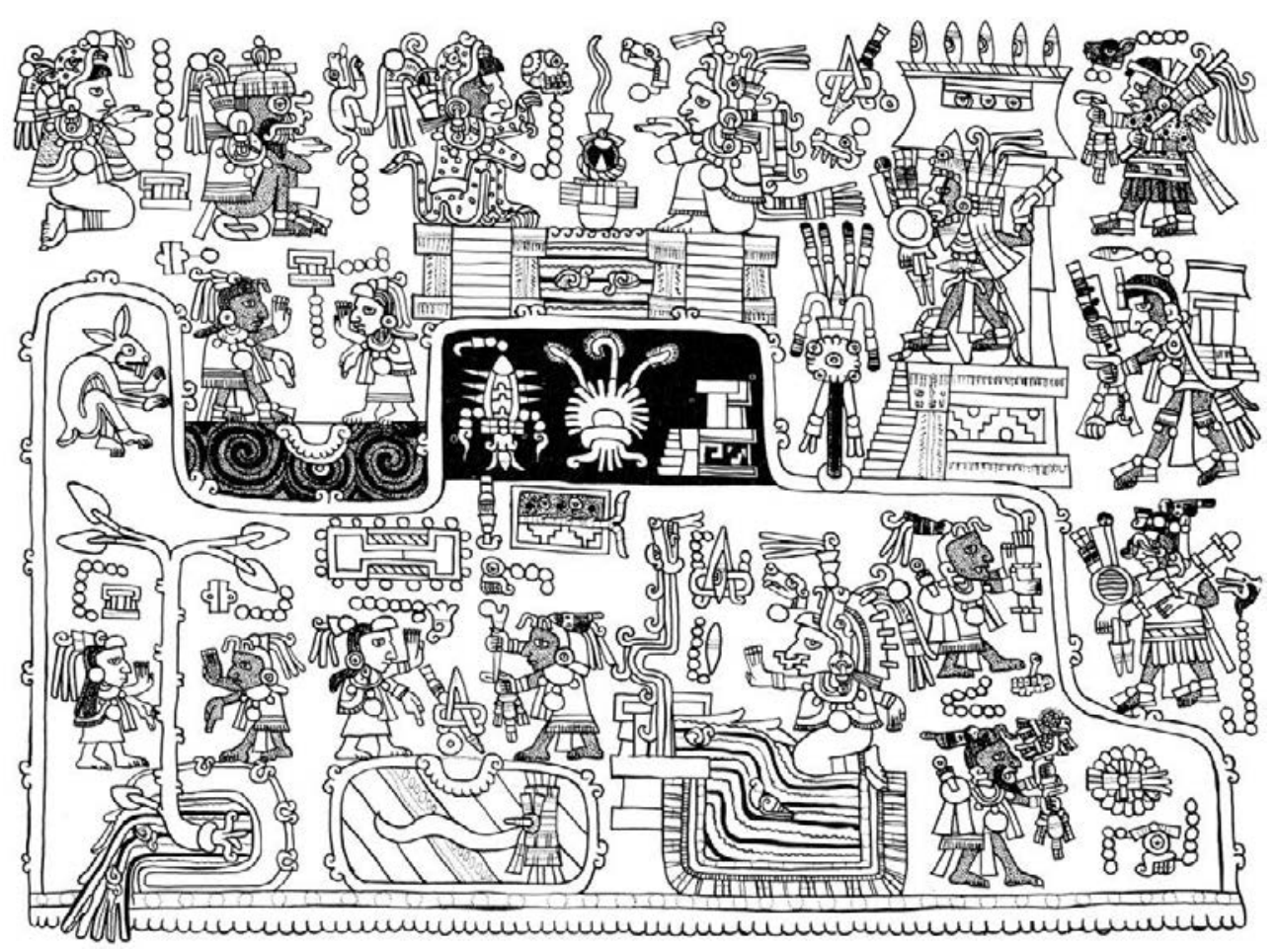

7.7. Codex Tonindeye, p. 22: the ancient landscape of Nuu Tnoo (Tilantongo).

the name given by the Relación Geográfica of Tilantongo to the large mountain, West of the town: Yuco Yuco, in Nahuatl Teopantepeque, i.e. 'Mountain of the Temple(s)' (Acuña 1984, I: 234-235). It is quite possible that rituals for water took place at this site: even today the main traditional rituals concern the rain, e.g. going to the caves where the Rain God resides (Vehe Sau or Vehe Savi, 'Houses of the Rain') to ask for the coming of the rains at the beginning of the rainy season, so that work on the land may start (especially May 3, the day of the Holy Cross).

In the landscape painting of Codex Tonindeye, p. 22, the Temple of Heaven is situated on a slope in front of the Monte Negro, which corresponds to the position of the Postclassic ceremonial center, where the town's church is now standing.

Hermann Lejarazu (2008c: 58) doubts the antiquity of the name Monte Negro and suggests that this Black Mountain might represent 
Nuu Tnoo (Tilantongo) itself. Given the fact that the place sign of the latter capital, Black Frieze, is ubiquitous in the Mixtec codices, it is reasonable to infer that the Black Mountain refers to a somewhat different site in the neighborhood. The dominant position of the Black Mountain in the landscape painting, and its association with altars, strongly suggests that the Monte Negro itself with its ancient archeological site is indeed meant. ${ }^{7}$

Fortunately there are more manuscripts that contain glosses that permit the secure identification of place signs, for example Codex Nuu Naha (San Pedro Cántaros) referring to the Mixteca Alta (Smith 1973b) and the Codex Nuu Naña (Egerton) referring to the Mixteca Baja. This corpus is the point of departure for identifying other primary centers on the basis of their association with known places and the correspondence of the sign to the toponym. A fundamental guide in this decipherment process is the monograph by Mary Elizabeth Smith (1973a), to be combined with the work of Gerhard (1972) on the 16th century historical geography and that of Mundy (1996) on the mapping of New Spain.

Naturally a first requirement is the coincidence of the picture with the etymology of the Dzaha Dzaui toponym. Friar Antonio de los Reyes includes in his grammar (1593, reprinted in 1976) a list of the Dzaha Dzaui names of the main towns in the region. Manuel Martínez Gracida gives additional valuable information in his Cuadros sinópti$\cos (1883)$. These historical data are to be combined with the locally known toponyms, existing etymologies and other traditions.

There are several problems here, however. First, the etymology of the toponym may not always be clear, due to the presence of many near homonyms in Dzaha Dzaui, often only distinguished by tones. Sometimes the names in Dzaha Dzaui and in Nahuatl coincide, but

${ }^{7}$ An additional toponymic qualifier of the Black Mountain in Codex Tonindeye, p. 22, is the palm flower: this element also occurs inside the Black Mountain that appears as the very last place sign in Codex Yuta Tnoho (p. 1). This would suggest that Codex Yuta Tnoho finishes with a reference to Monte Negro, just as its first topographic reference is to Black Frieze, i.e. the town of Nuu Tnoo (Tilantongo) on p. 52. On the other hand, the last place sign in Codex Yuta Tnoho also contains the sign of a spring. Black Mountain with Spring occurs as a polity in Codex Añute and in the Lienzo of Tlapiltepec (C 35): it may well represent Yucu Tnoo (Tiltepec) in the Valley of Yodzo Cahi (Yanhuitlan). More research is necessary for making a precise identification. 


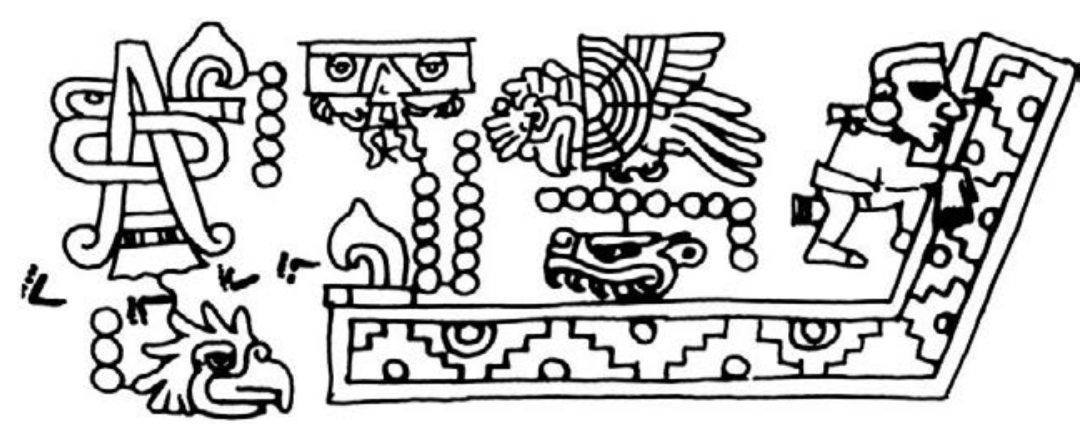

7.8. Codex Nuu Tnoo-Ndisi Nuu, p. 15-III: Chiyo Cahnu (Teozacualco) with the names of its rulers Lord 12 House 'Fire Serpent that flies through Heaven' and Lady 10 [elsewhere: 11] Alligator 'Quetzal Spiderweb'.

sometimes they do not. If they do coincide, the painted representation of the name does not necessarily conform to the meaning. The Nahuatl translations were often made quite quickly and superficially, using only one of the possible meanings, not necessarily the same as the one used by the Nuu Dzaui painters. And even if the etymology of the place name is clear, it may not have been possible or easy to render it in figurative painting, so that a homonym in Dzaha Dzaui had to be resorted to. The Map of Chiyo Cahnu provides an illustrative example. The main town Chiyo Cahnu, 'Big Altar' (corresponding to Teozacualco, 'Place of the Pyramid') is painted as Nuu Cahnu, 'Big Town': a frieze ( $\tilde{n} u$ ), which is bent or broken (cahnu) by a small anonymous man. The abstract qualification 'big' (cahnu) is expressed pictorially by resorting to its near homonym 'bent, broken' (cahnu with other tones): a case of phonetic writing. As a bent altar is awkward to paint, the image of a bent $\tilde{n} u u$ sign is used. ${ }^{8}$

A second problem is the fact that the same toponym may be applied to distinct localities, making it difficult to establish which place is actually represented by a certain sign. Consequently a place cannot be identified just because of a coincidence between a name and a sign. Methodically it is necessary to work with clusters of data: we have to establish a coherent series of several places, connected in a significant

\footnotetext{
${ }^{8}$ Caso's identification was confirmed by Mary Elizabeth Smith's analysis (1973a: 57-58). Our fieldwork on the spot enabled us to make a detailed comparison of the Chiyo Cahnu Map with geographic reality (reported in Anders \& Jansen 1988 and Anders \& Jansen \& Pérez Jiménez 1992a).
} 
way with each other and/or with other data. One also has to take into account the whole context and status of the toponym. Thus we have to distinguish between the very local designations of boundaries (dzañu) or fields (itu) and the more permanent names of city-states or sacred sites in the landscape. Early colonial lienzos and maps (such as the Lienzo of Zacatepec, the Lienzo of Coixtlahuaca, the Map of Chiyo Cahnu or the Map of Tuhu) often contain a central place (the citystate's capital) surrounded by a line of signs that define its external frontier - most likely this territorial demarcation is a colonial convention. In some cases the names of these $d z a \tilde{n} u$ were written alphabetically on pictorial documents (e.g. the Codex Iya Nacuaa, the Codex Ñuu Naha, or the Roll of Toavui-Yucu Yusi). Colonial documents in the archives contain a wealth of information on such names (often the topic of bitter land-disputes). Mary Elizabeth Smith (1973a) has studied and used these in an exemplary manner to identify their pictorial representation and elucidate the geographical character of the lienzos and maps. ${ }^{9}$ Obviously such names of boundaries and fields are not - at least not without further analysis on the spot - to be taken as a basis for identifying hieroglyphs of inhabited towns or ceremonial places.

Decipherments have to be constructed carefully on the basis of a wellstructured, coherent set of data, and have to make sense in the framework of what else we know about Nuu Dzaui history and geography. Fortunately a significant number of place signs in the codices have now been deciphered with a reasonable degree of certainty. Especially when such decipherments are derived from glosses (explicit identifications written alphabetically under the signs in colonial sources), they may be taken as a sound point of departure for further interpretive research.

\section{Mixteca Alta}

The most important place of origin for the Nuu Tnoo dynasty is represented as 'River with a Hand Holding Feathers'. Both the sign itself and the context point toward Yuta Tnoho (Santiago Apoala), mentioned by Friar Antonio de los Reyes as the place where the first Nuu Dzaui lords were born from a tree:

\footnotetext{
${ }^{9}$ Hamann (2008) has continued this work and made a useful collection ('atlas') of numerous examples of such local names.
} 
The general opinion among these Mixtecs was that the origin and beginnings of their Gods and Lords had been in Apoala, a village here in the Mixteca, which in their language is called Yuta tnoho, 'River from which the Lords came forward', because they say that they were plucked from some trees that grew out of that river, which had specific names. They also call that village Yuta tnuhu, 'River of the Lineages', which is the most appropriate name and the most fitting .... As for the Lords and their birth, it could be that in ancient times some Lords came from this village and that from there they dispersed over the other towns of La Mixteca, because of their eminence and success in war and that because of their heroic deeds they won specific names, as is now told about those who founded the principal towns in this Mixtec region.

This text provides different interpretations of the toponym:

1) Its first meaning is 'Plucking River', from the verb tnoho, 'to pluck or pull out'. Still today it is translated locally as 'Río que Arranca'.

2) Without nasalization, it can also be understood as 'River of the Lords' (Yuta Toho), from toho, 'lord, noble'. Friar Antonio de los Reyes explains this wordplay: "Yuta tnoho, which is River where the lords and ladies came from because according to tradition they were plucked of some trees".

3) With a slight difference in the pronounciation of the vowels it is 'River of the Lineages or of the Histories' (Yuta tnuhu) from tnuhu, 'word, history, lineage'.

Although this last etymology was said to be the most appropriate, the first was the most easily depicted. The painters designed a sign of a river (yuta) with in it a hand holding feathers: it suggests the act of plucking (tnoho), but the fact that the feathers are those of a quetzal bird is indicative of the status of nobles or lords (toho) and their bundling may symbolize the lineage (tnuhu).

The town's Nahuatl name, Apoala, is an example of sloppy translation of the Dzaha Dzaui toponym. Sloppy, because the translator did not pay attention to the fact that the word order in Dzaha Dzaui and Nahuatl toponyms is different. Yuta, 'river', becomes atl ('water'), which gives the first syllable: $A$ - in Apoala. Then tnuhu is understood as 'words' or 'story' and translated as poalli, 'count' or 'account'. A place-name suffix - $(t)$ lan is added. The final result is a Nahuatl name (a-poal-lan), which would actually mean something like 'Place of the counting of waters' instead of 'River of Words' or, more accurately, 'River of the Lineage Histories'. 


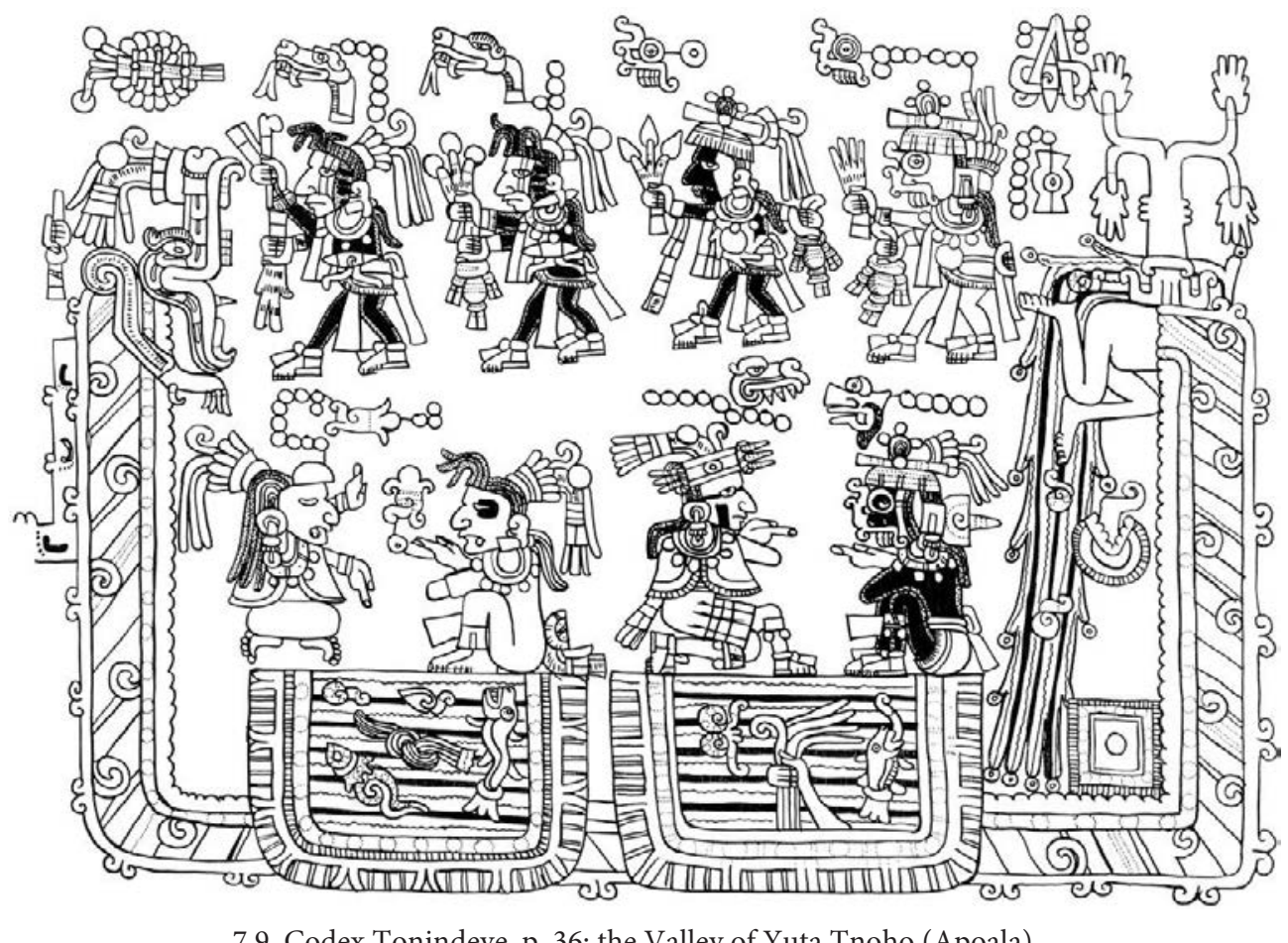

7.9. Codex Tonindeye, p. 36: the Valley of Yuta Tnoho (Apoala).

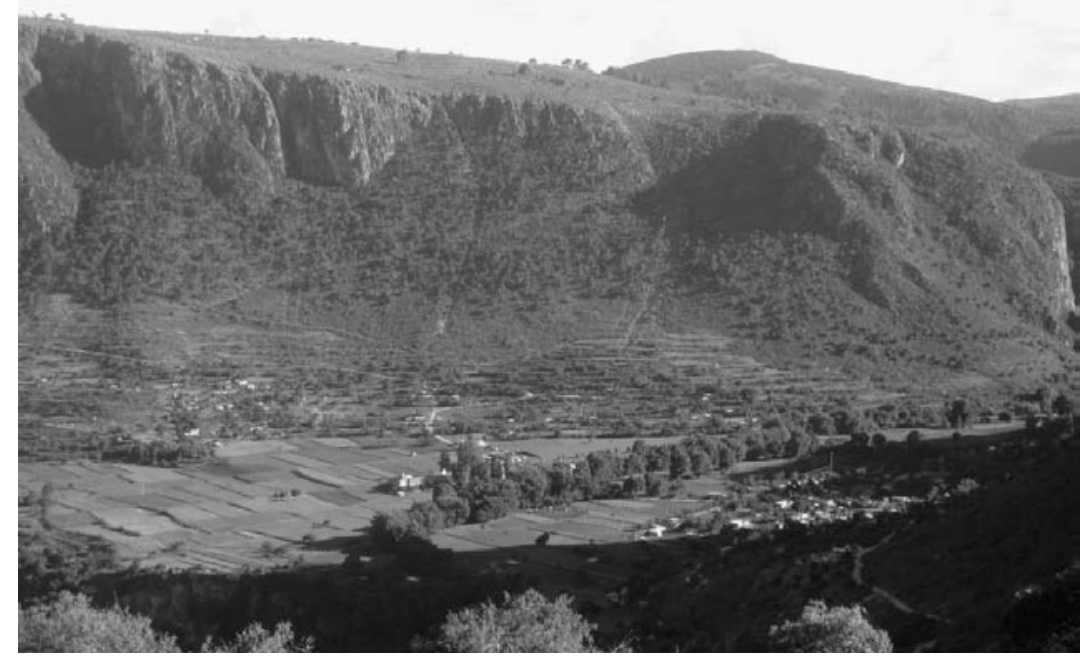

7.10. The Valley of Yutsa Tohon (Apoala). 


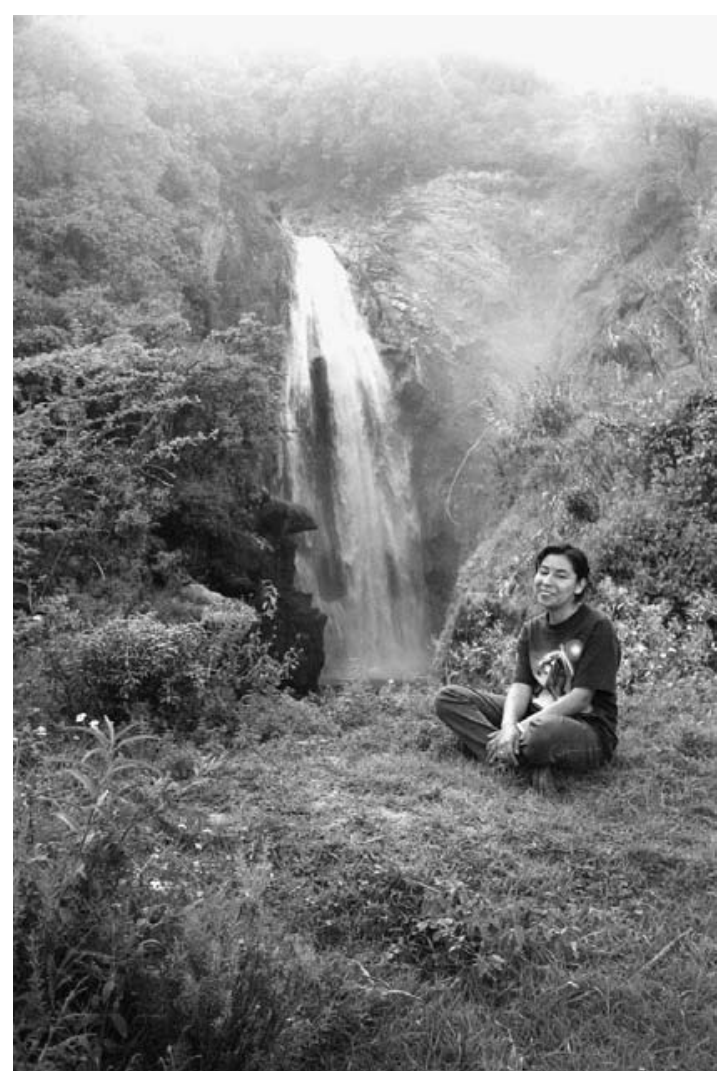

7.11. The waterfall at the end of the Valley of Yutsa Tohon (Apoala).

The identification of this place sign as Apoala had already been proposed by Caso (1957) and further analyzed by Smith (1973a:75). On the basis of toponymical research and other studies on the spot we were able to confirm their insights and add additional identifications of the associated landscape features in codices Yuta Tnoho and Tonindeye: the Sacred Valley with the confluence of two rivers, where the Tree of Origin once stood, with at its 'foot' the Cascade, at its 'head' the Cave of the Serpent (Yaui Koo Maa) and to the East the peak of the Mountain of Heaven (Kaua Kaandiui), offering an impressive view of the snow-topped Pico de Orizaba. ${ }^{10}$

${ }^{10}$ Jansen 1982b and Jansen \& Pérez Jiménez 2007a offer a more detailed discussion, while Geurds 2007 reports on the archeology of the Valley of Apoala. 


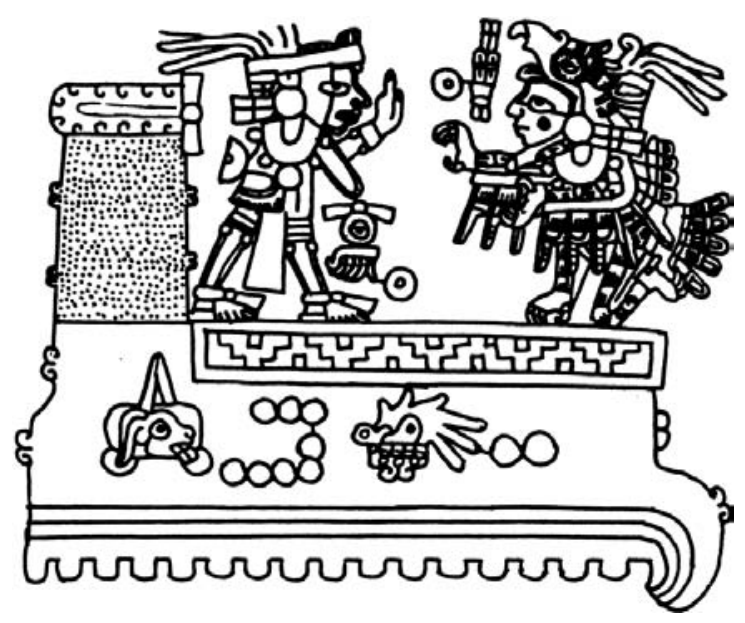

7.12. Codex Yuta Tnoho, p.1: Añute (Jaltepec).

In the list of names of primordial places in Codex Yuta Tnoho, two columns after Nuu Tnoo (p. 42-IV) we find a Mountain of Sand, which, on the basis of a similar representation in Codex Mendoza (p. 43), is immediately recognizable as Magdalena Jaltepec, the neighbor of Nuu Tnoo (Tilantongo). Its Nahuatl name means precisely: 'Mountain of Sand'. The Dzaha Dzaui name Añute is a near equivalent, meaning 'Place (a-) of Sand (ñute)'.

In the Codex Añute this toponym is painted as a mouth (the pictorial convention for the locative prefix $a$-) with sand. This place interacts frequently with Nuu Tnoo (Tilantongo) and must be in its vicinity. Mary Elizabeth Smith presented her identification of this place sign, formerly called 'Belching Mountain', as Tilantongo's neighbor Magdalena Jaltepec during the memorable session organized by Troike at the International Congress of Americanists in Mexico City 1974, in a paper which was later included in a volume on the archeology of Oaxaca edited by Kent Flannery and Joyce Marcus (1983). ${ }^{11}$

11 Méndez Martínez and Méndez Torres (2007b: 67) dismiss Smith’s well-founded identification as 'erroneous' because, in their opinion, the glyph of Xaltepec is very different (sic) from that of 'Belching Mountain'. They add that they themselves believe to know the location of the latter place, but cannot reveal this as they have not yet carried out the necessary archeological and historical research. In their footsteps, Acevedo Conde (2009: 101) also ignores Smith's identification and states that it has not yet been possible to determine the location of 'Belching Mountain'. 


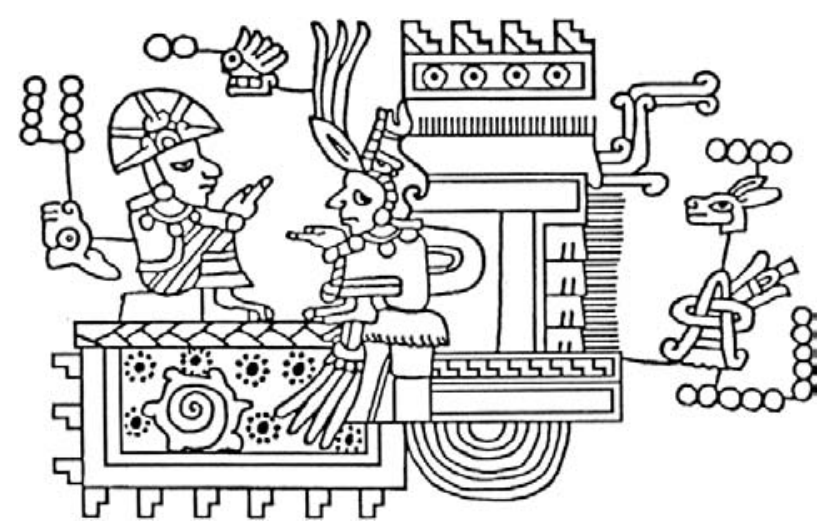

7.13. Codex Añute, p.2-II: In the year 10 Reed (AD 931), on the day 4 Deer, the founders of the Añute dynasty, Lord 2 Grass 'Dead Ancestor Plumed Serpent' and Lady 8 Rabbit 'Sun Head', marry at the Yoco (Spirit) Temple of Altar of the Spiderweb (Chindua).

The founding date that accompanies the sign in Codex Yuta Tnoho, year 8 Rabbit day 2 Grass, corresponds to the combination of the calendar names of the founding couple of the dynasty in Codex Añute (p. 2-II): Lady 8 Rabbit and Lord 2 Grass (Jansen 1988b). In the codices of Nuu Dzaui a cloud encircles the Mountain of Sand as a heraldic emblem. It clearly represents the clouds that often gather around the mountain top, especially in the morning and at the beginning of the rainy season.

Between Black Frieze and Sand Mountain in the list of Codex Yuta Tnoho (p.42-III) we find the Frieze with Flints. The sign next to it documents the presence of a 'Mountain of Flints, where Toltec rulers were seated'. Indeed it was here that Lord 4 Wind, recognized by the Toltecs as the successor of Lord 8 Deer and a central power figure in Nuu Dzaui, would found his capital. Using geographical criteria (the sign being situated between Nuu Tnoo and Añute) it must be Nuu Yuchi, 'Town of Flints', the present-day archeological site of Mogote del Cacique, located in the agencia of San José Tres Lagunas, somewhat to the South of both Nuu Tnoo (Tilantongo) and Añute (Jaltepec).

A carved stone from the site also contains an image of the Mountain of Flints. This scene was analyzed by Jansen and Winter (1980). Shortly after that article was finished, in the beginning of 1980, Don Fidelo Cruz Miguel, INAH guard in Tilantongo, clarified to us that the 


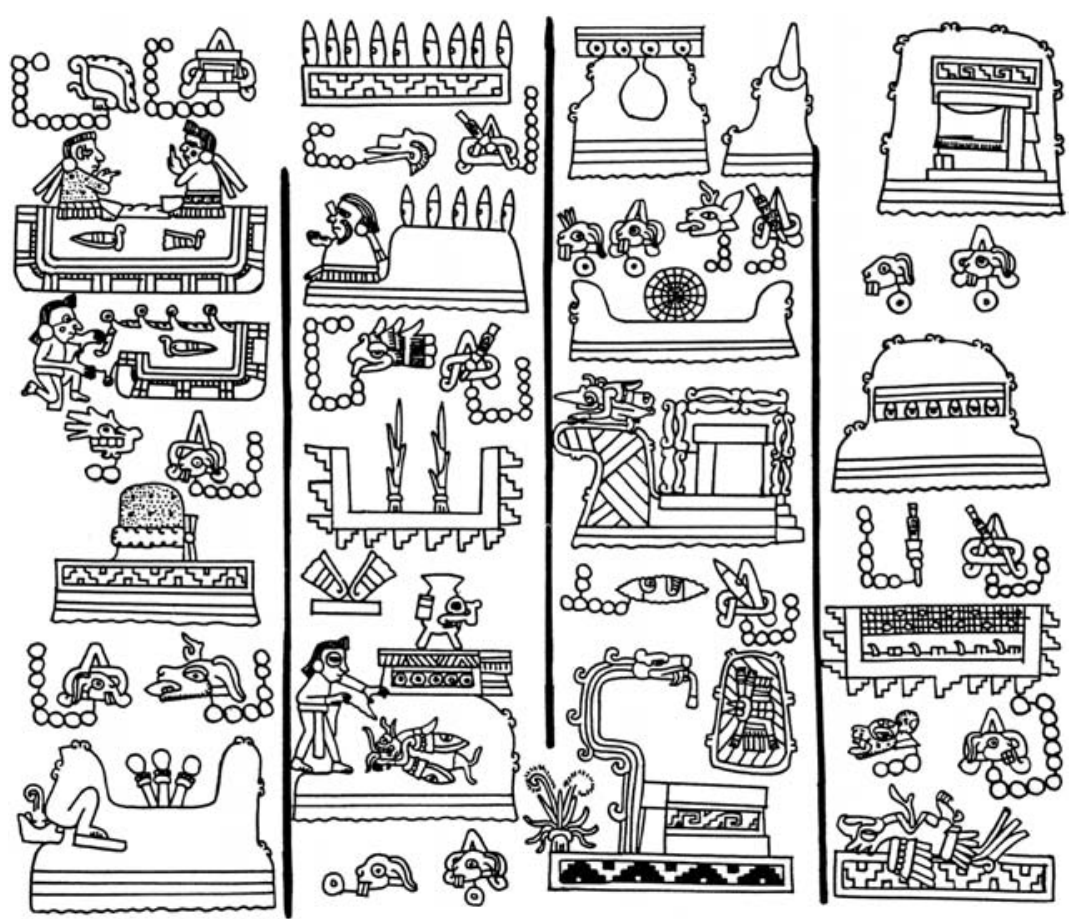

7.14. Codex Yuta Tnoho p. 42 (Lower Right to Lower Left, boustrophedon): list of place names and connected dates.

Mixtec name of the site was $N d u \tilde{N} u u c h i$, a contraction of Tinduu Nuu Yuchi, Mound of the Town of Flints. This enabled Jansen to identify the Mountain of Flints and the Town of Flints in Codex Yuta Tnoho, p. 42-III, as references to this very site (Jansen 1982b: 276). The archeological work in the region by Byland and Pohl (1994) has lent further support to this identification. ${ }^{12}$

Ñu Yuchi became famous in Mixtec history for a short period, during the reign of Lord 4 Wind in the 12th century. It is likely this ruler commissioned the carving of the stone as well as the construction of

12 Brief archeological descriptions with small maps are provided by Spores (1967: 44-45) and Byland \& Pohl (1994: 90-93). Alex Geurds, Laura van Broekhoven, and Ivan Kisjes also mapped the site in July 2001 (see Jansen 2003, Geurds 2007). For an updated and expanded interpretation of the carved stone, see Jansen \& Pérez Jiménez 2007a: 272-275. 

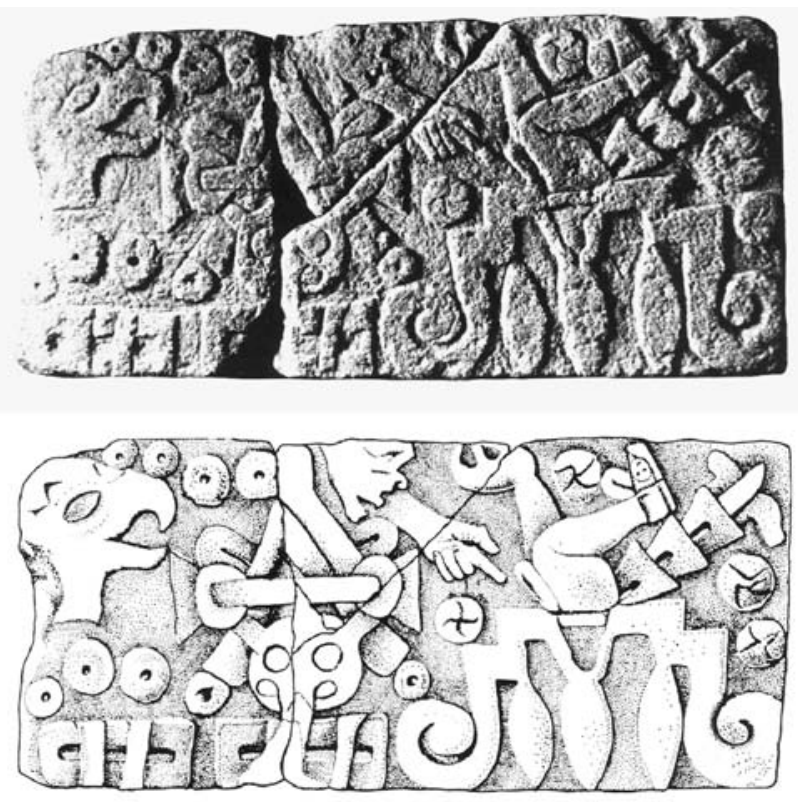

7.15. The carved stone from Mogote del Cacique (Nuu Yuchi): the year 13 Owl (corresponding to 13 House, likely AD 1129), the day 4 Vulture, ordered and observed the entrance of the yaha yahui priest [likely Lord 4 Wind] in a cave in the Mountain of Flints, where he stayed in a trance for four times twenty days.

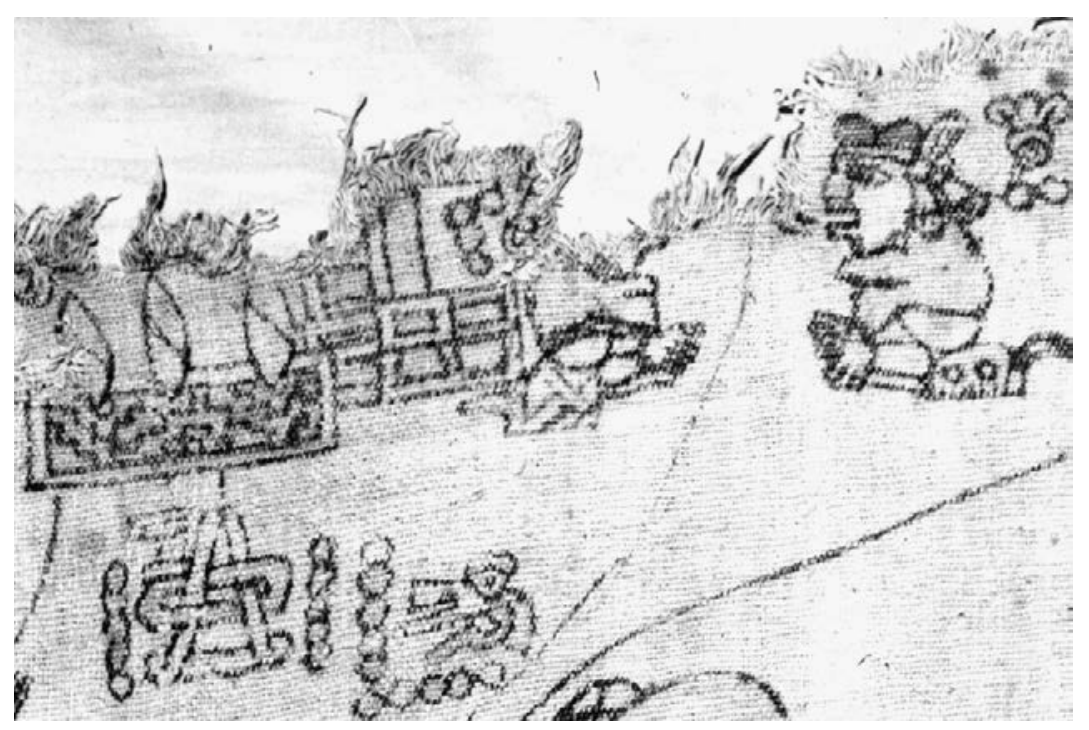

7.16. Lienzo of Tlapiltepec (E 37) Lord 2 Flower visits Town of Flints and converses with its ruler, Lord 4 [Wind]. 


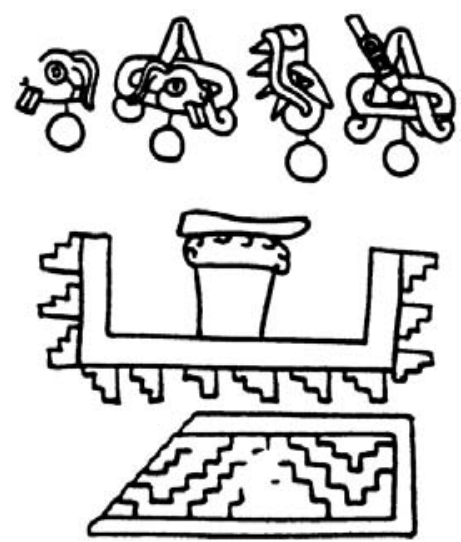

7.17. Codex Yuta Tnoho, p. 43-IV: Cut Town.

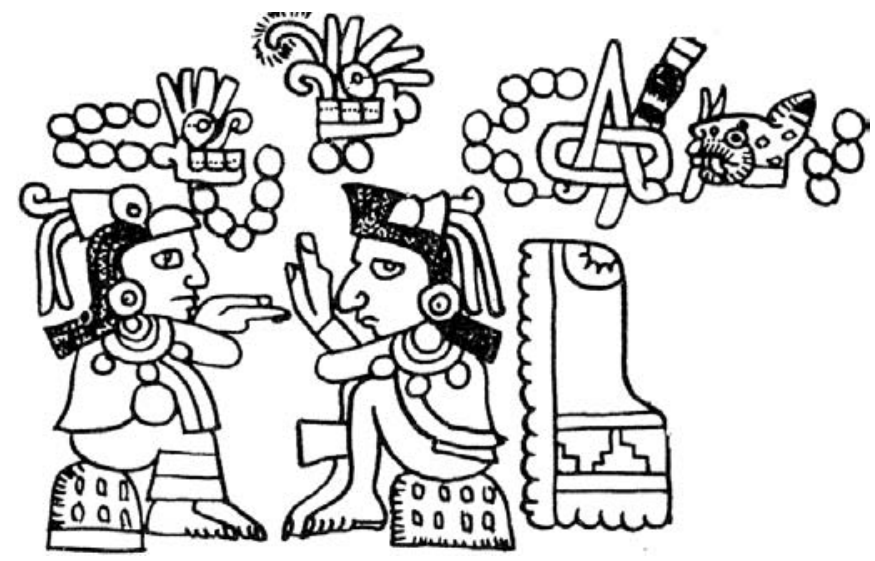

7.18. Codex Tonindeye, p. 23: Cut Mountain with Town, representing Nuu Ñañu (Tamazola), with the founders of its dynasty: Lord 2 Grass and Lady 13 Grass.

the main temples at the site. The same Town of Flints is represented on the Lienzo of Tlapiltepec (E 37): Lord 2 Flower, grandson of the founder of the Coixtlahuaca dynasty visits the place and its ruler Lord 4 [Wind].

Among the signs immediately before Nuu Tnoo in the same list of Codex Yuta Tnoho (pp. 43-IV and 42-I/II; cf. Códice Tonindeye, pp. 37-38) several places may be hypothetically identified supposing 
that they are in the vicinity of that town. The Cut Town (p. 43-IV) in this context may be Nuu Nañu, the name of the archeological site of Tamazola, as documented by its Relación Geográfica and the contemporary designation as Deke Ñeñu, 'above the abysm or peña tajada' A similar Cut Mountain with Town appears in Codex Tonindeye as the realm of Lord 2 Grass and Lady 13 Grass, who according to the same Relación Geográfica, were the founders of the dynasty of Tamazola (see: Jansen 1982b: 274-275).

Town of the Sacrified Quetzal (in Codex Tonindeye: Mountain of the Quetzal) is probably Nuu Ndodzo (Huitzo), 'Town of the Quetzal' (as suggested by Jansen 1998b: 90).

The following Mountain of the Horn might be Yucu Ndeq (Huauclilla), which means precisely 'Mountain of the Horn' (see our study of the Sosola Map, Jansen \& Pérez Jiménez 2000: ch. 2).

Next: the Valley of the Spiderweb may be Andua or Chindua, close to Yanhuitlan. The place sign of Andua (A-nduvua) also takes the form of a Valley with Mouth (a sign for the locative prefix: $a^{-}$) in combination with an arrow: nduvua (Smith (1973a: 42). The spiderweb is dzinduhua, which may have functioned as a homonym or as a more specific reference to the neighboring site of Chindua (contraction of Chiyo Dzindua, 'Altar of the Spiderweb'). The associated Mountain of the Insect may be nearby Tillo or Sayultepec. ${ }^{13}$

Another important ancient center in this area appears in Codex Nuu Naha, a colonial document containing glosses in Dzaha Dzaui that identify several place signs. We refer to the Altar of the Tree with White Flowers, or Mountain of the Flower and the Monkey, which is the major sovereign community right at the beginning of Mixtec history, in the opening chapter of Codex Tonindeye (pp. 1-8): Lord 8

${ }^{13}$ In Alvarado's orthography nduhua (with glottal stop) would differ from nduvua (without glottal stop), but in modern Sahin Sau 'spiderweb' is ndua or sndua without the glottal stop, similar to ndua, 'arrow, ray', which suggests to us that in this case the pronunciation of both terms was not radically different. See Jansen 1998b: 90 for this identification, as well as Jansen \& Pérez Jiménez 2000, where we read Altar of the Spiderweb in Codex Añute, p. 2-II, as Chiyo Nduhua, i.e. Chindua, and discussed this scene as well. Pohl (in Hendon \& Joyce 2004: 231-232) expresses the same opinion, suggesting that Place of the Arrow may have been Andua and Place of the Spiderweb Chindua. 


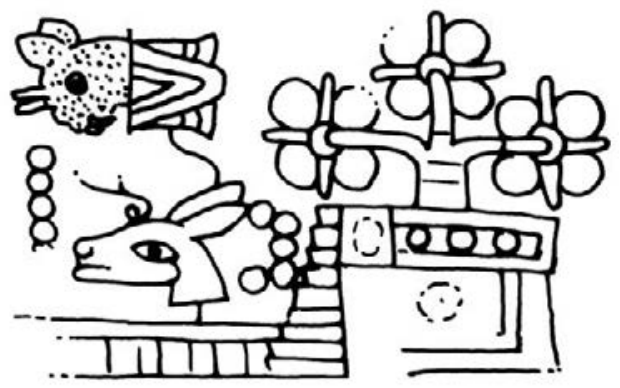

7.19. Codex Nuu Tnoo-Ndisi Nuu, p.6-V: Chiyo Yuhu with the name of its queen, Lady 10 Deer 'Jaguar Quechquemitl' (Dzico Ñaña).

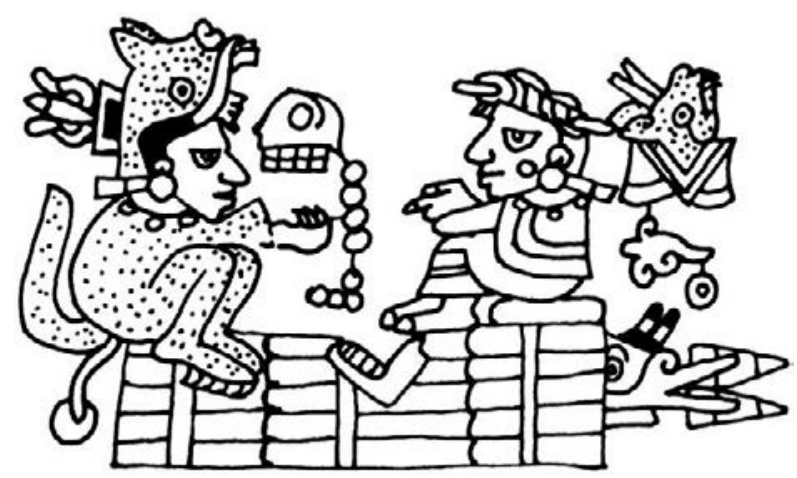

7.20. Codex Nuu Tnoo-Ndisi Nuu, p. 19-III: Lord 8 Death 'Jaguar - Fire Serpent (Yahui Ñaña)' and Lady 1 Flower 'Jaguar Quechquemitl (Dzico Ñaña)', rulers of Yanhuitlan.

Wind 'Twenty Eagles' ruled here at the beginning of the 11th century. ${ }^{14}$ This town can be identified with certainty as Chiyo Yuhu, present-day Santa María Suchixtlan, close to Yanhuitlan (Smith 1973b). We add that the toponym probably means 'Hidden or Secret Altar', but is represented as Chiyo Yuhndu, 'Altar of the Strawberry Tree'.

The Mountain of the Rain God - Black Mountain, the ancient ceremonial center, where Lord 8 Wind 'Twenty Eagles' was inaugurated as ruler (Codex Tonindeye, p. 2), therefore, has to be the nearby important archeological site Yucuñudahui - Yucu Noo (meaning pre-

${ }^{14}$ As Byland and Pohl (1994: 103) point out, in this Early Postclassic time the actual site referred to most likely was the archeological complex on the nearby Cerro Jazmín. See also Williams 2009. 
cisely 'Mountain of the Rain God - Black Mountain'), a Classic acropolis behind Chachoapan and close to Yanhuitlan (Jansen 1982b: 268-270).

The towns of Andua and Chiyo Yuhu were the antecedents of Yodzo Cahi (Yanhuitlan), which rose to supremacy in the early colonial period and became the seat of an impressive Dominican monastery. Both Andua and Chiyo Yuhu were included as subject towns in the Codex of Yodzo Cahi (Yanhuitlan). The Nahuatl place sign of Yanhuitlan, a (new) blanket is well documented in that manuscript as well as in Codex Mendoza, p. 43. Its Dzaha Dzaui correlate, which means 'Wide or Extended Plain', is also known as: 'Plain with Mouth - Bird with Arrow Beak'. This sign appears as the seat of Lord 8 Death and Lady 1 Flower (Codex Nuu Tnoo-Ndisi Nuu, p. 19-III), who were historically documented rulers of Yanhuitlan. ${ }^{15}$ The mouth $(a-)$ and arrows (nduvua) in the place sign suggest a connection with Andua, which appears with this sign in the Codex Yodzo Cahi itself. The plain is yodzo, but the reading of this specific bird has not yet been established, so we cannot tell whether it was a way of writing cahi or a reference to a different toponym.

An important town in the Mixteca Alta was and is Tepozcolula, which rose to the status of Alcaldía Mayor or regional capital in the colonial period. The colonial town, distinguished by many antique buildings, especially the royal palace in native style (Casa de la Cacica) and the important Dominican monastery and church with splendid Open Chapel, was a new foundation. The precolonial 'pueblo viejo' site is located on the nearby mountain Yucu Ndaa. ${ }^{16}$ The place sign in Codex Mendoza, 'Place of the Curved Axe', is a somewhat fanciful rendering of its Nahuatl name and, apart from its occurence in the colonial Codex of Yodzo Cahi (Yanhuitlan), has no correlate in the Mixtec

15 This couple appear as Namahu (8 Death) and Cahuaco (1 Flower) in an extensive document in the Archivo General de la Nación (AGN Civil 516, f. 24 v, reproduced by Paillés Hernández 1993b). See the studies by Caso (in Paddock 1966) and Mary Elizabeth Smith (1973a: 62-64). In addition, Hermann Lejarazu (2008a) proposes that Plain of the Quartered Circle with Quetzal Feathers and Crossed Legs of Stone in Codex Añute, p. 14-IV, may be an alternative glyph of Yanhuitlan (reading the quartered circle as cahi, 'patio', and the feathers as yodzo, 'plain'). Given the fact that this sign does not appear in a clear toponymic cluster and that not all of the component elements are well-identified, this suggestion remains without sufficient proof.

16 Recently an interesting relief in codex style was found at the site (Spores 2008). 


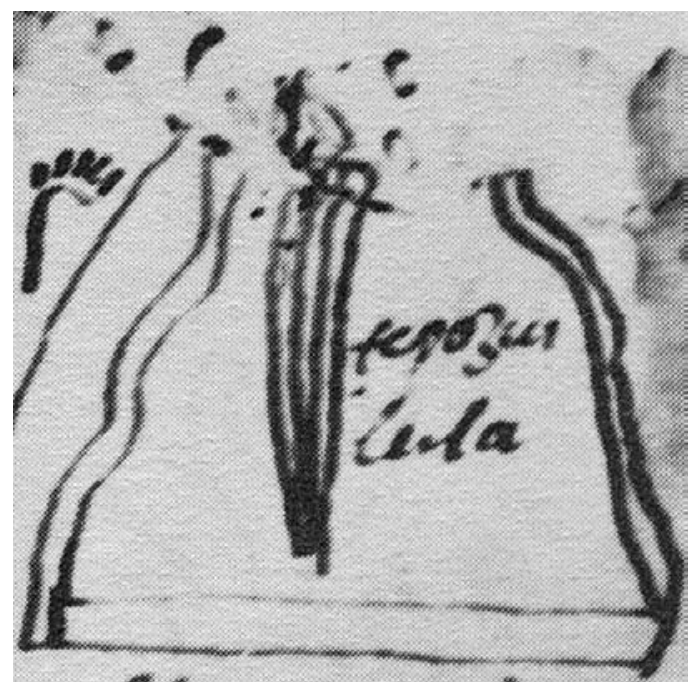

7.21. Genealogy of Tixii: the sign of Tepozcolula (Yucu Ndaa).

codices. According to Friar Antonio de los Reyes, an expert on Dzaha Dzaui, who spent many years in Tepozcolula, the meaning of Yucu Ndaa is 'Mountain of Fiber', as (ti)ndaa is the word for ixtle, a fiber got from the maguey plant. On the basis of this statement, it is plausible that at least one sign for Tepozcolula was the Mountain of Ixtle.

In the Genealogy of Tixii, also called 'Genealogy of Tlazultepec', but actually referring to the 'pueblo viejo' of San Agustín Tlacotepec (Smith 1998: 172-179), a barely visible Mountain of Hair or Fiber appears indeed as the sign of Yucu Ndaa (Tepozcolula).

Another occurrence, again barely visible, is in the Lienzo of Tlapiltepec (F 37 in the photo published by Caso 1961), where the sign is located on the other, i.e. Mixtec side of the three mountain tops of the so-called Nudo Mixteco (dominated by the Cerro Verde or Yucu Cuii, 'Green Mountain' in Dzaha Dzaui), which separates the Valley of Coixtlahuaca from the area of Tepozcolula. That means that the Lienzo of Tlapiltepec (which in this part distributes the place signs in space according to geographical criteria) indeed situates the Mountain of Hair or Fiber, or rather Mountain of Ixtle, roughly in the area of Tepozcolula.

Codex Nuu Tnoo-Ndisi Nuu (p. 14-I) tells the story of a ruler of the Nuu Tnoo dynasty settling in a very similar Mountain of Hair or Fiber. It is tempting to interpret this event as the taking over of 


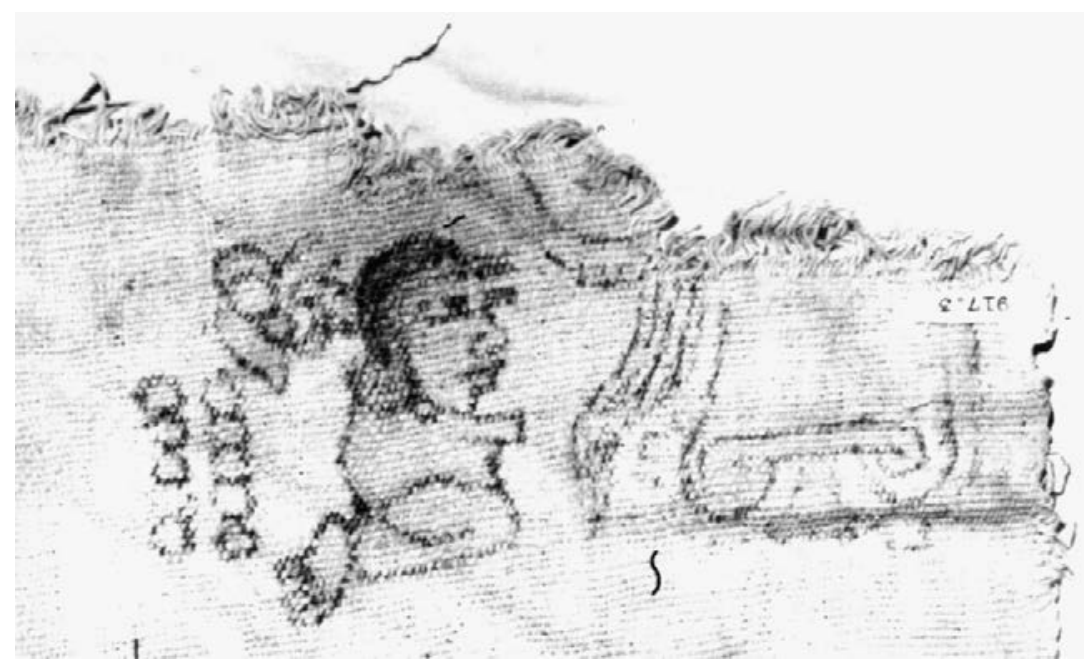

7.22. Lienzo of Tlapiltepec: the sign of Tepozcolula (Yucu Ndaa).

Tepozcolula by a Lord from Tilantongo, described by the same Friar Antonio de los Reyes in the prologue to his Arte (1593). ${ }^{17}$

A Mountain of Hair or Fiber is also mentioned in Codex Yuta Tnoho (p. 38-II), but does not play a significant role in the precolonial historiography. It is possible, however, that the River of Hair or Fiber, which appears as the seat of important primordial personages, is related to this town (Codex Tonindeye, p. 16; Codex Yuta Tnoho, p. 38-I).

There is also an adjective ndaa, meaning 'blue', which is generally painted as a turquoise jewel, for example in the sign of Tejupan: Nuu Ndaa (Smith 1973a: 60-62). A Mountain with a City of Turquoise appears in the Lienzo of Tlapiltepec close to the Nudo Mixteco (F 30 in the photo published by Caso 1961). In the past we thought that this might represent Tepozcolula, but now we are convinced that this sign

\footnotetext{
17 According to Reyes: "La lengua de Tilantongo es la mesma que la de Tepuzculula, con muy pocas diferencias, y segun sus antiguallas, en la division de los Señores que salieron de Apuala, como se dixo al principio, cupo en suerte al uno dellos el pueblo de Tilantongo, y fueron muy celebrados los Señores de aquel pueblo; y lo son oy dia, y muy estimados entre los naturales Mixtecos, y de alli vino un Señor desta linaje afamado a Tepuzculula, y poblo en el con gentes de Tilantongo, prevaleciendo a los naturales que dezian aver salido del centro, los quales vinieron a ser una mesma cosa, no solamente en Tepuzculula, donde hasta hoy ay barrios señalados de los que vinieron de Tilantongo, pero la lengua de ambos pueblos ha sido siempre una."
} 
most probably represents Tejupan, while the Mountain of Ixtle in this lienzo represents Tepozcolula. ${ }^{18}$

An illustrative example of how Nuu Dzaui and Mexica painters found different solutions to the problem of rendering a rather abstract toponym in pictography is the sign of Ndisi Nuu (Tlaxiaco). The Dzaha Dzaui name means 'clearly seen, well visible' or 'with clear sight, sharp eyed'. It is expressed by an eye (nuu) in combination with crossed beams or crossed legs, to be read as ndisi ('to lay crosswise'). As this sign was often placed in a house or temple, being a semantic determinant for 'place', the result was interpreted with some imagination as an 'Observatory. ${ }^{19}$ The Nahuatl name translates the original Ndisi Nuu as tla-chia-co, 'Place of Seeing Something. This was painted in Mexica manuscripts (such as Codex Mendoza) by resorting to a near homonym: tlach-quiauh-co, 'Place of Rain in the Ballcourt'. The Temple of the Crossed Beams and Eyes, Ndisi Nuu (Tlaxiaco), is not listed in this form among the primordial places in Codex Yuta Tnoho. Apparently people remembered that the site or polity designated with this toponym had not been founded in the time of creation but became

${ }_{18}$ The Lienzo of Tlapiltepec contains two toponyms with a jewel (turquoise) in it, located not far from each other: (1) a Mountain with a City of Turquoise (F 30 in the photo published by Caso 1961), which is followed by Mountain of the River of the Toad, i.e. Tamazulapan (Caso 1961: F 26), and (2) a Mountain with a Temple of Turquoise (Caso 1961: E 27), which is close to Altar of the Tules, i.e. Tulancingo (Caso 1961: DE 24). Our tentative first identification of the first (Mountain with City of Turquoise) as Tepozcolula, was inspired by the idea that the second (Mountain with Temple of Turquoise) might be Tejupan. Now, Van Doesburg (2001: 74-75) has argued that the latter place is not Tejupan, but another so-far unidentified site. This leaves the sign of Mountain with City (Nuu) of Turquoise (Ndaa) as the most logical candidate for Tejupan (and consequently not for Tepozcolula). Indeed, both its configuration as City ( $\tilde{N} u u)$ of Turquoise (Ndaa) and its location in line with Tamazulapan are strongly suggestive of it representing Tejupan. In another context Hermann Lejarazu (2006: 14), following an etymology of Yucu Ndaa as 'Blue Hill', has suggested that Blue Mountain of Maguey and Mountain of Sand, both conquered by Lord 8 Deer (Codex Iya Nacuaa II, p. 13-I), represent Yucu Ndaa (Tepozcolula) and Añute (Jaltepec) respectively.

19 This label was coined by Caso but has been taken seriously by several specialists in archeoastronomy. It is, however, nothing more than a combination of elements, used to express a place name, which is to be understood as 'Buena Vista' and, as such, does not contain any reference to an observatory (cf. Jansen \& Pérez Jiménez 1983). The identification of the sign as Ndisi Nuu (Tlaxiaco) was not proposed by Caso, but by Mary Elizabeth Smith (1973a: 58-60), whose idea was confirmed by Jiménez Moreno with his identification of the last ruler, Lord 8 Grass, as the king Malinalli of Tlaxiaco who is mentioned in Central Mexican sources (in: Gaxiola \& Jansen 1978). 


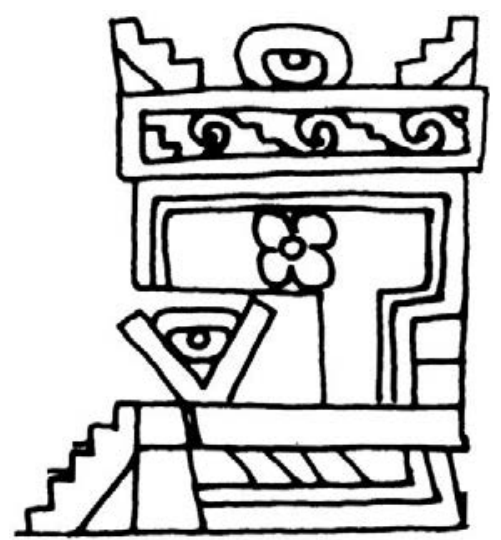

7.23a. Codex Nuu Tnoo-Ndisi Nuu, p. 15-V: Temple of the Crossed Beams and Eye (Ndisi Nuu).

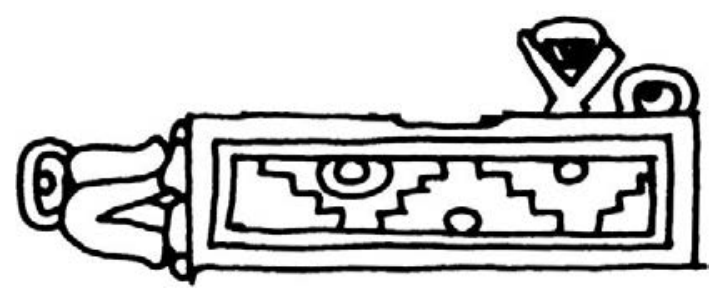

7.23b. Codex Nuu Tnoo-Ndisi Nuu, p. 15-II: Town of the Crossed Legs, Crossed Beams and Eye (Ndisi Nuu).

prominent later during the Postclassic: it is the main focus of the later part of the Reverse of Codex Nuu Tnoo-Ndisi Nuu.

Ñuu Ndecu (San Miguel Achiutla) was an important religious center and place of origin. Friar Francisco de Burgoa called it the "main temple of this nation, the oracle to consult for all matters of war and peace". Here a Sacred Bundle, containing the jade image of a serpent with wings, i.e. the famous Plumed Serpent, was venerated as 'Heart of the People' (Burgoa 1934b, I: 332 ss). The Nahuatl toponym Achiutlan is represented in Codex Mendoza, p. 45, as a bowl of red paint from the achiote plant. This plant does not grow at the site, however. The Dzaha Dzaui name is composed of a $\tilde{n} u \mathcal{u}$, 'town' and ndecu, which can be the verbal stem of 'sewing' or an adjective meaning 'burned' or 'burning', as in the metaphor for 'war': nduta ndecu, 'burning water'. Today a phonetical confluence has occurred between this ancient term 


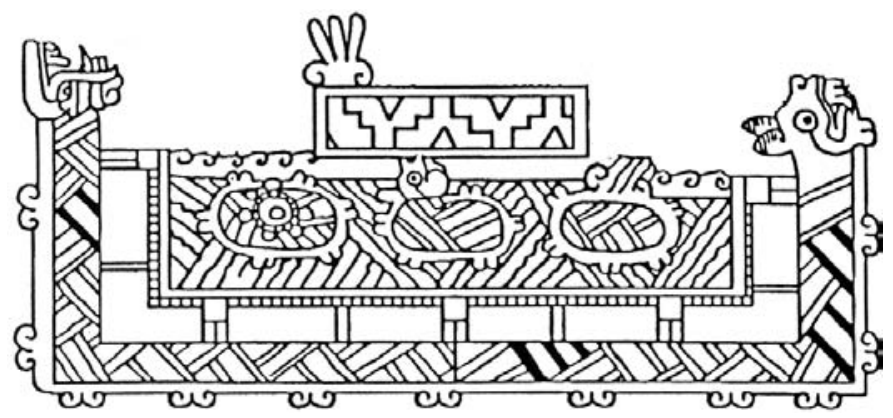

7.24. Codex Añute, p, 2-I: the landscape of Ñuu Ndecu (Achiutla).

ndecu and the verb ndico, 'to grind'. Wigberto Jiménez Moreno has convincingly identified its place sign: 'Town with Flames'. This community fits all the criteria: it appears as an important place of dynastic origin in Codex Añute (p. 2) and its royal family intermarries continuously with that of Ndisi Nuu (Tlaxiaco): an alliance policy, which not only suggests geographic vicinity, but also corresponds to what we know about the intimate connections between the lineages of Tlaxiaco and Achiutla in early colonial times. ${ }^{20}$

In telling the story of the dynasty of Añute (Jaltepec), Codex Añute, p. 2, locates the Tree of Origin at Town of Flames, i.e. Nuu Ndecu (Achiutla). That scene clearly indicates the significance of Nuu Ndecu as a sacred place. Studying its representation in Codex Añute, p. 2, more closely, we observe that three stones form part of the Nuu Ndecu toponym: Stone of Jade (or Jewel), Stone of the Puma and Stone of Flames. The latter of these three stones is probably connected with the toponym Town of Flames, the first two may represent two of the four wards mentioned with their Nahuatl names in an early colonial document known as the Suma de Visitas: Xiutepeque, 'Turquoise Mountain', and Miztepeque, 'Puma Mountain', respectively. The other two wards were called Iquipaltepeque, 'Throne Mountain', and Iztepeque, which may mean 'Knife Mountain' (itz-tepec) or 'Blood Mountain' (ez-tepec).

${ }^{20}$ Codex Nuu Tnoo-Ndisi Nuu Reverse, passim. See the contribution by Jiménez Moreno to Gaxiola \& Jansen 1978. The colonial dynastic relationships are clearly indicated in the testament of Don Felipe de Saavedra, cacique of Tlaxiaco (Spores 1967: 222-223). 


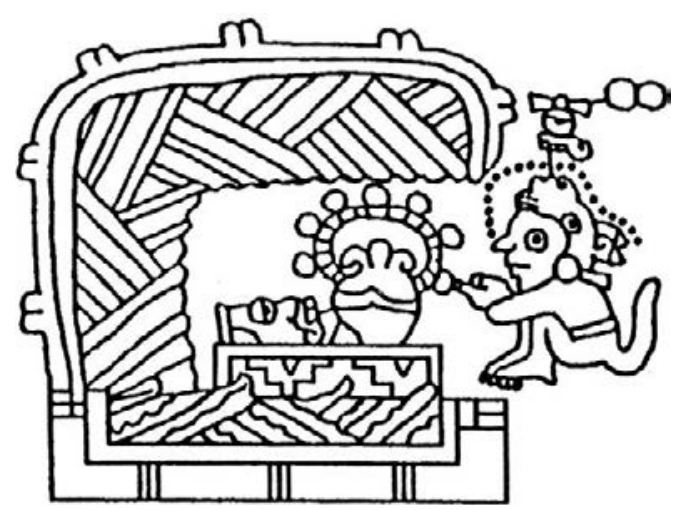

7.25. Codex Añute, p. 6-II: Lord 2 Rain 'Twenty Jaguars (Ocoñaña)' consults with the Heart of the Mixtec People in a cave.

Later in Codex Añute (p. 6-II) we find a reference to a cave where the Heart of Nuu Dzaui is located, clearly a reference to the oracle cave of Nuu Ndecu described by Burgoa. The heart is accompanied by a jewel or jade sign, which again suggests that Place of Jade (Jewel) was one of the ancient names of Nuu Ndecu, which later survived as the name of one of the wards that integrated the village-state. The toponym may refer to the confluence of rivers at the foot of the sacred mountain where the precolonial ceremonial center and the Dominican convent are located: Yuta Ndaa, 'Blue River' or 'Extended River'.

Symbolically the three stones in the painting of Codex Añute, p. 2, may represent the three hearth stones (yeye) which sustain the comal or round baking plate, and refer to the foundation of the world and domestic life. The extension of water in which they are situated most likely recalls the lagoon that, according to local legend, once occupied the valley. The main local river, Yuta Ndaa, 'Blue River', would be all that remains from that primordial lake. In view of these circumstances it is plausible that the Nahuatl toponym 'Achiutlan' does not come from achiote plants but is a corrupt rendering of A-xiuh-tlan, 'Place (-tlan) of the Turquoise (xihuitl) Water (atl)'.

While subscribing to Jiménez Moreno's identification of Town with Flames as Ñuu Ndecu, San Miguel Achiutla, Bruce Byland and John Pohl notice that the place of the ancient ceremonial center was traditionally known as Yuku Gandi (= Alvarado: Yucu Ndicandii), 'Mountain of the Sun' and suggest that the Temple of the Sun, where the Sun God Lord 1 Death (c.q. his high priest) resides, also represents 

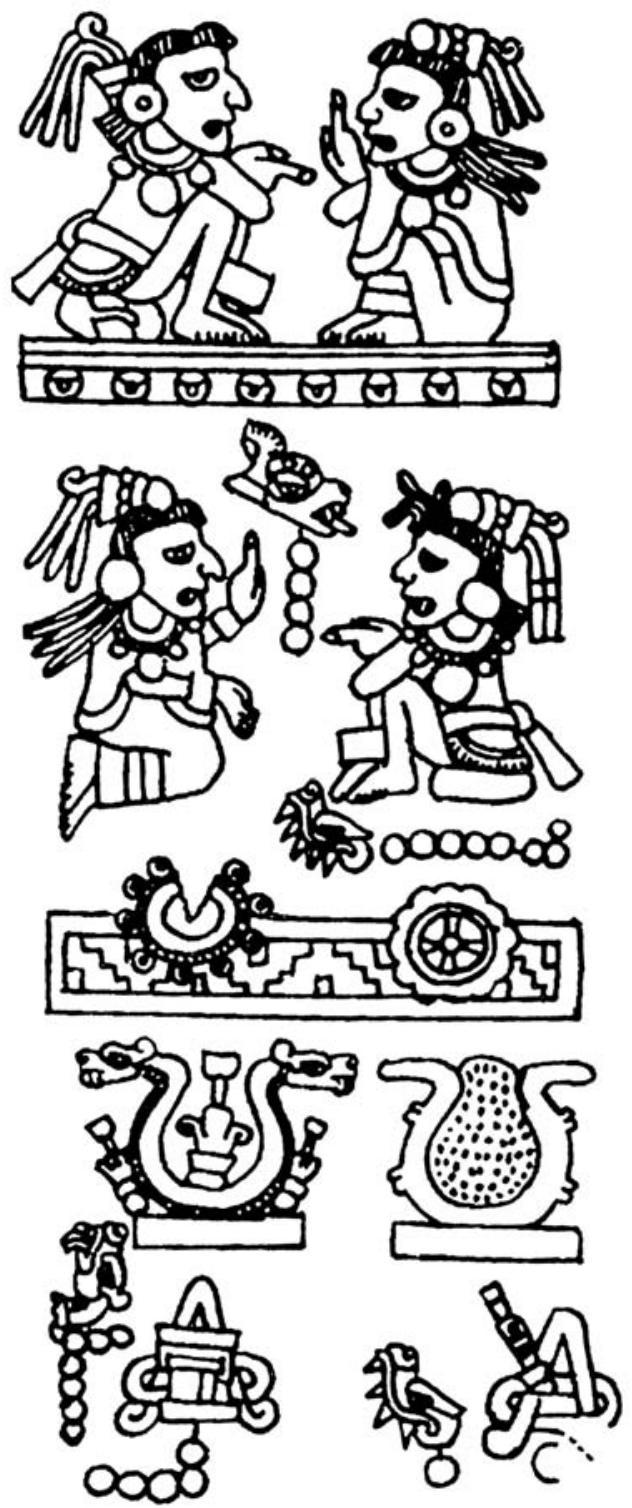

7. 26. Codex Yuta Tnoho, p. 49-I: divine founding couple seated at Town of Jade and Turquoise, and other primordial places. 
Achiutla. ${ }^{21}$ We are of a different opinion: taking into account the long journey of conquests that Lord 8 Deer undertook to reach this Temple of the Sun, passing an active volcano and crossing a tropical lagoon, we think that this emblematic place of the East must be located much further away, outside the Mixteca Alta. It is always possible, however, that one or more of the other references to a Sun Temple within the Nuu Dzaui region do represent the sanctuary of Achiutla or another ceremonial center dedicated to this deity.

The list of Codex Yuta Tnoho (pp. 47-38) mentions many places of religious importance but the usual sign of Nuu Ndecu, Town of Flames, is not among them. It would be strange if such a paramount ceremonial center was absent from this manuscript, so we suspect that it is represented with another sign. The genealogical history on the reverse side of Codex Nuu Tnoo-Ndisi Nuu suggests that Nuu Ndecu as an independent realm or village-state was a relatively late creation; this may be the reason that that toponym is not used in the chapter of Codex Yuta Tnoho which refers to the time of origin.

Instead we find a Town of Jade and Turquoise as an important primordial place with a status similar to that of the Mountain of Heaven at Yuta Tnoho (Apoala). The signs of jade, jewel and turquoise are intimately related and sometimes seem interchangeable, as general references to the preciousness and brilliance of blue or green stones. Town of Turquoise appears as the pictorial representation of Nuu Ndaa, 'Blue Town' (Tejupan) but the information about that polity does not correspond to the religious prominence given to this Town of Jade and Turquoise in Codex Yuta Tnoho. Additional toponymic signs are a double-headed snake with flowers and a moon sign or vessel, filled with dark sand or gravel. In the combination of the snake (coo) and moon sign or vessel (yoo) we read cohyo, 'cattails', emblematic of a Toltec place, where art and civilization flourish, Nuu Cohyo, 'Place of Cattail Reeds' being the Dzaha Dzaui name of Tollan or Tula. Looking for sanctuaries comparable to the Mountain of Heaven, we remember that the chronicle of Friar Francisco de Burgoa (1934b, I: 277) mentions two other places to which the Nuu Dzaui dynasties attributed their origin: Sosola and Achiutla. San Juan Sosola is called Tuhu, 'Old (Ruined) Place' in Dzaha Dzaui. The name of its close

21 Castellanos 1910: 21; Byland \& Pohl 1994: 82, 197 ff; Byland in Blomster 2008: 343 ff. Cf. Jansen 2006. 
neighbor, San Jerónimo Sosola, is Acuchi, "Place of Gravel". ${ }^{22}$ The dark sand or gravel in the vessel sign might indeed represent the latter. The turquoise and jade, however, point toward another place. In view of the prominent jewel sign associated with the waters of Nuu Ndecu in Codex Añute, p. 2, we speculate that this Town of Jade and Turquoise represents the primordial Achiutla. This Town of Jade and Turquoise turns out to be the magical birth place of Lord 9 Wind 'Plumed Serpent' (Codex Yuta Tnoho, p. 49), which fits Burgoa's report on this deity being worshiped as a Sacred Bundle in Achiutla.

\section{The Four Directions}

Friar Antonio de los Reyes and Friar Francisco de Burgoa tell us how the first Mixtec Lords and Ladies, born out of the Tree of Yuta Tnoho (Apoala) divided themselves into four groups and went out to the four directions to found the sovereign communities of Nuu Dzaui. The same account is given by Codex Yuta Tnoho: the primordial Lords and Ladies, coming from Yuta Tnoho, drilled the New Fire and made ceremonial cleansings in different places. Among these we find a canon of five landscapes associated with the four directions and the center. The main signs correspond to the Dzaha Dzaui terms for the cardinal points registered by Friar Francisco de Alvarado: ${ }^{23}$

\begin{tabular}{lll}
\hline Sign & Alvarado's term & Direction \\
\hline Heaven & $=$ Andevui, 'Heaven': & East \\
Checkerboard Hill $=$ Yucu Naa, 'Dark Mountain': & North \\
River of Ashes & $=$ Yaa Yuta, 'Ash River': & West \\
Temple of Death & $=$ Huahi Cahi, Andaya, 'Place of & South \\
& Death': & \\
\hline
\end{tabular}

22 As was suggested by Mary Elizabeth Smith, the Place of Gravel in Codex Añute, p. 9-II, is most likely Acuchi (San Jerónimo Sosola). See also Codex Ñuu Naha, p. 3 (Jansen 1994: 60). A Mountain with Mouth (locative prefix $a$-) and Dark Specked Material (gravel: cuchi) appears prominently in Codex Ñuu Tnoo-Ndisi Nuu Reverse: we suggest that this sign may also represent Acuchi (Jansen \& Pérez Jiménez 2005: 45).

${ }^{23}$ For the decipherment of the directional symbolism, see Jansen 1982b. In several manuscripts the landscapes are indeed situated in the four corners of a scene, e.g. in Codex Yada (Tututepetongo), p. 33 (Anders \& Jansen 1994: 295) and Codex Yecu or Fonds Mexicain 20/21 (Jansen 1998c). 


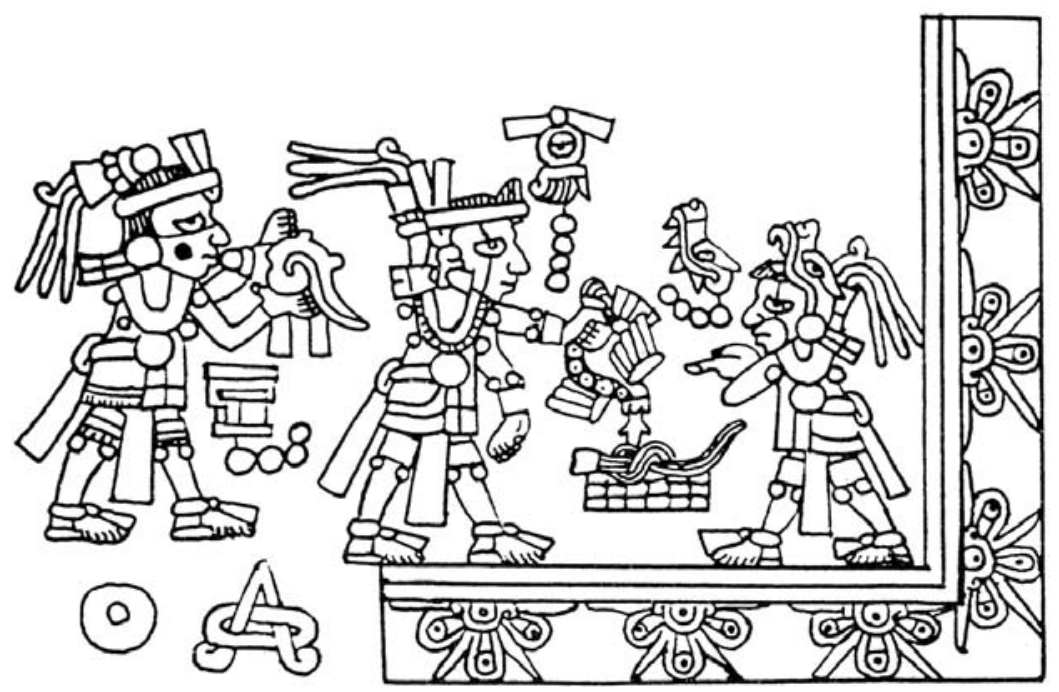

7.27. Codex Yuta Tnoho, p. 13. Heaven, representing the East.

In addition we have identified these sites as specific sacred places that roughly correspond to the cardinal directions for an area that comprises the Mixteca Alta and Baja:

East: the Mountain of Heaven in Apoala,

North: a mountain near Tepeji de la Seda

West: the Nejapa river

South: a cave in the area of Chalcatongo

Here we will analyze the toponyms in more detail.

The East (Codex Yuta Tnoho, p. 13; Codex Yecu: top right corner) is represented by the Place of Heaven (Andevui), which occurs frequently in combination with references to Yuta Tnoho (Apoala), e.g. in Codex Tonindeye, p. 18, and which we have therefore identified as Kaua Kandiui, 'Rock on which Heaven is stretched out' or 'Rock that rises into Heaven', a striking peak directly East of the Sacred Valley where the village of Apoala is located (Jansen 1979, 1982b).

The North (Codex Yuta Tnoho, p. 21; Codex Yecu: top left corner) is represented as a mountain with a checkerboard motif, often combined with a Split Mountain. It corresponds to Alvarado's term Yucu Naa, 


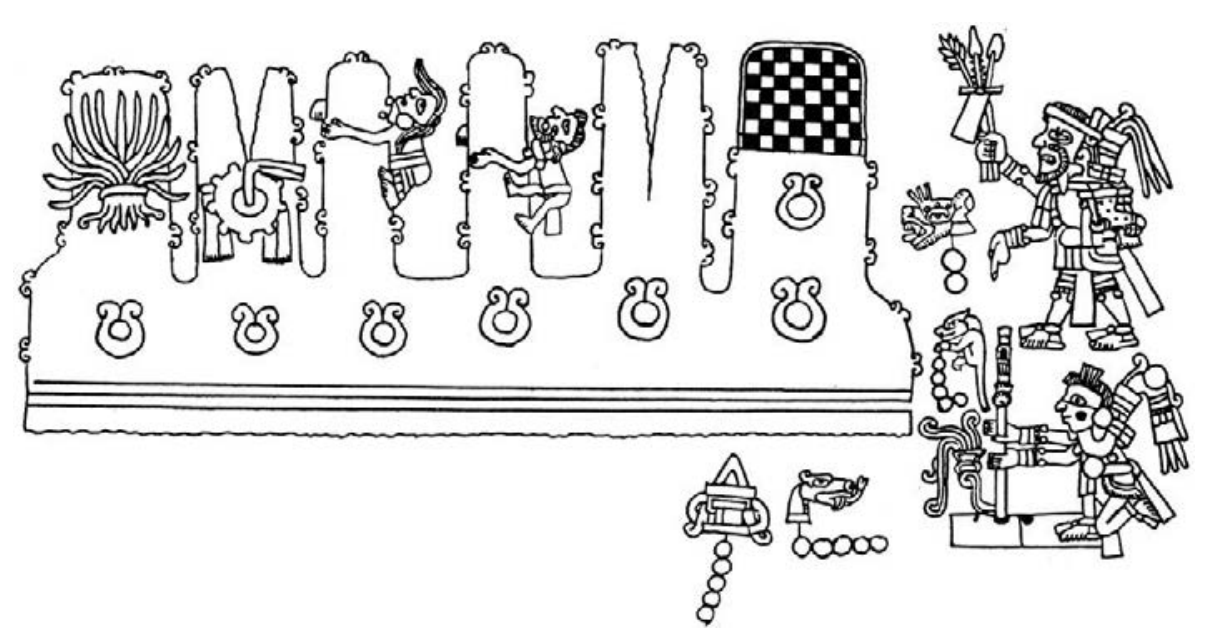

7.28. Codex Yuta Tnoho, p. 21: New Fire ceremony and ceremonial cleansing of the landscape of the North.

'Dark Mountain'. It is likely the sign refers to a specific mountain or ravine in the area of Tepexic (Tepeji de la Seda) in the southern part of the State of Puebla, because Tepexic is painted as a Split Mountain in the Nahuatl tradition. ${ }^{24}$ The two signs are accompanied by Mountains of the Elderly Man and Woman, likely referring to nearby Huehuetlan, 'Place of the Old Ones'. It is interesting to notice that the Relación Geográfica de Huehuetlan calls the big ravine where this village is located Tetlilucan, 'Place where stones become black' (Acuña 19841985, II: 211). Another toponym of the northern landscape in Codex Yuta Tnoho is the Mountain of the Maguey: a similar sign is used in Map II of Cuauhtinchan for the Tentzon mountain range in that same area (Yoneda 1991).

Brotherston finds that Split Hill appears very prominently in Codex Yuta Tnoho (p. 21), where it is "uniquely privileged by resting on a base raised to the middle of the page". Following our identification of this place as Tepeji, he concludes that "this formal arrangement in itself strongly points to Tepexic as the main focus of the narrative and hence its provenience". From here he proceeds to call the codex the "Annals of Tepeji", and to interpret its narrative as the expression of

${ }^{24}$ See Jansen 1982b and 1998c. Still today the Ngigua (Popoloca) of the State of Puebla consider Tepeji (in Ngigua: tha2'na2', translated as 'Oven of the Mountain' or 'Hand of the Mountain') to be the place of the North (Michael Swanton pers. com.). Its Mixtec name is Cavua, 'Cliff'. 


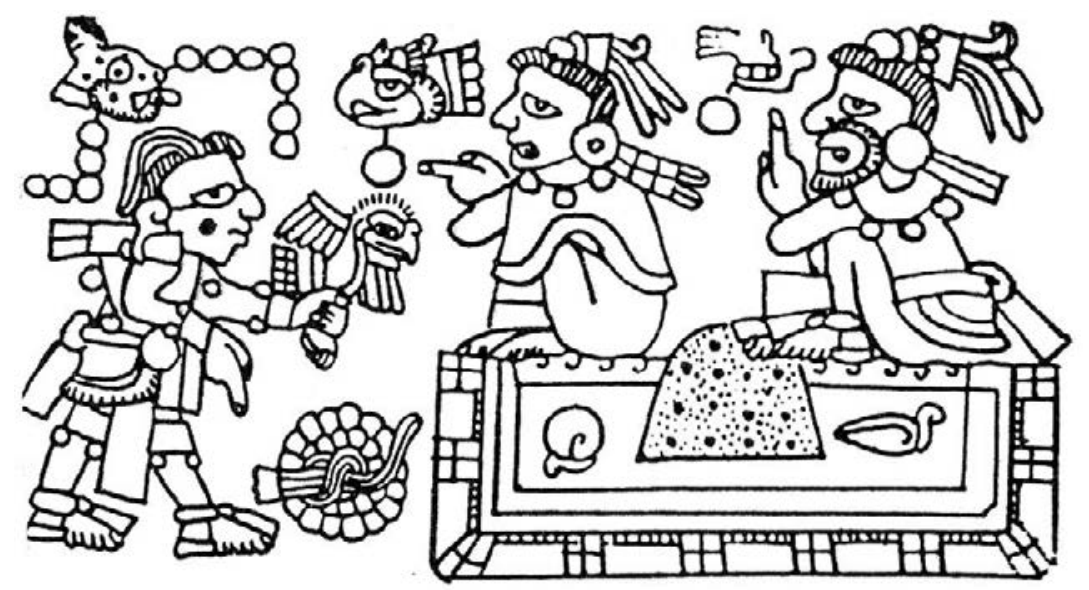

7.29. Codex Yuta Tnoho, p. 16: the Grandmother of the River, Lady of the West.

a "northern i.e. Toltec perspective" (Brotherston 1995: 106-108; 2007: 219-222).

But, as we have mentioned before, the Reverse of the Codex Yuta Tnoho contains a genealogical register of the dynasty of Nuu Tnoo and there are several prominent references to that town on the obverse side as well. This strongly suggests that the manuscript comes from Nuu Tnoo (Tilantongo) in the Mixteca Alta. Tepeji is mentioned, but not in such a special manner that it is justified to say that it is the primary focus of this codex. It is merely one of five major place-sign complexes that refer to the four directions and the center. Brotherston's idea is, therefore, unfounded and extremely unlikely.

The West (Codex Yuta Tnoho, pp. 15-14; Codex Yecu: lower left corner) is the River of Ashes (Yaa Yuta), i.e. the Río Nejapa, which still today marks the western boundary of Nuu Dzaui. This is the realm of Lady 1 Eagle, the Sitna Yuta or 'Grandmother of the River'.

In the South (Codex Yuta Tnoho, pp. 15-14; Codex Yecu: lower right corner) stands the Death Temple. The name for this direction in Alvarado's dictionary is Andaya, 'Place of Death', or Huahi Cahi, in which huahi means 'house' and cahi 'cemetery' (but this word can also have other meanings such as 'broad, wide', 'abundance' and 'to grab'). While cahi huahi is a patio, the combination huahi cahi is translated as 'cemetery'. Today the latter term is generally pronounced Vehe Kihin 
and is used for a cave where a dangerous, malignant spirit dwells, 'the devil', called El Gachupin, 'the Spaniard'. His Dzaha Dzaui name is Ja Uhu, 'Pain' (in Nuu Ndeya), or Xa Cuina, 'He who assaults and robs' (in the area of Atoco). ${ }^{25}$ Today many different caves are called Vehe Kihin, but we suppose that the place mentioned in the codices represents a major sanctuary. A further important criterion for its identification is that this place functioned as the emblematic place of the South. In a historical context this Temple of Death appears next to a Mountain of the Deer and Death Town. This connection points to the funerary cave, where all the sacred rulers of the Nuu Dzaui village-states were buried, located on a steep and very dominant mountain, the Cerro de los Cervatillos, 'Mountain of the Small Deer' in the ancient kingdom of Nuu Ndaya (Chalcatongo). ${ }^{26}$ The shrine was venerated throughout the whole region. After the Spanish conquest the Dominican monk Friar Benito Hernández found the place and destroyed it completely (Burgoa 1934b, I: 337-341).

The sovereign community of Nuu Ndaya (ancient Chalcatongo) was the northern neighbor of Yucu Satuta (Zacatepec) and is indeed represented as Skull Frieze in the corresponding position on the lienzo of that town. Nuu Ndaya is to be interpreted as 'Town of the Dead' or 'Town of the (entrance to the) Underworld'. Ndaya seems to be related (possibly as an archaic form) to ndeye, 'dead'. According to Alvarado, andaya (with the locative prefix $a$-) is the Underworld or Hell: infierno, lugar de dañados. Today Chalcatongo is called Nuu Ndeya, translated locally as 'Town of Abundance'.

Those who are not specialized in the language and culture of Nuu Dzaui, generally approach its pictorial texts from a Mexica-centered perspective. Nowadays some Nahuatl philology forms part of the training of most researchers in this field. The localization of the Temple of Death in a place now called Chalcatongo seems strange to them, because the latter toponym in Nahuatl does not contain a reference to death. A Town of Death in their mind has to be Mictlan or Mitlatongo (mic-tlan-ton-co, 'Small Place of the Land of Death'). Indeed Mitlatongo, called Dzandaya in Dzaha Dzaui, must also have

${ }^{25}$ At an early stage of our research Aurora Pérez recognized that the Temple of Death was a Vehe Kihin, and this has been a cornerstone of our subsequent interpretations (Jansen 1882: 248 ff.; Jansen 1998c; Jansen \& Pérez Jiménez 2000: 117-120).

${ }^{26}$ The clearest representation of this toponym we find in Codex Añute, p. 7-IV. Next to the Skull Place (Andaya) in Codex Nuu Tnoo-Ndisi Nuu, p. 4-III, a deer's hoof is painted, likely an indication of the Cerro de los Cervatillos. 


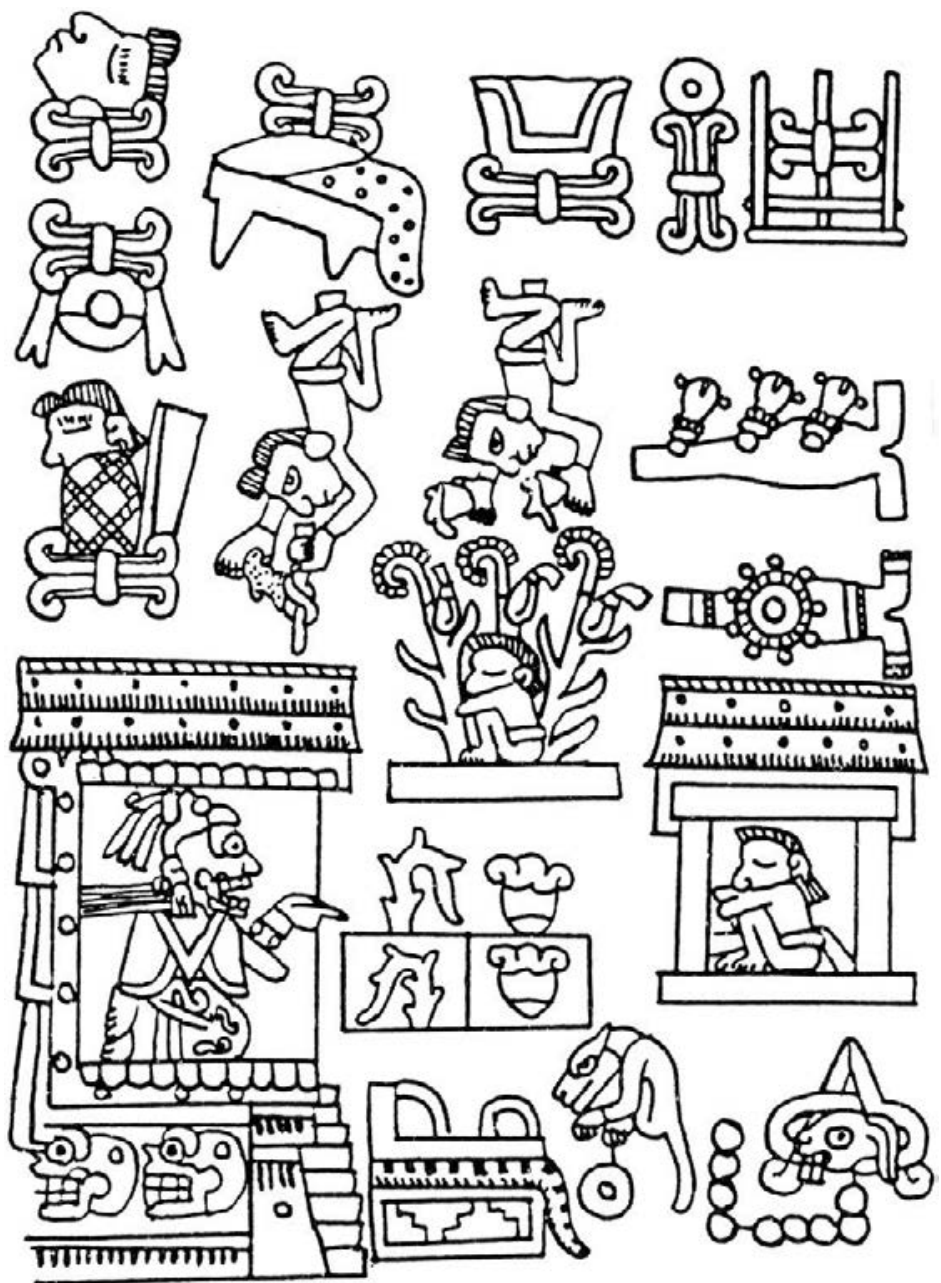

7.30. Codex Yuta Tnoho, p. 15: the Death Temple (Huahi Cahi) in the South.

had funerary associations but it does not make sense as a representation of the South, nor was it so venerated as a pan-regional royal sepulcher. ${ }^{27}$

27 Dzandaya (Mitlatongo) is represented as a Mountain of Skull - Place of Descending Clouds, associated with several other toponyms, in Codex Nuu TnooNdisi Nuu, p. 3-IV: the identification is certain because of the ruler of this place, Lord 1 Monkey, who is mentioned as the founder of Mitlatongo's dynasty in the corresponding Relación Geográfica (Acuña 1984, II: 237-238; cf our discussion in Jan- 
The Nahuatl name Chalcatongo is probably a contraction of Chalco Atenco. The present center of Nuu Ndeya was indeed situated on the bank of a big lagoon, which survived until the 1930s. Elderly people still recall the fish, the herons, the tule reeds and a small island with crosses where the 3rd of May was celebrated, the feast of the Holy Cross and the supplication for rain. This town seems to be an early colonial relocation. Its fertile valley is surrounded by archeological sites dating from the Classic Period (Yuku Chayu, Yuku Unkuu, Yuku Tahñu). The Postclassic capital seems to have been the "Pueblo Viejo" in the community Nduha Vee (Agencia Juárez) in neighboring Nuu Kahnu (San Miguel el Grande). It should be remembered that the extension of the ancient polity of Nuu Ndaya was much larger than that of the present-day municipio of Chalcatongo, included what are now the municipios of San Miguel el Grande, Santiago Nuu Yoo, and Santiago Yosondua, and went as far South as Cuanana and Santa Cruz Itundujia. It is therefore not easy to locate the ancient funerary cave of the Cerro de los Cervatillos. The area has many caves (and many unexplored archeological sites), many of which would qualify as a Vehe Kihin; the most well-known is a large cave in Cañada Galicia, a community of Santiago Yosondua.

In a flying visit to Chalcatongo, John Pohl interviewed some local inhabitants about that ancient cave. They communicated to him the local conviction that it may have been a cave in the Yuku Unkuu, a lower hill to the West of the present-day town of Chalcatongo, on top of which a Late Classic ceremonial center is situated. On the basis of this information and a quick archeological reconnaissance of the site, Pohl (2007: $37 \mathrm{ff}$ ) locates the Cerro de los Cervatillos at this place, which he transcribes as Yucu Cu. Actually his only argument for this identification seems to be that this is a mountain with a cave located close to the present-day town of Chalcatongo. But Pohl also refers to a field in the neighborhood which is now called 'El Cervatillo'. Although at first sight this seems suggestive, in reality such names of fields used to be extremely local, and there is no way to be sure about their permanence or significance. In any case this Cervatillo field is not generally known in the neighborhood. Thus, what remains for Pohl's theory is just a cave in an area full of caves and a mountain with

sen \& Pérez 2007a: 155-157). Probably the Temple of Bird (dzaa) and Death (ndaya) in Codex Añute, p. 14-II, is an alternative representation of the same place (cf. Jansen \& Pérez Jiménez 2007b: 259, 329). 
an archeological site in an area full of archeological sites. Its proximity to modern Chalcatongo is no argument either: the precolonial capital of the kingdom was located elsewhere and Burgoa does not suggest that the Cerro de Cervatillos was close to the town, but, instead, stresses that it was a very high mountain somewhere in the area of Chalcatongo. In fact, Burgoa's description of the cave and the mountain (que decollaba con eminencia sobre todos, donde la naturaleza o los estragos del diluvio hicieron una grandísima oquedad) does not fit the profile of Yuku Unkuu, which is not the highest mountain around, but a relatively unimpressive hill, with a few small cave entrances. No coincidence in names, no special religious value could be documented for this mountain, so it does not qualify as the emblematic Place of the South, where the important Cave of the Dead Rulers was located.

Several mountains in the relatively large area that once belonged to the ancient kingdom of Chalcatongo have names referring to deer. The Mixtec name of Yolotepec, another town in this same general area, is registered by Antonio de los Reyes as Yucu Neni, which may be translated as 'Cerro de los Cervatillos' (Alvarado: ñeni = 'cervatillo'). Taking into account contemporary traditions, however, we feel the best candidate is the Yuku Kasa (which might translate as 'Potent Mountain'), located relatively close to Itundujia: a high rising and impressive peak that marks the very southern end of the Mixteca Alta: its geographic position would certainly make it an excellent marker of the South. Moreover, in the southern Mixteca Alta Yuku Kasa is traditionally considered a 'gateway to Heaven', a place where the people who have died gather before going to the Hereafter. Here the living can still communicate with their lost loved ones, who get together with them in a sort of market. This is why Yuku Kasa is also known as Nuu Anima, 'Place of Souls', a name that corresponds well to the representation as Cave of Death. Future research may shed light on the exact location of the lost funerary cave of the Mixtec kings and queens.

In Codex Yuta Tnoho (p. 14) the Death Temple is accompanied by a cluster of toponyms. Supposing that these also formed part of the ancient city-state of Chalcatongo we propose the following very hypothetical identifications:

- Mountain and River (i.e. the community) of Death must be a general reference to Nuu Andaya (Chalcatongo). The river of Death is flowing over - which might be a reference to a local spring or waterfall such as the impressive waterfall in nearby Yosondua. 


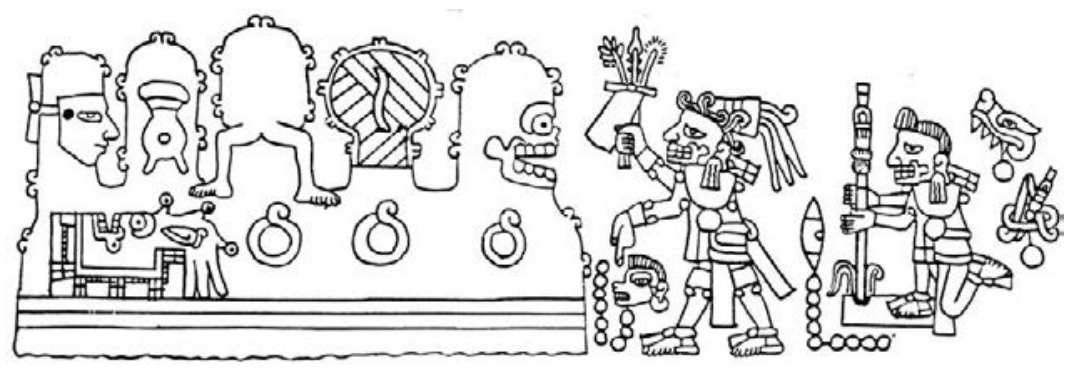

7.31. Codex Yuta Tnoho, p. 14: New Fire ceremony and ritual cleansing of the landscape of the South.

- Stone Mountain is a very general name: one of the candidates in the area is Yucu Yuu, 'Mountain of Stone', the dominating cliff of San Mateo Peñasco.

- Mountain of Feet might represent (a) the impressive Yuku Kuahan or Yuku Jehen (Yucu Quaha / Yucu Saha in Alvarado's orthography), 'Mountain that went away', next to Santa Catarina Yosonotú, or (b) the area of Nuu Yoo - Yucu Iti bordering on the tropical lowlands, known as Saha Yucu (locally Jiehe Yuku), 'at the foot of the mountains'.

- Mountain of the Jar is probably Yucu Tindoho.

- Mountain of the Mask would be neighboring Cuanana (Yucu-anana). ${ }^{28}$

In addition Codex Yuta Tnoho (p. 12) and Codex Yecu mention a specific sign for the center: the Heart of the Alligator, i.e. the Heart of the Earth (Ini Nuhu). This may be a general reference to a central place from where the world is seen, but may also point more specifically to the important central shrine of all Nuu Dzaui, the cave of Nuu

${ }^{28}$ Martínez Gracida (1883) says about Yucu Tindoo: "los terrenos en que existe [el pueblo] pertenecieron al cacique de Chalcatongo, pues aún conserva cierto reconocimiento al Común de dicho pueblo por aquella circunstancia." (see also Berlin 1947: 76; cf. Santos Gómez \& Villagómez Velázquez 1998). An interesting detail is noted by Martínez Gracida in his description of Cuanana: "Al S. a una legua en el Cerro de Yucuyiyi, existe una cueva de 8 metros de extensión por lado en su entrada, por 12 de longitud el interior, el cual sigue en dirección perpendicular, y después en un subterráneo extenso, contando la fábula ser una gran vivienda a manera de los Campos Elíseos, según la describen. En esta cueva iban antiguamente los habitantes de los contornos a tributar sus adoraciones ofreciendo carne, tortillas y legumbres, llevando los objetos ciertas contraseñas, que correspondían al individuo que los ofrecía.". 


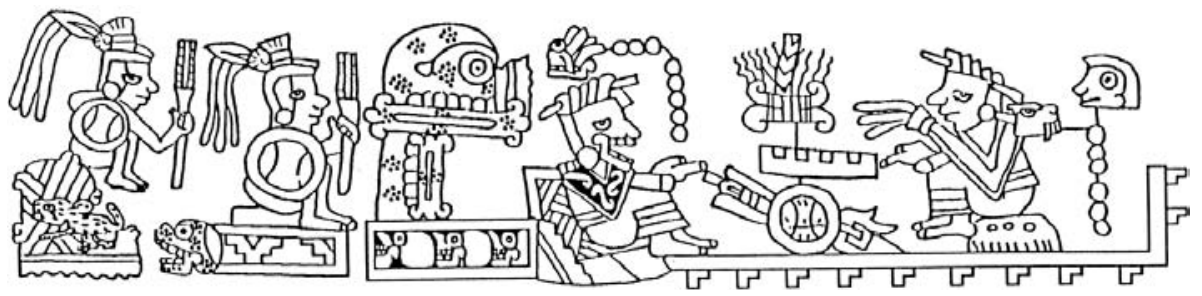

7.32. Codex Añute, p. 7-IV (Right to Left): Lady 6 Monkey consults with Lady 9 Grass, Patron of the Huahi Cahi and commander of the warriors from Death Town (Nuu Ndaya) and Mountain of the Deer (Cerro de los Cervatillos).

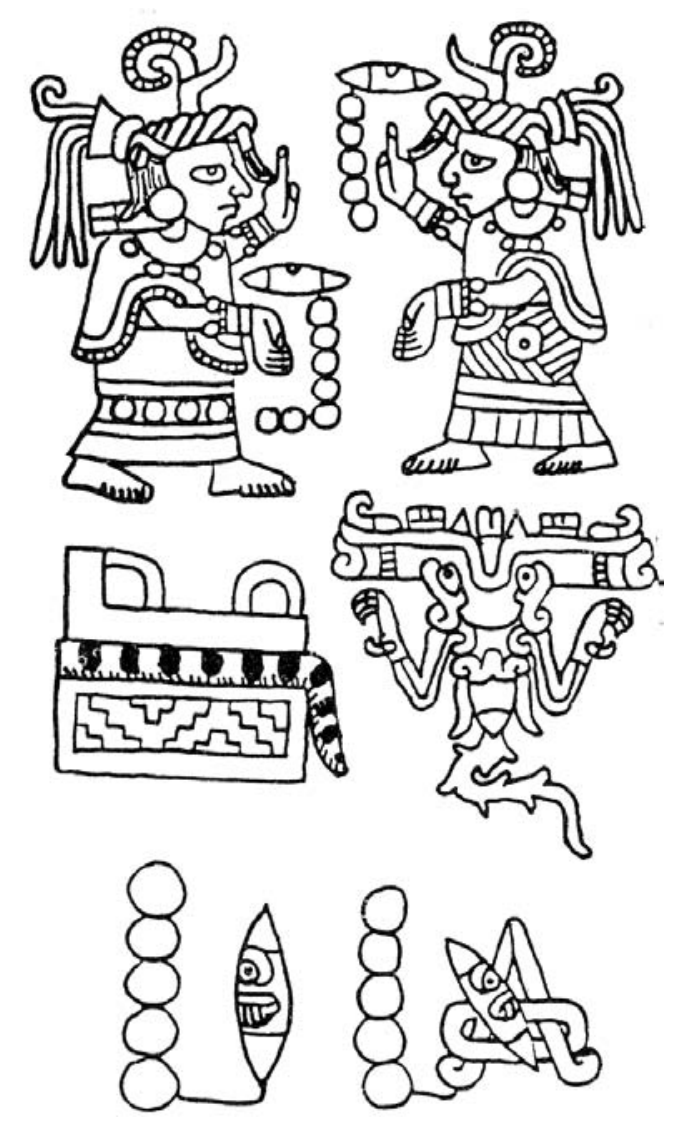

7.33. Codex Yuta Tnoho, p. 12: the Maize Ladies in Heart of the Alligator, i.e. the Center. 
Ndecu (San Miguel Achiutla), where the Sacred Bundle of the Plumed Serpent was venerated under the name of 'Heart of the People'.

Bruce Byland and John Pohl (1994: 81-82) have published a somewhat different interpretation of the signs of the four directions:

We concur that the East and South are represented by the communities of Apoala and Chalcatongo and that there may be a broad-scale directional structure in the Mixteca in general. The West and North are possibly, though not as securely, related to the places suggested by Jansen. The association of Achiutla with the center is relatively weak, as Jansen recognized.

On a smaller scale the directional structure of the southern Nochixtlan valley and adjacent areas can be much more completely defined. In the area immediately surronding Tilantongo and Jaltepec can be found places that have the iconograhic structure of each of the four cardinal directions as well as the center: East - Achutla, as Hill of the Sun; South - Mitlatongo, as Place of Death; West - Jaltepec, as Hill of Sand (glyphically equivalent to Hill of Ash); and North - Monte Negro, as Blackand-White Checkerboard Mountain. (Byland \& Pohl 1994: 81-82).

Obviously, it is quite possible (though not evident) that the directional structure would be repeated on different scales in Nuu Dzaui, but the identifications that Byland and Pohl propose do not make sense in geographic reality and are therefore counter-intuitive. Looking at the position of the four mentioned sites on the map, one immediately sees that Achiutla is to the West (not: East), Jaltepec to the East (not: West), Monte Negro does not occupy a specific northern position. Only Dzandaya (Mitlatongo) is indeed situated to the South of Tilantongo and the meaning of its name in both Dzaha Dzaui and Nahuatl, without doubt, characterizes it as a Place of (veneration of) the Dead; but as an emblematic place of the South it would exclude the whole large area of the southern Mixteca Alta from the area defined by the directional markers. As observed by Alfonso Caso (1960), Mitlatongo appears in Codex Nuu Tnoo-Ndisi Nuu, p. 3-IV, with the founder of its dynasty: Lord 1 Monkey, also mentioned in the Relación Geográfica of Mitlatongo (cf. Smith 1973a: 77-78).

\section{Valley of Oaxaca}

Adjacent to the Mixteca Alta, the Valley of Oaxaca was mainly inhabited by Beni Zaa, Zapotecs, with the exception of Cuilapan, where an influx of Mixtecs took place in the Postclassic. All authors, archeolo- 


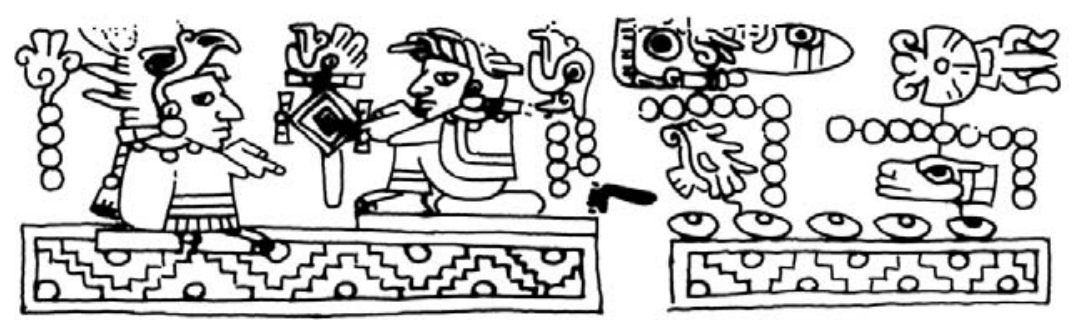

7.34. Codex Ñuu Tnoo-Ndisi Nuu, p. 18- I: Lord 4 Flower 'Pheasant' marries Lady 7 Vulture 'Quetzal Fan', daughter of [Lord] 10 Water 'Rain Knife' and [Lady] 11 Lizard 'Butterfly, Fire Serpent', rulers of Ñuu Nduchi (Etla).

gists and historians recognize the enormous influence from the Valley of Oaxaca on the Mixtec world, although the precise circumstances and nature of the interaction are a topic of debate. In the Classic time it was the great capital of Monte Albán that resonated in the whole Oaxacan region. During the (late) Postclassic the Nuu Dzaui had dynastic alliances as well as military conflicts with their Beni Zaa neighbors, according to the colonial sources (Relaciones Geográficas and Burgoa). Both areas were actually quite close: the Postclassic Beni Zaa city-state of Zaachila borders Teozacualco. Modern research is, however, subdivided into Mixtec and Zapotec specializations, which is a handicap for bringing to the fore the regional interaction and the intense relationships between the two peoples. Mary Elizabeth Smith (1988) has identified the place sign of Etla, Nuu Nduchi in Dzaha Dzaui: 'Town of Beans'. Codex Nuu Tnoo-Ndisi Nuu, p. 18-I, mentions the marriage between a princess from this polity and a ruler of Nuu Tnoo (Tilantongo). Here we will discuss other identifications, which so far have proved to be bones of contention.

Quite a few scholars are convinced that Mixtec codices refer exclusively to the Nuu Dzaui world, and therefore think it unlikely that these chronicles might contain information on neighboring peoples. We recognize the specific local realities and religiously charged landscapes of the home region of these documents, but do not believe it was an isolated area. On the contrary, we consider the Mixtec society very much an integral part of Mesoamerica, and see ancient Mesoamerica itself as a world-system, a large and dynamic region of much internal and external contact, due to marital alliances and military conflicts, pilgrimages and religious movements, trade and ritualized 


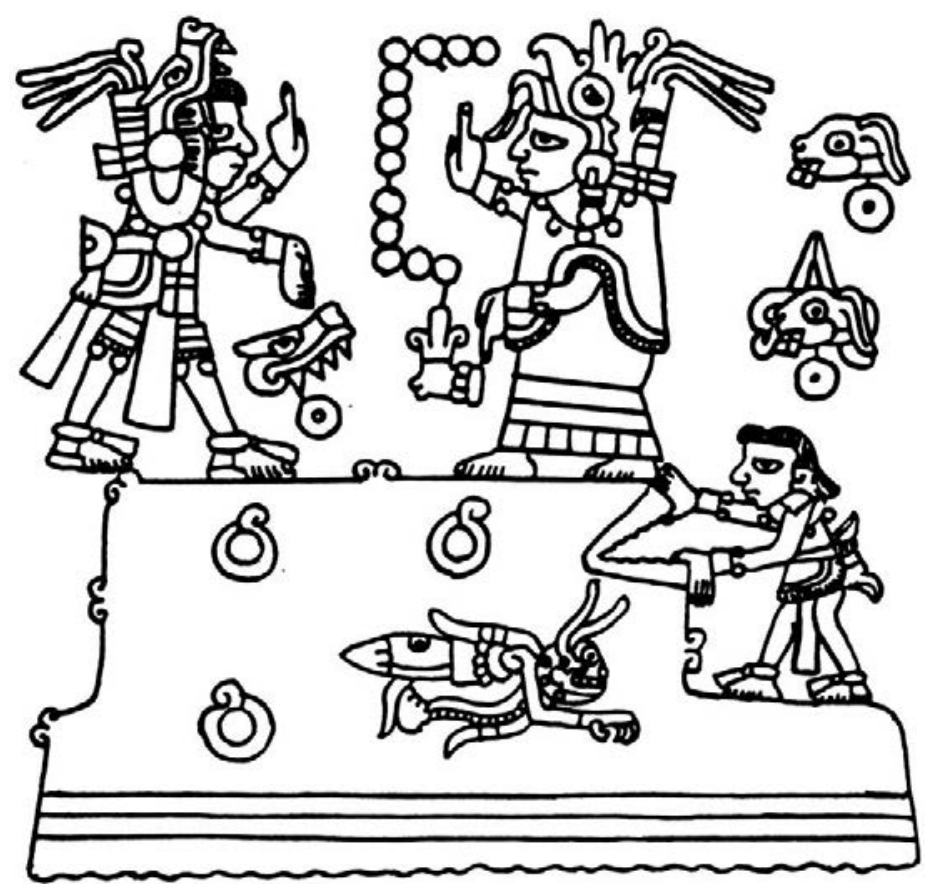

7.35. Codex Yuta Tnoho, p. 1: Mountain that is Opened - Insect.

exchange, and, last but not least, the diffusion of a specific style and code of pictorial writing (cf. Blomster 2008: ch. 1).

The place called 'Mountain that Opens - Bee' by Caso and 'Mountain that Opens - Insect' by several other authors, was a major ceremonial center in the very early period described by the codices, a place of origin for a series of princesses in the founding epoch of the dynasty of Ñuu Tnoo (Codex Ñuu Tnoo-Ndisi Nuu, pp. 3/4-II). Bent Rock Insect is an alternative representation (Codex Tonindeye, p. 19).

The same site occurs in the list of toponyms in Codex Yuta Tnoho (p. 42-III), next to the place sign of Nuu Tnoo. This would at first sight suggest a geographical proximity of these two towns, but, as we saw earlier, the precise 'rules' that determine the sequence of places and dates in this list are still unknown. Especially since Nuu Tnoo was dynastically linked to Mountain that Opens - Insect, their juxtaposition could be motivated by other (political) circumstances. 


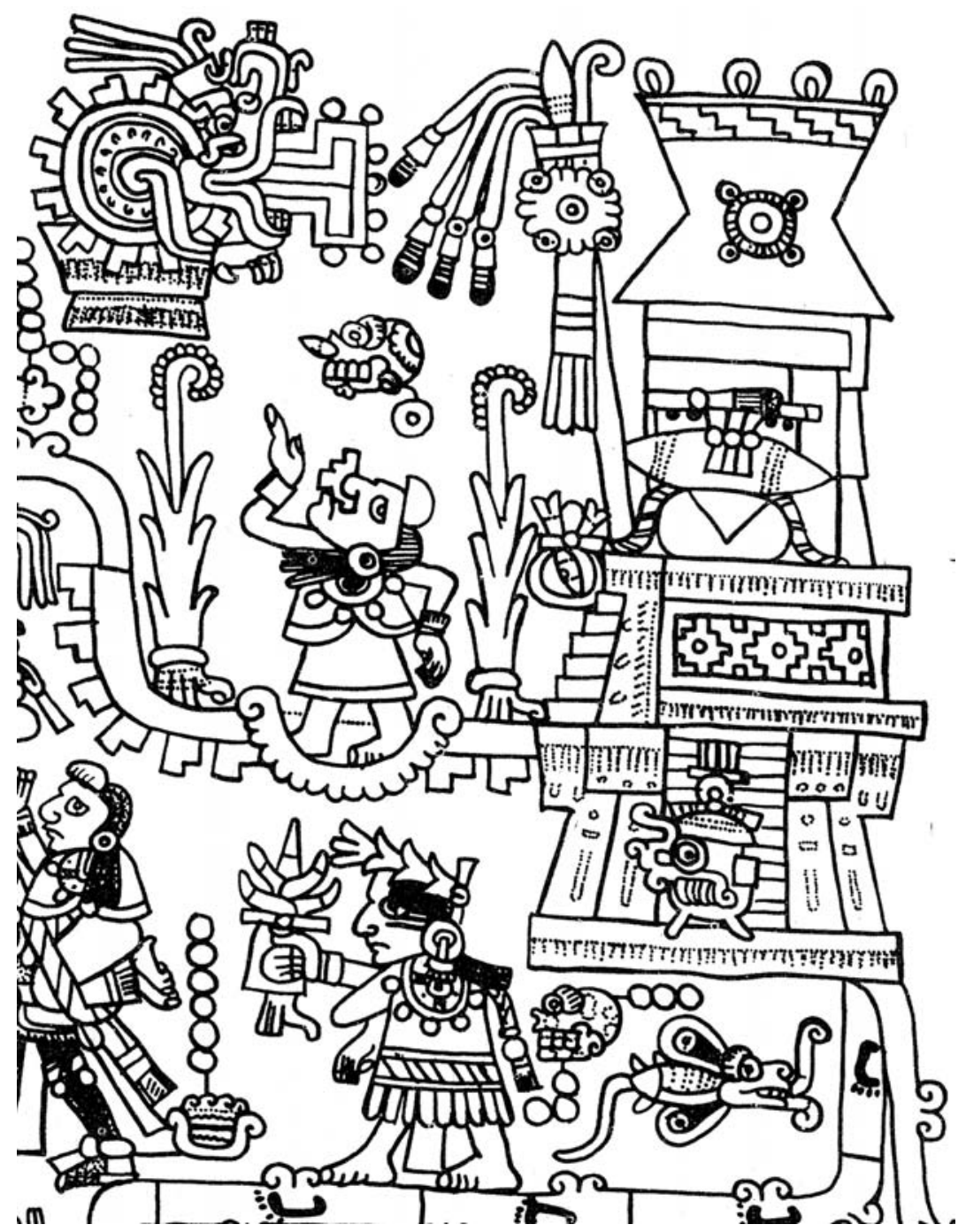

7.36. Codex Tonindeye, p. 19: the birth of Lady 1 Death in Place of the Reeds, Mountain of the Insect, Altar of the Rain God Vessel.

Many years ago, when doing our first research in Yutsa Tohon, we had the impression that it might be located close to that town (Yuta Tnoho, Apoala). We saw an association between the two places in Codex Tonindeye (p. 19), where Lord 12 Wind descends from the Place of Heaven (which we had identified as the Kaua Kaandiui, Mountain of 


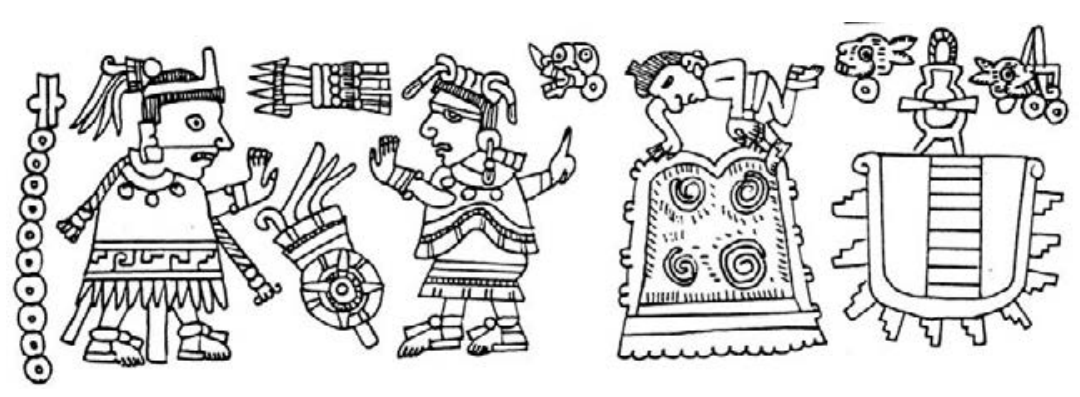

7.37. Codex Yuta Tnoho reverse, p. II-3: Lord 10 Movement visits lady 1 Death, ruler of Mountain that is Opened - Altar - Vessel.

Heaven, in Apoala) and arrives at the large ceremonial center of Bent Mountain - Insect. As our understanding of the geographical complexity of the Nuu Dzaui manuscripts advanced, however, we started to understand that this in itself was not a convincing argument: the distance between the Place of Heaven and Mountain that Opens Insect is not specified and may have been considerable.

Working from the observation that 'Mountain that Opens - Bee' appears next to Black Frieze in the long list of place signs in Codex Yuta Tnoho (p. 42-III), Bruce Byland and John Pohl set out to identify it in the vicinity of Nuu Tnoo. During their fieldwork in that area they found three archeological sites on the ridge between Nuu Tnoo (Tilantongo) and Añute (Jaltepec), occupied mainly during the Classic Period (Byland \& Pohl 1994: 94-98). The one that has architecture (a platform with a pyramid mound and a courtyard) is called Yucu Yoco, which can mean 'Hill of the Bee'. An alternative name is Ndua Que'a Sina. Byland and Pohl translate the latter as: 'Valley That Is Opened' or, more poetically, 'Valley That is Made Fertile' and conclude that the site Ndua Que'a Sina/Yucu Yoco is Mountain that Opens - Bee.

This reasoning provokes several doubts. First the etymology of the latter toponym is not certain. Byland and Pohl take que'a sina to be the equivalent of quena/sina, which is listed in the word list prepared by Arana and Swadesh as the combination of two stems (future and present) of a verb, which according to Alvarado may mean 'to open', but mainly in the sense of 'to clear' or 'to empty', although it occurs suggestively in the expression for dividing the waters of the Red Sea. The extended translation that Byland and Pohl propose, tries to include the meaning of its homonym: 'to grow, to be abundant' in 
some specific expressions. ${ }^{29}$ But the combination of two stems of the same verb (quena/sina) with different meanings in one toponym is strange, so the proposed etymology of the site's name is unconvincing. No explanation is given for the change of quena to que'a, which does not follow normal Mixtec phonetic developments.

Moreover it is not certain that the act depicted in the place sign represents the verb 'to open'; it actually seems closer to the bending, tearing apart or breaking (cahnu), which is used as a convention to express cahnu, 'big, large' (e.g. in the sign of Chiyo Cahnu, Teozacualco). The fact that the man tearing the mountain may be substituted by a bent rock (in Codex Tonindeye, p. 19) lends further support to a reading as cahnu, which means both 'bent' and 'big, large'. We read the opened, or rather torn mountain, therefore, as Yucu Cahnu, 'Big Mountain'.

The identification of the flying insect as a bee is not certain either. In some cases we see a yellow and/or black representation that indeed looks like a bee, but could equally represent a fly, while in other cases a different insect is clearly meant: with a skeletonized round head, claws and sharp pointed (knife-like) coverings or wings. The latter configuration suggests a harmful, unpleasant insect.

In the place-sign cluster the torn mountain or bent rock is not only combined with an insect but also with reeds, which may be substituted by a moon sign (Codex Añute, p. 7-III). This substitution points to a reading yoo, which means both 'reed' and 'moon' in Dzaha Dzaui. Finally the place-sign cluster contains an altar, characterized by a vessel with the face of the Rain God.

The Map of Xoxocotlan, a colonial pictorial manuscript, offers an important point of departure for identifying the cluster. Here two important hills of Monte Albán, the Classic acropolis in the center of the Valley of Oaxaca, are represented as Insect Hill and Reed Hill. Glosses identify them as Yucu Tiyuqh, 'Mountain of the Flies or Lice' and Yucu Yoo, 'Mountain of the Reed or Moon', Mixtec names that are translated into Nahuatl as Sayultepec, 'Mountain of Flies' and Acatepec, 'Mountain of Reed', respectively.

${ }^{29}$ See Alvarado: abrir camino apartando la gente, abrirse el cielo esclareciendo quitándose el agua, desocupar lugar quitándome de donde estoy sentado, vaciar como troje o casa, desocupado estar el lugar, but also dividirse una cosa como se dividió el mar bermejo en el tránsito de los hijos de Israel and hormiguear por criar, henchirse algo de gusanos. 


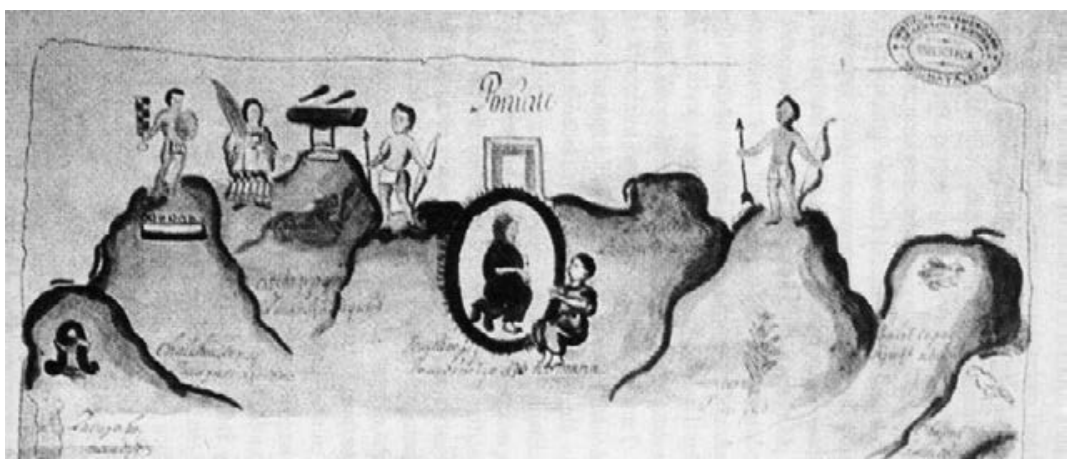

7.38. The 1619 version of the Map of Xoxocotlan, showing the slopes of Monte Albán: second and third from the right are Mountain of the Insect and Mountain of Reeds.

[For the color reproduction, see Ruiz Cervantes \& Sánchez Silva 1997].

We therefore postulate that 'Big Mountain', Yucu Cahnu, was a general name of Monte Albán. The insect incorporated in this place glyph would then be either a fly or a louse (both tiyuqh in Dzaha Dzaui), and refer to the Yucu Tiyuqh (Sayultepec). The moon or reed sign would represent the Yucu Yoo (Acatepec). We take the Altar to be a reference to the ancient ruins. The Vessel of the Rain God may represent the famous Classic urns with their diagnostic molded figures of Cocijo, the Rain God of the Beni Zaa (Zapotecs), found in abundance at the site. $^{30}$

${ }^{30}$ For the full argumentation, see Jansen in Jansen \& Kröfges \& Oudijk (1998). Arthur Joyce discusses the sacred character and ideological role of the site Monte Albán itself (in Hendon \& Joyce 2004; see also A. Joyce 2010). The Map of Xoxocotlan has been published and analyzed by Smith (1973a). In his contribution to the volume in honor of Mary Elizabeth Smith (Boone 2005: 109-127), John Pohl also studied the Xoxocotlan and Cuilapan maps and criticized our identification: Pohl's doubts and alternative proposals concern components of our reasoning, however, and do not invalidate the overall thrust of our argument. Pohl and Byland (1996) have proposed that the White Mountain with Flints, inserted in the landscape of Codex Tonindeye p. 19, is identical to the Mountain and Town of Flints, i.e. Nuu Yuchi, nowadays known as Mogote del Cacique. The ñu sign is absent in this depiction, however, and the firmly identified sign of Flint Town is not combined with a White Mountain elsewhere, so that this question remains undecided. Pohl and Byland mention a spot called Toto Cuisi, 'White Rock', near Mogote del Cacique. On the other hand there are several 'white places' in the Valley of Oaxaca to which Codex Tonindeye, p. 19, might be referring, among them the Tocuisi (Zaachila), which became the Zapotec capital later in the Postclassic Period. Clearly influenced by Byland \& Pohl's search for the Mountain that Opens - Insect in the vicinity of Tilantongo, but doubtful of their Ndua Quena/Sina - Yucu Yoco identification, Hermann Lejarazu (2008c: 51) has pro- 
An important consideration to strengthen this hypothesis is the fact that Mountain that Opens - Insect only occurs in the very beginning of the history registered in the codices, i.e. in the 10th century AD, mainly as an important site which was 'ancestral" to the Postclassic village-states, i.e. not as the thriving capital of an empire, but as a memory place, a source of power and legitimacy. This profile is consistent with what we might suppose for the ruined and largely abandoned site of Monte Albán in the Postclassic, which however retained religious meaning, for example as a place for dynastic burials such as the famous Tomb 7 (cf. Blomster 2008).

Nineteenth century sources have preserved a local traditional name for the central plaza of Monte Albán in Dzaha Dzaui: Kehyikanyi, i.e. kehe yikanyi (cahi ndicandii in Alvarado's orthography), 'Courtyard of the Sun', while a more general reference to the site was Sahandevui (saha andevui), 'Foot (or: Fundament) of Heaven' (cf. Pohl in Boone 2005: 117-118). These religiously charged names are comparable to that of the 'Sun Temple' of Teotihuacan, and likely link the ceremonial center both to the Time of Origin, or the Beginning of History (First Sunrise) and to ritualized observations of solar hierophanies (e.g. the zenith passage of the Sun). In this context it is interesting to note that the dynasty of Big Mountain (Monte Albán) was connected to a dynasty of Mountain of the Rising Sun. For example Lady 1 Death 'Sun Fan' is said to have emerged from (or to have been born in) the Mountain of Reeds area next to the main plaza of Monte Albán (Codex Tonindeye, p. 19), but two pages later she is presented as coming from Mountain of the Rising Sun (Codex Tonindeye, p. 21). Similarly the ancient ruler Lord 12 Lizard of Monte Albán was married to a queen from Mountain of the Rising Sun: Lady 12 Vulture (Codex Nuu Tnoo-Ndisi Nuu, p. 3-II).

The Bent Rock appears associated with the Valley of the White Carrying Frame, which is the toponym associated with the so-called Xipe dynasty in Codex Tonindeye and elsewhere. ${ }^{31}$ Both the outfit and the

posed that the Insect and Reeds in the Bent Mountain of Tonindeye, p. 19, might refer to local toponyms on the Monte Negro, the large archeological site next to Tilantongo. The spots in question seem of too little importance, however, and Hermann Lejarazu recognizes himself that his analysis is not conclusive.

${ }_{31}$ Codex Tonindeye, pp. 33-35 and p. 61; Codex Añute, p. 13-I. See Jansen 1982a, 1989, as well as Oudijk \& Jansen 2000, Oudijk in Blomster 2008, and the additional comments by De la Cruz 2008. 


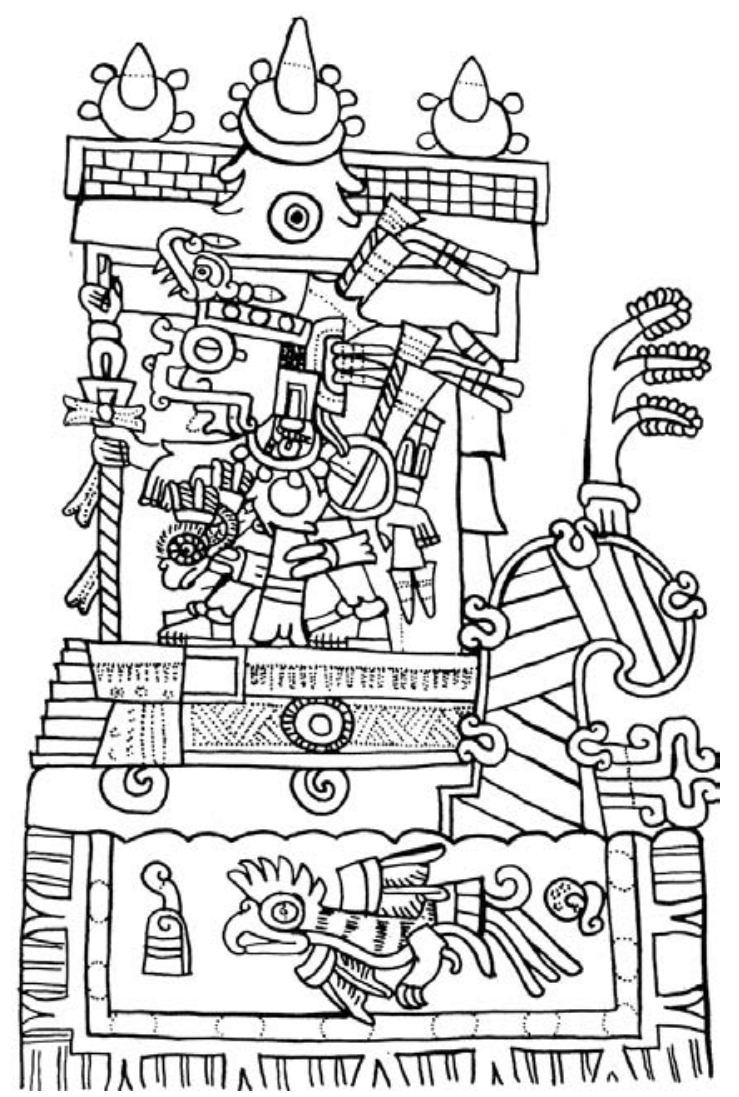

7.39. Codex Tonindeye, p.33: the capital of the 'Xipe Dynasty', i.e. Zaachila, at the foot of the Big Mountain, on the bank of the Quetzal River.

calendar names of these rulers (also depicted on the Beni Zaa Lienzos of Petapa and Guevea) have made it possible for us to identify this Xipe dynasty as the royal family that ruled Zaachila, the Beni Zaa capital in the Postclassic. The carrying frame (called cacaxtli in Nahuatl), is sito in Dzaha Dzaui. We propose that it was used as a homonym to represent the word sitoho, and also appears in shortened form as toho or to-, 'Lord'. In combination with the color white (cuisi), we obtain the reading To-cuisi, the Dzaha Dzaui name of Zaachila, home to the Xipe dynasty.

In several cases just the 'Valley of the Carrying Frame' was referred to, without the white color. In Codex Tonindeye, p. 61, we find the 


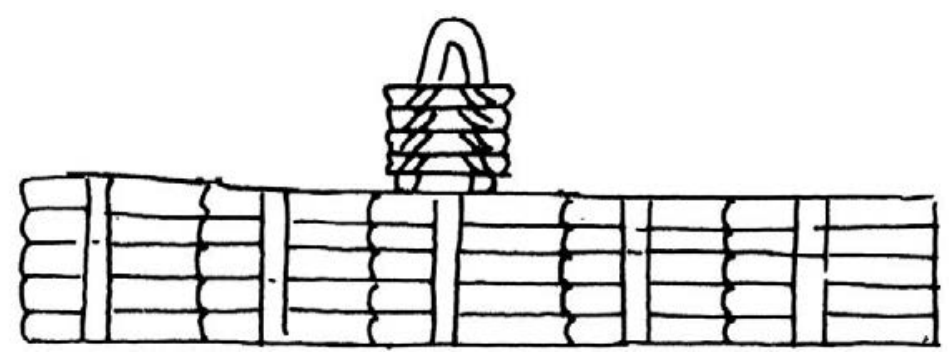

7.40. Codex Nuu Tnoo-Ndisi Nuu, p. 24-III: Plain of the Carrying Frame, Tocuisi (Zaachila).

White Frame as the base of a Palace (aniñe) next to a Bent Rock with Trees, all on top of a White Valley. The Bent Rock may represent Monte Albán as Yucu Cahnu, 'Great Mountain', certainly a very important place in the territory of Zaachila.

A scene in Codex Añute, p. 7-III, shows two men at Mountain of the Moon and Mountain of the Insect (Yucu Yoo - Tiyuqh, i.e. the northern part of Monte Albán), whose given names are registered as 'Long Hair of Bent Mountain' and 'Long Hair of Carrying Frame'. We interpret 'long hair' as a priestly title (cf.papahuaque in Nahuatl), and read these names in a combined fashion as 'long hairs of Bent Mountain - Carrying Frame', i.e. priests of Zaachila at Monte Albán.

\section{Mixteca Baja}

Once the Priest of Yuta Tnoho, Lord 12 Wind, had brought the liturgy of the Sacred Bundle to Monte Albán and married Lady 3 Flint there, a war broke out. Men, apparently belonging to the ancien régime, rose in rebellion against the cult community of primordial Lords and Ladies, born from the Sacred Mother Tree of Yuta Tnoho (Apoala). The association with an earlier order implies they would be described as 'those who were petrified when the new Sun rose' and be represented pictorially as 'Stone Men'. Antonio de los Reyes refers to this primordial people as tay nuhu, who had originated from the center of the Earth, Anuhu (1976: ii).

The war raged in a series of towns, mentioned in Codex Tonindeye, p. 3. We find the same toponyms associated with each other in Codex Yuta Tnoho (pp. 44-43 and 4-3). Assuming that they are towns 


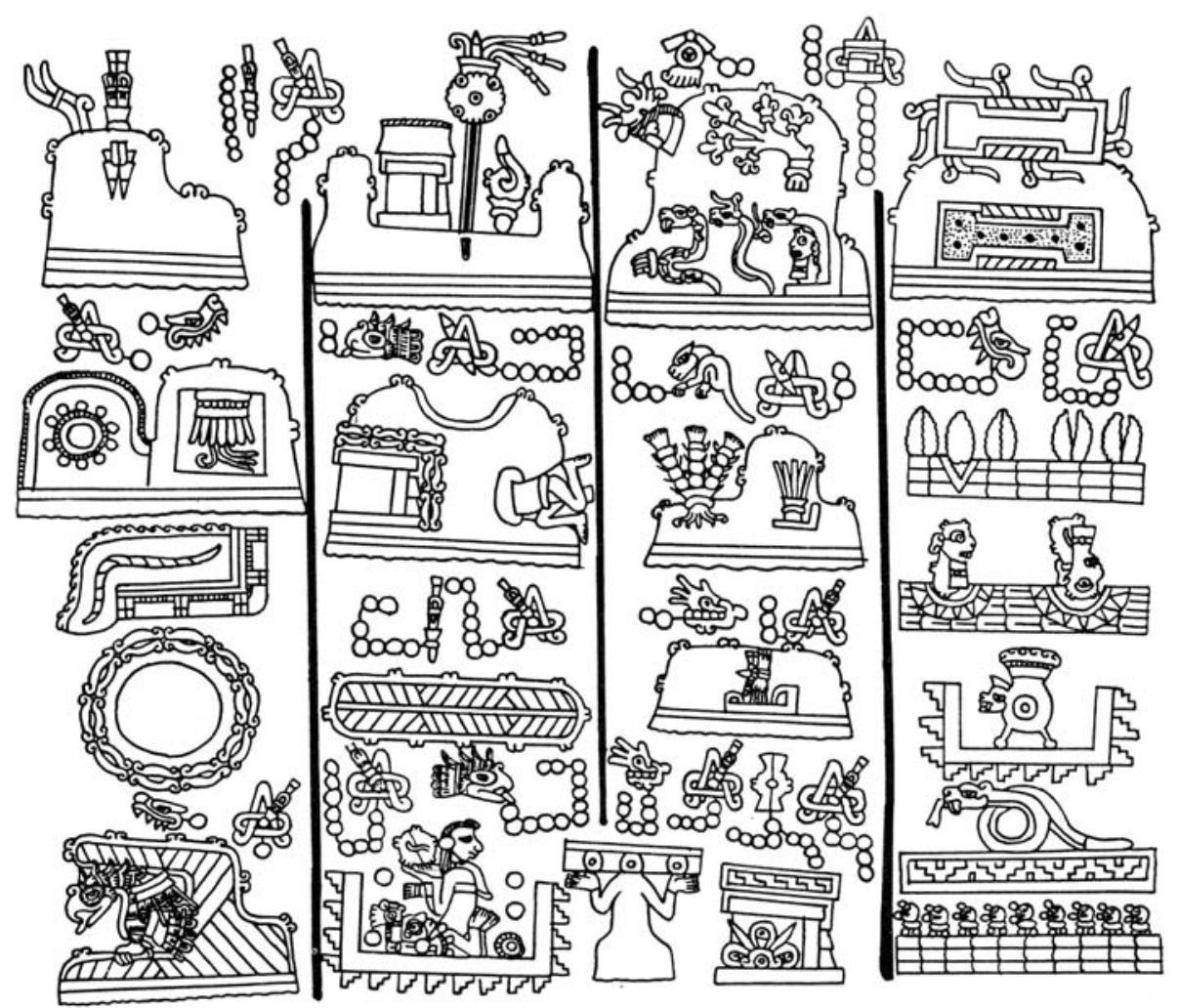

7.41. Codex Yuta Tnoho, p. 44 (Lower Right to Lower Left, boustrophedon): Places in the Mixteca Baja.

located in a coherent geographical area, and following the work of Mary Elizabeth Smith, we propose to identify them as a series of neigboring city-states in the Mixteca Baja region. John Pohl, however, situates these events and these places in the Valley of Nochixtlan (Hendon \& Joyce 2004: ch. 9; see also Williams 2009).

The Stone Men marched from two places. One is a complex place sign, dominated by the Town of Feet. Hermann Lejarazu (2008c: 18) proposes that this sign might represent Saha Chiyo, 'At the Foot of the Altar' (present-day Sachio close to Jaltepec) but does not explain the absence of any reference to an altar (chiyo) here. In Codex Yuta Tnoho (p. 44-III) a similar Mountain of Feet appears next to Valley of the Standing Conch Shell. Pohl (in Hendon \& Joyce 2004: 232) sug- 


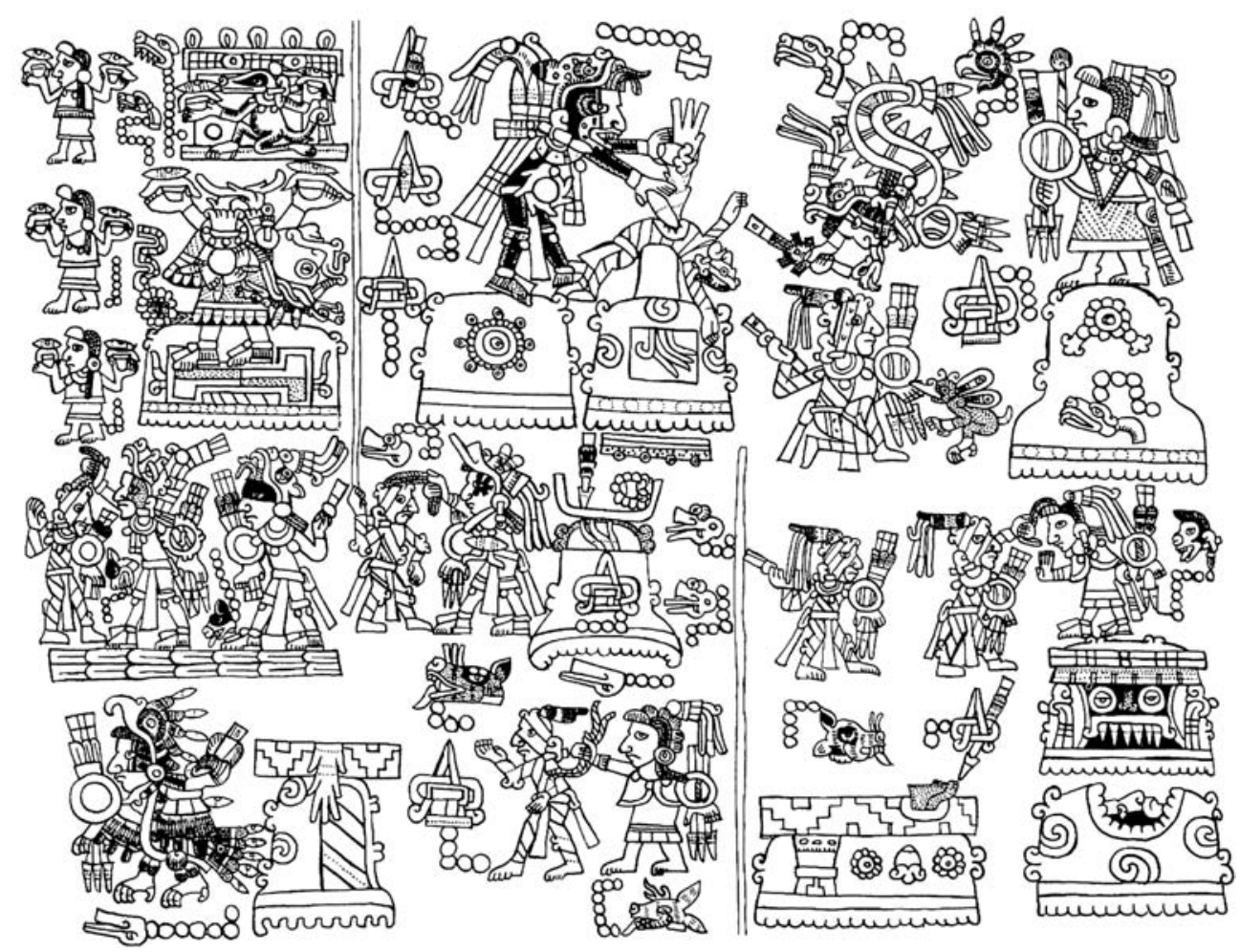

7.42. Codex Tonindeye, p. 3 (Lower Right to Upper Left, boustrophedon): war against the Stone Men.

gests that this Ravine of the Conch is "a major archaeological zone extending between Yanhuitlan and Yucuñudahui called La Concha (the Conch Shell)", but overlooks that the very similar Mountain of the Standing Conch Shell is securely identified as Yucu Ndaa Yee (San Pedro y San Pablo Tequixtepec) by glosses in Codex Ñuu Naña (see Smith 1973a: 76; cf. Jansen 1982b: 270-271). The Town of Feet next to Yucu Ndaa Yee (San Pedro y San Pablo Tequixtepec), we therefore conclude, is Nuu Saha (Icxitlan), which means precisely 'Town of Feet': both are neighboring towns in the Mixteca Baja. The latter toponym itself refers back to the time of origin: according to the Relación Geográfica of this town the feet belong to the discoverer or founder of the place, Lord Grass, who disappeared into the mountain when he died (Acuña 1984-1985, II: 53). Integrated in the sign is a standing drum, which might represent the neighboring town of Ahuehuetlan. 


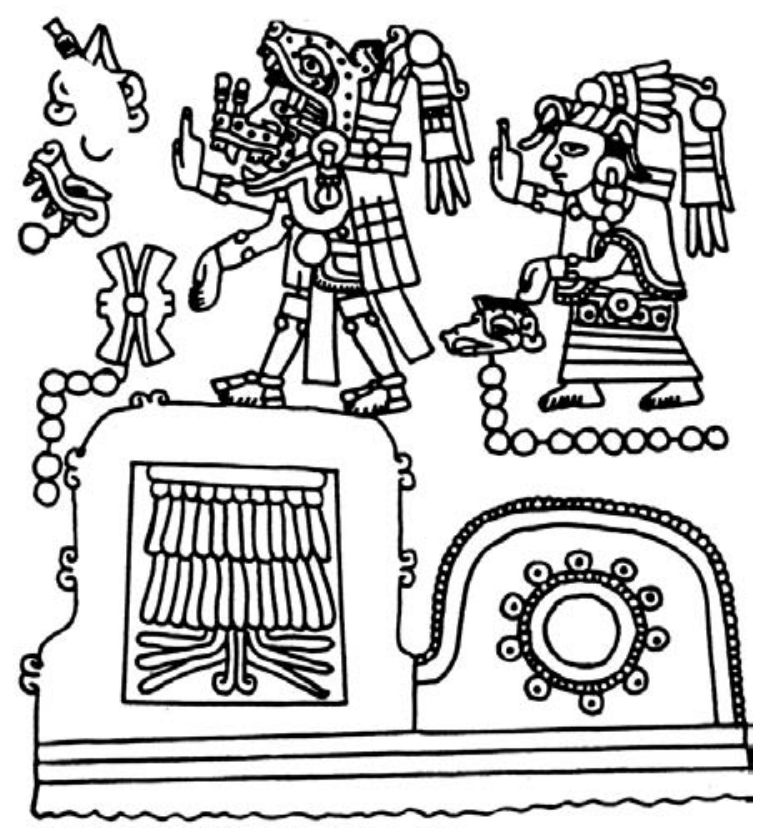

7.43. Codex Yuta Tnoho, p. 4-II: Yucu Yusi (Acatlan).

The other place, mentioned before Nuu Saha (Icxitlan), is the Mountain of an Emerging Human Face, which, we suspect, represents Anuhu, the Center of the Earth, where the Stone Men originated from. ${ }^{32}$ An alternative interpretation would be that this sign corresponds to Split Mountain, which appears in combination with Nuu Saha in Codex Yuta Tnoho (p. 44-III), and may represent neighboring Tepejillo.

The most important town in the conflict is Mountain of the Jewel and of the Quetzal Feather Tail. Its first element appears as the sign of Yucu Yusi (Acatlan) in the Mixteca Baja. The sign was deciphered by Smith (1973a: 60-62) on the basis of glosses in Codex Ñuu Ñaña.

Later (in Smith \& Parmenter 1991) she showed that the dynasty of this place is prominently represented in the Roll found in Yucu Nindavua (Huamelulpan). Both in that document and in Codex Yuta

${ }^{32}$ A similar place sign is mentioned in Codex Añute, p.1-I, where it might refer to the Valley of Puebla (Jansen \& Pérez Jiménez 2000, 2007b). 
Tnoho it is associated with Rock of the Eagle and River of the Ruler, i.e. Toavui (Chila).

Pohl (in Hendon \& Joyce 2004: 230-231) feels that Acatlan is too far from the Valley of Nochixtlan, where he prefers to locate the associated events, and points out a number of alternative possibilities: Ayuxi (close to Yanhuitlan), Cerro de la Joya (close to Nochixtlan), Sayucunda (close to Yucu Ita), Texupan or Tepozcolula. Hermann Lejarazu (2008c: 18) also feels that Nuu Ndaa, 'Blue Town', i.e. Texupan, would be an interesting alternative, without explaining, however, the absence of the nuu frieze in the place sign. A detailed examination of the evidence and the context makes us conclude that the identification proposed by Smith is well fundamented and reinforced by the other identifications we discuss in this section.

Next to this the codices mention the site of Mountain of the Standing Arrows. Pohl suggests that this may be Andua, 'Place ( $a-)$ of the Arrow (nduvua)' in the vicinity of Yanhuitlan (Hendon \& Joyce 2004: 232). We concur that Andua may indeed be represented as a Hill of Arrows, but, given the context, prefer the obvious alternative in the Mixteca Baja: Ndaa Nduvua, 'Standing Arrows', known with its cognate Nahuatl name Miltepec. It appears in combination with Mountain of Fire: probably Yucu Ihni (Tetaltepec). ${ }^{33}$

Closely associated with this cluster of towns in the Mixteca Baja is Mountain with Town of Blood, often combined with (Place of) a Wooden Fence (Codex Yuta Tnoho, p. 43-II, 3-II; Codex Tonindeye, p. 3-III and p. 51-I). Pohl recognizes: "No known toponym for Place of Blood has ever been identified in the northern Nochixtlan Valley" (in Hendon \& Joyce 2004: 231). Without considering the matter in depth and without examining the associations and substitution pattern, Hermann Lejarazu (2008c: 18) suggests that the sign might refer to a 'Red Town' and proposes San Esteban Atatlauhca in the southern Mixteca Alta, which does not explain the blood element, nor the fence, and does not make much sense in this context.

\footnotetext{
${ }^{33}$ See Jansen 1982b: 270-272. Codex Yuta Tnoho shows Mountain of Arrows in combination with Mountain of Flames (p. 44-IV) and mentions Burning Mountain separately (p. 43-II) - this last place seems to be identical to the Burning Mountain of Tonindeye, p. 3, where it is combined, however, with the Place of the Standing Arrow (Ndaa Nduvua, Miltepec).
} 


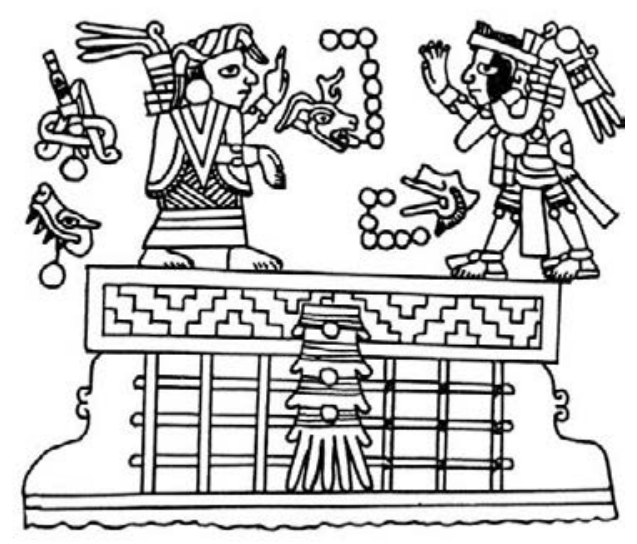

7.44. Codex Yuta Tnoho, p. 3-II: Ñuu Niñe (Tonala) and Ñuu Nduyu (Silacayoapan).

In our opinion a very good candidate is to be found in the Mixteca Baja. 'Blood' is neñe or niñe in Dzaha Dzaui, while 'fence' is to be read as $n d u y u$. The combination, therefore, is diagnostic of Nuu Niñe, (Tonalá), a town of major importance in the Mixteca Baja, and its main subject town Ñuu Nduyu (Silacayoapan). Apparently the Nahuatl translations Tonallan and Silacayoapan were based on an analysis of these toponyms as 'Town of Heat' (Ñu Niñe) and 'Place of Chilacayotes' (Nuu Tinduyu) respectively. Indeed the closeness in pronunciation of the words for 'heat' and 'blood' in Dzaha Dzaui made Martínez Gracida (1883) translate Nuu Niñe into Spanish as Tierra de Sangre ('Land of Blood').

Another argument is the substitution of the Mountain of Blood by Place of the Sweatbath. In Codex Yuta Tnoho (p. 3) the founders of Mountain with the Town of Blood and Wooden Fence are Lord 7 Wind and Lady 8 Deer. The same Lady 8 Deer goes to Place of the Sweatbath and Carrying Frame, in Codex Nuu Tnoo-Ndisi Nuu, p. $40-\mathrm{II})$. Temazcal was the place of origin of Lord 5 Wind, the important founding figure of Yuta Tnoho, and therefore should be located within the Nuu Dzaui region (Codex Ñuu Tnoo-Ndisi Nuu, p. 40-I). In a later occurrence (Codex Nuu Tnoo-Ndisi Nuu, p.11-V and p. 13-V) Temazcal appears dynastically related to Tollan-Cholollan, which suggests that is located near the Toltec influence sphere. This again points toward the Mixteca Baja. 


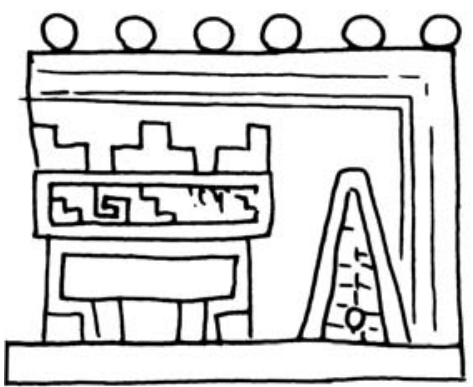

7.45. Codex Nuu Tnoo-Ndisi Nuu, p.11: Red Sweatbath, likely Ñuu Niñe (Tonalá)

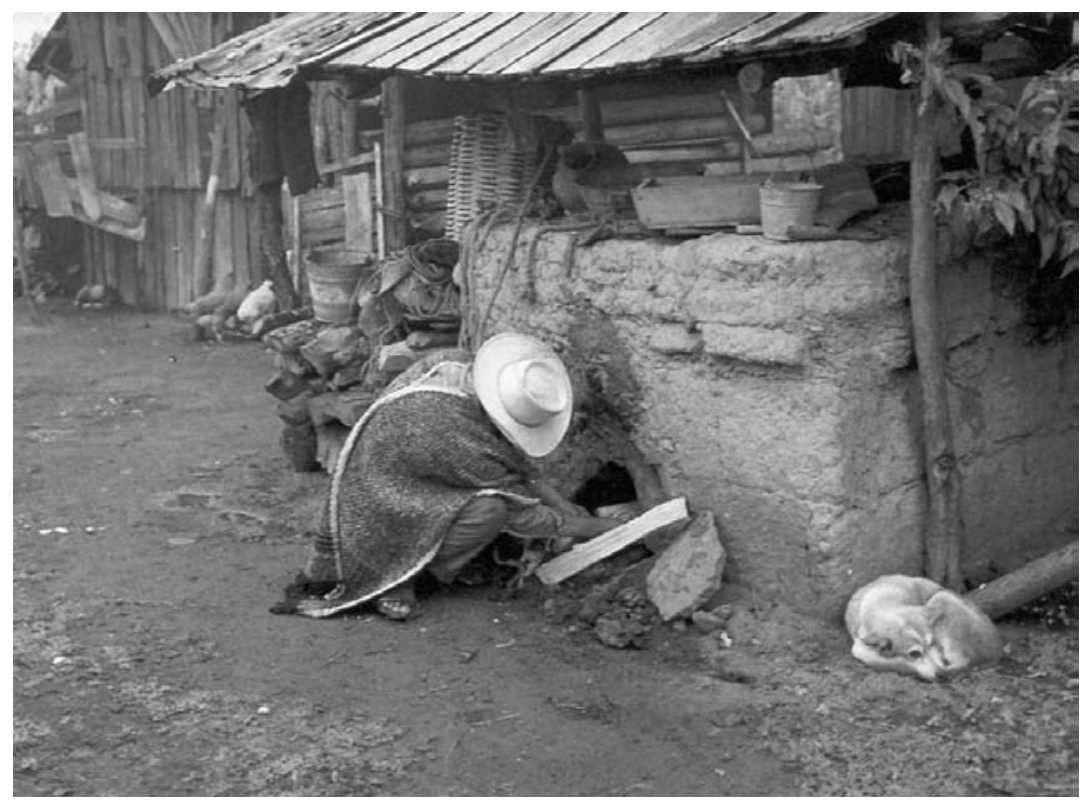

7.46. Temazcal (sweatbath) in the Mixteca Alta.

Temazcal or Place of the Sweatbath appears in Codex Nuu Ñaña, p. 15, where a gloss identifies it as Nuu Niñe, i.e. Tonalá in the Mixteca Baja (König 1979). Actually a steambath or temazcal is ñehe in Dzaha Dzaui, which is both phonetically and semantically close to niñe, 'heat'.

Another reference to Nuu Niñe may be the Sweatbath place that is mentioned in Codex Añute (p. 9-III). There it is located on top of a Cave of Water and Blood: a configuration highly suggestive of the 
Boquerón gorge, close to the town of Tonalá and still considered an enchanted area. ${ }^{34}$

The next toponym consists of a feather mat in the colors green and white. Such a mat usually represents a valley or plain (yodzo). No qualifying element seems to have been added, which leads us to believe that in this case the colors of the mat may be significant. We propose to read it as Green and White Plain, Yodzo Cuii Yaa, which would represent Yodzo Cuiya, the important town of Juxtlahuaca in the Mixteca Baja. In Codex Iya Cochi (Becker II) however, Yodzo Cuiya is painted as 'Plain of the Year Sign' (cuiya: 'year') .

The list in Codex Tonindeye, p. 3, ends with Mountain of the Ballcourt in Flames. This same place appears in Codex Yuta Tnoho (p. 3) with the addition that the walls of the ballcourt are made of stone and that the sign is integrated in Mountain of the Ballcourt of Gravel. Pohl suggests this may be Tlachitongo, Yucu Yuhua in Dzaha Dzaui, which indeed means 'Hill of the Ballcourt' and which is situated 10 kilometers South of Yanhuitlan (Hendon \& Joyce 2004: 230).

Taking into account the qualifying elements of the ballcourts, we think that the identification we proposed earlier in our commentary on Codex Añute (Jansen \& Pérez Jiménez 2000, 2007b) is more plausible. Ballcourt of Gravel is not a common toponym and therefore it is easy to identify this place in the Mixteca Baja region as Yuhua Cuchi (Guaxolotitlan), which means precisely 'Ballcourt of Gravel'. The Ballcourt of Stone in Flames may be a reference to a nearby important landmark and archeological site known as 'Peak of Fire' (Piedra de Lumbre). The Ballcourt of Gravel and Flames appears as one of the important regions of foundation, mentioned after the directional landscape of the North in Codex Yuta Tnoho (pp. 20-19). The associated Lord 4 Movement, coming from the Sacred Valley where the Mother Tree stood, is one of the central figures in the primordial times.

${ }^{34}$ For a political map see Gerhard 1972: 128-132. Note that in Codex Tonindeye p. 3 the town glyph is red, and that in Codex Nuu Tnoo-Ndisi Nuu the temazcal has the same colour, probably referring to the quality 'hot'. Hermann Lejarazu (2006: 34) identifies Mountain of Blood as Tiñeñe, a settlement pertaining to Coixtlahuaca, but the latter is represented in a slightly different manner and the context suggests that this is a different place. See our earlier discussion of this sign, in which we proposed that Town of Blood is Tonalá and that the sanctuary of Lady 9 Reed, the divine Patron of this place, was located near the Boquerón (Jansen \& Pérez Jiménez 2000: 139-140 / 2007b: 213; cf. Jansen \& Pérez Jiménez 2007a: 218). 


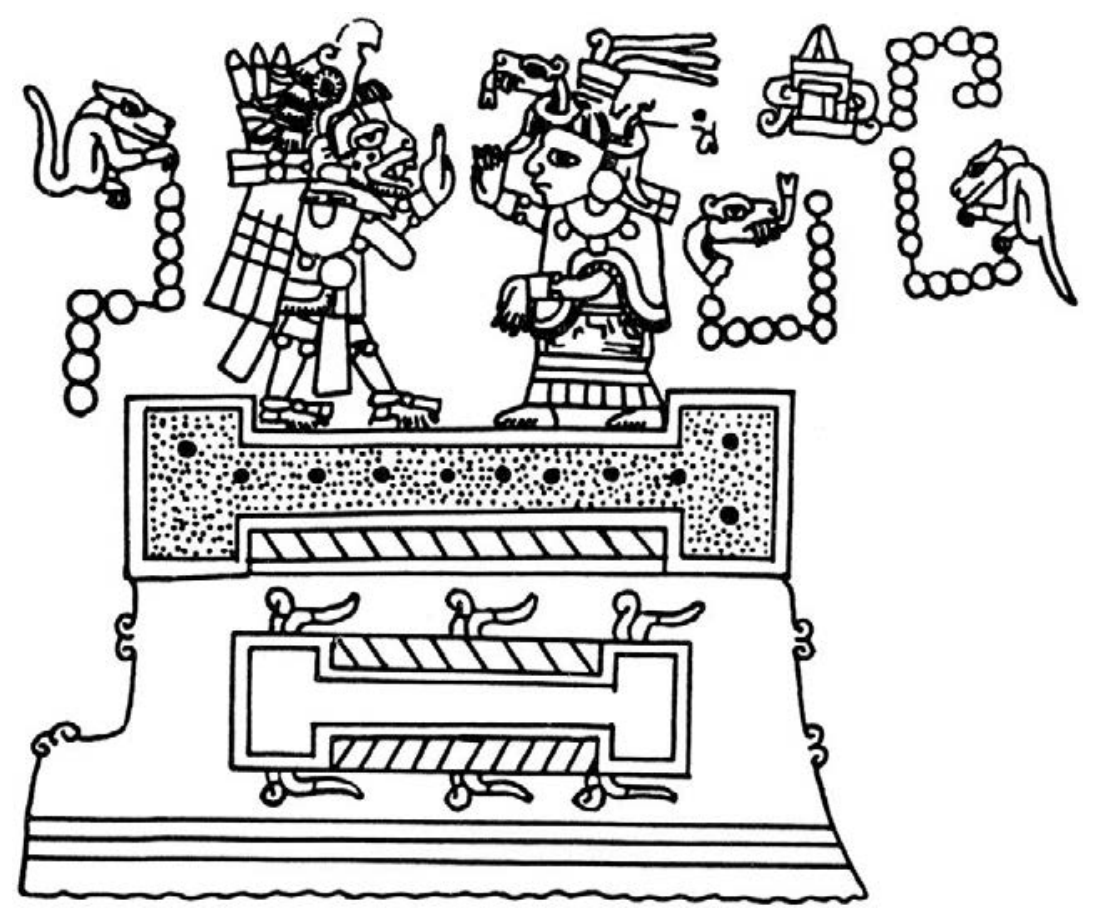

7.47. Codex Yuta Tnoho, p. 3-II: Ballcourt of Gravel, Yuhua Cuchi (Guaxolotitlan).

Codex Yuta Tnoho (p. 44-II) provides additional information about the region where the war with the Stone Men took place. One of the first places here is again Ballcourt of Gravel. This is followed by a mountain with five toponymic elements: Flowering Bush, Burning Face, Nuhu Serpent, Flame Serpent, and Teeth Serpent. Later in the same manuscript (p. 5) these toponyms integrate a range of separate mountain tops. The burning face may be read as sahmi nuu, the term for 'Mexican', i.e. speaker of Nahuatl. This suggests a reference to Toltec presence in the area. The Flame Snake may be synonymous with the Nuhu Snake, as both are to be read as Coo Nuhu. The Teeth Serpent has to represent a similar sounding name: Coo Noho. It might well be that the serpents represent ceremonially important caves. No reference is made to a Valley of Serpents or River of Serpents, which would make this a representation of Coixtlahuaca. Instead, the Flowering Bush seems to be the principal toponymic identifier. Looking for such a place in the Mixteca Baja, we find Yucu Ita Ino, 'Mountain of the 
Tobacco Flower', translated as Xochitepec in Nahuatl, as a plausible candidate. The ruling lineage of this town was of Toltec descent and is depicted in the Map of Xochitepec, now in Copenhagen (Caso 1958). Related to this cluster is Corner of the Cactus and Cradle of the Red and White Bundle of Sticks. The 'corner' probably represents the word siqui, which also means 'ward'. The cradle (dzoco) is often used to represent a sanctuary (dzoco). These signs probably represent subject settlements and ceremonial sites in the landscape.

The next town on p. 44 of Codex Yuta Tnoho is Temple of Venus, which may be Yucu Quimi, 'Mountain of Venus' or 'Temple of Venus', also in the Mixteca Baja. It appears paired with a Mountain that Carries the Heaven, a clear statement of its cosmological importance, similar to the Kaua Kandiui (Cavua Caa Andevui) near Yuta Tnoho. In another depiction (p. 4 of the same codex) the Temple of Venus is combined with Mountain of the Palm Tree. There are many toponyms with references to palms in the region (such as San Vincente del Palmar). Both toponymic signs also appear in association with the same primordial founders in the opening scene of the roll found in Yucu Nindavua (Huamelulpan), Lord 9 Movement 'Eagle' and Lord 7 Deer 'Deer'. That manuscript portrays the dynasties of Toavui (Chila) and Yucu Yusi (Acatlan), as demonstrated by Mary Elizabeth Smith (Smith \& Parmenter 1991). The divine founders are indeed mentioned in the corresponding Relación Geográfica as having been been treated with religious respect in that kingdom (Acuña 1984-1985, II: 36-37).

The next place sign (Codex Yuta Tnoho, p. 44-III) is a wall, patio or courtyard with an acrobat, standing on his head and shoulders, sustaining with his feet the head of a woman and a stone. The latter two elements recall the Nahuatl place name Tezoatlan, which could be understood as 'Place of the Stone Woman'. Indeed that is the meaning of the Dzaha Dzaui equivalent Nadii Toto (Nadzehe Toto in Alvarado's orthography), 'Woman of the Rock', registered by Mariano López Ruiz (in: Martínez Gracida, Obra Inédita, vol. 45).

Apparently the town was known under several Mixtec names. At present the toponym is Nuu Shaha, translated locally as 'Town of the Foot or Fundament'. The name registered in the 16th century by Antonio de los Reyes is Nuu Siya, which may be understood as 'Face (nuu) of $(s i)$ the Lord $(-y a)$ '. The morpheme si in siya may have been 
represented by pearls (sii), associated with the face (nuu) of a lord $(-y a)$. Indeed the acrobat-with-stone-and-woman's-head is surrounded by blue beads that may represent pearls. This leads us to suppose that Mountain of Pearls with (Lordly) Face in Codex Nuu Tnoo-Ndisi Nuu is an alternative writing of this same toponym. ${ }^{35}$

Although not all elements in this sign have been clarified, its context in Codex Yuta Tnoho makes it quite likely that Tezoatlan is meant.

Between the signs here identified as Nuu Siya (Tezoatlan) and Nuu Saha (Icxitlan) the sign Long Stone or Large Lying Stone is mentioned. The same place sign appears in Codex Yuta Tnoho, p. 4, combined with a Large Jeweled Standing Stone, which, we observe, is identical with the sign of Tiyusi, San Andrés Sabanillos in Codex Ñuu Naña, p. 31. About the identification of Long Stone or large Lying Stone itself, we can only speculate. A good candidate is Ayuu, 'Place of Stone' in the same area. The painter of Codex Yuta Tnoho did not use the convention of drawing an open mouth to represent the locative prefix $a$-; in this case he may have conceived the glyph thinking of the expression caa yuu, 'the stone lies down'.

Then, after the clearly identifiable places of Town of Feet or Nuu Saha (Icxitlan), Mountain of the Standing Conch Shell or Yucu Ndaa Yee (Tequixtepec), Mountain of the Standing Arrows or Ndaa Nduvua (Miltepec) and Mountain of the Jewel or Yucu Yusi (Acatlan), the Codex Yuta Tnoho (p. 44-IV) mentions Stone Circle, an important place under the patronage of Lady 9 Reed and associated with the First Sunrise (p. 23 of the same codex).

Reading the glyph as yuu dzahi, 'Stone - Ring', we identify it as a phonetic writing of Nuu Dzai (Huajuapan). Present-day knowledge does not identify the original meaning of Nuu Dzai, locally pronounced as Nuu Dee. The local translation 'Land of the Brave' (tierra de valientes) is not correct, as it confuses dee (Alvarado: $d z a i$ ) with ndee (Alvarado: ndai), 'strong, vigorous'. Colonial texts, such as the translation of Taix's treatise on the rosary, demonstrate that $d z a i$ is a contraction of a word written by Alvarado as $d z a h i$, which means

35 See our commentary on Codex Nuu Tnoo-Ndisi Nuu (Jansen \& Pérez 2005: 47). The sign appears prominently in the early history on the Reverse (p. 37-III). 


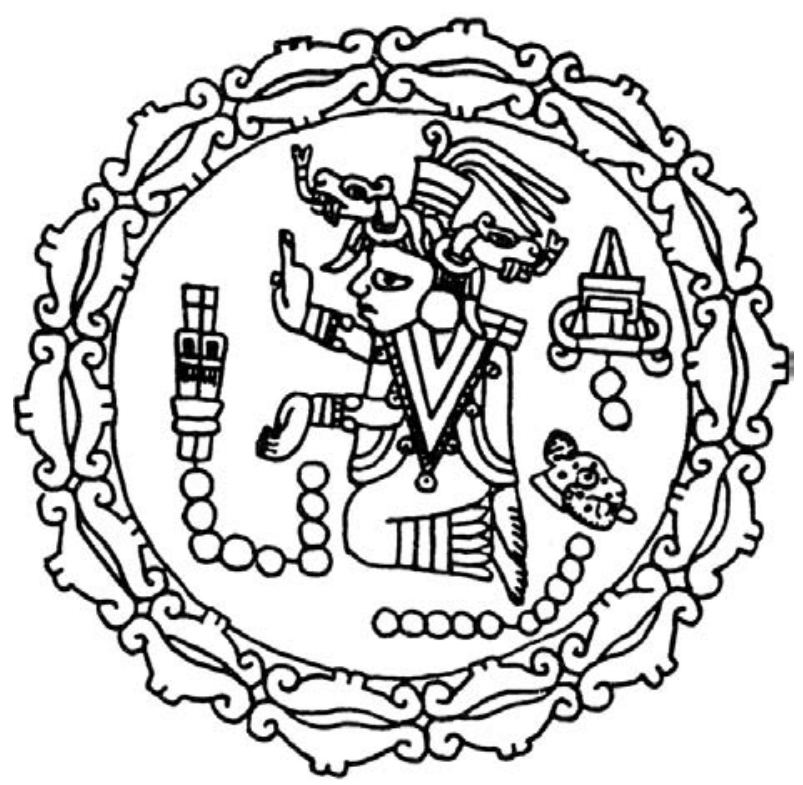

7.48. Codex Yuta Tnoho, p. 3-I: Stone Circle, Nuu Dzai (Huajuapan).

'ring' or 'hidden'. In the area of San Juan Diquiyú, the town of Huajuapan is still called $\tilde{N} u u$ Sehe, which is translated as 'Hidden Town' (pueblo escondido). Here the word sehe indeed has the alternative meaning of 'ring. ${ }^{36}$

One of the arguments for identifying Stone Circle as Nuu Dzai (Huajuapan) is precisely the fact that it appears next to the Rock Shelter of the Eagle, which is connected on the next page of Codex Yuta Tnoho (p.43-I) with River of the Sanctuary (dzoco N $u h u)$ and River of the Seated Lord.

This combination has been identified by Mary Elizabeth Smith (in Smith \& Parmenter 1991) as the sign of Toavui (Chila). Today this Dzaha Dzaui toponym appears in the name of one of the main mountains at Chila: the Yucu Ave. An important Mountain of the Eagle is

${ }^{36}$ We thank Maestro Máximo Sánchez Ventura for his help with this analysis. The substitution of the normal sign for 'town' ( $\tilde{n} u u)$, the rectangular frieze with stepped fret motif, by that of the somewhat similar sounding 'stone' (yuu) is unusual, but not impossible: Nuu Tiyaha, Town of Tecomates (Tecomatlan), is painted as Stone of the Eagle, Yuu Tiyaha, in Codex Añute, p. 13-IV. 


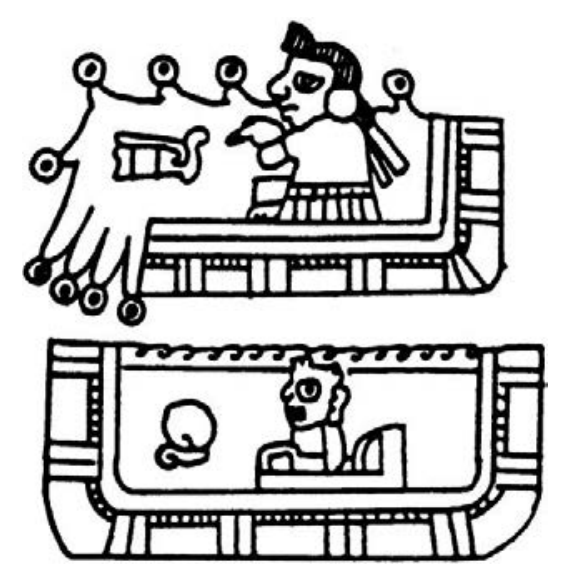

7.49. Codex Yuta Tnoho, p. 43-I: River of the Cradle (dzoco) of the Nuhu, i.e. a Sanctuary, and River of the Seated Lord.

located in nearby Ayuquila. In order to produce the Nahuatl translation Chilac, 'River of Chile Peppers', the Dzaha Dzaui toponym must have been understood as containing the words yuta, 'river' and yaha, which can mean 'chile pepper' but also 'eagle'.

The Seated Lord, dressed in a xicolli (tunic), probably represents the first syllable of Toavui: toho is 'lord, important person' and appears as to- in several toponyms (Tocuisi, Tocuii) - it may have created a preference for drawing a rock (toto) in the glyphic complex. The second part of the toponym seems to have been interpreted as coming from yahui, 'fire serpent', a term that, combined with eagle (yaha), stands for 'shaman priest' (Spanish: nigromántico señor). Thus the whole place name is painted as a River (yuta) of the Lord (toho), combined with a Rock (toto) or Cave (yavui) of the Eagle (yaha). Together these different elements, then, suggest that Toavui was conceived as a contraction of Yuta To-yaha-yahui, literally 'River of Lord Eagle - Fire Serpent'”, i.e. 'River of the Shamans'. ${ }^{37}$

${ }^{37}$ This toponymical sign is probably identical to the 'River of the Seated Man with Closed Eyes', a place painted in the cartographic part of the Lienzo of Tlapiltepec, more or less in the area of Toavui/Chila (Caso 1961: D8, cf. Smith \& Parmenter 1991: 30-33). The seated man with closed eyes clearly represents a lord in shamanic trance. The Relación Geográfica tells us that Chila was named after the place where its founders, lords from Yuta Tnoho (Apoala), came from (Acuña 1984-85, II: 43). Our interpretation of the toponym would suggest that it was considered to reproduce the shamanic title of those founders. 


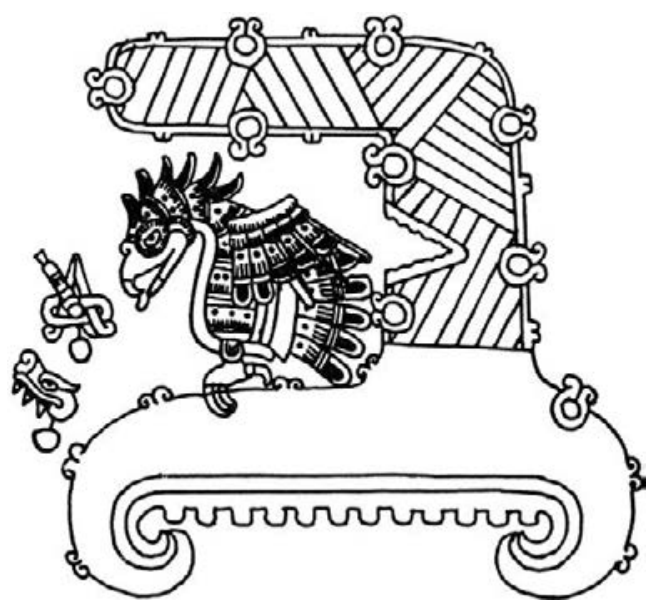

7.50. Codex Yuta Tnoho, p. 3-I: Rock of the Eagle, identified as Toavui (Chilac).

Continuing in the same direction, Codex Yuta Tnoho (p. 43-I) then lists the sign 'At the Foot of the Place of the Incense Burner', in combination with House of the Animal. We suggest these places are Saha Ñuu Quu (Piaztla) and Tuzantla. From here, the list continues to Town of Blood, i.e. Ñuu Niñe (Tonalá).

Noticeably, the Valley of Yodzo Coo (Coixtlahuaca), the region of the Ngigua (Chocho-Popoloca) people, is mostly absent from the Nuu Dzaui manuscripts, although this area itself has produced a rich and fascinating corpus of early colonial lienzos containing detailed geographical and historical information. In parts of this area Dzaha Dzaui was spoken too.

Given the presence of a Toltec dynasty, founded by Quetzalcoatl of Tollan-Cholollan, it is logical that the main capital of the region, Coixtlahuaca, or in Mixtec Yodzo Coo, 'Plain of the Serpents', was represented (e.g. on the Lienzo of Coixtlahuaca itself) as an impressive Plumed Serpent, which in turn contained a play on words: yodzo means both 'plain' and 'large feather' (such as those of the quetzal bird).

One of its wards, where Mixtec was spoken, had the Mixtec name Tineñe, 'Place of Blood'. The central place in the Lienzo of Coixtlahuaca II (Seler II), is, therefore, a large serpent which carries a Mountain of Blood. The glyphs of several other towns in the region are easy to 


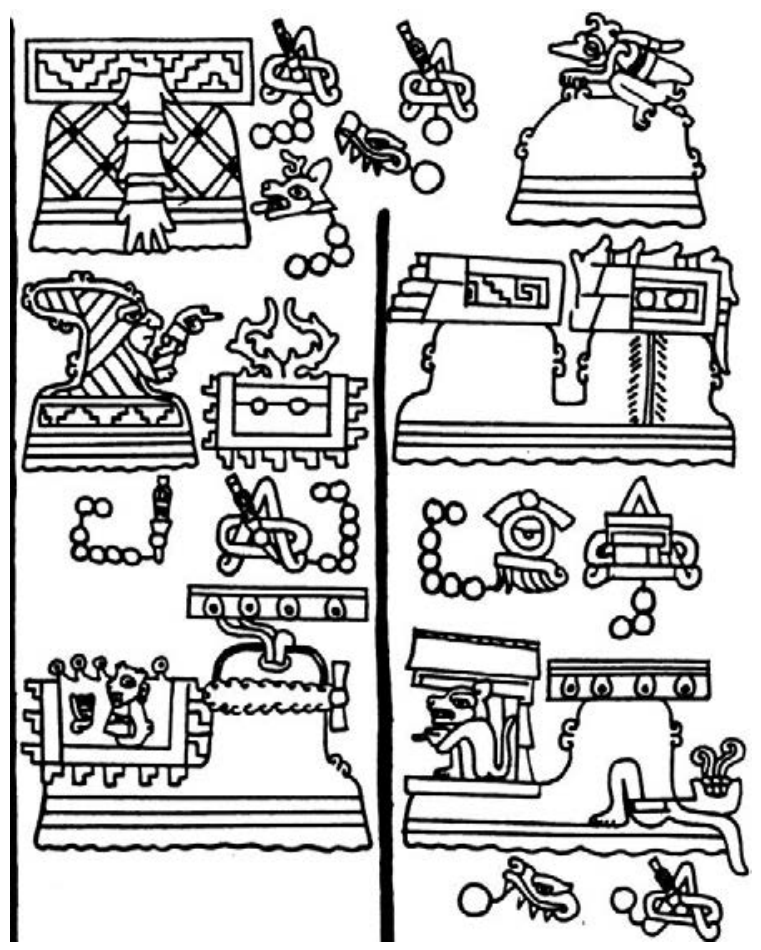

7.51. Codex Yuta Tnoho, p. 43-I/II (Lower Right to Lower Left, boustrophedon): the area of Piaztla, Tuzantla, and Tonalá.

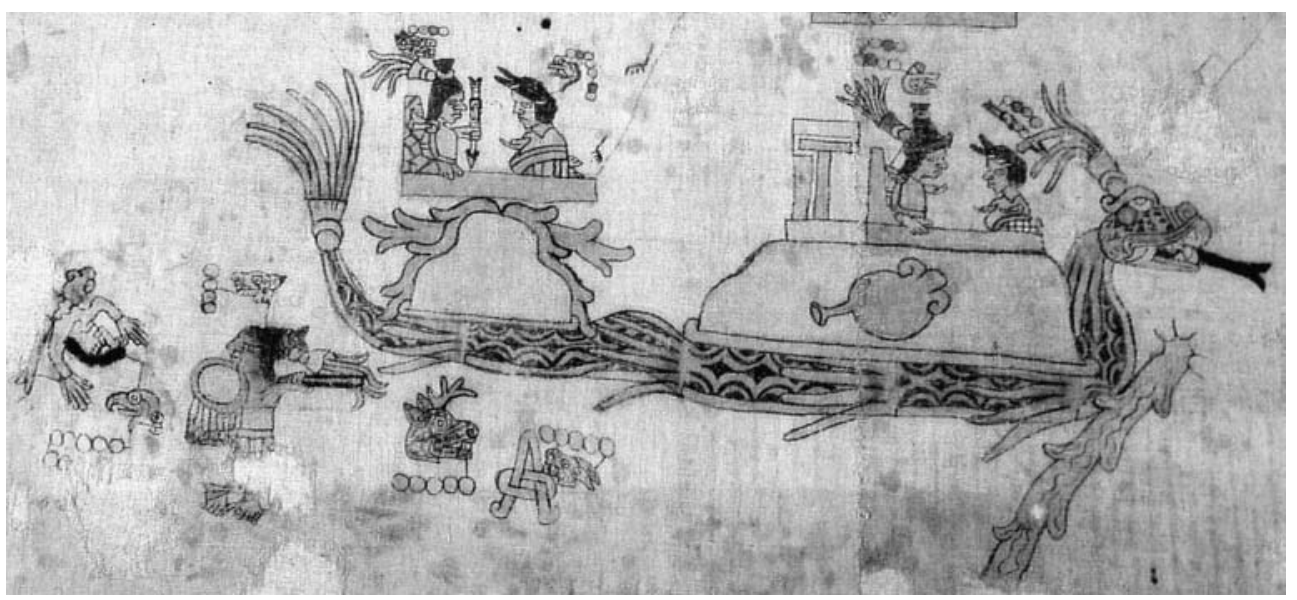

7.52. Lienzo Coixtlahuaca II (Seler II): the kingdom of Serpent Valley, i. e. Coixtlahuaca, including Mountain of Blood. 
identify because they appear situated in the scenes of the key lienzos according to their location in geographical reality: Hill of the Knot is Tlapiltepec, Valley of the Down Feathers is Ihuitlan, Altar of the Tule Reeds is Tulancingo, Mountain of the Conch Shell is Tequixtepec, and so on.

An example of its rich pictorial literature is the Lienzo of Otla, which we were able to study thanks to and in cooperation with architect Victor Hugo Ruiz Ortiz. ${ }^{38}$ This beautiful document is preserved in San Jerónimo Otla, located at the foot of the dominating Cerro Verde (Yucu Cuii), also known as the Nudo Mixteco, which is the watershed of springs and rivers flowing to either the Atlantic or the Pacific. At the same time it is the natural boundary marker between the Ngigua and Nuu Dzaui peoples. The place sign of Otla is painted on this document as a heart surrounded by four maize cobs. Trying to explain this sign in relation to the toponym Otla, we propose the following reconstruction. If Heart with Maize Cobs represents a Mixtec toponym it may be read in Dzaha Dzaui as Ini Ndedzi, 'In the Center (ini) of the Maize Cobs (ndedzi)'. As ndedzi is also the Dzaha Dzaui word for the alcoholic beverage pulque (octli in Nahuatl) this Mixtec toponym may have been translated into Nahuatl as 'Place of Pulque': Oc-tlan.

The same ambivalence of the name may have caused the representation of the town as a Place of Pulque in precolonial Mixtec pictography. We might speculate, therefore, that the Mountain of Pulque, which is mentioned prominently in Codex Yuta Tnoho (p. 47, p. 25 and p. 1), could be this same Otla, or rather a reference to the area around the important Cerro Verde immediately next to that village. The Mountain of Pulque is located at the very beginning of the long list of places in Codex Yuta Tnoho, p. 47, next to the two oceans. This would fit the Nudo Mixteco, which is a central watershed point from where the rivers flow to these different destinies.

${ }^{38}$ We were present when the authorities of San Jerónimo Otla showed architect Ruiz Ortiz their lienzo in January 2006. Since then Ruiz Ortiz has made a detailed documentation providing a good storage facility and a restoration of the document in situ. For a publication of the lienzo with a first analysis, see Ruiz Ortiz \& Jansen 2009, which includes the identification of place signs as toponyms in the area, as well as a preliminary analysis of the sacred landscape and its colonial transformation. While this investigation was already in progress, Rincón Mautner came across several photos of parts of the lienzo and published these with a brief article (2007). 


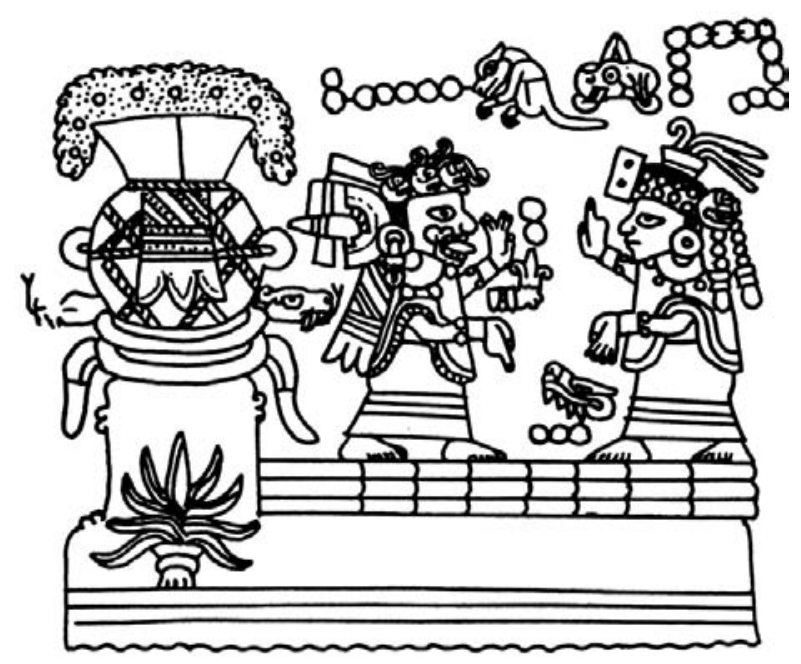

7.53. Codex Yuta Tnoho, p. 1-II: Mountain of Pulque.

A counter-argument, however, is that the Nudo Mixteco is represented in quite a different manner in the Lienzo of Otla and the Lienzo of Tlapiltepec: a set of three mountains, dominated by the Mountain of Leaves, representing its Mixtec name Yucu Cuii, the Green Mountain. ${ }^{39}$

The Mountain of Pulque appears later in the Codex Yuta Tnoho as the location of a pulque ceremony of important founding Lords and Ladies (p. 25) and at the very end (p. 1), where it follows the glyphs of Mountain that is Opened - Insect (Monte Albán) and Añute (Jaltepec), and precedes the final site mentioned in this document: Black Mountain. On the one hand this Mountain of Pulque seems to refer to a specific place, but the toponym does not occur as one of the polities that figure in the Nuu Dzaui dynastic history. On the other hand this sign evokes the narrative about the origin of pulque, i.e. it may well represent a sacred site similar to the mountain Chichinauhia-

${ }^{39}$ A similar mountain appears in Codex Yuta Tnoho, p. 38-I, immediately after a Valley of Stone with a Spring (p. 39-IV), which may represent the community in the direct vicinity of the Nudo Mixteco: Santa María Nativitas. The glyph for this town in the Lienzo of Nativitas itself is Stone in a River with Splashing Water (see the photographic reproduction in Van Doesburg 2001). In the complex of signs that follows in Codex Yuta Tnoho, p. 38-I/II we find a River of Ixtle and a Mountain of Ixtle, which may refer to Yucu Ndaa, Mountain of Ixtle (Teposcolula). 


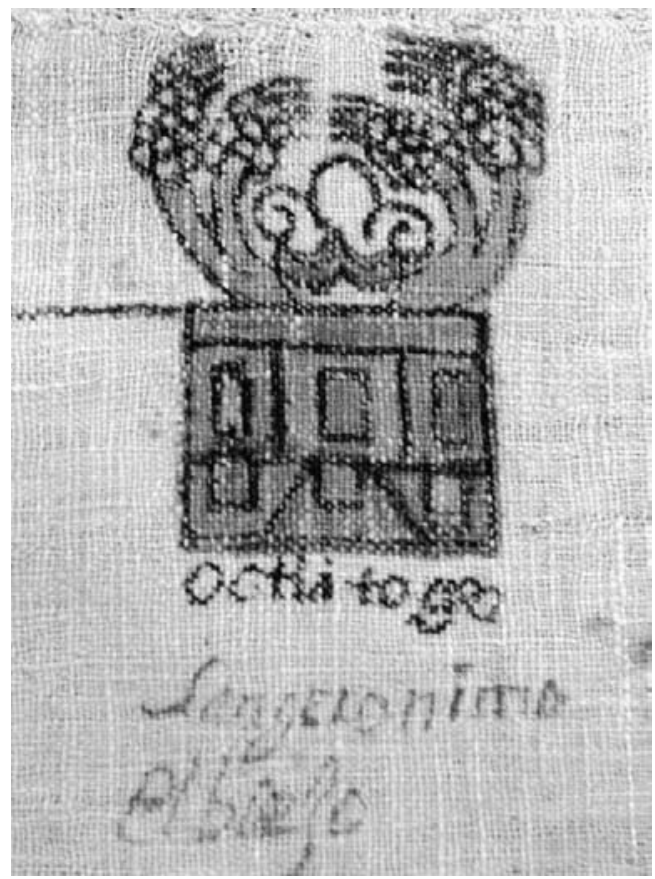

7.54. Lienzo of Otla: the place sign of otlato[n]go, i.e. San Jerónimo Otla.

Pozonaltepetl mentioned by Sahagún (Book X: chapter 29) as the place where 'wine' was prepared in primordial times and where the rulers went to drink it.

\section{Mixteca de la Costa}

In her classic monograph on Nuu Dzaui place signs (1973a: 67 ff.), Mary Elizabeth Smith presented a detailed analysis of the early colonial Lienzo of Yucu Satuta (Zacatepec) and the Lienzo of Nuu Sii Quaha (Jicayán), which have the well-known structure of a central place with a ruler, surrounded by a set of local toponyms that mark points of the frontier of the realm, and occasional signs for neighboring towns. Comparing these pictorial representations with geographical features and boundary names as registered in historical documents and still identifiable in the landscape, she provides us with a large set of signs for towns, mountains, valleys, caves, and rivers in this area close to the Pacific Coast. 


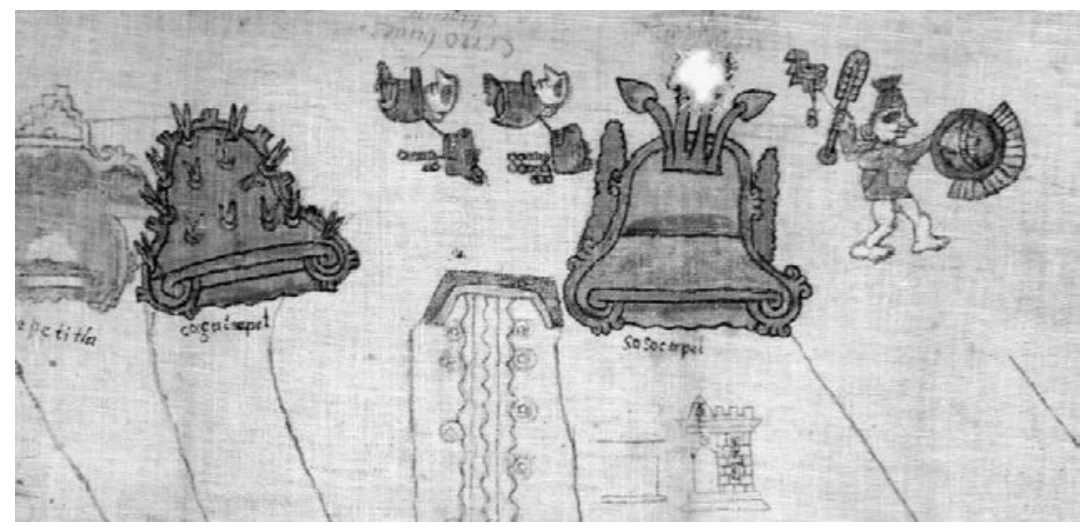

7.55. Lienzo of Otla: Cerro Verde.

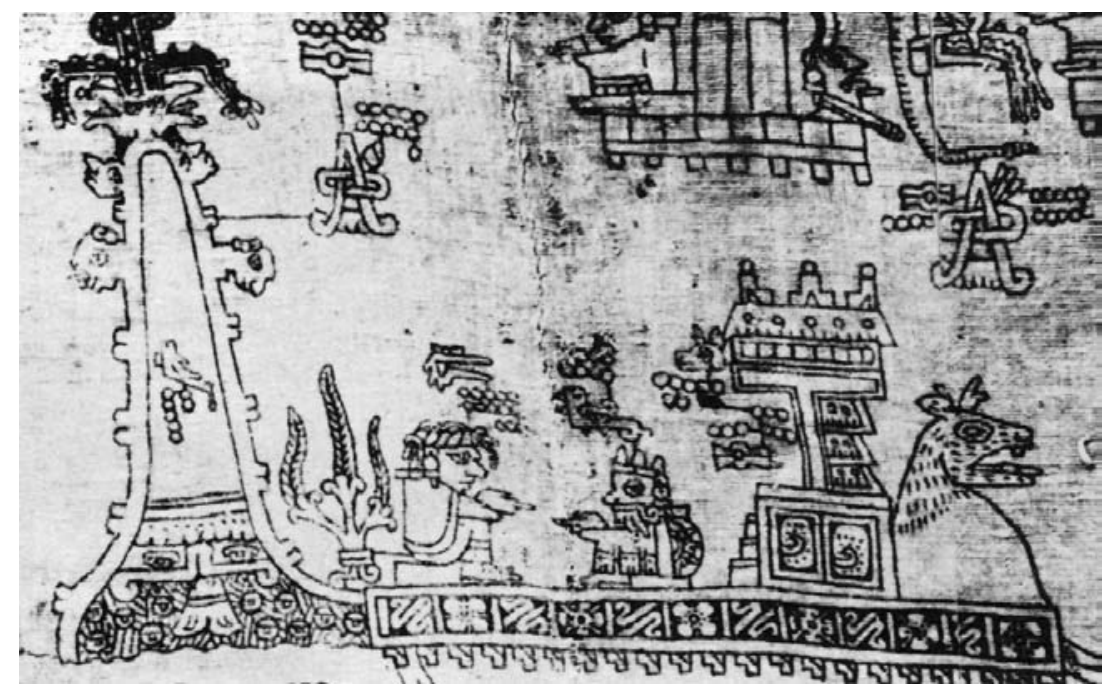

7.56. Lienzo of Yucu Satuta: the central Mountain of 7 Water (Yucu Satuta) guarded by a double-headed eagle.

Yucu Satuta (Zacatepec) itself is represented in a central position on the lienzo coming from this town as Mountain $(\mathrm{Yucu})$ of the calendrical sign 7 ( $\mathrm{Sa}$ ) Water (Tuta), which was convincingly identified by Smith (1973a: $96 \mathrm{ff}$.). This place is dominated by a Mountain of the Double-Headed Eagle, the present-day Cerro del Águila. In addition Smith identified several neighboring towns mentioned on the lienzo, such as Town of Axes, i.e. Nuu Caa (Putla), and River of the Hide, i.e. Yuta Nee (Ixtayutla). 


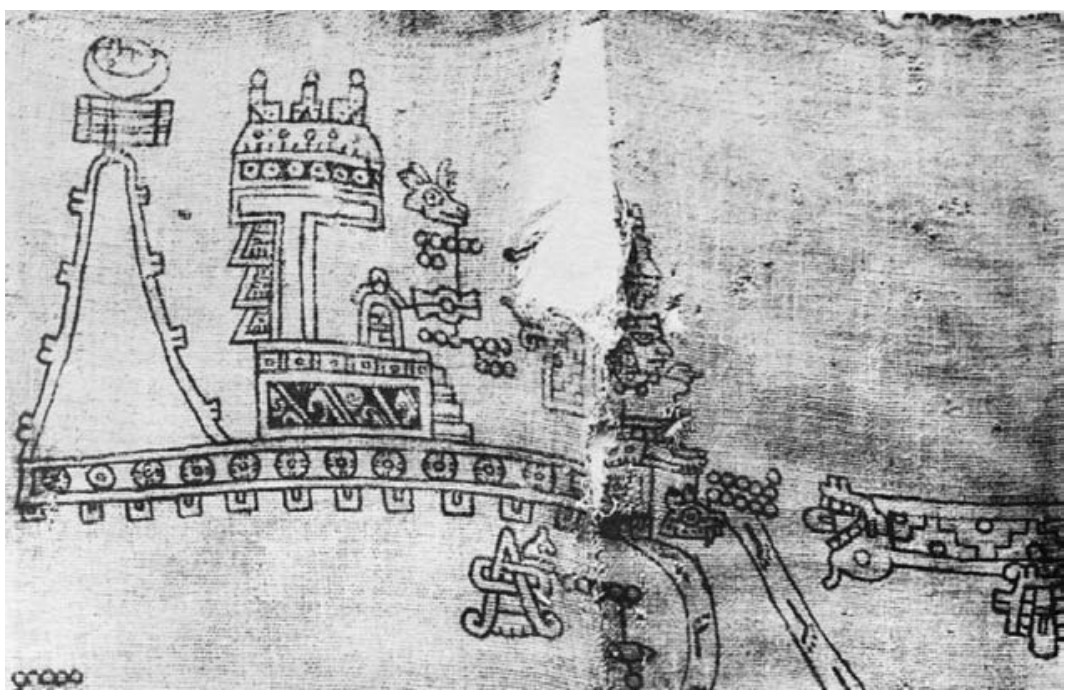

7.57. Lienzo of Yucu Satuta: Mountain of the Moon and the Fire-Wood (Nuu Yoo, Yucu Iti) and the Town of Death, i.e. Nuu Ndaya (Chalcatongo).

In the upper left-hand corner of the lienzo a historical link is made with Lord 4 Wind and Lady 10 Flower ruling at Ñuu Yuchi (Mogote del Cacique), while the neighboring town in that north-eastern area is the Place of Death, Nuu Ndaya (Chalcatongo). In the same upper band we find the combined sign of Mountain of the Moon and the FireWood, most probably the neighboring towns Nuu Yoo and Yucu Iti. Furthermore we recognize Temple of the Crossed Sicks and Face as Ndisi Nuu (Tlaxiaco) in the Mixteca Alta.

Mary Elizabeth Smith (1973a: 67-68) also discusses Yucu Dzaa (pronounced locally as Yuku Saa), 'Mountain of Birds', presently known as San Pedro Tututepec, which was the major village-state on the Pacific Coast. The archeological site has been investigated by Arthur Joyce et al. (2004). Its sign consists of a mountain (yucu), painted as a rock or stone $(y u u)$ with the head of a bird (dzaa), often combined with a human chin $(d z a a)$. This sign is, as we noted during a visit to the area, more than a general reference to Yucu Dzaa (Tututepec): it actually is the name of the central hill within the town: the Yuku Yuu Saa.

The original Nuu Dzaui land as defined by a canon of four directional sites did not include the coastal area. Apparently the strong Nuu 


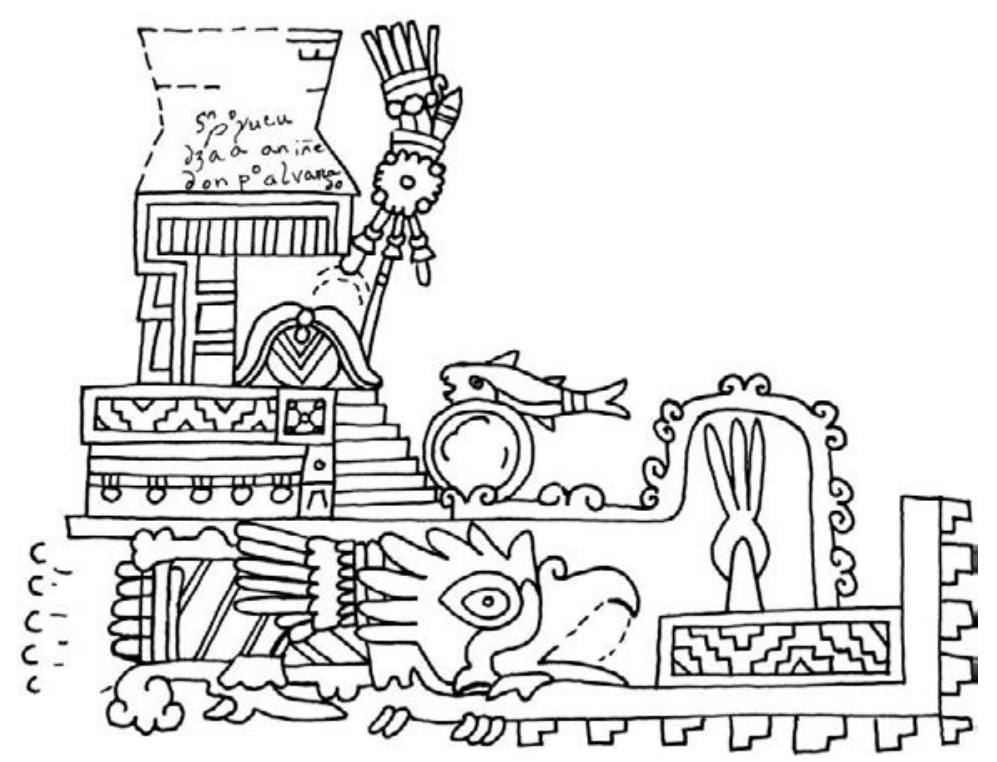

7.58. Codex Iya Nacuaa I, p. 5: Yucu Dzaa (Tututepec) and Ñuu Sitoho (Juquila).

Dzaui presence at the coast was considered a later development. Possibly the collective memory gave the credit of having taken possession of this region to Lord 8 Deer. After having visited the Huahi Cahi of Nuu Ndaya (Chalcatongo), he made his way to the coast, where he presented himself to the rulers of Town of the Hand Holding Feathers, a place convincingly identified by Smith (1973a: 75-76) as Nuu Sitoho, 'Town of the Lords', i.e. Juquila. This Chah Tnio (Chatino) capital, now a major pilgrimage center, probably dominated the coastal area at the time. From here Lord 8 Deer went on to found a Temple of Heaven on the Yucu Yuu Dzaa. Through a series of conquests he built a strong realm in this coastal area. Among the places identified by Smith are Dzini Titi ('Head of the Iguana', today San Andrés Huaxpaltepec) and Yucu Yoo ('Mountain of Reeds and of the Moonshaped Ornament', today Santa María Acatepec). ${ }^{40}$ The cohesion of these combined data means that the identification of Yucu Dzaa (Tututepec) is beyond doubt.

${ }^{40}$ See Smith 1973a, pp. 68-69. Codex Tonindeye, p.48-I and p. 48-III. 


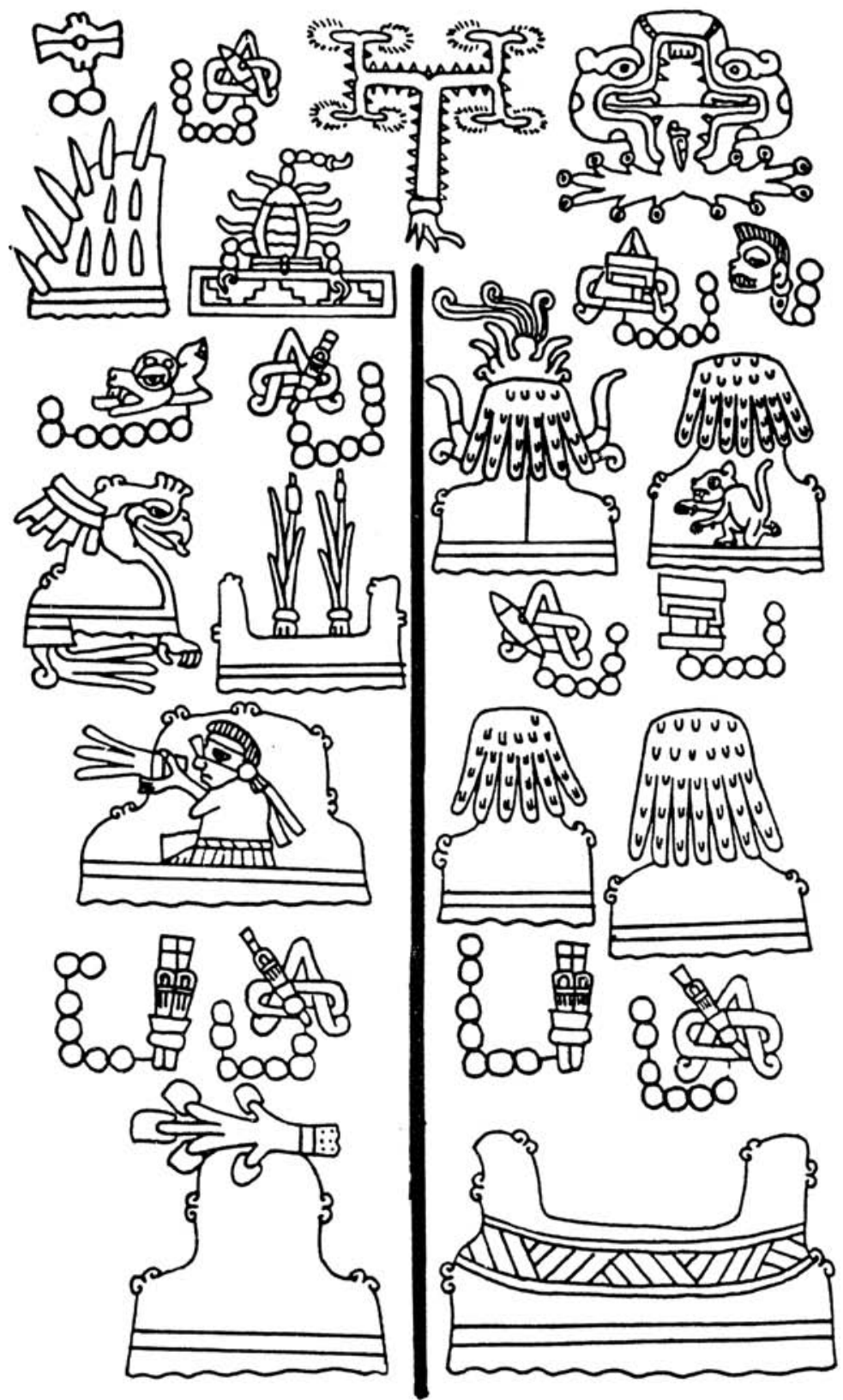

7.59. Codex Yuta Tnoho page 39 (I+II): the four volcanoes, the Cave of Origin and the Place of the Tule Reeds (Cholula). 


\section{The Valley of Puebla}

Near the end of the toponymic list in Codex Yuta Tnoho (p. 39-I) appear four mountains with distinguishing coverings of snow. In Mexican pictography this depiction characterizes the great volcanoes, yucu yuhua, 'mountains of ice' in Dzaha Dzaui. One of these volcanoes is colored white, another blue and a third one is represented as active, emitting flames and smoke. As Luis Reyes García has pointed out, this cluster corresponds to the unique configuration of Iztaccihuatl ('White Woman'), Matlalcueye ('She with the Blue Skirt') and Popocatepetl ('Smoking Mountain'). The fourth must refer to the Pico de Orizaba, the best visible of all from various sites in the Mixteca Alta. The distinguishing element is a rodent, which, according to Luis Reyes García may refer to the local kingdom Quimichtlan ('Place of Mice').

These volcanoes are followed in the codex by a reference to the Cave of Origin (Chicomoztoc) and a threefold place sign: Valley of the Cattail Reeds, Mountain of the Quetzal and Breast, and Mountain of the Toltec Ruler. The cattail reed is a diagnostic element in the toponym Nuu Cohyo, 'Place of Cattail Reeds', which nowadays refers to Mexico City, but in earlier times referred to the emblematic capital of the Toltecs: Tollan (Tula). In this geographical context we identify it as Tollan Cholollan, i.e. Cholula, situated in a large valley, surrounded by Iztaccihuatl, Matlalcueye and Popocatepetl (Jansen 1996, 2006).

As both 'quetzal' and 'breast' are ndodzo in Dzaha Dzaui, the second toponym has to be read as Yucu Ndodzo. We think that the translator was confused here and mistook the Nahuatl word tlachihual-, 'man-made' for chichihual-, 'breast'. The Tlachihualtepetl, 'Man-Made Mountain', is the great pyramid in Cholula.

The third sign is a mountain with a seated man, who wears a royal red xicolli and holds palm leaves, such as those normally used in rituals. The black marking around his eye qualifies him as a tay sami nuu, 'man with burned eye', i.e. a speaker of Nahuatl (Smith 1973a: 203). His turquoise nose-ornament indicates the Toltec nose-piercing ritual. From the Relación Geográfica of Cholula we know that this town was the place par excellence for such Toltec rulership ceremonies (Acuña 1984-1985, II: 130-131). 

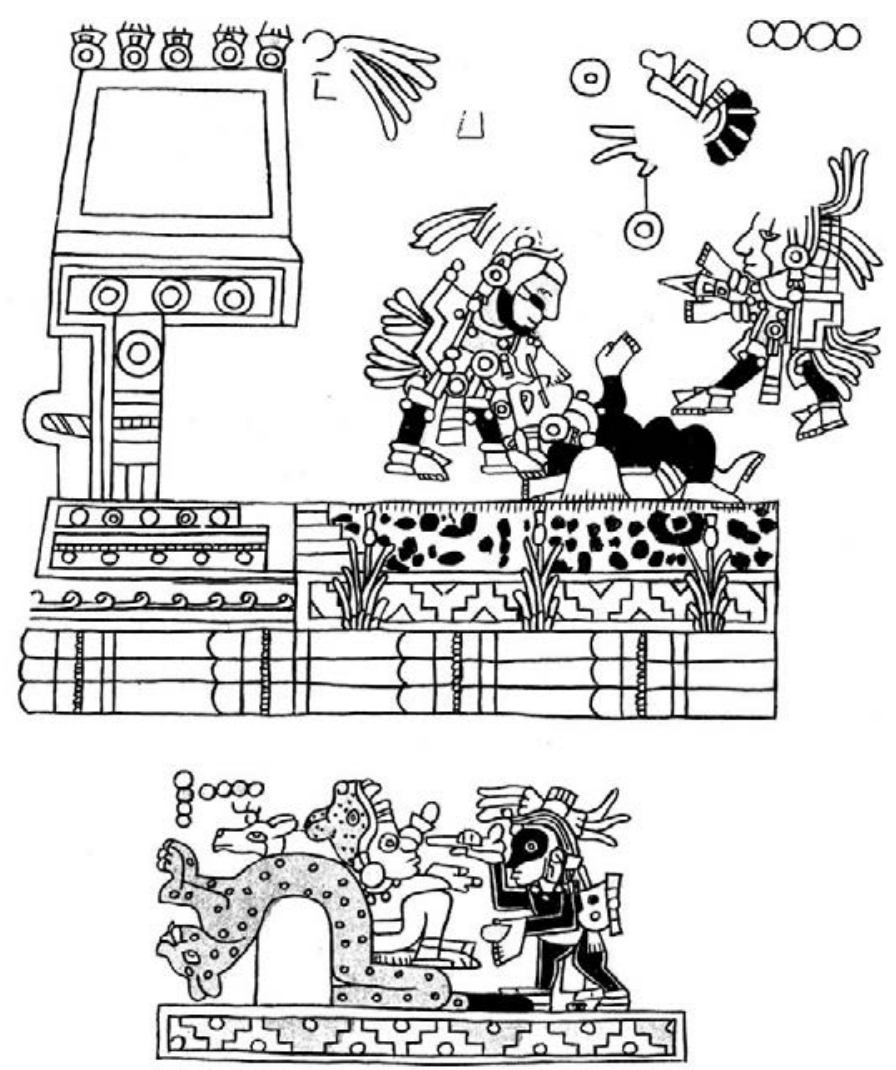

7.60. The Toltec nose-piercing ceremony in Codex Iya Nacuaa (top) and Codex Nuu Tnoo-Ndisi Nuu (bottom).

We find an impressive depiction of the same place in Codex Iya Nacuaa I, p. 13: after passing by a volcano, Lord 8 Deer receives the Toltec nose-plug in a precious temple in Nuu Cohyo, Town of Cattail Reeds, situated on a large plain, where he arrives after passing a snowtopped mountain. Clearly Tollan Cholollan is meant (cf. Jansen 1996, 2006). Later, Lord 4 Wind arrives at the same place after passing a Hummingbird river (Codex Nuu Tnoo-Ndisi Nuu, p. 34-II), which has to be the Huitzilapan, a diagnostic landmark in this area, also present in the name of the town of Puebla (in Mixtec: Yuta Ndeyoho, 'River of the Hummingbird').

A later expedition from the Mixteca Alta to southern Puebla took place in the 14th century. It is most explicitly referred to in the Historia 

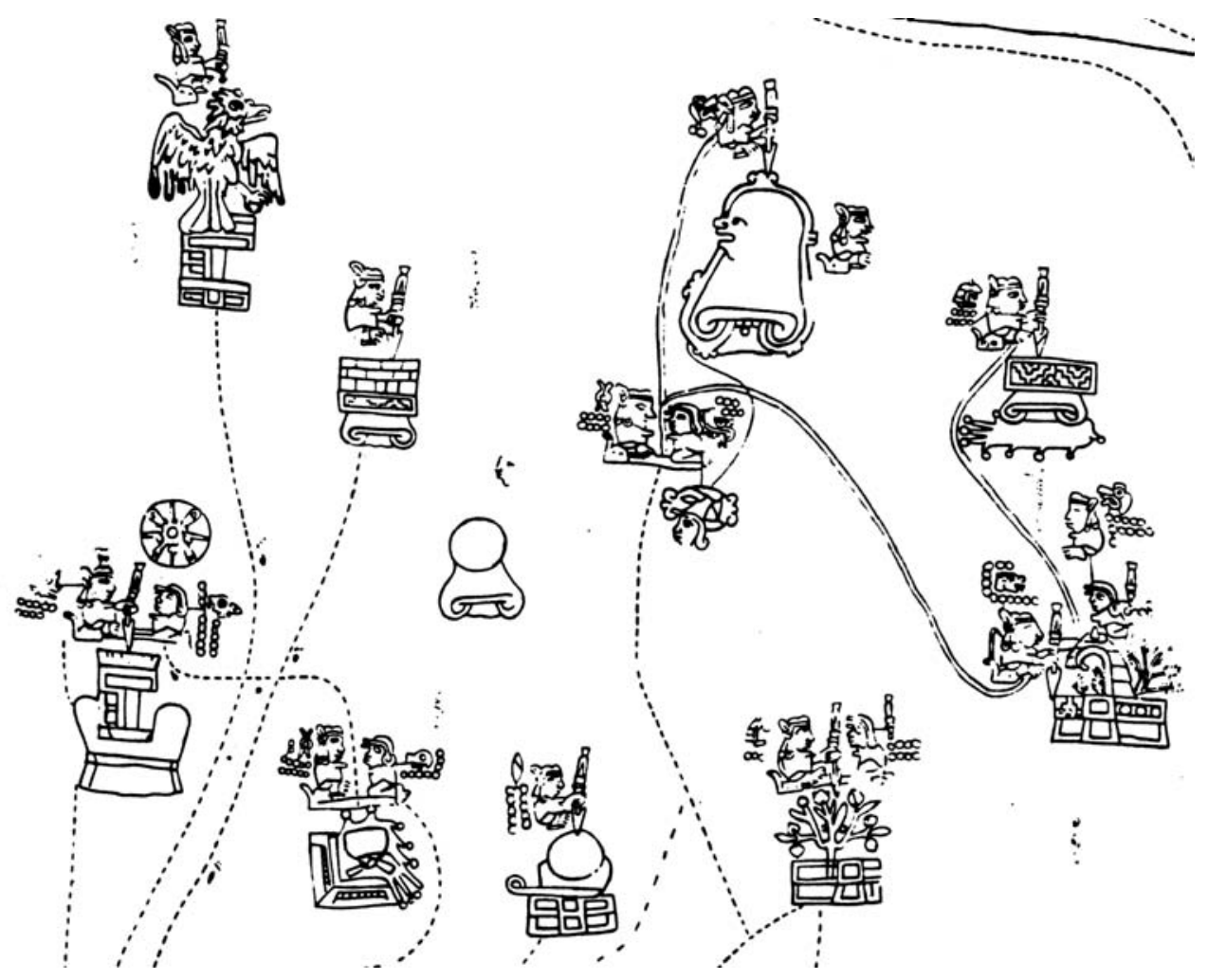

7.61. Lienzo of Tlapiltepec: the final phase of the campaign from the Coixtlahuaca area to the North. From left to right we recognize Tepeji (Split Hill), Cuauhtinchan (House of the Eagle), Tecalli (Wall, i.e. House of Stone), Oztoticpac (Head of the Stone, i.e. Above the Cave), Tepeaca (Mountain of the Face), Ichcaquiztla (Altar of Cotton), Quecholac (Mountain of the River), and Techamachalco (Altar with the Tree and Hut). [after Johnson 1997].

Tolteca Chichimeca and in the Lienzo of Tlapiltepec. The starting point was the Coixtlahuaca Valley. On the route several places in the Mixteca Baja are mentioned. The destinations reached were the towns of House of the Eagle (Huahi Yaha), Mountain of the Face (Dziñe Yucu), and Altar with the Tree and Hut (Chiyo Tnuyaca). Following Parmenter's identification of the geographical map-like character of the Lienzo of Tlapiltepec, we have proposed that this same character extends into the next segment of the lienzo and so have been able to identify these 
three towns as Cuauhtinchan, Tepeaca and Tecamachalco respectively in the southern part of the State of Puebla. ${ }^{41}$

\section{Experience and Memory}

The cases discussed above show that the Nuu Dzaui toponymical signs do not occur in isolation but as part of significant geographical contexts. It is this principle of clustering, coherence and significant relationship that should guide all identifications. Many place names repeat themselves frequently in the Mixtec region; in order to find out which place is meant by a glyphic reference, we have to situate it in its geographic context and propose an identification for the whole group of related signs.

The codices are filled with landscapes, but they do not represent these in the form of illusionistic panoramic paintings that are so prominent in the Western European artistic tradition. The main difference, once again, is the fact that the landscapes in the codices form part of a pictographic text and are basically sets of place signs. Still, they also transmit profound notions, connecting their position in the narrative with experienced landscapes 'out there', with symbolic associations and with the memory of dramatic events.

The study of the toponymic signs reveals the keen geographical consciousness of the ancient Nuu Dzaui painters. Each place has a special sacred foundation date, which connects it to the time of dawn and determines its ritual cycle. In this way it is qualified as a seat of power and agency, a node in a cosmic order. We particularly notice how the origins of the dynasties are connected to specific points in the natural and/or cultural landscape:

- The activities of Lord 9 Wind 'Quetzalcoatl', who brought heavenly water to the Mixtec world and initiated the founding of the villagestates, started in the Place of Heaven, i.e. on top of the Kaua Kaandiui near Apoala, from where he descended to Tilantongo (Codex Yuta Tnoho, p. 48).

${ }^{41}$ Parmenter and Jansen presented their findings already at a symposium in Oaxaca (Gaxiola \& Jansen 1978), and published them later in more detail: Parmenter 1982, Jansen 1992, and Jansen \& Pérez Jiménez 2000: 151-158 (= 2007b: 233-241). See also Johnson 1997. 
- The inauguration of the reign of Lord 8 Wind in the beginning of Codex Tonindeye (p. 2) took place on the Yucuñudahui mountain, where an important classic site is located.

- The dynasty of Nuu Tnoo (Tilantongo) traces its origin back to the ancient sites of Mountain that Opens - Insect, i.e. Monte Albán, and to the Black Mountain, i.e. Monte Negro (Codex Tonindeye, pp. 19, 22).

- Lord 8 Deer consecrated a Temple of Heaven on the Yucu Yuu Dzaa, the central hill of Tututepec (Codex Iya Nacuaa I, p. 5).

- The dynasty of Coixtlahuaca was founded by the Toltec ruler Lord 4 Jaguar on the Cerro Verde (Nudo Mixteco), according to the Lienzo of Tlapiltepec (A-14/15 in Caso 1961). The same mountain is a 'cornerstone' for the Lienzo of Tlapiltepec (in the upper righthand corner) and a central point of orientation in the Lienzo of Otla.

The places and regions play their role in experience and in history, while simultaneously connecting the past to a lived present and to the planning or anticipation of future events. As people we are not separated from the landscape but active participants, engaging with, and to some extent determined by, our natural surroundings:

The landscape, in short, is not a totality that you or anyone can look at, it is rather the world in which we stand in taking up a point of view on our surroundings. And it is within the context of this attentive involvement in the landscape that the human imagination gets to work in fashioning ideas about it. For the landscape, to borrow a phrase from Merleau-Ponty (...), is not so much the object as 'the homeland of our thoughts'. (Ingold 1993: 171).

Landscape, on the intersection of space and time, becomes a framework and precondition for memory, for cultural-historical awareness and for the very process of communication (overcoming distances). As Braidotti (1994) has observed: looking back at the places where we have been is a formative factor for our identity as "nomadic subjects". Traveling through the Land of the Rain was/is simultaneously a recapitulation of its history and its worldview. Through their inclusion in the codices and ritual recitations, Mixtec places too became lieux de mémoire, locales of memory (Nora 1989) and articulations of identity.

The subdivisions of the region are all represented in the codices, as well as the main neighbors of the Mixtec people: the Mexica and Beni 
Zaa (Zapotecs). The ethnic identity of the region itself was expressed with the sign of Frieze (Nuu) of the Rain God (Dzaui), which occurs in names of individuals, but also on crucial occasions in the narrative of the codices. It is to the mountains of Nuu Dzaui that the Primordial Plumed Serpent, Lord 9 Wind, brings the waters of Heaven. It is to the Heart of Nuu Dzaui that a young prince in distress (Lord 2 Rain 'Ocoñaña') resorts for counsel and spiritual assistance. ${ }^{42}$

Today the place signs as emblems of communities may become concrete attachment points for the revitalization, restoration and decolonization of memory. The textual and material sources for memory, such as archeological artefacts, historical documents and oral history, may be brought together with local interests at concrete sites, to make the important step from archive to repertoire, from silent and inert data to renewed performance (cf. Hedeen 2005). In this way, Ñu Dzaui history may come back to the Nuu Dzaui region and again become inspiring to the Nuu Dzaui people.

${ }^{42}$ Codex Yuta Tnoho, p.47, and Codex Añute, p.6-II respectively. See also Terraciano 2001, ch. 9, on Nuu Dzaui ethnicity in the colonial period. 


\section{PART THREE}

YAA TNUHU:

DYNASTIC HISTORY 
Maarten Jansen and Gabina Aurora Pérez Jiménez - 978-90-04-19358-1 Downloaded from Brill.com@4/26/2023 11:36:13AM 


\section{CHAPTER EIGHT}

\section{FOUNDATION NARRATIVES}

Nuu Dzaui history is composed of many individuals, related to each other through time, place, family ties and activities. With his comprehensive index of all these personages, Alfonso Caso (1977-1979, vol. II) guides our reconaissance of this complex world, while Emily Rabin and other colleagues have done much to complete and correct his pioneering work.

The complex genealogy of the ruling families of Nuu Dzaui goes back to the 9th century AD, the fascinating period at the end of the Classic and the beginning of the Postclassic. The existent manuscripts do not explain the situation of crisis that must have prevailed in those days, but emphasize the aspect of a new beginning of history through the use of metaphors and ritual references. Referring to times of a similar character, the early Medieval historians in Europe connected the founding fathers and mothers of the ruling dynasties to ancient Germanic Gods (Odin, Freya) or to the myths of Classical antiquity (the Trojan war). Rocks, trees, caves, and springs were the places the early Mixtec rulers originated from, generally in connection with the First Sunrise and with the creative actions and words of specific deities. The main symbol was Sacred Mother Pochote (thorny ceiba tree), giving birth to the first Lords and Ladies in Yuta Tnoho (Apoala). A similar Tree of Origin stood in Nuu Ndecu (Achiutla). The historiography of the sovereign communities stresses that those Founding Ancestors were sacred, divine Lords and Ladies (Iya), who had power because they were linked to the land and the Forces of Nature.

In the version of Codex Yuta Tnoho, it was Lord 9 Wind 'Plumed Serpent' (Coo Dzavui, Nahuatl: Quetzalcoatl), embodiment of the great power of the cloudy whirlwind, bringer of rain and life, who acted as the divine creator of dynasties. He was born from a magic, divine Flint, a Stone with thirteen names and thirteen powers, venerated in the Town of Jewels, most likely ancient Ñu Ndecu (San Miguel Achiutla). 


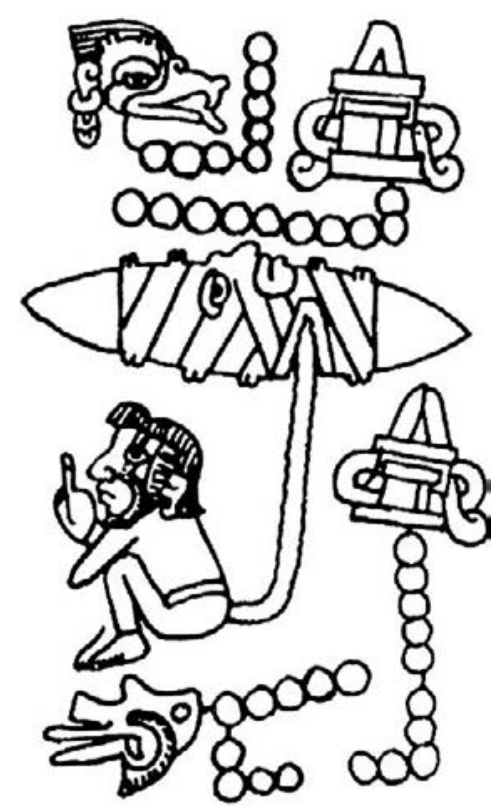

8.1. Codex Yuta Tnoho, p. 49-IV: the birth of Lord 9 Wind.

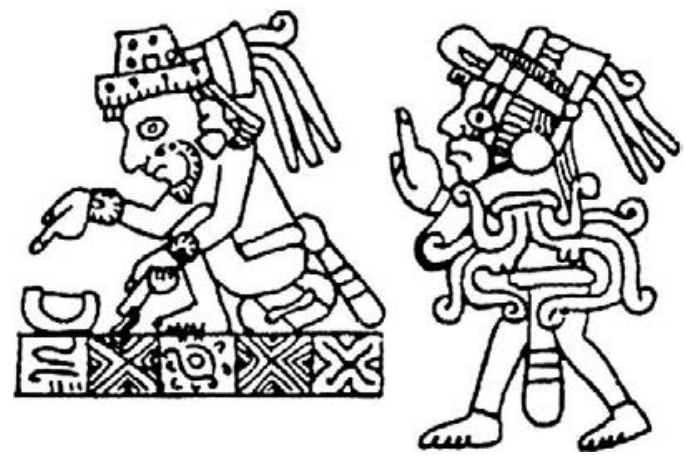

8.2. Codex Yuta Tnoho, p. 48-II: Lord 9 Wind as Giver of divine inspiration and Primordial Instructor in Painting Codices.

He is characterized as the bringer of civilization, the divine quality of art, literature and writing as well as the courage of the warriors and the piety of the priests.

Having received his instructions and symbols of power from the primordial couple Lady 1 Deer and Lord 1 Deer in the Place of Heaven, i.e. on top of the Kaua Kandiui mountain, East of the Sacred Valley of 
Yuta Tnoho (Apoala), Lord 9 Wind 'Plumed Serpent' came down as a powerful nahual, a yaha yahui, 'eagle, fire serpent' along a sacred rope, the whirlwind. Thus he arrived at Nuu Tnoo, to bring water, life, and ritual order to the Nuu Dzaui world. ${ }^{1}$

Then he convoked an assembly of Spirits of Nature (Black Stone and Normal Stones, Black Tree and Normal Trees, Burning Stone and Earthquake, Maguey and Water), amongst whom were seated: the Spirit-Priest of Day 7 Eagle and the Spirit-Priest of Day 7 Rain, sacred to the Nuu Dzaui (Mixtecs) and the Beni Zaa (Zapotecs) respectively.

The outcome of the meeting was that the Spirit-Priest of Day 7 Eagle and the Spirit-Priest of Day 7 Rain started working together on the bark of the Great Mother Ceiba in the Sacred Valley, carving the symbols of rulership (the disks representing the aniñe, 'palace') and of conquest (the arrows, nduvua), i.e. creating history.

From this Ceiba 51 primordial personages were born, two of whom married and had a daughter, Lady 9 Alligator, making it a complete group with the symbolically significant number of 52 members. Lord 9 Wind then acted as a marriage ambassador and arranged for her to marry in Yuta Tnoho.

The account of the origin of the dynasty of Añte (Jaltepec) goes back to the time of First Daylight, when the volcanoes took their seats. It tells how two priests, the old Lord 10 Lizard 'Jade Axe' and the young Lord 10 Flint 'Head of the Cave (Cult)' came together at a river and from there went to visit this Lady 9 Alligator and her husband in Yuta Tnoho, where she instructed them and blessed their magic Stones of Rain (with the face of the Rain God and the face of his helper, the lizard). From there the two priests traveled to the Valley of Nuu Ndecu, and there, at the shore of the large primordial lake, they put down the magic stones and made offerings of tobacco.

The big Ceiba (yutnu nuu) there, guarded by mysterious, visionary powers in the guise of serpents of mist and darkness, opened and gave birth to seven Lords, the most important of whom, Lord 2 Grass 'Dead Ancestor who manifests himself as the Plumed Serpent', became the founder of the dynasty. He received jewels and gold (dzeque, dziñuhu), the shamanic powers of transforming into eagle and fire serpent (yaha,

\footnotetext{
1 Codex Yuta Tnoho, pp. 49-48 and 38-35. Compare the opening scene of the Roll of the New Fire (Selden Roll). See also Jansen 1982b and Jansen \& Pérez Jiménez $1992 \mathrm{a}$ and 2007a.
} 


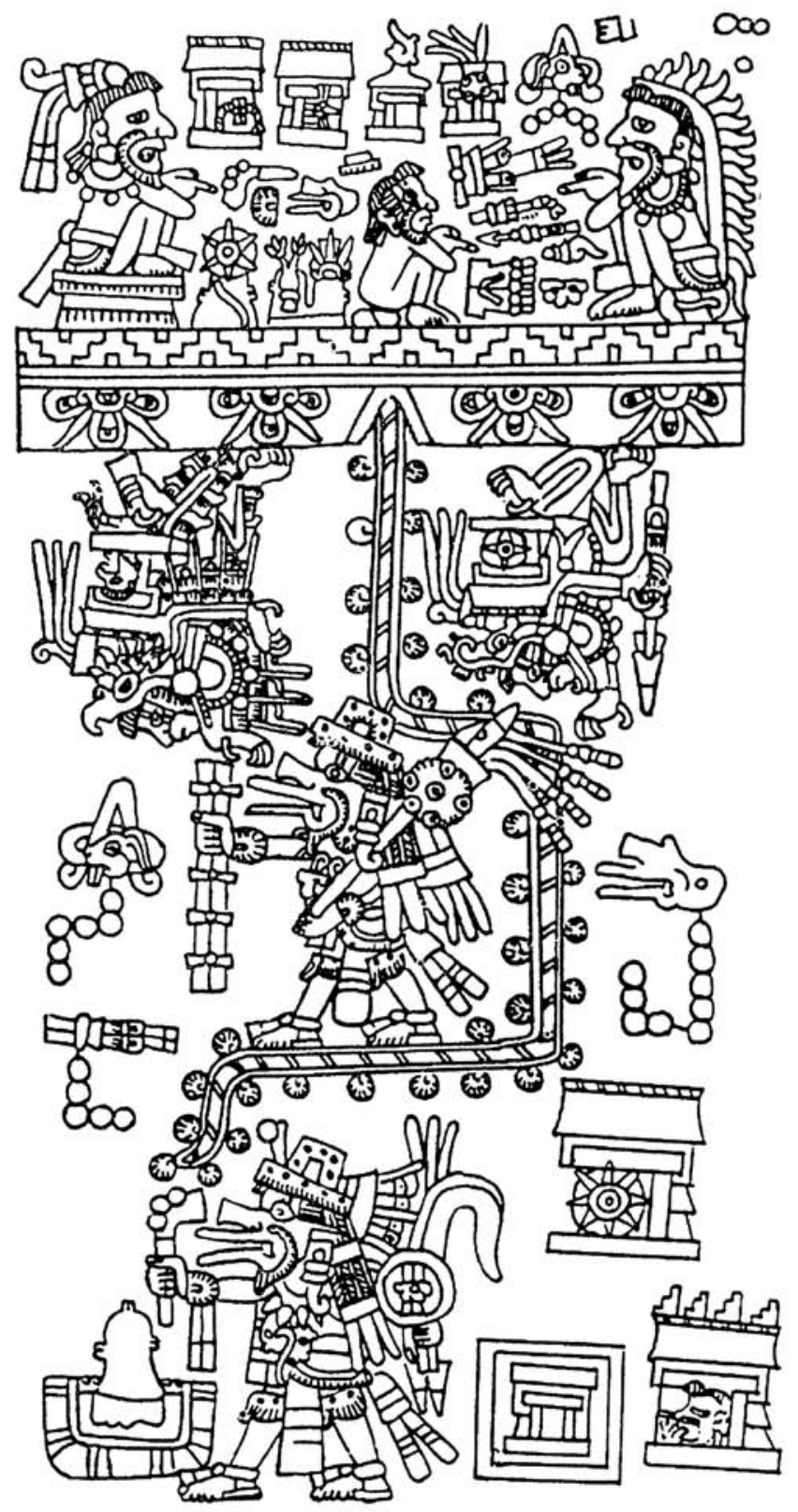

8.3. Codex Yuta Tnoho, p. 48-III: Lord 9 Wind receives instructions from the Ancient Ones in the Place of Heaven and comes down as nahual to the communities (water and mountain) on earth. 


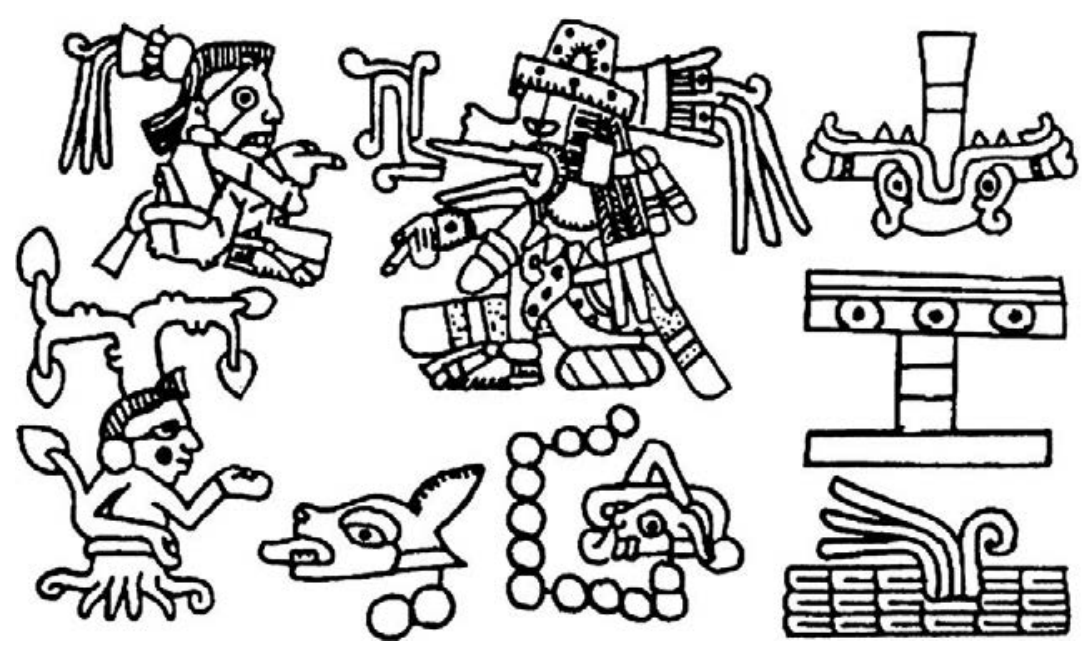

8.4. Codex Yuta Tnoho, p. 37: after a statement referring to the Mixtec world as "the green and precious valleys", as "what has Heaven as its roof" and "what is grounded in earth", Lord 9 Wind is shown speaking to the Spirits (Nuhu) of Rocks and Trees...

yahui), i.e. of flying during day and night time, as well as the power of justice, to bind and execute people. His six brothers became important Spirits of Nature: two became (helpers of the) Rain Gods, two became Quail and Turkey, two became Maguey and Water. ${ }^{2}$

It is in itself significant that the Postclassic dynasties claimed their own specific origins and did not connect to the rulers of earlier times: a clear and conscious break occurred, which allowed for a new era, a new sun, and a new political structure. As in the Popol Vuh, the First Sunrise, adequately prepared by the celebration of rituals (dealing with corn, pulque and hallucinogenic mushrooms) marks the beginning of human society, half way in Codex Yuta Tnoho (p. 23).

After that, the primordial Lords and Ladies, together with the other divine powers, initiated the founding and inauguration of ceremonial centers in the whole of Ñuu Dzaui (Codex Yuta Tnoho, pp. 22-5). The account starts with a sacred date and a Lord or Lady in charge of the ritual, often holding the bound volutes of 'speaking to the four directions'. The topic of the ritual is identified by a cradle (dzoco) and a frieze $(\tilde{n} u \mathcal{u})$, a combination which both semantically and phonetically

${ }^{2}$ Codex Añute, pp. 1-2. See Jansen \& Pérez Jiménez 2007b. 


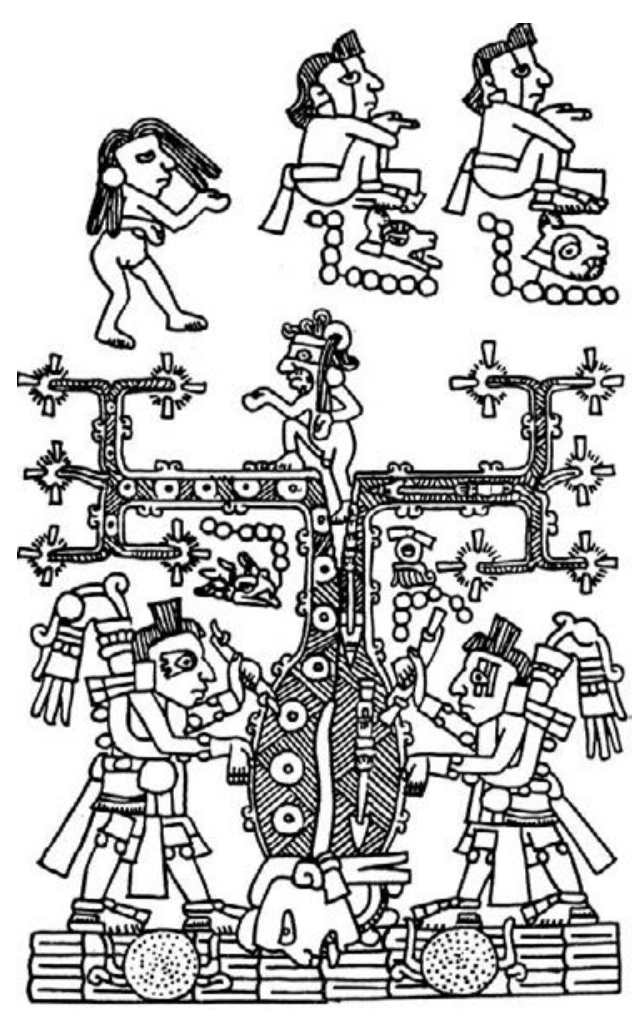

8.5. Codex Yuta Tnoho, p. 36: the Priests/Spirits of the Days 7 Rain and 7 Eagle decorate and open the Mother Tree in the Sacred Valley (of Yuta Tnoho).

refers to the origin $(d z o c o)$ of village-states $(\tilde{n} u u)$, connoting the verb yodzoco, 'to dedicate'.

In most cases the $\tilde{n} u u$ frieze is covered with a white elongated element with black stripes and a hair-like rim. At first sight this - apparently optional - element is similar to a tail (dzuma), which, however, does not produce any significant reading. We interpret it as a covering, a hide or a blanket. Several phonetic readings are possible. The identification of the element as 'hide' (ñee) would give an interesting combination with (and reinforcement of) dzoco, as ñee dzoco is 'womb'. The identification as a blanket could lead to the reading dzama, 'cloth', which in turn might have been used to write the verb yodzama (chiyo), 'to build' or 'to put the fundament'. Given the context, this is a tempting hypothesis, but we are hesitant as 'cloth' is 


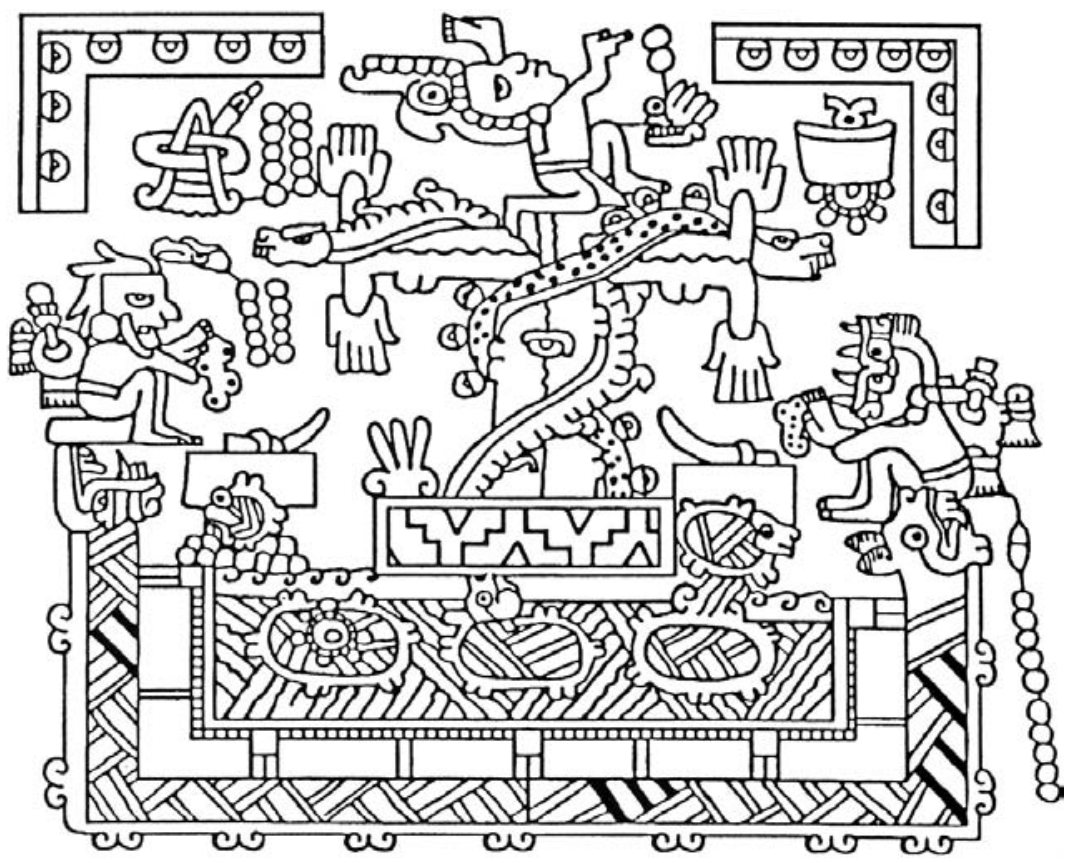

8.6. Codex Añute, p. 2: two ancient priests making offerings to the Mysterious Tree of Origin at the bank of the primordial lake in the Valley of Nuu Ndecu.

actually $d z a h m a$, and the ancient verb yodzama seems to lack the glottal stop. A different reasoning brings to mind that a blanket is used in Nahuatl pictography to transmit the notion of 'new' (yancuic), for example in the place sign of Yanhuitlan in Codex Mendoza. In Dzaha Dzaui the corresponding term is saa, 'new'. In that case we might read the combined sign as dzoco ñu saa, 'origin of new settlements'. Semantically, the blanket may be understood as an additional reference to the uncovering and becoming manifest (yotuvui) of the towns.

We should note that the inauguration ceremony itself was foreseen (or even ordered) in the previous ritual with hallucinogenic mushrooms, during which the cradle (dzoco) appears together with the combined signs 'town-palace' (ñu aniñe) and 'mat-throne' (yuvui tayu), clearly referring to the foundation of village-states (Codex Yuta Tnoho, p. 24).

The representation of the ceremony itself consists of different sets of objects, which most of the time are ordered in pairs, suggesting that 


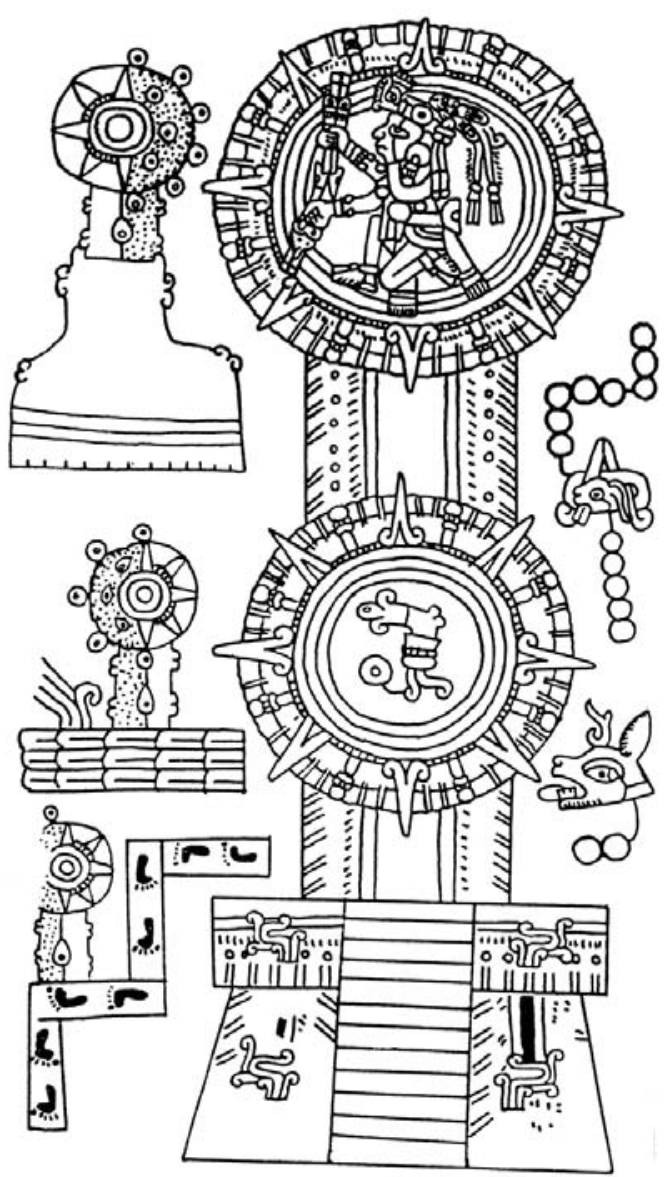

8.7. Codex Yuta Tnoho, p. 23: Lord Sun, the Warrior, rose in a stream of light above the Altar of Songs (a famous ancient ceremonial center); the sun rose from the darkness above the mountains, the valleys and the roads.

we are dealing here with the written form of a ceremonial address $(s a h u)$. A similar text occurs in Codex Añute (p. 3), when the first ruler of Añute takes power. Although the versions in the codices are different, they have several elements in common. Both are constructed in pairs, and both mention, for example, the 'Sacred Round Bundle' and the 'Bound Xipe Bundle', the large amount of fire-wood (still today an important element in the preparation for a fiesta), the difrasismo 'blood and heart' (neñe ini, also used for 'sustenance'), red and white paint (in Codex Yuta Tnoho qualified as $\tilde{n} u h u$, 'divine' or 'sacred'), and down feathers for head and arm. Where Codex Yuta Tnoho men- 


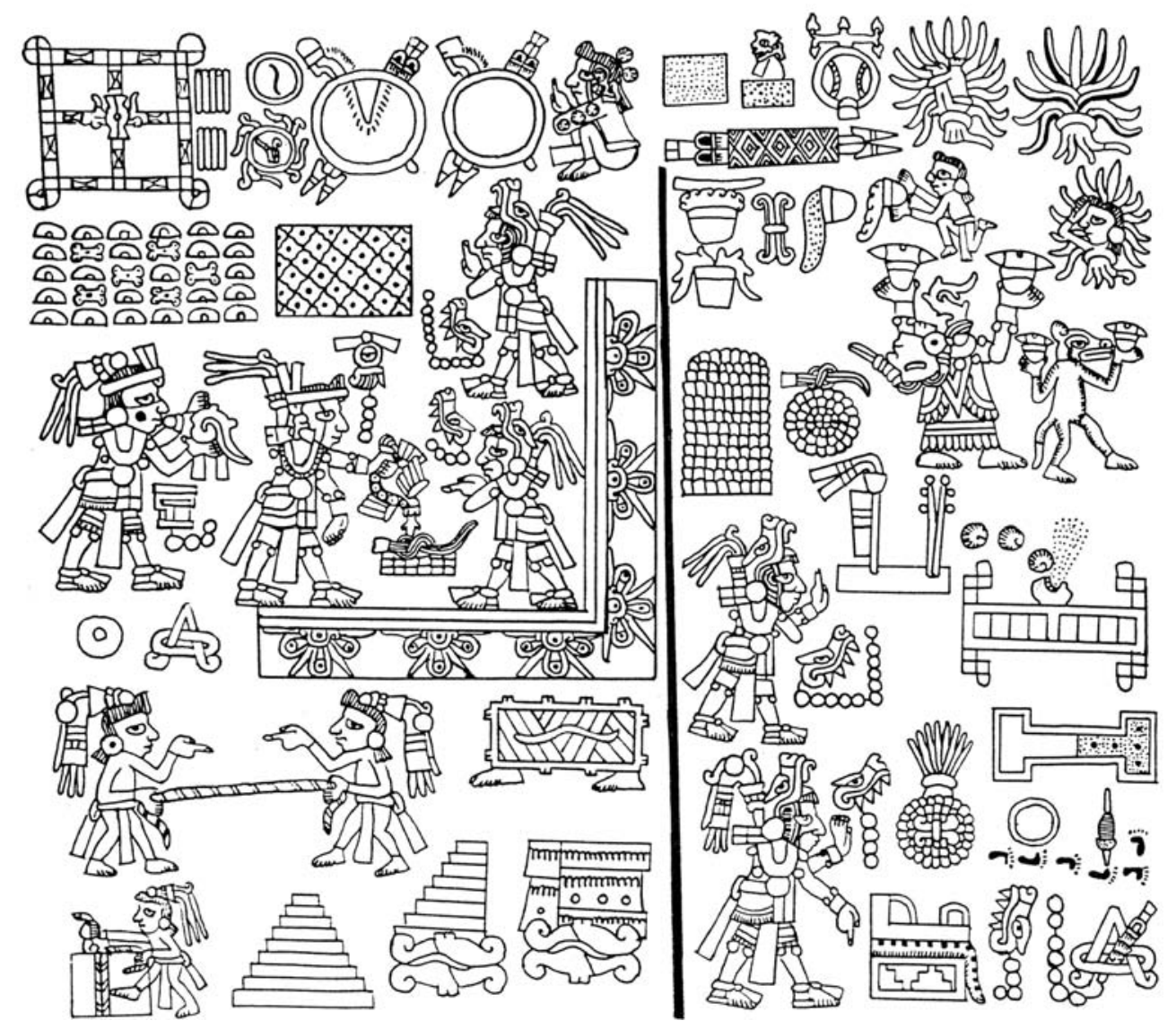

8.8. Codex Yuta Tnoho, p. 13: the foundation ritual carried out in the East (Place of Heaven).

tions 'arrows, spear-thrower, and shield' (nduvua cusi yusa, a general expression for 'fighting forces'), Codex Añute gives a shield and an arrow tainted with blood, topped with the $\tilde{n} u h u$ figure, signaling its divine power. But, although several signs refer to courage and success in war, no battle scenes follow these statements: it is really just a discourse.

The sequences in Codex Yuta Tnoho contain explicit difrasismos such as 'xicolli tunic (dzico) decorated with a band (huatu) of the stepfret motif ( $\tilde{n} u u)$, xicolli tunic (dzico) with a band (huatu) of disks (aniñe)', giving us the difrasismos dzico ñuu huatu ñuu, dzico aniñe huatu aniñe, 'power and glory of towns and palaces'. 


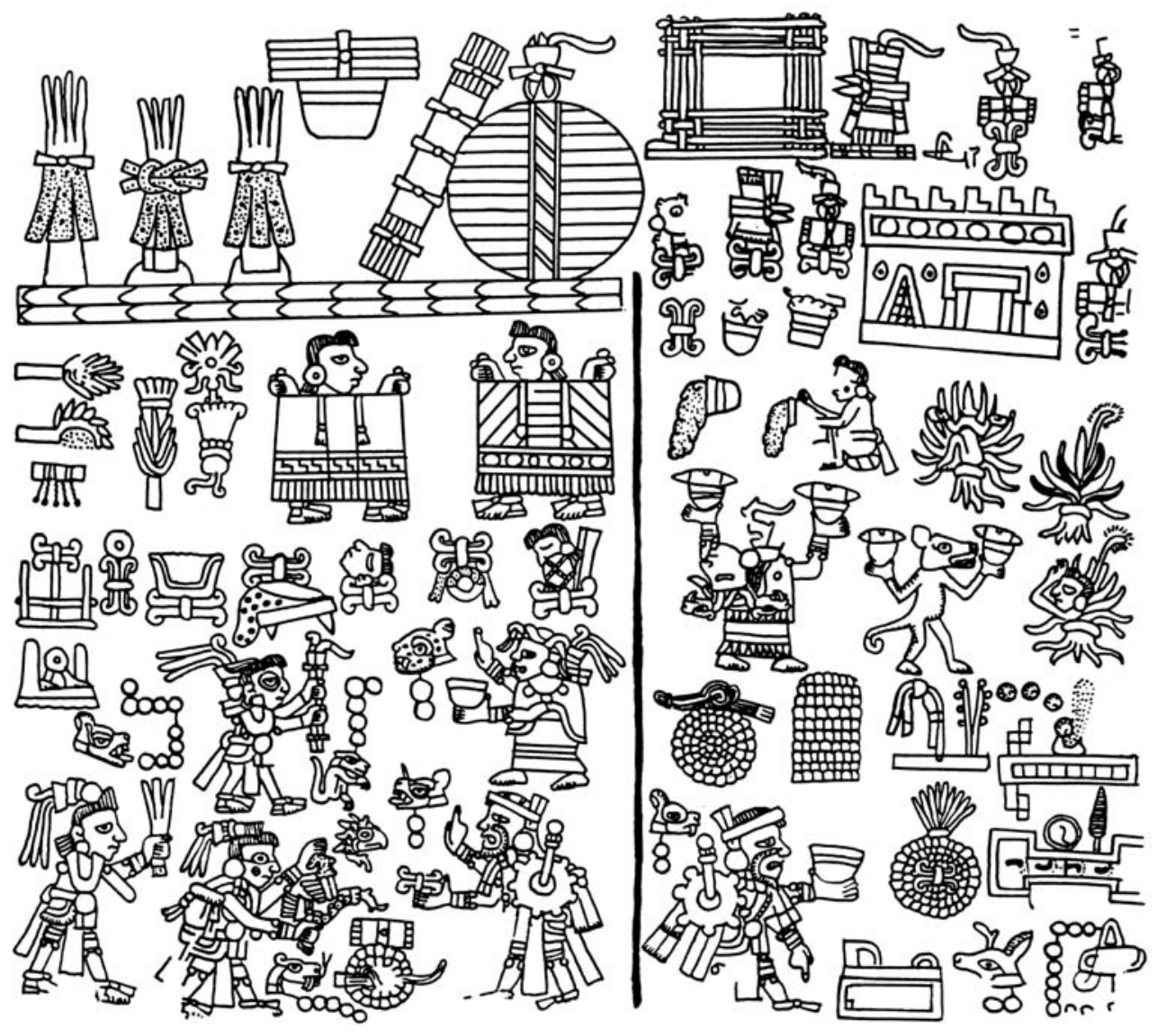

8.9. Codex Yuta Tnoho, p. 22: the foundation ritual carried out in the North.

References to the playing of a ball-game are combined with the sign of a mouth, spitting dotted material and down balls - we read these latter elements as yaa ('ashes') and with other tone: 'song' and huii ('soft'), forming the expression yaa huii, 'sweet and soft song' (Spanish: dulce $y$ suave canto) in Alvarado's dictionary. This is followed by a split stick, which may indicate dzee, 'split' (and with other tone: 'happy') and a banner, which is huayu, a word that can also mean

3 The same sign represents the song of a drum player in Codex Iya Nacuaa II, p. 7-III. The downball feathers are generally used to consecrate sacrificial victims (cf. Codex Vaticanus A, f 54v): therefore we read them as the term ii, 'sacred, delicate' or the phonetically and semantically close huii, 'soft, nice, honorable'. 
'nice, beautiful'. In combination these signs seem to register an expression for elegant and beautiful speech (cf. yocaha huayu, yocaha huii, 'hablar elegantemente'; sa dzee sa canda ini, 'lo hermoso y maravilloso').

The next phrase is introduced by a reference to 'the thirteen rosettes, the rosettes of bound grass', objects similar to the present-day wreaths of the cucharilla plant (tiyeye in Alvarado, chichi in Chalcatongo today), with which altars, churches and arches are decorated on festive occasions. ${ }^{4}$ In the codices such rosettes are laid out to sacrifice quails on top of them. The following sentence deals with the maguey plant and, therefore, refers back to the ritual of pulque drinking, done in preparation for the First Sunrise.

Here the action is initiated by a person dressed as an opossum, the animal that according to different accounts brought pulque into the world. He is followed by a decapitated woman, a manifestation of Lady 9 Reed, wearing the huipil and skirt decorated with flint knives (dzico yuchi, huatu yuchi, 'power and glory of knives'). Both are carrying small bowls or 'jícaras' (yasi ndaha) topped with knives and walk toward three maguey plants. The first maguey has a human head and makes the gesture of alarm or lamentation, the third maguey contains a decapitated individual. Clearly these are representations of the maguey as a plant spirit (like the tree spirits mentioned above): Iya Yavui, 'Lord Maguey'. The observation of the present-day pulque making process clarifies this sequence. The knives and bowls are clearly the implements used for cutting and scraping the maguey plant (done with a metal implement still designated as yuchi, 'knife') in order to scoop out the juice, which can then be added to already existing 'mother pulque' (ndavui) in order to ferment. This explains the gesture of the maguey plant, which is going to be 'decapitated'. The opossum is likely a symbolic representation of the man who is going to cut the maguey (yotahui yavui) in order to start the extraction of aguamiel for the production of pulque. The impersonator of Lady 9 Reed has to be the woman who is going to scrape the inner part of the maguey plant to extract the juice (yoñahi yavui; yonatehui ndudzi). Her action is integrated in her body but has to be read separately: she

\footnotetext{
4 We interpret the sign as a round covering made of green leaves (cf. Anders \& Jansen \& Pérez Jiménez 1992a: 82-83). Aguilera (2002) proposes an alternative (less convincing in our eyes): a black ball covered with green feathers.
} 


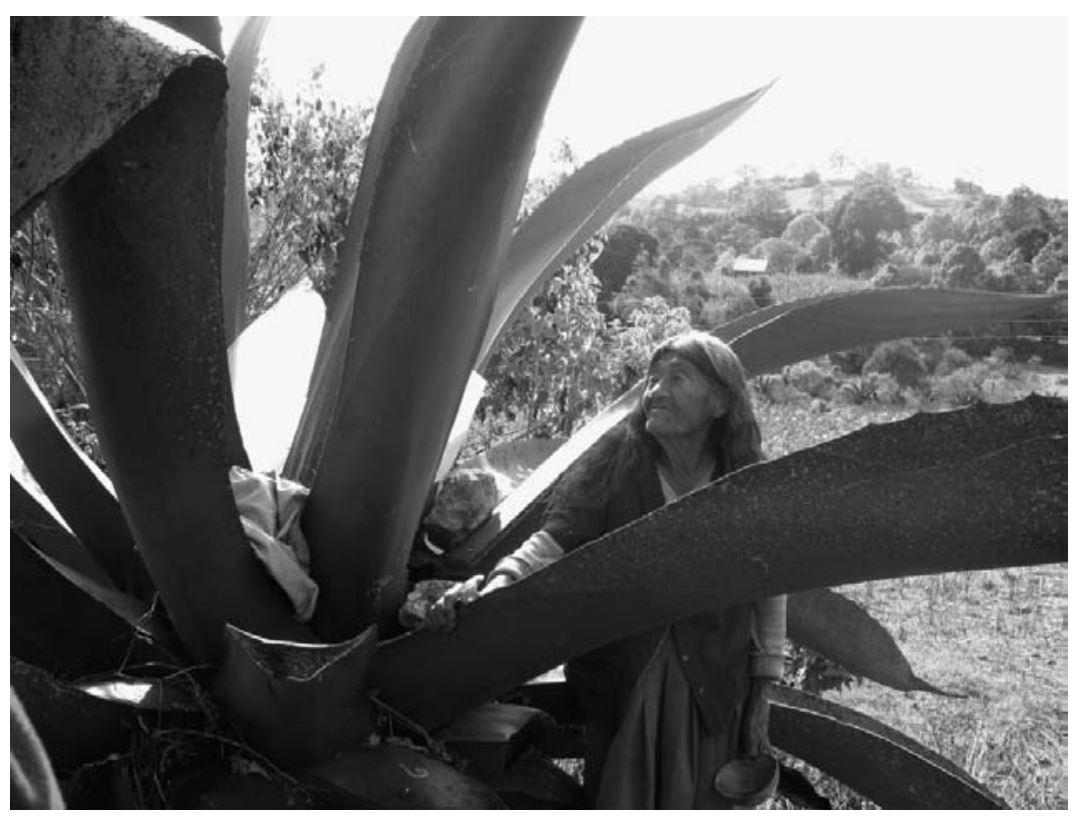

8.10 Scraping the maguey for making pulque, Nuu Ndeya (Chalcatongo).

is not decapitated herself but is 'going to decapitate (the maguey)'. Man and woman operate here in a complementary, parallel fashion, as they still do today.

The renewal of pulque ( $n d e d z i$, nduta cuisi) by adding new maguey juice was apparently used as a metaphor for the initiation of a new life cycle, a new political system. The references to the ball-game and to the patolli board-game may express the wish for good luck. Thus, dynastic history in the codices was initiated with a flowery speech. In the same manner the story-teller would pronounce such a discourse himself before starting the reading or declamation of the pictorial manuscript.

\section{First Generations}

The Codex Yuta Tnoho Reverse (p. I-3) and the Codex Nuu TnooNdisi Nuu Obverse (p.1-IV/III) both start by referring to the Founding Father mentioned in the Relación Geográfica of Nuu Tnoo: Lord 4 Alligator 'Blood Eagle' (Iya Qh Quehui 'Yaha Neñe'), who was born 

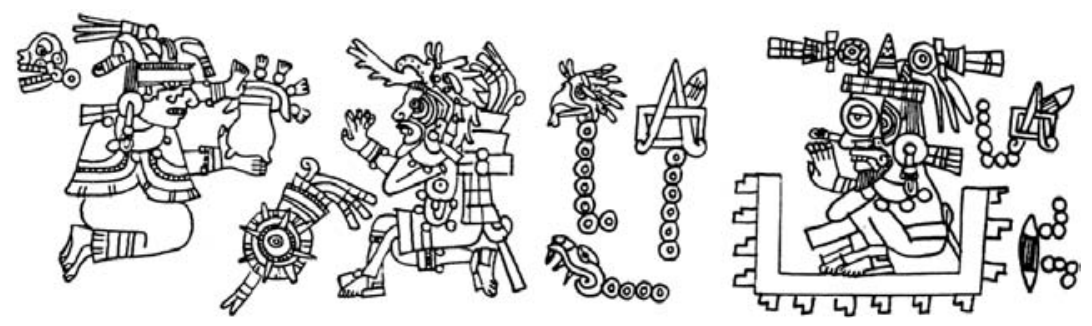

8.11. Codex Yuta Tnoho Reverse, p. I-3: Lord 4 Alligator, from the Region of the Rain (Ñuu Dzaui) marries Lady 1 Death.

from Earth itself, presumably in a specific sacred spot within the Nuu Tnoo territory. He also appears in Codex Tonindeye in the beginning of the segment on the Nuu Tnoo dynasty (p. 21). Only Codex Yuta Tnoho Reverse gives the date of Lord 4 Alligator's marriage: the day 7 Eagle of the year 6 Flint, which, if historical, would be in AD 940.

His wife, Lady 1 Death 'Sun Fan', must have been a very important person. According to Codex Nuu Tnoo-Ndisi Nuu (p.1-V) she proceeded from the Sacred Mother Pochote Tree of Yuta Tnoho, but Codex Tonindeye (p. 19) states that she was born at an impressive ceremonial site, called 'Mountain that Opens - Bee' by Caso and identified by us as Monte Albán. This place played a dominant role in the very early period described by the codices. It is here that a priest coming from the Place of Heaven, i.e. the ceremonial center on the Kaua Kaandiui, 'Mountain of Heaven', in Yuta Tnoho (Apoala) arrived to introduce the cult of the Culture Hero, Lord 9 Wind 'Quetzalcoatl'.

The founding marriage of the Nuu Tnoo dynasty then, involves a princess from Monte Albán, and a local lord from an important site in Nuu Dzaui. They had only one daughter: Lady 1 Vulture 'Precious Spirit', who married Lord 4 Rabbit, also associated with Monte Albán (Codex Ñuu Tnoo-Ndisi Nuu, p. 3-I).

This couple had three daughters, of whom the first-born, Lady 5 Reed 'Dzico Dzavui', i.e. 'Virtue of the Rain God' or 'Honor of Nuu Dzaui', married Lord 9 Wind 'Stone Skull', a local prince of Nuu Tnoo, whose parents were Patrons of the River of the Serpent nearby. The date for this marriage is the day 7 House of the year 4 Rabbit (990). ${ }^{5}$ The two other daughters became connected through matrimony to the

\footnotetext{
${ }^{5}$ Codex Yuta Tnoho Reverse, p. IV-1; cf. Codex Nuu Tnoo-Ndisi Nuu, p. 4-V and Codex Tonindeye, p. 23.
} 


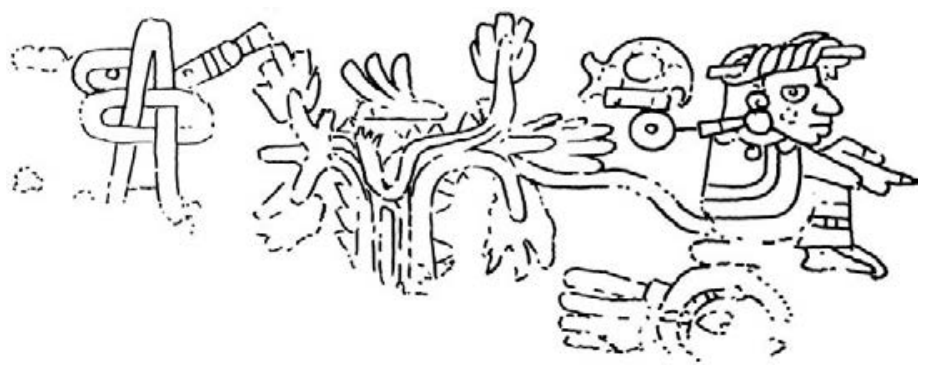

8.12. Codex Nuu Tnoo-Ndisi Nuu, p. 1-V: the birth of Lady 1 Death from the Sacred Tree.

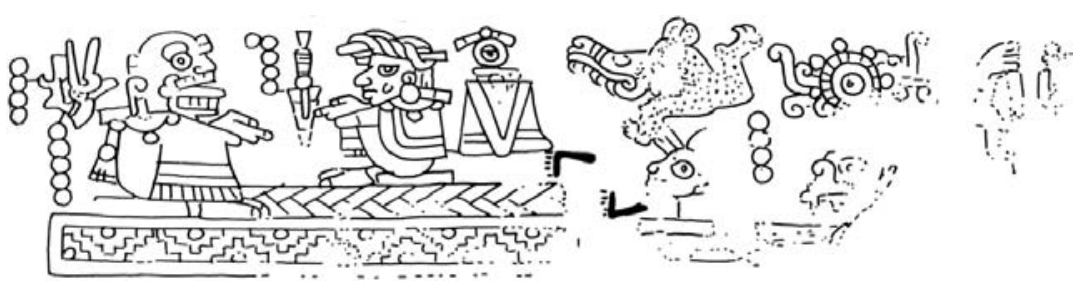

8.13. Codex Nuu Tnoo-Ndisi Nuu, p. 4-V: the marriage of Lord 9 Wind 'Stone Skull' and Lady 5 Reed 'Dzico Dzavui'.

dynasty of Town of the Xipe Bundle, which is the focal point for the reverse side of the Codex Nuu Tnoo-Ndisi Nuu.

A parallel development is highlighted at the beginning of Codex Tonindeye (pp. 1-5): the enthronement of Lord 8 Wind 'Twenty Eagles' as ruler of Altar of the Tree with White Flowers, which is identified as Chiyo Yuhu (Suchixtlan). Early Mixtec history evolves around these two poles of power: on the one hand Chiyo Yuhu, a prominent site in the large and fertile Valley of Yodzo Cahi (Yanhuitlan) with its Classic antecedents Cerro Jazmín and nearby Yucuñudahui, and on the other Nuu Tnoo in the mountains, more to the South, close to the Early Classic site of Monte Negro. Both strong men, Lord 8 Wind of Chiyo Yuhu and Lord 9 Wind of Nuu Tnoo, had, or at least claimed ties to the Tree of Origin in Yuta Tnoho (Apoala), which we interpret as the symbol of a 'crisis cult community' in the aftermath of the demise of Monte Albán. ${ }^{6}$

${ }^{6}$ We have elaborated this interpretation in our Encounter with the Plumed Serpent (2007a: chapter 4). The biography of Lord 8 Wind has also been studied by Furst (1978b ) and Williams (2009). 
The first son of Lord 9 Wind (of Nuu Tnoo) and Lady 5 Reed (from Monte Albán) was Lord 10 Flower, born in the year 6 Flint (992). In the year 1 House (1013) this prince of Ñu Tnoo married Lady 2 Serpent 'Feathered Serpent', the daughter of Lord 8 Wind of Chiyo Yuhu and Lady 10 Deer, who belonged to the dynasty of Añute (Jaltepec). This was a crucial dynastic event, which is documented in Codex Ñuu Tnoo-Ndisi Nuu (p. 5-V), Codex Yuta Tnoho Reverse (p. IV-2) Codex Tonindeye (p. 23) and Codex Añute (p. 5-IV). Lady 2 Serpent points her finger, the gesture of giving instructions and orders, while Lord 10 Flower answers with the raised hand of obedience and tribute. We may interpret this as an indication of the dominant position of the kingdom of Altar of the Tree with White Flowers, i.e. Chiyo Yuhu (Suchixtlan) where she came from.

From here onward the codices Nuu Tnoo-Ndisi Nuu (pp. 5-8), Yuta Tnoho Reverse (pp. V-VII), and Codex Tonindeye (pp. 23-26) follow the male line of descendants of the House of Nuu Tnoo during three generations:

- Lord 12 Lizard,

- Lord 5 Movement,

- Lord 2 Rain 'Twenty Jaguars' (Ocoñaña).

This last prince died at the age of 21, in the year 6 Flint (1096), before actually having acceded to the throne. With him the first dynasty of Nuu Tnoo came to an end. ${ }^{7}$ Meanwhile, due to many political conflicts and the weakening of the ruling dynasty, the effective power in Nuu Tnoo was exercised by the High Priest Lord 5 Alligator 'Rain Sun', head of the Council of Four, which controlled local politics. On the day 7 Movement of the year 13 House - also represented in an archaic way as $13 \mathrm{Owl}$ (a sign that spelled death) - i.e. $1025 \mathrm{AD}$, this Lord 5 Alligator had started his service in the Temple of Heaven in Nuu Tnoo. After having completed the four priestly levels, he was free to leave the priesthood and to marry. On the important ritual day 7 Eagle, either in the year 5 Reed (1043) or in year 6 Flint (1044), he married a Beni Zaa princess, Lady 9 Eagle 'Cacao Flower', with whom he had several children.

\footnotetext{
${ }^{7}$ See Jansen \& Pérez Jiménez 2007a for an analysis of the circumstances.
} 
- Later, in the year 10 House (1061), apparently after the death of his first wife, Lord 5 Alligator remarried, this time to Lady 11 Water 'Blue Parrot'. From this second marriage, was born the historical figure to whom the Nuu Dzaui rulers traced the origin of their status and power: Lord 8 Deer Jaguar Claw (1063 - 1115 AD). Through his exploits he would achieve great respect and take over the throne of Nuu Tnoo, after the death of Lord 2 Rain 'Twenty Jaguars' in 1096.

Thus the early history of Nuu Tnoo is marked by the recurrent significance of the year 6 Flint:

- 940: marriage of Lord 4 Alligator 'Blood Eagle' and Lady 1 Death 'Sun Fan'.

- 992: birth of Lord 10 Flower.

- 1044: marriage of Lord 5 Alligator 'Rain Sun' and the Beni Zaa princess Lady 9 Eagle 'Cacao Flower'.

- 1096: death of Lord 2 Rain 'Twenty Jaguars'.

Codex Añute (pp. 5-IV / 6-I) follows another dynastic line: that of Lady 9 Flint, a younger daughter of Lord 8 Wind of Chiyo Yuhu and his wife, Lady 10 Deer. The mother, who belonged to the Añute dynasty, instructed her daughter (with pointed finger) to go to take possession of the kingdom of Añute and the father (with stretched out hand) accepted and approved. This Lady 9 Flint married Lord 10 Eagle from Nuu Tnoo, in the year 3 House (1041). He was the second son of Lord 10 Flower of Nuu Tnoo (who himself had married Lady Flint's older sister, Lady 2 Sepent). We notice the hand gestures indicating that the Lady has the dynastic power to give orders (pointed finger) while the Lord admits and obeys (stretched out hand). Lady 9 Flint and Lord 10 Eagle had three sons who all died in sacrifice (apparantly after having been taken captive in war), and one daughter, who would survive and become a central figure in Nuu Dzaui history: Lady 6 Monkey 'Virtue of the Plumed Serpent'.

The relative abundance of genealogical data permits us to follow still another line of descendance. The youngest daughter of Lord 10 Flower of Nuu Tnoo and Lady 2 Serpent from Chiyo Yuhu was Lady 7 Reed 'Feathered Serpent, Flower-Jewel'. She married Lord 13 Death 


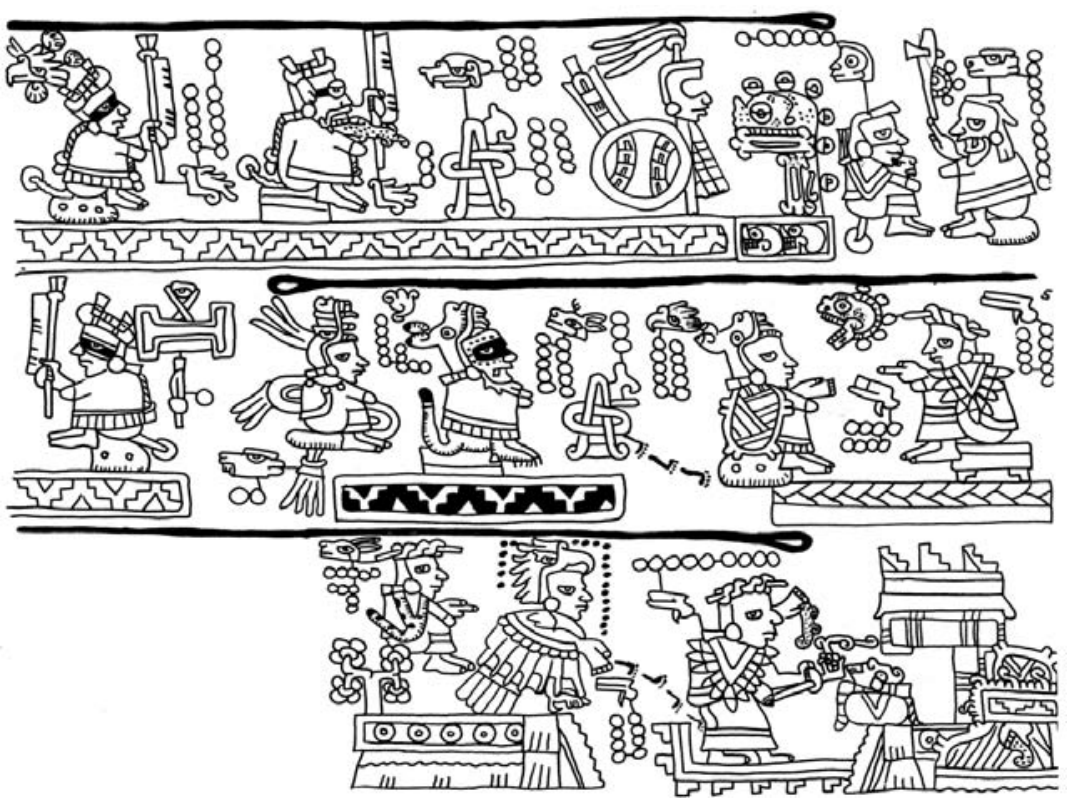

8.14. Codex Añute, pp.5-6 (Bottom to Top, boustrophedon): Lady 9 Wind making offerings for the Sacred Bundle in the temple of Añute, i.e. taking possession of the kingdom. Her marriage, three sons and one daughter, Lady 6 Monkey.

'Setting Sun'. Their daughter, Lady 10 Vulture 'Brilliant Virtue', would later marry Lord 8 Deer, in the year 2 House (1105). ${ }^{8}$

\section{The Tragedy of Lord 8 Deer and Lady 6 Monkey}

The codices portray Lord 8 Deer 'Jaguar Claw' as a great conqueror and unifier of the Nuu Dzaui region. It is intriguing that he himself did not originally belong to a ruling lineage. As the eldest son of the second marriage of a High Priest of Tilantongo, he had an important political background, but did not possess the birth-right to become king. The codices Tonindeye (pp. 42-84) and Iya Nacuaa (complete), as well as Codex Nuu Tnoo-Ndisi Nuu (pp. 7-14), go into a lot of detail in order to explain his road to power; with good reason, as most subsequent rulers based their legitimacy on their descent from Lord

\footnotetext{
${ }^{8}$ Codex Ñuu Tnoo-Ndisi Nuu, p.5-IV and p.12-III/IV.
} 
8 Deer. A true epic is presented, full of literary elements that enhance the suspense of the story. As we have commented on this impressive text elsewhere in detail (Jansen \& Pérez Jiménez 2007a), we limit ourselves here to a synthesis of the main points.

Codex Tonindeye (p. 43) begins this biographical narrative with characterizing Lord 8 Deer as a successful young warrior (very young indeed: 8 years old). In Codex Ñu Tnoo-Ndisi Nuu (p. 9-V) he starts out, somewhat older (at the age of 18 or 19), with a series of ritual acts, which emphasize his piety and suggest the presence of divine will and providence. We see him coming out of a cave, a liminal place apt for visions and other religious experiences, after which he finds a chest full of jade beads, a treasure, in a cave in a Big Mountain (painted as curved or bent, which results in the reading cahnu, 'big'). Smoke rises from the ground, an element explained by present-day oral tradition: hidden treasures from the past are supposed to produce vapors or light effects in the twilight, night or dawn. The same idea has been documented by Sahagún (Book X: ch. 29), who ascribed to the Toltecs the ability to discover precious stones in this manner:

when [it was] still dark, they came forth; they placed themselves somewhere on a high place; they placed themselves facing the sun. And when the sun came up, they took great care to look carefully in all directions, they say, in order to see by means of wet earth where the precious stones (tlazotetl) were in the ground. And when the sun shone, especially when it appeared, they say, a little smoke, a little mist (poctontli, ayauhtontli), arose there where the precious stone was, either in the ground or within a rock. When they saw it, it was as if the rock were smoking. (Translation Dibble \& Anderson).

In the year 6 Reed (1083) Lord 8 Deer traveled in a shamanic flight to the Vehe Kihin (Temple of Death) of Nuu Ndaya (Chalcatongo). There, together with the young princess of Añute (Jaltepec), Lady 6 Monkey, he invoked the help of the powers of death. The detailed description of this cave by Burgoa makes it clear that it was the common burial place of the Nuu Dzaui kings, so, we conclude, Lord 8 Deer turned to the dead and deified Ancestors for guidance. On the one hand we may read these scenes as a search for ideological legitimation in the eyes of posterity. On the other they express a profoundly critical attitude on the part of the ancient authors as to the hybris of seeking so great and superhuman a power.

It is interesting to understand this scene also as a variant of a much wider occurring theme which has been analyzed in psychological 


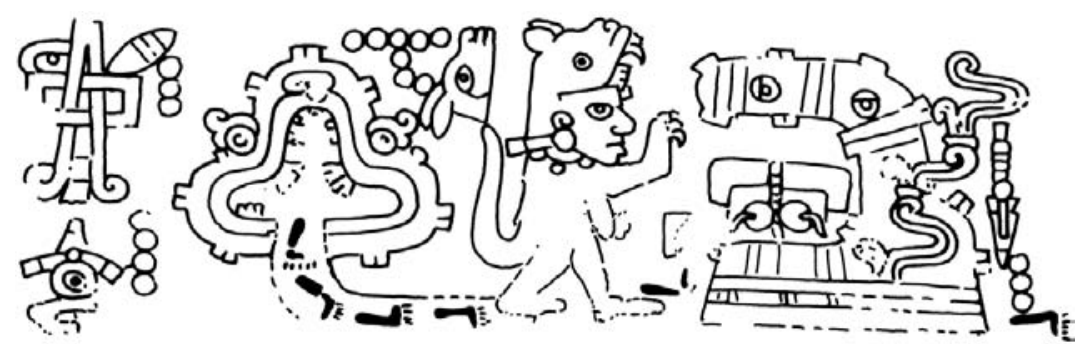

8.15. Codex Nuu Tnoo-Ndisi Nuu, p. 9-V: young Lord 8 Deer finds a treasure.

terms by Clarisse Pinkola Estés (1992: ch. 2). An ancient Russian narrative tells about the young woman Vasalisa who has to ask the help of the 'witch' (Baba Yagá) living in the woods in a house of bones and skulls. Such an archetypical journey to the 'Wild Woman' and to the 'Realm of Death' may be interpreted on a spiritual level as a quest (and a test) to mobilize deep resources of the psyche. Will the human protagonists be able to realize the symbolic power in a positive way in their own life and work according to the ethos and instructions of the Wise One, who speaks to them from beyond the divide between life and death? Or will they fall victim to the evil streak in power, impulsing the individual to sacrifice the life of others to his/her own ambitions and to neglect religious respect and ritual obligations? We are not suggesting that we should read the visit to the Vehe Kihin this way, but we do think that Estés's work helps us to value the wisdom and protective power manifest in Lady 9 Grass above her fear-inspiring aspects.

Lady 9 Grass Cihuacoatl, the awe-inspiring Patron of the Vehe Kihin, ordered the two youngsters to separate. Lady 6 Monkey would marry an older man, Lord 11 Wind from Town of the Xipe Bundle, whose first wife had been the half-sister of Lord 8 Deer. The Codex of Añute tells in detail how young Lady 6 Monkey did not pay attention to the ominous words that two priests of Zaachila shouted to her from the slopes of Monte Albán (yuchi yuchi, 'you will be killed by a knife'), but took these warnings as threats, killed the priests, and went on to Town of the Xipe Bundle, where she ruled several years with her husband and had two sons.

Lord 8 Deer himself in his reaction to the divine orders dedicated himself to warfare. He left Nuu Dzaui Ñuhu (the Mixteca Alta) for Nundeui (the Mixtec Coast), where he founded the kingdom of Yucu 


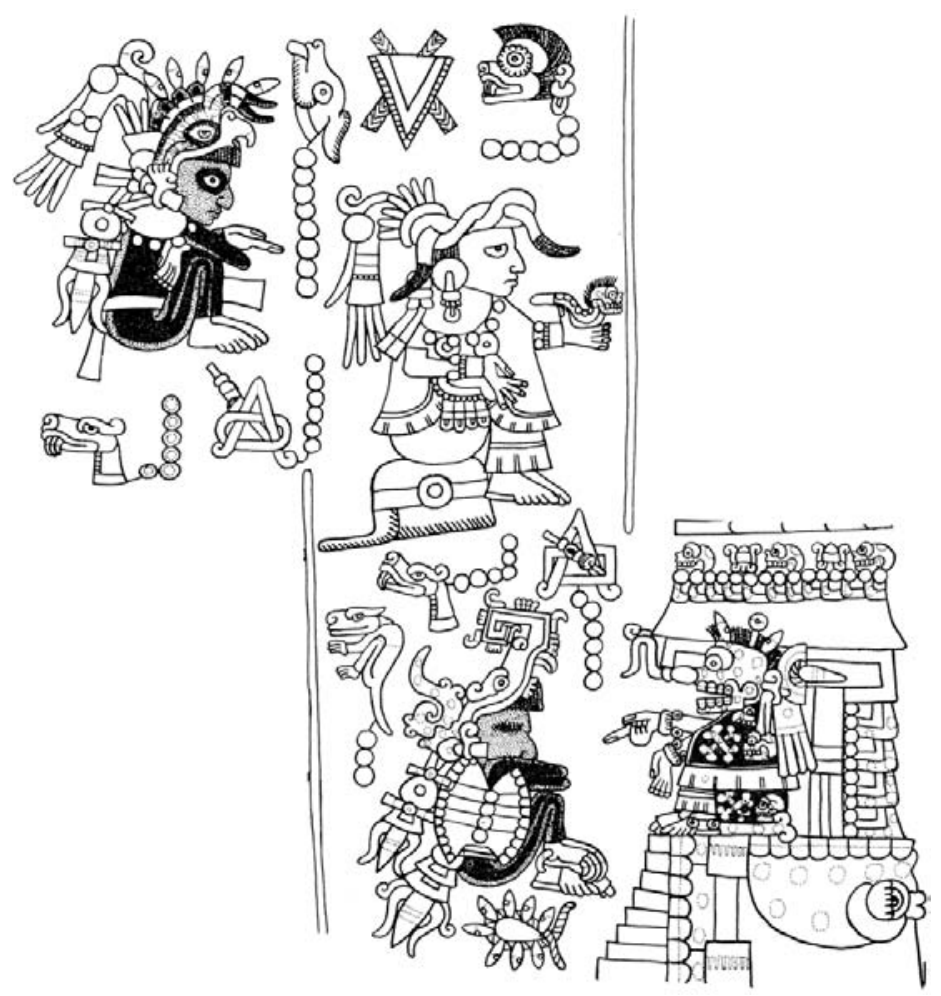

8.16. Codex Tonindeye, p. 44: Lady 6 Monkey and Lord 8 Deer, guided by the nahual priest Lord 3 Lizard, visit the Vehe Kihin.

Dzaa (Tututepec). Conquests of neighboring towns alternate with the celebration of rituals, such as offerings to the Trees of the Four Directions. After all this, Lord 8 Deer invoked the help of a second important Goddess: Lady 9 Reed of Tonalá.

Thus, in the year 7 House (1097), thanks to her interference, he added significantly to his prestige by concluding an alliance with a foreign priest-king, Lord 4 Jaguar, who ruled in 'Place of Cattail Reeds'. This important and powerful character had sent an embassy of four noble priests to Lord 8 Deer, residing in Yucu Dzaa, and as a reward for his military support he bestowed upon Lord 8 Deer the high status that enabled him to become ruler of Nuu Tnoo: during a ceremony in 'Place of Cattail Reeds' Lord 8 Deer received a turquoise nose-ornament. This is a clear example of an honorific status symbol, which accompanied the protagonist, as a memento of his crucial con- 


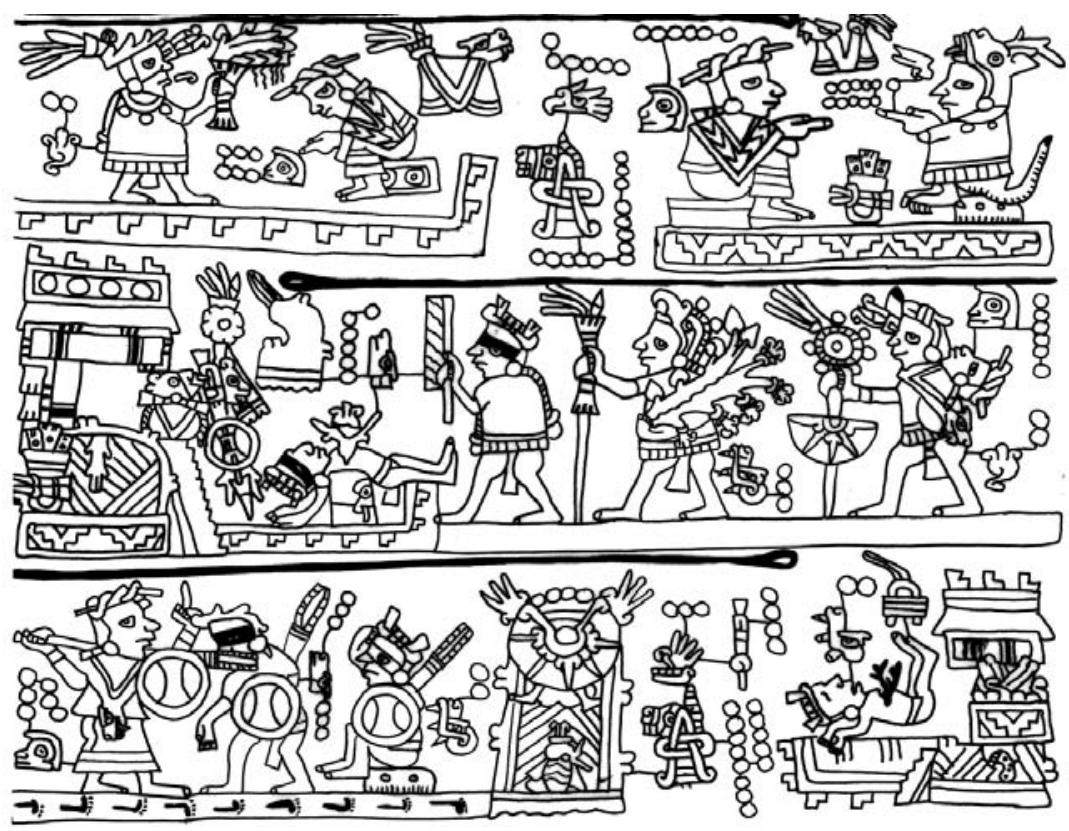

8.17. Codex Añute, p. 8-I/III (Lower Left to Upper Right, boustrophedon): Lady 6 Monkey attacks the two priests ('Long Hairs') of Tocuisi (Zaachila) who had shouted 'knife, knife' to her, burns their place of residence (Monte Albán), sacrifices one in Añute and takes the other to the town of her husband to have him executed there. After undergoing a ceremonial cleansing, she marries Lord 11 Wind in Town of the Xipe Bundle.
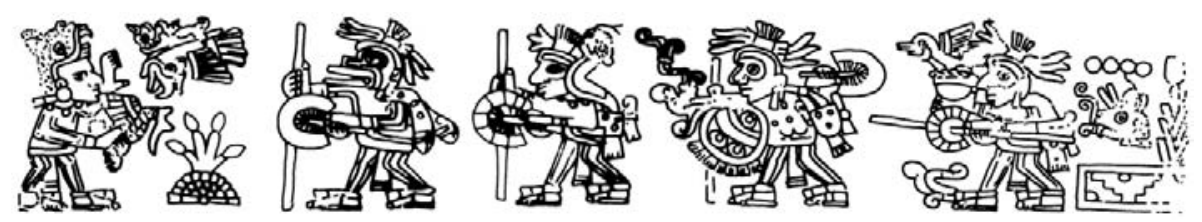

8.18. Codex Ñuu Tnoo-Ndisi Nuu, p. 10-III: Lord 8 Deer receives the four Toltec ambassadors sent by Lord 4 Jaguar of Tula-Cholula.

tact and alliance with a prestigious, superior outsider who provided legitimacy and power.

The place sign 'Town of Cattail Reeds (or Tules)' is to be read in Dzaha Dzaui as as Nuu Cohyo, which corresponds to Tollan, often written as Tula, in Nahuatl. This was the emblematic center of the successive empires of the Toltecs and the Mexica, to the North of the 


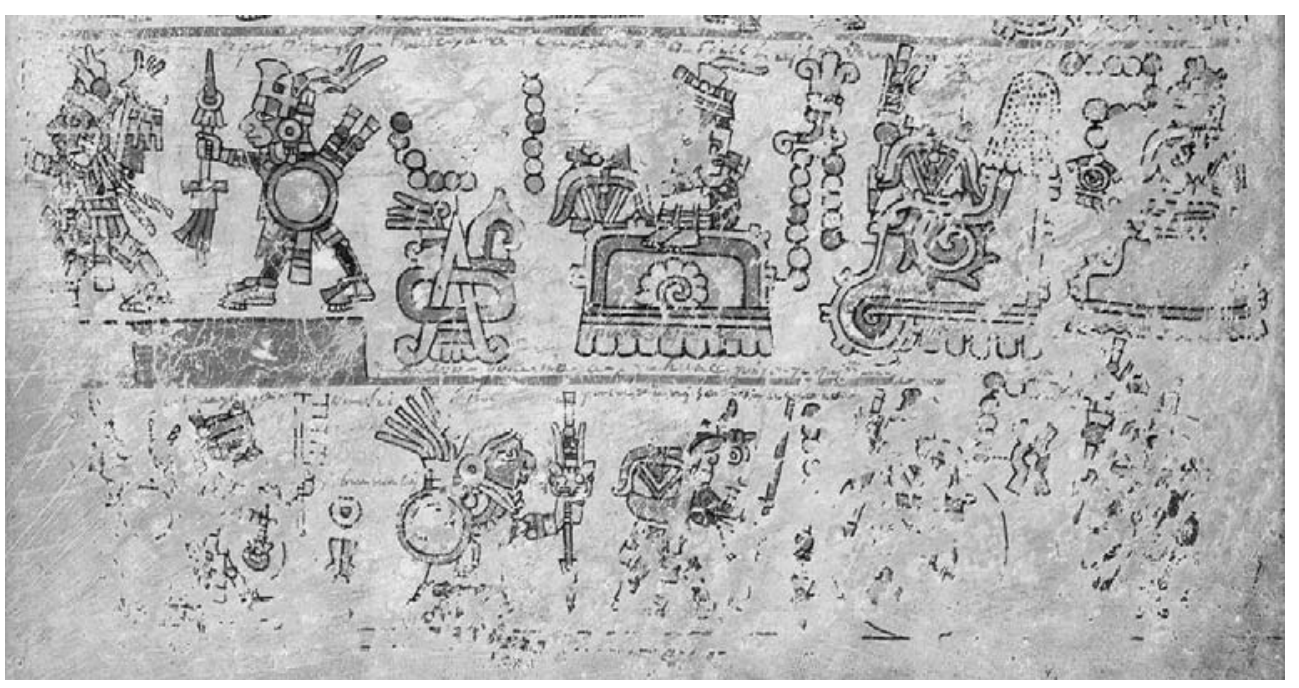

8.19. Codex Iya Nacuaa I, p. 14 (Lower Left to Upper Left, boustrophedon): Lord 8 Deer travels in procession toward Tula-Cholula, passing several sacred mountains, among which is a snow-topped volcano.

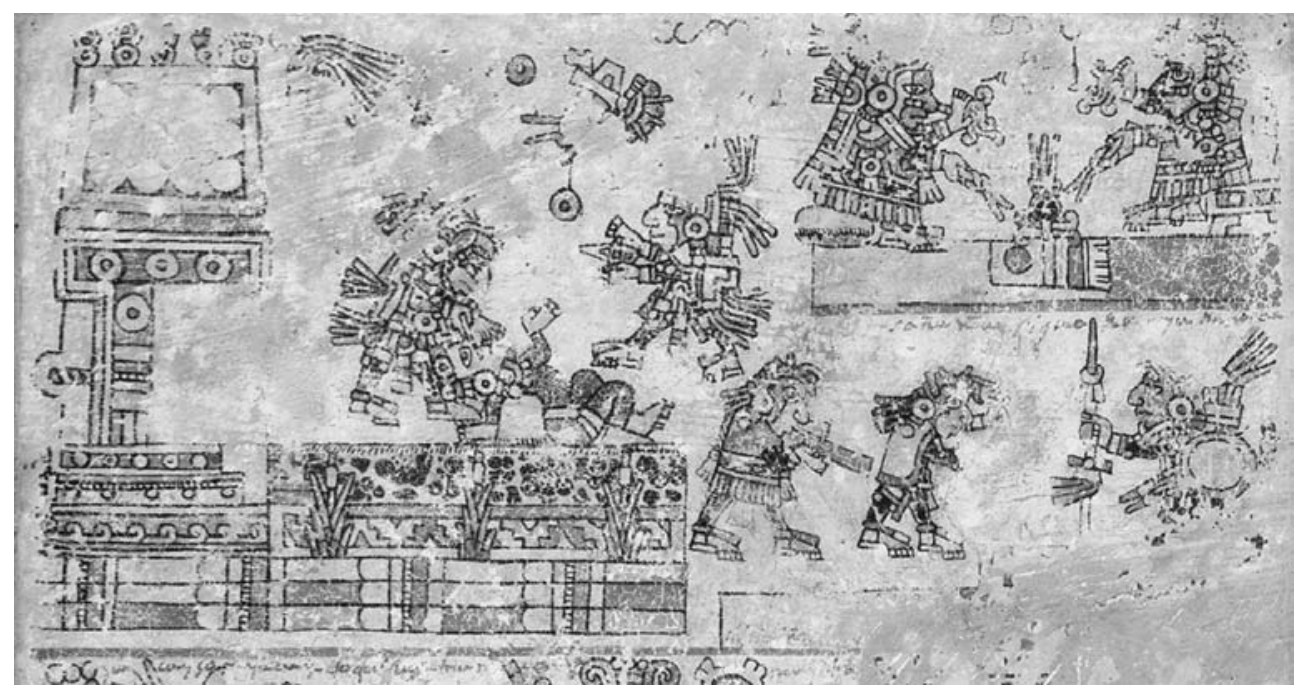

8.20. Codex Iya Nacuaa I, p. 13: Nose-piercing in the ceremonial center of Place of the Cattail Reeds (Tula-Cholula), situated in a large valley. 
Ñuu Dzaui lands. It was not only a name for several important capitals, but also a concept: a 'center of civilization, metropolis'. Most likely it was already the name or title of the Classic metropolis Teotihuacan. The same toponym was applied to Cholula, and afterward to Tenochtitlan. Nuu Cohyo is still the Dzaha Dzaui name for Mexico City. ${ }^{9}$

The Nuu Dzaui codices distinguish Lord 4 Jaguar and his people by depicting them with black or red markings around their eyes, meaning tay sami nuu, 'Men of Burned Faces', i.e. speakers of Nahuatl. Their capital was situated in a large valley, where one arrives after passing a snow-topped volcano (Codex Iya Nacuaa I, p. 14) or, in another case, a Hummingbird river (Codex Ñu Tnoo-Ndisi Nuu, p. 34-II). This fits the geographical situation of Cholula, the volcano being either the Matlalcueye (Malinche) or the Popocatepetl, depending on the route one takes, and the river being the Huitzilapan, which gave its name to the town of Puebla (in Mixtec: Yuta Ndeyoho, 'River of the Hummingbird'). Cholula was specifically and uniquely renowned throughout the Postclassic world as an ideological center where rulership was bestowed by a ceremony of nose-, lip- or ear-piercing (Acuña 19841985, II: 130-131). Similar symbols mark the royal status that, according to the Popol Vuh, the founders of the K'iché dynasties in Guatemala received from King Nacxitl, also known in the sources as Topiltzin, Ce Acatl or Quetzalcoatl. This famous Toltec ruler had his power-base in Cholula and also had direct influence in the Mixtec region:

[Quetzalcoatl] left Tula very annoyed and came to Cholula, where he lived many years with his people, several of which he sent from there to the provinces of Oaxaca, to populate it [i.e. to occupy positions of power there], and to the whole Mixteca Baja and Alta and to the Zapotec regions. And those people, they say, made those big and luxurious roman buildings in Mitla ... (Torquemada, book III: ch. 7; cf. Acuña 1984-85, I: 129).

Comparing the narrative of our manuscripts with the information in Central Mexican sources we identify Lord 4 Jaguar as that famous Nacxitl Topiltzin Quetzalcoatl, the emblematic king of the Toltec realm. Not only does his representation include the body-paint of Quetzalcoatl and of the Venus deity Ce Acatl (cf. Codex TellerianoRemensis, f. 14v), as well as a special feather-crown (apanecayotl), but also a specific physical detail: a pimple or tumor between his nose and

\footnotetext{
${ }^{9}$ See also the Codex of Tejupan ('Codex Sierra'), pp. 18, 34, 38.
} 


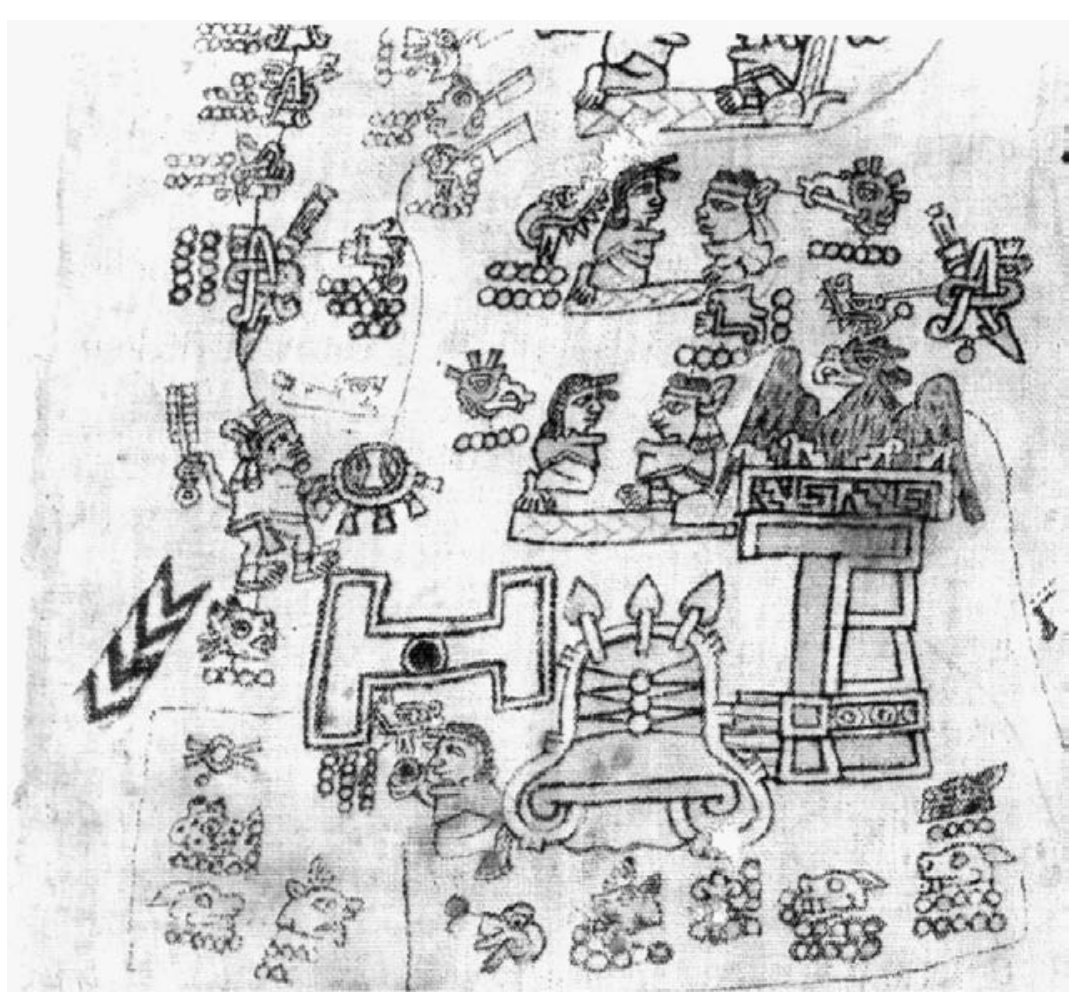

8.21. Lienzo of Tlapiltepec: Warrior Lord 4 Jaguar participates in the enthronement of Lord 7 Water (Atonal), founder of the Coixtlahuaca dynasty.

forehead, which is explicitly mentioned by the chronicler Diego Durán (1967, I: 9, 14). Nacxitl is a calendar name, a contraction of naui icxitl, '4 Foot'. The day name 'Foot', does not belong to the Nuu Dzaui or Mexica calendar, but to the earlier calendrical system of Xochicalco; the Nuu Dzaui appparently translated this name as 4 Jaguar.

In the Lienzo of Tlapiltepec Lord 4 Jaguar supervises the foundation of the dynasty of Coixtlahuaca, initiated by Lord 7 Water from 'House of the Eagle'. ${ }^{10}$ The enthronement ritual itself is situated on the Mountain of Pointed Leaves, i.e. the Cerro Verde, a very prominent and sacred mountain in the Coixtlahuaca Valley. The scene corresponds to information provided by the Anales de Cuauhtitlan about

${ }^{10}$ Caso 1961: A 14-15. For the importance of Cerro Verde, see also Ruiz Ortiz and Jansen 2009. 
the founder of the dynasty of Coixtlahuaca being Atonal ('Lord Water'), who originally came from Ancient Cuauhtitlan ('Place of the Eagles'). Connecting the story told by the Anales de Cuauhtitlan to the data given by Torquemada and others, we cannot escape the conclusion that this happened in the time that Nacxitl Topiltzin Quetzalcoatl was the ruler of Cholula. In other words, the Toltec ruler (of Cholula) who was responsible for the enthronement of Lord 7 Water or Atonal in Coixtlahuaca was, according to the combined Central Mexican sources Nacxitl Topiltzin Quetzalcoatl, and according to the Lienzo of Tlapiltepec, Lord 4 Jaguar. Conclusion: Nacxitl Topiltzin Quetzalcoatl and Lord 4 Jaguar are one and the same person. It was the same Lord 4 Jaguar who in the following year became an ally of Lord 8 Deer. ${ }^{11}$ The Central Mexican sources tell us that at the end of his reign Nacxitl Topiltzin Quetzalcoatl marched away to the East, to Tlapallan and there crossed the Laguna de Términos (Acallan, Xicalango), after which he entered the Maya region. Quetzalcoatl used to say that the Sun himself had called him:

And when the people asked him what he was going to do there, Quetzalcoatl answered that the ruler of those lands, who was the Sun, had called for him. This story was wide-spread among the Mexicans. (Torquemada, book VI: ch. 24).

This statement is formulated in the lordly language of metaphors, according to which 'going to the realm of the Sun God' means 'looking for fame', following the destiny of a warrior (cf. Sahagún, book VI: ch. 4, 21 and 33).

${ }^{11}$ See the key text of the Annales de Cuauhtitlan in the edition by Lehmann 1938: 107-109. According to the Lienzo of Tlapiltepec (Caso 1961: A 14-19), Lord 4 Jaguar had been engaged in warfare in the region between the year 10 Reed and the year 6 Flint before the enthronement of Lord 7 Water. According to the Mixtec codices, the encounter between Lord 4 Jaguar and Lord 8 Deer took place in the year 7 House, i.e. in the year immediately following the year 6 Flint. That we are dealing with the very same years 6 Flint -7 House here, is confirmed by further information in the Lienzo of Tlapiltepec: the grandson of Lord 7 Water (founder of the Coixtlahuaca dynasty when he was already an adult) visited Lord 4 Wind in Town of Flints (Caso 1961: E 37). This Lord 4 Wind was Lord 8 Deer's successor as strong man in the Nuu Dzaui Highlands, precisely in Nuu Yuchi, Town of Flints, now an archeological site known as Mogote del Cacique near Tilantongo. The chronological relationship established by the direct contact between the grandson of Lord 7 Water and Lord 4 Wind, means that Lord 7 Water and Lord 4 Jaguar were indeed contemporaneous with Lord 8 Deer. The overall picture is that of a Toltec expansion from Cholula to the South and East, first reaching the Coixtlahuaca Valley, then the Mixtec region, and, after having settled matters there, continuing to Yucatán. 


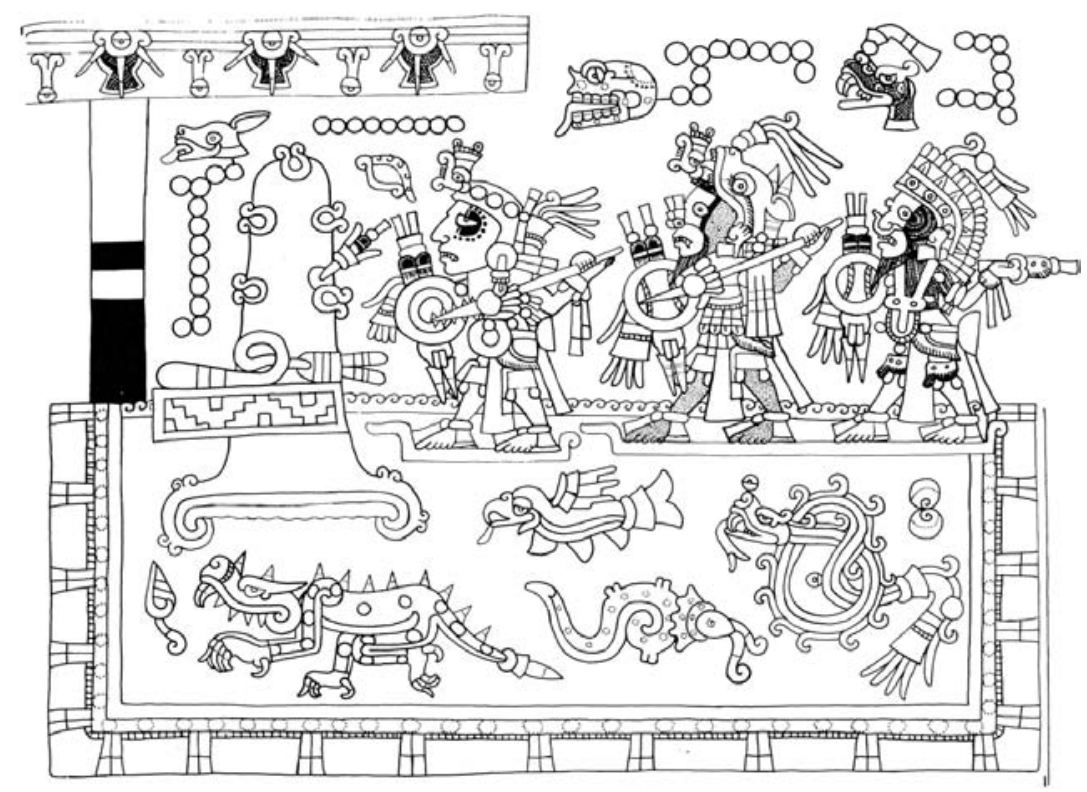

8.22. Codex Tonindeye, p. 75: Lord 8 Deer and Lord 4 Jaguar, crossing a tropical lagoon and conquering an island.

The Mixtec codices Tonindeye and Iya Nacuaa show that Lord 8 Deer accompanied his Toltec ally and mentor Lord 4 Jaguar on a large expedition eastward (to the great Temple of the Sun God), toward the end of which they conquered an island in front of the coast. The location and description of the place in these codices ('there where the Heaven rests upon the water and where there are alligators, flying fish, and big conches') suggests that this is precisely that area of the Laguna de Términos, Xicalango and Acalan on the Mexican Gulf Coast, the land of the Putún, which, as we know from historical sources and from archeological data, was strongly influenced by the Toltecs, and functioned as a gateway to the Yucatan peninsula.

Here the epic story of Lord 8 Deer connects explicitly with the legendary expedition of the Toltec ruler Nacxitl Topiltzin Quetzalcoatl or Kukulkan from his capital Cholula to the lands of the Maya, establishing his rule in Chichen Itza. Bishop Diego de Landa documents the prominence of a Sun Priest (and therefore of a Sun cult) at this site: the Ah Kin May, who seems to have been the central religious authority among the Mayas of Yucatan (Tozzer 1941: 27). 
This expedition is a well-known theme in Central Mexican sources, as well as in the Popol Vuh and several Yucatec chronicles. It should not come as a surprise to find references to this important legitimating narrative in sources about this period that come from the Nuu Dzaui region, which is situated in beween Central Mexico and the Maya. Of course, what we are concerned with here is the coincidence in literary narrative between these different historical texts. The actual historical reality and its reflection in the archeological record is quite a different question. $^{12}$

After his alliance with the Toltecs and the blessings of Quetzalcoatl, which made him king of Nuu Tnoo, and, in fact, of a large part, if not the whole, of Nuu Dzaui, and after the fabulous campaign to the land of the Mayas, Lord 8 Deer returned to Nuu Tnoo and became involved in a series of politically motivated killings. His elder halfbrother was murdered in a steambath, possibly on the orders of Lord 8 Deer himself. Apparently putting the blame on other descendants of the first marriage of his father, Lord 8 Deer attacked Town of the Xipe Bundle, where at that time Lady 6 Monkey was ruling with her husband, Lord 11 Wind. This couple were killed, together with the two sons of Lord 11 Wind's earlier marriage to the half-sister of Lord 8 Deer. The daughter of that earlier marriage, Lady 13 Serpent was left alive, and the son of Lady 6 Monkey herself with Lord 11 Wind, Lord 4 Wind, also escaped execution.

In order to take over and monopolize the power of this lineage, Lord 8 Deer married the unfortunate Lady 13 Serpent, his half-niece, in the year 13 Reed (1103). For several years she did not give birth to a heir, until she and her husband made offerings to a temple and communicated with a large Vision Serpent. Nine months later a child,

${ }^{12}$ Invoking "overwhelming archeological and ethnohistorical evidence to the contrary", John Pohl dismisses our intepretation as "clearly more interested in trying to aggrandize Mixtec history by associating place signs with world-renowned archaeological sites rather than actual Mixtec communities" (in Hendon \& Joyce 2004). A more detailed review has been published by Henry B. Nicholson as a contribution to the volume in honor of Mary Elizabeth Smith (Boone 2005: 143-160). Nicholson, who has published an important monograph on the historical Quetzalcoatl (2001), points out - correctly - that each of our arguments in itself is not conclusive, but he does not take into account the compelling effect of the combination and coherence of all these arguments together. See Jansen 2006 for a full presentation of the reasons to identify the Town of Tules as Cholula and its ruler as Quetzalcoatl. Some other relevant publications on this enigmatic and legendary figure are: Stenzel 1980, Carrasco 1982, Graulich 1988 and 2002, Ringle et al. 1999, Florescano 2004. 


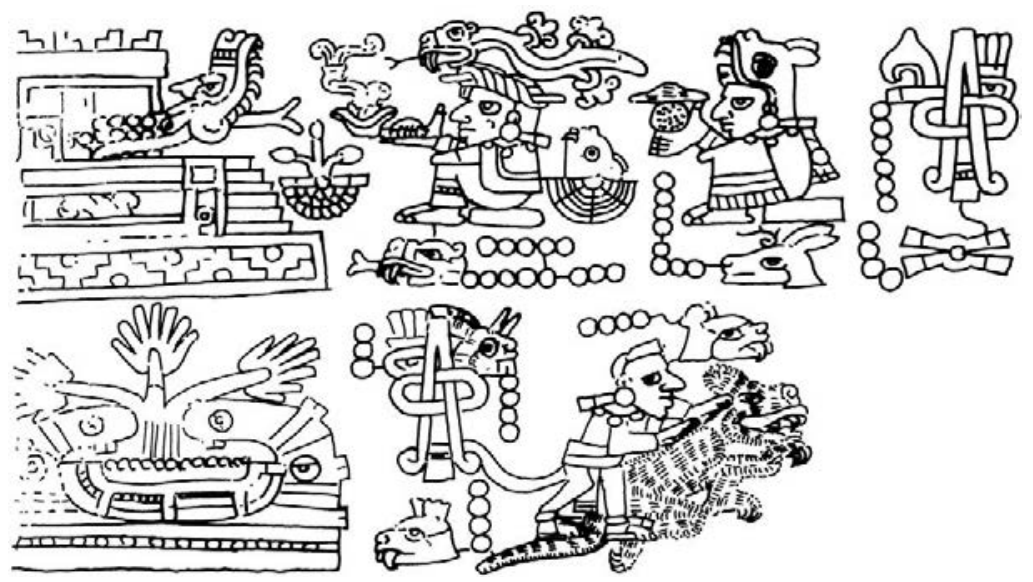

8.23. Codex Ñu Tnoo-Ndisi Nuu, p. 11-II/III (Upper Right to Lower Left, boustrophedon): Lord 8 Deer and Lady 13 Serpent visit a temple to meet a Vision Serpent. The following year their first son, Lord 4 Dog, is born.

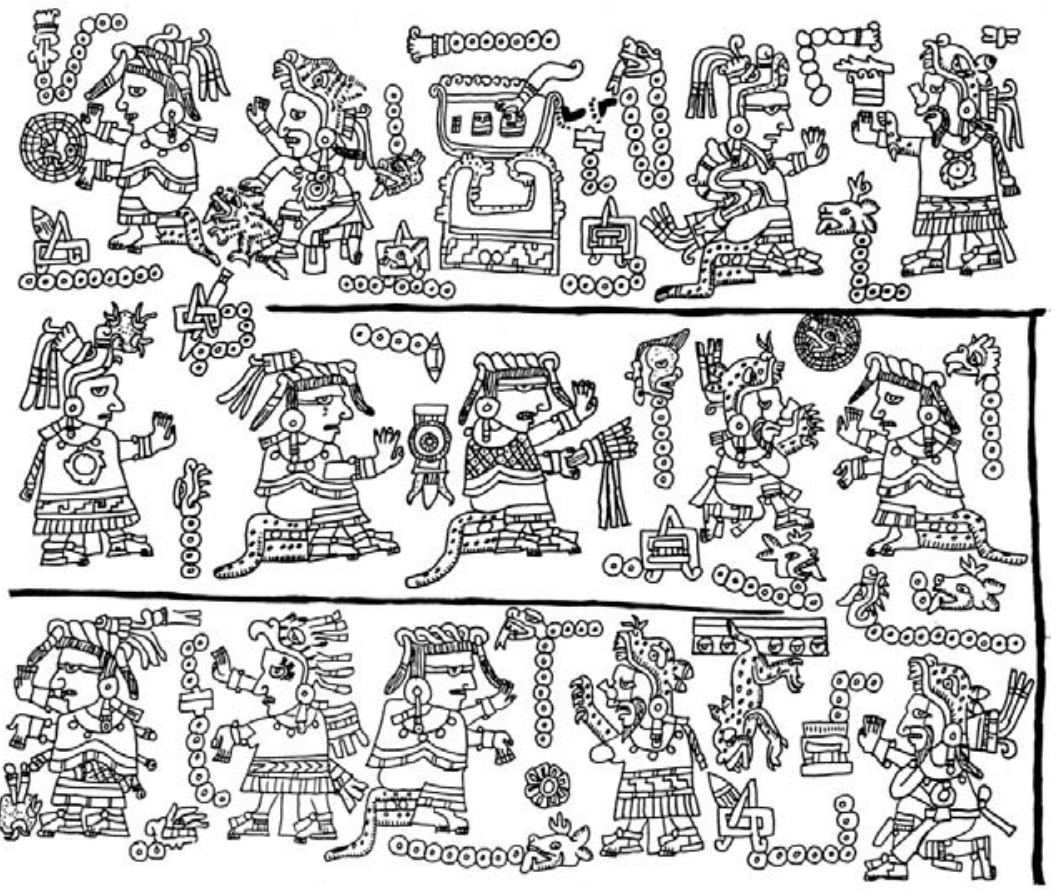

8.24. Codex Yuta Tnoho Reverse page VIII (Upper Right to Lower Left, boustrophedon): 1) the marriage of Lord 8 Deer and Lady 13 Serpent, followed by their son, Lord 4 Dog and four other children, 2) the marriage of Lord 8 Deer and Lady 6 Eagle, 3) followed by their son, Lord 6 House; the marriage of Lord 8 Deer and Lady 11 Serpent, followed by a son and a daughter. 


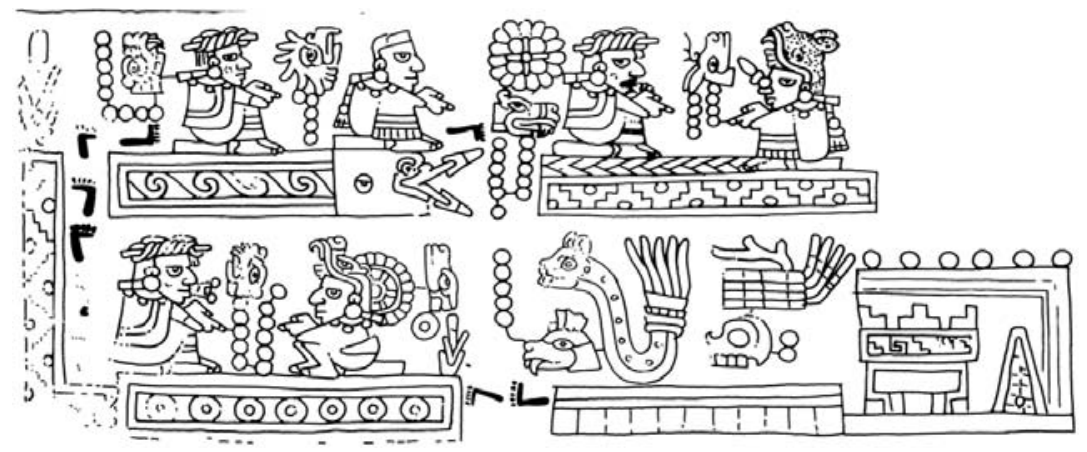

8.25. Codex Ñuu Tnoo-Ndisi Nuu, p. 11-IV/V (Upper Right to Lower Left, boustrophedon): Lord 8 Deer marries Lady 11 Serpent, daughter of the royal couple of Totomihuacan (?) and of Toltec descent (ultimately coming from Temazcal, i.e. Tonalá).

Lord 4 Dog, was born, who was to begin the dynasty of Chiyo Cahnu (Teozacualco).

Meanwhile, in the year 2 House (1105), Lord 8 Deer had married a second wife: Lady 6 Eagle from Ñu Ndaya (Chalcatongo), the daughter of his own sister. Lady 6 Eagle left for him her former husband, the ruler of Mountain of the Seven Stones (Yuu Usa, present-day Santa Catarina Yuxia). She was soon to bear him a child, Lord 6 House, who was to become the ancestor of the lineages of Yucu Dzaa (Tututepec) and Nuu Tnoo (Tilantongo).

That same year 2 House, Lord 8 Deer further confirmed his legitimacy by marrying a princess of the prestigious dynasty of Nuu Tnoo, Lady 10 Vulture, on the specific holy day used by members of this lineage for such ceremonies. To indicate his permanent alliance with the Toltecs, he chose as his fourth wife Lady 11 Serpent, who came from Place of Bird with Arrow-Pointed Beak (probably Totomihuacan) and was of Toltec descent.

Probably for similar reasons he finally married Lady 6 Wind 'Quetzal Feather of Royal Blood'. She came from Jaguar Town, Nuu Naña (Cuyotepeji), where a new dynasty had been put in place by Lord 1 Deer 'Serpent - Earplug' (Coanacoch in Nahuatl), an important ambassador of Nacxitl Topiltzin Quetzalcoatl (as explained in the first pages of Codex Ñuu Naña). 

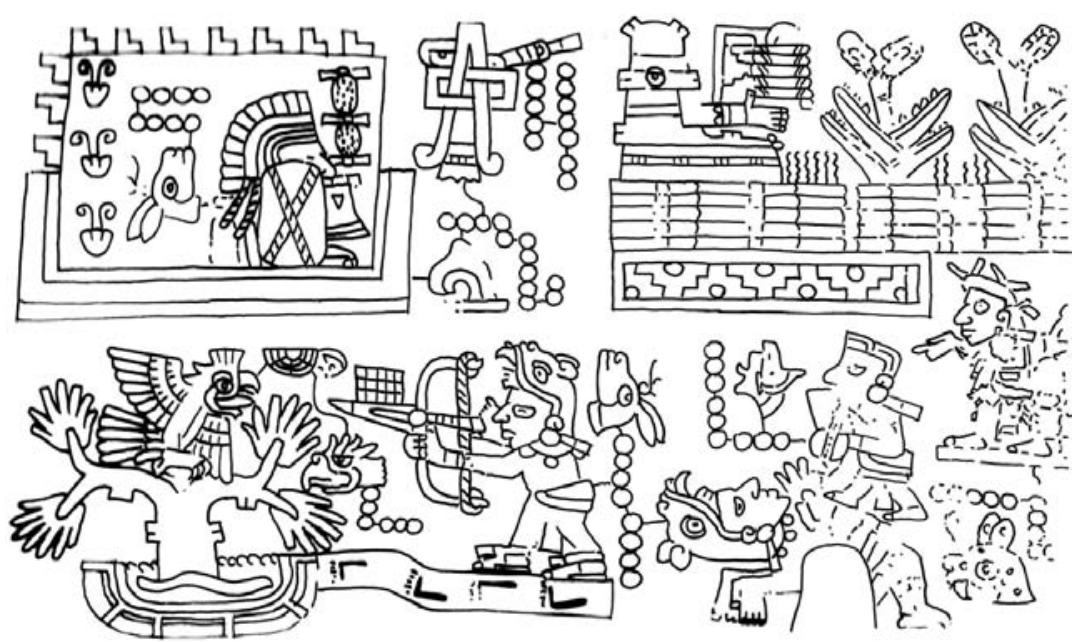

8.26. Codex Ñuu Tnoo - Ndisi Nuu, p. 14-V/IV (Lower Left to Upper Left, boustrophedon): the Death of Lord 8 Deer.

In the year 12 Reed (1115), when he completed a cycle of 52 years, Lord 8 Deer went out hunting precious birds, apparently at the instigation of Lady 6 Eagle, as her name is connected to his bow and arrow, as well as to a sign for darkness. There he was murdered. Codex Iya Nacuaa I, p. 16, clarifies that this happened on the orders of Lord 4 Wind, the son of Lady 6 Monkey. It was an act of revenge for the killing of his parents by Lord 8 Deer. In fact the fatal day, 12 House, suggests that the ambush was planned to honor Lord 4 Wind's father, Lord 11 Wind (whose name day precedes 12 House).

After Lord 8 Deer's dramatic death, the distinct lineages, that had sprung from his successive marriages, divided - and probably disputed - the inheritance. Although Nuu Dzaui was never united again under one ruler, the idea of real or fictitious kinship bonds between the 'one great family of kings and queens', subsisted as a memory of Lord 8 Deer's dream. It became the conceptual base for a well calculated marital alliance policy, aimed at enhancing the prestige of each lineage and at keeping the mat and throne (and the corresponding privileges and tribute rights) united. 


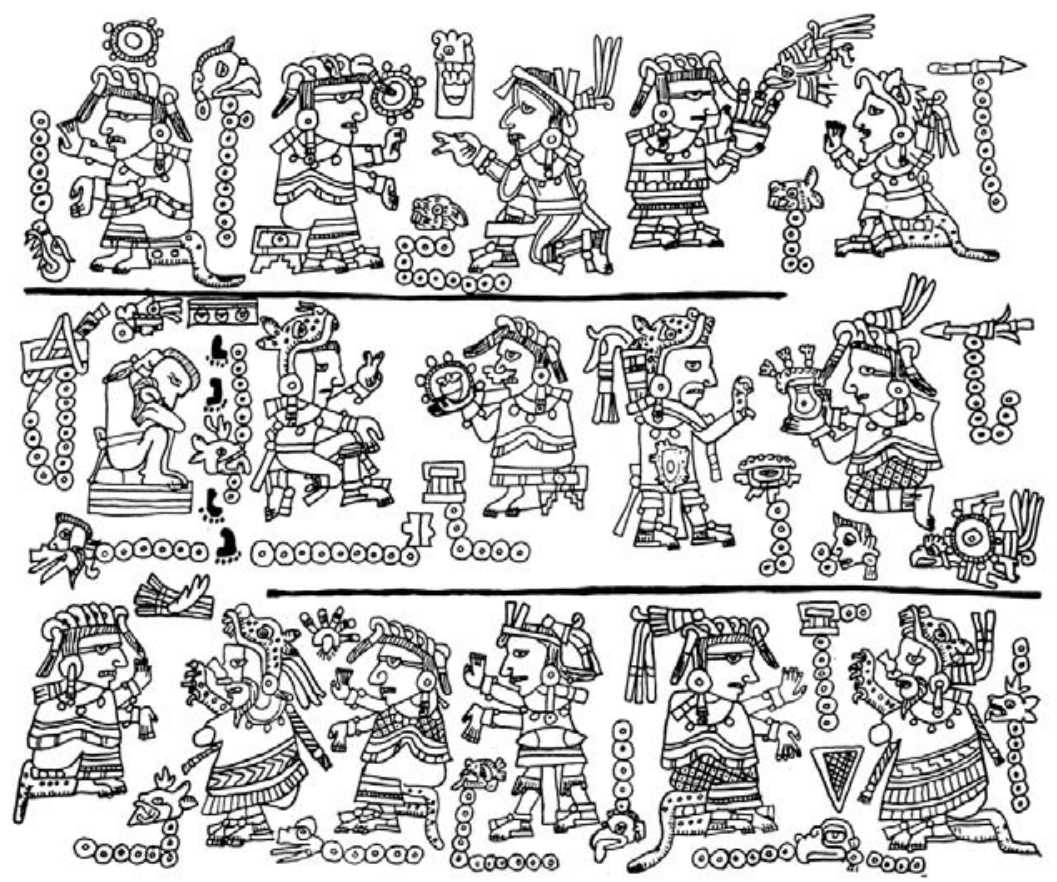

8.27. Codex Yuta Tnoho Reverse Page IX (Lower Right to Upper Left, boustrophedon): 3) Lord 8 Deer marries Lady 10 Vulture, two children are born; Lord 8 Deer marries Lady 6 Wind. 2) In the year 12 Reed, day 1 Grass, Lord 8 Deer dies. His son, Lord 6 House, marries Lady 9 Movement. They have a son, Lord 5 Water, who marries Lady 10 Reed. 1) The children of this couple are: a) Lord 8 Reed, b) Lady 5 Rabbit (who marry), c) Lord 11 [likely an error for 10] Rabbit, who marries Lady 10 Vulture, and d) Lady 6 Alligator.

\section{Arrangements After the Death of Lord 8 Deer}

After initially being persecuted by Nacxitl Topitzin Quetzalcoatl, Lord 4 Wind was ultimately pardoned by the great Toltec ruler and recognized as the new 'strong man' in Nuu Dzaui. As symbol of this status he also received the turquoise nose-ornament in Cholula. In the year 4 Flint (1120), Lord 4 Wind, who was now reaching the age of 28, founded a new capital at Nuu Yuchi, Place of Flints, presently the archeological site of Mogote del Cacique, somewhat to the South of Nuu Tnoo, in the present-day agencia of San José Tres Lagunas. 


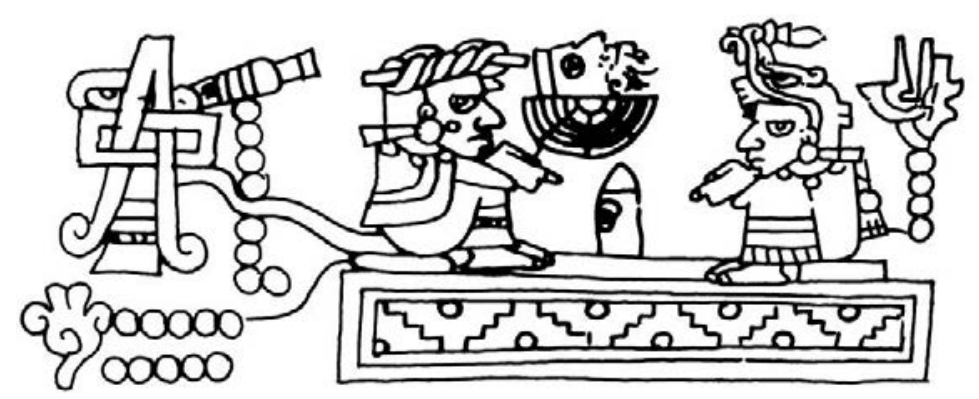

8.28. Codex Ñuu Tnoo-Ndisi Nuu, p. 11-III: the daughter of Lord 8 Deer, Lady 10 Flower 'Spiderweb of Rain' (Dzinduhua Dzavui), who had been born in the year 8 Reed, marries Lord 4 Wind 'Fire Serpent'; they rule the kingdom of Flint Town (Nuu Yuchi).

In order to establish his local authority Lord 4 Wind married Lady 10 Flower 'Rain Spiderweb', the daughter of Lord 8 Deer and Lady 13 Serpent. This was in the year 8 Flint (1124).

Two years later their only child was born: Lady 13 Flower 'Precious Bird'. But before that happened, Lord 4 Wind had already married a second wife: Lady 5 Lizard 'Zacate [leaves] - Pulque Vessel'. They had several children:

- Lord 1 Reed 'Jaguar with Flames', who was probably born in the year 10 Rabbit (1126).

- Lord 11 Flower, 'Xicolli of Clouds', who was probably born in the year 3 Flint (1132).

- Lady 5 Wind, 'Hair of Clouds', who was probably born in the year 5 Rabbit (1134). ${ }^{13}$

The last two of these children, Lord 11 Flower, 'Xicolli [tunic] of Clouds' and Lady 5 Wind, 'Hair of Clouds', were to contract a brothersister marrriage. Lord 4 Wind set them up as rulers of Flame Town, Ñuu Ndecu (Achiutla), mentioned here for the first time as a separate kingdom. The given name of their older brother, Lord 1 Reed 'Jaguar with Flames', also suggests a link with Ñuu Ndecu. This kingdom was probably set apart for the children of Lady 5 Lizard 'Zacate [leaves]

13 Codex Ñuu Tnoo-Ndisi Nuu p. 30-III. Caso (1960) has reconstructed the sequence on the basis of the chronological context. The codex actually gives 9 Rabbit (1138), 2 Flint (1144), and 4 Rabbit (1146), but these seem too late - maybe they refer to the birth of other children. See below. 
- Pulque Vessel', either because she had unique rights to that area or because Lord 4 Wind wanted to create a special mat and throne for her descendants.

Meanwhile the daughter of Lord 4 Wind's first marriage, Lady 13 Flower 'Precious Bird', married Lord 4 Alligator 'Sacred Alligator', a son of Lord 8 Deer 'Jaguar Claw' and his first wife Lady 13 Serpent 'Flower Serpent'. He had been born in the year 9 Flint (1112) and was her maternal uncle. ${ }^{14}$ We suspect that the marriage formed part of an alliance policy promoted by the widow queen, Lady 13 Serpent, herself: first she had given the hand of her daughter, Lady 10 Flower, to Lord 4 Wind; now she confirmed that link by having her son marry the only daughter of Lord 4 Wind and Lady 10 Flower. At the same time we see it as an example of Lord 4 Wind's attempts to connect his own house with the prestigious and politically most important wife of his predecessor, who happened to be his own elder half-sister.

These links were also some form of compensation for the fact that he was not giving Lord 8 Deer's first wife, Lady 13 Serpent 'Flower Serpent', control over the central kingdom of Nuu Tnoo. That privilege went to Lord 6 House 'Jaguar that came down from Heaven', the son of Lord 8 Deer's second wife, Lady 6 Eagle, and in reality the firstborn son of the great ruler. Perhaps this too was the fulfilment of a promise that Lord 4 Wind had made to Lady 6 Eagle in return for her assistance in preparing the murder of Lord 8 Deer. We also take it as a move to co-opt the faction that supported the descendants of the second marriage of Lord 8 Deer's father. We have to remember that Lady 6 Eagle was the daughter of Lord 8 Deer's sister and therefore a direct descendant of Lord 5 Alligator's second marriage, through the female line.

At the age of 29, Lord 6 House 'Jaguar that came down from Heaven' married Lady 9 Movement 'Jade Heart', on the day 4 Deer of the year 9 Rabbit, which would correspond to 1138 . She was the daughter (maybe granddaughter) of Lord 1 Death 'Sun Serpent' and Lady 11 Serpent 'Flower - Quetzal Feathers', who were already rulers of Ñu Sitoho (Juquila) in 1083 when Lord 8 Deer had arrived on the coast. The time span between the marriage of her parents and her own mar-

\footnotetext{
${ }^{14}$ Codex Nuu Tnoo-Ndisi Nuu, pp. 11/12-III. We interpret the sign of burning tobacco in his name as 'venerated' or 'sacred'.
} 
riage seems unusually long. Maybe the year 9 Rabbit is an error and should actually have been 10 Rabbit (1126), when Lord 6 House was 17 years old.

The connection with a princess from the Chah Tnio (Chatino) people suggests that Lord 6 House not only succeeded his father in Nuu Tnoo in Nuu Dzaui Ñuhu (the Mixteca Alta), but also in Yucu Dzaa on the coast.

Only one son is mentioned for this couple: Lord 5 Water 'Stone Jaguar', but we suppose that he was the descendant who was going to continue the dynasty in Nuu Tnoo and that there were probably other children who may have stayed in the coastal area. The manuscripts that deal with this time period (Codices Nuu Tnoo-Ndisi Nuu, Yuta Tnoho Reverse and Añute; Map of Chiyo Cahnu) are all from the Mixteca Alta and do not refer to the mat and throne of Yucu Dzaa anymore. The fact that the house of Yucu Dzaa descended from Lord 8 Deer explains the presence of a major biography of that great ruler, Codex Iya Nacuaa, in its royal library.

The fact that Lady 6 Eagle obtained the kingdoms of Nuu Tnoo and Yucu Dzaa for her son must have been a setback for the widow queen, Lady 13 Serpent. We suspect that she used her political and family influence on Lord 4 Wind to obtain a similar position for her own firstborn son, Lord 4 Dog 'Coyote Catcher'. ${ }^{15}$ Consequently Lord 4 Wind arranged a special kingdom of his own for this prince, setting him up in Chiyo Cahnu (Teozacualco), which now became independent of Nuu Tnoo. In creating this new polity and dynasty, Lord 4 Wind cleverly involved Lord 8 Deer's last wife, Lady 6 Wind 'Quetzal Feather of Royal Blood', who had advised him and intervened as an intermediary in his contact with Lord 4 Jaguar 'Nacxitl Topiltzin Quetzalcoatl'. In playing this intermediary role she had benefitted from her association with Jaguar Town, Ñuu Naña (Cuyotepeji), the place where Lord 1 Deer 'Coanacoch', an important ally and ambassador of Lord 4 Jaguar 'Nacxitl Topiltzin Quetzalcoatl' had founded a new dynasty. After Lord 8 Deer's death she had married Lord 5 Dog 'Coyote', who

${ }^{15}$ Caso used to transcribe the name as 'Tame Coyote'. The reading of the extended hand above an animal in place signs such as Michmoloyan, Chapolmoloyan and Cacalomaca (Codex Mendoza, pp. 31, 32, 33) suggests, however, that the verb 'to catch' is meant. 
was a son of the couple enthroned in Nuu Naña by the Toltec Lord 1 Deer 'Coanacoch'. ${ }^{16}$

Codex Tonindeye, p. 28-I, places the year 9 House, day 6 Eagle next to the marriage of Lady 6 Wind and Lord 5 Dog. They would function as the Founding Ancestors of the first dynasty of Chiyo Cahnu, because it was to their daughter, Lady 4 Death 'Jewel', that Lord 4 Dog 'Coyote Catcher' would propose marriage.

Thus Lord 4 Dog and Lady 4 Death were installed as rulers in Chiyo Cahnu. Their first son and heir was Lord 13 Dog 'Venus Eagle'. Codex Tonindeye (pp. 27-III and 28-I) shows Lady 4 Death giving birth to a boy and mentions the year 8 House, day 4 Dog between this explicit scene and the next, which is the marriage of Lord 13 Dog to two princesses. Lord 13 Dog's son and successor, Lord 7 Water 'Red Eagle', was born in the year 7 House. Later, Lord 7 Water 'Red Eagle' would be succeeded by his son, Lord 13 Eagle 'Sacred Rain'.

Reading this series of years within the chronological framework after the death of Lord 8 Deer (1115), we obtain the following equivalences:

a) 9 House, associated with the marriage of Lady 6 Wind to Lord 5 Dog, presumably followed immediately by the birth of their daughter, would be 1125 .

b) 8 House, associated with the birth of their grandson, would be 1137.

c) 7 House, associated with the birth of their great-grandson, would be 1149 .

The third correlation (the birth of Lord 7 Water in 1149) fits well with the other genealogical-chronological data for this period. But in total the series of given year dates is extremely short for the span of these generations. Recently Emily Rabin (2004) has proposed an alternative interpretation, reversing the first two years and suggesting, as Alfonso Caso had already done, that Lady 6 Wind had married Lord 5 Dog before she married Lord 8 Deer. This results in the following sequence:

\footnotetext{
${ }^{16}$ Codex Tonindeye, pp. 27/28; Codex Ñuu Tnoo-Ndisi Nuu, p. 14-V; Codex Ñuu Ñaña, pp. 1-6.
} 


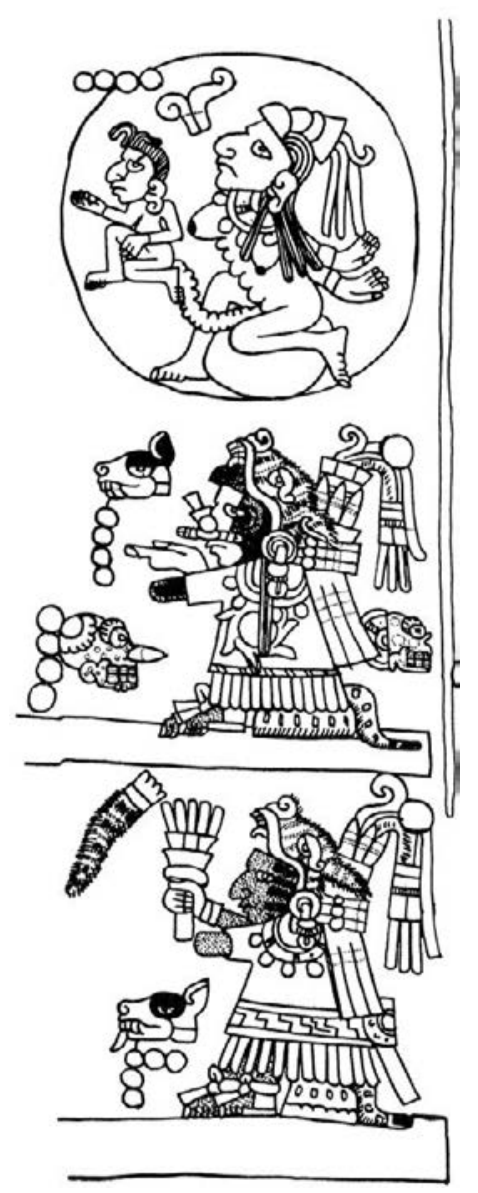

8.29a. Codex Tonindeye, p. 27 (Left half, connecting with p. 28 on the left: reading from Right to Left). In the center: Lord 4 Dog.

a) 8 House (1085) for the marriage of Lady 6 Wind to Lord 5 Dog,

b) 9 House (1125) for the marriage of their daughter, Lady 4 Death, to Lord 4 Dog.

The implications would be that Lord 5 Dog's parents ruled in Nuu Naña in the 1050s and that Lady 4 Death would have been approximately 20 years older than her husband, Lord 4 Dog.

The rule of Lord 5 Dog's parents, however, seems to have been inaugurated by Lord 1 Deer 'Coanacoch', who acted as ambassador of Lord 


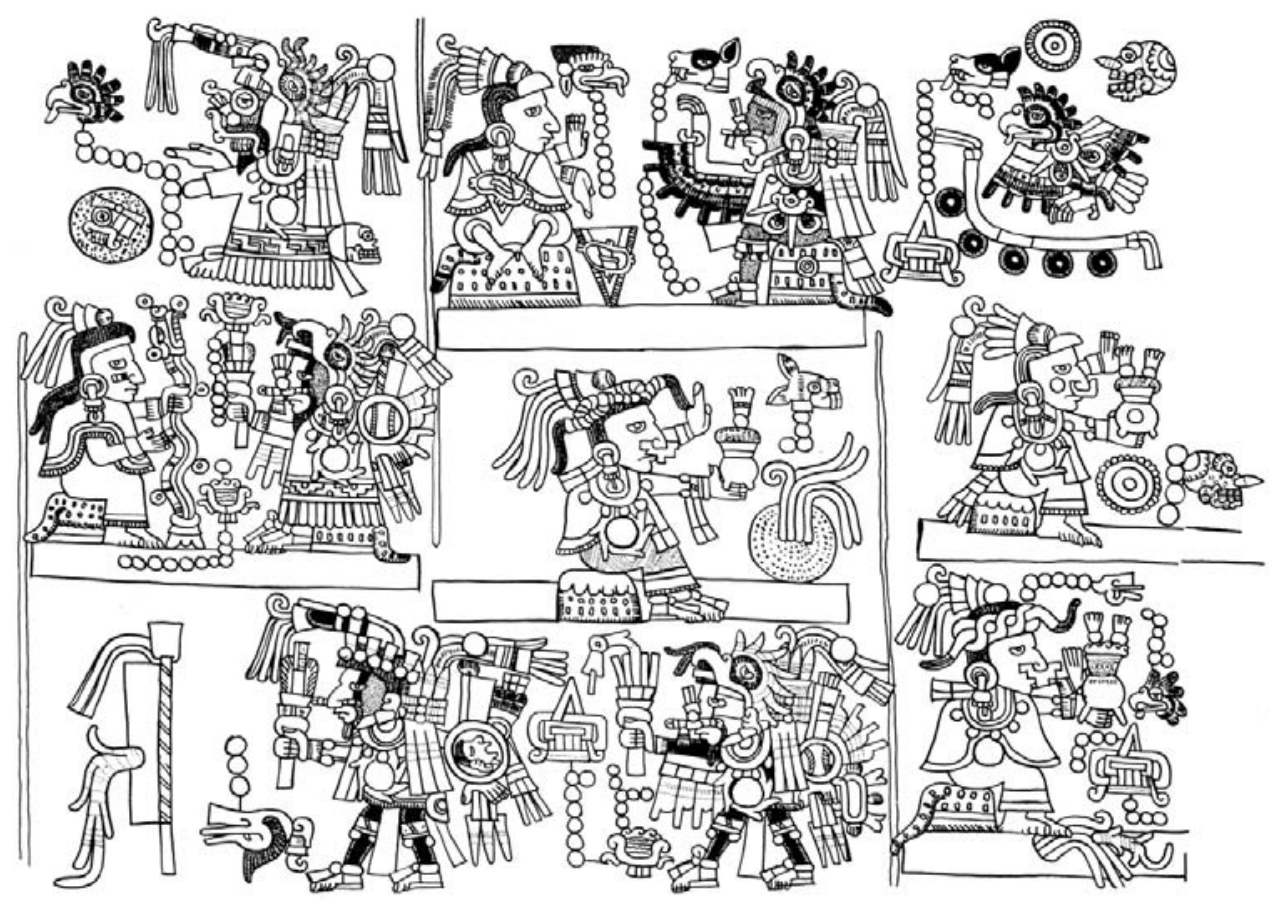

8.29b. Codex Tonindeye page 28 (connected on the right to p. 27: reading from Right to Left, boustrophedon, following the guide lines). Marriage of Lord 4 Dog to Lady 4 Death, the birth of their son Lord 13 Dog, his marriage and sons, Lord 7 Water and Lord 3 Wind. The marriage of Lord 7 Water and the birth of his son, Lord 13 Eagle.

4 Deer 'Nacxitl Topiltzin Quetzalcoatl' to Lord 8 Deer in the year 7 House (1097). Therefore it is more plausible that Lord 5 Dog's parents were in power around 1090-1100 and that he himself was also born in that period. This context suggests that Lord 5 Dog and Lady 6 Wind married shortly after the death of Lord 8 Deer (1115). The year 9 House (1125), day 6 Eagle, therefore, fits better as the date for the marriage of their daughter, Lady 4 Death, to Lord 4 Dog, who was then 15 years old. ${ }^{17}$ There is no need to invert the sequence of dates; we would just have to suppose that in copying an earlier document, the

${ }^{17}$ In proposing this new interpretation of Codex Tonindeye pp.27-28, we correct our reading of many years ago (in: Anders \& Jansen \& Pérez Jiménez 1992b). Hermann Lejarazu (2008c: 70) mentions the problem too, but does not offer a solution of his own. 
Tonindeye painter by mistake placed the year 9 House, day 6 Eagle, with the anteceding couple, one generation too early. This is perfectly conceivable, even more so because the marriage of Lord 4 Dog, son of Lord 8 Deer, was the event of central historical importance here, the marriage of his parents-in-law being little more than a parentage statement for his wife.

As Lady 4 Death was still quite young (less than 10 years old) at the time of marrying Lord $4 \operatorname{Dog}(1125)$, it would have taken a couple of years before their son, Lord 13 Dog, was born: approximately till 1132. In this line of thought it is plausible that year 8 House (1137), day 4 Dog, actually dates the marriage of Lord 13 Dog, only a few years after his birth. Obviously this was a ceremonial arrangement, on a day chosen to honor the ruler Lord 4 Dog. The real marriage must have been consummated much later, so that the first child was not born until 1149.

\section{The Short-Lived House of Nuu Yuchi}

Let us return to Flint Town, Nuu Yuchi. The first-born and apparently only child of Lord 4 Wind's first marriage, Lady 13 Flower 'Precious Bird', stayed there with her husband, her maternal uncle Lord 4 Alligator 'Sacred Alligator'. They had several children. ${ }^{18}$ The first three sons married three daughters of Lord 11 Flower, 'Xicolli [tunic] of Clouds' and Lady 5 Wind, 'Braided Hair of Clouds' (who were both children of Lord 4 Wind with his second wife, and who had been granted the rulership of Nuu Ndecu). The three sons and their wives were:

1. Lord 7 Eagle 'Flames' and Lady 3 Serpent 'Sacred Jewel'. Both stayed in Flint Town.

2. Lord 4 Jaguar 'War Jaguar' and Lady 8 Jaguar 'Serpent Jewel'. Both stayed in Flint Town.

3. Lord 4 Water 'Rain Jaguar' and Lady 1 Grass 'Eagle Wing'.

One would assume that these three boys were born between the years 12 Reed (1139) and 5 Reed (1147), when their mother was between 13 and 21 years old. Maybe the years 9 Rabbit (1138), 2 Flint (1144), and

\footnotetext{
${ }^{18}$ Codex Nuu Tnoo-Ndisi Nuu p. 29-III/II.
} 
4 Rabbit (1146), given by Codex Nuu Tnoo-Ndisi Nuu as birth years of the children of Lord 4 Wind and Lady 5 Lizard, are clearly out of the chronological sequence there, and actually represent the birth years of these three princes. That would mean that their mother was still very young (12) at the birth of her first son, however. Their wives must have been born around 1150, as they were daughters of a mother who herself had been born in the year 5 Rabbit (1134).

Lord 4 Wind himself probably arranged the marriages beforehand, to the effect that the three sons of the daughter from his first marriage married three daughters of the son and daughter from his second marriage. This points toward a strengthening of his house, but at the same time toward an inward looking policy.

The infant princess Lady 13 Flower 'Precious Bird' and her husband Lord 4 Alligator had many more children:

4. Lord 3 Vulture, 'Arrow Fire-Serpent', born in the year 6 Flint (1148).

5. Lady 8 Lizard 'Butterfly of Knives' (clearly named after the Goddess known as Itzpapalotl in Nahuatl), born in the year 7 House (1149).

6. Lady 1 Rabbit 'Breath of the Earth', born in the year 8 Rabbit (1150).

7. Lady 13 Grass 'Fan of Clouds', born in the year 9 Reed (1151).

8. Lord 13 Serpent 'Eagle', born in the year 10 Flint (1152).

9. Lady 11 Deer 'Quetzal Jewel', born in the year 11 House (1153).

10. Lord 4 Wind 'Jaguar Sun', born in the year 12 Rabbit (1154).

In the year 13 Reed (1155), on the day 7 Water, Lord 4 Water 'Rain Jaguar' and Lady 1 Grass 'Eagle Wing' went to visit the mountain shrine of 1 Alligator and 13 Flower. These calendar names must refer to the Lord 1 Alligator and Lady 13 Flower, who were the ancestral figures connected with Monte Albán. ${ }^{19}$ Lord 4 Water and Lady 1 Grass were probably participating in a ritual in the ruined but still very respected ceremonial center of that Classic metropolis. We notice that one of the deified ancestors invoked had the same calendar name as the infant princess and mother of Lord 4 Water: Lady 13 Flower. The ritual was probably done on her behalf. That would explain why it interrupts the list of her children. Without additional information it is not possible to

${ }^{19}$ Codex Yuta Tnoho, p. 1; Codex Tonindeye, p. 19. 
be sure of what is going on, but we speculate that offerings were made for Lady 13 Flower's well-being, to restore her health and strength. At the same time the connection with those ancient Ancestors, associated with Classic Monte Albán, provided the celebrants with a great legitimizing power.

The one who is shown as the first protagonist of this clearly important religious act, Lord 4 Water, was Lady 13 Flower's third son, who at that time must have been between 8 and 10 years old. His companion, Lady 1 Grass, must have been even younger, at the most 7 years old. The ritual may have coincided with Lord 4 Water's first entrance into the temple as a boy and with the planning of his future marriage. Obviously it must have had a special impact on the course of events; otherwise it would not have been registered in this special way. The place of celebration was a Sacred Precinct of Sand or Ashes. We prefer the latter reading, Precinct of Ashes, as this name would refer to the West (Yaa Yuta, 'River of Ashes'), the realm of the Grandmother, Lady 1 Eagle, the Goddess of procreation.

The main consequence seems to have been the birth, five years later, of a boy, Lord 1 Eagle 'Rain', who was born in the year 5 Flint (1160). It is not clear if he is an eleventh and last son (xocoyote) of Lady 13 Flower, who was only 34 years old at the time, or of the last mentioned couple, Lord 4 Water 'Rain Jaguar' and Lady 1 Grass 'Eagle Wing'. The latter interpretation seems the most logical in view of the pictographic conventions, but would make Lady 1 Grass an extremely young mother. It is safe to assume that the birth of this boy was a direct outcome of the visit made by Lord 4 Water and Lady 1 Grass to the mountain shrine.

The day 1 Eagle is dedicated to the Goddess of procreation, known as the Grandmother of the River (Sitna Yuta), the Lady of the West, who appears as married to a Lord 1 Grass. ${ }^{20}$ The coincidence of both calendar names meant that Lady 1 Grass and the new born Lord 1 Eagle entered into a special religious relationship with that divine couple. Maybe this was the outcome of a vow made during the aforementioned ritual. It would be the destiny of the boy to take care of a Toltec arrow, supposedly a Sacred Arrow, dating from the earlier contact with Lord 4 Jaguar 'Nacxitl Topiltzin Quetzalcoatl'. Eventually he would go with this religious power object to the Ash River (Río

${ }^{20}$ See Codex Yuta Tnoho, p. 16, and Codex Tonindeye, p. 16. 


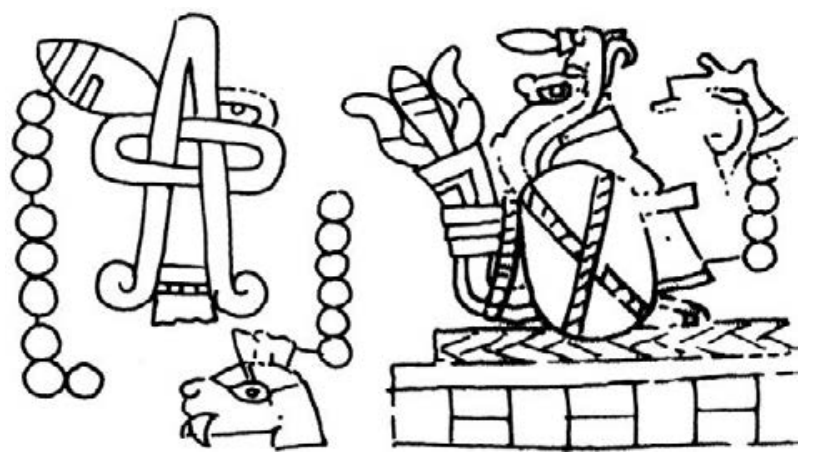

8.30. Codex Nuu Tnoo-Ndisi Nuu, p. 28-II: the death of Lord 4 Wind.

Nejapa), the emblematic western frontier of Nuu Dzaui, and deposit it there, as an offering to Lady 1 Eagle and Lord 1 Grass, the divine rulers of the West. After taking a ceremonial bath in the river he was to die there, together with Lady 1 Grass.

\section{The Aftermath of Lord 4 Wind's Rule}

Before Lady 1 Eagle and Lord 1 Grass met their tragic destiny, two of the younger children of Lady 13 Flower married each other: Lord 13 Serpent 'Eagle' married his sister Lady 11 Deer 'Quetzal Jewel' in the year 8 Reed, on the day 5 House (1163). They were 11 and 10 years old respectively.

The next year, 9 Flint (1164 AD), on the day 6 Dog, Lord 4 Wind died, at the age of $72 .^{21}$

Although his marriages had resulted in a number of descendants, it seems to have been difficult to designate a successor. The Toltec empire, which originally backed the existence of Nuu Yuchi as a new central capital for the Ñuu Dzaui region, was no longer a factor of importance. At the same time the competing houses of Nuu Tnoo and Chiyo Cahnu were regaining strength. The combination of these circumstances led to a fatal weakening of Nuu Yuchi. Possibly during the first years after the death of Lord 4 Wind the rule was in the hands of the two eldest sons of the daughter of his first marriage: Lord 7 Eagle

${ }^{21}$ Codex Nuu Tnoo-Ndisi Nuu p. 28-I/II. Lord 4 Wind had been born in the year 2 Flint (Añute, p. 8-IV). 


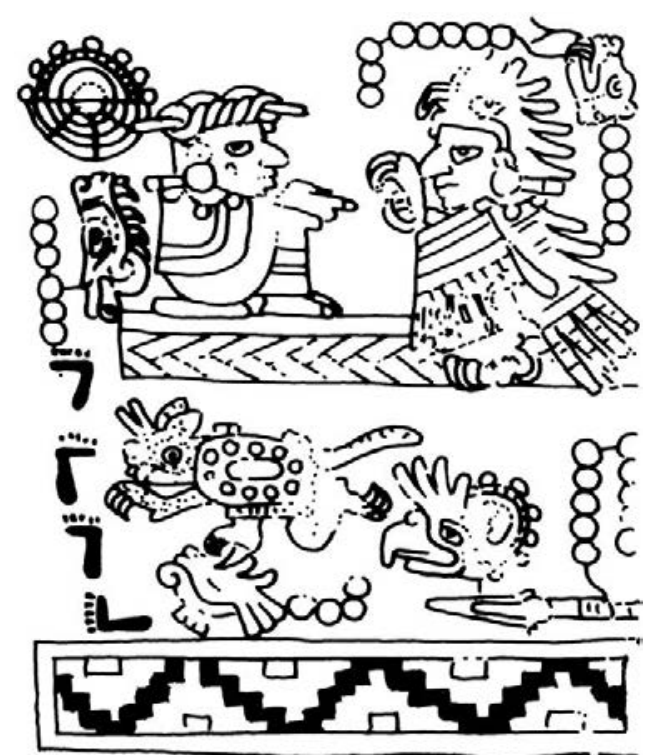

8.31. Codex Ñuu Tnoo-Ndisi Nuu, p. 28-III: Lord 13 Serpent marries Lady 6 Alligator, daughter of Lord 5 Water and Lady 10 Reed, rulers of Nuu Tnoo.

'Flames' and Lord 4 Jaguar 'War Jaguar', who are both depicted as seated on the glyph of Flint Town.

Their younger brother and sister, Lord 13 Serpent 'Eagle' and Lady 11 Deer 'Quetzal Jewel', were the first ones to have a descendant in the next generation. Eventually a son was born to them: Lord 7 Reed 'Pheasant'.

Lord 13 Serpent 'Eagle' then married again, this time to Lady 6 Alligator 'Jewel Spiderweb', daughter of Lord 5 Water 'Stone Jaguar' and Lady 10 Reed 'Quetzal Jewel, rulers of Nuu Tnoo. ${ }^{22}$

To get a more precise idea of the background of Lady 6 Alligator, we have to focus again on the dynasty of Nuu Tnoo. ${ }^{23}$ We saw above that this prestigious mat and throne had been occupied by Lord 6 House 'Jaguar that came down from Heaven', the son of Lord 8 Deer's

22 Codex Ñuu Tnoo-Ndisi Nuu p. 28-III/IV. See also Nuu Tnoo-Ndisi Nuu, p. 14-III, where the couple is seated (ruling) at Flint Town.

${ }^{23}$ Codex Nuu Tnoo-Ndisi Nuu, pp. 13/14; cf. Codex Yuta Tnoho Reverse, pp. IX/X. 
second wife, Lady 6 Eagle. This Lord 6 House had married a Chah Tnio (Chatino) princess and the lineage had been continued through their son Lord 5 Water 'Stone Jaguar'. This descendant, in turn married Lady 10 Reed 'Quetzal Jewel', who belonged to the Toltec branch of the family. The latter couple, Lord 5 Water and Lady 10 Reed, sat on the mat of Nuu Tnoo and had several children:

- Lord 8 Reed 'Pheasant', born in the year 8 Rabbit (1150), probably to be corrected to 7 Rabbit (1162).

- Lady 5 Rabbit 'Jewel'.

- Lord 10 Rabbit 'Ñuhu Heart', who married Lady 10 Vulture 'Jewel Fan' from Monkey Place (Teita?). ${ }^{24}$

- Lord 7 Lizard 'Arrows', who married Lady 2 Rain 'Red Fan' from Ñuu Niñe, a younger sister of his mother and daughter of his grandmother Lady 1 Flower who had married in Tollan-Cholollan. Lord 7 Lizard and Lady 2 Rain ruled Plain of the Sinking Disk. ${ }^{25}$

- Lord 4 Wind 'Sacred Rubber Ball', who married Lady 10 Wind from Monkey Place (Teita?), probably a sister of the wife of his elder brother (Lord 10 Rabbit).

- Lord 4 Flower 'Digging Stick', who married Lady 7 Lizard 'Irrigated Lands' from Stone of the Xipe Bundle (an important founding community of Nuu Tnoo).

- Lady 6 Alligator 'Jewel Spiderweb', who married Lord 13 Serpent 'Eagle' from Flint Town - the couple we just discussed.

- Lady 9 Dog 'War Jewel', who married Lord 1 Lizard 'Sacred Serpent' from Tollan-Cholollan.

In this generation we see the last interaction with the Toltec nobility. This confirms the picture that the Toltec empire was coming to an end toward 1200.

${ }^{24}$ This Place of the Monkey is also represented as Stone of the Monkey with Flowers (Codex Añute, p. 18-III). It had close ties with Nuu Tnoo and Añute. The 'Mat and Throne of Monkey (Place)', yuhui tayu Ticodzo, was part of the name of San Juan Teita (AGN-Tierras 44:1, f 195), the other part, Te-ita, meaning 'flower (place)'.

${ }^{25}$ Plain of the Sinking Disk only occurs in this part of Nuu Dzaui history. Therefore it doesn't seem to have been one of the main village-states, but either the local seat of a noble house or a minor community outside the Mixteca Alta. Manuel Hermann brought to our attention that a very similar sign, Plain of the Sun, is mentioned as one of the subject settlements on the map that accompanies the Relación Geográfica of Yucu Nama (Amoltepec), as well as a Plain of the Shield (Acuña 1984, II: 147-151). 
Codex Nuu Tnoo-Ndisi Nuu, p. 13-III, seems to give the year 8 Rabbit for the birth of the first-born, Lord 8 Reed. This would be 1150. If we accept the date for the marriage of his grandfather as given, year 9 Rabbit (1138), this would leave only 12 years for his father to be born and to grow up. Alfonso Caso therefore proposed to read the birth year of Lord 8 Reed as 7 Rabbit (1162). As we saw, one could speculate that the year 9 Rabbit for the marriage of the grandfather is rather late and might be a mistake for 10 Rabbit (1126), in which case the time span for the father would be 24 years. But, on the other hand the mother of Lord 8 Reed was the daughter of Lady 1 Flower, who in turn was the daughter of Lord 8 Deer's son and daughter with his fourth wife. So between the birth of those children of Lord 8 Deer $( \pm 1112)$ and the birth of Lord 8 Reed 'Pheasant' three generations of women reached the age of motherhood: Lady 2 Grass - Lady 1 Flower - Lady 10 Reed. A period of 38 years (1112-1150) would be extremely short for that, so that Caso's proposed reading is generally accepted.

As noted above, it was the seventh child, Lady 6 Alligator 'Jewel Spiderweb', who became the second wife of Lord 13 Serpent 'Eagle' from Flint Town. He was born in the year 10 Flint (1152), and this marriage seems to have taken place between the years 9 Flint (1164) and 3 Reed (1171). The groom was still a boy. Lady 6 Alligator 'Jewel Spiderweb' herself can have been little more than a baby. Again we are dealing with an early betrothal, motivated by political necessities, rather than a real marriage. The somewhat overshadowed Nuu Tnoo dynasty had a clear interest to achieve good relations with a possible successor of Lord 4 Wind, and similarly those who looked after the interests of the young boy saw the marital alliance with the former capital of Lord 8 Deer as a reinforcement of his position.

The year 3 Reed (1171) marked the 52nd anniversary of Lord 4 Wind's enthronement. The day 7 Flower was selected for the ritual, commemorating Lord 4 Wind's visit to the divine ancestor Lord 7 Flower in the year 4 Flint (1120). The Bundle in the temple of Flint Town was honored, the priests consulted with each other, singing songs about the glorious past and considering the uncertain political future. ${ }^{26}$

${ }^{26}$ Codex Nuu Tnoo-Ndisi Nuu, p. 28-V. Of the number that accompanies the day sign only 6 dots are visible (but compare the ritual function of the day 7 Flower in Codex Nuu Tnoo-Ndisi Nuu, p. 32-V). The priests are dressed in xicollis. Their speech scrolls consist of dotted lines, a convention for sand or ashes: we read them as yaa, 


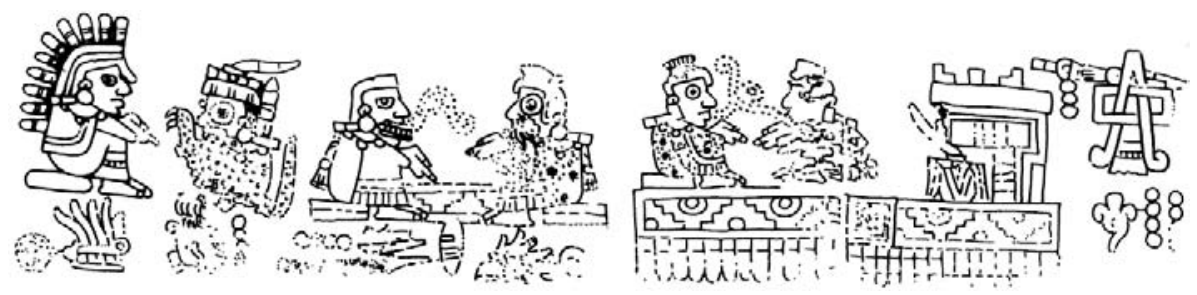

8.32. Codex Nuu Tnoo-Ndisi Nuu, p. 28-V: discussions about the succession in Nuu Yuchi.

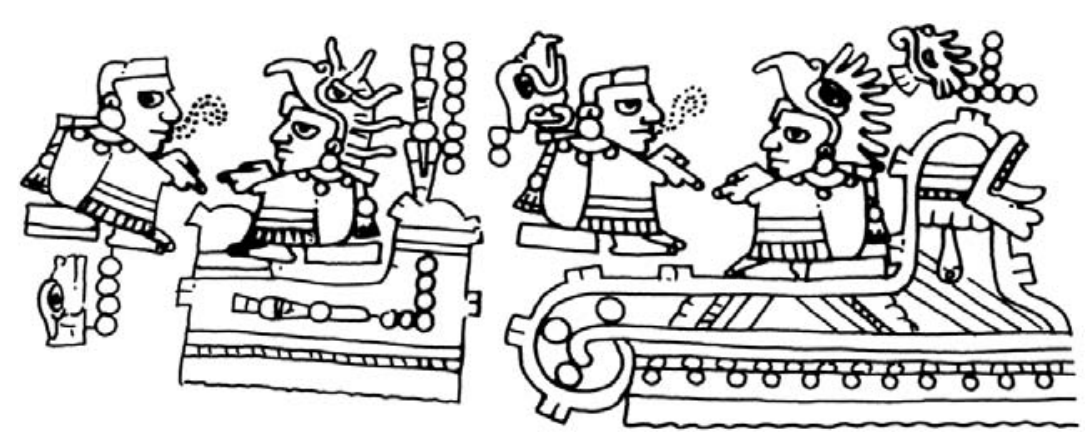

8.33. Codex Nuu Tnoo-Ndisi Nuu, p. 28-III: negotiations with other rulers.

Then three men in red xicollis (tunics), probably members of the Supreme Council, went out to make an arrangement. First their leader, the Death Priest (cihuacoatl), Lord 9 Wind, spoke to Lord 1 Eagle 'Rain' in Nuu Yuchi. This young boy, only 11 years old, was dressed in a priestly xicolli of white cotton, speckled with black rubber. Perhaps this indicates that he was to fulfil certain ritual duties in order to become the designated heir. Immediately afterward Lord 4 Water and Lady 1 Grass, whom we consider his parents, are mentioned: they probably had to act as regents. From the earlier scenes we know, how-

which (with different tones) means 'ashes' and 'song'. It is intriguing that the combination yocaha ('to speak') yaa ('song') means 'to compose (fiction)' (Alvarado: hablar de gracia componiendo de su cabeza), and even 'to lie'. The combination of 'yaa speech' with downball feathers in Codex Yuta Tnoho (as part of the New Fire ceremony, p. $22 \mathrm{ff}$.) and Codex Iya Nacuaa II, p.7-III (where it emerges from the mouth of a drum player), suggests, however, that this sign refers to song or elevated discourse (yaa huii). Similar conventions occur in the Codex of Yucunama (Jansen 1994) and in a land document from Tilantongo (Oudijk \& Van Doesburg 2007). 
ever, that Lord 1 Eagle and his mother, Lady 1 Grass, were going to die in the West. The designation of Lord 1 Eagle as the future king would, therefore, turn out to be only a temporary solution.

Simultaneously a second man in a red xicolli, Lord 4 Lizard, probably another member of the Supreme Council of Nuu Yuchi, spoke to Lord 7 Reed 'Pheasant', who, we remember, was the son of Lord 13 Serpent of the house of Nuu Yuchi and also still a very young child. This happened on the Mountain of 6 Reed (Ñhuiyo), which is probably a phonetic writing of Nuu Huiyo (Tuctla), 'Place of the Young Maize Plant', known as 'the entrance to the Mixteca Alta', between Ñuu Dzai (Huajuapan) and Tequevui (Tamazulapan). ${ }^{27}$

A third man in a red xicolli, Lord 2 Vulture, again probably a member of the Supreme Council of Nuu Yuchi, then spoke to Lord 7 Water 'Red Eagle', ruler of Mountain with Mouth. The latter had been born in the year 7 House (1149); he was not a descendant of Lord 4 Wind, but belonged to the house of Chiyo Cahnu (Teozacualco). ${ }^{28}$ The date associated with this conversation was the day 1 Jaguar in the year 7 Reed (1175).

The result of all these consultations is not clear. Actually the two boys spoken to were still small children. Both were the youngest direct descendants of Lord 4 Wind. These boys were probably instructed by the Supreme Council to become successors to the dead ruler, but they were clearly too young and too weak.

The third party, however, Lord 7 Water 'Red Eagle', represented a growing force in Ñu Dzaui politics. He was probably first called upon as a protector of the infants, but he seems to have taken matters into his own hands pretty soon. The next thing we read is that his son, Lord 13 Eagle 'Sacred Rain', attacked the temple of Ndisi Nuu (Tlaxiaco). ${ }^{29}$ Lord 8 Jaguar 'Blood Coyote' defended the temple. It is not clear who won the battle - maybe both parties claimed victory - but Ndisi Nuu seems to have remained under the control of Lord 8 Jaguar.

The context of the scene suggests that we are seeing here a crucial event in the history of the kingdom of Ndisi Nuu (Tlaxiaco), which from this scene onward becomes the major topic of Codex Nuu TnooNdisi Nuu Reverse. We have to remember that thanks to the special

${ }^{27}$ For a description of the place we refer to the work of Suárez de Peralta (1949: 86). Both huiyo (in Dzaha Dzaui) and toctli (in Nahuatl) mean 'young maize plant'.

28 See Codex Tonindeye, p. 28

${ }^{29}$ Codex Nuu Tnoo-Ndisi Nuu, p. 28-II/I. 
attention given to it by Lord 4 Wind, the temple of Ndisi Nuu had become an important sanctuary, probably in honor of Lady 9 Reed and the Sacred Bundles of the Primordial Lords 9 Movement and 7 Deer. As a ceremonial center it had strong influence and fame, at least in the area of Yucu Satuta (Zacatepec), as demonstrated by the lienzo of that town. In those days Ndisi Nuu was not yet a separate kingdom of its own. Apparently its sanctuary was located in an area ruled by Lord 8 Jaguar 'Blood Coyote', probably a vassal lord or 'governor' within the realm of Lord 4 Wind.

The armed conflict may indicate that after the great ruler's death, the different regions and noble houses claimed their independence. Also Lord 8 Jaguar 'Blood Coyote' took advantage of the power vacuum to formalize his control over the Ndisi Nuu area, with the ambition to convert it into a mat and throne of its own.

About Lord 8 Jaguar's background we know little: he was married to Lady 2 Vulture 'Jewel Fan'. Together they ruled the kingdom River of the Animal. ${ }^{30}$ The date associated with this couple is the year 6 House, day 9 Eagle, which may be the sacred foundation date, but, in view of the fact that days Eagle (like the days Deer) are those selected for weddings, it could also be the date of their marriage. In the latter case, the year 6 House would correspond to 1161, still during the lifetime of Lord 4 Wind and well before the war broke out.

Possibly Lord 8 Jaguar (iya Nahuidzu) is identical to the cacique Ñeichuizu or Ñehuizu mentioned by Mariano López Ruiz in his reading of a now lost lienzo (1898: 445-446; Smith 1998). He is credited with the foundation of a realm and dynasty in the Ndisi Nuu (Tlaxiaco) area, apparently after the Lord 4 Wind episode. In consultation with three other lords he set up 'seven mats and seven seats' in order to put an end to the political turmoil ('the continuous revolutions of their tribes'). As in Codex Nuu Tnoo-Ndisi Nuu, two sites are associated with his new foundation of government: the mountain Yucu Tnuchi and the lagoon Tixahui. We do not know if these toponyms come from glosses related to the pictorial text or from a 'written map' of boundary names. It is interesting to notice that Codex Nuu TnooNdisi Nuu also gives two toponyms for the realm of Lord 8 Jaguar. The River of the Animal would then correspond to the lagoon Tixahui near

${ }^{30}$ A similar glyph appears in the Lienzo of Tlapiltepec (Caso 1961: B 35), where it may represent Yuta Nani (Chachoapan). 
Yucucuaño (probably Yucuañe, Malinaltepec). Yucu Tnuchi means 'Mountain of the Crater or Hole', which might correspond to the site Split Mountain of Wind, where Lord 8 Jaguar founded a second dynasty according to Codex Nuu Tnoo-Ndisi Nuu (especially as the day sign Wind may represent the syllable chi).

López Ruiz gives two dates here: Ñeichuizu/Ñehuizu would have been born in 1113, a year xacuxi, i.e. 7 Flint. The next individual, cacique Xixañuu, is called his son and would have been born in the year xavaxi, day $n[e] c o o$, i.e. the year 7 Flint, day 8 Rain, correlated as 1115. As is true for the whole text of López Ruiz, there are several problems here. First the correlation does not work, as 1113 would be 10 House (or the year before, 9 Flint) and 1115 would be 12 Reed. Second, it is highly improbable that Neichuizu/Ñehuizu would have fathered a son 2 years after his own birth. We suppose that these are sacred dates. The second one - year 7 Flint, day 8 Rain - especially gives that impression. Maybe the first year 7 Flint has to be read in combination with the day cahuiyo, 1 Reed, interpreted as a given name by López Ruiz. Going even further, we speculate that Xixañuu is actually Lord 13 Eagle (iya Sisa), not the son but the rival of Lord 8 Jaguar. Chronologically it is possible that Lord 8 Jaguar was born in 1113 . He would then have been an elderly man at the time of the conflict. The birth of Lord 13 Eagle in 1115 would not fit Emily Rabin's correction of Caso's synchronology. Therefore it would have to be 52 years later. Still, the coincidences between the text of López Ruiz and Codex Ñu Tnoo-Ndisi Nuu are fascinating. The list of boundary names given by López Ruiz have been identified to a large extent by Smith (1998: 78-79): they seem to define a large area around Ndisi Nuu, probably including places such as Yucu Cuiñe (Cuquila) and Yucu Iti (Ocotepec), and extending as far South as Nuu Numa (Putla). This may well have been the original kingdom of Lord 8 Jaguar. The words put in the mouth of the old ruler reflect the traditional art of the flowery discourse (parangón), certainly apt for the occasion:

My son: the Gods and the rulers of this powerful nation have bestowed upon thee the supreme dignity to rule over her, they have great expectations of your equity and justice. Be the father to your people and obey the wise counseling of these elders, who from now onward will be your council of government. (López Ruiz 1898: 446). 


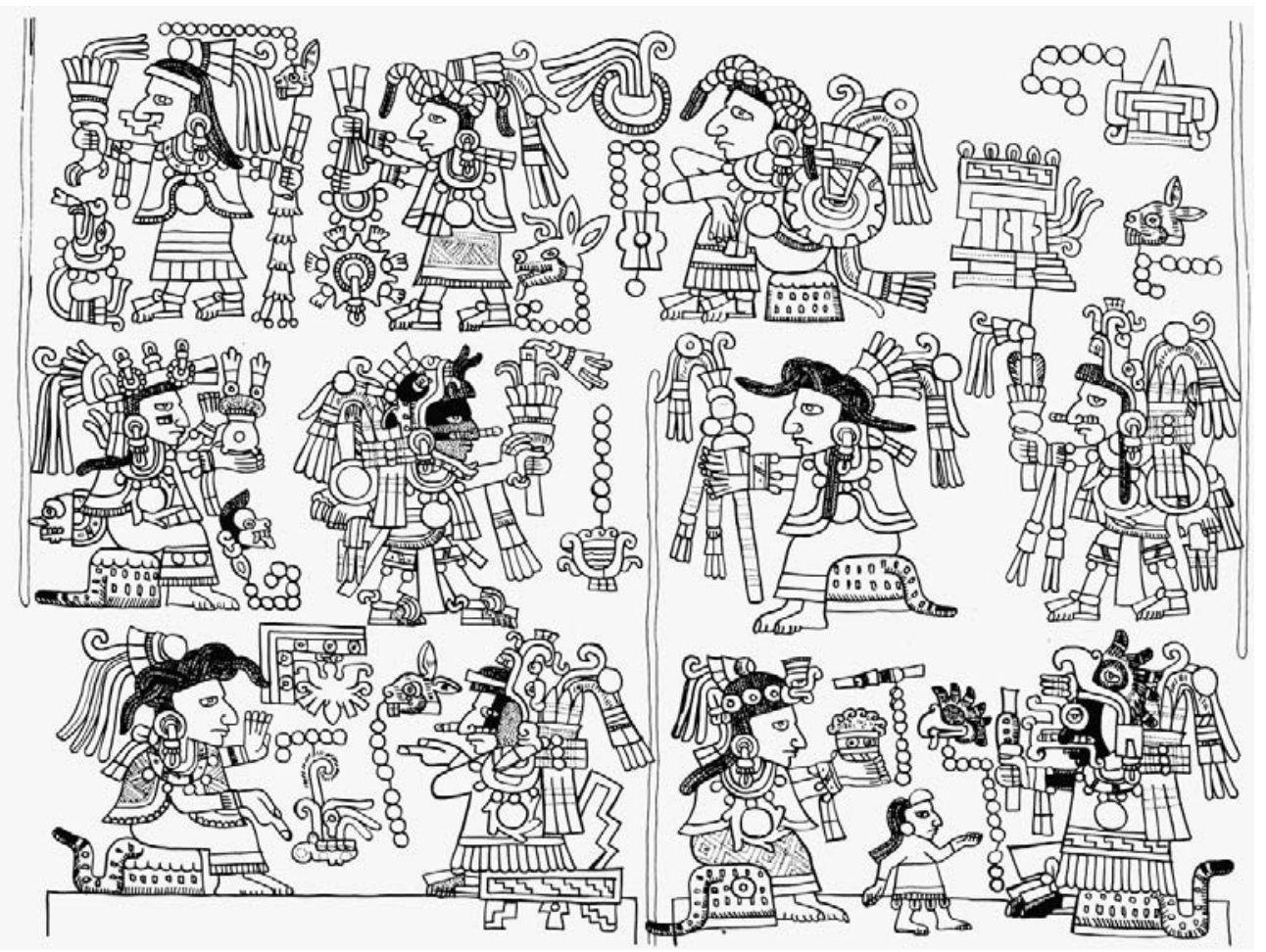

8.34. Codex Tonindeye, p. 30 (Lower Right to Lower Left, boustrophedon): Lord 8 Rabbit and his relatives.

Let us return to the story in Codex Nuu Tnoo-Ndisi Nuu. If the policy of the three men in red xicollis was to preserve the unity of the Nuu Yuchi influence sphere, they failed. Apparently the sanctuary of Ndisi Nuu became a bone of contention between Lord 8 Jaguar, who was and remained in control locally, and the ruling family of Chiyo Cahnu, which was striving to occupy the power vacuum and to take over part of the pan-regional role of Nuu Yuchi.

Lord 13 Eagle 'Sacred Rain' became an important ruler, who married several women. His first wife, Lady 8 Reed 'Precious Girl', became the mother of his heir, Lord 8 Rabbit, who was born in the year 8 House (1189) and received the commemorative name Nuhu Ndisi $\mathrm{Nuu}$, 'Fire of Tlaxiaco'. ${ }^{31}$ Lord 13 Eagle married his second wife in the

31 Codex Tonindeye, p. 30; Codex Ñuu Naha, p. 2. 
year 5 Reed (1199): her children would play a crucial role in founding a new dynasty for the kingdom of Yucu Yusi (Acatlan) in the Mixteca Baja. ${ }^{32}$ Thus the attack on Ndisi Nuu was just a less successful incident within a wider range of activities that demonstrate the growing influence of Chiyo Cahnu.

It was the great ruler Lord 4 Wind himself who had started to break up the territorial unity created by Lord 8 Deer. He divided Ñuu Tnoo, Chiyo Cahnu (Teozacualco) and Yucu Dzaa among the descendants of his predecessor. At the same time he set up kingdoms in Nuu Ndecu (Achiutla), Yucu Satuta (Zacatepec) and possibly several other places. When he died, it was only logical that the local lord who controlled the religious center of Ndisi Nuu (Tlaxiaco) took possession of that area, adjacent to Ñuu Ndecu and Yucu Satuta, defending it against other pretenders and establishing his own mat and throne there.

With the demise of Nuu Yuchi the region entered a phase of 'balkanization': the central power gave way to the rise of many small kingdoms proud to be independent. The rulers strove to reinforce their position through traditional tactics, trying to connect the local economy to interregional trade networks, trying to impose themselves on their neighbors through military force and trying to create political alliances through marriage. In this highly complex situation, Nuu Dzaui recorded history focuses on the ups and downs of four main houses and dynastic lines in the Mixteca Alta: those of Nuu Tnoo (Tilantongo), Chiyo Cahnu (Teozacualco), Nuu Ndecu (Achiutla) and Ndisi Nuu (Tlaxiaco).

${ }^{32}$ Codex Tonindeye, p. 29; Roll of Huamelulpan. 


\section{CHAPTER NINE}

\section{THE NOBLE HOUSES}

Nuu Dzaui history may really be divided into the periods before and after the dramatic episode of Lord 8 Deer and Lady 6 Monkey. Their tragedy was crucial in shaping the Mixtec politics of the Late Postclassic, and most likely it was repeated, ceremonially performed, at dynastic events (such as enthronements, marriages or New Fire rituals) to explain precisely the resulting structure of independent small polities (yuvui tayu) to the rulers themselves and to their people. Lord 8 Deer had tried to unify the Mixtec world under his rule and to transform it into a homogeneous state after the Toltec model. This intent, however visionary and courageous, had failed, because of his excessive ambition and violence. His assassin and successor as 'strong man' in the region, Lord $4 \mathrm{Wind}$, lived in a time when the Toltec empire itself disintegrated after the death of its great king Nacxitl Topiltzin Quetzalcoatl; he reinstalled the policy of a mosaic of independent peer polities involved in loose alliances, a policy which was to prevail until the Spanish invasion. Obviously this was a subject of political reflection and debate in the late 15th and early 16th century, when the Mexica armies could subdue large parts of Nuu Dzaui, precisely because of its internal factionalism and lack of unity. It was those reflections and debates that determined the telling and reproduction of Mixtec history in the codices we now know.

In this chapter we give an overview of the period between the death of Lord 8 Deer and the Conquista, just as it is described by the codices. In accordance with the style of Mixtec historiography the information is largely genealogical, with a bewildering abundance of calendar names and given names of individuals related to each other by direct succession or by complex kinship ties. Behind those ties we try to discover the ancient alliance policies, factionalism and other dynamics of power. At the same time this structure permits us to locate the dates of the the successive life spans - given in the 52 years' cycles of the Mixtec calendar - in a linear order and to establish their correlation with the Christian calendar. ${ }^{1}$

\footnotetext{
${ }^{1}$ We refer again to the enormous work of Alfonso Caso (1977-79) and the corrections made by Emily Rabin (2004).
} 


\section{Ñuu Tnoo and Chiyo Cahnu Reunited}

After Lord 4 Wind's death it was the ruling family of Chiyo Cahnu (Teozacualco) that rose to prominence. But what happened to the ancient capital, Nuu Tnoo (Tilantongo)? After the last links with the distant Toltecs became irrelevant, the infant prince, Lord 8 Reed 'Pheasant', married his sister Lady 5 Rabbit 'Jewel'. This was a good strategy to consolidate their estate and keep it within the family, but also limited the possibilities of expanding the influence of their house through marital alliances with important lineages from elsewhere. ${ }^{2}$

This couple had two sons:

1. Lord 2 Movement 'Serpent with Markings' (or: 'Serpent of Authority'), who, while in Nuu Tnoo, married twice. His first wife was Lady 4 Eagle 'Blood Quechquemitl', daughter of his uncle Lord 10 Rabbit 'Ñuhu Heart' and Lady 10 Vulture 'Jade Fan', the rulers of Monkey Place (Teita?). His second wife was Lady 10 Eagle 'Serpent Spiderweb' from Town of Head and Hands.

2. Lord 2 Eagle 'Smoke Eye', who married Lady 8 Serpent 'Flower Garland'. They were seated at Flowered Feline Town. ${ }^{3}$

The first-born, Lord 2 Movement 'Serpent with Markings', was the heir to the throne.

From his first marriage was born Lord 1 Lizard 'Blood Jaguar'; from the second Lord 8 Grass 'Coyote Sacrificer'. ${ }^{4}$ Both half-brothers were engaged in religious duties. Lord 1 Lizard 'Blood Jaguar' made offerings in the Temple of Blood and Cacao. Lord 8 Grass 'Coyote Sacrificer' made offerings in the Temple of Heaven.

Both played music, sounding the teponaztle drum and the rattle, for the Sacred Bundle of 4 Alligator, the deified founder of the Nuu Tnoo lineage.

${ }^{2}$ Codex Ñuu Tnoo-Ndisi Nuu, p. 14-II.

${ }^{3}$ We suspect that this place is a reference to the Postclassic settlement on Monte Albán. Several people associated with it have a smoke curl around their eye, a sign that characterizes visionary priests.

${ }^{4}$ The sequence of generations in Codex Nuu Tnoo-Ndisi Nuu, p.14/13-II, is open to different interpretations, but Codex Yuta Tnoho Reverse, p. X, clarifies that Lord 2 Movement and Lord 2 Eagle were brothers and that Lord 1 Lizard was the son of Lord 1 Movement. 


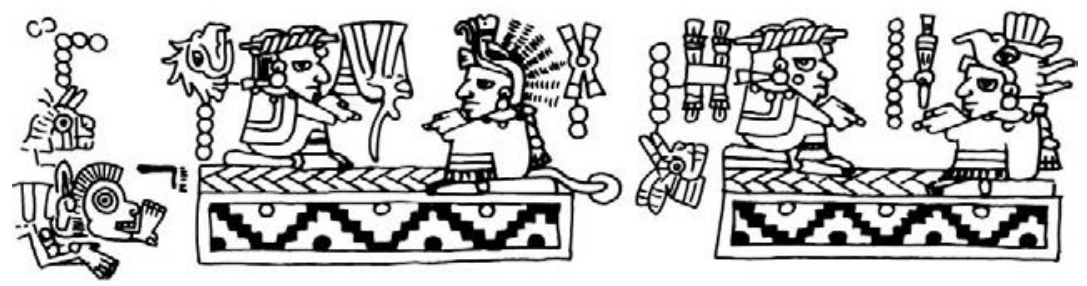

9.1. Codex Nuu Tnoo-Ndisi Nuu, p. 14-II (Right to Left): Lord 8 Reed and Lady 5 Rabbit, of the Nuu Tnoo dynasty, marry and have a son, Lord 2 Movement, who married Lady 4 Eagle from Monkey Place.

Then a conflict arose between the two. Lord 1 Lizard 'Blood Jaguar' chased his brother Lord 8 Grass 'Coyote Sacrificer' from the Temple of the Brazier. He beat him with sticks; this act suggests an accusation of breaking the vows of chastity. ${ }^{5}$

As a consequence of this family conflict, Lord 8 Grass 'Coyote Sacrificer' and his father Lord 2 Movement 'Serpent with Markings' became the enemies of Lord 1 Lizard and went away into exile. ${ }^{6}$ In the year 12 Rabbit (1206), on the day 5 Lizard, they arrived in Mountain of Hair or Ixtle Fiber, possibly Yucu Ndaa (Tepozcolula). There Lord 2 Movement married again. The name of his third wife was Lady 12 Flint 'Jewel Hummingbird'. They had a daughter: Lady 3 Flint 'Jade Bird'. Lord 8 Grass 'Coyote Sacrificer' also married there. His wife's name was Lady 10 Jaguar 'Jewel of Heaven'.

Meanwhile Lord 1 Lizard remained in Nuu Tnoo. He married Lady 6 Reed 'Jewel', the daughter of his grand-uncle Lord 7 Lizard 'Arrows' and Lady 2 Rain 'Red Fan', the rulers of Plain of the Sinking Disk. Their marriage is mentioned after the above, but probably took place earlier, before Lord 1 Lizard chased away his half-brother and his father.

Lord 1 Lizard and Lady 6 Reed had the following children:

${ }^{5}$ A similar brazier is depicted in the Libro de la Vida (Codex Magliabechi), p. 74r. Herrera explains: "cuando alguno quebraba la castidad, era muerto a palos" (decade XIII, book XIII: ch. 12).

${ }^{6}$ We read the feet (nduvua in reverential speech) and flames ( $\left.\tilde{n} u h u\right)$ as nduvua $\tilde{n} u h u$, 'arrow and fire', a difrasismo (hendiadys) for 'war'. The expressions 'throwing someone out' (yodzaquay ñahandi) and 'putting someone in the mountain and on the road' (yosaq yucu ichi ñahandi) also mean 'sending someone into exile'. 


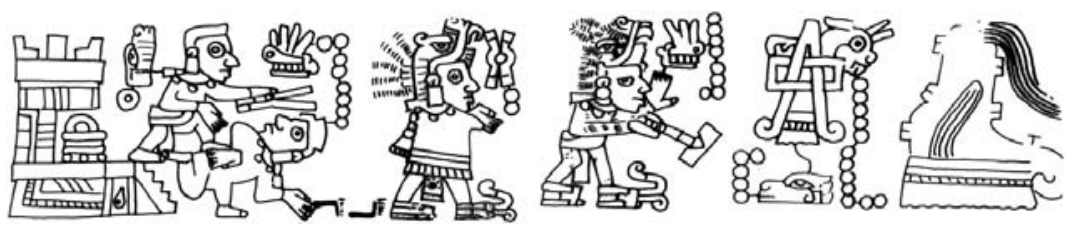

9.2. Codex Ñuu Tnoo-Ndisi Nuu, p. 14-I (Left to Right): the conflict between Lord 1 Lizard and Lord 8 Grass.

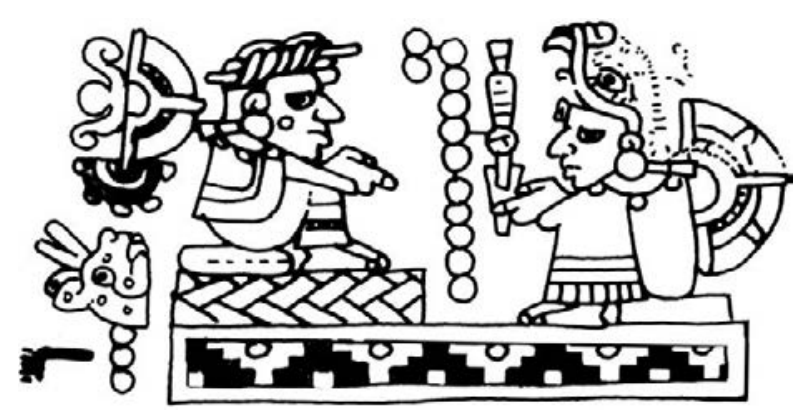

9.3. Codex Nuu Tnoo-Ndisi Nuu, p. 16-II: Lord 12 Reed and Lady 3 Jaguar, ruling Nuu Tnoo.

1. Lord 12 Reed 'Coyote Sun'.

2. Lady 3 Jaguar 'Precious Butterfly Sun'.

3. Lord 8 Jaguar 'Burning War Venus'.

4. Lady 6 Grass 'Transparent Butterfly'. She was to marry Lord 8 Rabbit of Chiyo Cahnu, who had been born in the year 8 House (1189) as the son and heir of Lord 13 Eagle. ${ }^{7}$

5. Lord 7 Movement 'Blood Jaguar', who married Lady 3 Water 'Venus Quechquemitl' and so became ruler of Puma Town.

6. Lord 4 Jaguar 'Serpent, War Snare' who married Lady 13 Flower 'Jewel of the Rising Ñuhu': both ruled Place of the Drum (Añuu, Soyaltepec?).

The first two children, Lord 12 Reed 'Coyote Sun' and Lady 3 Jaguar 'Precious Butterfly Sun', contracted a brother-sister marriage. They ruled in Nuu Tnoo, where they had two children:

${ }^{7}$ Codex Nuu Tnoo-Ndisi Nuu, p. 16-I; cf. Cf. Tonindeye, p. 30 and Codex Nuu Naha p. 2. Chiyo Cahnu is represented here with its alternative glyph, Flower Town, which probably refers to the specific location of the settlement, Yuu ita ini (Smith 1973a: 58). 
1. Lady 1 Monkey 'Jade Quechquemitl', who married Lord 12 Rain 'Fire Serpent with Bloody Claw' of Ndisi Nuu (Tlaxiaco). ${ }^{8}$

2. Lord 5 Rain 'Sun Movement'.

The second child, Lord 5 Rain 'Sun Movement', married his niece Lady 13 Lizard 'Truly Precious Butterfly', the daughter of his father's brother Lord 7 Movement 'Blood Jaguar' and Lady 3 Water 'Venus Quechquemitl', the rulers of Puma Town.

Their son was Lord 13 Wind 'Fire Serpent', who married his father's cousin Lady 1 Eagle 'Jade Fan' on the day 3 Eagle of the year 5 House (1277). ${ }^{9}$ She was a daughter of Lord 12 House 'Fire Serpent that Flies through Heaven' and Lady 11 Alligator 'Quetzal Spiderweb', rulers of Chiyo Cahnu (Teozacualco), both children of Lady 6 Grass 'Transparent Butterfly' and Lord 8 Rabbit. ${ }^{10}$

The marriage of Lady 6 Grass 'Transparent Butterfly' and Lord 8 Rabbit 'Fire Serpent, Destruction of Ndisi Nuu' had been an important dynastic event, as it reunited the leading noble houses of the neighboring polities Nuu Tnoo and Chiyo Cahnu. It was in the latter place that the couple ruled, which suggests that Chiyo Cahnu had now become the more prestigious capital.

Their first son and heir was Lord 12 House 'Fire Serpent that Flies through Heaven', who married his sister, Lady 11 Alligator 'Quetzal Spiderweb'. Apparently this marriage was arranged to keep the kingdom of Chiyo Cahnu undivided within the family.

A second son, Lord 1 House 'Killer Jaguar from Heaven' would become the Founding Father of the Nuu Naha dynasty. ${ }^{11}$ A delegation of nobles from that town went to see Lady 6 Grass and Lord 8 Rabbit in Chiyo Cahnu, to ask them for a prince as ruler. This shows the great prestige that the ruling couple now had. They seem to have acted as active brokers in constructing marital alliances.

\footnotetext{
8 The representation in Codex Nuu Tnoo-Ndisi Nuu, p. 15-II, would permit the suggestion that Lord 5 Rain was the son of Lady 1 Monkey and Lord 12 Rain, but the parallel passage in Nuu Tnoo-Ndisi Nuu, p. 26-IV, shows that this was not the case. There the same marriage is mentioned as part of the Ndisi Nuu dynastic history, but no reference is made to Lord 5 Rain; instead the couple have a daughter: Lady 8 Serpent 'Sun Spiderweb'.

9 According to Codex Yuta Tnoho Reverse, p. IX-2, the year was 1 House, which would be 1273 .

${ }^{10}$ Codex Nuu Tnoo-Ndisi Nuu, p. 15-III, cf. Codex Tonindeye, p. 31.

${ }^{11}$ See Codex Tonindeye, p. 31; cf. Codex Nuu Naha, pp. 1/2.
} 


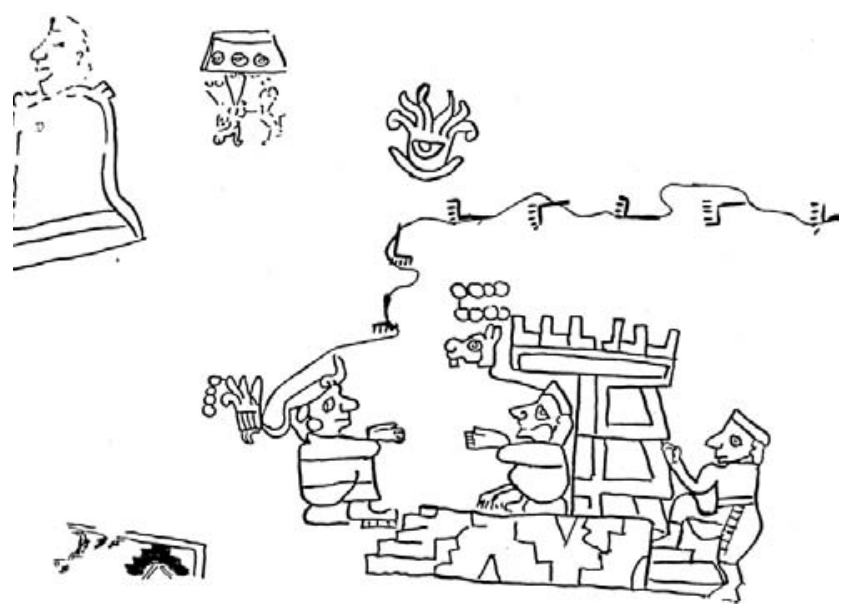

9.4. Codex Nuu Naha, p. 2: Lady 4 [6] Grass and Lord 8 Rabbit ruling Chiyo Yuhu.

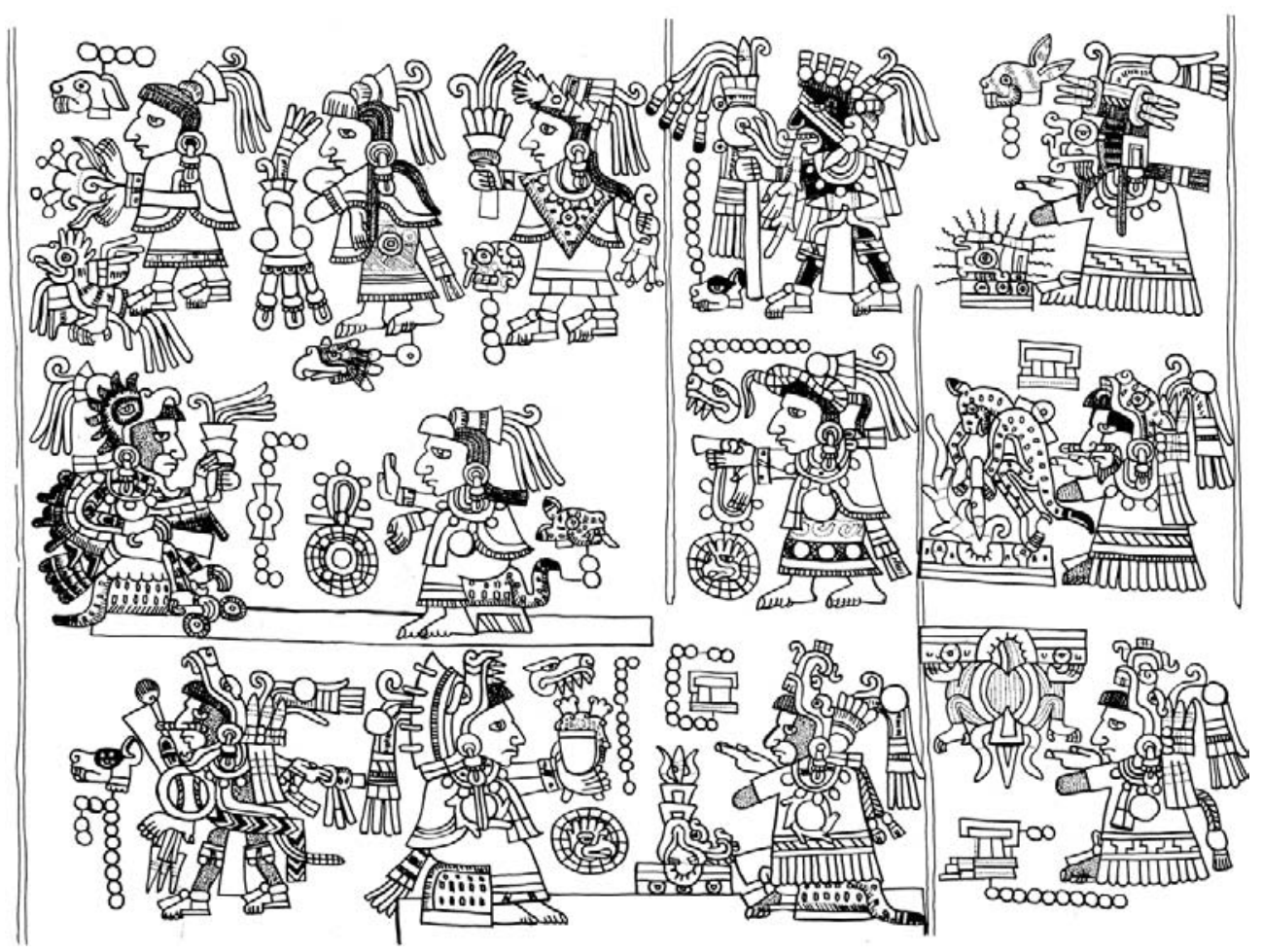

9.5. Codex Tonindeye, p. 31 (Lower Right to Upper Left, boustrophedon): the birth of Lord 12 House, his brothers and sisters, his marriage and descendants. 


\section{The First Marital Alliance with Zaachila}

A brother-sister marriage was arranged for two of Lord 12 House's and Lady 11 Alligator's children: Lord 9 Movement 'Precious Eagle' and Lady 2 Jaguar 'Jewel Spiderweb'. This union seems to have remained without offspring, however. About still another son, Lord 12 Dog, we do not get any more information: probably he died at an early age, before marrying.

Thus the focus shifts toward the three daughters of Lord 12 House and his wife-sister, Lady 11 Alligator. One of them, Lady 1 Eagle 'Jade Fan', as we saw, married the Nuu Tnoo infant Lord 13 Wind, while her younger sister, Lady 4 Rabbit 'Quetzal', married a prince from Zaachila, Lord 5 Flower, thereby becoming a Beni Zaa (Zapotec) queen. ${ }^{12}$ This was a major political alignment, in which the house of Chiyo Cahnu reinforced the link with Nuu Tnoo and at the same time connected itself with its other most important neighbor, the Beni Zaa capital in the Valley of Oaxaca. In all probability this is the marriage mentioned by the Relación Geográfica of Zaachila, when it tries to explain the presence of Nuu Dzaui people in Saha Yucu (Cuilapan):

Asked how they came to this Zapotec province, being Mixtecs themselves, they answer that it was because of a marriage between a Mixtec woman and a Lord of Zaachila. They came here more than 300 years ago... (Acuña 1984, II: 157).

As the Relación Geográfica was written in 1580, the reference "300 years ago" would give us a date somewhat before 1280 for the marriage in question. ${ }^{13}$

12 See Codex Tonindeye, p. 33. The members of the dynasty of Zaachila wear a distinctive outfit, identifying themselves with their Patron Deity, Xipe (Jansen 1989, Oudijk 2000).

${ }^{13}$ It was a crucial connection between the two dynasties, worth remembering. In Codex Tonindeye no date is given for the event, but in Codex Nuu Tnoo-Ndisi Nuu (p. 15-III) we read that Lady 4 Rabbit's elder sister, Lady 1 Eagle, married in the year 5 House. According to Rabin's chronology that is 1277 , which fits remarkably well. Caso's calculation is one cycle too early: 1225 . Of course, one might argue that 1225 is also more than 300 years before 1580 (cf. Stokes 1997), but given the Mesoamerican custom of thinking in 52 year cycles, we think that the statement of the Relación Geográfica of Zaachila should be taken seriously, as meaning 'approximately 6 cycles', contrasting with the 'approximately 7 cycles' or 'more than 350 years', which would be necessary to arrive at 1225 . Mixtec-Zapotec relations and the chronological framework have been a topic of study and debate: see for example Paddock 1966 and the contribution by Marcus in Flannery \& Marcus 1983: 301-308. Michel Oudijk contributed a convincing synthesis to the volume edited by Blomster (2008). 
No heir was born to the brother-sister marriage of Lord 12 House's two inheriting children. Thus the dynastic succession switched to the marriage of Lady 4 Rabbit 'Quetzal' to Lord 5 Flower of Zaachila. Their youngest son, Lord 3 Alligator, inherited the kingdom of his father, Zaachila. In fact he became the direct successor to his paternal grandfather, Lord 9 Serpent. The other son - mentioned in Codex Tonindeye as the first-born - Lord 2 Dog 'Rope and Knives', was to inherit his mother's mat and throne, Chiyo Cahnu.

But coming from Zaachila, Lord 2 Dog had to find a way to strengthen his ties with the Chiyo Cahnu dynasty, in order to foster his claim to the throne. That proved difficult, as there were few possible marriage partners at that moment. The obvious place to look for a bride was the noble house of Nuu Tnoo, where his mother's sister, Lady 1 Eagle 'Jade Fan' had married the infant Lord 13 Wind 'Fire Serpent'. But this couple only had a son, Lord 9 Serpent 'Jaguar that Lightens the War'. So Lord 2 Dog chose to wait for the daughter of Lord 9 Serpent, Lady 6 Reed, to grow up. That princess would give him legitimacy. It was on her 'birthday', the day 6 Reed in the year 10 House (1321) that he entered the kingdom of Chiyo Cahnu, with her as his wedded wife at his side. ${ }^{14} \mathrm{He}$ must have been a mature man, his parents having married before 1280; she was much younger, being the daughter of his cousin.

Let us examine the whole genealogical context. Lord 9 Serpent had married two sisters: Lady 8 Flint and Lady 7 Flower, both from Mountain of Flowers (Yucu Ita?), daughters of 6 Flower and 6 Death.

Their children were:

1. Lord 4 Water 'Blood Eagle', born in the year 3 House (1301), who was to marry his niece Lady 6 Water 'Quetzal, Jewel of the Flower War', daughter of his sister Lady 6 Reed and Lord 2 Dog of Chiyo Cahnu.

2. Lady 6 Reed 'Plumed Serpent', who, as we saw, married her father's cousin, Lord 2 Dog 'Rope and Knives' of Chiyo Cahnu.

3. Lady 4 Monkey 'Precious Fire Serpent', who traveled far to marry Lord 7 Rain 'Flame of the Rising Nuhu', Prince of Mountain of the Precious Mask.

\footnotetext{
${ }^{14}$ Codex Ñuu Tnoo-Ndisi Nuu, p. 15-III; see also the Map of Chiyo Cahnu (Teozacualco).
} 


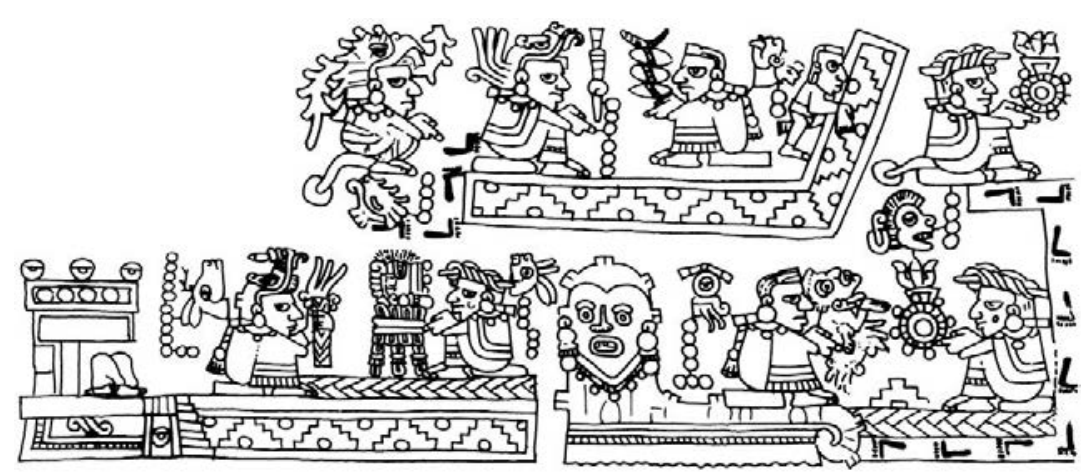

9.6. Codex Nuu Tnoo-Ndisi Nuu, p. 16-III/IV (Upper Left to Lower Left, boustrophedon): Lord 4 Water and his sisters.

4. Lady 6 Rabbit 'Jewel Seed', who married Lord 12 Deer 'Fire Serpent that Lightens the War', ruler of Ndisi Nuu. Her father and her husband were both great-grandsons of Lord 12 Reed of Ñuu Tnoo. ${ }^{15}$

Thus the marriages of the two eldest children of Lord 9 Serpent strengthened the links with the house of Chiyo Cahnu, re-establishing the marital alliance of Lord 8 Rabbit and Lady 6 Grass. One daughter married a prince from Mountain of the Precious Mask, a town that we have not yet heard about in this dynastic history, and another married into the Ndisi Nuu dynasty.

Lord 9 Serpent did not rule in Nuu Tnoo himself, but he was extremely important in genealogical terms: his children played crucial roles in the dynasties of the major polities in the Mixteca Alta, aligning Nuu Tnoo, Chiyo Cahnu and Ndisi Nuu. As a forger of marital alliances of great political importance, Lord 9 Serpent, without doubt assisted by his wives, followed in the footsteps of his maternal grandparents Lady 11 Alligator and Lord 12 House, as well as in those of his great-grandparents Lady 6 Grass and Lord 8 Rabbit.

At the same time Lord 2 Dog of Chiyo Cahnu was keen to strengthen the links with the prestigious Nuu Tnoo dynasty: first he himself married Lord 9 Serpent's daughter, Lady 6 Reed, then he and his wife arranged for their eldest daughter, Lady 6 Water, to marry Lord 9

${ }^{15}$ Codex Nuu Tnoo-Ndisi Nuu, p. 16-III ff.; cf. Codex Yuta Tnoho Reverse, p. XI-1 and Codex Ñuu Tnoo-Ndisi Nuu p. 25-III/IV. 
Serpent's eldest son and heir, Lord 4 Water. ${ }^{16}$ The son of Lord 2 Dog and Lady 6 Reed was Lord 9 House, who would play an important role in Nuu Dzaui history, as we will see below.

\section{Early Rulers of Ndisi Nuu}

The marriage of two of Lord 9 Serpent's daughters to princes of Chiyo Cahnu and Ndisi Nuu brought the latter towns into an indirect but important realignment: their queens now were sisters, their kings brothers-in-law.

As we recall, some 150 years before, Lord 13 Eagle of Chiyo Cahnu had attacked the temple of Ndisi Nuu and confronted the local ruler, Lord 8 Jaguar 'Blood Coyote' in battle. Now again, these two powers entered into contact. What had happened in the meantime to Ndisi Nuu?

Its original defender, Lord 8 Jaguar 'Blood Coyote', and his wife, Lady 2 Vulture 'Jewel Fan', ruled at least two kingdoms: River of the Animal and Split Mountain of Wind. From this couple originated a tripartite division of dynastic lines. ${ }^{17}$

The first two came from the marriage of their son, Lord 4/5 Grass 'Sun Knife', to Lady 6 Reed 'Venus Face'. The son of this couple, Lord 2 Wind 'Blood Rain', married Lady 4 Death, daughter of Lord 10 Alligator 'Digging Stick of Ñu Dzaui' and Lady 11 Alligator 'JewelAlligator', rulers of Ñu Ndecu (Achiutla).

Lord 2 Wind and Lady 4 Death became the first official rulers of Ndisi Nuu (Tlaxiaco). Obviously the connection with their important neighbor Nuu Ndecu was a crucial element in getting recognition of their realm. By now the temple of Ndisi Nuu (apparently controlled by Lord 8 Jaguar) is represented as a town ( $\tilde{n} u u)$. So, Lord 2 Wind was made ruler of a kingdom by his parents, or, more probably, his grandparents.

In other words, the religious site of Ndisi Nuu, which had become important during the reign of Lord 4 Wind, was now transformed into an independent village-state. Nuu Ndecu (Achiutla) seems to have passed through a similar development. It was already important as a religious site, but it seems to have gained the status of sovereign community only under Lord 4 Wind, who may have founded it as such

16 Codex Nuu Tnoo-Ndisi Nuu, p. 15-IV; cf. Codex Tonindeye, p. 32.

17 Codex Nuu Tnoo-Ndisi Nuu, p. 28. 
especially for the children of his second wife. Lord 8 Jaguar 'Blood Coyote' seems to have done the same with Ndisi Nuu for his grandson. It was probably this very plan of his that provoked the attack by Lord 13 Eagle, who hoped to bring Ndisi Nuu within the Chiyo Cahnu influence sphere.

It seems that the first rulers of Ndisi Nuu, Lord 2 Wind and Lady 4 Death, did not have any offspring. That is why the story in Codex Nuu Tnoo-Ndisi Nuu Reverse follows other dynastic lines. The main line of succession in the newly founded realm of Ndisi Nuu passed on to another son of Lord 8 Jaguar 'Blood Coyote' and Lady 2 Vulture 'Jewel Fan': Lord 2 Movement 'Fire Serpent of Flames (Nuu Ndecu)'. ${ }^{18}$ This man married Lady 2 Death 'Feathered Sun', daughter of earlier rulers of Nuu Ndecu, Lord 10 (?) Flower 'Jaguar of Flames', and Lady 7 (?) Flower 'Butterfly of Heaven'. ${ }^{19}$

It is tempting to suppose that Lord 10 (?) Flower 'Jaguar of Flames' was simply the son and successor of Lord 11 Flower 'Xicolli of Clouds' and Lady 5 Wind 'Hair of Clouds', who were the first mentioned rulers of Nuu Ndecu, one generation earlier $( \pm 1150) .{ }^{20}$

Lord 2 Movement and Lady 2 Death had a son: Lord 3 Serpent 'Rain of Flames', whose name suggests that he formed part of the Nuu Ndecu dynasty. He married two princesses from Flowered Mountain of the Puma Warrior: Lady 12 Wind 'Quetzal Jewel' and Lady 7 Death. ${ }^{21}$

The parentage statement is missing here, as it is in the cases of the following couples. Apparently the author of Codex Nuu Tnoo-Ndisi Nuu was copying data from a codex that did not register the parents, but he hoped to fill these gaps later. This suggests that according to the author of Codex Nuu Tnoo-Ndisi Nuu we are dealing here with successive generations. The following sequence (pp. 27-26) is difficult, but a plausible reading may be reconstructed by looking at the precise

\footnotetext{
18 The parents are shown as rulers of Split Mountain of Wind, associated with the year 8 Reed, day 7 Flower. This does not seem to be a marriage date, but may be the sacred date of Split Mountain of Wind and its dynasty, or a date of ritual importance, e.g. that of their enthronement or taking posession of the kingdom. In that case it would correspond to 1163 .

19 Probably, as Caso already noted, these rulers of Nuu Ndecu are one generation earlier than Lord 10 Alligator and Lady 11 Alligator, mentioned before.

${ }^{20}$ It is interesting to notice that Lord 10 (?) Flower's given name was the same as that of the elder brother of Lord 11 Flower and Lady 5 Wind.

${ }^{21}$ It is not clear if this place is the same as Flowered Feline Town.
} 
yuq yuq (boustrophedon) pattern and the spaces left open for parentage statements. ${ }^{22}$

We read then that Lord 3 Serpent and his wives had two children:

1. Lady 12 Water 'Quetzal Fan', who married Lord 10 Eagle 'War Venus (from Ndisi Nuu)'. As they were not an inheriting couple, no place for a parentage statement was reserved.

2. Lord 1 Deer 'Eagle - Ndisi Nuu', who married Lady 10 Grass 'Precious Butterfly'.

Here we encounter again the sign of Ndisi Nuu, but as part of the Lord's given name - not as place sign. Still it is possible that he became the successor of Lord 2 Wind, the last person explicitly qualified as ruler of Ndisi Nuu. A void space for a parentage statement after his wife confirms that this is supposed to be the inheriting marriage.

Lord 1 Deer and Lady 5 Grass had two children:

1. Lady 13 Flower 'Jewel Spiderweb', who married Lord 13 Serpent 'Rain'. Again there is no space reserved for a parentage statement, which means that this is not the inheriting marriage. Also the reading order suggests that Lady 13 Flower was the first named. In fact it is a curious coincidence that the names of this Lady and her brother are on following days: were they twins?

2. Lord 12 Rain 'Blood Jaguar', who married Lady 1 Monkey 'Quechquemitl (Beauty) of Jade'. Her parentage is stated: she was the daughter of Lord 12 Reed 'Coyote Sun' and Lady 3 Jaguar 'Sun Butterfly', from Nuu Tnoo. ${ }^{23}$

Lord 12 Rain and Lady 1 Monkey had a daughter: Lady 8 Serpent 'Sun Spiderweb' who married Lord 3 Dog 'Venus Sun', son of Lord 7 Serpent 'Eagle' and Lady 3 Jaguar 'War Quechquemitl (War Fame)'.

${ }^{22}$ See the analysis of this convention by Troike 1979.

${ }^{23}$ This marriage is also mentioned in Codex Nuu Tnoo-Ndisi Nuu, p. 15-II where Lord 12 Rain is explicitly shown as a ruler of Ndisi Nuu: he was the logical successor to his father, and he was probably also ruler of Split Mountain of Wind, as we will see (Codex Nuu Tnoo-Ndisi Nuu, p. 26-II), but that is of lesser importance here as Codex Ñuu Tnoo-Ndisi Nuu Reverse is mainly interested in the realm and perspective of Ndisi Nuu. Codex Nuu Tnoo-Ndisi Nuu Reverse registers 'Jewel Arrow' as the Lady's given name. 
A separate chapter clarifies the genealogical background of Lord 3 Dog. His line of descent goes back to another son of Lord 4/5 Grass and Lady 6 Reed as rulers of Dark Speckled Mountain. ${ }^{24}$ The date given with this couple is year 6 Rabbit, day 7 Alligator. It does not seem to be a marriage date, as it does not contain a day Deer or Eagle. Later we will see that 7 Alligator was a special day for this dynasty, so we interpret it here as a dynastic date. If it is historical (e.g. referring to the enthronement of the ruler), the year could be correlated with 1174. As the attack by Lord 13 Eagle came the next year, it is possible that the enthronement of Lord 8 Jaguar's son in Dark Speckled Mountain was actually another important reason for the conflict to erupt.

Three couples follow the marriage of Lord 4/5 Grass and Lady 6 Reed. We take them to be successive generations, which parallel the above-mentioned three generations of descendants of Lord 2 Movement, Lord 8 Jaguar's other son.

The couples in question are:

- Lord 1 Movement 'Fire Serpent with Black Feathers' and his wife, Lady 2 House 'Precious Quechquemitl'.

- Their son, Lord 4 House, married to Lady 5 House.

- From this couple was born Lord 7 Serpent 'Eagle', who married Lady 3 Jaguar 'War Quechquemitl (War Fame)'.

These three generations are not shown seated on the glyph of Mouth of the Dark Speckled Mountain. Apparently the place was still ruled by Lord 4/5 Grass and his wife.

Lord 3 Dog, then, was the son of Lord 7 Serpent and Lady 3 Jaguar. When he was born he was set on the road to Ndisi Nuu, which suggests that his marriage to the Heir Princess of the Ndisi Nuu dynasty was planned from the beginning. ${ }^{25}$

\footnotetext{
${ }^{24}$ Codex Nuu Tnoo-Ndisi Nuu, p. 27-I. This is the same place that played an important role in the biography of Lord 8 Deer. We identified it hypothetically as Acuchi (San Jerónimo Sosola). Its last known ruler before this couple was Lord 10 Flower, who attended, already as an old man, the enthronement of Lord 4 Wind (Codex Nuu Tnoo-Ndisi Nuu, p. 32-II, cf. pp. 9/10-V). This place seems to have been the throne and inheritance of Lord $4 / 5$ Grass, but it is not mentioned among the possessions of his father. We therefore speculate that Lord $4 / 5$ Grass inherited it from his mother, Lady 2 Vulture. She may have been a descendant of Lord 10 Flower.

${ }^{25}$ Compare the study 'Roads as Connectors in Mixtec Pictorial Histories', contributed by Nicholas Johnson to the volume in honor of Mary Elizabeth Smith (Boone 2005: 129-142).
} 
After the birth of this son, Lord 7 Serpent 'Eagle' became ruler of Serpent Mountain. Maybe the town was an inheritance from his mother. His wife was seated on an altar, which suggests that she was in charge of an important ceremonial site.

Their son, Lord 3 Dog, married Lady 8 Serpent, the daughter of Lord 12 Rain of Ndisi Nuu and Lady 1 Monkey of the Nuu Tnoo dynasty. At that time Lord 7 Serpent and Lady 3 Jaguar are shown as rulers of Dark Speckled Mountain, which suggests that by then Lord 4/5 Grass had died.

Lord 3 Dog 'Venus Sun' and Lady 8 Serpent 'Sun Spiderweb' had two children:

1. Lord 12 Deer 'Fire Serpent that Lightens the War'. ${ }^{26}$

2. Lady 10 Dog 'Jewel Butterfly of the Flower War', who married Lord 8 Deer 'Smoke Claw'. They ruled Ñuu Ndecu. ${ }^{27}$

As we noted above, Lord 3 Dog's parents, Lord 7 Serpent and Lady 3 Jaguar, had established themselves in Serpent Mountain. ${ }^{28}$ Then Lord 7 Serpent's father, Lord 4 House, married again, this time to Lady 9 Water. They had a son, Lord 3 Water.

This probably means that Lord 4 House's first wife, Lady 5 House, had died. If Lord 7 Serpent had indeed inherited from her the right to rule Serpent Mountain, her death and the second marriage of his father may have angered Lady 5 House's relatives and made them dispute Lord 7 Serpent's succession in Serpent Mountain.

On the day 1 Grass of the year 5 Rabbit (1290) Lord 2 Grass attacked Lord 7 Serpent, who defended Serpent Mountain. Maybe Lord 2 Grass was a relative (brother) of Lady 5 House, trying to reclaim the late

${ }^{26}$ Codex Nuu Tnoo-Ndisi Nuu, p. 26-II. Actually it is not clear if Lord 12 Deer was the son of Lord 3 Dog and his wife Lady 8 Serpent, or the brother of Lady 8 Serpent. The first interpretation seems the most plausible: two more children of Lord 3 Dog follow (the last of which was the son of another wife).

${ }_{27}$ In Codex Nuu Tnoo-Ndisi Nuu, p. 26-III her calendar name is given as 11 Lizard, but in a later statement (Ñu Tnoo-Ndisi Nuu, p. 25-III) as 10 Dog. The confusion seems due to the fact that Lady 11 Lizard was the daughter of Lady 10 Dog.

${ }^{28}$ It is interesting to notice that a Serpent Mountain appears prominently on the Lienzos of Atatlauhca and Philadelphia as a (far-away) place of dynastic origins (Smith 1998: 156, 166). The Relación Geográfica of the Beni Zaa kingdom of Coatlan ('Place of the Serpent') mentions a Lord Dog (tlatoani itzcuintli) who went to Nuu Dzaui, where he 'learned how to make sacrifices'; the latter, however, seems to have been identical to the Founding Father Petela, whose calendar name corresponds to 2 Dog or 5 Dog (Acuña 1984, I: 84, 89. Clearly a totally different episode is meant. 


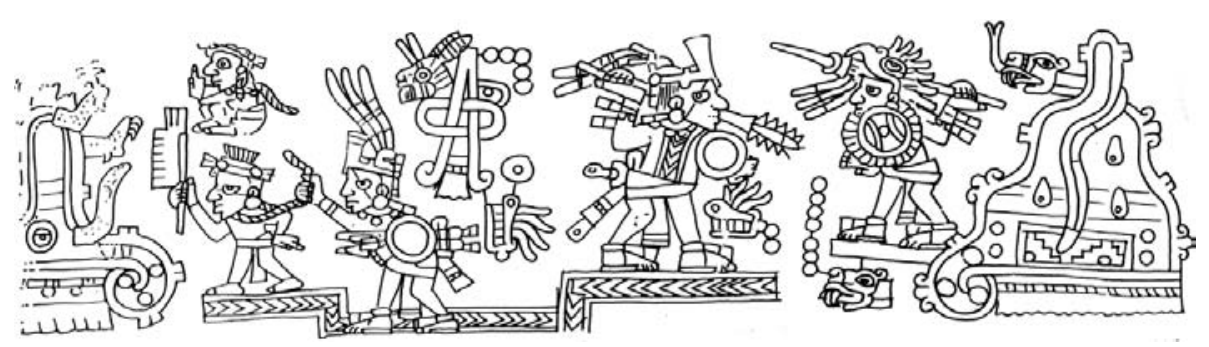

9.7. Codex Nuu Tnoo-Ndisi Nuu, p.25-I (Right to Left): Lord 7 Serpent defending Serpent Mountain.

Lady 5 House's inheritance. In any case he was a rich and noble lord, distinguished by a golden crown with quetzal feathers.

The attack seems to have ended without a clear victory: neither of the warring parties subdued or conquered the other. Lord 2 Grass took several prisoners and had them sacrificed in his hometown, Jaguar Mountain. But Lord 7 Serpent does not seem to have suffered a decisive defeat. In the following scenes he is shown seated in different places, either taking possession of a wider realm or looking for counsel in different sanctuaries. The last of these places is Mountain of the Precious Mask. There he and his wife watched the wedding of his halfbrother, Lord 3 Water, to Lady 9 Monkey.

Shortly after, Lord 7 Serpent married Lady 4 Serpent and went to live with her in Mountain of the Precious Mask, where a Temple of Blood and Cacao was prominent in the ceremonial center. ${ }^{29}$ Lord 7 Rain 'Flame of the Rising Nuhu' was probably the son of this second marriage of Lord 7 Serpent, because he became the successor of the royal couple in Mountain of the Precious Mask. It was in that condition that he married Lady 4 Monkey from the Nuu Tnoo dynasty. ${ }^{30}$

In the year 7 House (1305), Lord 12 Rain died in Split Wind Mountain. As a consequence a division into two roads, i.e. into two dynastic lines, occurred. ${ }^{31}$ Both started on the day 6 Jaguar of the year 7 House

${ }^{29}$ Codex Nuu Tnoo-Ndisi Nuu, p. 22-I. Caso (1960) situates the Temple of Blood and Cacao in Chiyo Cahnu (Teozacualco), but its occurrence as one of the four temples in the foundation ritual, repeated all over Nuu Dzaui, in Codex Yuta Tnoho (pp. 22-5), suggests that it was a type of temple that was not limited to one specific place, but formed part of most Nuu Dzaui ceremonial centers.

${ }^{30}$ Codex Ñuu Tnoo-Ndisi Nuu, p. 16-IV.

${ }^{31}$ Codex Nuu Tnoo-Ndisi Nuu, p. 26-II. 
(1305). This was the day before 7 Eagle, the favorite day for dynastic marriages.

One is the road of Lord 3 Dog, the son-in-law of Lord 12 Rain. First he spoke with his mother-in-law, Lady 1 Monkey. Both were seated on the marriage mat: apparently they agreed to marry. This is an interesting example of the son-in-law marrying the widow of his father-inlaw, i.e. the mother of his wife. Later a son was born: Lord 11 Serpent 'Rain that Lightens the War', half-brother to Lord 12 Deer. Both halfbrothers - the son born from this second marriage and the son born from the first - are connected through their given names: Lord 11 Serpent's given name is Dzavui Tnoo Tnañu ('Rain that Lightens the War'), that of Lord 12 Deer is Yahui Tnoo Yecu, ('Fire Serpent that Lightens the War'). These names form a pattern of initial rhyme (Yahui - Dzavui) and final difrasismo (yecu tnañu).

The same day 6 Jaguar of the year 7 House (1305) was the beginning of a religious pilgrimage for Lord 3 Dog. Painted black as a priest, he went on his way, followed by another priest, who was holding an incense burner and carrying the image of Lady 9 Reed, the Patron Deity of Ndisi Nuu. ${ }^{32}$ On the next day, 7 Eagle, both arrived at Sacred Precinct of Sand or Ashes (a sanctuary dedicated to the West?), where they celebrated the Bundle ritual.

Lady 9 Reed, personifying the late Lord 12 Rain, spoke to Lord 13 Serpent, who was Lord 12 Rain's brother-in-law, and to Lord 5 Reed, who functioned as a fellow priest and may have been Lord 13 Serpent's associate or kin. The priest, who on the day 6 Jaguar had taken up the task of carrying Lady 9 Reed (and here receives the calendar name 6 Jaguar), was killed in sacrifice. This suggests that it was a dangerous journey. In his place Lady 8 Serpent, Lord 3 Dog's wife, took care of the deity, following her husband.

Lord 3 Dog went hunting deer in the mountains and visited several sanctuaries: the oracle of Venus Mountain, the Great Plain of Feathers and Down Balls and the Temple of Death. These signs correspond to toponyms such as Yucu Quimi, Ihuitlan and the famous Huahi Cahi of Nuu Ndaya respectively, but, as we are not sure of the area, and don't even know if towns or temples are meant, we cannot identify these places with certainty. Lord 5 Reed, who was probably accompanying Lord 3 Dog, died on the road. Finally Lord 3 Dog joined his

32 Codex Nuu Tnoo-Ndisi Nuu, p. 30-V. The day 6 Jaguar is associated with the priest that follows the king, but it seems to be a chronological indicator. 


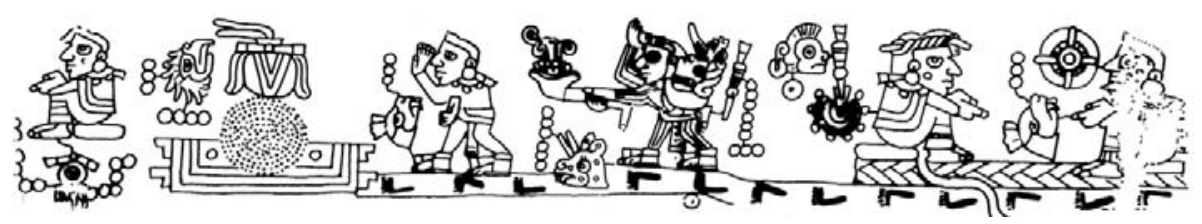

9.8. Codex Nuu Tnoo-Ndisi Nuu, p. 25-II (Right to Left): Lord 3 Dog, his marriage and pilgrimage.
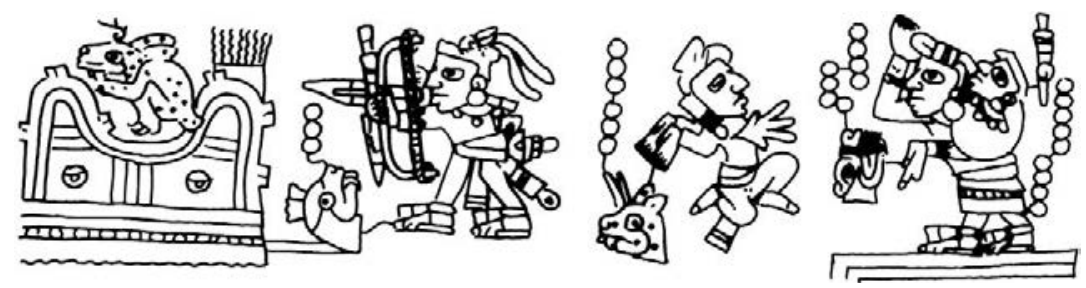

9.9. Codex Ñuu Tnoo-Ndisi Nuu, p. 24-II (Right to Left): Lord 3 Dog hunting a deer, while his wife carries the Bundle of Lady 9 Reed.
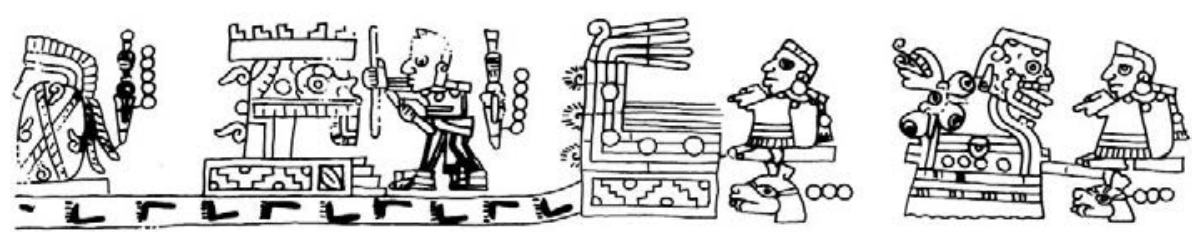

9.10. Codex Ñuu Tnoo-Ndisi Nuu, p. 23-II (Right to Left): Lord 3 Dog at Venus Mountain.

father, who had just remarried and was ruling Mountain of the Precious Mask.

In telling us that Lord 3 Dog made that pilgrimage and ended up in another place, the codex explains why he did not become ruler of Ndisi Nuu. That privilege fell to the son who had been born to him and his first wife, daughter of the former ruler of Ndisi Nuu. That son was Lord 12 Deer. He is the protagonist of the other road that started when Lord 12 Rain died in Split Mountain of Wind.

On the day 6 Jaguar of the year 7 House (1305) Lord 12 Deer immediately married his niece, Lady 11 Lizard, 'Jewel of Flames (Ñu Ndecu)', the daughter of his sister Lady 10 Dog 'Butterfly (Jewel) of the Flower War' and Lord 8 Deer 'Smoke Claw', rulers of Nuu Ndecu. Later Lord 12 Deer would marry a second woman: Lady 6 Rabbit, daughter of Lord 9 Serpent 'Jaguar that Lightens the War' and Lady 8 


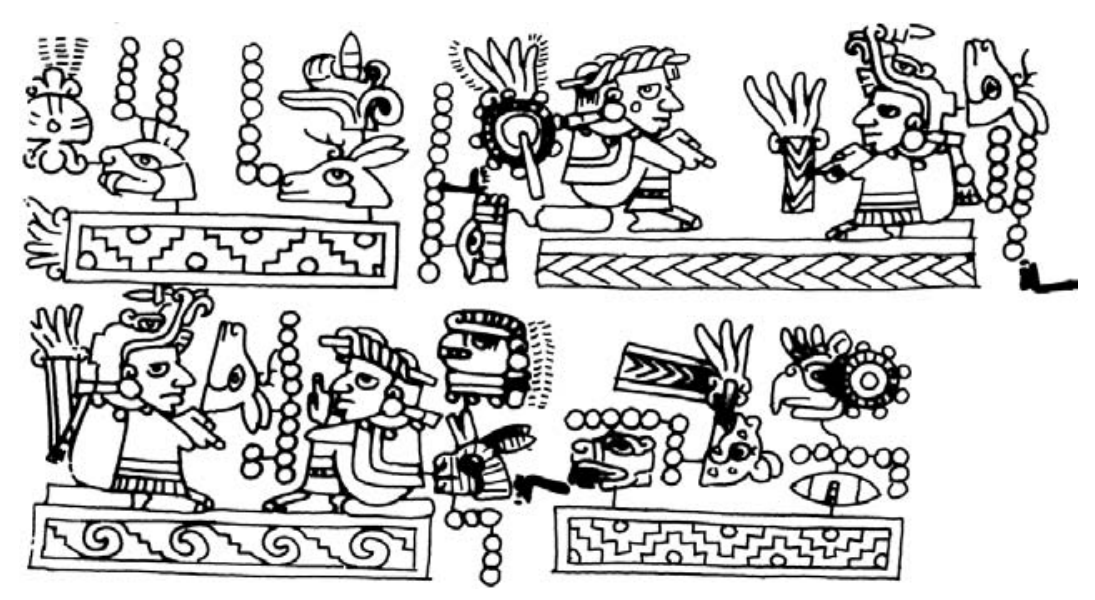

9.11. Codex Nuu Tnoo-Ndisi Nuu, p. 25-III/IV (Upper Right to Lower Right, boustrophedon): the two marriages of Lord 12 Deer.

Flint 'Quetzal Jewel', of the prestigious Nuu Tnoo dynasty. ${ }^{33}$ By then Lord 12 Deer had become the next ruler of Ndisi Nuu. ${ }^{34}$ Apparently they did not have children (at least no children that survived), because here a dynastic break occurred.

After Lord 12 Deer died without heirs, there was a shift in the dynasty. ${ }^{35}$ The next rulers associated with the Ndisi Nuu place glyph are Lord 10 Rabbit 'Blood Jaguar' and Lady 11 Rabbit 'Jewel of the Rising Nuhu'. These must have been ruling in Ndisi Nuu in the 1330s, as their son married in 1343 and was qualified then as a prince of Ndisi Nuu. The sequence of dates suggests that Lord 10 Rabbit and Lady 11 Rabbit succeeded Lord 12 Deer. ${ }^{36}$

Lord 10 Rabbit was the son of Lord 4 Movement 'Rain that Came Down from Heaven' and Lady 2 Eagle 'Sun Flower'. The mother's parentage is not given, but the father, Lord 4 Movement, was the son of

${ }^{33}$ This marriage would have been some years later, as Lady 6 Rabbit was born somewhere between 1305 and 1315 .

${ }^{34}$ Codex Ñuu Tnoo-Ndisi Nuu, p. 16-IV establishes that Lord 12 Deer was ruler of Ndisi Nuu when he married Lady 6 Rabbit of the house of Nuu Tnoo. She was the younger sister of Lord 4 Water, who had been born in Year 3 House (1301 AD). See also Codex Yuta Tnoho Reverse, p. XI-1.

${ }_{35}$ A vertical line in Codex Ñuu Tnoo-Ndisi Nuu p. 25-IV indicates the interruption of the genealogical story.

${ }^{36}$ Such an interpretation would explain why we don't find a place sign and sacred date when they appear for the first time in Codex Nuu Tnoo-Ndisi Nuu, p. 26-V: it is not a new foundation of the house of Ndisi Nuu, but a continuation. 


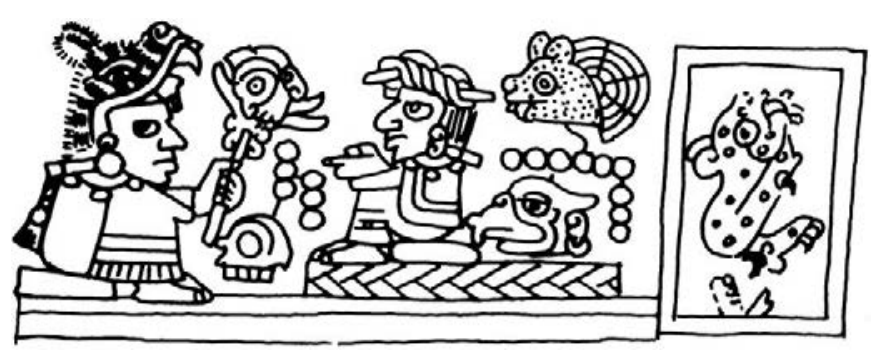

9.12. Codex Nuu Tnoo-Ndisi Nuu, p. 25-IV: Lord 6 Death and Lady 9 Vulture.

Lord 6 Death 'Coyote that Burns the Mexicans' and Lady 9 Vulture 'Jaguar Spiderweb', rulers of a place represented by a Red Square, a Mouth and a Jaguar. ${ }^{37}$ The toponym is associated with Lady 9 Vulture. In fact, her given name may also be interpreted as 'Spiderweb from Jaguar [Place]'. The author is probably copying from a dynastic record without referring to the founding of the lineage, which is normally given at the beginning of the record. Originally this scene may have been part of a parentage statement for their son, Lord 4 Movement.

Thus Lord 10 Rabbit was not a member of the house of Ndisi Nuu, but his wife Lady 11 Rabbit 'Jewel of the Rising Nuhu' was. She came from Flame Town, Nuu Ndecu. There had been important links between the Ndisi Nuu and Nuu Ndecu dynasties. The most recent one was the marriage of Lady 10 Dog (Lord 12 Deer's sister) of the house of Ndisi Nuu to Lord 8 Deer, ruler of Nuu Ndecu. Their daughter had been one of Lord 12 Deer's wives. Lady 11 Rabbit was probably also a daughter of that couple, i.e. a daughter of Lord 12 Deer's sister (and consequently a sister of Lord 12 Deer's wife). When Lord 12 Deer died without offspring, Lady 11 Rabbit was a logical heir. She was married, so her husband shared the rulership and became known as Lord 10 Rabbit 'Jaguar of Ndisi Nuu'. This, we notice, is a typical given name for rulers of Ndisi Nuu. The name of the town means 'Clear View' and was incorporated in the given names of several of its rulers, resulting in word-plays like 'Clear View Jaguar', which can mean both 'Jaguar with Sharp Eyesight' and 'Jaguar of Ndisi Nuu (Tlaxiaco)'. ${ }^{38}$

${ }^{37}$ Maybe the combined glyph indicates the combination (alliance?) of two towns. In the general area of Ndisi Nuu we find Nuu Cuaha, 'Red Place' (Atatlauhca) and Nuu Cuiñe 'Place of the Jaguar' (Cuquila). On the other hand, the mouth usually indicates the locative prefix $a$-.

${ }^{38}$ Codex Nuu Tnoo-Ndisi Nuu, p. 26-V, cf. p. 15-V. The original name of Lord 10 Rabbit 'Jaguar with Bloody Claws' commemorates the name of an earlier person, 
At the time of succession, Lord 10 Rabbit and Lady 11 Rabbit already had two sons: Lord 9 Rain 'Blood Jaguar' and Lord 4 Death 'Quimi Yecu Ndisi Nuu', 'War Venus of Tlaxiaco'. The first-born was to continue the dynasty.

\section{Wars and Expansion}

The death of Lord 4 Wind and the demise of the central authority of Ñu Yuchi seem to have been followed by a 'dark century', a difficult period of political atomization, in which noble houses struggled to affirm their local power bases. The important marital alliance of the most successful of these, Chiyo Cahnu, with the Beni Zaa capital Zaachila, started to change the picture. The fruit of this alliance was Lord 2 Dog, son of a mother from Chiyo Cahnu and a father from Zaachila.

Another factor was the marriage policy that Lord 9 Serpent of Nuu Tnoo and his two wives set out for their children. They had one son, Lord 4 Water, and three daughters. Of these, the first, Lady 6 Reed, married Lord 2 Dog: together they established a new dynasty in Chiyo Cahnu, taking possession of the territory in 1321 and building a new palace in the center of the town. The second daughter of Lord 9 Serpent, Lady 4 Monkey, went to Mountain of the Precious Mask to marry Lord 7 Rain. The third, Lady 6 Rabbit, married Lord 12 Deer of Ndisi Nuu. In other words, the wives of Lord 12 Deer, of Lord 7 Rain and of Lord 2 Dog were sisters.

Then Lord 9 Serpent's first-born son, Lord 4 Water 'Blood Eagle', married Lady 6 Water 'Quetzal, Jewel of the Flower War', the daughter of his sister, Lady 6 Reed, and her husband Lord 2 Dog.

This complex web of marriages connected the major dynasties of the Mixteca Alta among themselves and with the Beni Zaa ruling family of Zaachila. It also forms the background of a series of armed conflicts, which probably reflect a new sense of confidence and ambition.

The son of Lady 6 Reed and Lord 2 Dog was Lord 9 House, born in the year 12 Reed (1323). ${ }^{39}$ Given the intricate family relationships, he was a nephew to Lord 7 Rain of Mountain of the Precious Mask, who

important in the life of Lord 2 Rain 'Ocoñaña' and Lord 8 Deer (Codex Tonindeye, p. 13).

${ }^{39}$ Codex Yuta Tnoho Reverse, p. XII-3 


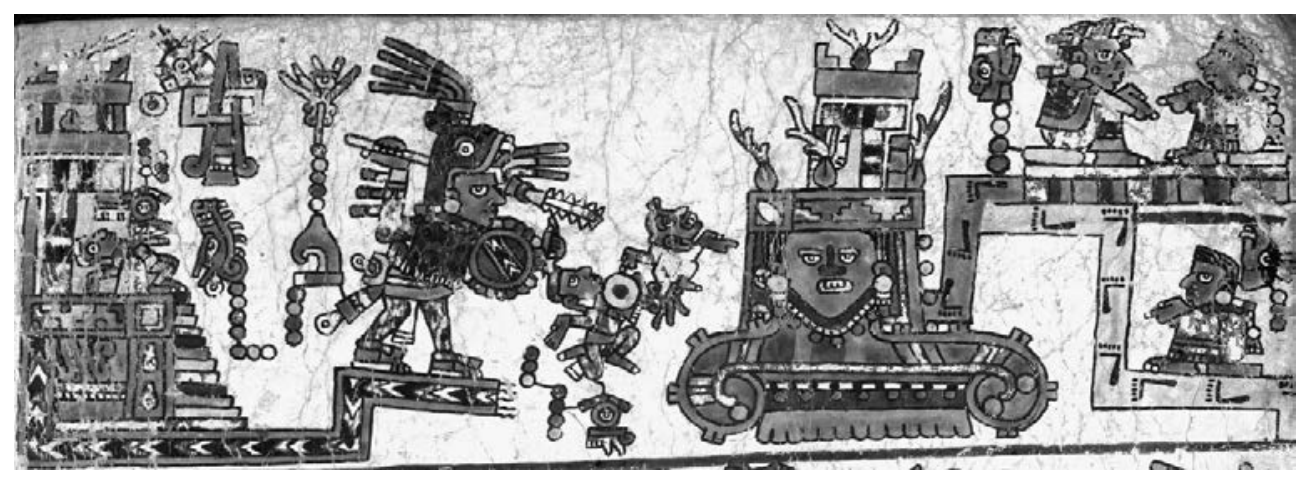

9.13. Codex Nuu Tnoo-Ndisi Nuu, p.22-I (Right to Left): Lord 3 Dog arrives at Mountain of the Mask; Lord 9 House attacks and sacrifices Lord 7 Rain.

had married a younger sister of his mother. In the year 1 Rabbit (1338) Lord 9 House attacked Mountain of the Precious Mask, took Lord 7 Rain prisoner and had him sacrificed on the day 7 Alligator in the Temple of Blood and Cacao. The reason for this assault is not clear. It is mentioned in the context of a chapter in Codex Nuu Tnoo-Ndisi Nuu (pp. 25/23-II and p. 22-I), which apparently tries to explain how Lord 3 Dog, who had married into the Ndisi Nuu dynasty, by going away to live in Mountain of the Precious Mask, left the succession in Ndisi Nuu to his son Lord 12 Deer. The attack on Mountain of the Precious Mask meant that this genealogical line was broken off, so that no prince from there (as a descendant of Lord 3 Dog) could ever claim succession rights to the throne of Ndisi Nuu.

Our interpretation is hampered by the fact that we cannot be sure of the identification of Mountain of the Precious Mask. There are at least two places with the corresponding Nahuatl name of Xayacatlan: one near Atatlauhca in the Cuicatec Cañada, one near Yucu Yusi (Acatlan) in the Mixteca Baja. The latter, San Jerónimo Xayacatlan, is, indeed, situated close to a Yuku Nahna, 'Mountain of the Mask'. The dynasty of Chiyo Cahnu (Teozacualco) had a link with Yucu Yusi (Acatlan), as demonstrated by the roll of Toavui-Yucu Yusi (found in Huamelulpan). Another possibility is, somewhat further to the North, the archeological site of Cutha, which means 'Mountain of the Mask' in the Popoloca language. This is indeed a strategically located capital town. Furthermore there would be interesting candidates in this area for Serpent Mountain (Coatepec) and Jaguar Mountain (Tehuacan), 
but these names are too general and too wide-spread to allow for a conclusive positive identification. ${ }^{40}$ In any case, it is likely that Lord 9 House's attack on Mountain of the Precious Mask was the beginning of the Ñuu Dzaui expansion into the southern part of the present-day State of Puebla, which followed immediately afterward.

As far as the role of these events in the dynastic history of Ndisi Nuu is concerned, the following political considerations may have been important. After the death of Lord 12 Deer, the succession in Ndisi Nuu was disputed. One of the pretenders may have been Lord 7 Rain, who seems to have been the younger half-brother of Lord 12 Deer's father, Lord 3 Dog. If we suppose that Lord 7 Rain grew up under the regency of Lord 3 Dog in Mountain of the Precious Mask, it is even more plausible that he considered himself more like a son of Lord 3 Dog and therefore as a younger half-brother of Lord 12 Deer. He would then indeed have had some claim to the succession in Ndisi Nuu. This claim was reinforced when he married a Ñu Tnoo princess, who was a sister of Lord 12 Deer's second wife.

The other party in the conflict rallied round Lady 11 Rabbit, who was probably the younger sister of Lord 12 Deer's first wife and moreover descended from Lord 12 Deer's own sister. She reinforced her position by arranging a marriage between her eldest son, Lord 9 Rain 'Blood Jaguar' and Lady 7 Flint, a daughter of Lord 2 Dog of Chiyo Cahnu and Lady 6 Reed (who was yet another sister of Lord 12 Deer's wife). In this way Lady 11 Rabbit cleverly prevented that the powerful Ñu Tnoo - Chiyo Cahnu family would support Lord 7 Rain. On the contrary, now Lady 7 Flint's brother, Lord 9 House, launched a full attack on Lord 7 Rain and had him sacrificed in the Temple of Blood and Cacao. This meant the end of the pretensions of Mountain of the Precious Mask and strongly established the new dynasty of Ndisi Nuu:

${ }^{40}$ Codex Nuu Tnoo-Ndisi Nuu, p. 22-II. A similar glyph does appear as an important place, next to the Black Mountain (supposedly Monte Negro of Nuu Tnoo), in Codex Yuta Tnoho, pp. 10-9, where the ancient Nuu Dzaui 'realm' was founded. Apart from the episode we are discussing here, Mountain of the Precious Mask does not play an important role in the dynastic history as reported by the codices of the Mixteca Alta. The references to it stress that those who went there had to make quite a journey (painted as a long road). Thus we may assume that it is located at a considerable distance from the nuclear area of the Mixteca Alta. The area of Coatepec and the site of Cutha are described by Johnson 1997, see also the archeological monograph on Cutha by Castellón Huerta 2006. For the story of the migration from the Coixtlahuaca Valley to the North, see the Lienzo of Tlapiltepec and the Lienzo of Coixtlahuaca II (Jansen 1992; Van Doesburg \& Van Buren 1997: 121-122). 


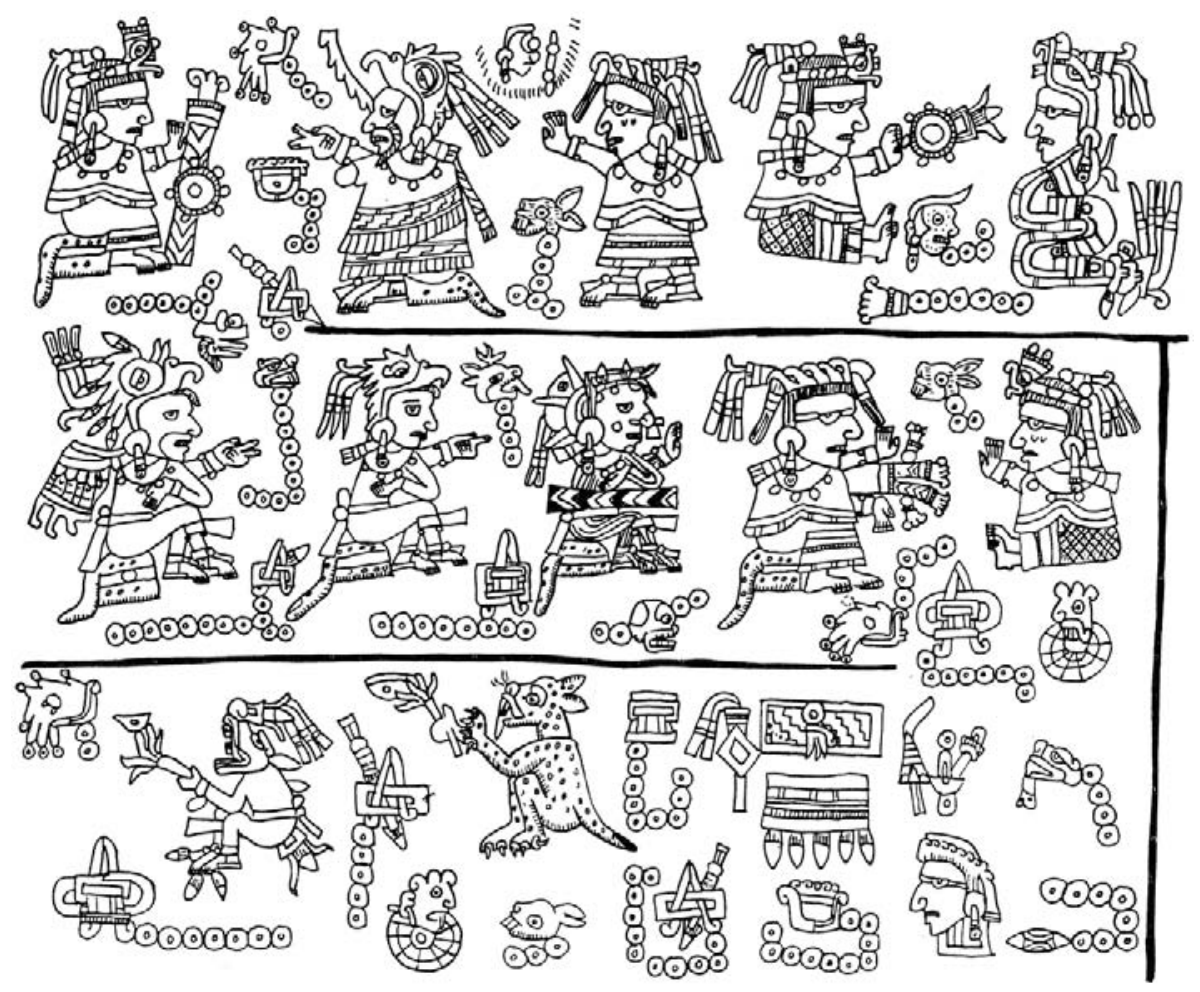

9.14. Codex Yuta Tnoho Reverse. p. XII (Upper Right to Lower Left, boustrophedon): 1) Lady 6 Reed [here erroneously called: 6 Flower] 'Plumed Serpent' and two other sisters of Lord 4 Water, the marriage of Lord 4 Water and Lady 6 Water; 2) their children, the second marriage of Lady 6 Water to Lord 4 Death and their children, the first-born being Lady 3 Rabbit, 3) sisters of Lady 3 Rabbit, her marriage to Lord 9 House, and the birth of their son, Lord 2 Water, in the year 7 House.

Lady 11 Rabbit and her husband, Lord 10 Rabbit became the rulers, and their son, Lord 9 Rain with his wife, Lady 7 Flint, would be their successors.

At the same time Lord 9 House convincingly established his reputation as someone capable of resolving complex dynastic problems through drastic action.

Another event that had consequences for the new Ndisi Nuu dynasty was the death of Lord 4 Water 'Blood Eagle' of Nuu Tnoo (Lord 9 Serpent's first-born son) on the day 7 Wind of the year 4 House (1341) together with a Lord 9 Alligator 'Eagle', possibly one of 


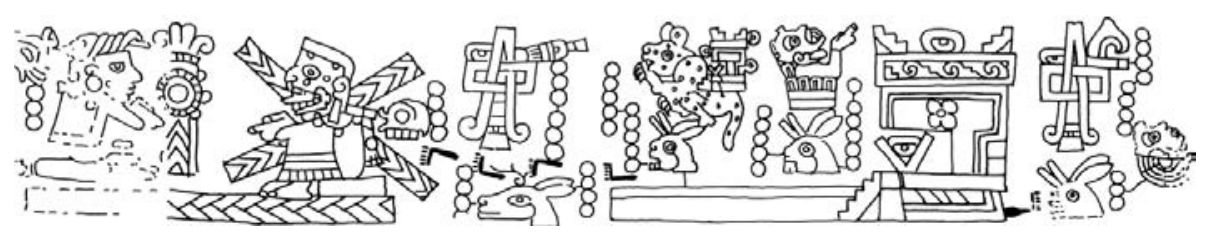

9.15. Codex Nuu Tnoo-Ndisi Nuu, p. 15-V (Left to Right): the marriage of Lady 6 Water and Lord 4 Death from Ndisi Nuu, son of Lord 10 Rabbit and Lady 11 Rabbit.

his own sons ${ }^{41}$ The death of the two men together points in the direction of an unnatural cause, possibly war.

Lord 4 Water's wife, Lady 6 Water 'Quetzal, Jewel of the Flower War', after the death of her husband, married again, choosing Lord 4 Death 'Quimi Yecu Ndisi Nuu', 'War Venus of Tlaxiaco', the second son of Lord 10 Rabbit 'Ndisi Nuu Jaguar' and Lady 11 Rabbit 'Jewel of the Rising Nuhu (East)', rulers of Ndisi Nuu. This marriage was celebrated in the year 6 Reed (1343), on the day 8 Deer. ${ }^{42}$

Given the links between Lord 12 Deer and the Nuu Tnoo dynasty (through his wife and his grandmother), it was logical that both princes of Ndisi Nuu, Lord 9 Rain 'Blood Jaguar' and Lord 4 Death 'WarVenus of Ndisi Nuu', should look for their partners in that direction in order to reinforce their rights of succession. Indeed they both married daughters of Lady 6 Reed of Nuu Tnoo and Lord 2 Dog of Chiyo Cahnu. As we saw above, the oldest son, Lord 9 Rain, had married the second daughter of Lady 6 Reed and Lord 2 Dog, Lady 7 Flint ${ }^{43}$ - they were to continue the Ndisi Nuu lineage. Now, the second son, Lord 4 Death, married the first daughter of that same couple, Lady 6 Water they were to continue the Nuu Tnoo lineage. ${ }^{44}$

From this second marriage of Lady 6 Water 'Quetzal, Jewel of the Flower War' several children were born:

${ }^{41}$ Codex Yuta Tnoho Reverse, p. XII-2, mentions two sons: Lord 8 Wind 'Eagle', born in the year 12 Flint (1336), and Lord 10 Serpent 'Quetzal', born in the year 1 Reed, probably to be corrected to 2 Reed (1339). There are quite a few errors in Codex Yuta Tnoho Reverse; the names of the sons may be written wrongly.

${ }^{42}$ Codex Yuta Tnoho Reverse, p. XII-2, gives the year 8 House (1345) and the day 4 Deer.

${ }^{43}$ She is called 6 Flint in Codex Tonindeye, p. 32.

${ }^{44}$ Codex Ñuu Tnoo-Ndisi Nuu, p. 24-V, cf p. 15-V. 
1. Lady 3 Rabbit 'Ñuhu Spiderweb', in the year 8 House (1345).

2. Lady 4 Serpent 'Jewel of Ndisi Nuu', who married Lord 7 Grass 'Blood Jaguar' of Monkey Town (Teita?).

3. Lady 8 Flint 'Cloud Head', who married Lord 13 Lizard 'Blood Rain' of Mountain of Flowers (Yucu Ita?).

4. Lady 10 Water 'Ñu Dzaui Fan', who first married Lord 11 Serpent 'Eagle of the Ballcourt' from River of Gold and Feathers, and then Lord 13 Jaguar 'War Beard', King of Ñu Ndaya (Chalcatongo). ${ }^{45}$

In this case after the death of the ruler (Lord 4 Water) the power of his house did not pass to a collateral line, but was maintained by his widow. Lord 4 Water did not have a brother, but four sisters. His widow was herself a daughter of one of those sisters (Lady 6 Reed) and therefore belonged to the Nuu Tnoo lineage. By remarrying, she allied herself with the new Ndisi Nuu dynasty, but, as her second husband was a second son and not the heir to the throne there, the couple probably stayed in Nuu Tnoo and claimed the kingdom for their first-born daughter, Lady 3 Rabbit - there were no sons to inherit. The position of this child was reinforced through her marriage to Lady 6 Water's younger brother, the above-mentioned Lord 9 House, also a descendant of Lady 6 Reed of the Nuu Tnoo dynasty.

This sequence of marital decisions and related claims to the throne of Nuu Tnoo demonstrates that in this case the estate and tribute rights of the noble house were mainly passed on through the female line: Lady 6 Reed - Lady 6 Water - Lady 3 Rabbit. The marriage of Lady 3 Rabbit to Lady 6 Reed's son, Lord 9 House, reconnected this female heritage line with the male line of the same lineage. At the same time it kept the rule of Nuu Tnoo and Chiyo Cahnu in one family, which created a strong political power base. Lord 9 House added military prowess to this, engaging in several armed conflicts.

In the same period an alliance of Nuu Dzaui kings was engaged in extending their sphere of influence into the Nahuatl speaking territories, through a series of military campaigns, which seem to have taken several years. Their starting point was Yodzo Coo (Coixtlahuaca) and they reached towns as far North as Cuauhtinchan, Tepeaca, Quecholac and Tecamachalco, where they intermarried with local lineages. XIII.

${ }^{45}$ Codex Nuu Tnoo-Ndisi Nuu, pp. 17/18, cf Codex Yuta Tnoho Reverse, pp. XII/ 


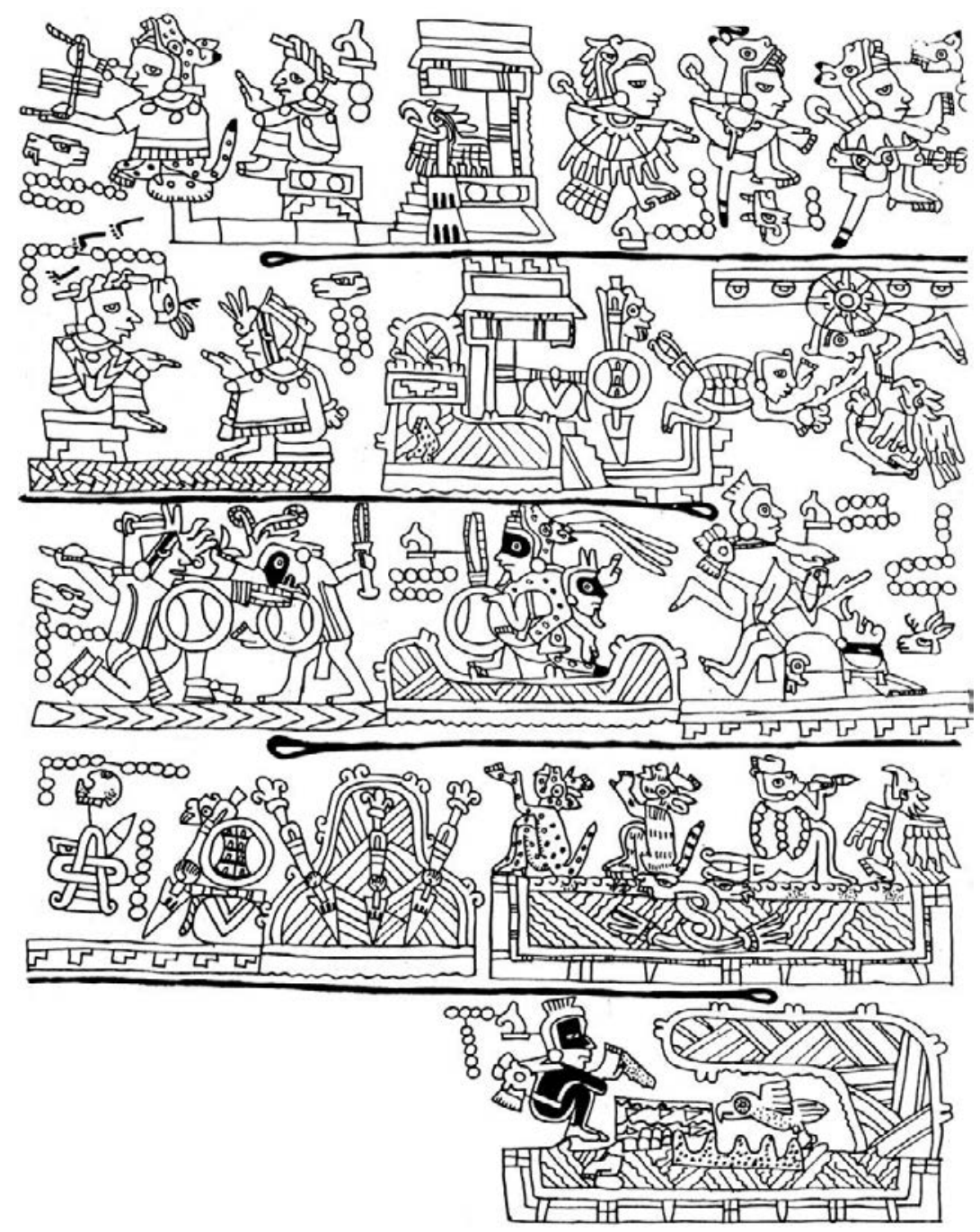

9.16. Codex Añute, p. 11-III / p. 12-III (Lower Right to Upper Right, boustrophedon): the expedition to Cuauhtinchan.

According to the Historia Tolteca Chichimeca this process started in 1339, i.e. immediately after Lord 9 House's attack on Mountain of the Precious Mask. Codex Añute shows how Lord 9 House, together with his loyal ally and friend Lord 9 Lizard of Añute, participated successfully in raids in the Tepexi area. They initiated their war campaign by 
celebrating a Bundle Ritual in Ndaa Nduvua (Miltepec) in the year 7 Flint (1344). ${ }^{46}$

Through his military victories and bravery Lord 9 House gained the honorific name of 'Jaguar that Burns the Nahuas'. Then, in the year 3 House (1353) on the day 4 Eagle, he wed Lady 3 Rabbit 'Nuhu Spiderweb', Heir Princess of the Heaven Temple (of Nuu Tnoo) and of Mountain of Flowers (probably because of the marriage of her sister to a ruler of that place).

Lady 3 Rabbit and Lord 9 House married in the year 3 House (1353), according to Codex Nuu Tnoo-Ndisi Nuu (p. 17/18-V), or in the year 5 Reed (1355), according to Codex Yuta Tnoho Reverse (p. XII-3). These different dates do not necessarily contradict each other, as they may refer to two different preparatory rituals, which preceded the actual consummation of the marriage. On both occasions Lady 3 Rabbit was still a young child ( $8-10$ years old), but her husband, born in 1323 , was already an adult (30-32 years old).

We notice that in Codex Nuu Tnoo-Ndisi Nuu the position of the marrying couple is inverted in relation to the reading order. Lord 9 House is mentioned first, instead of Lady 3 Rabbit. This obliged the painter to put Lord 9 House's parental statement behind his wife. This irregularity may be due to a change in the codex from which the data are copied. It also draws attention to the fact that Lord 9 House had his own right to the throne of Nuu Tnoo, due to being Lady 6 Reed's son.

Lord 9 House and Lady 3 Rabbit had the following children:

1. Lord 2 Water 'Fire Serpent that Burns the Nahuas', who was born in the year 7 House (1357). ${ }^{47}$

46 Codex Añute, p. 11/12 (cf. Jansen 1992; Jansen \& Pérez Jiménez 2000: 151-158). The Valley of Coixtlahuaca is represented as intertwined plumed serpents in Codex Añute, p. 11-IV (cf. Smith 1973a: 65-66). The preparatory ritual meeting took place at a river, which may be identified as a local site, Omeapan (Van Doesburg \& Van Buren 1997: 122). This series of events provides another circumstantial argument that supports the proposed correction of Emily Rabin. Central Mexican sources, like the Historia Tolteca Chichimeca, suggest strongly that this campaign from the Yodzo Coo (Coixtlahuaca) area towards Cuauhtinchan took place in the 14th century, making the associated year 7 Flint (Añute, p. 11-IV) correspond to 1344. If we follow Caso, who calculated this year 7 Flint as 1292, we would have to postulate that a very similar campaign happened exactly one cycle earlier (without leaving any traces in the Central Mexican records).

${ }^{47}$ Cf. Rabin in Whitecotton \& Bradley Whitecotton 1982: 365 (note 9). In Codex Tonindeye, p. 32, his name is 'Fire Serpent Burning Foot', to be read as Yahui Nduhua 


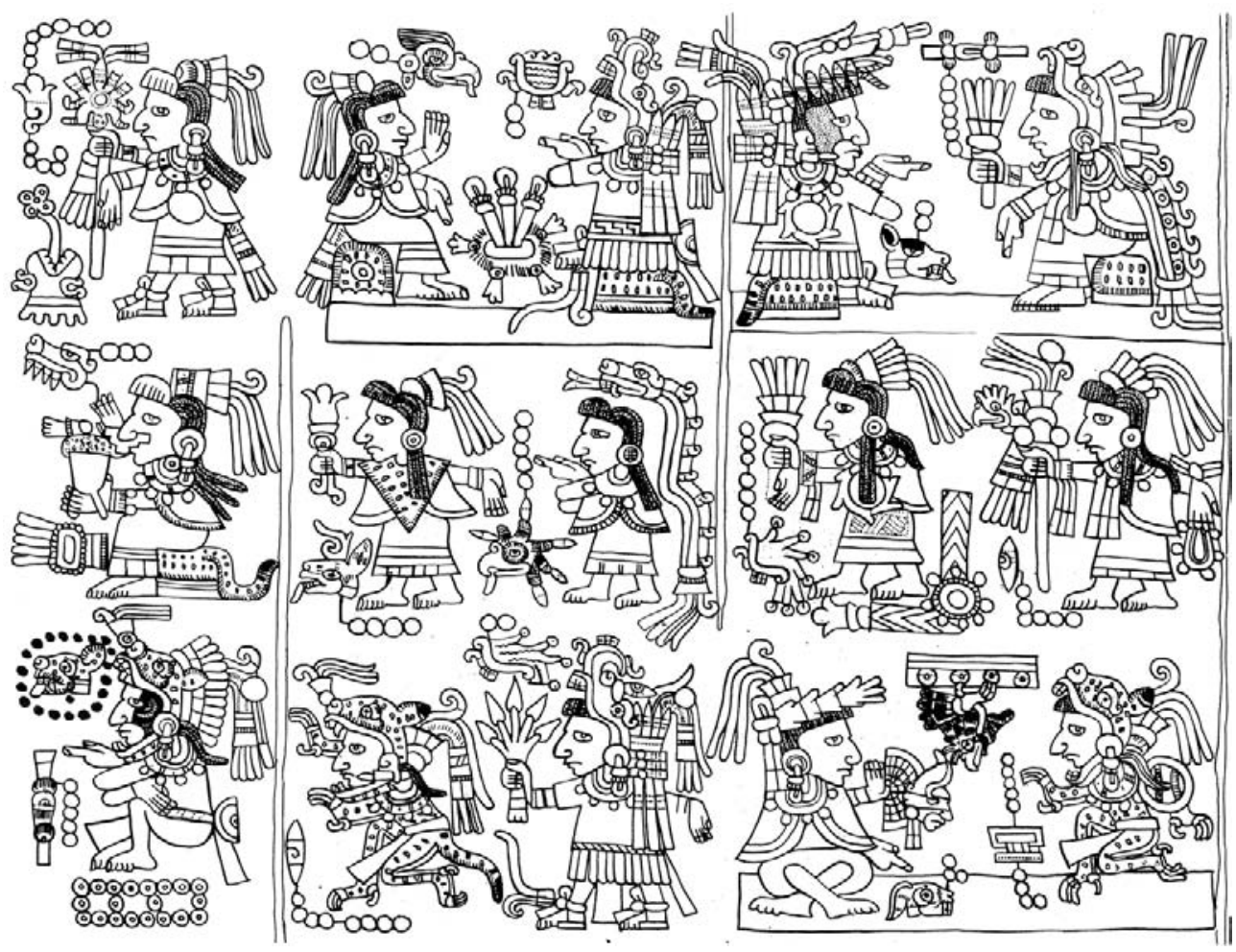

9.17. Codex Tonindeye, p. 32 (Upper Right to Lower Left, boustrophedon): Lord 2 Dog and Lady 6 Reed with their descendants until Lord 5 Reed Ocoñaña.

2. Lady 13 Flint 'Precious Quetzal'.

3. Lady 5 Eagle 'Flower Serpent'.

4. Lady 10 Deer 'Jaguar Quechquemitl'.

5. Lady 11 Serpent 'Plumed Serpent'.

6. Lady 1 Serpent 'Fan of the Rising Sun'.

Codex Ñuu Tnoo-Ndisi Nuu (p. 18-V) gives the year 4 House (1341 or 1391) for the birth of Lord 2 Water, but this does not fit in the chronological sequence, given the marriage of his parents in 13531355. The much more plausible date of 7 House (1357) is documented

$\tilde{N} u h u$, 'Fire Serpent of War'. Notice how the nduhua ñuhu part in the name is a male version of the nduhua nuhu 'Divine Spiderweb' in the name of his mother. Later the 'war' was specified as an armed conflict with the Mexica. 
by Codex Yuta Tnoho Reverse (p. XII-3). At that time his mother was 12 years old.

\section{The Second Marital Alliance with Zaachila}

In the year 9 Flint (1372) Lord 9 House's friend and ally, Lord 9 Lizard of Añute got involved in an armed conflict with Zaachila. In the Beni Zaa realm a young ruler had come to power: Lord 6 Water (who must have been born around 1350). He was the son of Lord 11 Water, who corresponds to Cosijoeza I of the dynasty of Zaachila, and who in turn was the son of Lord 3 Alligator, the younger brother of Lord 2 Dog (cf. Oudijk, in Van Doesburg 2008: 89-116). Lord 6 Water made a violent incursion into the Mixteca Alta, into the territory of Añute. A battle took place at Mountain of Axes, probably Yucu Nuu Caa. ${ }^{48}$ Two princes were taken prisoner: Lord 7 House and Lord 3 Alligator, the two eldest sons of Lord 9 Lizard. In a 'war ritual of bow and arrow' at Place of Gravel or Ashes (possibly the nearby Tenexpa) they were shot with arrows, i.e. executed. ${ }^{49}$ Only one other son survived, probably because he was still a child and did not participate in the battle: Lord 2 Jaguar.

The king of Nuu Tnoo, Lord 9 House, hurried to manifest his old friendship with Lord 9 Lizard of neighboring Añute and, in order to safeguard the continuity of that noble house, arranged a marriage between his own youngest daughter, Lady 1 Serpent, and the surviving prince Lord 2 Jaguar. The wedding took place at short notice, only fifteen days after the battle, in the same year 9 Flint (1372).

The conflict must have estranged the nobility of the Mixteca Alta from the Beni Zaa royal family for some time.

The first-born son of Lord 9 House and Lady 3 Rabbit, Lord 2 Water 'Fire Serpent that Burns the Nahuas' married Lady 2 Vulture 'Flower

${ }^{48}$ This identification is suggested because of the combination of Mountain of the Axe with Mountain of Deer (Codex Añute, p. 4-III) and the fact that both Yucu Nuu Caa and Mazaltepec were subject towns of Añute.

${ }^{49}$ Codex Añute, p. 12-IV and p. 13-I. The two men were still quite young. Only Lord 7 House was married - to a woman from Town of the Chayotes (probably Chayoltongo, a subject town of Nuu Tnoo). As Michel Oudijk (2000) has shown, this same war in the area of Huitzo is mentioned in the Genealogy of Macuilxochitl, where Lord 7 Owl (the equivalent of 7 House in the Beni Zaa calendar) and Lord Alligator are taken prisoner by the same Lord 6 Water. For a representation of ritual execution through the shooting of arrows, see Historia Tolteca Chichimeca, f 28r. 
Jewel', daughter of Lord 7 Grass 'Blood Jaguar' and Lady 6 Rabbit 'Sun Quechquemitl' (Dzico Ndicandii, 'Virtue or Power of the Sun'), rulers of Monkey Town (Teita?). ${ }^{50}$ This was a renewed effort by the house of Nuu Tnoo to establish a marital alliance with that place, apparently to strengthen its own political clout in the nuclear area of the Mixteca Alta.

With similar objectives Lord 9 House and Lady 3 Rabbit had one of their daughters, Lady 5 Eagle, marry Lord 2 Vulture 'Eagle', King of Drum Town (Añuu, Soyaltepec?). Lord 9 House divided the conquered lands near Mountain of the Precious Mask among his sons-inlaw, Lord 2 Vulture and Lord 2 Jaguar.

Another daughter of his, Lady 11 Serpent, married her cousin Lord 6 Vulture 'Jaguar with Knife', ruler of Mountain of the Xipe Bundle. He was a prince of the Ndisi Nuu dynasty: his father was Lord 9 Rain 'Blood Jaguar' and his mother was Lady 7 Flint, a sister of Lord 9 House..$^{51}$ The marriage reinforced the good relationship Lord 9 House had with that family and strengthened the ties between Nuu TnooChiyo Cahnu and Ndisi Nuu, which was in the mutual interest of the parties involved.

It was this policy of marital alliances that led to a new understanding between the dynasties of Nuu Dzaui Nuhu (the Mixteca Alta), more and more constituting one family, and the king of Zaachila. In order to get a good view of that development, we have to focus again on the rulers of Ndisi Nuu. ${ }^{52}$

The marriage between the first-born son, successor to the lineage of Ndisi Nuu, Lord 9 Rain 'Blood Jaguar', and Lady 7 Flint 'Quetzal-Fan', the daughter of Lord 2 Dog, probably took place in the 1340s. Their children were:

1. Lord 11 Wind 'Smoking Claw'.

2. Lord 7 Vulture 'Jaguar with Claws like Flints', who went to Mountain of Xipe Bundle-Eye-White Flower, where he eventually married Lady 11 Serpent 'Plumed Serpent', a daughter of Lord 9 House.

${ }^{50}$ Codex Tonindeye, p. 32 (where the wives of Lord 2 Water appear in chronological order) and Nuu Tnoo-Ndisi Nuu, p. 18-III. One generation earlier Lady 4 Serpent, the younger sister of Lord 9 House's wife (Lady 3 Rabbit) had married Lord 7 Grass of Monkey Town. Here a daughter, his from another marriage, is brought into the house of Nuu Tnoo.

${ }^{51}$ Codex Ñuu Tnoo-Ndisi Nuu, p. 18-IV and p. 24-V.

${ }^{52}$ Codex Ñuu Tnoo-Ndisi Nuu, pp. 24/23. 


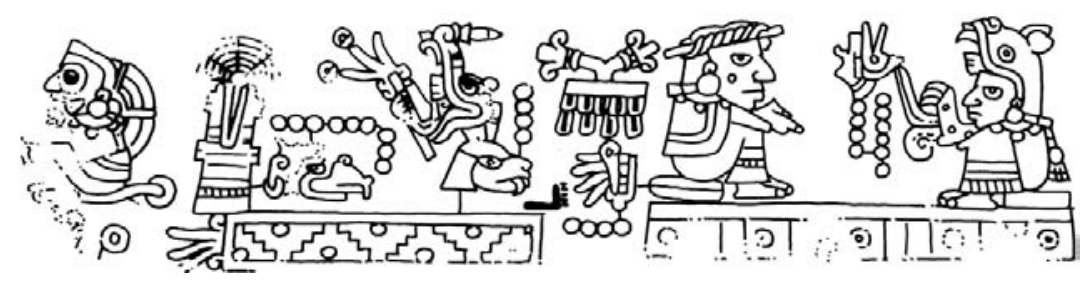

9.18. Codex Nuu Tnoo-Ndisi Nuu, p. 23-V (Right to Left): the marriage of Lord 11 Wind and Lady 4 Grass from Nuu Ndecu; the birth of their son, Lord 1 Monkey.

3. Lady 6 Wind, who went to Mountain of the Feline, where she married Lord 1 Dog.

The first-born son of Lord 9 Rain and Lady 7 Flint, Lord 11 Wind 'Smoking Claw' was the successor to the Ndisi Nuu lineage. He married a princess from Nuu Ndecu: Lady 4 Grass, 'Flower Jewel', daughter of Lord 4 Dog 'Fire Serpent that burns the Nahuas' and Lady 9 Vulture 'Spiderweb of Split Mountain'. This marriage must have taken place in the 1360s. Their children were:

1. Lord 1 Monkey 'Rain Sun'.

2. Lord 13 Jaguar 'Eagle'.

3. Lady 7 Rabbit, who married Lord 13 Wind from Monkey Town (Teita?).

4. Lady 12 Death 'Flower Jewel Venus', who married Lord 7 Movement 'Blood Shedding Rain' and ruled with him in Nuu Ndecu.

5. Lady 7 Rain 'Ndisi Nuu Fan', who married Lord 5 Water 'Ndisi Nuu Jaguar' and ruled with him in Añute. ${ }^{53} \mathrm{He}$ was the son of Lord 2 Jaguar and Lady 1 Serpent who had married as a young couple in Year 9 Flint (1372). Lady 7 Rain's son, Lord 10 Monkey 'War Rain of Heaven' was born in the year 2 Reed (1391).

6. Lady 2 Flint 'Quetzal Jewel', who married Lord 9 Reed and ruled with him in Flowered Feline Town.

Lord 1 Monkey 'Rain Sun' married Lady 5 Flint 'Heavenly Fan'. She came from Mountain of Thorns but was a descendant of Lord 10 Rabbit and Lady 11 Rabbit (founders of this segment of the Ndisi Nuu

${ }^{53}$ Cf. Codex Añute, p. 13-IV and p. 14-I. Probably the Ndisi Nuu element was added to the given name of Lord 5 Water precisely because of this marriage. 


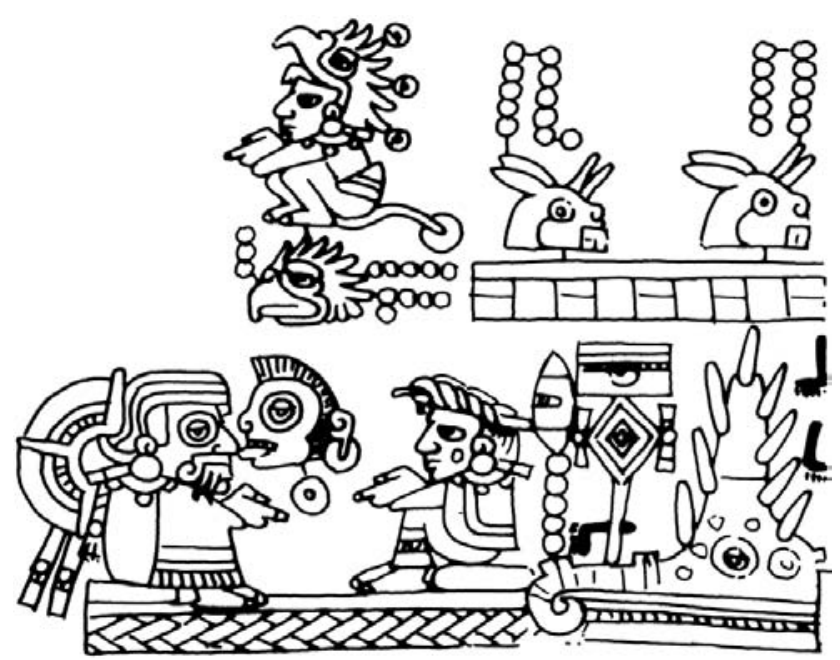

9.19. Codex Ñuu Tnoo-Ndisi Nuu, p. 24-IV/III (Lower Left to Upper Left, boustrophedon): marriage of Lord 1 Monkey and Lady 5 Flint; birth of their son, Lord 13 Eagle.

dynasty). ${ }^{54}$ The marriage probably took place in the 1380 s. Three children were born:

1. Lord 13 Eagle 'Eagle of Ndisi Nuu', the successor to the throne.

2. Lady 1 Reed 'Jewel Sun'.

3. Lord 3 Reed 'Smoke Eye'.

An important political marriage was now arranged: the Princess Lady 1 Reed married Lord 6 Water from Zaachila. ${ }^{55}$ This was an extraordinary move, because Lord 1 Monkey's younger sister had married

${ }^{54}$ She was probably not their daughter: in that case she would have come from Ndisi Nuu. The difference in place suggests a difference in generation. It was important, however, to recall her link with the founding couple. A Mountain of Thorns is also mentioned in Codex Nuu Tnoo-Ndisi Nuu, p. 21-I, as being a place given by Lord 9 House - as a result of his victory over Lord 7 Rain of Mountain of the Precious Mask - to his son-in-law, Lord 2 Vulture. Maybe Lady 5 Flint was the daughter of this Lord 2 Vulture and Lady 5 Eagle. Through her mother she would then have been the grand-daughter of Lady 3 Rabbit, who was the daughter of Lord 4 Death, the son of Lord 10 Rabbit and Lady 11 Rabbit (Codex Ñuu Tnoo-Ndisi Nuu, pp. 15/18-V).

${ }^{55}$ Lord 6 Water is also mentioned in Codex Tonindeye, p. 35, as well as in the Lienzos of Guevea and Petapa (see Oudijk \& Jansen 2000, Oudijk 2000). Lady 1 Reed must have been considerably ( \pm one generation) younger than her husband. It is therefore not plausible that her parents married much later than the 1380s. 


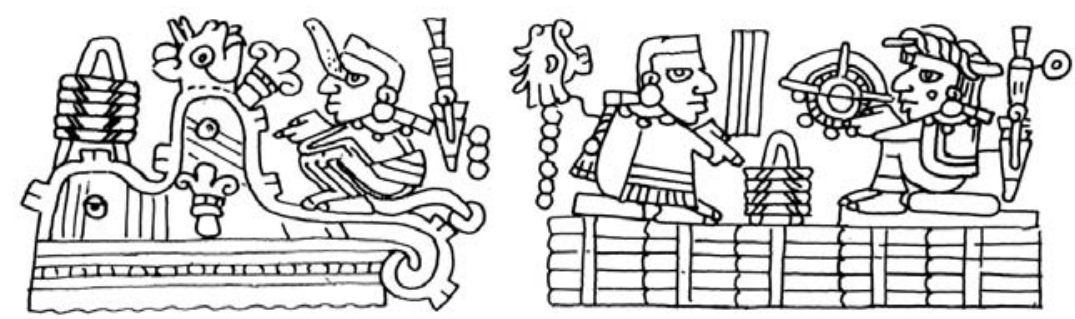

9.20. Codex Ñu Tnoo-Ndisi Nuu, p. 24-III (Right to Left): the marriage of Lady 1 Reed and Lord 6 Water.

a prince of Añute. Thus the Ndisi Nuu dynasty, concretely Lord 1 Monkey, brought together the former enemies.

The renewed marital alliance with Zaachila was not limited to this marriage alone. The older sister of the Beni Zaa ruler, Lady 3 Alligator, married Lord 2 Water of Nuu Tnoo and Chiyo Cahnu. She became his second wife - we saw already that he had first married Lady 2 Vulture from Monkey Town. ${ }^{56}$ In this way the houses of Nuu Tnoo-Chiyo Cahnu, Añute, Ndisi Nuu and Zaachila were all intimately related, guaranteeing peace and prosperity for the region.

The arrangement was not to last, however. A problem arose when Lord 6 Water and Lady 1 Reed did not have any children. Probably in reference to this period the Relación Geográfica of Saha Yucu (Cuilapan), tells the following story. A Nuu Dzaui woman had come to marry in Zaachila. Her son, fearing that an insult was being prepared against him, went back to 'his land of origin'. There he began a war against Zaachila. Seeing that the others were winning, the leading faction of Zaachila fled to the region of Tehuantepec. ${ }^{57}$ In dynastic historiography the Nuu Dzaui woman who came to marry in Zaachila must have been a princess, and by marriage must have become a queen of Zaachila. This profile fits Lady 1 Reed. The Relación Geográfica

${ }^{56}$ Codex Nuu Tnoo-Ndisi Nuu, p. 17-IV, clarifies that Lady 3 Alligator was the daughter of Lord 11 Water 'Rain Knife' (Cocijoeza I) and Lady 13 Serpent 'Plumed Serpent', rulers of Cacaxtli Plain, i.e. Tocuisi (Zaachila). Cf. Codex Tonindeye, pp. 32 and 35 .

57 We summarize the Spanish text, which says: "por cierta injuria que se temió que se quería hacer al hijo de una india que vino de la Mixteca a casarse en Teozapotlan [Zaachila], se fue este indio a la tierra de donde era oriundo, y allí fabricó guerra con los de Teozapotlan, los cuales, reconociendo ventaja a éstos, se huyeron a tierra de Teguantepec." (Acuña 1984, I: 181). See also the analysis given by Oudijk in Van Doesburg 2008 and Blomster 2008. 
states that the woman in question did have a son, though 'his land of origin' was apparently not Zaachila but Nuu Dzaui. That brings us to the hypothesis that the boy was the son of an earlier marriage of Lady 1 Reed. A political crisis occurred when this 'Ñuu Dzaui (step)son' was 'offended'. Interpreted in a dynastic context, this phrase points toward a situation in which the Beni Zaa king died without a clear designated heir: the son of his wife was for some reason not recognized as legitimate by the Zaachila nobles and not taken into account for the succession. The rejected son of Lady 1 Reed went back to where he (c.q. his mother) came from, i.e. Ndisi Nuu, and there he started to mobilize resentment and enmity against the Beni Zaa.

The Zaachila nobles, in turn, seem to have recurred to a parallel family-line: a descendant of Lord 1 Grass, a younger brother of Lord 6 Water's father. The new ruler, who was named Cosijopij (I), indeed transferred the center of Beni Zaa power to Tehuantepec around the middle of the 15th century. ${ }^{58}$ The displacement of the capital was for the Beni Zaa rulers probably a matter of geopolitical necessity, given their successes in that area, but the Nuu Dzaui interpreted it as 'a flight'. The Beni Zaa view is echoed in the Relación Geográfica of Zaachila (Teozapotlan), the Nuu Dzaui version is found in the Relación Geográfica of Saha Yucu (Cuilapan).

Codex Nuu Tnoo-Ndisi Nuu mentions a Lord 3 Reed 'Smoke Eye' as having been born after Lady 1 Reed. Normally we would have to read this sequence as indicating that he was her younger brother, i.e. the third child of Lord 1 Monkey and Lady 5 Flint. In view of the above-mentioned Relaciones Geográficas, however, we think he might be the son of Lady 1 Reed. In that case, Codex Ñuu Tnoo-Ndisi Nuu is suggesting that his father was Lord 6 Water of Zaachila, which would be in agreement with the dynastic pretensions of his faction. Lord 3 Reed 'Smoke Eye' is shown to have gone to Mountain of the Jaguar and Flowers, supposedly close to Zaachila. The toponym Mountain of the Jaguar in the vicinity of Zaachila, may be identified hypothetically as Monte Albán. The given name 'Smoke Eye' suggests that Lord 3 Reed dedicated himself to shamanic priestly activities

${ }^{58}$ Lord 1 Grass is mentioned by the Lienzo of Guevea as successor to Lord (6) Water and in Codex Tonindeye, p. 34, as a younger brother of Lord 11 Water (= Cocijoeza I). His descendant, Cocijopij I, should not be confused with his descendant, Don Juan Cortés Cocijopij (II), who was the cacique in the early colonial period. See Oudijk 2000, Oudijk \& Jansen 2000, and Oudijk in Van Doesburg 2008 and in Blomster 2008. 
there. We are probably dealing with one of the many Postclassic settlements in the area that later became the mat and throne of Saha Yucu (Cuilapan). The Flowers may refer, for example, to the name of nearby Yuta Ita, 'River of Flowers', later known as San Juan Chapultepec. ${ }^{59}$

\section{Succession in Ñu Tnoo}

A sister of Lord 6 Water, Lady 3 Alligator 'Jade Fan', princess of Zaachila, had married Lord 2 Water 'Fire Serpent that Burns the Nahuas', who was the inheritor of the combined kingdoms of Nuu Tnoo and Chiyo Cahnu. He was born in the year 7 House (1357) as the son of Lord 9 House and Lady 3 Rabbit. Through both his mother and his father he descended from Lord 2 Dog, who had come from Zaachila to found a new dynasty in Chiyo Cahnu. Lady 3 Alligator was his second wife, but was without doubt an influential political personality. Their marriage re-established the alliance of Nuu Tnoo and Chiyo Cahnu with Zaachila.

Lady 3 Alligator bore several children:

1. Lord 5 Reed 'Ocoñaña (II)', born in the year 8 House (1397).

2. Lord 5 Rain 'Eagle that comes down from Heaven', born in the year 12 House (1402).

3. Lady 11 Reed 'Jewel of the Flower War'.

4. Lady 8 Wind 'Flower of the Rising Nuhu'.

5. Lord 8 Vulture 'Fire Serpent in Flames'.

6. Lord 10 Movement 'Coyote Sun'.

The first son, Lord 5 Reed 'Ocoñaña' indeed became ruler of Chiyo Cahnu, and is remembered as such by the Relación Geográfica of that town. The second, Lord 5 Rain married a princess of Ndisi Nuu, reinforcing the alliance with that noble house. ${ }^{60}$

${ }^{59}$ See Jansen 1994: 93-100.

${ }^{60}$ Cf. Codex Nuu Tnoo-Ndisi Nuu, p. 23-III. This is also the last information that the sources have conserved about the precolonial rulers of Chiyo Cahnu. The fact that Ocoñaña was remembered in the Relación Geográfica suggests that he reigned for a long time, until the last generation before the Spanish invasion. 


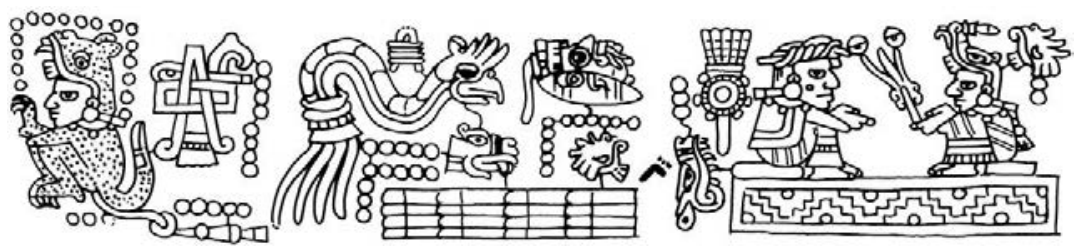

9.21. Codex Ñuu Tnoo-Ndisi Nuu, p. 17-IV (Right to Left): the marriage of Lord 2 Water and Lady 3 Alligator; birth of their son Lord 5 Reed Ocoñaña.

With his first wife Lady 2 Vulture 'Flower Jewel' from Monkey Town (Teita?) Lord 2 Water 'Fire Serpent that Burns the Mexicans' had a daughter: Lady 12 Flower 'Split Mountain Butterfly'. She married Lord 13 Eagle 'Blood Jaguar' of Chiyo Yuhu, the son of Lord 12 Movement 'Jaguar that Burns the Mexicans' and Lady 1 Jaguar 'Heavenly Fan'.

At that moment Codex Nuu Tnoo-Ndisi Nuu (p. 18-II) mentions the third marriage of Lord 2 Water, that to his younger sister, Lady 12 or 13 Flint 'Precious Quetzal'. Actually this marriage might have preceded the other two. If the idea was that the first-born fruit of that union would inherit the kingdom, it proved a failure: their son, Lord 11 Rain 'Dark Eagle', went to a sanctuary, painted as the cradle of a Nuhu (dzoco Nuhu) in a cave, and seems to have dedicated himself wholly to the religious service.

This scene is followed by a series of children:

1. Lord 6 Deer, 'Sacred Rain', whose birth is dated in the year 7 House.

2. Lady 9 Eagle 'Cacao Flower', who married Lord 13 Jaguar 'War Eagle' of Monkey Town (Teita?).

3. Lady 5 Serpent 'Plumed Serpent', who married Lord 3 Monkey 'Jaguar that Burns the Mexicans', King of Andua in the Valley of Yodzo Cahi (Yanhuitlan).

4. Lady 2 Flower 'Jewel of the Rising Nuhu', who married Lord 6 Death from Nuu Naha (San Pedro Cántaros).

The normal reading order would suggest that these are brothers and sisters of Lord 11 Rain. There are various problems with this interpretation, however. The year 7 House for the birth of Lord 6 Deer would correspond to 1409. At that time his father would have been 52 


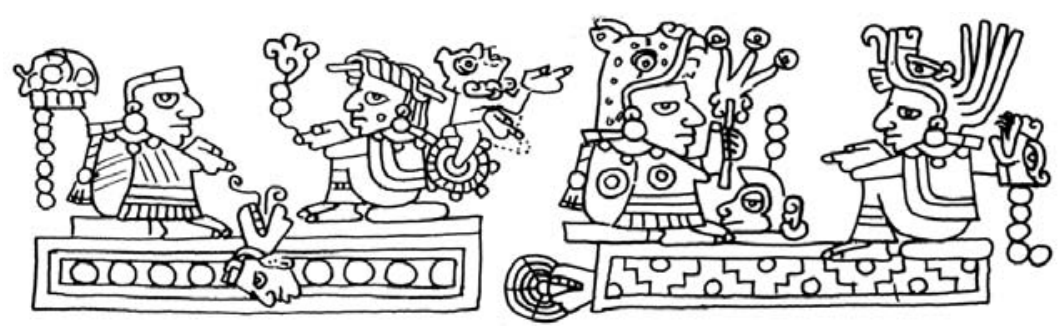

9.22. Codex Nuu Tnoo-Ndisi Nuu, p. 17-II (Right to Left): Lady 5 Serpent married Lord 3 Monkey from Andua and Lady 2 Flower married Lord 6 Death from Nuu Naha.

years of age, but his presumed mother, the younger sister of his father, would have been over the normal child-bearing age.

The last of the four mentioned youngsters, Lady 2 Flower, also appears with her husband in Codex Nuu Naha, p. 6. She is seated on Altar of the Tree with Flowers, i.e. Chiyo Yuhu (Suchixtlan). A gloss in Dzaha Dzaui explains:

ñuñumahu dzavi jicaji niduvi sihi ñucavaco yusi tedzadodzo niday chiyo yuhu

The late Lord 6 Death 'Rain Sun' married the late Lady 2 Flower 'Quetzal-Jewel', who came from Chiyo Yuhu (Suchixtlan).

Although there is a slight discrepancy in the given name of Lady 2 Flower, we do think that we are dealing with the same person. The place sign on which the couple are seated in Codex Nuu Tnoo-Ndisi Nuu (p. 17-II) consists of a frieze of disks (aniñe, 'palace', synonymous with $\tilde{n} u u$, 'town'), with a head (dzeque or dzini) on the back of which a mouth (standing for the locative prefix $a$-) is placed from which come speech scrolls. The head forms part of the Nuu Naha place sign in the Codex Nuu Naha, pp. 2-3, which is a Mountain of Head with Open Mouth, at the foot of which is placed a Bead (possibly dzeque, 'jewel'). Mary Elizabeth Smith (2000) has argued that the latter configuration represents the neighboring town - and probably twin capital - of San Miguel Adeques, which corresponds to A-dzeque, 'Place of Head or Jewels' in the orthography of Alvarado. In view of this, it is highly probable that the place sign with the Head and Mouth indeed represents Adzeque (Adeques). The speech scrolls in this position might add the phonetic value of the verbal root yo-naha, 'to indicate, to teach, to know', to express the notion of naha, 'ancient'. 
Accepting that Lady 2 Flower and Lord 6 Death, rulers of Nuu Naha, are the same people in Codex Nuu Tnoo-Ndisi Nuu and in Codex Nuu Naha, we have to explain the statement, both in the pictorial and in the alphabetical text, that Lady 2 Flower came from Chiyo Yuhu. If she was the daughter of Lord 2 Water and his younger sister, her antecedents do not show a connection with that village-state. Looking at the sequence of scenes in Codex Nuu Tnoo-Ndisi Nuu (p. 18-III/II), however, we see that an earlier recorded marriage is that of Lady 12 Flower (Lord 2 Water's daughter) to Lord 13 Eagle of Chiyo Yuhu. If we suppose that the passage depicting the marriage of Lord $2 \mathrm{~W}$ ater to his younger sister and their son going to the cave sanctuary (dzoco Nuhu) is an inserted scene, we can read the sequence of four children from Lord 6 Deer till Lady 2 Flower as the offspring of Lady 12 Flower and Lord 13 Eagle of Chiyo Yuhu, in other words as grandchildren of Lord 2 Water. Indeed, the genealogical column on the Map of Chiyo Cahnu (Teozacualco) confirms that Lord [6 Deer], 'Sacred Rain' was the direct succesor (and presumably the son) of Lady [12 Flower] 'Split Mountain Butterfly' and Lord [13 Eagle] 'Blood Jaguar'.

The extra generation would accommodate the relatively long time span between the births of Lord 2 Water and Lord 6 Deer, but we are not satisfied with that, as the dates for the following generations also create problems. It is suspicious that the date given for the birth of Lord 6 Deer is precisely the year 7 House that has to be reconstructed for the birth of Lord 2 Water (although erroneously a year 4 House is given in Codex Nuu Tnoo-Ndisi Nuu). We will come back to the chronological problem shortly.

Apparently, when it was clear that the son of Lord 2 Water's brothersister marriage would not succeed as ruler, another specific arrangement was made. The children of Lord 2 Water's first wife (Lady 2 Vulture 'Flower Jewel') would inherit Nuu Tnoo and those of his second wife (Lady 3 Alligator) Chiyo Cahnu. ${ }^{61}$

The line of succession on the mat and the throne of Nuu Tnoo passed from Lord 2 Water via his daughter to his grandson, Lord 6 Deer, 'Sacred Rain'. This king married Lady 13 Wind 'Seed of Split Hill', daughter of Lord 5 Water 'Ndisi Nuu Jaguar' of the Añute

${ }^{61}$ Codex Nuu Tnoo-Ndisi Nuu, p. 17-III/II; cf. Codex Tonindeye, pp. 32/33. 

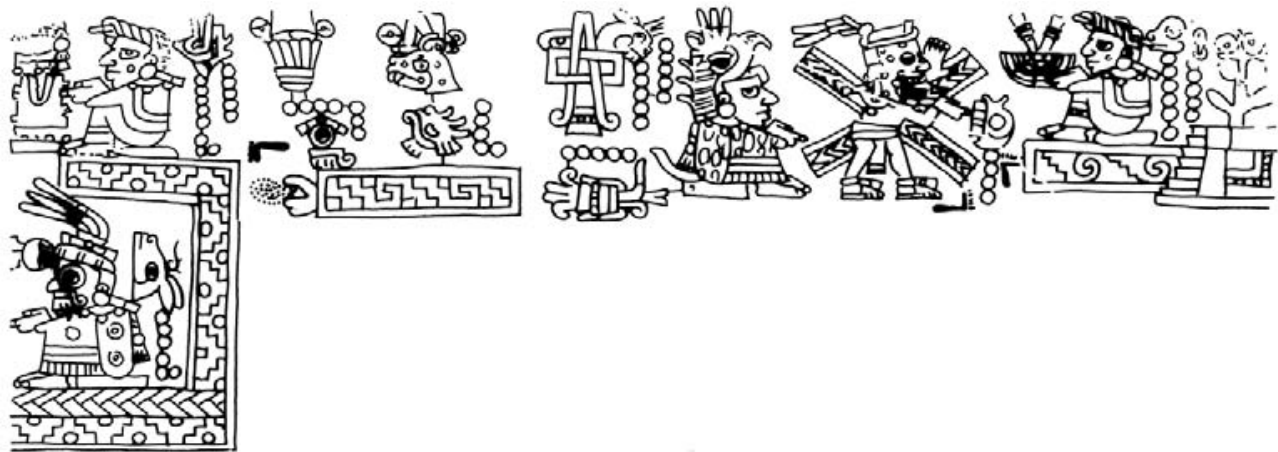

9.23. Codex Nuu Tnoo-Ndisi Nuu, p. 17-I (Left to Right): the marriage of Lord 6 Deer and he birth of Lord 5 [elsewhere: 4] Flower.

dynasty and Lady 7 Rain 'Ndisi Nuu Fan' of the house of Ndisi Nuu. ${ }^{62}$ By now we recognize this choice as motivated by the wish to continue the traditional marital alliances.

Lord 6 Deer and Lady 13 Wind ruled in Nuu Tnoo and had two sons:

1. Lord 4 Flower 'Pheasant', born in the year 10 Rabbit. ${ }^{63} \mathrm{He}$ married Lady 7 Vulture 'Quetzal Fan', the daughter of Lord 10 Water 'Rain Knife (Cocijoeza)' and Lady 11 Lizard 'Butterfly - Fire Serpent', rulers of Bean Town, Nuu Nduchi (Etla).

2. Lord 4 Death 'War Venus', who married Lady 11 Monkey 'Jade Spiderweb', a princess from Chiyo Yuhu and Stone of Xipe Bundle (apparently now unified within one village-state).

Lord 4 Flower and Lady 7 Vulture had the following children:

1. Lord 10 Rain 'Rain Sun', whose birth date is given as the year 9 Flint.

${ }^{62}$ Cf. Codex Añute, p. 13-IV, and Codex Nuu Tnoo-Ndisi Nuu, p. 23/24-IV. Lady 13 Wind's elder brother, Lord 10 Monkey, was born in the year 2 Reed (1391), so she must have been approximately the same age as her husband, for whom we postulate 1393 as the year of birth.

${ }^{63}$ Codex Nuu Tnoo-Ndisi Nuu, p. 18-I (on p. 17-I he is called 5 Flower), and p. 21-III. 


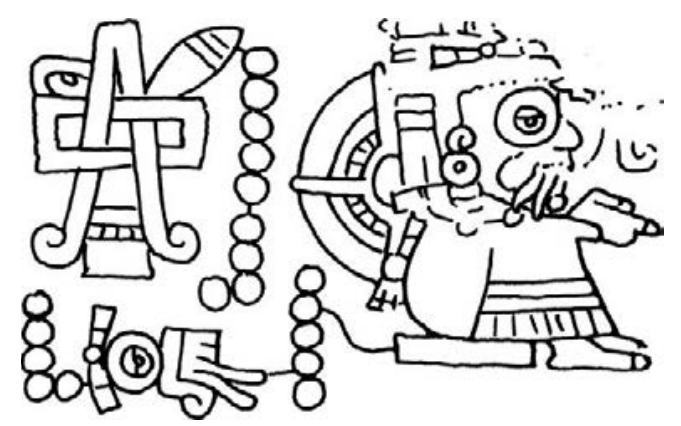

9.24. Codex Nuu Tnoo-Ndisi Nuu, p. 18-I: the birth of Lord 10 Rain.

2. Lady 7 Water 'Plumed Sun', who married Lord 1 Monkey 'Rain Sun' of Añute in the year 6 Reed (1447) and bore him a son, Lord 4 Serpent, in the year 10 Reed (1451). ${ }^{64}$

3. Lord 13 Grass 'Serpent with Markings', who married Lady 10 Vulture, the daughter of Lord 11 Jaguar and Lady 12 Flint, rulers of Mountain of Flowers (Yucu Ita?). They established themselves in Valley of the Sand Vessel, the Rosette and the Tree, an unidentified place.

4. Lady 4 Water 'Butterfly with Red Spots', who married Lord 8 Monkey of Chiyo Yuhu (Suchixtlan).

5. Lord 7 Reed 'Blood Jaguar'.

6. Lord 11 Rain 'Sun Coyote', who settled in Black Valley and married Lady 8 Deer from Mountain of Flowers - she was probably the sister of his elder brother's wife: both came from the same town and probably belonged to the same generation.

7. Lady 9 Deer, who married Lord 8 Grass 'Rain Sun', the ruler of Ndisi Nuu.

Lord 10 Rain 'Rain Sun' would marry his cousin, Lady 5 Wind 'Cacao Flower'. Their first two children were:

1. Lady 5 Monkey 'Seed of Split Hill', born in the year 12 Rabbit (1466).

${ }^{64}$ Codex Añute, p. 16-II and p. 16-IV. Between those two events Añute was attacked by Lord 3 Monkey, who lived in the time of the Mexica invasion. 
2. Lord 4 Deer 'Ndisi Nuu Eagle', whose birth year, curiously enough, is left open by the author of Codex Nuu Tnoo-Ndisi Nuu. He is the last precolonial ruler, mentioned in the Relación Geográfica of Nuu Tnoo (Acuña 1984, II).

Alfonso Caso has proposed the following correlation of the dates in these final pages of Codex Nuu Tnoo-Ndisi Nuu Obverse (17-20):

- Lord 6 Deer, born in the year 7 House: 1357.

- Lord 4 Flower, born in the year 10 Rabbit: 1386.

- Lord 10 Rain, born in the year 9 Flint: 1424.

- Lord 4 Deer, born in an unknown year, after 1466.

The generation spans become unusually long here: 29-38-42 years. The circumstance that at the birth of the last ruler, Lord 4 Deer, a year-bearer sign is given, but without specifying the year itself is very peculiar. Contextual information also suggests that Caso's chronology here is one cycle too long. It is quite difficult, however, to produce an alternative. In an earlier publication (2000) we proposed a preliminary set of amendments:

- We observed that the year 4 House actually fitted much better as the birth year of Lord 6 Deer and suggested therefore that it was switched with the birth year of Lord 2 Water. If this is indeed the case, Lord 6 Deer was not born in 7 House but in 4 House, which would be 1393 .

- The birth year of Lord 4 Flower, given as 10 Rabbit, does not fit the chronological sequence and should be changed, for example into 8 Rabbit, which would be 1410 .

- If the birth year of Lord 10 Rain, given as 9 Flint, is correct, it would correspond to 1424. In this year his father, Lord 4 Flower, would still have been very young, only 14 years old. This is possible, but it could also indicate that the year refers to another event, e.g. the marriage of the parents, or is simply an error. It is more likely that Lord 10 Rain's birth actually took place some years later, e.g. in 13 Flint (1428) or 4 Flint (1432).

This brings us closer to a plausible chronological sequence, but we still need a theory to account for the anomalies. And, of course, changing the dates themselves remains a rather arbitrary procedure and is not convincing without further evidence or some form of explanation. 
Trying to understand the structure and composition of this section of Codex Nuu Tnoo-Ndisi Nuu, we arrive at the following suggestion.

The birth year of Lord 2 Water given in Codex Nuu Tnoo-Ndisi Nuu is clearly wrong: 4 House instead of the 7 House, which is correctly registered by Codex Yuta Tnoho Reverse. This indicates the presence of an error in this part of the historical record. Maybe it has to do with the painter shifting to another source of information already suggested by the anomalous position of the bride and groom in the representation of the marriage of Lady 3 Rabbit and Lord 9 House.

Anyhow, the year 4 House, wrongly given as the birth year of Lord 2 Water, actually makes a lot of sense as the birth year of his grandson and the next ruler, Lord 6 Deer. It would then correspond to 1393. In that case, the time lapse between the birth of Lord 2 Water (born in 7 House, 1357) and that of his grandson (son of his daughter) would have been 36 years.

We speculate that the following birth years are also displaced one generation. Such an error can easily occur in the process of copying data from another source if that source is organized as a list of persons (successive rulers), painted sequentially in a row, with dates put seperately behind them: the dates can then become mistakenly associated with the earlier individual.

In accordance with this hypothesis we move all birth years of these infant princes one generation forward and arrive at the following sequence.

- Lord 2 Water, whose birth year is given erroneously in Codex Nuu Tnoo-Ndisi Nuu as 4 House, was born in the year 7 House, as stated in Codex Yuta Ynoho Reverse: 1357.

- Lord 6 Deer, whose birth year is given as 7 House, would then have been born in the year 4 House (which appears with his grandfather, Lord 2 Water): 1393.

- Lord 4 Flower, whose birth year is given as 10 Rabbit, would then have been born in the year 7 House (which appears with his father, Lord 6 Deer): 1409.

- Lord 10 Rain, whose birth year is given as 9 Flint, would have been born in the year 10 Rabbit (which appears with his father, Lord 4 Flower): 1438.

- Lord 4 Deer, whose birth year is not given, but should be placed after that of his elder sister (1466), would have been born in the year 9 Flint (which appears with his father, Lord 10 Rain): 1476. 
The result is a consistent and therefore convincing chronological picture. The added advantage of this hypothetical reconstruction is that it solves the absence of a birth year for Lord 4 Deer: it can now be filled in with the date originally given for the birth of his father, but obviously it has shifted to the following cycle of 52 years and therefore has to correspond to 1476 .

\section{Succession in Ndisi Nuu}

What had happened in the meantime in Ndisi Nuu? Probably around 1400 Lord 13 Eagle 'Eagle of Ndisi Nuu' married his cousin, Lady 8 Jaguar, daughter of his father's sister Lady 12 Death 'Flower Jewel Venus' and Lord 7 Movement 'Blood Shedding Rain' of Nuu Ndecu. ${ }^{65}$ They had a daughter, Lady 5 Flower 'Quetzal Sun', who married Lord 5 Rain 'Eagle that came down from Heaven'. This man, as we saw earlier, was the son of Lord 2 Water and Lady 3 Alligator. As Lord 5 Rain was born in the year 12 House (1402), his marriage may be dated around 1420.

Lady 5 Flower and Lord 5 Rain did not become king and queen of Ndisi Nuu, but were an important link in the genealogy. There are considerable difficulties in identifying the exact relationships between the couples mentioned after them in Codex Nuu Tnoo-Ndisi Nuu (pp. 22-21).

The next person mentioned is probably the daughter of Lady 5 Flower and Lord 5 Rain: Lady 8 Deer 'Quetzal Spiderweb'. She married Lord 10 Alligator 'Jaguar with Claws like Flints', son of Lord 9 Wind 'Yahui Sun' and Lady 8 Alligator 'Fan of the Rising Nuhu', rulers of Nuu Ndecu. Lady 8 Deer had rights to the throne of Ndisi Nuu as the successor of her maternal grandparents, Lord 13 Eagle and Lady 8 Jaguar. Her husband, Lord 10 Alligator, belonged to the Nuu Ndecu dynasty and was consequently a near relative.

Then the following children are listed:

- Lord 8 Deer 'Fire Serpent'.

- Lord 3 Serpent 'Venus Sun'.

- Lord 8 Grass 'Rain Sun', born in the year 7 Reed (1435).

${ }^{65}$ Codex Nuu Tnoo-Ndisi Nuu, p. 23-III. 


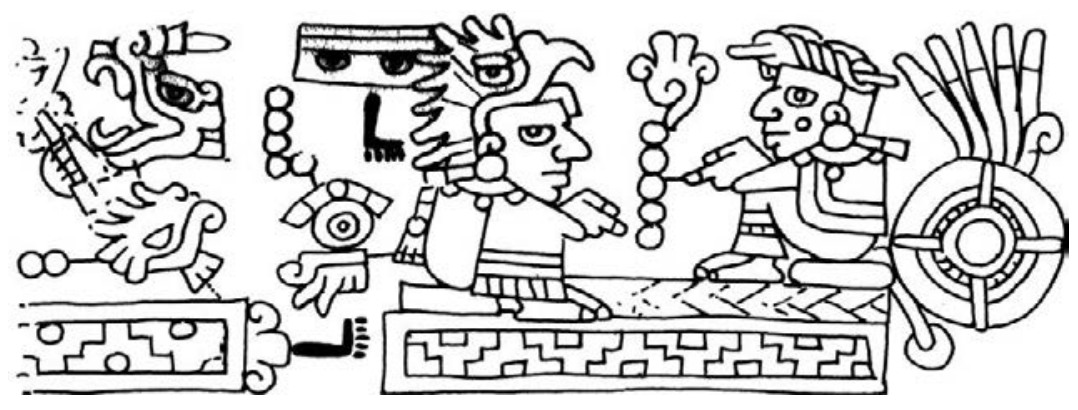

9.25. Codex Ñu Tnoo-Ndisi Nuu, p. 23-III : the marriage of Lady 5 Flower and Lord 5 Rain.

Frankly, we are not sure how to read this sequence. If we take the presence of a parentage statement for the partner of the ruler as a division of generations, these three lords should all be interpreted as the children of Lady 8 Deer and Lord 10 Alligator. The most plausible chronological reconstruction puts the birth of Lord 5 Rain in 1402 and that of Lord 8 Grass, 33 years later, in 1435. If three generations are involved, Lord 5 Rain must have married in 1416-1417, and his daughter, Lady 8 Deer, must have been born shortly after, to have three children in the early 1430 s. The time span is awfully short for such a sequence. Thus we are tempted to interpret Lady 8 Deer, Lord 8 Deer, Lord 3 Serpent and Lord 8 Grass as sister and brothers. The parentage statement for the husband of Lady 8 Deer must then be seen as additional genealogical information (important as he came from the neighboring realm of Nuu Ndecu) and not as a way to mark the division in generations. Lady 8 Deer and Lord 8 Deer may then have even been twins.

The next child, Lord 8 Deer, did not remain in Ndisi Nuu but went to Zaachila. It is not clear if this means that he became a ruler there. Supposedly a power vacuum occurred in the Beni Zaa capital when Cocijopij I moved the seat of rulership to Tehuantepec. In the latter half of the 15th century Cuilapan and Zaachila seem to have become rivals. As a grandson of Lady 3 Alligator, Lord 8 Deer may have been a pretender to the Zaachila throne, supported by the house of Ndisi Nuu. ${ }^{66}$ We already saw that his grand-uncle, Lord 3 Reed, had gone to a realm defined as Mountain of the Jaguar and Flowers next to

${ }^{66}$ See also the reconstruction proposed by Oudijk (2000: 106-107, cf. Oudijk in Van Doesburg 2008 and in Blomster 2008). 
Zaachila, which may represent a site in the area which later formed part of the mat and throne of Saha Yucu (Cuilapan).

The younger brother of Lord 8 Deer, Lord 3 Serpent 'Venus Sun', remained in Ndisi Nuu and married Lady 11 Movement 'Jewel Sun'. This couple are depicted as seated on the place sign of Ndisi Nuu: apparently they succeeded Lady 8 Deer. The reigns of both Lady 8 Deer and of Lord 3 Serpent only lasted a short while, and no children were born to them.

The parentage of Lady 11 Movement is not stated, which makes it very clear that the dynastic line did not continue here. The following person, then, was not the child of this couple but a younger brother of Lord 3 Serpent: Lord 8 Grass 'Rain Sun', born in Year 7 Reed (1435). This was the ruler of Ndisi Nuu called Malinaltzin ('Lord Grass') by Torquemada: he fought the advancing Mexica armies of both Motecuhzomas, but was ultimately subdued under the rule of Motecuhzoma II. ${ }^{67}$

\section{The Time of the Mexica Invasion}

Halfway through the 15th century the expanding Mexica under Motecuhzoma (I) Ilhuicamina started to invade Nuu Dzaui. They met with strong resistance, which at first seems to have been coordinated by a religious leader from Nuu Ndecu. His success was immortalized in frescoes and codices, which only survive in a summary description by Friar Francisco de Burgoa (1934, I: 319-320). The name of this 'captain' was Dzavui Ndanda. He was in charge of 'the armies of his temple'. It is said that he went up to a mountain top sanctuary and prayed to the Gods to give him warriors. Innumerable men then came out of his priest's incense bag, with whom he was able to beat the enemy and actually put pressure on Motecuhzoma to accept peace.

Actually it is not clear which of the two Motecuhzomas is meant in the text, but the success of the Nuu Dzaui troops suggests it was the first Mexica ruler of that name, because later it was the Mexica who were victorious and able to subjugate large parts of the region. ${ }^{68}$ The story about armies coming out of a bag seems to be based on a picto-

67 Torquemada, Book II, ch. 48, 69 and 79. The fall of Ndisi Nuu (Tlaxiaco) is also depicted in Codex Telleriano-Remensis, p. 42v. King Malinaltzin was identified as Lord 8 Grass by Jiménez Moreno (in: Gaxiola \& Jansen 1978).

${ }^{68}$ Martínez Gracida, following a suggestion by Gay, dated these events in Toltec times (cf. Jansen 1987). The name Dzavuindanda means 'Rain that lifts and goes away'. Caso interpreted it as 'Falling Rain' and took it to be the reading of the onomas- 


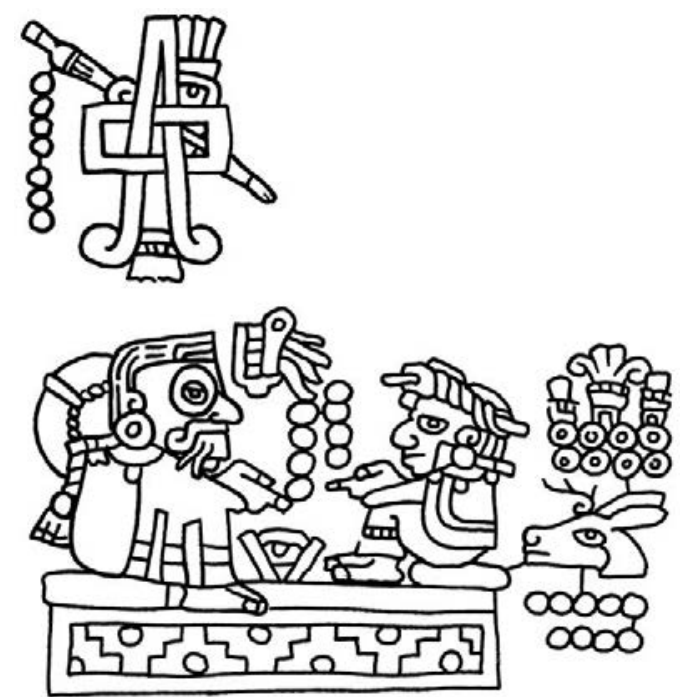

9.26. Codex Nuu Tnoo-Ndisi Nuu, p. 21-IV: Lord 8 Grass (Malinaltzin) and his wife Lady 9 Deer.

graphic scene. The priest's copal bag (xiquimilli in Nahuatl) usually functions as a numerical sign for large quantities (8000). The original image probably represented the military alliance of different Nuu Dzaui village-states under the leadership of a religious and charismatic authority. Looking at the dynastic relationships, we suspect that Ndisi Nuu, which had become more and more powerful, was one of the main allies of nearby Nuu Ndecu. It is illustrative of the biased local view of ancient historiographers that the Nuu Dzaui victory is not mentioned in Mexica sources, just as the later Mexica successes are totally absent from the Nuu Dzaui codices.

The 'friendship treaty' with which this first large-scale conflict ended, explains why the ruler of Ndisi Nuu, Lord 8 Grass (called Malinalli or Malinaltzin in Nahuatl sources) became an ally of the huey tlatoani Motecuhzoma I 'Ilhuicamina', and even permitted the presence of a Mexica stronghold in his territory. This was a major concern of the King of Coixtlahuaca, Lord 6 Water (called Atonal in Nahuatl). ${ }^{69}$ He had successfully engaged in rivalries and wars with his

tic sign 'Rain that Comes Down from Heaven' (e.g. Lord 5 Wind in Codex Nuu TnooNdisi Nuu, pp. 40-39 or Lord 5 Rain in Nuu Tnoo-Ndisi Nuu, p. 23-III).

${ }^{69}$ Lienzo of Tlapiltepec A 33 (Caso 1961: plate III). 
neighbors, but was now anticipating a Mexica attack. On his request, the city-states of Tlaxcala and Huexotzingo, traditional enemies of the Mexica, supplied him with auxiliary troops. When these armies arrived, he sent them first to Ndisi Nuu to eliminate the dangerous threat from that side. A successful blow was delivered to the Mexica and their Ndisi Nuu allies (Torquemada, book II: ch. 48).

Lord 8 Grass (Malinaltzin) of Ndisi Nuu immediately informed the Mexica ruler of what had happened. We suspect that in doing so he may have been playing one threatening force against the other. Anyhow, the following year the Mexica took their revenge and attacked Coixtlahuaca. It was the year 5 Rabbit in the Mexica year count, which corresponds to 4 Rabbit in the Nuu Dzaui system, i.e. $1458 .^{70}$ Once in control of Coixtlahuaca, the Mexica formed a direct threat to the economically and strategically important Valley of Yodzo Cahi - Atoco. The sovereign communities in this area united under Lord 3 Monkey 'Jaguar that Burns the Mexicans', the King of Andua. His wife, the Queen 5 Serpent 'Plumed Serpent', was the granddaughter of Lord 2 Water of Nuu Tnoo and Chiyo Cahnu. There were underlying rivalries in the Nuu Dzaui camp, however. In the year 8 House (1449), Lord 3 Monkey had attacked one of Andua's neighbors, Añute (Jaltepec). ${ }^{71}$

Maybe these internal conflicts led to the treason that ended his life and the independence of that area. It all happened during the reign of the Mexica King Motecuhzoma I (1440-1469):

In those days, Moctezuma I, who was anxious to finalize the conquest of this Mixtec kingdom, but saw that he could not do so just by military force, found a way so that the cacique of Yanhuitlan, called 3 Monkey (Tres Micos), a valiant man, who resisted him successfully, was killed by treason. With his death, all surrendered...” (Herrera, Decade III, book 3: ch.13).

This treacherous murder must have been a traumatic experience for the Nuu Dzaui people. But neither this tragedy nor the lost battles were recorded in the epic historiography of the Nuu Dzaui codex painters. The whole Mexica domination was simply ignored and deemed irrelevant in their register of royal genealogies.

${ }^{70}$ Annals of Cuauhtitlan (Lehmann 1938: 252) and Chimalpahin (1998, I: 261 and II: 91).

${ }^{71}$ Codex Añute, p. 16-III; cf. Codex Ñuu Tnoo-Ndisi Nuu, p. 17-II. 
The year 8 House, in which Lord 3 Monkey 'Jaguar of the Mexicans' (i.e. 'Jaguar who was victorious in the war with the Mexica') attacked Añute (not far from Andua), was correlated with 1449 by both Alfonso Caso and Emily Rabin. This fits well with Lord 'Tres Micos' being contemporaneous with Motecuhzoma I.

Herrera calls him a 'cacique of Yanhuitlan'. The latter town was, as the Nahuatl toponym indicates, a 'new place' (yancuic-tlan). In view of the above we interpret this as a reference to a settlement that had been newly founded after the Aztecs had destroyed the area. In the early colonial times the formerly important village-states of Andua and Chiyo Yuhu were its tributaries (sujetos). The importance of their place-name signs in the earlier segments of the codices suggests that they were the original capitals of that area, the antecedents of Yanhuitlan. In retrospect, therefore, a ruler of Andua would have been referred to as a cacique of Yanhuitlan in a colonial document.

Codex Ñuu Tnoo-Ndisi Nuu, p. 17-II, tells us that Lord 3 Monkey of Andua married Lady 5 Serpent, a younger sister of Lord 6 Deer of Nuu Tnoo. The birth date given for this Lord 6 Deer is the year 7 House, which, as a consequence of the conspicuously long generation spans at the end of the lineage, was calculated by Caso as 1357. It is, however, chronologically inconsistent to fight battles around 1449 and to be married to a wife born somewhat after 1357. It was clear, therefore, that in this part of the sequence of dates an error must have crept in and that Caso's correlation should be corrected here by taking out one cycle of 52 years. The solution suggested in the foregoing paragraph, the reinterpretation of the dates associated with the last precolonial rulers of Nuu Tnoo (Lord 2 Water - Lord 4 Deer), takes care of this problem: Lord 6 Deer was born in 1393 and his younger sister Lady 5 Serpent (the wife of Lord 3 Monkey) may have been born around 1400 .

A still younger sister of Lord 6 Deer and Lady 5 Serpent was Lady 2 Flower, who, as we mentioned earlier, married a ruler of Nuu Naha, Lord 6 Death. Codex Nuu Naha, p. 6, gives a barely visible date for their son, Lord 3 Dog and his wife Lady 7 Grass: year 7 House, day 5 Serpent. It is not clear to which event the date refers, but if it was the enthronement, the year might correspond to $1461 .{ }^{72}$

${ }^{72}$ Hermann Lejarazu 2007a discusses different possible chronological interpretations. His suggestion that a later ruler of Nuu Naha, Lord 3 Monkey, the grandson of Lord 3 Dog and Lady 7 Grass, would be the same individual as the Lord 3 Monkey who attacked Añute in 1447 (Códice Añute, p. 16-III), however, is speculative and 


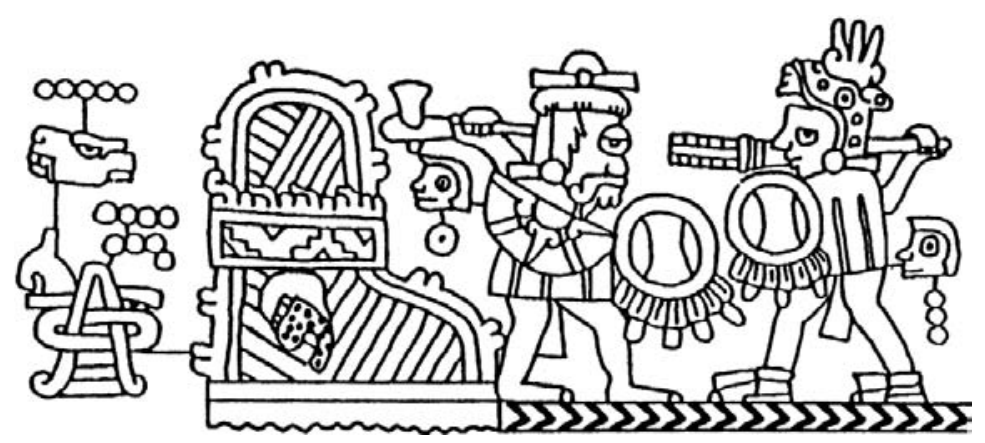

9.27. Codex Añute, p. 16-III: Lord 3 Monkey attacks Añute in the year 8 House.

Meanwhile Lord 8 Grass of Ndisi Nuu had married two women. His first wife was Lady 9 Deer 'Jewel Flower', daughter of Lord 4 Flower 'Pheasant' and Lady 7 Vulture 'Precious Fan' of Nuu Tnoo. She was probably only a few years younger than her husband; we suppose that this first marriage took place in the 1450s. The second wife was Lady 1 Serpent 'Butterfly with Quetzal feathers', who came from Bat Hill. ${ }^{73}$ Obviously the first marriage was a reinforcement of the ties with Nuu Tnoo. From the second marriage, which seems to have taken place much later, a daughter was born: Lady 13 House 'Bat Flower', who was to marry a prince from Añute, Lord 2 Vulture (born in 1483) and to rule Nuu Ndecu with him.

Due to the Mexica conquests in the Coixtlahuaca and the Yodzo Cahi Valleys, the relations between Ndisi Nuu and that expanding power had become more and more tense. During the reign of the huey tlatoani ('great speaker', i.e. ruler) Motecuhzoma II an open conflict erupted. Different explantions of the motive exist. According to the Historia of Friar Diego Durán (1967, II: 479 ff.), warriors from Ndisi Nuu intercepted the tribute that Coixtlahuaca had to pay to the Mexica king. This was something that the Mexica often used as a reason or pretext to start a war. Friar Juan de Torquemada, on the other hand,

confusing. The latter is the Lord 'Tres Micos' we have referred to before. The Lord 3 Monkey of Nuu Naha has another given name, was married to another wife and lived much later.

${ }^{73}$ This couple is also mentioned in Codex Añute, p. 17-IV. The chronological context of this latter marriage suggests that Lord 8 Grass married Lady 1 Serpent a substantial time afterward, maybe as much as twenty years later than his first wife. 
makes references to an element of elite poetical discourse: the flower as symbol of sovereignty:

In the second year of his reign, Motecuhzoma (II) sent ambassadors with a fine gift to the province of Tlaxiaco, to its ruler Malinal. When they entered his palace they told him: 'Motecuhzoma, our lord and your relative, sent us to you, with the message that King Ahuizotl, his uncle, left word to him that you have in your gardens a tree called tlapalizquixochitl of beautiful and fragrant flowers, which he would like to have in his gardens, and, since he is very busy, he did not remember to ask you for it, but now, longing for the great fame of that tree, he begs you as relative and friend that you give it to him and then he will compensate you in everything you want.

Malinal listened to the message and instead of giving a polite answer (as he did not want to hand over the tree that such a powerful king sent for with such care) he told the ambassadors: 'What are you asking me? It seems that you have lost your mind. Who is this Motecuhzoma that you speak about and with whose messages you come to my court? Did not Motecuhzoma Ilhuicamina die many years ago, and wasn't he succeeded by many other kings in the Mexican realm? Who is this Motecuhzoma that you refer to? And if there is indeed one (of this name) now governing Mexico, go and tell him that I consider him my enemy, that I do not want to give my flowers and let him be aware that the Smoking Volcano marks my frontier'.

With this he indicated: tell him that he may be king, but so am I, I have enough vassals to make war with him, and I am not afraid of his name. (Torquemada, book II: ch. 69).

The same version is preserved by Burgoa, who adds that the flower in question blossomed in the gardens of the town of Yucuañe:

Tradition has it that a certain small tree was brought from far away to a garden of the ruler, and that it had such beautiful and fragrant flowers that because of its rare and special character the fame reached the ears of the Emperor Moctezuma in Mexico. With the jealousy of pride he sent to ask for it, to have it in his own palace, with the intent that if it would fail, no other lord would possess something of such status that he did not have, and that if it would succeed, only he would deserve to have it in his power, and as the local lord did not want to hand it over, he sent a large army, which, after killing many people, took the local lord prisoner. And the tree, uprooted, withered .... (Burgoa 1934, I: 352).

Obviously we are dealing here with political symbolism. At first sight one might think that the flower was a metaphor for a princess, but the precise description of Torquemada speaks against such an idea. Sahagún (book XI: ch. 7) lists the tlapalizquixochitl as a plant with red stained flowers. According to the comments by Garibay (1975: 954) 

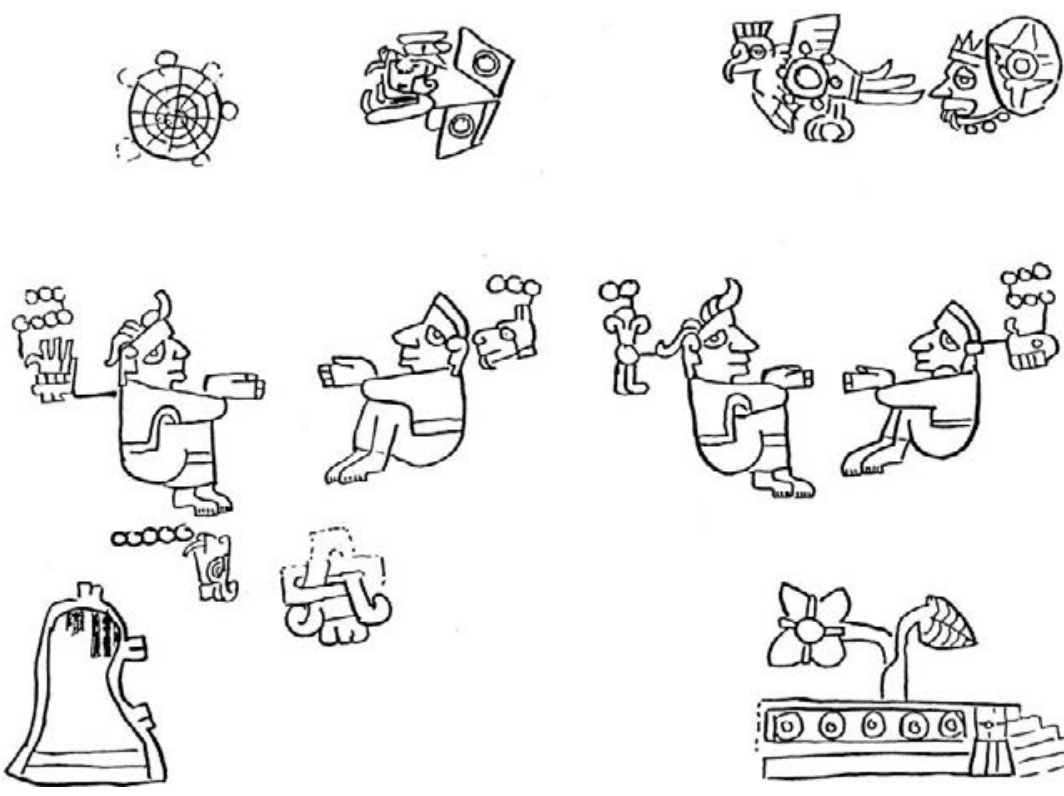

9.28. Codex Nuu Naha, p. 6 (right to left): Lord 6 Death marries lady 2 Flower from Chiyo Yuhu. They have a son: Lord 3 Dog.

it was a bourreria. Therefore we think that Motecuhzoma II solicited it as a suchil, i.e. the branch of flowers that a subject had to surrender to his master. In this light the versions do not contradict one another. The conflict may well have been initiated by warriors intercepting the tribute, and then have resulted in an ultimatum by Motecuhzoma II to Lord 8 Grass, summoning him in polite but authoritarian terms to hand over the flower of independent life. Lord 8 Grass's refusal was answered with a war campaign. ${ }^{74}$ The war proved fatal for Ndisi Nuu and its king: the town was completely destroyed and Malinal was taken to Tenochtitlan as a prisoner to be sacrificed in 1511 (Torquemada, book II: ch. 79).

\section{Ñu Tnoo on the Eve of the Conquest}

Proceeding from Coixtlahuaca, the Mexica conquest campaign seems to have followed the Valley of Tequevui (Tamazulapan) and

${ }^{74}$ The Relación Geográfica of Yodzo Nuu Huico (Mixtepec) gives a short description of the Ndisi Nuu troops (Acuña 1984, I: 295). 
Nuu Ndaa (Tejupan), and from there the next Valley of Yodzo Cahi (Yanhuitlan), Atoco (Nochistlan) and Añue (Jaltepec), in a clear strategy to cross the Mixteca Alta toward Huitzo (Guaxilotitlan) and Etla, where it could enter the Valley of Oaxaca. The Mexica had to pass through lands belonging to Yucu Ndaa (Tepozcolula), so they subjugated that town too. Other towns in the central Mixteca Alta, such as Nuu Tnoo and Chiyo Cahnu, located in the mountains to the South of the main Valley of Yodzo Cahi and Atoco, were left untouched for the moment. Consequently they are not mentioned in the tribute list of Codex Mendoza (pp.43-45). The expedition to Nuu Ndecu (Achiutla), Yucuañe (Malinaltepec) and Ndisi Nuu (Tlaxiaco) was a necessary divergence to the South. The powerful kingdom of Yucu Dzaa (Tututepec) stopped further Mexica expansion in that direction.

Meanwhile in Nuu Tnoo, Lord 10 Rain 'Rain Sun' had become king. He married his cousin, Lady 5 Wind 'Cacao Flower', the daughter of his father's brother, Lord 4 Death 'War Venus', and Lady 11 Monkey 'Jade Spiderweb', rulers of Chiyo Yuhu. They had several children:

1. Lady 5 Monkey 'Seed of Split Hill', born in the year 12 Rabbit (1466). She married Lord 4 Serpent 'Blood Eagle', Prince of Añute, with whom she had her first child in the year 1 House (1481) ${ }^{75}$

2. Lord 4 Deer 'Ndisi Nuu Eagle', the inheriting prince, whose birth year is not given, but according to our hypothesis it would be the year 9 Flint: 1476.

3. Lord 7 Reed 'War Venus', who married Lady 4 Alligator 'Spiderweb', a princess of At the Foot of the Altar (Sachio?).

4. Lord 8 Death 'Jaguar, Fire Serpent', who married Lady 1 Flower 'Jaguar Quechquemitl', who ruled in 'Plain with Mouth - Bird with Arrow Beak', which must refer to Yodzo Cahi (Yanhuitlan), as that is the place where this couple were ruling according to colonial sources. $^{76}$

75 Codex Ñuu Tnoo-Ndisi Nuu, p. 19-II and Codex Añute, p. 17-II/III.

76 A document in the Archivo General de la Nación (AGN Civil 516, f. 24 v) mentions Lord 8 Death (Namahu) and Lady 1 Flower (Cahuaco) as the precolonial rulers of Yodzo Cahi (Yanhuitlan), confirming that Lord 8 Death was the son of Lord 10 Rain (Xico): "el dicho namahu era hijo de xico, cacique que fue del dicho pueblo de Tilantongo, y desde alli se vino el dicho namahu a casar con cavaco su mujer a este pueblo de Yanhuitlan según su antigüedad ..." (Paillés Hernández 1993b: 18). The couple had five children, among whom was Don Domingo de Guzmán, who was born in 1510, and became cacique of Yanhuitlan; he died in 1558 (cf. Spores 1967). 
One may speculate that several towns were destroyed during the Mexica invasion and that Yodzo Cahi, as its Nahuatl name Yancuictlan, 'New Place', indicates, was a new foundation, replacing the earlier capitals of Andua and Chiyo Yuhu. These two important communities had been united under Lord 3 Monkey of Andua and his wife, Lady 5 Serpent, who came from Chiyo Yuhu. ${ }^{77}$ Now both were reduced to subject towns of the new center at Yodzo Cahi.

The Nuu Tnoo infant Lord 4 Deer 'Ndisi Nuu Eagle' married Lady 11 Serpent. The obverse side of Codex Nuu Tnoo-Ndisi Nuu ends with the scene of this pair ruling Nuu Tnoo. It is therefore plausible that the manuscript was prepared precisely for this marriage, leaving a lot of space open to continue the history with the children and grandchildren that this couple were expected to have. Curiously enough, no parentage statement is given for Lady 11 Serpent. Instead, the reverse side of the codex was used to include the dynasty of Ndisi Nuu, ending with the second marriage of Lord 8 Grass.

From other sources we know that Lord 4 Deer later married Lady 12 Vulture 'Sun Fan', a princess of Añute, who was born in the year 4 Flint (1484).$^{78}$ A son of this couple was Lord 13 Grass 'Fire Serpent', who became ruler of Añute in 1520.

Codex Nuu Tnoo-Ndisi Nuu gives the impression of being a finished document, but, at the same time, leaves ample open space at the ends of both sides to continue the historical register (presumably that of the descendants of Lord 4 Deer and Lord 8 Grass respectively), thereby presenting the ruling couples of Nuu Tnoo and Ndisi Nuu not as 'the end of history', but as having a - still undefined - future, as links in the chain of time. The connection between the houses of Nuu Tnoo and Ndisi Nuu was obviously the marriage between Lord 4 Deer's aunt, Lady 9 Deer, with Lord 8 Grass, which may have occurred around 1460.

Still, why these two lineages in one document? In 1580 the Relación Geográfica of Nuu Tnoo (Tilantongo), encapsulating the story of the Bodley Obverse in one sentence, states that Lord 4 Deer, named Yya

77 Codex Nuu Tnoo-Ndisi Nuu, p. 17-II. In our view Lady 5 Serpent was the daughter of the rulers of Chiyo Yuhu, just like her sister, Lady 2 Flower (cf. Codex Nuu Naha, p. 6).

78 Codex Añute, p.18-I\&IV. 


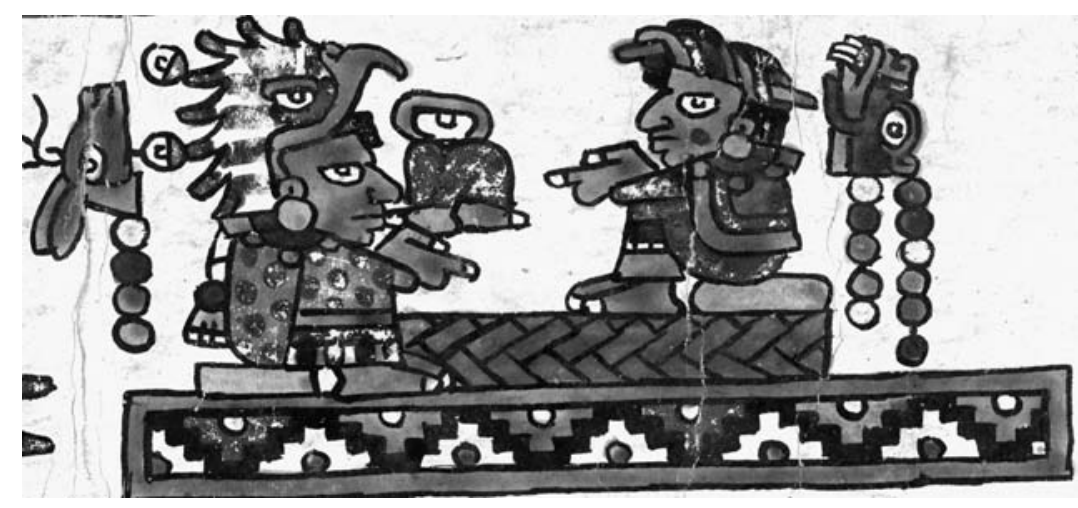

9.29. Codex Nuu Tnoo-Ndisi Nuu, p. 19-III: Lord 4 Deer 'Ndisi Nuu Eagle' marries Lady 11 Serpent.

Qh Cuaa in Mixtec and Nahui Mazatzin in Nahuatl, descended in a direct line from the founder of the Nuu Tnoo dynasty, and:

... he was the ruler when the marqués [Cortés] came to conquer New Spain... This lord was not baptized because he died soon after... His kingdom included the provinces of Teposcolula, Tlaxiaco, Atoyaquillo and Teozacualco, which are among the most important towns in the whole Mixtec region. These communites came to pay tribute of golden beads and precious stones and blankets and featherwork; in the ancient times these towns were distributed among brothers. (Acuña 1984, II: 231-232).

The reference to the rulers as being brothers is not surprising in view of the intimate ties between the ruling families and the equivalence of 'brother' and 'cousin' (both ñani) in Nuu Dzaui kinship. It may also reflect the general ideology of all dynasties belonging to one large family. Further this text indicates that Lord 4 Deer of Ñu Tnoo - probably because of this real or ideological parentage - ruled or pretended to have the right to rule the kingdom of Ndisi Nuu as well. This situation was not permanent and probably arose only in the period immediately after the mighty Lord 8 Grass of Ndisi Nuu had been captured and executed by the invading Mexica in 1511. Lord 4 Deer's pretension is expressed in his given name Yaha Ndisi Nuu, which means both 'Sharp-eyed Eagle' and 'Eagle of Ndisi Nuu'.

Both this pretension and the combination of the two dynastic records in Codex Ñuu Tnoo-Ndisi Nuu would be explained if Lord 4 
Deer's wife belonged to the house of Ndisi Nuu, e.g. was a daughter of Lord 8 Grass and Lady 9 Deer - in which case Lord 4 Deer would have married his cousin. Unfortunately this is not made clear in the pictorial record.

In the middle of this intricate political scenario of alliances and conflicts, and the threat of being totally overrun by the Mexica armies, the Nuu Dzaui kings and queens were surprised by the arrival of the Spanish conquistadors, 'out of the clouds and the mists', from another world, from where the Sun rises over the sea, from the realm of Quetzalcoatl. These white men quickly and miraculously brought the Mexica invasion to a standstill and then took over that 'evil empire'. Lord 4 Deer of Ñuu Tnoo sent ambassadors to Hernán Cortés with his most precious ñee ñuhu, a screenfold book that would call the attention of the stranger toward the sacred order of the Land of the Rain God and the story of the common origin of its ruling lineages, the Codex Yuta Tnoho... 


\section{COLONIAL TRANSFORMATION}

The Spanish conquest (AD 1521) was a destructive interruption of the autonomous development of Middle America, causing a tremendous and traumatic demographic tragedy, as a consequence of introduced illnesses, bad treatment and coercive labor. At the same time a new religion and a new economy were introduced. In towns such as Yodzo Cahi (Yanhuitlan), Nuu Ndecu (Achiutla), and Yucu Ndaa (Tepozcolula) the ancient temple pyramids were replaced with huge Dominican monasteries and churches. The early colonial Aniñe in Tepozcolula, known locally as the 'Casa de la Cacica', is a beautiful example of an indigenous palace, demonstrating how ancient Nuu Dzaui architecture and aesthetics could be combined with European techniques. Recently restored and partially reconstructed, this building is evidence of how the descendants of the rulers (iya tonine) of the precolonial yuvui tayu, 'mats and thrones', continued to enjoy the high profile social status of an indigenous aristocracy, with its corresponding material splendor for some time (Kiracofe 1995; Terraciano 2001). It is oriented toward and aligned with the Dominican monastery and church: a clear indication of the mental reorientation and political realignment of the inhabitants.

The artistic quality and social meaning of this architecture is paralleled by a small number of fascinating pictorial manuscripts, which were produced for the early colonial indigenous rulers (caciques). The role of the native nobility in New Spain has received renewed interest in recent years (e.g. Chance 2000; Pérez-Rocha \& Tena 2000; GonzálezHermosillo Adams 2001). The Mixtec case was already a focus of Spores' groundbreaking The Mixtec Kings and their People (1967) and is particularly interesting because of the extensive precolonial and early colonial documentation in the form of both pictorial manuscripts and related alphabetic documents in Spanish and in Dzaha Dzaui (Jansen 1994; Terraciano 2001; Jansen \& Pérez Jiménez 2009b). These sources provide unique insights into what went on inside the noble residences and missionary convents. Generally painted from the caciques' perspective, they illustrate the ideology of the ruling families 
and their handling of the complex cultural interactions, mental changes, and social readjustments after the foreign invasion. Continuing the ancient pictographic tradition while adapting to a changing socio-political context, these manuscripts may be analyzed as attempts to reassess and (re)create cultural memory. ${ }^{1}$

\section{Different Styles and Ideologies}

The Codex Añute or Selden 3135 (A.2), from the town of Jaltepec in the Valley of Nochixtlan, was painted in 1556-1560, but is completely precolonial in style and iconography, stressing precolonial symbols of dynastic legitimization. Going back to the First Dawn and the birth of the Founding Father from the Ceiba tree in Nuu Ndecu, mentioning the devotion of the rulers to the Sacred Bundle, its narrative was not painted to be presented to a Spanish court or audience (as suggested by Smith 1994), but represented the nostalgia of a conservative indigenous ruler and his entourage. The document was probably prepared under the supervision of the ruler Lord 10 Grass 'Jaguar, Breath of the Earth', born in 1527 and baptized as Don Carlos de Villafañe. Given the precolonial conventions and the pre-Christian discourse, one suspects that this codex was to be used (recited and performed) in the context of a native ritual occasion, possibly the ceremony of designating the heir to the throne - in this case Don Angel de Villafañe, who became the cacique of Jaltepec in the 1560s. The message of the old ruler to his heir was phrased and produced in conservative terms, in the form of a precolonial screenfold book with polychrome paintings, stressing the ancient values of the dynasty. Both the Aztec military expansion and the Spanish conquest, however, are passed over in silence.

It is interesting and illustrative of the different ideological currents at the time to see a completely different style and contents in the Codex Yodzo Cahi (Codex of Yanhuitlan), which must have also been painted around the middle of the 16th century, in the town of Yodzo Cahi

${ }^{1}$ For the concept of cultural memory as social (re)construction of identity referring to a common image of the past and a shared canon of ancient 'mythical' models, see the work of Jan Assmann (1992), in connection with Aleida Assmann's insights into memory and historical trauma (2007). We thank Daniel Graña-Behrens for having stimulated our study along these lines: a first version of this chapter was published in the volume he edited (2009) - for a Spanish adaptation see Jansen \& Pérez Jiménez 2009b, ch. 5 . 
(Yanhuitlan), quite close to Añute (Jaltepec). It is an 'explicitly' colonial book, on European paper and in European fashion, but still containing a pictorial text. This combination is of course innovative: the author has created a particular new style from Mesoamerican (both Ñuu Dzaui and Mexica) conventions and European elements and techniques, which has resulted in a remarkable work of art. Although he could copy earlier manuscripts for some of the information, the majority of his drawings are original compositions. As in several other early colonial manuscripts, the pictorial content is not in the traditional polychrome style but in black and white line-drawings: partly because of the change in material (European paper being a less suitable support for such paintings), partly because of the wish to give the artistic product the new look of a Spanish manuscript with ink drawings. In European usage writing is done with black signs (alphabetic text and illustrations) on white paper. By executing the whole pictorial manuscript in this way, the author also stresses its qualities as 'book' and 'writing' in the new canon.

Just as the style speaks of the interaction of the two worlds, the contents also deal with the relationship of the successive native rulers or caciques with Spanish encomenderos and Dominican monks. No explicit references to precolonial worldview here. Instead of the ancient temple with the Sacred Bundle, we see images of the Catholic Church and the rosary. The representation of the cacique himself does not show the power of the nahual, as was customary in precolonial art, but, instead, stresses the acculturation to Spanish fashion and obedience to the Spanish authorities. We conclude that the persona of the ruler was no longer constructed in the interaction with the indigenous community but in conformity with the colonizer.

\section{Diverse Fragments}

Unfortunately, the interpretation of the Codex Yodzo Cahi is handicapped by the fact that the manuscript is incomplete and survives today in three fragments, which are themselves internally out of order:

a) The main part is in the University Museum of Puebla, consisting of 11 leaves with drawings on both sides and one additional leaf, which is a composite of several loose fragments. Wigberto Jiménez Moreno and Salvador Mateos Higuera (1940) have published these 
24 pages (as 'plates I-XXIV'), adding a detailed commentary, now a classic of our discipline.

b) 4 leaves (8 pages with paintings) have been preserved in the Archivo General de la Nación, Mexico City (AGN Ramo de Vínculos volume 272, expediente 10), where they were discovered by Heinrich Berlin, who published them in an important small monograph (1947) as 'plates A-H'.

Both fragments were united in a facsimile publication by María Teresa Sepúlveda y Herrera (1994), who added an estudio preliminar and proposed a reconstruction of the sequence of leaves ('plates I-XXXII'). The dimensions of the pages are approximately $31 \mathrm{~cm}$ (high) $\times 22 \mathrm{~cm}$ (wide); the watermarks confirm that the book must have been painted after 1544 (a date given in the Nuu Dzaui calendar near the end of the manuscript).

c) Heinrich Berlin had already noted that the important Oaxacan historian Manuel Martínez Gracida describes in his unpublished works several scenes from a 'Codex of Tututepec', which seemed to be related to the Codex Yodzo Cahi. Some of these plates appear in a partial publication of Martínez Gracida's main opus (1986). Having had the opportunity to consult and study the still mostly unpublished works of Martínez Gracida, now in the Oaxaca Public Library, with the professional and helpful assistance of its custodians, we were able to confirm Berlin's suggestion and to identify 6 paintings (presumably 3 leaves) as copies from now lost pages of the Codex Yodzo Cahi in Martínez Gracida's Los Indios Oaxaqueños y sus monumentos arqueológicos: volume III, plate 14 and volume V, plates 27, 29, 40, 42 and 62. Apparently, these parts of the codex were copied for Martínez Gracida while still in an archive or collection in Tututepec, on the Nuu Dzaui coast. This is interesting in view of the fact that the fragment that ended up in the Archivo General de la Nación is appended to the acts of a lawsuit brought by Don Francisco Pimentel y Guzmán, cacique of Tepozcolula and Yanhuitlan, to obtain control of the cacicazgo of Tututepec in $1653 .^{2}$

\footnotetext{
${ }^{2}$ For the social and historical background, see Chance (2008), who analyzes the marital alliances of the Mixtec caciques in colonial times.
} 
We made a hypothetical reconstruction of how these six drawings could have fitted together as obverse and reverse sides of three folios. Fortunately, after we finished our study, the three original folios came to light and confirmed our reconstruction. At the same time our suspicion that the color in the plates in the work of Martínez Gracida was a reconstruction by his expert draughtsman (E. Arias) was confirmed.

The three fragments together do not form a complete document. There are several scraps of pages in addition to an unknown number of leaves which have been completely lost.

Given the state of the source it is difficult to reconstruct the order of the loose leaves. We have to take into account:

a) the dates in the Nuu Dzaui calendar given on several pages,

b) the physical connection between the obverse and reverse sides of the leaves,

c) the context of historical events that took place in the region and that seem to be referred to by several images of the codex,

d) the internal 'logic' of the narrative.

The main primary sources for reconstructing the history of events in Yanhuitlan in the 16th century are the 17th century chronicle of the Dominican mission by friar Francisco de Burgoa and a number of archival documents, such as lawsuits about the succession and tribute rights of the cacique (Paillés Hernández 1993ab), the Proceso Inquisitorial of 1544 against the cacique and gobernadores of Yanhuitlan (Sepúlveda y Herrera 1999), and incidental letters, such as that by Juan de la Zarza to the encomendero Francisco de Las Casas in 1529, and that by Alonso Caballero, a local Spanish inhabitant of Yanhuitlan, to the visitador Valderrama in 1563 (Scholes \& Adams 1961). Synthesizing these and other data, the studies by Jiménez Moreno \& Mateos Higuera (1940), Spores (1967) and Pérez Ortiz (2003), have constructed a progressively clearer image.

\section{Caciques, Monks and Encomenderos}

The names of the protagonists of the Codex Yodzo Cahi, the native rulers, have often been damaged (probably due to alterations in later use of this document in colonial lawsuits concerning privileges and 
succession rights), but other historical documents permit us to reconstruct the dynastic sequence. We note that in contrast to precolonial codices, which focus on the couple of Lord (iya) and Lady (iyadzehe) as the unit of authority and lineage history, this pictorial text, influenced by Spanish colonial mentality, is only concerned with the male line of rulers leaving the women to disappear from history. ${ }^{3}$

Combining different lines of evidence, we may reconstruct the dynasty and so still find a story-line, albeit hypothetical, as a further step toward the general understanding of this source. For the identification of the pages we use the initials of the authors of the works in which the plates appear: JM. (Jiménez Moreno \& Mateos Higuera 1940), HB. (Berlin 1947), SH. (Sepúlveda y Herrera 1994) and MG. (Martínez Gracida 1986, i.e. the manuscript of Los Indios Oaxaqueños y sus Monumentos Arqueológicos, the copies of which correspond to the three recently surfaced original folios).

The first page (JM: II / SH: II) contains an important opening scene, which may be analyzed as a composition of two crossing diagonal lines. The first line mentions place and time, fundamental categories that are also often present in precolonial codices. In the upper lefthand corner we see a building in frontal view with disks in stone mosaics in the roof (as in the Casa de la Cacica of Tepozcolula). It is glossed as aniñe, 'palace' and indeed the convention of such disks in the roof is a diagnostic sign for the tecpan in Central Mexican sources. This palace is located on a place sign that is the Aztec convention to represent Yanhuitlan, the 'New Town', consisting of a white blanket. In Codex Mendoza, p. 43, a tooth, tlantli, is added to assure the reading of the locative suffix -tlan. As we saw earlier, the Mixtec toponymic sign was quite different: Plain (yodzo) - Mouth $(a-)$ - Specific Bird (cahi?) with Arrowheads (nduvua) on its beak. We may reconstruct the aniñe in our imagination as similar to the Casa de la Cacica in Tepozcolula, but today this precolonial building has disappeared and only the crumbling and overgrown adobe-walls of a later version (the residence of Don Gabriel de Guzmán) are still standing in the center of the village. ${ }^{4}$

\footnotetext{
${ }^{3}$ See Terraciano's study' Reading Women into Mixtec Writings', a contribution to the volume in honor of Mary Elizabeth Smith (Boone 2005: 345-361).

${ }^{4}$ This later palace is described in early colonial texts as a large complex of nine courtyards: "unas cassas grandes en que ay nuebe patios que llaman la cassa de la tecpa" (AGN Civil 516). Some of these had columns, and domed rooms around them
} 


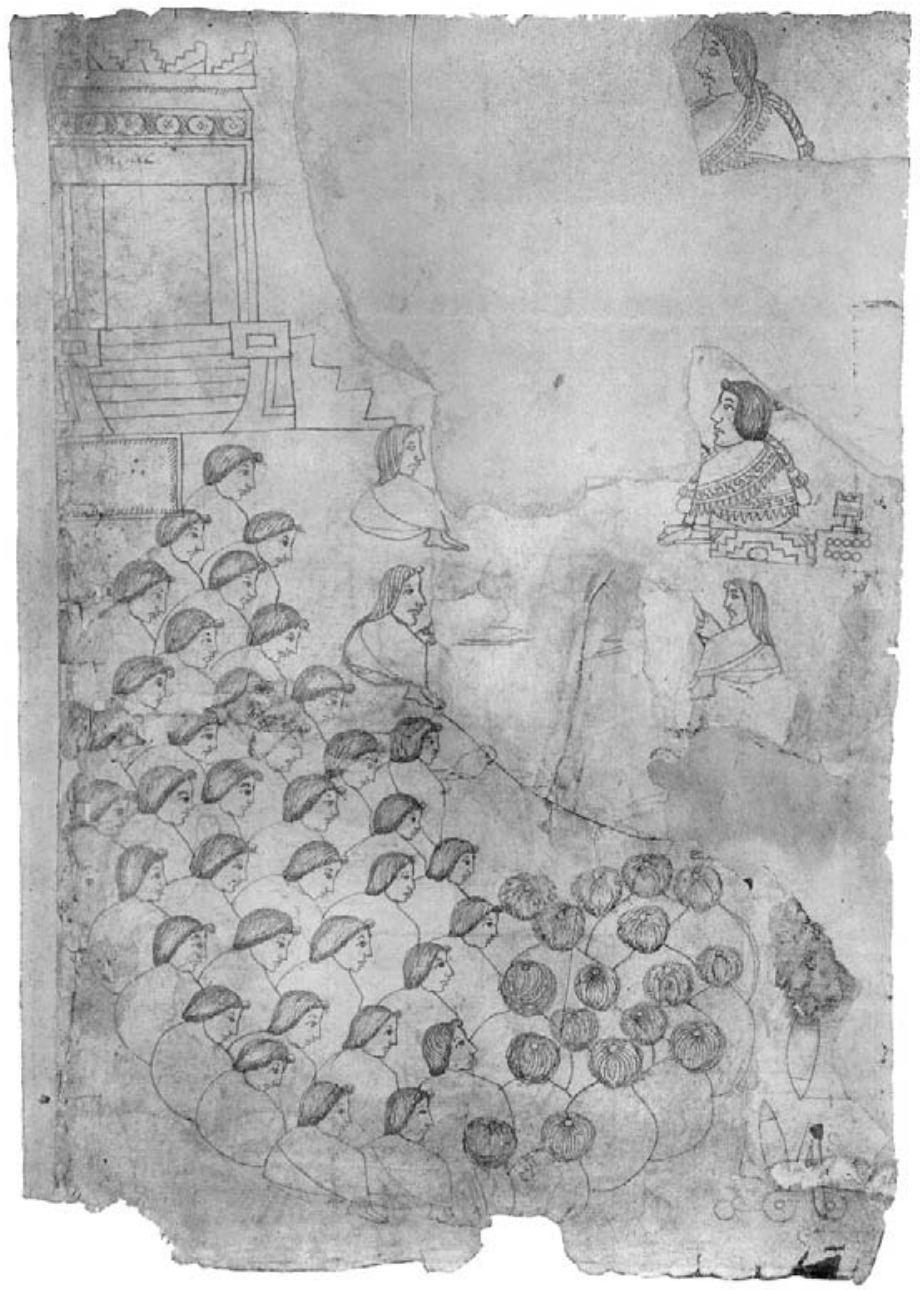

10.1. Codex Yodzo Cahi: Assembly in front of the palace (J.M.: II).

In the lower right-hand corner a date is given: the year 1 Flint, and a day Flint. Its position and configuration recall the sacred founding dates so abundantly mentioned in Codex Yuta Tnoho. We suppose that the day is 1 Flint, which would make it the 'year-bearer' or first day of the Mixtec year 1 Flint, i.e. March 24 of 1520.

(Cobo, cited by Jiménez Moreno \& Mateos Higuera 1940: 49). For the identification of the aniñe / tecpan glyph see Batalla Rosado in Jansen and Reyes García 1997. 
The other diagonal line is that of the ruler Lord 9 House (in the upper right-hand section) facing an assembly of the people (in the lower left-hand section). This cacique is represented in precolonial style, wearing a tunic (dzico) and seated in profile on the rectangle with step-fret motif, i.e. $\tilde{n} u u$, 'town'.

A letter from a Spanish inhabitant of Yodzo Cahi in 1563 identifies Francisco Calci as the ruler of this place at the time of the conquest: "Francisco Calci, el cual cuando la tierra se ganó era cacique y señor en el dicho pueblo" (Scholes \& Adams 1961: 300). He is also mentioned in the records of the 1544 Proceso Inquisitorial against a later cacique (Don Domingo de Guzmán) and two gobernadores of Yodzo Cahi: at that time the deceased Calci received offerings as an earlier ruler of the town. ${ }^{5}$ Calci (Cal-tzin) means 'Lord House' in Nahuatl and is obviously a reference to a calendar name - the number is not specified in the cited document, but the comparison with the Codex of Yanhuitlan shows it to be 9 .

Ronald Spores (1967: 66, 132) has pointed out the importance of the voluminous document on the conflict between Nuu Yaha (Tecomatlan) and Yodzo Cahi (Yanhuitlan) in the Archivo General de Indias in Sevilla (AGI, Escribanía de Cámara 162) and noted that this lawsuit of 1582-84 refers to a Lord Nabacaltzin or Nabalcaltzin, king and cacique of the whole Mixteca Alta and Baja. We should distinguish between Yodzo Cahi's Calci and this ancient ruler however, as the latter lived more than 400 years earlier; it was from his son, Matlacce Itzli [11 Flint], that the dynasty of Nuu Yaha (Tecomatlan) descended: "desde que fue casique matlace yztli hijo de naba caltzin rrey e cacique de toda la misteca alta y baxa que abra mas de quatrocientos años" (AGI, Escribanía de Cámara 162, f 38v). This statement is most likely a reference to Naui Eecatzin, the famous Lord 4 Wind, who was indeed ruler of a large part of the Mixteca Alta and Baja in the 12 th century.

Returning to the middle section of the first page of the Codex Yodzo Cahi, in front of Lord 9 House we see four priests, who seem to be offering leaves with birds. In one case, in the heavily damaged part on the left, we recognize a turkey. The same action is performed by the central person in the first row of the assembly: a sort of 'people's representative', who seems to hold a quail. The offering of birds is similar to the decapitation of a quail, which has been recognized in the pre-

\footnotetext{
${ }^{5}$ Jiménez Moreno \& Mateos Higuera 1940: 44; Sepúlveda y Herrera 1999: 163.
} 
colonial Nuu Dzaui codices as a 'ceremonial salute', generally part of an 'offering of royalty'. 6

In the upper right-hand corner we see another individual, similar in appearance to Lord 9 House, seated above him. This is a loose part of the paper, however, so we are not completely sure whether this figure really belongs here, although among the preserved pages there is no other place where he would easily fit. If this man is indeed part of the scene, he is obviously a second important native authority. We might think of a co-ruler or important ally, but most likely he would be Calci's father. In that case the scene would represent the ruler's designation of his heir and the acceptance of that appointment by the people.

The reverse side of this leaf (JM:I / SH:I) depicts a confrontation between Spanish conquistadors and native warriors on a dam between canals. We recognize the image as a scene of the Noche Triste (June $30,1520) .{ }^{7}$ Here it serves as a general reference to that dramatic turning point in Mesoamerican history: the battle for the Aztec capital. The drawing is turned 90 degrees, so that the painter could present a panoramic view of the battle scene. It is quite possible that he copied it from an earlier representation and preferred not to adjust it to the format of his own book. At the same time this device underscores that the scene is not directly part of the narrative: it was included as an event that took place elsewhere, but was nevertheless an important point of reference. Earlier studies took this as the opening scene and the first page; we think that the codex started in accordance with the Nuu Dzaui canon: focusing on a rulership ceremony and clearly stating place and (sacred) time.

The date Year 2 House, i.e. 1521, when the Spaniards conquered the Aztec capital Tenochtitlan, defines the position of the next page (JM: III / SH: III). The underlying theme seems to be the change of power to a pro-Spanish ruler. Two roads, i.e. missions, are coming from a place called Black Palace, situated in the mountains. The sign might in

${ }^{6}$ Cf. Codex Yuta Tnoho passim. Compare the traditional sacrifice of quails demanded from the whole population by the native priests in order to avoid the wrath of the ancient deities and avert illness, as described in the Proceso Inquisitorial (Sepúlveda y Herrera 1999: 168).

7 Compare the images in the Lienzo of Tlaxcala (Chavero 1979: 40 ff.) and Sahagún (1950-78, Book 12, fig. 91). 
principle refer to a place name such as Yucu Tnoo, 'Black Mountain' (Tiltepec) near Yodzo Cahi in the same valley, but the mountainous environment suggests that Yodzo Cahi's powerful southern neighbor Nuu Tnoo is meant. The same focal points that we encountered at the very beginning of Mixtec Postclassic history are mentioned here.

The ruler seated in the mountain palace is wearing a European hat, an indication that he is manifesting himself as an ally of the Spaniards, already at this early date. The whole image gives the impression of being retouched. The number of his calendar name is 8 , but the day sign has been altered beyond recognition; maybe the sign Deer was originally painted here. At the time Nuu Tnoo was still ruled by Lord 4 Deer. The number of the calendar name of the individual in the codex makes us think of his younger brother: Lord 8 Death (Iya Namahu), who was married to the crown princess of Yodzo Cahi, Lady 1 Flower (Iyadzehe Cahuaco).$^{8}$ Possibly the alteration of the name of the ruler in the mountains on this page of the Codex Yodzo Cahi was done with the aim of substituting Lord 4 Deer by Lord 8 Death as protagonist of the actions depicted.

On the upper road of our page the ruler of Black Palace sends a negotiator (Lord 2 Eagle) to visit Lord 9 House and establish some important agreement with him. On the lower road, two carriers (one of them wearing sandals, suggesting that he has the status of a cacique) travel with food (a huge turkey and a basketful of tortillas) to a large palace, the drawing of which unfortunately is quite damaged. On the staircase of the palace several native shields have been deposited. In view of the date and the Spanish hat of the ruler, we suppose he sent these gifts as symbols of his friendship to the conquistadors. ${ }^{9}$

The two roads seem to represent two simultaneous aspects of a project initiated by a prince of Nuu Tnoo, probably Lord 4 Deer. Later Lord 8 Death was credited with having been the (intellectual) author of these actions. By manifesting himself as an ally of the new colonial power, he started a process aimed at taking over the throne of Lord 9

8 This couple is represented in Codex Nuu Tnoo-Ndisi Nuu (Bodley), p. 19-III. Alfonso Caso (in Paddock 1966; Caso 1977-79, II: 154) made the original identification. Codex Ñuu Tnoo-Ndisi Nuu concurs with AGN Civil 516 in identifying Lord 8 Death (Namahu) as the son of Lord 10 Rain (Xico) of Tilantongo.

9 The same act of giving turkeys and tortillas is represented in the drawings of the Lienzo of Tlaxcala as a symbol of support to Cortés' troops (Chavero 1979: $53 \mathrm{ff}$.). The shields may represent the native allies or subdued armies that by now had pledged alliance to the conquistadors (cf. Chavero 1979: 43). 


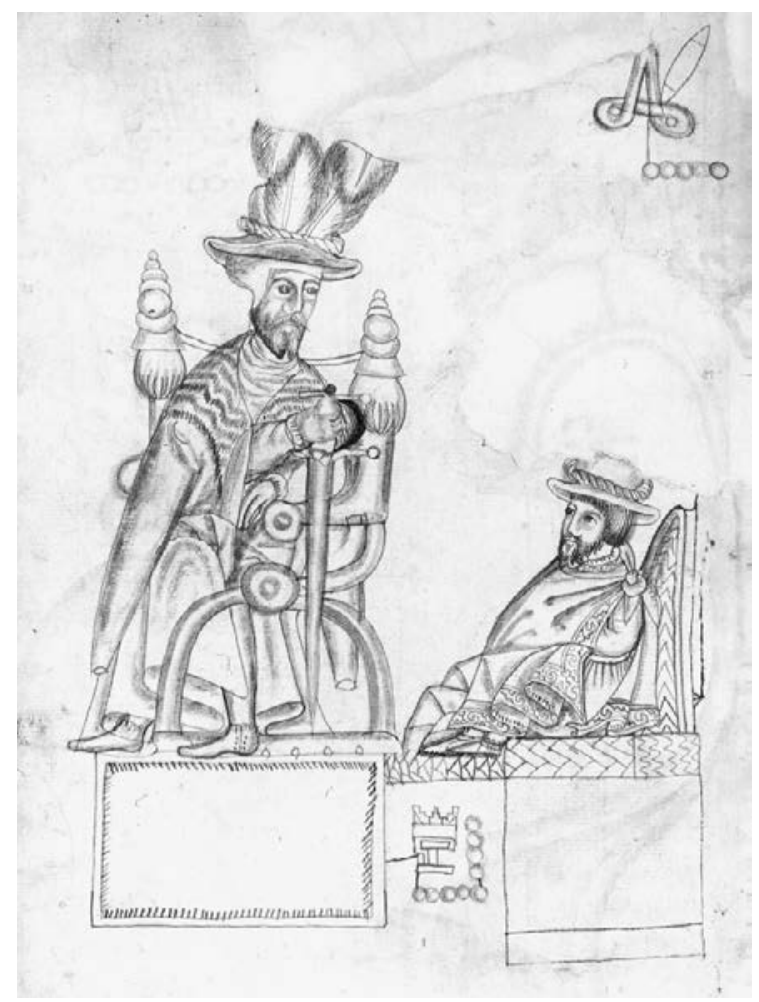

10.2. Codex Yodzo Cahi: encomendero y cacique (SH: VII).

House. The ambassador sent to Lord 9 House would suggest to the reader that this happened with the consent of the ruler of Yodzo Cahi himself.

Starting on the reverse side, a traditional assembly of rulers of subject settlements and neighboring towns is inserted here as the ritual recognition of a new ruler (JM: IV-V-VI / SH: IV-V-VI). The place signs completely conform to Nuu Dzaui conventions and are clearly copied from an original in precolonial style.

This line of settlements and nobles leads us to an image of the cacique on the throne of rulership. We find this image on a fascinating page (HB: E / SH: VII), which also contains a date: the year 5 Reed (1524). But the native ruler is not the protagonist of the scene. That role is taken by a Spanish conquistador, seated on a European chair (the new, colonial seat of authority) on top of the place sign of Yodzo 
Cahi (Yanhuitlan), and holding a sword, as the symbol of military conquest. ${ }^{10}$ This must be Francisco de Las Casas, who took possession of Yodzo Cahi as encomendero in this year. In front of him appears the native cacique, seated on the mat and the throne, i.e. conserving some of his rights from the earlier political structure of the yuvui tayu. The rectangle under him indicates that he still controls some lands, but no longer the town itself. By imitating the Spanish fashion in hat and beard, and combining the traditional cape with a European shirt, the cacique expresses his acculturation and obedience to the new regime. His name has been torn out, probably due to an alteration of the narrative, adapting it for a specific court case, but given the date and the external information he must have been Iya Namahu, Lord 8 Death 'Jaguar, Fire Serpent' (Naña Yahui), the prince from Tilantongo who married the crown princess from Yodzo Cahi, Lady 1 Flower (Iyadzehe Cahuaco) 'Jaguar Quechquemitl' (Dzico Naña), i.e. 'Virtue or Force of the Jaguar'. In 1580-81 elderly people remembered that Namahu and Cauaco had been caciques of Yodzo Cahi some 55 years ago. ${ }^{11}$

This means that Lord 8 Death (Namahu) and Lady 1 Flower (Cauaco) had become the successors of the above-mentioned Lord 9 House (Calci) in 1525. The fact that this Lord 9 House of Yanhuitlan was baptized as Don Francisco and his son as Don Gonzalo suggests, however, that he was still alive when the first friars passed through Yanhuitlan in the late 1520s. The generational sequence of names Don Francisco - Don Gonzalo clearly follows the name of the Spanish encomendero Don Francisco de Las Casas and his son Don Gonzalo de Las Casas. ${ }^{12}$

Calci's son, Don Gonzalo, later claimed that his father had died when he himself was still a small child and that he was succeeded directly by Don Domingo de Guzmán, which would mean that Calci lived till the end of the 1530s. ${ }^{13}$ Although the overall picture is far from clear, we get the impression that Lord 8 Death's enthronement as cacique in 1524 was not because his predecessor Calci had died, but as a

${ }^{10}$ See the excellent study by Wood (2003) on the representation of Spaniards in early colonial pictorial manuscripts, as well as the contribution by Lori Boornazian Diel to the volume in honor of Mary Elizabeth Smith (Boone 2005: 301-317), which specifically discusses the Spanish chair as an icon of rule, appropriated and incorporated by the Mesoamerican nobility.

11 AGN Civil 516 (Pailles Hernández 1993b: 15).

${ }^{12}$ See their short biographies in Himmerich y Valencia (1991: 137).

${ }^{13}$ Scholes \& Adams 1961: 300. 


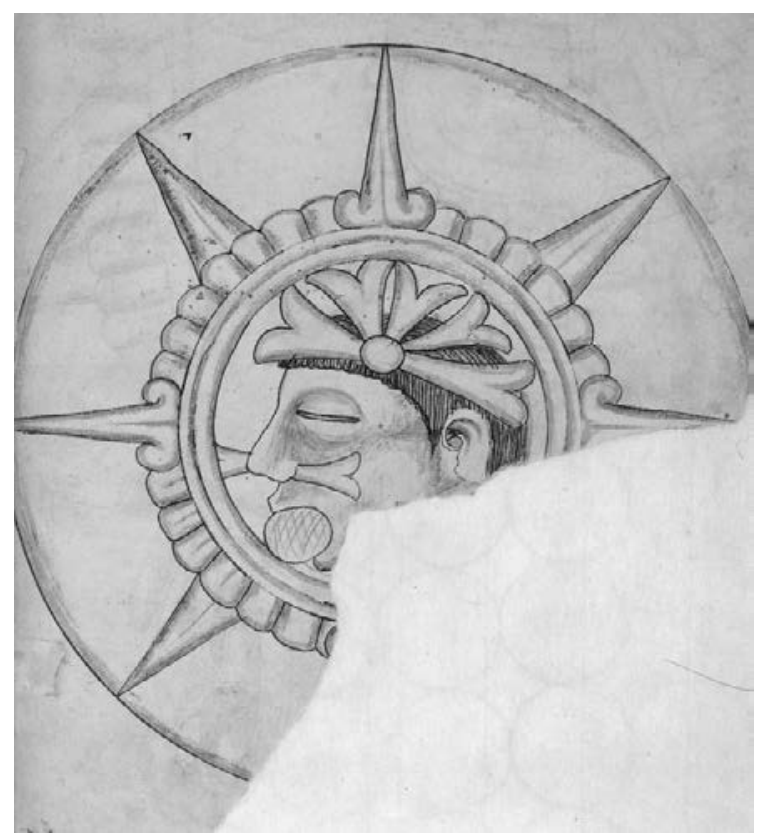

10.3. Codex Yodzo Cahi: Tlacaxipehualiztli (SH: X).

consequence of a political shift, in which Lord 8 Death allied himself with the Spanish conquistadors and was recognized as the new ruler. This is likely to be the reason why the cacicazgo still appears connected to the name of Lord 9 House, who appears to have lived on for quite some time, but without his former royal authority.

On the reverse side (HB: F / SH: VIII) we find the following year: 6 House (1525). The large head of an alligator, the first day sign of the 260-day count, introduces a temporal topic. That is why we think it introduces a set of pages that refer to the times in which tributes had to be handed in to the cacique (HB: B, A, C; SH: X, IX, XI). These were specific twenty-day periods (veintenas) in conformity with general practice in ancient Mexico :

- Tlacaxipehualiztli ('Flaying People', 2nd veintena of the Aztec calendar, 1st of the Mixtec), represented as a Sun disk with the face of the God Xipe (the Flayed One). 


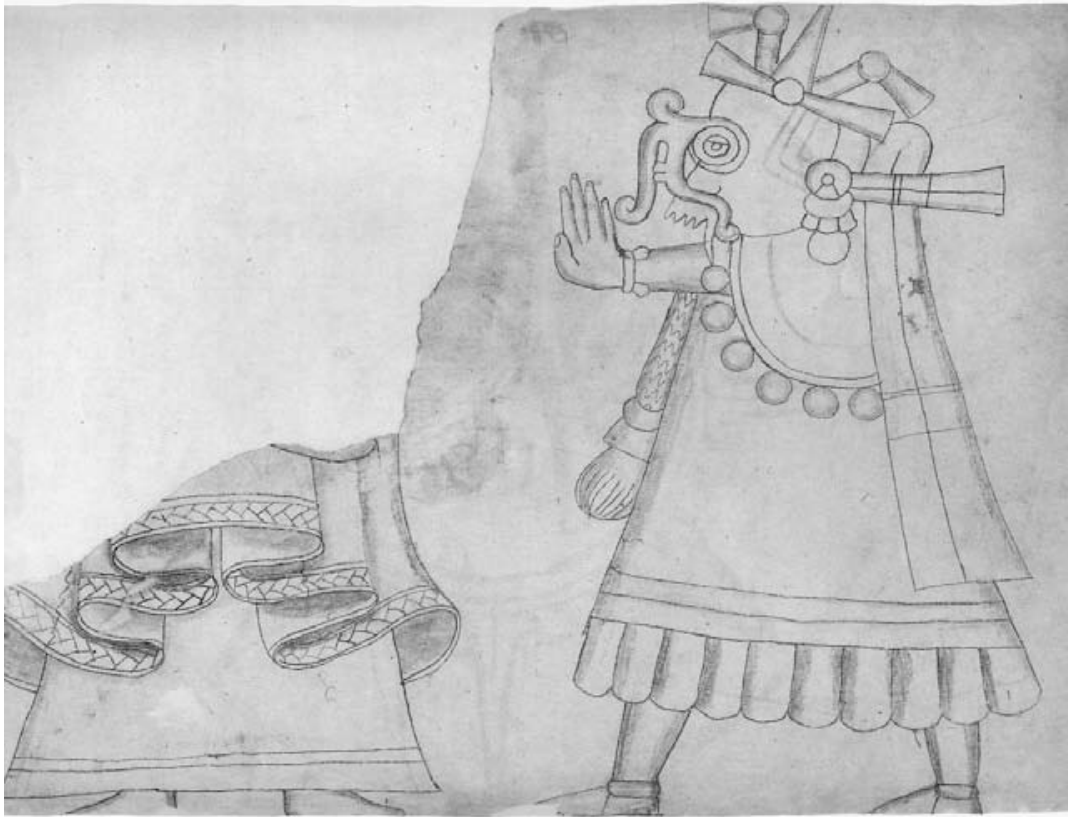

10.4. Codex Yodzo Cahi: Etzalcualiztli and Ochpaniztli (SH: IX).

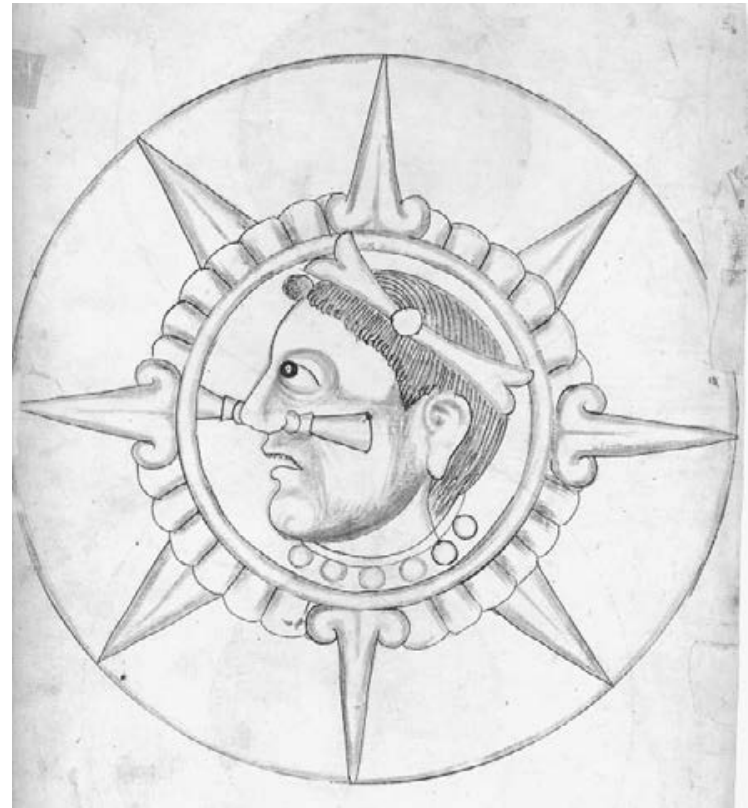

10.5. Codex Yodzo Cahi: Panquetzaliztli (SH: XI). 
- Etzalcualiztli ('Eating beans and maize', 6th veintena of the Aztec calendar), represented by an image of the Rain God (Tlaloc in Nahuatl, Dzavui in Mixtec).

- Ochpaniztli ('Sweeping the roads', 11th veintena of the Aztec calendar), represented by an image of the Mother Goddess Tlazolteotl (the image is severely damaged; part of the headdress - the typical 'hat' of the Goddess - is to be found on a loose scrap of paper: JM: XXIII / SH XXXI).

- Panquetzaliztli ('Raising the Banners', the 15th veintena of the Aztec calendar), represented as a Sun disk with the Sun God in the center, which is different from the Aztec convention of painting their tribal God Huitzilopochtli. ${ }^{14}$

Etzalcualiztli and Ochpaniztli are combined on one page, which must be rotated 90 degrees in order to be read. In doing so, we notice that the reading sequence of these two fiestas is from the right to the left. Clearly, the painter copied this part from a codex in precolonial style.

The order of these veintenas is given by the Mesoamerican calendar. The Codex Yodzo Cahi then gives a detailed list of all the artefacts and services that the people offered to this cacique - as a norm, no doubt, for the continued payment of such tributes in later time. ${ }^{15}$

This ritualized payment included:

- two silver plates, identified by a gloss: platos de plata (HB: D / SH: XII) - the position of this page (and the topic introduced here) is

14 The four tribute periods may be connected to the four feasts celebrated annually in Yanhuitlan (Sepúlveda y Herrera 1999: 142). Seler (1960-61, I: 164-169) already identified and discussed these four tribute periods and their signs, as appearing in one of the Humboldt manuscripts in Berlin. Similar signs of Flayed Face and Sun combined with temples may represent the Mixtec equivalents of Tlacaxipehualiztli and Panquetzaliztli in Codex Yuta Tnoho (Vindobonensis), p. 48. On a carved stone in Cuilapan the month Panquetzaliztli - including the day 11 Death of the Year 10 Flint, i.e. November 15, 1568 - is represented as Ritual ('the speaking to the four directions') of the Banner on the Altar (Jiménez Moreno \& Mateos Higuera 1940: 69). Following the same correlation, the other feast sign on that stone, Ritual of the Macana ('Sword'), including the days 11 Serpent - 6 Reed of the Year 10 Reed, must represent the Mixtec equivalent of the Aztec veintena Tecuilhuitontli.

${ }^{15}$ Compare the lists of tributes to be paid to Don Domingo, Don Gabriel and to the encomendero (Jiménez Moreno \& Mateos Higuera 1940: 36-37 and 33 respectively). 


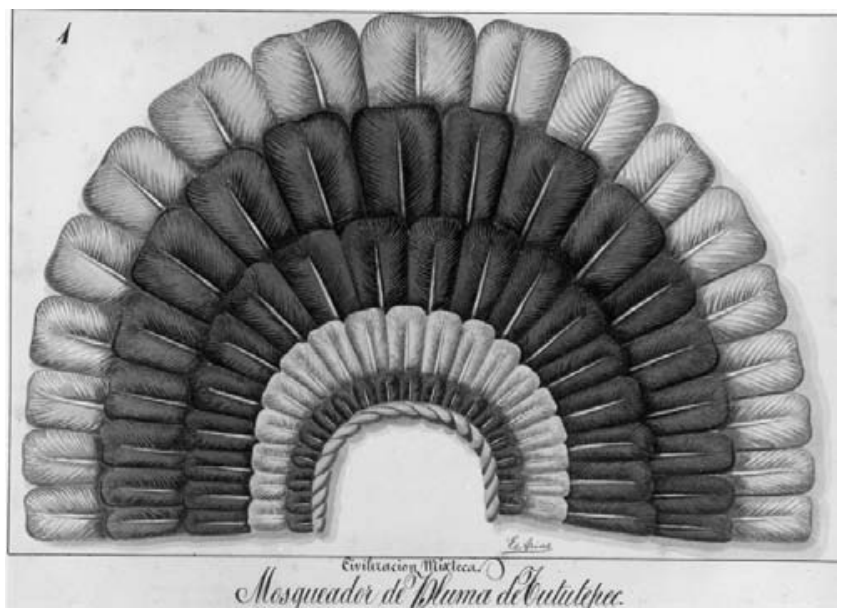

10.6. Codex Yodzo Cahi: feather crown ( MG: V-62).

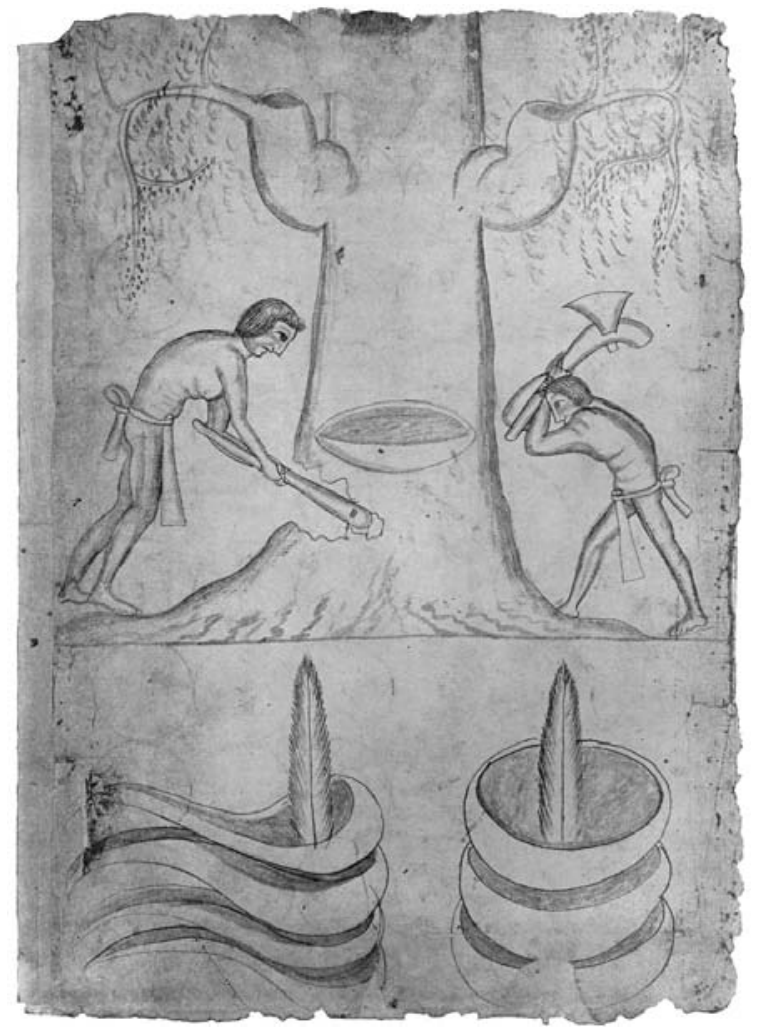

10.7. Codex Yodzo Cahi: Cutting wood as 'tribute' (JM: XXI). 


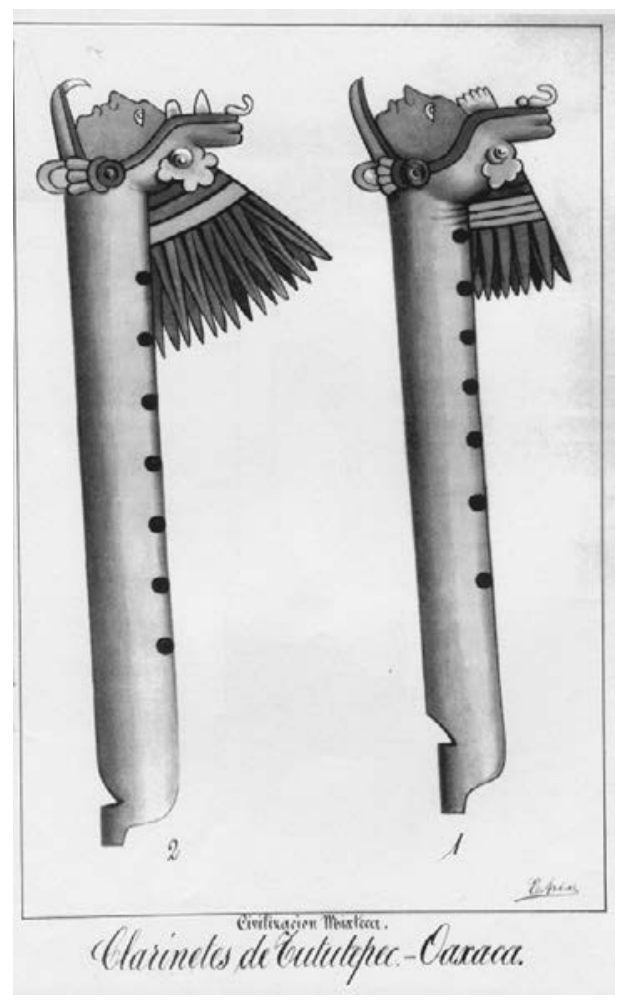

10.8. Codex Yodzo Cahi: two flutes (MG: V-29).

guaranteed by the scene being drawn on the reverse side of the Panquetzaliztli image.

- two flutes (MG: V-29) - an image that fits well in this context as it also shows a set of two gifts.

- two feather headdresses (MG: V-62 and HB: G / SH: XIII), which seem to form a pair (although preserved in different collections).

- a large number of blank disks on two opposing pages that seem to form a thematic unit (HB: H / SH XIV and JM: XXII / SH 24). ${ }^{16}$

16 We count $54+48=102$ disks on these two pages, but small fragments preserved (JM: XXIII; SH: XXXI) suggest that there may have been one or more other folios in between with a similar amount. The meaning of the disks is not clear. In the Codex Texupan or Sierra (León 1982) such blank disks represent tomines, while disks with crosses or 8's identify pesos. The period that these pages of the Yanhuitlan codex refer to, seems too early for a reference to money. 


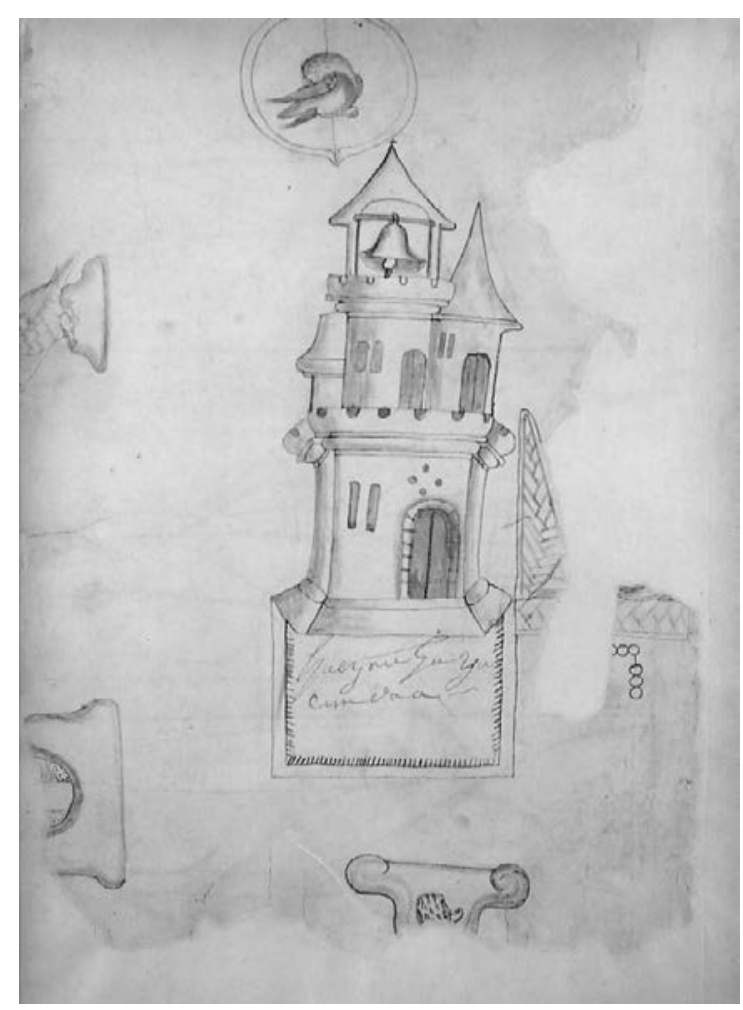

10.9. Codex Yodzo Cahi: the cacique (Don Diego Nuqh) and the colonial town (SH: XV).

- the cutting of wood; four hundred spoons and bowls (JM: XXI / SH: XXIII).

- the service of grinding and carrying corn and of four hundred men attending the cacique, ruling the cacicazgo of (Lord) 9 House (JM: XII / SH XXII).

- four houses or granaries filled with corn, glossed ytu huiyo, 'maize field' (JM: XI / SH: XXI).

- continuing the same type of information: one house with baskets filled with dots, representing small kernels or powdered material such as salt ${ }^{17}$, one house filled with chile peppers, glossed ytu yaha si yya toniñe, 'field(s) of chile peppers belonging to the cacique',

${ }^{17}$ It seems too early for these baskets with small kernels to represent wheat. Gold dust - another iconographic possibility, seems out of place as the house with these baskets is listed between one with maize and one with chile peppers. 


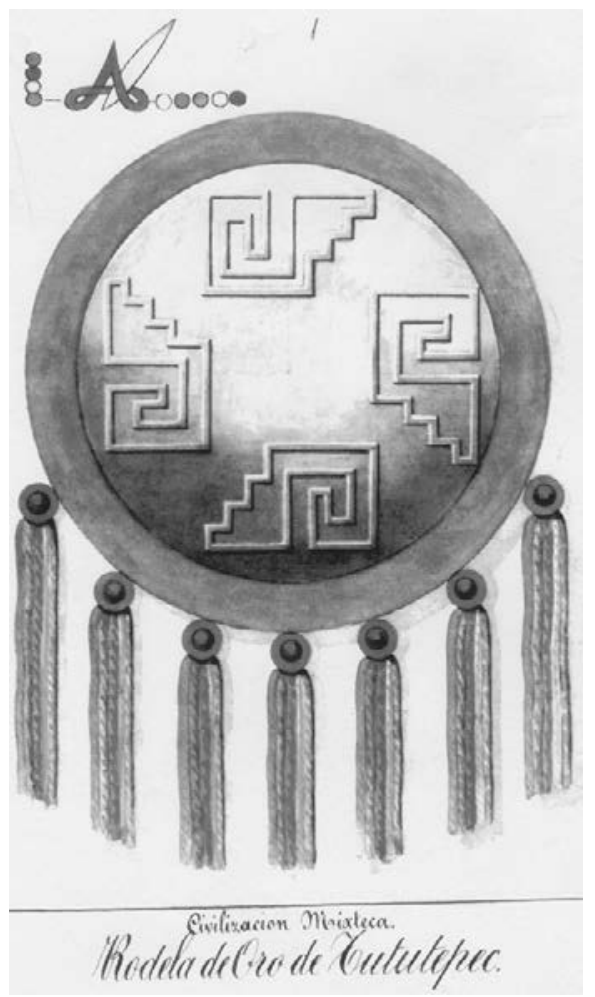

10.10. Codex Yodzo Cahi: golden shield as special gift (MG: V-27).

and one with beans, glossed ytu nduchi tnuu, 'field(s) of black beans' (JM: X / SH XX).

This list is followed by a description of how gold-dust was obtained from the rivers of three specific places (JM: IX / SH: XIX). Spanish soldiers are shown supervising these actions, which suggests that they immediately usurped this part of the tribute.

As a final tribute the cultivation of three corn-fields is mentioned (JM: XVII / SH: XVI).

After this, we see the Europeanized town of Yodzo Cahi (Yanhuitlan), surrounded by boundary markers. On the mat and throne, leaning on this city, sits its new ruler, of whose calendar name only 6 dots remain. 


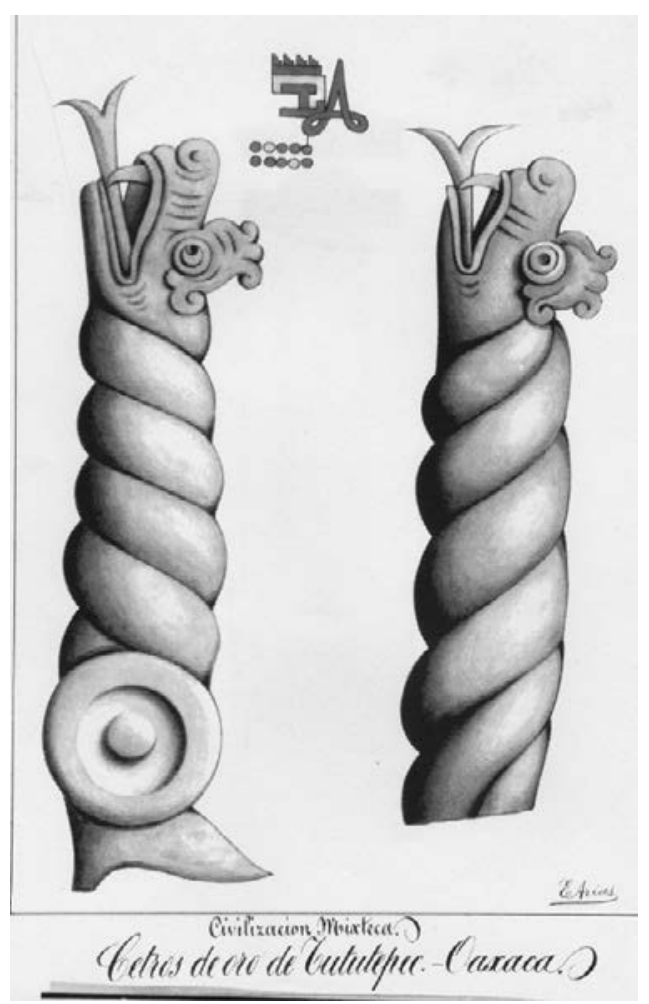

10.11. Codex Yodzo Cahi: two spear-throwers, identified by Martínez Gracida as 'scepters' (MG: V-27)

The year in which the first Dominican missionaries visited Yanhuitlan, started to baptize people and founded a monastery, was $1527 .{ }^{18}$ On August 25, 1529, Juan de la Zarza, the mayordomo of Francisco de Las Casas wrote from Mexico to the encomendero about the situation in New Spain and in Yodzo Cahi in particular. Describing how in Las Casas's absence another Spaniard, Escobar, claimed to have received control over the town and abused those powers, Zarza briefly noted: "the cacique of Yanhuitlan has died; they said Escobar has killed him, he has been jailed for this, but has escaped". This short remark dates and explains the death of Iya Namahu. ${ }^{19}$

18 Sepúlveda y Herrera 1999: 132.

19 Otte 1970: 110-111. Cf. Pérez Ortiz 2003: 76-80. 


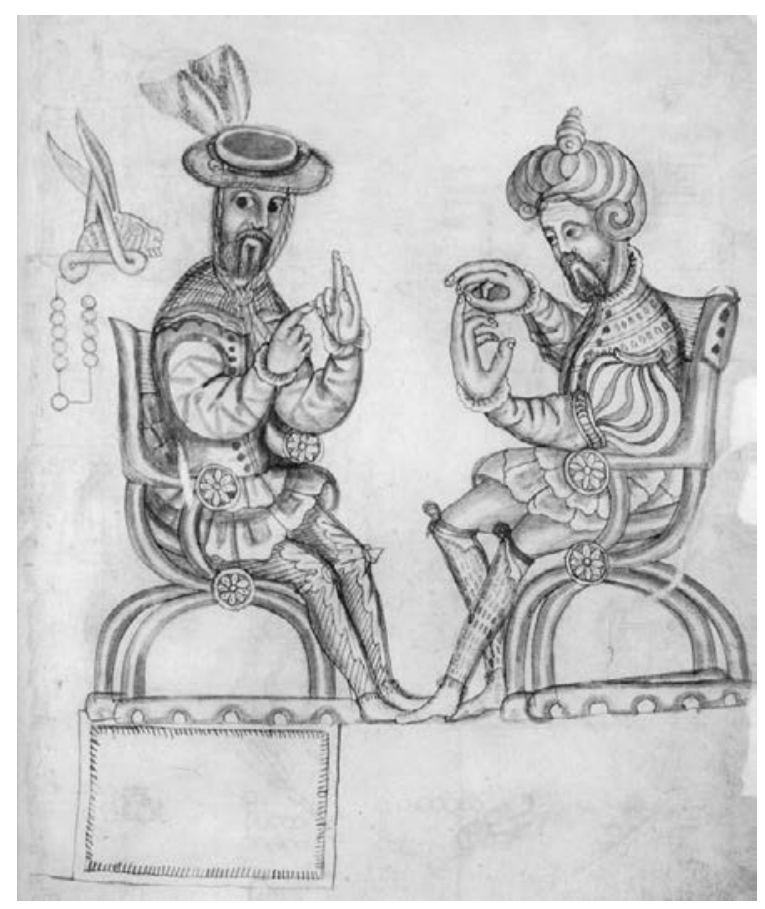

10.12. Codex Yodzo Cahi: the two encomenderos (SH: XVII).

In our reconstruction of the page order, the scene with the ruler on the mat (JM: XVIII; SH: XV) occurs shortly after that tragic event. It is likely that this ruler was Iya Namahu's male successor, i.e. his sonin-law, Iya Nuqh, 'Lord 6 Movement', baptized as Don Diego, from the dynasty of Yuta Nani (Chachoapan) and Yahua (Tamazola). Actually, the power passed on to Iya Namahu's daughter, Lady 2 House (Iyadzehe Coquahu), baptized as Doña María, who married Don Diego Nuqh soon afterward, but her role is diminished according to the colonial perspective. ${ }^{20}$ The place sign (blanket) clearly represents the Nahuatl name of Yanhuitlan, but is glossed as huey ñuhu yucundaa, 'the church of Tepozcolula', signaling the main missionary center at the time.

20 The family relationships and rules of inheritance are clarified in AGN Tierras 3343 and AGN Civil 516 (Pailles Hernández 1993b: 16). 
The cacique received special gifts on this occasion: a golden shield in the Year 9 Flint, i.e. 1528 (MG: V-27) and two spear-throwers in the form of coiling serpents in the year 10 House, i.e. 1529 (MG: III-14).

Twelve places are listed as the subject or allied communities of Yodzo Cahi (Yanhuitlan) at the time, which, by their position in front of the main sign of the town (and after the precious gifts), recognize the new ruler (JM: VII / SH: XVIII). The most easily identified are:

- Altar of Flowers: Chiyo Yuhu (Suchixtlan).

- Mountain of the Staff: Yucu Tatnu (Topiltepec).

- Mountain - Foot - Altar: Sachio.

- Mouth with Arrow: Andua.

Zarza's letter also announces a change of encomendero. In 1529-1530 due to political intrigues in New Spain politics, power was temporarily taken away from Francisco de Las Casas and given to other Spanish officials. This seems to be represented in the codex under the year 11 Rabbit (1530) in which we recognize Francisco de Las Casas on the left-hand side of the page and another Spaniard with a turban in front of him (JM: VIII / SH: XVII). The first is seated on the place sign, i.e. as the 'rightful encomendero'. Looking at the reader he makes a public statement, pointing with his right index finger to the two raised fingers of his left hand. The other Spaniard touches with his right hand index and thumb the second finger of his right hand. It is likely he is the infamous Juan Peláez de Berrio, who received large benefits and powers in Oaxaca - among them the encomienda of Yodzo Cahi - from his brother, licenciado Diego Delgadillo, one of the members of the Audiencia, which was set up as the new colonial authority, and, very hostile toward Cortés and his faction, ousted Las Casas from his possessions. ${ }^{21}$ Being from Granada, Peláez de Berrio is represented as a 'moro', an image that at the same time may include a covert criticism of his cruel, 'un-Christian' behavior. Further, the native historiography glosses over those internal conflicts of Spanish rule by suggesting a rather peaceful transition. The gestures of both Spanish men on this page stress the middle finger, which in this context probably refers to a second and intermediary position. Las Casas seems to say: "Here I appoint my temporal successor, the second encomendero", while

\footnotetext{
${ }^{21}$ Otte 1970; Pérez Ortiz 2003: 52-61.
} 


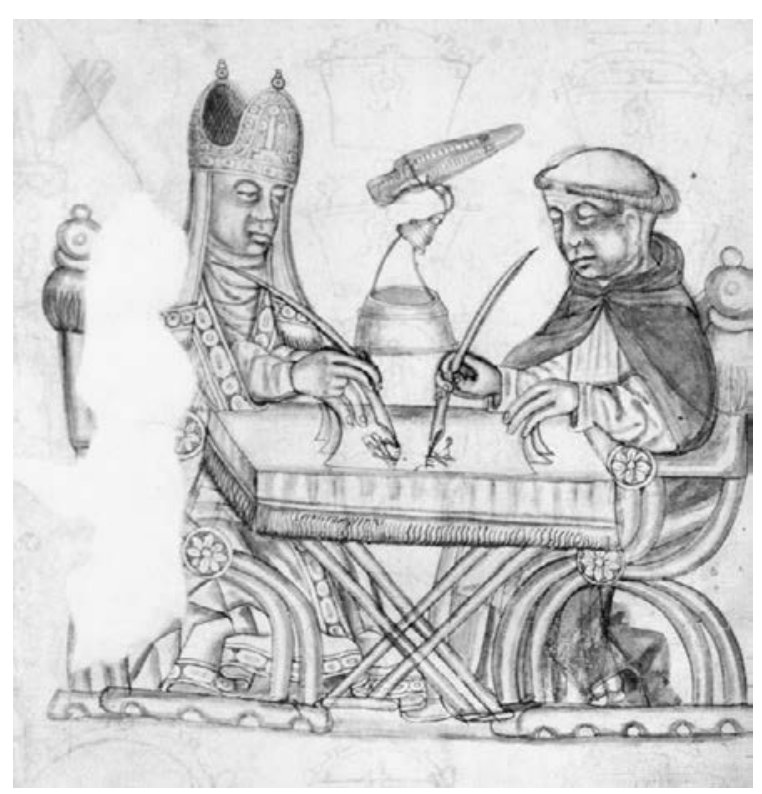

10.13. Codex Yodzo Cahi: the bishop and the Dominican provincial (SH: XXV).

Peláez de Berrio accepts this designation. Indeed the encomienda would return to Las Casas several years later.

In the Year 12 Reed (1531) the freshly appointed second encomendero demanded a major tribute: 18 buckets, which have a 'metallic' appearance and, therefore, may have been filled with gold-dust (JM: XIII / SH: XXVI). The number suggests that such a bucket had to be paid each of the 18 twenty-day periods (veintenas) of the year.

The next section, starting on the reverse side of the preceding page, focuses on the introduction of Christianity by Dominican monks. This is the background for what in the second half of the 16th century would become the magnificent monastery and church of Yodzo Cahi. ${ }^{22}$ A first step in this project was the signing of a plan by the bishop and the provincial of the Dominican order. Both are seated on chairs (being colonial authorities), at a European table (JM: XIV / SH: XXV).

${ }^{22}$ Ortiz Lajous 1994; Mullen 1995. A detailed monograph is the Ph.D. thesis of Frassani (2009). 
Already at the first capitulo of the Dominican province (1535) a strategy was designed to evangelize La Mixteca. Fray Domingo de Betanzos, the first provincial of the order in Mexico, heeded the request of the first bishop of Oaxaca, Juan López de Zárate and sent missionaries to that region. ${ }^{23}$ It is likely that these two men are represented here. Between them, suspended in the air, is a configuration of three objects: possibly a colonial pictographic identification of the bishop. If Nahuatl is used here as the language of reference, we might read the signs as a maize cob (eLOtl) and a pot ( $a P A Z t l i)$ with its cover, rendering the Spanish name lo-pez. At the time of the second capitulo (1538) a 'house' of the Dominican order was already in existence in Yanhuitlan and the decision was taken to continue and intensify the evangelization of the region. We see here the follow-up of the papal bull Sublimis Deus issued by Pope Paul III in 1537, recognizing that the indigenous peoples of the Americas were persons endowed with reason and capable of becoming Christians. ${ }^{24}$ The provincial elected at the third capitulo, fray Domingo de la Cruz, formalized the official foundation of the monastery in 1541, designating fray Domingo de Santa María to be the vicario. ${ }^{25}$ The latter soon started a building project.

In the Year 8 Flint (1540) and the Year 9 House (1541) two important local personalities - Lord 7 Serpent, whose sandals indicate that he had cacique status, and Lord 4 Reed, likely an assisting local noble (gobernador?) - are standing in the middle of an area delimitated by two rivers that join in the upper right-hand corner of the page (MG: $\mathrm{V}-40$ ). Corn grows in the area, suggesting that we are dealing with a specific stretch of fields. In the lower left-hand corner a place name is given: River of the Bundles of Rope or Fiber (Ixtle?), where a family is residing: Lord 7 Deer and a couple - probably his parents - Lord 10 Monkey and Lady 8 House. We might interpret this scene as the offering of a large plot of land by the cacique, gobernador and local landowners for the construction (expansion) and maintenance of the monastery and church. ${ }^{26}$ The cacique of Yodzo Cahi at the time was

${ }^{23}$ Burgoa 1934b, I: 280-281; Gillow 1978: 76-77. For an overview of the Dominican mission in Oaxaca, see the classic study by Wigberto Jiménez Moreno in his edition of the work of Alvarado (1962), as well as, for example, Díaz Nuñez 2006, and our study of the Mixtec texts produced in this context (Jansen \& Pérez Jiménez 2009b).

24 Pérez Ortiz 2003: 101-106; Zavala 1991.

25 Burgoa 1934b, I: 286, 290.

26 Compare the donation of land to this effect by Don Gabriel de Guzmán (Jiménez Moreno \& Mateos Higuera 1944: 34). The church and monastery were constructed on a large platform, on the South side of which precolonial temples had been located 


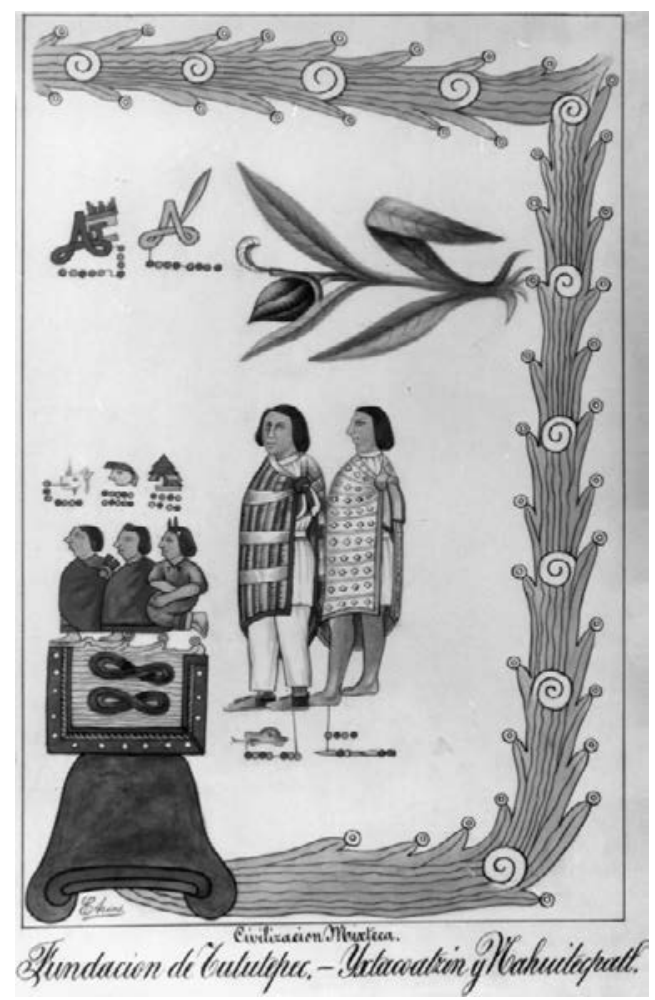

10.14. Codex Yodzo Cahi: the cacique (Don Domingo de Guzmán), a gobernador, and the land between two rivers (MG: V-40). Martínez Gracida identifies the scene erroneously as the foundation of Tututepec.

Don Domingo de Guzmán ( \pm 1510 - 1558). He was the brother of Doña María Coquahu and ruled after her death ( \pm 1540$)$ as a regent for her son Don Gabriel de Guzmán, who had been born in 1537 and was the legitimate heir to the throne (Spores 1967: 134-135).

According to Alonso Caballero's letter, however, Don Domingo de Guzmán succeeded his brother Calci (Scholes \& Adams 1961: 300). The latter statement cannot be correct, as we are well informed about don Domingo's immediate kin: Calci was not one of his brothers. Maybe Caballero just made a mistake, but it is also possible that his statement was derived from local information and should therefore be

(Sepúlveda y Herrera 1999: 140). The whole complex is indeed bordered by two small streams coming from the Eastern hills. 


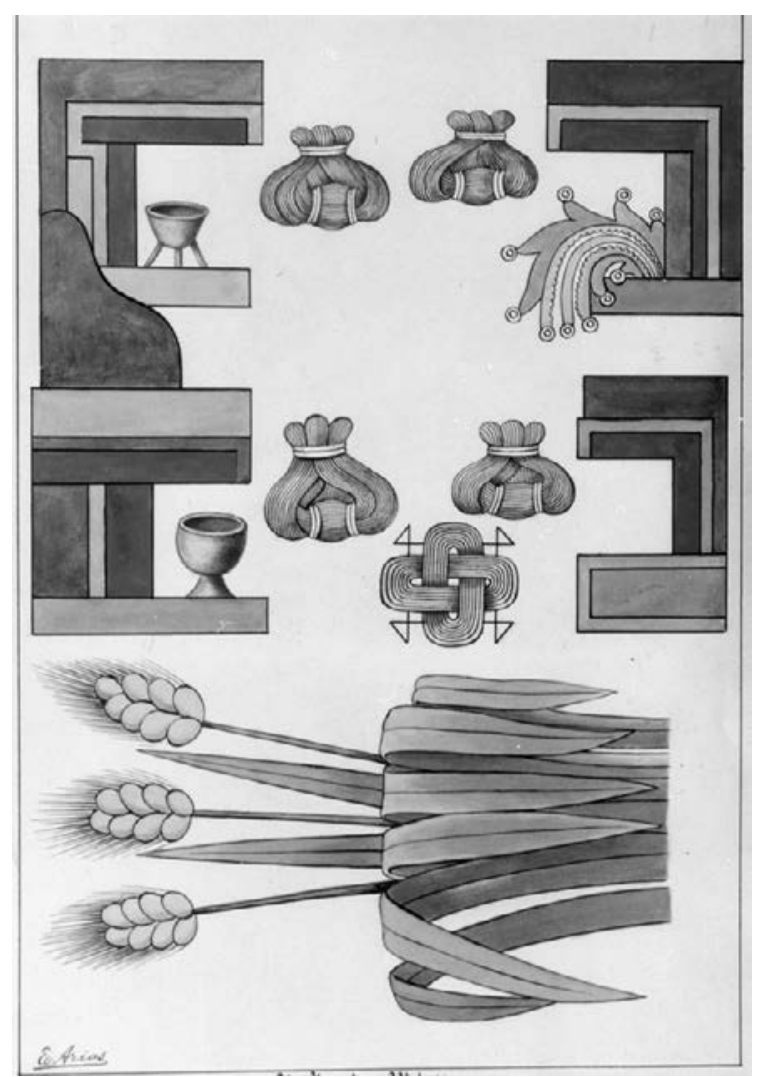

10.15. Codex Yodzo Cahi: four settlements, producing silk and weat (MG: V-42).

understood in Mixtec kinship terms. In Dzaha Dzaui the word for 'brother' (ñani) also means 'cousin', which may have caused confusion and thus the use of hermano ('brother') instead of primo hermano ('cousin') in the Spanish text.

The Proceso Inquisitorial of 1544 mentions Acace as predecessor and uncle (tío) of Don Domingo de Guzmán. ${ }^{27}$ It has been suggested that Acace is a misspelling of Calci. If Calci was indeed an uncle of Don Domingo, he was most likely the brother of Lady 1 Flower (Cauaco), Don Domingo's mother. On the other hand, Acace seems to be a rendering of the calendar name Acatzin, 'Lord Reed', which would make him a distinctly different individual. In that case the two sources may

27 Jiménez Moreno \& Mateos Higuera 1940: 15, 38; Sepúlveda y Herrera 1999: 117. 
be complementary rather than contradictory, as Don Domingo de Guzmán could have been the nephew of Acace and the cousin of Calci. In this line of thought, Calci might have been Acace's son and Lady 1 Flower Acace's sister. Definitive proof for either one of these scenarios should be looked for in the archives.

On the reverse side of the aforementioned page four houses, i.e. subject settlements or wards, are depicted (MG: V-42). In the upper row we recognize Molcaxtepec (House of the Tripod Bowl) and Axomulco (House of the Corner of the Stream), two estancias of Yodzo Cahi. In the lower row we find a third estancia, House of the Cup (?) and the glyph of Yodzo Cahi (Yanhuitlan) itself - the latter is clearly visible in the original but not well rendered in the copy in Martínez Gracida's work. The reference is to the local economy and supposedly to the maintenance of the church and convent, through the production of silk and wheat, promoted as 'cash crops' by the Spaniards from around 1540 onward. ${ }^{28}$

This was the time in which a new cult was introduced into the Nuu Dzaui region: that of the rosary, which appears in the codex as a large, impressive chain of beads. A four-fold bell connected to one end indicates the announcement of its importance to the four directions (JM: XV/SH: XXVIII). We notice the Mesoamerican art-work on the golden beads, stressing that this artefact (and the related practice) was assimilated into the native tradition.

The large rosary continues on the next page. An encomendero, whom we recognize as the very same Francisco de Las Casas, mentioned at the beginning of the manuscript, instructs Mixtec caciques in 'counting the precious necklace of the Lady', yocahui dzeque iyadzehe, i.e. telling one's beads, saying/praying the rosary (JM: XVI / SH: XXVII). ${ }^{29}$

${ }^{28}$ Spores 1967: 81-84. Compare the representation of silk in Codex Texupan (Códice Sierra), p. 47 ff (León 1982).

${ }^{29}$ Compare the representation of the rosary in codices Telleriano-Remensis, p. 46r, and Vaticanus A, p. 93r (Anders \& Jansen 1996: 366). The Dominicans were very much devoted to this special cult, which they promoted especially from 1538 onward (Fernández Rodríguez 1994: 164-165). For an overview of 16th century Spanish folk religion, see Christian 1981. A treatise on the miracles of the rosary was translated into the Mixtec language (see Jansen 1998). As Frassani (2006) has pointed out, a painting of the Virgin of the Rosary is a prominent part of the 16th century main altar-piece (retablo) in the church of Yanhuitlan. The encomendero Francisco de Las Casas played a dominant role in local religious affairs, much to the anger of the 


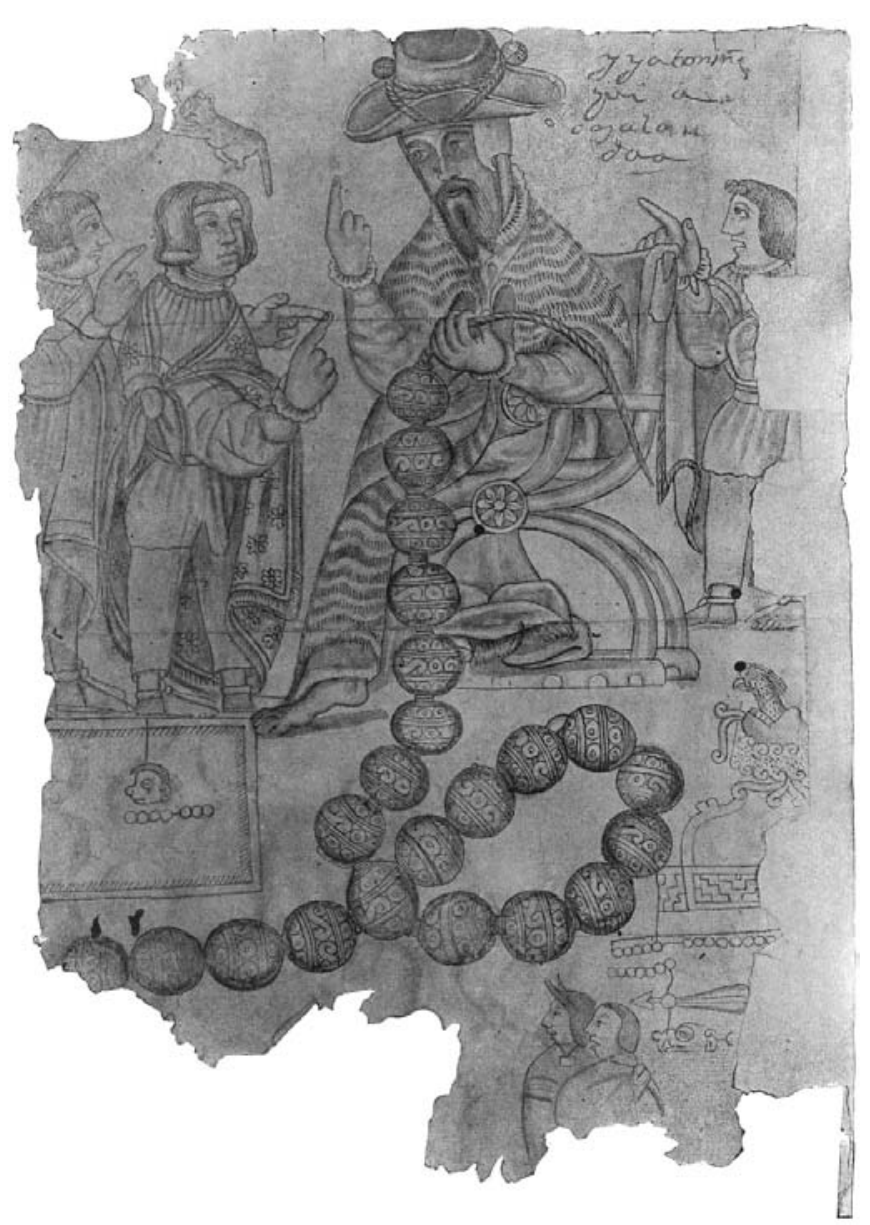

10.16. Codex Yodzo Cahi: the encomendero teaches the Mixtec caciques (Don Gabriel and Don Domingo) to pray the rosary (JM: XVI).

According to this reconstruction, the date must be at the beginning of the 1540s, most likely the first half of 1544 . On the Nahuatl place sign of Yodzo Cahi two caciques are standing (their status is indicated by this very act as well as by their elaborate clothing and their sandals). They would be Don Domingo (approximately 34 years old), on our left, and his nephew, young Don Gabriel (actually only 7 years old) directly in front of the encomendero. He is identified with the calendar

Dominicans: "él era obispo y papa en su pueblo" (Sepúlveda y Herrera 1999: 190, cf. $160,167)$. 
name Lord 7 Monkey and the native given name 'Jaguar with Torch'. ${ }^{30}$ Naturally, Don Gabriel is shown here in a central protagonist role because the codex really deals with his lineage, focusing on his direct ancestors: his father Don Diego Nuqh and his grandfather Iya Namahu. His cape is embroidered with floral motifs, as the dzoo yehe ita, 'cloth containing flowers', mentioned by Alvarado (Spanish: manta labrada).

On the other side of the encomendero a third cacique is mentioned, identified by a gloss as the ruler (iya toniñe) of Yucu Ndaa (Tepozcolula), whose calendar name is transcribed as qui a co, possibly Quihuaco, '4 Flower'. ${ }^{31}$

In the lower right-hand section of the page a reference is made to a noble couple associated with one of the subject settlements of Yodzo Cahi: they must have played a crucial role in the local introduction of the rosary cult.

Interestingly, shortly after, in the years 1544-46, the cacique regent Don Domingo was persecuted by the Spanish Inquisition and jailed in Mexico City because of his continued devotion to the ancient Nuu Dzaui religion. ${ }^{32}$ This codex implicitly contradicts that accusation by stressing the piety and loyalty of the local caciques.

Indeed, there was an important local conflict going on. In 1541 the encomendero Francisco de Las Casas, as well as the cacique Don Domingo and the local nobles, saw the building activities initiated by fray Domingo de Santa María as detrimental to their interests, burdening the local population and so interfering with their own collection of tributes and services. The resulting opposition made the Dominicans decide to leave Yodzo Cahi (Yanhuitlan) and to withdraw to their convent in Yucu Ndaa (Tepozcolula). ${ }^{33}$

${ }^{30}$ N.B. this is clearly an example of a well-known Mixtec personal name, which we also find represented in other codices. The formal similarity with the representation of the Dominican order in Spanish iconography as Domini canis, 'Dog of the Lord' (as suggested by Jiménez Moreno) is no argument for identifying the name of this person as Domingo.

${ }^{31}$ At the time the cacique of Tepozcolula was Don Diego de Orozco, whose son and inheritor, Don Diego de Mendoza, was born in in 1542 (Paillés Hernández 1993b: 20).

32 Sepúlveda y Herrera 1999; Jansen \& Pérez Jiménez 2000 / 2007b: ch. IV. See also Jiménez Muñoz \& González Medina 2009 for the general context.

${ }^{33}$ Sepúlveda y Herrera 1994: 34-35 and 1999: 153. 


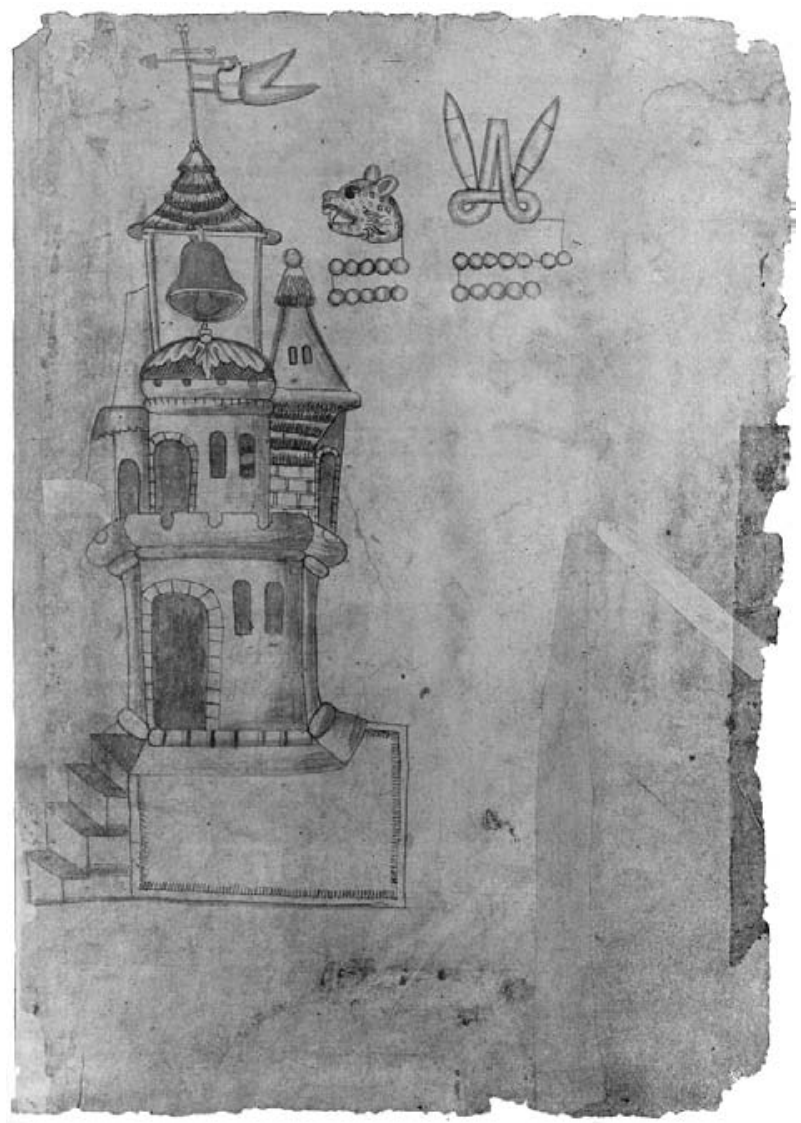

10.17. Codex Yodzo Cahi: the Christian town of Yanhuitlan (JM: XX).

The Codex Yodzo Cahi now seems to show that as a result of the cacique Lord 7 Monkey (supposedly Don Gabriel de Guzmán) being instructed in praying the rosary, an embassy was sent to the Dominican friars in Yucu Ndaa to convince them to come back. Possibly this group involved several people, including nobles from Mouth - Cactus (Atoco, Nochixtlan) and River of the Mole (Yuta Nani, Chachoapan) now shown on a scrap of paper (JM: XXIII/SH: XXXI). The leaders of this diplomatic mission were Lord 7 Deer and his father Lord 10 Monkey (also mentioned on an earlier page, MG: V-40), who present themselves to a Dominican monk, absorbed in his writing (looking the other way, i.e. still annoyed) in Mountain of the Axe (JM: XIX/SH: 
XXIX). The importance of the friar is clearly manifest in his disproportional large size vis-à-vis the Mixtec ambassadors. ${ }^{34}$

The outcome of the diplomatic mission sent to Yucu Ndaa was the triumph of Christianity in Yodzo Cahi: the Europeanized town is dominated by the church tower with its prominent bell and cross (JM: XX/SH: XXX). The date is Year 12 Flint, day 10 Jaguar, which corresponds to June 2, 1544 (shortly before the inquisitorial process against Don Domingo would start), or to February 17, 1545 (260 days later). Connected to the cross, a banner moves in the wind. Clearly the combination signals the Christian victory. In the Codex Texupan (Sierra), p. 39, such a banner appears as the symbol of Santiago, the Patron Saint of the conquest (León 1982). We also encounter the cross with banner in the pictographic catechisms (the so-called Testerian manuscripts) as an attribute of Saint John the Baptist and in the ideographic representation of the verb 'to liberate'. ${ }^{35}$ Thus, this sign may stress spiritual conquest, but at the same time it voices the religious desire for liberation.

\section{Sword and Rosary}

The main theme of the Codex Yodzo Cahi is the development of native rulership in colonial times. The protagonists are the caciques of this town. They did not operate in isolation but rather interacted with and depended on the community at large (symbolized by the toponymic sign). This relationship is represented (and implicitly legitimated) by the seat of authority (palace, mat and throne) and made explicit in the rendering of tribute. As an emblem for his people the cacique also takes positions vis-à-vis the Spanish authorities. Interestingly enough, the main ingredients of this theme are already present on the very first page of the manuscript.

The codex contains several scenes that may have been copied from earlier originals, such as that of the Noche Triste, which most likely comes from a Central Mexican source, and the lists of Mixtec place

\footnotetext{
${ }^{34}$ Cf. Wood 2003: 39. Compare the proportions of the encomendero and the indigenous ruler at the beginning of the codex (HB: E / SH: VII).

${ }_{35}$ Anders \& Jansen 1996: 87-88. For a dictionary of signs and an excellent overview of this interesting genre of an early colonial 'hybrid', or rather innovative, religious pictography, see Resines Llorente 2007.
} 
signs, which presumably reproduce locally available drawings. Most of the codex, however, is an original composition in a new style that integrates European representational techniques in ancient pictographic conventions. It is likely that this precious work was made for a special, official occasion within the life of one of the Mixtec caciques of Yodzo Cahi: a dynastic ritual in which memory, legitimacy and historical reflection were important ingredients. Given the absence of Ladies and couples, it is clear that the occasion was not a cacique marriage.

Reading the whole codex in its cultural and historical context, we see how the pictorial text makes most sense as a document of Don Gabriel de Guzmán: it stresses how his lineage was always very loyal to the Spaniards and immediately embraced the new order as well as Christianity, while at the same time mentioning his ancestral rights to rule the town and receive tributes. All this would be explained by the hypothesis that the codex was painted for Don Gabriel de Guzmán on the occasion of his official succession and enthronement as cacique of Yodzo Cahi in 1558.

That succession was not uncontested: Don Gonzalo, son of Calci, also claimed this inheritance but was not successful. ${ }^{36}$ Thus, the political background of the Codex of Yanhuitlan was also a covert rivalry between two intimately related dynastic lines: that of Don Francisco Calci (and his son Gonzalo) and that of Iya Namahu - Don Diego Nuqh - Don Gabriel de Guzmán (with his uncle Don Domingo de Guzmán temporarily acting as a regent). Both parties obviously tried to win the sympathy and support of the different Spanish authorities. Don Gonzalo received the sympathy of a local Spanish inhabitant, Alonso Caballero, who wrote a letter in his favor to the visitador Valderrama. The encomendero Francisco de Las Casas had a good relationship with the regent cacique Don Domingo de Guzmán, while Don Gabriel de Guzmán (probably remembering the inquisitorial persecution of Don Domingo in 1544-46) shifted his loyalty to the Dominican monks.

Thus the drawings of the Codex Yodzo Cahi refer to specific historical events, but also reflect underlying ideologies and cultural dynamics. By combining representational techniques from the two main cultures that entered into contact during colonization, the

\footnotetext{
36 Paillés Hernández 1993b: 21; Scholes \& Adams 1961: 300-301.
} 
draughtsman was able to create a multi-layered narrative precisely about the development of the complex relationships between people, institutions, values and interests of both worlds. ${ }^{37}$

Such a complex work demands an interdisciplinary approach. The very first page is a good illustration of that. Iconographical analysis permits us to identify the forms and primary meanings of the images (e.g. the decorated roof as a representation of - and a sign for - aniñe, the palace). The archeological dimension is the interpretation of palaces and plazas as stages for such social and political happenings. Ethnography informs us about the continued central importance of the people's assembly in the political life of contemporary communities. History provides other data to clarify the sequence of events and helps to identify the protagonists.

Using the tools for analyzing textual or visual works, we may go a step further. ${ }^{38}$ Taking into account that the European reading order tends to steer the perception or decoding of a figurative scene from left to right and top to bottom, we think it is significant that the first element in such a sequence is precisely the aniñe or palace of Yodzo Cahi (Yanhuitlan). This position corresponds to the thematic focus of the codex on rulership, revealed immediately on the first page.

On that first page we see further the designation of an heir to the throne, but at the same time a new 'social contract' between the ruler (claiming his traditional rights) and the people (a new protagonist) in the new time that starts with the colonial era. According to our hypothesis, the occasion for which the codex was produced was similar in nature, so that the first page registers an earlier occurrence of that ritual event, in the 'time of (new) foundation', providing a paradigmatic antecedent. The central action for this theme is the assembly, which takes place in the plaza in front of the aniñe. The assembly of so many people is a new element. Precolonial codices only give assemblies of nobles or rulers of subject settlements or neighboring villages. Here we see the antecedent of the 'asamblea popular', which would become very important as the heart of the decision-making (and sovereignty) in the 'república de indios' during the colonial time, as is still the case nowadays in indigenous communities. Interestingly, this new protagonist of local history, the people, is drawn in the new style

${ }^{37}$ On the conceptual and artistic interaction of Mesoamerica and Christianity see for example the profound studies by Gruzinski 1988 and Burkhart 1989.

${ }^{38}$ See for example the inspiring study by Bal (1994). 
(suggesting some form of European perspective as introduced by the Spanish), vis-à-vis the ruler in precolonial style. The painter situates himself and us behind this group, as part of the assembly. The central person in the front line acting on behalf of the people is indicative of the cargo system, which became so important in the colonized communities. A lot is implied here: those who carry the burden of the cargo become socialized by it and grow personally through it.

The indication of time in this scene leads us to consider not only the chronological correlation with a specific dramatic moment in historical time (1520), but also - in view of similar place-date combinations in the Nuu Dzaui codices, referring to sacred time - may be read as a new 'founding date' to be ritually commemorated. Being a colonial work, the Codex Yodzo Cahi, in contrast to the Codex Añute, disregards the long precolonial history of the Nuu Dzaui village-states and so creates a tabula rasa, on which the history of the new (colonial and Christian) epoch may be inscribed, or where the European stories about the past (including the whole biblical narrative) may enter as substitutes for native historiography. This setting of a new foundation moment and point of departure for cultural memory reminds us of the ideology of a new beginning in crisis cults. In fact, we see a prefiguration of this scene in the foundation rituals with their sacred days in Codex Yuta Tnoho.

On the other hand, the document's temporal structure itself remains firmly rooted in the indigenous tradition. It would have been easy for the author/painter to include a correlation for the dates as glosses under the year signs, but this was consistently avoided. In the whole work the indications of time as such are all in the precolonial system - the Mixtec year-dates and the signs of the months for paying tribute - as if the codex is saying that in spite of all political and cultural innovations, time itself has not changed. Similarly, all individuals are identified with their calendar names, without adding a gloss with the Christian name.

In the following pages we see the development of the place sign (emblem of the community) and the palace (rulership) of Yodzo Cahi in the early colonial period. First, the encomendero Francisco de Las Casas takes possession with the sword, a weapon that establishes intertextual links with the expansionist aspect of Christianity (symbolized in San Pablo), with the Patron Saint of the reconquista and conquista (Santiago Matamoros/Mataindios) and with San Miguel Arcángel who wins the apocalyptic battle against evil. Interestingly enough, this 
image of the encomendero would enter the popular imagination as $E l$ Gachupin, the Spaniard, i.e. the Devil.

The relationship of the encomendero and the cacique is clearly determined by the power of the first over the second. With the sword a Spanish chair (authority) is established, which now controls Yodzo Cahi (the place sign under that seat). Later the religious authorities (bishop, monks) are also seated on such chairs. The cacique may keep his traditional role (yuvui tayu, 'mat and throne') in a form of indirect rule, as long as he accepts the Spanish regime and cultural values (here visually indicated by the Spanish hat and beard). In this way, the painter, employing the Mesoamerican concept of 'being seated' as a metaphor for rulership, is able to express the complex nature of power in the colonial world: two types of seats refer to two forms (extensions) of rulership.

At the end of the codex the relationship between encomendero and cacique enters into a new phase, symbolized no longer by the sword but by the rosary. The young cacique, following the encomendero's teaching of this new cult, is again standing on the place sign: being a good Christian and accepting the rosary (both as an act of devotion and as a liturgical discipline) returns to him the right to rule the cacicazgo. In other words, Don Gabriel uses the Christian discourse to regain agency and at the same time to win the rivalry with Calci's son Don Gonzalo.

The same development is represented in the building that crowns the place sign. On the first page this is the precolonial palace, explicitly glossed as aniñe, but later it is substituted by the image of a European Christian town, a civitas dei, with the gloss huey ñuhu (huahi ñuhu in standard orthography), 'house of God' or 'church'. As in other similar pictorial manuscripts from this period, the bell (Spanish: campana) is prominently present in this image. On the one hand it will become a new marker of communal identity, on the other it documents, together with the daily discipline of praying the rosary, the introduction of European 'clock time' in the region.

In this process of change and adaptation the colonial cacique does not appear as a passive victim, but as an active protagonist, who makes interesting choices and influences the course of events. ${ }^{39}$ It is he who,

${ }^{39}$ See also Wood 2003 and the general comments by Gosden (2004: 25) on colonialism paradoxically often being a source of creativity, having a transformational influence on all parties involved. 
according to the codex, succeeds in convincing the encomendero of his devotion to the rosary and consequently succeeds in pacifying and calling back the Dominican monks. In adapting to Spanish fashion (hat, hair, beard), the cacique nevertheless retains his precious embroidered cape (Nahuatl: tilmatl) and his sandals. Consciously or unconsciously, the iconographic scheme points toward the head as the main locale of acculturation, while the body combines elements from both cultures (cape vs. shirt with trousers) and the feet remain firmly connected to the ancestral tradition and land (sandals).

The relationship of the cacique with his people is defined mainly in terms of tribute, which, in turn, hints at a system of redistribution. A first tribute category consists of food and related materials (wood, without doubt for cooking; spoons and plates, people to prepare tortillas and to help the cacique). Looking at present-day customs we immediately recognize this not as food for the cacique himself but as what is needed for the preparation of fiestas, especially of big meals, to which large groups of people could be invited. ${ }^{40}$

The second category is that of paired precious items, which were probably to be used by the ruler or ruling couple at the same fiestas (silver plates) and during the accompanying dances (flutes, headdresses). Finally, some very special and valuable gifts (golden shield and two staff-like objects in the form of coiled serpents) were meant to distinguish the persona of the cacique as adornments. The golden shield - similar to the famous 'escudo (chimalli) de Yanhuitlan' - contains the step-fret motif, qualifying the holder of this shield as the defender and protector of the $\tilde{n} u u$, the town and the people. Paired with the shield, the spear-throwers (atlatl), in the form of coiling serpents, may allude to the nahual powers of the ruler to be used for the same purpose in that ceremonial context. ${ }^{41}$ There is a strong sense of social ethos and aesthetic value in these objects, which contrasts sharply with the metal buckets that the Spanish authority demanded as taxes. $^{42}$

${ }^{40}$ Compare the interpretation of Mixteca Puebla style pottery by Hernández Sánchez (2005) in the context of feasting and ritual.

${ }^{41}$ The Proceso Inquisitorial (Sepúlveda y Herrera 1999: 126) documents the use of shields and flutes (rodelas y flautas) during traditional ceremonies. Seler wrote a classic article on ancient Mexican spear-throwers (1960-61, vol II: 368-396). For an image of the chimalli of Yanhuitlan, or rather yusa of Yodzo Cahi, see Spores 1997: 72.

${ }^{42}$ Gosden (2004: 36-39) discusses the contrast between (a) valuables and services that primarily express quality through social or religious associations, and (b) dematerialized and disembedded quantifiable objects (money). The first are part of living 
The same indigenous aesthetic drive becomes manifest in the religious sphere: the regalia of the bishop and the decoration of the beads of the rosary reflect the Mesoamerican artistic tradition and so become incorporated in the native worldview.

Read in its context, the Codex Yodzo Cahi provides a key to the cultural processes going on within the walls of the cacique residences. It is a profound indigenous reflection on the socio-political and mental changes taking place in the colonial period. Although it does not go the road of complete denial and resistance, which characterizes the Codex Añute (Selden), the Codex Yodzo Cahi contains a clear ideological perspective with many subliminal criticisms of the colonial condition. But at the same time it tries to build bridges, searching for a new religiously inspired social coherence (convivencia). Accordingly, it lays the foundation for a new cultural memory. Although no specific data are available about the circumstances under which these two manuscripts were created, we speculate that both had a similar function: to be presented at the appointment of an heir to the throne. If so, both reflect different attitudes among the indigenous nobles toward the 'new times' and different strategies for dealing with the past (and the future). Where the Codex Añute looks back to the precolonial roots and practices (suggesting a mood of nostalgia and resistance), the Codex Yodzo Cahi looks forward to the new order of colonial society. Precisely by breaking with the past, by manifesting obedience to the Spanish lords and by incorporating Christianity, it aims at continuing the ancient political structure.

The subdued people of Nuu Dzaui are not directly visible in this ideological discourse. They were the ones who really suffered the consequences of the colonial process: the violence, epidemics and discrimination that cultural contact brought, the deprivation that the extra payments to the encomendero implied, and the forced labor that was demanded from them to build the cacique's palace and the Dominican monastery, occupations which did not leave them time nor energy to cultivate their lands. ${ }^{43}$ After having been mentioned

social networks, the latter become vehicles for individualist structures of colonial exploitation.

43 "Asimismo los frailes de Yanguitlan persuadieron a don Gabriel, cacique del dicho pueblo, a que hiciese una casa muy suntuosa a fin de detener la obra del monasterio, porque si se acaba perderán los intereses que llevan a los indios y las sobras que les son mandadas dar. $\mathrm{Y}$ de hacer casa el cacique se sigue gran daño a los pobres porque .... ellos no tengan lugar a labrar sus tierras ni a ganar para pagar los tributos al 
prominently on the first page and more incidentally in the tribute pages, their absence from the rest of the codex is conspicuous and significant: dum tacent, clamant.

encomendero, porque les cabe a cada uno cuatro semanas cada un año ir a la obra de la iglesia y dos a sacar piedras a la cantera y dos a hacer cal y una al monte a cortar madera y otra a traer la cal al monasterio y otra coger zacate para los frailes y comunidad y servicios de frailes, caciques y comunidad, y seis a hacer las milpas del cacique hasta se lo dar encerrado en su casa y otras seis a los frailes en la milpa que siembran de trigo y maíz, pues si sobre lo que está ya dicho han de dar otras cuatro semanas a la casa del cacique, que no les queda a ellos tiempo para hacer ni labrar sus milpas, y a esta causa padecen necesidad muy grande los pobres. Y de todos estos tequios y obras no les dan paga alguna a los indios más de cómo se lo mandan los frailes y el cacique, así lo hacen, porque no hay por la parte de los pobres quien responda.” (Scholes \& Adams 1961: 301-302). 
Maarten Jansen and Gabina Aurora Pérez Jiménez - 978-90-04-19358-1 Downloaded from Brill.com@4/26/2023 11:36:13AM 


\section{CONCLUSION}

NUU TAYU:

THE SOVEREIGN COMMUNITY 
Maarten Jansen and Gabina Aurora Pérez Jiménez - 978-90-04-19358-1 Downloaded from Brill.com@4/26/2023 11:36:13AM 


\section{CHAPTER ELEVEN}

\section{POLITICAL AND IDEOLOGICAL DYNAMICS}

Reading what has been preserved of Nuu Dzaui historical records, we now understand that the pretensions of Don Felipe de Austria/de Santiago in the early colonial period were a logical continuation of the precolonial worldview, the heritage of Lord 8 Deer. Indeed Nuu Tnoo (Tilantongo) and its dynasty occupied a central role among the sovereign communities of Ñuu Dzaui, as far as the ancient historiography is concerned. Its position was not that of the capital of a large realm, however, but rather that of a site with special authority and prestige in a landscape of peer polities (the 'city-state culture').

Trying to make some generalizations about the contents of Mixtec historiography, we find that its immediate concern was the intricate web of relationships of lineages and polities, predetermined by the deeds of the Ancestors, and, on a higher level, the dealings of humankind with power. The codices, therefore, provide insights into the ancient Nuu Dzaui political dynamics and ideology. Characteristically the genealogical account starts with a place sign, often accompanied by a sacred foundation date. The place, being the seat of a Patron Deity and the locale of rituals, has strong religious associations, important to the ethos and identity of its inhabitants. This is the base for the seating of the first ruling couple. We read this imagery as an indication that actually the community was considered the true protagonist of history, the rulers being its representatives or emblems (yuhu nuu, 'mouth and face'). The attention given to their names, regalia, attributes, participation in rituals and family relationships, is to be read as an assessment of their correct behavior and moral authority. The rulers are the mother and father (dzehe dzutu) of the community, while the inhabitants are the children of the village (dzaya ñuu). ${ }^{1}$ Both the capital and the rulers are referred to with the term 'head' (dzini), while the secondary settlements and the subjects in general are ndaha saha, 'hands and feet', a term used for the executive force and its resources,

\footnotetext{
1 The Dzaha Dzaui terms are reconstructed on the basis of present-day expressions in Yuta Tnoho/Yutsa Tohon (Apoala): tadehe, 'father-mother' for the authorities and daha ñuu, 'child of the village' for citizens (López García 1998).
} 
but later translated by the Spaniards as 'slaves'. The inhabitants of subject settlements would address those of the main town (cabecera) as ñani nuu, sanu nuu, 'older brother, older sister-in-law'. ' We suppose that the iya toniñe and iyadzehe toniñe, the king and queen, of Nuu Tnoo were equally treated as ñani nuu, sanu nuu by those seated on other mats and other thrones.

\section{Regional Developments}

The historiography of Nuu Dzaui city-states, or rather village-states $(\tilde{n} u u)$, shows both individualizing and group-oriented tendencies, which likely correspond to the reality of the underlying social structures. ${ }^{3}$ The formation of social boundaries is manifest in the marking of the ruler's body with nice clothing, jade ear-spools, turquoise necklaces, golden jewels and quetzal feathers, in the distinction of the ruler's palace with fine stonework, mosaics and relief carvings, in the ornamentation of the ruler's tomb with paintings and funerary offerings. On the other hand lineage-history does not focus on the human individual as such but on kinship structures. All those kings and queens, though identified by name, are painted in the same generalizing manner, as incidental players of permanent roles within a communitarian ethos.

In an important programatic article, Blanton, Feinman, Kowalewski, and Peregrine (1996) point out two different but always coexisting political strategies in Mesoamerica: (1) the exclusionary rule, based on (the striving for) monopoly control of resources and locally exercised through a network of patron-client relationships, and (2) the corporate governance, in which "the distribution of power is structured, determined, legitimated, and controlled within the limits set by the prevailing cognitive code" (op. cit.: 2). The latter aspect has received less interest in modern archeological studies of archaic states, but is clearly very important in the Postclassic polities of Nuu Dzaui, where

\footnotetext{
${ }^{2}$ Such expressions were used by the people of Nuu Yoo who until recently used to contribute to the Patron Feast of Nuu Ndeya (Chalcatongo), the town that inherited the status of capital of the precolonial village-state to which Nuu Yoo also belonged (a relationship which continued until late colonial times).

3 This distinction, originally introduced by Renfrew, is discussed by Earle (1991: $3 \mathrm{ff}$.) and Blanton et al. (1996). It should not be interpreted as a fundamental opposition between different types of social-political organization, but as a dualism of different tendencies within each particular community.
} 
religious ethics determined the social ethos. The fundamental reality of the $\tilde{n} u u$ (city-state/village-state) was its political autonomy (defined as its yuvui tayu, 'mat and throne' and manifested in its ruling noble house) in combination with the need for economic exchange (implying long-distance trade, shared technologies and artistic styles). As a result the 'village-state culture' was a network of independent but interacting communities, each of which was internally structured around the noble house as a set of kinship and patron-client relationships.

Both the historiography and the ritual performance pointed toward the pivotal position of the ruling couple. As for its local dimension, the discourse focused on the narrative of the noble house in relation to the community, its sacred origin, its connection to the land, its pious compliance with ritual obligations, its heroic exploits and tribute rights. 'Propaganda' is not a good term for this important element of the social communication. Rather we may call it 'patrimonial rhetoric', as pointed out by Blanton et al. (1996).

The 'prestige good system' - another concept used by Blanton et al. - is an important dynamic that underlies the network of regional contacts, manifest in conquests and alliances. The main segment of the codices deals with the genealogical connections between the noble houses, as a chart for identifying prospective marriage partners and the implications of kinship policies as to heritage rights (tributes and other privileges). In accordance with this reading we may interpret the marital alliances (and the accompanying dynastic epics) not only as links between members of a large, supralocal ruling family but also as interactions between communities. Within the 'natural order' of the political landscape, these units related to each other as peer polities. Given the obstacles of the rugged terrain, distances and the lack of means of transportation (no carrying animals, no wheels) none of these settlements was capable of establishing a permanent hegemony. On the other hand, the ecological diversity promoted a system of exchange through markets cyclically organized on successive days among neighboring towns (in cycles of five days) and through ritual occasions such as religious feasts or royal marriages.

Internally the communities were composed of different social strata and interest groups (factions), not as separate independent and static 'essences' but as interacting dynamic forces. Rituals and economics created spheres of integration. Arthur Joyce (in his contributions to Hendon \& Joyce 2004 and Blomster 2008) has stressed the ideological 
component of this society and the ways its internal stratification uses (and negotiates) polyvalent symbolism:

Political formations therefore are historically constituted through the ongoing interaction of people of different social positions, such as nobles and commoners, women and men, urban and rural dwellers, and people of the core and periphery. Political systems, including ruling ideologies and institutions, are not simple reflections of elite interests imposed on subordinates. The outcome of the negotiation of power may bolster the social position of nobles, but it usually does so in ways that reflect some degree of compromise resulting from the interactions of varied social actors. Subordinates always have some degree of penetration of domination, which can be actualized by engaging with elites in ways that affect systems of domination.... (Joyce in Blomster 2008: 223).

It was in this "arena" that native writing and historical consciousness developed and became itself an active agent in the formation of society. Where archeological surveys show the process of nucleation and growth of primary centers, the pictorial manuscripts and oral traditions provide an emic perspective. In the Nuu Dzaui codices we find a specific narrative identity underlying and explaining the political relations between the different communities. Of course, this is an epic form of historiography, focusing on the aristocracy, without explicit attention to the 'common people'. The resulting narrative is an ideologically idealized memory, which is interesting as a mental construct of this culture, but which is not necessarily an exact and complete reproduction of historical and social realities.

The noble houses were all connected through marital alliances and symbolic markers as parts of one big family. The beginnings of this 'grand dynasty' are told as a creation story, shrouded in sacred mystery and metaphors: the First Rulers were children of Dawn, born from Earth or from the Sacred Mother Tree. The earliest historical data suggest that at the end of the Classic Era, around $900 \mathrm{AD}$, the region was a periphery or margin of the Monte Albán influence sphere. The historiographic focus was the developments in the Valley of Atoco - Yodzo Cahi (Nochistlan - Yanhuitlan) with primary centers such as Chiyo Yuhu (Suchixtlan) and Añute (Jaltepec). Nuu Tnoo (Tilantongo) looked to this rich and fertile plain from its mountain position in the South. The demise of Monte Albán itself was not recorded; it may have been the background for a primordial conflict, which led to the victory of a new generation of nobles over the members of the ancien régime, represented as 'Stone Men'. In the aftermath the princes of insurgent 
towns in Nuu Dzaui still looked to that ancient capital or regional center as a source of legitimation for their rule, marrying princesses who traced or linked their lineage to this iconic place of cultural memory. This probably reflects an earlier custom of connecting local power to the core through marital alliances. At the same time it is stressed that the new polity was integrated in an assembly of different locally important families. On an ideological level the revival and expansion of the cult of the Plumed Serpent, personalized as Lord 9 Wind, the Culture Hero, and venerated as a Sacred Bundle, was a driving force. Codex Yuta Tnoho therefore portrays this deity as the True Founder of the polities, the one who initiated the ceremonies of the New Fire. The sanctuaries of Yuta Tnoho (Apoala) and Nuu Ndecu (Achiutla), both in the Mixteca Alta, were the religious focal points of this 'crisis cult'. ${ }^{4}$

In writing down their history, then, the dynasties of the Postclassic did not present themselves as a continuation of the Classic predecessors but stressed that their own rule was a new foundation, indeed a new era with a new 'Sun'. This disjunction coincides with archeologically observable shifts of the primary centers within the village-states: a change of ruling family meant a relocation of the seat of power. ${ }^{5}$

It is interesting to compare this process to similar historical occurrences elsewhere. The end of the (Western) Roman empire in the 6th century AD also produced a political disjunction, accompanied by a break in ruling lineages. This relatively well documented case demonstrates that such a process is complex and takes more than one generation. For quite some time an internal religious revolution (from Roman religion to Christianity) had interacted with economic problems, ethnic upheaval and military conflicts (the migration of Germanic tribes, the invasion by the Huns etc.). Although there was some continuity in literacy, there was also a reorientation, part of the

\footnotetext{
${ }^{4}$ Cf. Jansen in Robles 2004; Jansen \& Pérez Jiménez 2007a. It is likely this 'crisis cult' was a Mesoamerican epiclassic phenomenon, producing a revitalization of ancient concepts and powers, such as the Plumed Serpent (cf. Ringle, Gallerta and Bey 1999). See also A. Joyce 2010: ch. 8.

${ }^{5}$ Arthur Joyce discusses archeological evidence for the disjunction in ruling strata and ideologies between Classic and Postclassic, concluding: "The regional data indicate that the Classic period collapse most dramatically affected rulers, ruling institutions, and the dominant ideologies that legitimated their authority.... The data from the lower Verde not only indicate the collapse of ruling institutions but also the denigration by commoners of objects, symbols, spaces and buildings associated with Lata Classic rulership." (in Blomster 2008: 240).
} 
general social-cultural disjunction, which produced a 'bottleneck' or rather a liminal period in memory itself. The end of state-controlled historiography and education paved the way for an era of sagas, such as those about King Arthur and the Nibelungen, which in turn became the foundation narratives for Early Mediaeval society. Episodes such as the War against the Stone Men or the Origin of Dynasties from the Trees in Yuta Tnoho, as referred to in Nuu Dzaui codices, likely belong to a similar liminal period.

The life and times of Lord 8 Deer and Lady 6 Monkey are an example of an epic tale, a dramatic composition of ambition and power. The text was probably recited during rituals of commemoration, which also served as a mechanism to create a narrative identity and so to integrate the communities. In this period the horizon widened to include the whole of Nuu Dzaui (Mixteca Alta, Costa and Baja) as well as important neighboring areas. The source of external validation shifted from Monte Albán to Tollan-Cholollan, the Toltec capital in Central Mexico, although major deities and shrines of the Ñuu Dzaui region, such as the Huahi Cahi of Lady 9 Grass 'Cihuacoatl' in Nuu Ndaya (Chalcatongo) and the Boquerón Cave of Lady 9 Reed 'Itzpapalotl' in Ñuu Niñe (Tonalá) continued to play a determinant part. This was a time of warfare, expansion and regional integration, the Sun God being the supreme symbol of power. From an overall perspective, looking at Mesoamerica as a 'World-System', we might point to Tollan-Cholollan as the core and interpret Nuu Dzaui as a periphery. ${ }^{6}$ Interestingly, the codices document the participants' point of view, focusing on the internal dynamics of the region and on the agency of local leaders such as Lord 8 Deer and Lord 4 Wind. From the peripheral perspective the process is not interpreted as the annexation of Nuu Dzaui by a predatory state but as the forging of a successful alliance. Where centralist historiography only refers to the Toltec ruler Lord 4 Jaguar (Nacxitl Topiltzin Quetzalcoatl) as a divine hero, the Nuu Dzaui codices show Lord 8 Deer as the protagonist who takes the initiative and the lead in

${ }^{6}$ In the past decades the World Systems Theory, originally formulated by Wallerstein to describe the expansion of (neo-)colonial empires and the capitalist economy, has become increasingly popular in archeological research, as an interpretive framework for studying large-scale interactions between regions. Core and (dependent) periphery are key concepts. Several authors have pointed out that major adaptations of the theory are necessary before applying it to precapitalist societies. See Kardulias 1999 for a theoretical discusion from different angles. 
their military campaign. A similar phenomenon is documented for the indigenous troops of Tlaxcala and Cuauhquechollan that participated in the Spanish conquest (Asselbergs 2004). Moreover the idea of rulership rooted in an assembly is incorporated in this presentation: a large section of Codex Tonindeye (pp. 54-68) is devoted to listing all the nobles from many different towns, who came together to install Lord 8 Deer on the throne in Nuu Tnoo.

In Toltec historiography (echoed in the early colonial sources from Central Mexico) Nacxitl Topiltzin Quetzalcoatl is described as a legendary and liminal figure: indeed the end of his life and rule coincides with a major political disjunction (the 'fall' of the Toltec empire). Nuu Dzaui codices, however, portray Lord 8 Deer, as a historical ruler, a Founding Father of lineages, a protagonist of impressive epics of clearly literary character, but not a liminal figure. This makes the account of the encounter and alliance between both very interesting.

Associating his realm with the Toltec imperial expansion, Lord 8 Deer may have adopted some of his ally's centralizing policies: he was probably the Flechador del Sol ('Shooter of the Sun') who truly founded Nuu Tnoo and he may have introduced the vision of this town as a primary polity within the Nuu Dzaui village-state culture. After having killed Lord 8 Deer, Lord 4 Wind followed in his footsteps, transferring the capital to nearby Nuu Yuchi (Mogote del Cacique). But as the Toltec empire came to an end, he would have lacked the external support to impose a form of centralized rule effectively, and the different noble houses, regaining political importance, would start reclaiming their local independence.

Marrying various wives, Lord 8 Deer also became the founder of several lineages, including those of Nuu Tnoo and Chiyo Cahnu. Their intensive interactions with each other and with other polities formed the genealogical-chronological framework for Nuu Dzaui history in the following four centuries. The choices of marital alliances reflect the geographical horizon of the sovereign communities. The demise of the Toltec empire - the collapse of the 'core' - is followed by a period of reduced agency: the polities look inward and have few if any longrange contacts. New sovereign village-states are founded, such as Chiyo Cahnu (Teozacualco), Nuu Ndecu (Achiutla), Ndisi Nuu (Tlaxiaco), and Yucu Satuta (Zacatepec). This was probably not a fission of existing polities, but the rise of new royal lineages, accompanied by a relocation of their capitals. Still, this signals a process of 
political fragmentation, fostering 'inward-looking' or 'isolationist' attitudes.

At the end of the 13th century this tendency changes with the marital alliance between Lady 4 Rabbit of Chiyo Cahnu and Lord 5 Flower of Zaachila. Then we find new ambitions and wider horizons again. The splendor of the funerary gifts that accompany the remains of Lord 5 Flower in Tomb I at Zaachila documents the wealth of the first half of the 14th century: beautiful polychrome vessels, incised bones, and golden ornaments. (Caso in Paddock 1966; Jansen 1982a). Another thrust forward is the expansion toward the area of Cuauhtinchan. All this leads again to regional interaction on a much larger scale. In the second half of the 15th century we see a counterpart phenomenon: the struggle against the invading Mexica and conflicts with the Beni Zaa (Zapotec) rulers in the Valley of Oaxaca, followed by the Spanish conquest (1521) and the incorporation of both the Mexica realm and the Ñuu Dzaui village-states into the Spanish colonial empire.

\section{Power and Interaction}

In our days it is common to analyze ancient rulership as based on control of strategic resources and trade routes, in combination with the coercion of people, mainly through military force and warfare, while ideological indoctrination and manipulation provide legitimacy. Ñuu Dzaui historiography, however, stressed other, less materialist, aspects of power. Land was not seen as a commodity but as the living space of a deity, the N $u h u$. The basic social-religious covenant was that those who venerated the divine Patron or true Owner of the place were allowed to use the land to plant and to harvest. In this context the ruler becomes an intermediary, or rather a connection, between society ( $\tilde{n} u u)$ and the sacred (ii). This makes the iya toniñe a pivot in the diverse domains of social life. Consequently the stories about creation and the common origin of dynasties as well as those about the dramatic destinies of Lord 8 Deer and Lady 6 Monkey have moral and religious implications. These early chapters of Nuu Dzaui history show a concept of power derived from the Divine Forces of Nature, from visionary encounters with the Ancestors and the Gods, from Sacred Places in the landscape, a power that is delicate and has to be treated carefully, as it may destroy those who wield it with ambition and arrogance. 
In addition, the genealogical register suggests that in the villagestate culture influence was exercised more through alliances than through military means and (the threat of) war. Delicate diplomacy, reciprocity and respect for important elders and neighbors were key elements for success. It is likely this goes back to the early chiefdoms in the region. Conflicts are inherent to political organization, but, as argued by Drennan (in Earle 1991: 279-285), the struggles between those ancient communities did not arise over the possession of land, but rather as the consequence of status rivalry between the leaders. Drennan concludes:

However important warfare may have been in playing the chiefly game, it was not important in the processes that wrote the rules. (Earle 1991: 280).

Similarly in a non-monetary and non-accumulating economy, the receiving of tribute also meant its redistribution, i.e. generally in the form of gifts, which were an investment in social relationships. Reciprocity, often ritualized, was the corner-stone of the system, the underlying moral principle of tributary obligations, gift-giving and even honest bartering in the market. This behavior found its logic not only in kinship relations but also in the landscape. From very early times the Nuu Dzaui economy must have been determined by the vertical differentiation of production, which naturally promoted a mutual dependency and symbiosis between the cold mountainous areas of the Highlands (above 2000 metres a.s.1.) and the tropical zones of the deep river gorges and the coastal lowlands. ${ }^{7}$ Specific resources such as salt or obsidian, as well as local specializations in craft production (ceramics, basketry, weaving) certainly gave additional impulses to the exchange networks. Getting small precious objects (jade, feathers, gold, shell, turquoise) from far away was crucial for expressing high status, but by definition was a limited affair. As Drennan rightly observes:

Trade or exchange at long distance, then, provided the plumes of the chiefly peacock, not its basic diet. (in: Earle 1991: 281).

Instead, Drennan concludes, the main motor of social stratification in Oaxaca was the mobilization of resources toward public work programs designed to create communal ritual spaces, which later became

\footnotetext{
7 See the article on 'Irrigation and Ecological Complementarity in Mixtec Cacicazgos' by John Monaghan (in Marcus \& Zeitlin 1994: 143-161), A. Joyce 2010: ch. 2, as well as Katz's study of Mixtec meteorology (2008).
} 
points of departure for the development of state institutions. We see both the construction activities and the regional interaction as expressions of community agency and integrating force. These two aspects were already manifest in the Preclassic, and became a hallmark of Mesoamerican civilization, promoted by the expanding influence spheres ('empires') of Teotihuacan, Cholula and Tenochtitlan. In the social dynamics both individualizing tendencies and corporate cohesion play a role:

A corporate strategy emphasizes collective representations and the accompanying ritual based on broad themes such as fertility and renewal in society and cosmos. The corporate strategy is thus able to transcend the scale and scope limitations of patrimonial rhetoric, which emphasizes the controlling roles of particular individuals based on gender, generation and primacy of descent from common ancestors. A cognitive restructuring involving transcendent themes of cosmic renewal not only allows the incorporation of disparate ethnically defined subgroups but also legitimates the appropriation of surpluses of primary production, especially agricultural goods... (Blanton et al. 1996: 6)

Pictorial writing - and its public performance - probably played a major role in the process of local and interregional communication and network forming. The recitation of such texts was an essential part of community rituals and therefore of the construction of corporate identity. At the same time codices are easy to transport; so, they would have permitted the communication of narratives and ideas over linguistic boundaries. The use of the same stylistic and iconographical elements as decoration on items of material culture throughout Mesoamerica, specifically on the so-called 'codex-type ceramics' of the Postclassic, indicates that the entire cultural region shared one symbolic language and took part in a more or less unitary intellectual discourse and common value system.

The precolonial scriptures - a particularly telling example is Codex Yuta Tnoho - are not primarily concerned with the extension of the lands of each $\tilde{n} u u$ (village-state), but mention different outstanding centers with their sacred dates and foundation rituals. The emphasis is on the central sanctuaries and the related seats of rulership. The giving of precious gifts expresses respect and gratitude for specific services, counsel or help, and is generally part of (re) affirming a bond or alliance. Clearly, economic resources played their part in history, but the main focus of the manuscripts is the warp and woof of family relationships. We are reminded of the importance of $d z a h a$-relation- 
ships in contemporary communities: the term $d z a h a$ stands for a ritualized obligation of mutual assistance and reciprocity. As an obvious continuity of a pre-monetary stage and morality, people invest in relationships: whenever necessary (e.g. in the case of feasts or similar family occasions) they help other members of the community with (consumption-) goods or services, certain that they will receive the equivalent when they need it. Through sharing a specific responsibility in the religious sphere, such a relationship may take the form of ritual kinship. Today this is modeled on the function of godparents at a baptism ceremony and is known as compadrazgo.

Marriages are the example par excellence of occasions for dzaha. Dynastic marriages, therefore, are to be considered true alliances between sovereign communities with important consequences for commitment to loyalty and mutual support. Other forms of contact and interaction must have complemented the marital alliances. The bride or groom who left her/his own 'house' to live in another polity was probably accompanied by personal attendants and counsellors, and must have gone back regularly to her/his home-town to participate in rituals and important family events. At the same time s/he received part of the inheritance of her/his parents, which led to a continuous connection with the tribute paying vassals of the original estate. These personal relationships functioned against the background of cycles of supralocally important rituals, pilgrimages, markets and long-distance trade, which brought about a religious-economic integration on a regional level. Cultivating such interactions and relationships was a crucial part of the village-state culture.

The social reality of contemporary communities shows that such a system in practice may also be abused and may rapidly degenerate because of ambitious manipulation, competence, envy, and backstabbing factionalism. It is likely that such problems were already present in the precolonial era as well, and only became worse with the longterm negative impact of colonialism.

The genealogical history introduces a time depth of many generations, which permits a long chronological perspective. There is no dramatic emotion here, but a calculated framework for the politics of the noble houses. Generally lineage-historiography followed the line through the first-born son, but the intricate web of marital alliances also made it possible and necessary to follow the other lines. By including parentage statements for the wives, the codices register not only the male line 
of descent but also, in a more implicit way, the female line. Thus the record obtains the intertwined structure of a woven mat. Indeed, this is the central symbol of both marriage and rulership.

The choice of a partner was determined by the parents and confirmed by those who acted as the marriage ambassadors, the wise elders of the community, the prefigurations of the present-day padrinos and madrinas. According to Nuu Dzaui custom the parents of the prospective groom took the initiative, and those of the bride held the key to the outcome. Therefore in the negotiation both parties, that of the man and that of the woman, were equally important. Although at first sight it was the father of the crown prince who appeared as the great planner of the alliance, present-day practice makes us suspect that in reality it was the mother of the future queen who decided. While the stories of the great kings and queens were recited and performed in the plazas of the ceremonial centers, dynastic policies with their alliances and marriages were discussed and planned around the central fireplace of the royal residences. This realm of the hearth was probably the sphere of female action and decision-making. We should not idealize this situation, however. The assembly that came together for the offering of royalty was an exclusively male affair, indicating that men controlled the public sphere of power. Moreover the fact that princesses were often very young at the time of getting married indicates that there was no real concern for their personal will or opinion, much less a concept of individual development. Arranged and forced marriages seem to have been the rule. Just as in other early state societies the young couple had to subject personal considerations and feelings of love to dynastic politics, the age-old paradigmatic structure of relationships between the noble families. Only thus could the rights and privileges of the mat - symbol of marriage and of power - be obtained. Self-realization was produced through self-sacrifice. A similar message was contained in the rituals that each generation had to perform: the invariable sequence of penitence and visionary experiences was the spiritual backbone of royalty, mediating between the community and the Forces of Nature in their age-old covenant. In general this type of historiography must have imbued the members of the royal family with a sense of belonging and commitment.

The position of the rulers, then, was to a large extent based on the way in which they succeeded in investing in their relationships with others, both inside their realm and abroad, through family ties, gifts, ritual kinship and dzaha. The same holds for the different $\tilde{n} u u$ (village- 
states) themselves, which did not derive their prestige and influence from coercive force, but from being a node in a complex interactive system. A graphic representation of this arrangement is found in the Map of Chiyo Cahnu: the main town is the place where all roads unite. In order to be successful the village-state had to be a node of marital and other political alliances, a node of trade routes and vertical economic exchange, a node of pilgrimages and, last but not least, a node of stories told to the future generations, a node in the narrative identity of the region and the people.

Thus kinship, both real and ritual, was a crucial element in Nuu Dzaui political thought. It was the model for power structure within the village-state itself as well as for the regional interaction between the polities. We now understand that the genealogical accounts are much more than a family history. On an ideological level they document the kinship-based worldview of the village-state culture: this was a landscape of autonomous units, all governed by their own dynasty, but at the same time all ideally connected through bonds of brotherand sisterhood.

On the one hand we may interpret these dynamics as moving toward social harmony, as functionalist interpretations within anthropology would suggest. The corresponding Dzaha Dzaui concept is huii ndaa huii nani (today: vii ndaa vii nene), a difrasismo that expresses the beauty and peace of good relationships. On the other hand there were - and are - many seeds for conflict, especially in the sphere of political and economic interests. Precisely the focus on family relationships, coupled with split inheritance, must have been a permanent source of rivalry, gossip and quarrels between individuals, factions and communities. In the sovereign community harmony and conflict are just two sides of the same coin, creating permanent tension as well as a strong bonding. ${ }^{8}$

The hendiadys yuvui tayu, 'mat and throne', expresses both aspects of power, as represented in the codices: the importance of the network, symbolized by the mat (yuvui), and the inheritance of central authority, symbolized by the throne (tayu). The first aspect was dominantly a female sphere of action, while the second concerned mostly, though not exclusively, the males (first-born sons). As one could not exist

\footnotetext{
${ }^{8}$ Compare the famous discussion between the opposed (and complementary) interpretations of Mexican community and family life by Robert Redfield and Oscar Lewis (Hewitt de Alcántara 1982).
} 
without the other, however, power became represented as carried by an undivided couple, seated on the mat and the throne of the community $(\tilde{n} u u)$.

\section{Noble Houses and Communities in Colonial Time}

The years immediately after the conquista constituted a period of conflict and armed struggle between Spaniards and Native American peoples, immediately followed by devastating epidemics, demographic decimation and the collapse of the native economy. In combination with the predatory and depreciatory nature of colonialism, this led to a tragic destruction and degradation of Mesoamerican civilization. Deprived of its sovereign thinking, its creativity and self-development, the native community fell into a culture of misery. As a consequence alcoholism - which may have been under strict control in precolonial times - became wide-spread, brutalizing all behavior, while male chauvinism (machismo) subjected women and girls to domestic violence, social marginalization and other kinds of oppression and abuse. Cultural traditions, no longer reformed and adapted to a developing society, lost most of their inspiring force and became a strait-jacket, invoked to legitimize the interests of dominant groups and to oppose change and emancipation.

On the other hand a complex process of contact, acculturation and symbiosis of peoples, languages, cultural traditions and ideologies resulted in new cultural expressions and social forms. Interestingly enough, the landscape of autonomous communities ( $\tilde{n} u u)$, the villagestate culture of the Postclassic Era, in many cases remained in place. The 'mat and throne' was now identified as a cacicazgo structure and reinterpreted in terms of the feudal control over land and resources. Today the term cacicazgo remains in use for patron-client systems in Mexico and other countries, and, as such, plays a major part in the discussions about modern Latin-American society. The evolution and actuality of this institution, therefore, is both an interesting frame of reference and a challenge for interdisciplinary research on the development of the relationship between rural communities and the state in the Americas.

Historically it can be shown that the precolonial ruling families were not exterminated, but in fact underwent a complex transformation. The Spanish replaced the top of the Mexica empire with their 
own colonial administration and often left the lower authorities and local caciques in charge. These, after some initial resistance, adapted in a relatively quick and easy way to the colonial administration, which was founded, of course, on European feudal concepts. The native nobles converted to Catholicism, as the legitimizing ideology of the new world-system they had now become part of, and, as 'His Majesty's loyal and pious vassals', they tried to maintain their most essential privileges as hereditary local leaders, shrewdly using the existing work-ethos and traditional obedience of the people. In this way they proved themselves to be indispensable as brokers and middlemen in this variant of indirect rule, much needed by the colonial empire.

Nuu Dzaui artists kept producing pictorial manuscripts during the latter half of the 16th century, partly continuing the precolonial tradition, partly in an innovative way, incorporating European artistic elements and techniques. Their attention shifted, obviously, according to the new reality and focused on the relations between colonizer and colonized, as well as on their position in the new legal framework. A clear consequence of this shift was the thematic disjunction with the precolonial 'cultural logic of power': the story of Lord 8 Deer and Lady 6 Monkey fell completely into oblivion. The legend of the 'Flechador del Sol' may be a late and distorted echo, product of recalling ancient dramatic performances, but the ancient tragedy about power did not survive in oral tradtion, nor was it recreated as literature in the new Christian context (as happened to the stories of Beowulf, King Arthur and similar legendary heroes). Clearly the transformation of the native aristocracy and its worldview had been so profound and dramatic that the colonial caciques did not cultivate this ideology-laden memory of their past any further.

As colonialism and Spanish education advanced, the codices gave way to alphabetic texts. Writing in Spanish or in their own languages with the new, phonetic script, the indigenous ruling families produced documents in order to claim their privileges, translated into the terms of the new order. Also the communities, organized along the lines of Spanish cabildos and municipios, started to manifest themselves as relatively independent units, defining their territories, protesting against abuses and creating a rather egalitarian ethos of defense at the grass-root level. Much less do we know about the native priests: lacking any official structure and finding their ancient knowledge outlawed, many probably gave up, but others remained active with a low profile as nahual guardians of the community and healers (curande- 
ros), blending the tradition with the new faith into a fascinating syncretism. Native society, thus, was not decapitated nor killed, but transformed and adapted to a new era.

John Chance has admirably reconstructed this blend of interactions, changes and continuities in relation to the noble houses of Tecali in Central Mexico:

In prehispanic times all the nobles resided in a nucleated settlement that contained separate barrios for each teccalli. Yet the noble house as a whole had no geographical unity nor precise boundaries, for its land and commoners were scattered about the countryside, intertwined with those of other houses ... Indeed I have argued that prehispanic Tecali was a society based on personal loyalties, and that the more territorially oriented system of pueblos and barrios that arose in the colonial period was contingent on the political eclipse of the noble house and the decay of many of the interpersonal ties associated with it.... Yet aspects of its internal organization were reproduced as vital elements of the colonial Indian culture: the sense of a shared estate among related nobles, cognatic descent from founding ancestors, bilateral inheritance, strong sibling ties and patron-client relationships between nobles and commoners. (Chance 2000: 499).

The cultural-historical restructuring is reflected in the native manuscripts that were produced during the colonial period. They shed light on the transformation of the 'mat and throne' into the colonial cacicazgo, and on that of the precolonial noble, closely related to the Gods, into the acculturated cacique, as well as on the relations between the native communities, its nobility and the Spanish colonial administration in general. Often these documents contain an internal stratification, in which an original precolonial layer of information is reformulated and reinterpreted from an early colonial perspective. This is clearly reflected in early colonial pictography: the cacique wears Spanish clothes (instead of the prehispanic insignia), identifying with the new, dominant culture, and he sits on a Spanish chair (instead of on the 'mat and throne').

The Spanish conquerors brought with them an ideology of male chauvinism, an outcome of the value put on military force during the Reconquista (the war against the 'Moros') and Conquista, in conjunction with the patriarchal tradition of Classical Antiquity and Catholicism. This led to further marginalization of women. In the genealogy of the Tira of Yodzo Yaha, for example, we note that, contrary to precolonial practice, the names of most Ladies are left out: 
a clear indication of their diminished importance in the male-dominated politics of colonial society.

The social, economic, religious and political impact of the conquest also led to changes in the settlements. Often the primary center of authority was relocated and the population recongregated. The temple-pyramids were torn down and churches were erected. In collective memory the place for the new sanctuary was chosen by the Patron Saint, often after a specific itinerary, in a similar way as the Plumed Serpent had created and indicated the Postclassic seats of power. Such stories may also contain precolonial symbolism. Contemporary tradition in Nuu Ndeya (Chalcatongo), for example, situates the appearance of the Patron, la Virgen de Natividad (whose fiesta falls on September 8) in a bush of tule reeds and connects the construction of the church to a child sacrifice (probably an imaginary memory):

The Virgin of our village came from Nuyoo it is said. There she was going to be (i.e. to have her sanctuary); therefore she still has her banana plantation there in Nuyoo. But she did not want to remain there and so she arrived at the site where our village was before. There she was going to be, but then she did not want to stay, although people already were building a church for her there. She left and went from one place to the other. People were looking for her, but she had gone. And as she was walking around, they found her in a spot where tule reeds were growing, precisely there where now the church stands, a round place of dark tule reeds. When the people arrived they found the Virgin in the middle of those tule reeds. They took her (image) back, and she went with them. But suddenly she was not with them any more; she had returned to the tule place. Therefore they built her church on that spot, it is said. And when they were constructing the church they put a child there, a little boy. They made him sit down there, heaped fruits on him and built over him, so he remained there (in the foundation), it is said.

One of the interesting and unexpected consequences of the Spanish rule was the legal status and relative local autonomy granted to the native communities as repúblicas de indios. As these slowly grew in power, many managed to become safe havens of tradition. The pressure of the conquests and associated incorporation, first by the Mexica and then by the Spaniards, caused the precolonial village-state culture to go back to its egalitarian roots and to develop a stronger sense of ethnic identity. Thomas Hall observed the same phenomenon regarding the Diné (Navajo):

While language, customs, and some vague sense of being the same 'people' predate the arrival of Europeans, a strong Diné-wide identity 
was only created in the course of interaction with succeeding European invaders. A formal tribal government was a twentieth-century Navajo invention, which was developed, I would add, precisely to deal with incorporation into American society and the capitalist world-system. (in Kardulias 1999: 12).

In this process, the interplay of the native aristocracy and their tributary communities gained a new dimension. Already in precolonial historiography a distinction had been present: the Mexica ruler Motecuhzoma traced his dynastic rights back to the Toltec ruler Quetzalcoatl, but his people, organized in cult- and family groups (calpulli), situated their origin in Aztlan, a kind of projection of their capital Tenochtitlan back into the past, a symbol belonging to the sacred time of origins. But in the colonial situation this distinction deepened. As the communities started to become protagonists of history too, the native nobility integrated itself definitively in the colonial system, in order to preserve at least some of its prestige and position. The social and mental changes demanded a renewal of the legitimacy regarding the power and privileges, the control over land, population and tributes.

In his detailed analysis of the status of the early colonial Nuu Dzaui caciques Ronald Spores already concluded:

The breakdown of central authority in the pre-Conquest empires was not carried over into the local community kingdoms. In these areas, following the initial shock of conquest, there was a rapid adjustment to the imposition of Spanish dominion. At the community level native political institutions survived with a high degree of continuity during the sixteenth century... Many facets of native life, such as formal religion, militarism (characteristic of certain areas, but not of others), and a strong merchant class were suppressed, but the Spanish gave active support to a traditional inclination and ability of the Mesoamerican Indian to govern themselves... Only the directing force at the top of the hierarchy had been shifted or extended. Whereas power in pre-Conquest times had been vested in local kings or princes, the chain of authority now extended from the local cabildo, governor, or cacique through an alcalde mayor or corregidor to the viceroy and audiencia and, ultimately, to the Spanish Crown. From the standpoint of the native in the Indian community, however, authority descended from the traditional source, the native lords, princes, or caciques, and the supporting nobility. (Spores 1967: 119-120).

The native community (república de indios) was recognized as such under colonial rule, but had to rely on its internal social cohesion 
(collaboration, reciprocity and other communal mechanisms) in order to defend itself against abuses and exploitation. The colonial administration imposed the notions of continuous territoriality and the possession of land as a commodity, a territory that was circumscribed and could be owned and sold by individuals. These concepts introduced from Europe made it necessary to define the frontiers of the communities. Invading entrepreneurs made the communities rapidly and painfully aware of the need to entrench themselves behind clearly drawn boundaries.

This not only created many conflicts between communities but also implied a new relationship with the cacique. The precolonial and early colonial sources generally refer to the tribute obligations and to subjects that worked the dispersed lands of the noble lords ('personal bond'), but in the later colonial documents the owned land itself, and especially the circumscribed territory of a community ('territorial bond'), occupies a central place.

The república de indios became the new manifestation of the sovereign community: a structured territorial unit, under the protection of one Patron Saint. Interestingly enough, the native república regained the position of a central historical agent. The focus of the documents moved back from the iya to the fundamental locale or primordial protagonist of the events, the community. The royal palace (aniñe) became the municipal palace (still known as anii). This phenomenon is well documented in Nahuatl colonial sources:

$\ldots$ in these documents was enshrined the local vision of history, of corporate integrity, and of the nature of the corporate landbase. This vision, when integrated firmly in a context provided by other Nahuatl and even Spanish records, is a revealing one for those of us who seek to understand the Indian municipality as a landholding entity...

Without a landbase a town could not survive, either physically or spiritually. The active preservation of these older traditions fortified the municipal bodies as they struggled against mounting challenges to their corporate identity. (Haskett in Ouweneel \& Miller 1990: 137-38).

A series of lawsuit-acts and legal documents accompanies this fascinating transformation, which is at the base of the complex present-day political structure of Mexico. There are also many Native American testimonies written in Spanish or in Amerindian languages (using the introduced alphabet). An interesting colonial product is the group of so-called títulos primordiales, land-titles, created as a new form of communal indigenous historiography. In early colonial times, there is 
still a connection between community and indigenous aristocracy (the cacique often functioning as gobernador). Some dynastic precolonial histories were reused as land-titles: the names of the toponyms that mark the borderline were inscribed on them. Other 16th century indigenous documents, such as the Map of Chiyo Cahnu (Teozacualco) or the Lienzos of Guevea and Petapa, combine the genealogical structure of precolonial historiography with a geographical representation of the community and its lands. ${ }^{9}$

Here again we find that the socio-political and ideological disjunction of Early Colonial times was accompanied by a liminal period in memory. The process is less clear, however, due to the fact that historiography was hispanicized and therefore completely changed focus, format and language. The Mesoamerican historical experience became as marginalized as the Mesoamerican peoples themselves. The imposition of a new religion (Christianity) implied new rituals, new sacred dates and new stories, which replaced the ancient narratives. Still, in order to be acceptable to the native peoples, these new introductions had to be translated into and adapted to the pre-existing visions and mental frameworks of the great Mesoamerican civilization. Cultural interaction produced complex and often occult forms of syncretism and continuity. Thus several, more indirect witnesses of this traumatic transformation may be found by close reading the documents produced by native authors and by analyzing in depth the symbolic layers of oral literature. Figures such as the Ayuuk (Mixe) hero Condoy, but also the new image of a 'devil' in the form of a dark and fear-inspiring Spanish horseman (El Gachupin, 'the man with spurs') belong to this sphere.

A particularly interesting symbolic element is the bell tower, which appears prominently in the depiction of churches in Codex Yodzo Cahi (Yanhuitlan) and many other colonial pictorial manuscripts. In the Map of Chiyo Cahnu it is clearly visible in the main town, between the church and the rulers' palace. Also the Lienzo of Ocotepec shows the colonial juxtaposition of the bell tower and the ancient ruler's house. In addition, the bell towers of chapels in two maps of Cuquila,

${ }^{9}$ For the Lienzos of Guevea and Petapa, see Oudijk \& Jansen 2000 and De la Cruz 2008. For questions concerning the composition and internal dynamics of colonial sources on indigenous culture and history, see for example the studies of Gruzinski (1988) and Florescano $(1999,2002)$. The latter author discussed specifically the titulos primordiales in his contribution to the third Mesa Redonda de Monte Albán (Robles García 2004). 
reproduced by Mary Elizabeth Smith (1998: 181-182), even contain the signs for $\tilde{n} u u$, 'town' or aniñe, 'palace', emphasizing the close link between the bell tower and the community. This icon reminds us of the many stories that people tell about the 'golden bell' of their village. Clearly the bell functions as a visible and auditory symbol of a community's identity, just as the Patron Saint is a unifying symbol, often represented as the spiritual founder and protector. ${ }^{10}$ The bell takes the place of the precolonial Sacred Bundle as the 'Heart of the People'. Originally its connection with the colonial church stressed the pious and moral character of the community. Later its presence in the iconography of the Mexican Independence reinforced the connotation of sovereignty and liberation. According to the native narratives it is made of gold: an indication of its extraordinarily precious character and eternal strength. Due to adverse forces of destiny it was lost: colonial exploitation and fragmentation introduced a deep crisis in the community. But somewhere it is waiting to be found again....

\section{Roots of Contemporary Conflicts}

In ancient times land had been the manifestation of divine presence $(\tilde{N} u h u)$, just as gold and preciosities had been valued as items of ritual exchange, religious seals of alliances. Now, for the colonial expansion these elements became commodities, the value of which was determined entirely in economic terms. The defining of communities as territories and the tracing of frontiers between them immediately provoked bitter disputes among the people over those boundary lines (linderos). To the Machiavellian satisfaction of the colonial administrators, this process of internal division of the colonized society only deepened as more and more communities claimed their own municipal independence and broke away from the former urban nucleus and from their neighbors. In the early colonial time codices, lienzos and títulos were produced to lay down and fix the territorial extension of the community and to legitimate its existence.

${ }^{10}$ Hassig (2001: chapter 6) analyzes the colonial introduction of clock time. Bartolomé (1997: 86-89) discusses the bell as a marker of 'acoustic territory' and as an emblem of 'the voice of the people'. This identitarian meaning of the bell has clearly medieval roots in Mediterranean society: our colleague John Bintliff has called our attention to the fact that similar projections of community identity - and rivalry - are found in the villages of Spain and in Italy, where they are known even today as campanilismo (cf. Freeman 1970 and Tak 1990). 
When the cacique became totally usurped in the colonial administration, and divorced and alienated from his people, a significant portion of historical-geographical manuscripts passed from the cacique families to the municipal archive. In the documents themselves the references to the precolonial dynasties were reduced to vague indications, ultimately disappearing altogether and leaving only the pictorial representation or written descriptions of the community's territory.

This process was clearly under way in the time of the Bourbon reforms, when the communities tried to reaffirm their rights amidst palpable social changes, but in Oaxaca it took until the first decades after the proclamation of Independence, in the first half of the 19th century, for their native nobility to disappear as such and their cacicazgos to dissolve. It was then that many documents changed hands again. Sometimes these historical testimonies still play a part in ongoing conflicts. Even now in several places a low-intensity but continuous and bloody warfare is going on between neighboring villages, fuelled by the intrigues of political parties and local power brokers.

As the last descendants of the precolonial Mesoamerican kings and queens faded away, their place has been taken by other local potentates, 'the modern or capitalistic caciques', whose local power is based on economic strength and, often, intimidation through the ruthless application of illegal force. ${ }^{11}$ Consisting of big landowners, the new rich and intermediaries without scruples, whites, mestizos and alienated Native Americans, these powerful local families have generally turned their back on the grassroots people and identified with the dominant class and the ruling party on the national level. They control the commerce in the center of town and in this unequal situation commerce almost automatically becomes abuse: those who have some economic power get the monopoly, can set the prices, buying the local products cheaply and selling the industrial products of the city expensively. Such a person can trick people into debts impossible to

${ }^{11}$ Monaghan, Joyce, and Spores (2003) show that the caciques themselves and their communities took an active part in the 19th century transformation of the cacicazgo. González Casanova (1967) and Bartra $(1975,1984)$ placed the modern cacique in context. Flanet (1977), Bustamante et al. (1984), and Greenberg 1989 provide clarifying case studies of the traditional situation in the Oaxaca countryside, while Bartolomé (1997, 2008), Julián Caballero (2002, 2009), Maldonado Alvarado (2002), and Van Broekhoven (2006), for example, give a contemporary perspective, paying due attention to issues of cultural identity and autonomous development. 
repay, taking advantage of their dependence, which provides him with a source of cheap labor. With the selling of liquor (aguardiente), the promotion of electronic games and gambling machines, intimidation and other forms of brutality, he plays a pivotal role in the spread of corruption and the pattern of deprivation. This local power-class does not feel any commitment toward the community, and does not participate in it in a constructive or supporting way, but perpetuates a colonial attitude, ready to exploit or sell out whatever natural or cultural resources (including archeological monuments) the region may have. As patrons and padrinos, these modern, capitalist caciques have constructed impressive client networks throughout the national society and politics. There is corruption even in the judicial system, with the result that the caciques are hardly ever controlled by the law. The powerful stick together because of common interests, economic goals, and family-alliances. In the elections they oblige the inhabitants of 'their' towns, with promises, tricks or intimidation, to vote for their party, or they falsify the results altogether. No longer an aristocracy, their power may still continue for several generations. Although in some cases they may have Native American roots, they identify fully with Western Europe and the U.S.A.. In the state, the cacique networks are often an obstacle to democratization, social planning and the improvement of living conditions. In the Native American communities, the modern cacique is often an outsider or an ally of outsiders, and opposed to the traditional, more collective authority of principales and the spiritual guidance of healers (curanderos). The physical and cultural erosion, poverty and discrimination, coupled with the pressures of corrupt administrators, aggressive religious sects and violent narcotraficantes, constitute the arena in which these modern caciques continue to flourish.

\section{Closure}

The Mixtec pictorial manuscripts deal with time, with the passage of days and years, with human history and drama, as well as with time as the structuring principle for worldview and memory. The use of calendar names made people 'children of time', connecting their birth, but also their health, mentality and ability, to the presence (and the active veneration of) divine powers. This use still survives in several contemporary indigenous communities in the Oaxaca region (e.g. the Ayuuk 
or Mixe people) and among Maya peoples in Guatemala. The basic 260-day cycle, formed by symbolically charged and interactive cycles of thirteen numbers and twenty day signs, created a cyclical experience of the passage of time, as well as a religious-ethical interpretation of events, actions and auguries. The codices of the Teoamoxtli (Borgia) Group document an ancient codification of those symbolic meanings of time and world-directions. The modern reader tends to differentiate strongly between the genre of the mantic-ritual manuscripts and that of the historical codices, but in the minds of the protagonists and primordial interpreters - the Mesoamerican priests and rulers - both types of manuscript must have been intimately related.

On the basic and sacred structure of the calendar, history was lived and memory constructed in cycles of 52 agricultural years: this unit was an ideal chronological framework, as it comprised what must have been an average life expectancy. The elderly and experienced people were those who lived more than one calendar round. Reaching the age of 104 years, two calendar rounds, was very exceptional for human individuals, but such a period represented a practical historical horizon, within which memory was passed on through communication between three or four generations. It was also the period in which the dart-throwing celestial deities, Sun and Venus, markers of sunrise, light, and therefore of the beginning of all history, reunited in the same position within the calendar cycle. Similarly, within this horizon the cyclical repetition of days that had become associated with significant moments and individuals of community history could be cyclically remembered and ritually commemorated. The calendar names of the ancestors and the dates associated with their most significant actions obtained additional religious meaning and power because of their connection to the mantic-ritual symbolism of those days in the calendar. Furthermore the codices - both those of the Teoamoxtli type and those that registered dynastic history - were connected to the building or amplification of monuments and art-works - with their associated ritual acts and observations - providing a lively interactive cultural system of continuity and renewal, while inscribing the memory community on and within a sacred landscape. The cyclical renewal of the community through the ritual celebration and performance of this collective and cultural memory was also a form of reflection, closure, and healing.

The Nuu Dzaui pictorial manuscripts are testimonies of such a system and therefore of a specific memory community, flourishing 
between two major crises: that of the Classic-Postclassic divide (around $900 \mathrm{AD}$ ) and that of the Spanish colonization (in the 16th century). Those transformations on the one hand were certainly dramatic times of violence and suffering, implying mnemonic and narrative disjunctions, but on the other show the resilience of ethnic and cultural identity. Given this underlying continuation, the testimonies of the past may be reintegrated, reinterpreted and revitalized in contemporary memory.

The Mesoamerican conceptualization of sacred time and landscape as a liminal sphere of communication and exchange between human and divine forces, survived throughout colonial times, adapting progressively in a syncretistic manner to the new European religious and economic order. Nearly everywhere on the American continent the colonization led to the annihilation of ancient time-counts. Only in some cases, the 260-day count, with its different divisions, is still the basis for their divinatory practices and complex counting-mechanisms, involving the casting of beans and/or crystals. The count is used by 'day-keepers', traditional healers, mediators in conflicts, and religious specialists: they fulfil a crucial role as interpreters of the divine will, which they recognize and read in the names of days and associated deities. Calendar ceremonies are carried out at specific locales in the sacred landscape in and around the villages. The associated prayer texts are generally esoteric in character and language, using archaic terms, as well as the typical Mesoamerican metaphors and literary forms (parallelism, hendiadys). Ancient deities and myths were fused with Saints and Christian concepts. The focal points of the indigenous liturgical cycle are now the Days of the Dead (Oct. 31/Nov. 2) and the Day of the Holy Cross (May 3), the first being a family ceremony which to some extent continues the ancient ancestor worship, the second involving a collective ritual for the Rain God. Carnival has taken the place of the five-day period at the end of the year, while the Holy Week coincides with the end of the dry season, when the Maize God - Christ - has died. In this way part of the calendar's cosmological character and ritual function is maintained.

Simultaneously the colonial and modern industrial use of time and land as measurable and quantified commodities has introduced severe modifications in community life and ethics. Present-day communities are predominantly the result of a complex colonial transformation and on-going neo-colonial expansion, involving exploitation, discrimination and the internalization of a colonial ideology. Especially 
Mixtec society today is heavily influenced by an intense process of migration to the major cities in Mexico, and particularly to different areas in the United States (particularly the West Coast), where the migrants suffer many hardships and from where they are occasionally pushed back to their country of origin in times of economic crises. The process of migration has contributed to the further disintegration of the indigenous communities and traditions, but has also promoted a strong awareness of ethnic identity as well as economic solidarity and support for those who remained in the villages.

Consequently an ambivalent vision dominates contemporary indigenous society. On the one hand there are still many oral traditions (narratives, metaphors etc.) about the presence of divine forces (invoked in healing rituals for example), on the other a rapid erosion of such ideas and of the landscape itself is now taking place. Specifically important is the bond which migrants maintain with their place of origin ('where the umbilical cord is buried'), its liturgical fiestas and its traditional ceremonial landscape, as a spot to return to from a nomadic experience. Here we see the social-cultural potential of concepts, actions and texts to provide a narrative cohesion, an identity to groups and individuals.

Interpreting the codices in relation to such social dynamics, we see how they are both sources and subjects of history, products and stimuli of cultural memory, elements of heritage and identity. In this sense, they should be part of national literature, and figure prominently in indigenous emancipatory education. We feel connected to the way in which the Nuu Dzaui teacher and historian Abraham Castellanos understood and dealt with this history in his mystical and revolutionary reading of Codex Iya Nacuaa (Colombino). One century after the Mexican Revolution his voice of protest against domination, an inspiring call for a new, different development, remains strong and valid:

They promised you liberty, but after the victory you don't even have the most basic rights. 'It is just an Indian', the oppressors say, and the Indian passes by, with his soul in pain.

They promised you prosperity, and the caciques keep exploiting your work. 'After all, it is only an Indian', the caciques say, and the Indian passes by, with his soul in pain.

Having seen your misery, I spoke to our common Mother, I spoke to the mountain, so that mankind may hear me, and I repeat it here: 'The Indians groan and ask for help, nobody has reached out a saving hand to them; they fell into their misfortune four hundred years ago, and they 
live because they are strong, because they are patient and brave, because they were taught so by the good God.

Wake up, Mother Ixtaccihuatl, and take care of your children...!' But you too, wake up, my brothers! (Castellanos 1910: 85-86). 
Maarten Jansen and Gabina Aurora Pérez Jiménez - 978-90-04-19358-1 Downloaded from Brill.com@4/26/2023 11:36:13AM 


\section{REFERENCES}

Acevedo Conde, María Luisa. 2009. Nombres mixtecos, nahuas y cristianos de los pueblos de la Mixteca en el siglo XVI. In: El Significado de los Sueños y otros temas mixtecos (Reina Ortiz Escamilla, ed.): 93-128. Universidad Tecnológica de la Mixteca, Huajuapan.

Acuña, René (ed.). 1984. Relaciones Geográficas del siglo XVI: Antequera (I, II). UNAM, Mexico.

— 1984-1985 Relaciones Geográficas del siglo XVI: Tlaxcala (I, II). UNAM, Mexico.

Adelhofer, Otto. 1974. Codex Vindobonensis Mexicanus 1. ADEVA, Graz.

Aguilera, Carmen. 2002. Descubriendo a un niño sol. Arqueología Mexicana X. Núm. 55: 58-63.

Agustín Aquino, Octavio Alberto. 2007. Geometría prehispánica mixteca. In: Raíces mixtecas (Reina Ortíz Escamilla \& Ignacio Ortíz Castro, eds.): 149-176. Universidad Tecnológica de la Mixteca, Huajuapan.

Alavez Chávez, Raúl G. 1997. Nayiu xindeku nuu Ndaa Vico Nu’u. Los habitantes del Lugar de las Nubes. CIESAS, Mexico \& Instituto Oaxaqueño de las Culturas, Oaxaca.

.1988. Toponimia mixteca. Armella, Mexico.

2006. Toponimia mixteca II. Mixteca Alta, comunidades del distrito de Tlaxiaco. Publicaciones de la Casa Chata, CIESAS, Mexico.

Alcina Franch, José. 2000. Temazcalli: higiene, terapéutica, obstetricia y ritual en el Nuevo Mundo. Escuela de Estudios Hispano-Americanos / Consejo Superior de Investigaciones Científicas, Sevilla.

Alexander, Ruth Mary. 1980. Gramática Mixteca, mixteco de Atatlahuca. Instituto Lingüístico de Verano, Mexico.

Alvarado, Fray Francisco de. 1962 (1593). Vocabulario en Lengua Mixteca. INAH \& INI, Mexico.

Alvarado Bárcenas, Luz María \& María de los Ángeles Ojeda Díaz. 2009. La Sexualidad Femenina en los Códices Ñu Savi (Mixtecos). In: El Significado de los Sueños y otros temas mixtecos (Reina Ortiz Escamilla, ed.): 63-92. Universidad Tecnológica de la Mixteca, Huajuapan.

Anders, Ferdinand. 1963. Das Pantheon der Maya. ADEVA, Graz.

-1975. Kunst und Kunstgewerbe Altmexikos. Kroon-voordracht, Amsterdam. 1978. Der altmexikanische Federmosaikschild in Wien. Archiv für Völkerkunde 32: 67-88.

1999. Die mexikanische Codexliteratur und ihre Editionen. Im Eigenverlag, Klosterneuburg/Vienna.

Anders, Ferdinand \& Maarten Jansen. 1986. Altmexiko: Mexikanische Zauberfiguren, Alte Handschriften beginnen zu sprechen. Katalog zur Ausstelling, Stadtmuseum Linz-Nordico, Linz.

.1988. Schrift und Buch im alten Mexiko. ADEVA, Graz.

1993. El Manual del Adivino. Libro explicativo del llamado Códice Vaticano B. Fondo de Cultura Económica, Mexico.

- 1996. Religión, Costumbres e Historia de los Antiguos Mexicanos. Libro explicativo del llamado Códice Vaticano A (Códice Vaticano 3738). Fondo de Cultura Económica, Mexico. 
Anders, Ferdinand \& Maarten Jansen (with a contribution by Alejandra Cruz Ortiz). 1994. Pintura de la Muerte y de los Destinos. Libro explicativo del llamado Códice Laud. Fondo de Cultura Económica, Mexico.

Anders, Ferdinand \& Maarten Jansen et al. (contributions by Jessica Davilar and Anuschka Van't Hooft). 1996. Libro de la Vida. Texto explicativo del llamado Códice Magliabechiano. Fondo de Cultura Económica, Mexico.

Anders, Ferdinand \& Maarten Jansen \& Peter van der Loo (with contributions by Eduardo Contreras Martínez and Beatriz Palavicini Beltrán). 1994. Calendario de Pronósticos y Ofrendas. Libro explicativo del llamado Códice Cospi. Fondo de Cultura Económica, Mexico.

Anders, Ferdinand \& Maarten Jansen \& Luis Reyes García. 1991. El Libro del Ciuacoatl. Homenaje para el año del Fuego Nuevo. Libro explicativo del llamado Códice Borbónico. Fondo de Cultura Económica, Mexico.

- 1993. Los Templos del Cielo y de la Oscuridad: Oráculos y Liturgia. Libro explicativo del llamado Códice Borgia. Fondo de Cultura Económica, Mexico.

Anders, Ferdinand \& Maarten Jansen \& G. Aurora Pérez Jiménez. 1992a. Origen e Historia de los Reyes Mixtecos. Libro explicativo del llamado Códice Vindobonensis. Fondo de Cultura Económica, Mexico.

—_ 1992b. Crónica Mixteca: El rey 8 Venado, Garra de Jaguar, y la dinastía de Teozacualco-Zaachila. Libro explicativo del llamado Códice Zouche-Nuttall. Fondo de Cultura Económica, Mexico.

- 1994. El Libro de Tezcatlipoca, Señor del Tiempo. Libro explicativo del llamado Códice Fejérváry-Mayer. Fondo de Cultura Económica, Mexico.

Arana, Evangelina \& Mauricio Swadesh. 1965. Los Elementos del Mixteco Antiguo. INI \& INAH, México.

Arellano Hoffmann, Carmen. 1998. Die Mesoamerikanische Schreiber und seine Schreibutensilien. In: Die Bücher der Maya, Mixteken und Azteken (Carmen Arellano Hoffmann \& Peer Schmidt eds.): 201-234. Vervuert Verlag, Frankfurt am Main.

Artís, Gloria (ed.). 2005. Encuentro de Voces. La etnografía de México en el siglo XX. Instituto Nacional de Antropología e Historia, Mexico.

Assmann, Aleida. 2007. Der lange Schatten der Vergangenheit. Erinnerungskultur und Geschichtspolitik. Bundeszentrale für politische Bildung, Bonn.

Assmann, Jan. 1992. Das kulturelle Gedächtnis. Schrift, Erinnerung and politische Identität in frühen Hochkulturen. Beck, Munich.

Asselbergs, Florine G.L. 2004. Conquered conquistadors. The Lienzo de Quauhquechollan: a Nahua vision on the conquest of Guatemala. $\mathrm{PhD}$ dissertation, Leiden.

Báez Pérez, Miguel Ángel. 2008. 8 Venado - Garra de Jaguar. Agencia y estructura en la Mixteca. In: Perspectivas de la Investigación Arqueológica III (Fernando López Aguilar \& Walburga Wiesheu \& Patricia Fournier, eds.): 61-84. Instituto Nacional de Antropología e Historia, Mexico.

Bakewell, Liza \& Byron Hamann (coords.). 2000. Mesolore. CD-ROM, Brown University, Providence.

Bal, Mieke. 1994. On Meaning Making. Essays in Semiotics. Polebridge Press, Sonoma. 1997. Narratology: introduction to the theory of narrative. University of Toronto Press.

Balkansky, Andrew K., 1998. Origin and Collapse of Complex Societies in Oaxaca (Mexico): Evaluating the Era from 1965 to the Present. Journal of World Prehistory 12 (4): 451-493. 2001. Book review of Jansen, Maarten, Peter Kröfges \& Michel Oudijk. The Shadow of Monte Albán. Journal of the Royal Anthropological Institute 7 (1): 175-177. 
Balkansky, Andrew K., Stephen A. Kowalewski, Veronica Perez Rodriguez, Thomas J. Pluckhahn, Charlotte A. Smith, Laura R. Stiver, Dmitri Beliaev, John F. Chamblee, Verenice Y. Heredia Espinoza, and Roberto Santos Perez. 2000. Archaeological survey in the Mixteca Alta of Oaxaca, Mexico. Journal of Field Archaeology 27: 365-389.

Barabas, Alicia M. 2006. Dones, Dueños y Santos. Ensayos sobre religiones en Oaxaca. INAH \& Miguel Ángel Porrúa, México.

Barba de Piña Chan, Beatriz. 2002. “.. y a sus reyes muertos los vieron como dioses”. In: Iconografía mexicana IV: Iconografía del poder (Beatriz Barba de Piña Chan, ed.): 35-47. Instituto Nacional de Antropología e Historia, Mexico.

Bartolomé, Miguel A. 1997. Gente de costumbre y gente de razón. Las identidades étnicas en México. Siglo XXI \& INI, Mexico.

. 2008. La Tierra Plural. Sistemas Interculturales en Oaxaca. Instituto Nacional de Antropología e Historia, México.

Bartra, Roger, et.al. 1975. Caciquismo y poder político en el México rural. Siglo XXI Editores, Mexico.

-1984. Campesinado y poder político en México. Ediciones Era, Mexico.

Batalla Rosado, Juan José. 1994. El Códice Falso del Museo de América. Anales del Museo de América 2: 131-147.

. 1999. Estudio codicológico del Códice Tudela. Anales del Museo de América 7: 7-63.

—.2006. Estudio codicológico de la sección del xiuhpohualli del Códice Telleriano Remensis. Revista Española de Antropología Americana 36 (2): 69-87.

. 2008. Los códices mesoamericanos: métodos de estudio. Itinerarios 8: 43-65. Warsaw.

Bellas, Monica L. 1999. Women in the Mixtec Codices: ceremonial and ritual roles of Lady 3 Flint. In: From the Ground Up: Beyond Gender Theory in Archaeology (Nancy L. Wicker \& Bettina Arnold, eds.): 49-65. British Archaeological Reports, International Series, 812, Oxford.

Berlin, Heinrich. 1947. Fragmentos desconocidos del Códice de Yanhuitlan y otras investigaciones mixtecas. Antigua Librería Robredo \& José Porrúa e Hijos, Mexico.

Bhabha, Homi. 1994. The Location of Culture. Routledge, London.

Bintliff, John. 2002. Going to market in antiquity. In: Zu Wasser und zu Land. Verkehrswege in der antiken Welt (Eckart Olshausen \& Holger Sonnabend, eds.): 209-250. Stuttgarter Kolloquium zur historischen Geographie des Altertums 7. Franz Steiner Verlag, Stuttgart.

Blanton, Richard E. \& Gary M. Feinman \& Stephen A. Kowalewski \& Peter N. Peregrine. 1996. A Dual-Processual Theory for the Evolution of Mesoamerican Civilization. Current Anthropology 37 )1): 1-14.

Blanton, Richard E. \& Gary Feinman \& Stephen A. Kowalewski \& Linda Nicholas \& Rita P. Wright. 1999. Ancient Oaxaca. The Monte Albán State. Cambridge University Press.

Blomster, Jeffrey P. (ed.) . 2008. After Monte Albán. Transformation and Negotiation in Oaxaca, Mexico. University Press of Colorado, Boulder.

Boone, Elizabeth Hill . 2000. Stories in Red and Black. Pictorial histories of the Aztecs and Mixtecs. University of Texas Press, Austin.

.2007. Cycles of Time and Meaning in the Mexican Books of Fate. University of Texas Press, Austin.

Boone, Elizabeth Hill (ed.). 2005. Painted books and Indigenous Knowledge in Mesoamerica. Manuscript studies in honor of Mary Elizabeth Smith. Middle American Research Institute Publication 69. Tulane University, New Orleans. 
Bradley, C. Henry \& Barbara E. Hollenbach (eds.). 1988-1992. Studies in the Syntax of Mixtecan Languages vols. 1-4. Summer Institute of Linguistics, publications 83, 90, 105, 111. University of Texas, Arlington.

Braidotti, Rosi. 1994. Nomadic Subjects. Embodiment and sexual difference in contemporary feminist theory. Columbia University Press, New York.

Broda, Johanna \& Félix Báez-Jorge (eds.). 2001. Cosmovisión, ritual e identidad de los pueblos indígenas de México. Consejo Nacional para las Culturas y las Artes / Fondo de Cultura Económica, Mexico.

Brotherston, Gordon. 1983. The Year 3113 вС and the Fifth Sun of Mesoamerica: an orthodox reading of the Tepexic Annals (Codex Vindobonensis obverse). In: Calendars in Mesoamerica and Peru. Native Amercan computations of time (Anthony F.Aveni \& Gordon Brotherston, eds.): 167-220. BAR International Series 172, Oxford.

- 1985. The Sign Tepexic in its Textual Landscape. Ibero-Amerikanisches Archiv N.F. Jg. 11, H. 2: 209-251.

1995. Painted Books from Mexico. British Museum Press, London. 2007. Historia. ¿Legible en los codices? In: Indios, mestizos y españoles. Interculturalidad e historiografía en la Nueva España (Danna Levin \& Federico Navarrete, eds.): 203-222. Universidad Autónoma Metropolitana, Azcapotzalco.

Brown, Walden. 2000. Sahagún and the Transition to Modernity. University of Oklahoma Press, Norman.

Brück, Joanna. 2005. Experiencing the past? The development of a phenomenological archaeology in British prehistory. Archaeological Dialogues 12 (1): 45-72. Cambridge University Press.

Brumfiel, Elizabeth M. \& John W. Fox. 1994. Factional competition and political development in the New World. Cambridge University Press, Cambridge.

Bueno Bravo, Isabel. 2007. La Guerra en el Imperio Azteca. Expansión, ideología y arte. Editorial Complutense, Madrid.

Burgoa, Fray Francisco de. 1934a. Palestra Historial. Publicaciones del AGN 24, Mexico.

—. 1934b. Geográfica Descripción (I, II). Publicaciones del AGN 25, 26, Mexico (original edition: 1674). Reimpresión Editorial Porrúa, México 1989.

Burkhart, Louse M. 1989. The Slippery Earth: Nahua-Christian Moral Dialogue in Sixteenth-Century Mexico. Tucson: University of Arizona Press.

Burland, Cottie A. \& Gerdt Kutscher. 1955. The Selden Roll. Gebr. Mann, Berlin.

Burland, Cottie A. 1965 Codex Egerton 2895. ADEVA, Graz.

Bustamante, René, et al. 1984. Oaxaca, una lucha reciente: 1960-83. Ediciones Nueva Sociología, Mexico.

Butterworth, Douglas. 1977. Tilantongo: comundiad mixteca en transición. Instituto Nacional Indigenista, Mexico.

Byland, Bruce E. \& John M.D. Pohl. 1994. In the Realm of 8 Deer. University of Oklahoma Press, Norman / London.

Caballero Morales, Gabriel. 2008. Diccionario del Idioma Mixteco. Tutu Tu’un Ñuu Savi. Universidad Tecnológica de la Mixteca, Huajuapan.

Cabrera Guerrero, Martha. 2008. Escudo de Acapulco, Guerrero. Arqueología Mexicana XV, Núm. 90: 14-15.

Carmack, Robert M. \& Janine Gasco \& Garry H. Gossen. 1996. The legacy of Mesoamerica. History and Culture of a Native American Civilization. Prentice Hall.

Carmagnani, Marcello. 1988. El regreso de los dioses. El proceso de reconstitución de la identidad étnica en Oaxaca. Siglos XVII y XVIII. Fondo de Cultura Económica, Mexico. 
Carrasco, David. 1982. Quetzalcoatl and the Irony of Empire. Myths and Prophesies in the Aztec Tradition. University of Chicago Press, Chicago.

Caso, Alfonso. 1949. El Mapa de Teozacoalco. Cuadernos Americanos VIII (5): 145181.

— 1950. Explicación del reverso del Codex Vindobonensis. Memoria de El Colegio Nacional V (5): 9-46.

- 1957. Lienzo de Yolotepec. Memoria de El Colegio Nacional 3 (4): 41-55.

. 1958. El Mapa de Xochitepec. Acts of the XXXII International Congress of Americanists: 458-466. Copenhagen. 1959. Book review of Mixtec Ethnohistory by Philip Dark. American Anthropologist 61: 147-151.

- 1960. Interpretación del Códice Bodley 2528. Sociedad Mexicana de Antropología, Mexico.

- 1961. Los Lienzos Mixtecos de Ihuitlan y Antonio de León. In: Homenaje a Pablo Martínez del Río: 237-274. Mexico.

—. 1964a. Interpretación del Códice Selden 3135. Sociedad Mexicana de Antropología, Mexico.

— 1964b. El Lienzo de Filadelfia. In: Homenaje a Fernando Márquez-Miranda, arqueólogo e historiador de América: 138-144. Publicaciones del Seminario de Estudios Americanos y el Seminario de Antropología Americana, Madrid.

- 1966a. Interpretación del Códice Colombino (with Mary Elizabeth Smith: Las Glosas del Códice Colombino). Sociedad Mexicana de Antropología, Mexico.

- 1966b. Mapa de Santo Tomás Ocotepeque, Oaxaca. In: Summa Anthropologica en homenaje a Roberto J. Weitlaner: 131-137. Instituto nacional de Antropología e Historia, Mexico.

- 1967. Los Calendarios Prehispánicos. UNAM, Mexico.

- 1969. El Tesoro de Monte Albán. Instituto Nacional de Antropología e Historia, Mexico.

. 1977-1979 Reyes y Reinos de la Mixteca (I, II). Fondo de Cultura Económica,
Mexico.

Castañeda de la Paz, María. 2006. Pintura de la Peregrinación de los CulhuaqueMexitin (El Mapa de Sigüenza). Análisis de un documento de origen tenochca. El Colegio Mexiquense, Zinacantepec/Instituto Naiconal de Antropología e Historia, Mexico.

Castellanos, Abraham. 1910. El Rey Iukano y los Hombres del Oriente. Leyenda indígena inspirada en los restos del 'Códice Colombino'. A. Carranza e Hijos, Mexico.

. 1914. Al Caer el Sol (desde mi celda). Teogonías Mexicanas. A. Carranza e Hijos, Mexico.

Castellón Huerta, Blas Román. 2006. Cutha, el Cerro de la Máscara: Arqueología y Etnicidad en el Sur de Puebla. Instituto Nacional de Antropología e Historia, Mexico.

Chadwick, Robert. 1971. Native pre-Aztec History of Central Mexico. In: Handbook of Middle American Indians (Robert Wauchope, ed.) IX, pp. 474-504. University of Texas Press, Austin.

Chance, John K. 2000. The Noble House in Colonial Puebla, Mexico: Descent, Inheritance, and the Nahua Tradition. American Anthropologist 102(3): 485-502.

-2008. Alianzas matrimoniales coloniales entre caciques mixtecos: El caso de Acatlan-Petlalcingo. Anuario de Estudios Americanos 65 (1): 71-86. Sevilla.

Chavero, Alfredo. 1892. Antigüedades Mexicanas, publicadas por la Junta Colombina de México en el cuarto centenario del descubrimiento de América. Secretaría de Fomento, Mexico.

- 1979. El Lienzo de Tlaxcala. Editorial Cosmos, Mexico. 
Chevalier, Jacques M. \& Andrés Sánchez Bain. 2003. The Hot and the Cold. Ills of Humans and Maize in Native Mexico. University of Toronto Press. Toronto / Buffalo / London.

Chimalpahin, Domingo. 1998. Las Ocho Relaciones y el Memorial de Colhuacan (I, II). Consejo Nacional para la Cultura y las Artes, Mexico.

Chistensen, Alexander F. 1998. Ethnohistorical evidence for inbreeding among the pre-Hispanic Mixtec royal caste. Human Biology 70 (3) [jun. 1998]: 563-577.

Christian, William A. 1981. Local Religion in Sixteenth-Century Spain. Princeton University Press, Princeton.

Churchill, Ward. 1998. Fantasies of the Master Race. Literature, cinema and the colonization of American Indians. City Light Books, San Francisco.

Ciruelo, Pedro. 1628. Tratado de las Supersticiones. Barcelona (facsimile edition: Universidad Autonoma de Puebla 1986) [first edition: \pm 1530].

Claessen, Henri J.M. \& Oosten, Jarich G. (eds.). 1996. Ideology and the Formation of Early States. E.J. Brill, Leiden.

Clark, James Cooper. 1912. The Story of "Eight Deer" in Codex Colombino. Taylor and Francis, London.

- 1938. Codex Mendoza (3 vols.). Waterlow \& Sons, Oxford / London.

Clavijero, Francisco Javier. 1976. Historia Antigua de México. Editorial Porrúa, Mexico.

Codíces:

Codex Añute (= Codex Selden), see Caso 1964a, Jansen \& Pérez Jiménez 2007b.

Codex Cihuacoatl (= Codex Borbonicus), see Anders \& Jansen \& Reyes 1991.

Codex Iya Nacuaa (= Codex Colombino-Becker), see León-Portilla 1996.

Codex Iya Nacuaa I (= Codex Colombino), see Caso 1966a.

Codex Iya Nacuaa II ( = Codex Becker I), see Nowotny 1961b.

Codex Magliabechi, see Anders \& Jansen et al. 1996.

Codex Mendoza, see Clark 1938.

Codex Mictlan (= Codex Laud), see Anders \& Jansen 1994.

Codex Ñuu Naha (= Codex San Pedro Cántaros = Codex Muro): see Smith 1973b and Jansen 1994.

Codex Ñu Ñaña (= Codex Egerton 2895), see Burland 1965 and Jansen 1994.

Codex Ñuu Tnoo-Ndisi Nuu (= Codex Bodley), see Caso 1960.

Codex Telleriano-Remensis, see Quiñones Keber 1995.

Codex of Texupan (= Codex Sierra), see León 1982.

Codex Tezcatlipoca (= Codex Fejérváry-Mayer), see Anders \& Jansen \& Pérez Jiménez 1994.

Codex Tlamanalli (= Codex Cospi), see Anders \& Jansen \& Loo 1994.

Codex Tonalpouhqui (= Codex Vaticanus 3773 or "Vaticanus B"), see Anders \& Jansen, 1993.

Codex Tonindeye (= Codex Zouche or Codex Nuttall), see Anders \& Jansen \& Pérez 1992b.

Codex Vaticanus 3738 ("Vaticanus A"), see Anders \& Jansen 1996.

Codex Yada or Codex Tututepetongo (= Codex Porfirio Díaz), see Van Doesburg 2001.

Codex Yecu (= Fonds Mexicain 20/21), see Jansen 1998c.

Codex Yoalli Ehecatl (= Codex Borgia), see Nowotny 1976 and Anders \& Jansen \& Reyes García, 1993.

Codex Yodzo Cahi (= Codex of Yanhuitlan), see Jiménez Moreno \& Mateos Higuera 1940, Sepúlveda y Herrera 1994.

Codex / Tira of Yodzo Yaha (= Codex of Tecomaxtlahuaca), see Jansen 1994.

Codex Yuta Tnoho (= Codex Vindobonensis Mexicanus 1), see Anders \& Jansen \& Pérez 1992a. 
Conquistador Anónimo. 1986. Relación de la Nueva España. Ediciones Polifemo, Madrid.

Conrad, Geoffrey W. \& Arthur A. Demarest. 1984. Religion and Empire. The dynamics of Aztec and Inca expansionism. Cambridge University Press.

Cordero Avendaño de Durand, Carmen. 1997. La Vara de Mando. Costumbres jurídicas en la transmisión de poderes. Carteles, Oaxaca.

- 2004. Interpretación y Estudio del Lienzo de San Juan Chicomezúchitl. El Mapa o Pintura de los Cogues o Señores. Instituto Oaxaqueño de las Culturas \& Gobierno del Estado, Oaxaca.

Corona Nuñez, José. 1964-1967. Antigüedades de México, basadas en la recopilación de Lord Kingsborough (I-IV). Secretaría de Hacienda y Crédito Público, Mexico.

Corona Sánchez, Eduardo. 2002. Los espacios de poder en el Acolhuacan. In: Iconografía mexicana IV: Iconografía del poder (Beatriz Barba de Piña Chan, ed.): 95-108. Instituto Nacional de Antropología e Historia, Mexico.

Cortés, Hernán. 1963. Cartas y Documentos. Editorial Porrúa, Mexico.

Cruz Ortíz, Alejandra. 1998. Yakua kuia: el nudo del tiempo. CIESAS, Mexico.

2009. Tradición Oral de la Mixteca de la Costa: el significado de los sueños. In: El Significado de los Sueños y otros temas mixtecos (Reina Ortiz Escamilla, ed.): 129-170. Universidad Tecnológica de la Mixteca, Huajuapan.

Curet, Luis Antonio. 1992. The Development of Chiefdoms in the Greater Antilles. Arizona State University.

Dahlgren de Jordán, Barbro. 1954. La Mixteca: su cultura e historia prehispánicas. Imprenta Universitaria, Mexico.

Dark, Philip. 1958. Mixtec Ethnohistory. A method of analysis of the codical art. Oxford University Press, New York.

De la Cruz, Victor. 2007. El Pensamiento de los Binnigula'sa': cosmovisión, religión y calendario con especial referencia a los Binnizá. Publicaciones de la Casa Chata, CIESAS / INAH / IEEPO / Casa Juan Pablos, Mexico.

.2008. Mapas genealógicos del Istmo oaxaqueño. Colección Diálogos, Oaxaca.

De la Fuente, Beatriz \& Bernd Fahmel Beyer . 2005. La Pintura Mural prehispánica en México: Oaxaca. Universidad Nacional Autónoma de México, Mexico.

Dehouve, Danièle. 2007. Offrandes et Sacrifice en Mesoamérique. Riveneuve Éditions, Paris.

Deloria, Vine. 1969. Custer died for your sins. Avon Books, New York, 1970.

Demarest, Arthur A. \& Geoffrey W. Conrad . 1992. Ideology and Pre-Columbian Civilizations. School of American Research Press, Santa Fe.

Denzin, Norman K. \& Yvonna S. Lincoln \& Linda TuhiwaiSmith (eds.). 2008. Handbook of Critical and Indigenous Methodologies. Sage Publications, Los Angeles/ London / New Delhi / Singapore.

Díaz Nuñez, Luis Gerardo. 2006. La presencia itinerante de los Dominicos en Oaxaca y la Mixteca durante los siglos XVI al XVIII. In: Nuu Savi, la Patria Mixteca (Reina Ortíz Escamilla \& Ignacio Ortiz Castro, eds.): 87-156. Universidad Tecnológica de la Mixteca, Huajuapan.

Donan, Christopher B. 1978. Moche Art of Peru. Pre-Columbian Symbolic Communication. Museum of Cultural History, University of California, Los Angeles.

Durán, Fray Diego. 1967. Historia de las Indias de la Nueva España e Islas de la Tierra Firme (2 vols.). Editorial Porrúa, Mexico.

Duverger, Christian. 1979. La Fleur Létale. Économie du sacrifice aztèque. Seuil, Paris.

Dyk, Anne. 1959. Mixteco Texts. Summer Institute of Linguistics, Norman.

Dyk, Ann \& Betty Stoudt. 1973. Vocabulario mixteco de San Miguel el Grande. Instituto Lingüístico de Verano, Mexico. 
Eagleton, Terry. 1991. Ideology. An Introduction. Verso, London / New York.

Earle, Timothy (ed.). 1991. Chiefdoms: power, economy, and ideology. Cambridge University Press, Cambridge.

Eco, Umberto. 1978. Tratado de Semiótica General. Ed. Nueva Imagen y Lumen, Mexico.

Eriksen, Thomas Hylland. 1993. Ethnicity and Nationalism. Anthropological perspectives. Pluto Press, London / Boulder.

Eschmann, Anncharlott. 1976. Das religiöse Geschichtsbild der Azteken. Indiana Beiheft 4, Berlin.

Estés, Clarissa Pinkola. 1992. Women who run with the Wolves. Myths and Stories of the Wild Woman Archetype. Ballantine Book.

Evans, Susan T. 2004. Ancient Mexico and Central America. Archaeology and Culture History. Thames \& Hudson, New York.

Fabian, Johannes. 1983. Time and the Other. How anthropology makes its object. Columbia University Press, New York.

Fagel, Raymond. 2005. Dos mundos aparte. La historia de España y de Hispanoamérica en Holanda. In: Memorias para el futuro. I Congreso de Estudios Hispánicos en el Benelux (Robin Lefere, ed.): 137-157. Presses de l'Université de Bruxelles, Brussels.

Fernández Rodríguez, Pedro . 1994. Los Dominicos en la Primera Evangelización de México. Editorial San Esteban, Salamanca.

Fernández Gatica, Andrés \& José Alberto Figueroa Silvestre. 2002. Los Dos Lienzos de Zacatepec, Oaxaca Siglo XVI. Asociación Anahuacayotl de Tlaxcalancingo, Puebla.

Fischer, Edward F. 1999. Cultural Logic and Maya Identity: Rethinking Constructivism and Essentialism. Current Anthropology 40 (4): 473-499.

Flanet, Véronique. 1977. Viviré si Dios quiere. Un estudio de la violencia en la Mixteca de la Costa. INI, Mexico.

Flannery, Kent \& Joyce Marcus (eds.). 1983. The Cloud People: Divergent Evolution of the Zapotec and Mixtec Civilizations. Academic Press, New York.

Florescano, Enrique. 1999. Memoria Indígena. Taurus, Mexico. 2002. Historia de las Historias de la Nación Mexicana. Taurus, Mexico.

. 2004. Quetzalcoatl y los mitos fundadores de Mesoamérica. Taurus, Santillana Ediciones Generales, Mexico.

Foucault, Michel. 1980. Power/Knowledge. Selected interviews and other writings 1972-1977. Pantheon Books, New York.

Fowler, Chris. 2004. The Archaeology of Personhood. An anthropological approach. Routledge, London.

Fox, Jonathan \& Gaspar Rivera Salgado (eds.). 2004. Indigenous Migrants in the United States. University of California, San Diego.

Frassani, Alessia. 2006. Tribute and Festivals in Codex Yanhuitlan. Paper presented at the 52nd International Congress of Americanists, August 17-24, 2006, Seville. . 2009. The Church And Convento Of Santo Domingo Yanhuitlan, Oaxaca: Art, Politics, and Religion in a Mixtec Village, Sixteenth Through Eighteenth Centuries. $\mathrm{Ph} . \mathrm{D}$. thesis, The City University of New York (http://alessia.frassani.googlepages .com/dissertation).

Freeman, Susan Tax. 1970. Neighbours. The Social Contract in a Castilian Hamlet. University of Cicago Press, Chicago.

Freidel, David \& Linda Schele \& Joy Parker. 1993. Maya Cosmos. Three thousand years on the shaman's path. Morrow, New York.

Fuente, Beatriz de la (ed.). 1995. La pintura mural prehispánica de México I: Teotihuacan. Universidad Nacional Autónoma de México, Mexico.

Furst, Jill L. 1977. The Tree Birth Tradition in the Mixteca, Mexico. Journal of Latin American Lore 3 (2): 183-226. 
1978a. Codex Vindobonensis Mexicanus I: A Commentary. Institute of Mesoamerican Studies, State University of New York, Albany.

2-37.

1982. Skeletonization in Mixtec Art: A Re-evaluation. In: The Art and Iconography of Late Post-Classic Central Mexico (Elizabeth H. Boone ed.), pp. 207-225. Dumbarton Oaks, Washington.

- 2002. Codex Selden: the story of 6-Monkey. Codex 11 (1-2): 10-17. Philadelphia.

Gabriel Hernández, Franco. 1982. 'Los indígenas de México' en México y la lucha de los indígenas en México. In: Los Indígenas de México en la época precolombina y en la actualidad (Maarten Jansen \& Ted Leyenaar eds.): 386-405. Rijksmuseum voor Volkenkunde, Leiden.

Galarza, Joaquín. 1979. Estudios de escritura indígena tradicional azteca-nahuatl. Archivo General de la Nación, Mexico.

—_ 1990. Amatl, Amoxtli. El papel, el libro. Los códices mesoamericanos. Guía para la introducción al estudio del material pictórico indígena. TAVA editorial, Mexico.

- 1992. In Amoxtli in Tlacatl. El libro, el hombre. Códices y Vivencias. TAVA editorial, Mexico.

García, Fray Gregorio. 1981 (1729). Origen de los Indios del Nuevo Mundo. Fondo de Cultura Económica, Mexico (first edition: 1607).

García Leyva, Jaime. 2005. Oralidad, ritualidad e identidad de Ñuu Savi de la Montaña de Guerrero. In: Pasado y presente de la Cultura Mixteca (Reina Ortiz Escamilla \& Ignacio Ortiz Castro, eds.): 165-198. Universidad Tecnológica de la Mixteca, Huajuapan.

García Valencia, E. Hugo. 1989. Señores y reyes, parientes y soberanos: los reyes de Tilantongo. Notas Mesoamericanas 11: 194-204

Garza Tarazona de González, Silvia. 1978. Códices Genealógicos: Representaciones Arquitectónicas. Instituto Nacional de Antropología e Historia, Mexico.

Gaxiola, Margarita \& Maarten Jansen (eds.). 1978. Primera Mesa Redonda de Estudios Mixtecos. INAH, Oaxaca.

Gelner, Ernest. 1983. Nations and Nationalism. Blackwell, Oxford.

Gerhard, Peter. 1972. A Guide to the Historical Geography of New Spain. Cambridge University Press, Cambridge.

Geurds, Alexander. 2007. Grounding the Past: the praxis of participatory archaeology in the Mixteca Alta, Oaxaca, Mexico. CNWS Research School of Asian, African and Amerindian Studies, Leiden.

Geurds, Alexander \& Maarten Jansen. 2008. The Ceremonial Center of Monte Negro. A cognitive approach to urbanization in Nuu Dzaui / El Centro Ceremonial de Monte Negro: un acercamiento cognitivo sobre la urbanización entre los Nuu Dzaui In: Urbanism in Mesoamerica / El Urbanismo en Mesoamérica, vol. II (Alba Guadalupe Mastache, Robert H. Cobean, Angel García Cook, Kenneth G. Hirth, eds.): 371-421. INAH \& Pennsylvania State University, Mexico.

Gillow, Eulogio G. 1978. Apuntes Históricos sobre la idolatría y la introducción del cristianismo en la diócesis de Oaxaca. Akademische Druck- und Verlagsanstalt, Graz.

Glass, John B. 1975. A Survey of Native Middle American Pictorial Manuscripts. In: Handbook of Middle American Indians (Robert Wauchope ed.) XIV, pp. 3-80. University of Texas Press, Austin.

Glass, John B. \& Donald Robertson. 1975. A Census of Native Middle American Pictorial Manuscripts. In: Handbook of Middle American Indians (Robert Wauchope ed.) XIV, pp. 81-252. University of Texas Press, Austin. 
Gledhill, John \& Barbara Bender \& Mogens Trolle Larsen (eds.). 1988. State and Society. The emergence and development of social hierarchy and political centralization. Unwin Hyman, London.

González Casanova, Pablo. 1967. La democracia en México. Serie Popular Era, Mexico.

González-Hermosillo Adams, Francisco. 2001. Gobierno y economía en los pueblos indios del México colonial. Instituto Nacional de Antropología e Historia, Colección Científica 437, Mexico.

Goody, Jack. 2000. The Power of the Written Tradition. Smithsonian Institution Press, Washington / London.

Gosden, Chris. 2004. Archaeology and Colonialism. Cultural contact from 5000 BC to the present. Cambridge University Press.

Gould, Richard A. (ed.). 1978. Explorations in Ethnoarchaeology. University of New Mexico Press, Albuquerque.

Graham, Richard. 1994. The idea of race in Latin America 1870-1940. University of Texas Press, Austin.

Graña-Behrens, Daniel (ed.). 2009. Das Kulturelle Gedächtnis mesoamerikas im Kulturvergleich zum alten China. Rituale im Spiegel von Schrift und Mündlichkeit. Ibero-Amerikanisches Institut: . Estudios Indiana 2, Gebr. Mann Verlag, Berlin.

Graulich, Michel. 1988. Quetzalcoatl y el Espejismo de Tollan. Instituut voor Amerikanistiek, Antwerp. 2002. Los Reyes de Tollan. Revista Española de Antropología Americana 32: 87-114.

Greenberg, James B. 1989. Blood Ties. Life and violence in Rural Mexico. University of Arizona Press, Tucson / London.

Greenleaf, Richard E. 1978. The Mexican Inquisition and the Indians:sources for the ethnohistorian. The Americas XXXIV (3): 315-344. Washington D.C.

Grupo de Barbados. 1979. Indianidad y descolonización en América Latina. Editorial Nueva Imagen, Mexico.

Gruzinski, Serge. 1988. La colonisation de l'imaginaire. Sociétés indigènes et occidentalisation dans le Mexique espagnol XVe-XVIIIe siècle. Éditions Gallimard, Paris.

Gutiérrez Mendoza, Gerardo \& Constantino Medina Lima . 2008. Toponimia Náhuatl en los Códices Azoyú 1 y 2. Un estudio crítico. Publicaciones de la Casa Chata, Centro de Investigaciones y Estudios Superiores en Antropología Social, Mexico.

Gutiérrez Solana, Nelly. 1987. Avances en los Estudios sobre los Códices Mixtecos (1973-84). Anales del Instituto de Investigaciones Estéticas 58: 35-45. Universidad Nacional Autónoma de México.

Guzmán, Eulalia. 1937. Une tablette de terre cuite des collections mexicaines des Musées royaux d'Art et d'Histoire à Bruxelles. Bulletin de la Société des Américanistes de Belgique 24: 89- 96.

Guzmán Flores, René Enedina . 2005. Raigambre Púrpura. Imágenes de Pinotepa de Don Luis. Fondo Editorial del Instituto Estatal de Educación Pública de Oaxaca, Oaxaca.

Haly Meyer, Richard. 1992. Bare Bones. Rethinking Mesoamerican Divinity. History of Religions 31 (3): 269-304. University of Chicago.

Hamann, Byron E. 1997. Weaving and the Iconography of Prestige: The royal gender symbolism of Lord 5 Flower's / Lady 4 Rabbit's family. In: Women in Prehistory. North America and Mesoamerica (Cheryl Claessen \& Rosemary Joyce, eds.): 153172. University of Pennsylvania Press, Philadelphia.

- 2002. The Social Life of Pre-sunrise Things. Current Anthropology 43(3): 351382.

- 2004. Seeing and the Mixtec Screenfolds. Visible Language 38 (1): 66-124. 2008. A Mixtec-language Atlas of the Mixteca Alta. FAMSI report (www .famsi.org). 
Hansen, Mogens Herman. 2000. A comparative study of thirty city-state cultures. Historisk-filosofiske Skrifter. Copenhagen.

Hartau, Claudia \& Viola König \& Renate Löschner. 2001. Zwölf Wind und Drei Feuerstein. Vom Leben in Alt-Mexiko, seiner Zerstörung und Neu-Entdeckung. Edition Temmen, Bremen.

Harvey, H.R. (ed.). 1991. Land and Politics in the Valley of Mexico. A Two-ThousandYear Perspective. University of New Mexico Press, Albuquerque.

Hassig, Ross. 1992. War and Society in Ancient Mesoamerica. University of California Press, Berkeley/Los Angeles/Oxford.

- 2001. Time, History and Belief in Aztec and Colonial Mexico. University of Texas Press, Austin.

Hawkes, Terence. 1977. Structuralism and Semiotics. University of California Press, Berkeley / Los Angeles.

Headrick, Annabeth. 2007. The Teotihuacan Trinity. The Sociopolitical Structure of an Ancient Mesoamerican City. University of Texas Press, Austin.

Heath, Shirley Brice. 1986. La Política del Lenguaje en México: de la Colonia a la Nación. INI, Mexico.

Hébert, Louis. 2006. Tools for text and image análisis. An introduction to applied semiotics. Editor: Texto! www.revue-texto.net

Hedeen, Katherine M. 2005. Decolonizing culture: visual arts, developmental narratives and performance in the Americas. Latin American Research Review 40 (3): 244-253.

Heijmerink, Johannes J. 1973. La Tenencia de la Tierra en las Comunidades Indígenas en el Estado de Oaxaca. El caso de Santo Tomás Ocotepec en la región de la Mixteca Alta. Revista Mexicana de Sociología 35 (2): 289-299.

Hendon, Julia A. \& Rosemary A. Joyce. 2004. Mesoamerican Archaeology. Blackwell Publishing, Oxford.

Heredia Espinoza, Verenice Y. 2006. Cities on Hills: Classic Society in Mesoamerica's Mixteca Alta. British Archaeological Reports, International Series 1728, Oxford.

Hermann Lejarazu, Manuel A. 2003. Códice Muro. Un documento mixteco colonial. Gobierno del Estado de Oaxaca / Secretaría de Asuntos Indígenas / Biblioteca Nacional de Antropología e Historia / CONACULTA-INAH, Oaxaca.

—. 2006. Códice Nuttall. Lado 1: la vida de 8 venado. Arqueología Mexicana, edición especial 23, Mexico.

- 2007a. La historia prehispánica de los señores de Nuu Na’a a través del Códice Muro. In: Raíces Mixtecas (Reina Ortiz Escamilla \& Ignacio Ortiz Castro, eds.): 93-147. Universidad Tecnológica de la Mixteca, Huajuapan.

— 2007b. Símbolos de Poder: un análisis comparativo entre la iconografía maya y los códices mixtecos. Estudios de Cultura Maya XXX: 79-106.

- 2008a. Los códices de la Mixteca Alta: historias de linajes y genealogías. Arqueología Mexicana XV, Núm. 90: 48-52.

- 2008b. Religiosidad y Bultos Sagrados en la Mixteca prehispánica. Desacatos 27: 75-94.

—. 2008c. Códice Nuttall Lado 2: La Historia de Tilantongo y Teozacualco. Arqueología Mexicana, edición especial 29, Mexico.

Hermann Lejarazu, Manuel A. \& Krystyna M. Libura. 2007. La Creación del Mundo según el Códice Vindobonensis. Ediciones Tecolote, Mexico.

Hernández Sánchez, Gilda. 2004. Temas rituales en la cerámica 'tipo códice' del estilo Mixteca-Puebla. Journal de la Société des Américanistes 90 (2): 7-34.

- 2005. Vasijas para Ceremonia. Iconografía de la Cerámica Tipo Códice del Estilo Mixteca Puebla. CNWS Research School of Asian, African and Amerindian Studies, Leiden. 
2006. Pre-columbian codex-style vessels from Central and South Mexico. A view into ancient ritual and worldview. Leiden Journal of Pottery Studies 22: 5-26.

- 2007. On the changes and continuities of present-day traditional pottery in Central Mexico. Leiden Journal of Pottery Studies 23: 159-176.

Herrera, Antonio de. 1947. Historia General de los Hechos de los Castellanos en las Islas y Tierra firme del Mar Océano. Madrid.

Hewitt de Alcántara, Cynthia. 1982. Boundaries and Paradigms: the anthropological study of rural life in postrevolutionary Mexico. Ph.D. dissertation, Leiden University.

Heyden, Doris,. 1974. La diosa madre: Itzpapalotl. Boletín del INAH, época II, 11: 3-14.

Himmerich y Valencia, Robert . 1991. The Encomenderos of New Spain, 1521-1555. University of Texas Press, Austin.

Historia Tolteca Chichimeca: see Kirchhoff \& Odena Güemes \& Reyes García 1976.

Hochleitner, Franz Joseph \& Ana Paula de Paula \& Helmut Krumbach. 1987. Novas Interpretações do Codex Vindobonensis. Universidade Federal de Juiz de Fora.

Hodder, Ian. 1995. Theory and Practice in Archaeology. Routledge, London / New York.

Houston, Stephen \& David Stuart \& Karl Taube . 2006. The Memory of Bones. Body, Being, and Experience among the Classic Maya. University of Texas Press, Austin.

Ibach, Thomas J. 1980. A Man Born of a Tree: a Mixtec Origin Myth. Tlalocan VIII: 243-247.

Ingold, Tim. 1993. The Temporality of the laqndscape. World Archaeology 25 (2): $152-174$.

- 2000. The Perception of the Environment. Essays in livelihood, dwelling and skill. Routledge, London \& New York.

Jansen, Maarten. 1979. Apoala y su importancia para la interpretación de los códices Vindobonensis y Nuttall. Actes du XLII Congrès International des Américanistes VII: 161-172. Parijs.

- 1982a. Viaje al Otro Mundo: La Tumba I de Zaachila. In: Los Indígenas de México en la época precolombina y en la actualidad (Maarten Jansen \& Ted Leyenaar eds.): 87-118. Rijksmuseum voor Volkenkunde, Leiden.

- 1982b. Huisi Tacu, estudio interpretativo de un libro mixteco antiguo: Codex Vindobonensis Mexicanus I. CEDLA, Amsterdam.

— 1985. Las lenguas divinas del México precolonial. Boletín de Estudios Latinoamericanos y del Caribe 38: 3-14. Amsterdam.

- 1987. Dzavuindanda, Ita Andehui y Iukano: historia y leyenda mixteca. Boletín de Estudios Latinoamericanos y del Caribe 42: 71-89. Amsterdam.

- 1988a. The Art of Writing in Ancient Mexico: an ethno-iconological perspective. Visible Religion VI: 86-113. E.J. Brill, Leiden.

. 1988b. Dates, Deities and Dynasties: non-durational time in Mixtec historiography. In: Continuity and Identity in Native America (Maarten Jansen \& Peter van der Loo \& Roswitha Manning eds.): 156-192. E.J. Brill, Leiden.

- 1989. Nombres históricos e identidad étnica en los códices mixtecos. Revista Europea de Estudios Latinoamericanos y del Caribe 47: 65-87. Amsterdam.

- 1992. Mixtec Pictography: Conventions and Contents. In: Handbook of Middle American Indians, Supplement 5: Epigraphy (Victoria Reifler Bricker ed.): 20-33. University of Texas Press, Austin.

- 1994. La Gran Familia de los Reyes Mixtecos. Libro explicativo de los llamados Códices Egerton y Becker II. Fondo de Cultura Económica, Mexico. 1996. Lord 8 Deer and Nacxitl Topiltzin. Mexicon XVIII (2): 25-29. 
1997a. Símbolos de Poder en el México Antiguo. Anales del Museo de América, 5: 73-102. Madrid.

- 1997b. La Princesa 6 Mono y el Héroe 8 Venado: una epopeya mixteca. In: Historia del Arte de Oaxaca (Margarita Dalton Palomo \& Verónica Loera y Chávez eds.) I: 211-237. Gobierno del Estado de Oaxaca.

— 1998a. El 'Rosario' de Taix y la Literatura Mixteca. Acervos 8/9: 24-32. Oaxaca. 1998b. Monte Albán y Zaachila en los Códices Mixtecos. In: The Shadow of Monte Albán. Politics and Historiography in Postclassic Oaxaca, Mexico (Maarten Jansen \& Peter Kröfges \& Michel Oudijk): 67-122. CNWS, Leiden.

- 1998c. La Fuerza de los Cuatro Vientos. Los manuscritos 20 y 21 del Fonds Mexicain. Journal de la Société des Américanistes 84 (2): 125-161. Paris. 1999. Los fundamentos para una 'lectura lírica' de los códices. Estudios de Cultura Náhuatl 30: 165-181. UNAM, México.

- 2002. Una mirada al interior del Templo de Cihuacoatl. Aspectos de la función religiosa de la escritura pictórica. In: Libros y Escritura de Tradición Indígena. Ensayos sobre los códices prehispánicos y coloniales de México (Carmen Arellano \& Peer Schmidt \& Xavier Noguez, eds.): 279-326. El Colegio Mexiquense, Zinacantepec.

- 2003. Monument en Verhaal in het Land van de Regengod. Inaugural address Leiden University, Koninklijke Nederlandse Akademie van Wetenschappen, Amsterdam.

- 2004. Archaeology and Indigenous Peoples: Attitudes towards Power in Ancient Oaxaca. In: A Companion to Archaeology (John Bintliff, ed.): 235-252. Blackwell Publishers, Oxford.

— 2006. Los Señoríos de Ñuu Dzaui y la Expansión Tolteca. Revista Española de Antropología Americana 36(2): 175-208. Universidad Complutense, Madrid.

Jansen, Maarten \& Peter Kröfges \& Michel Oudijk. 1998. The Shadow of Monte Albán. Politics and Historiography in Postclassic Oaxaca, Mexico. CNWS, Leiden.

Jansen, Maarten \& Ted J.J. Leyenaar. 1975. De Amate-geesten van San Pablito. In: Verre Naasten Naderbij 9 (1): 29-60. Leiden.

Jansen, Maarten \& G. Aurora Pérez Jiménez. 1980. Stoombaden in het Mixteekse Hoogland. Verre Naasten Naderbij 14 (3): 70-90. Rijksmuseum voor Volkenkunde, Leiden.

- 1983. The Ancient Mexican Astronomical Apparatus: an iconographical criticism. In: Archaeoastronomy VI (1-4): 89-95.

-1986. Iyadzehe Añute: valor literario de los códices mixtecos. In: Etnicidad y pluralismo cultural. La dinámica étnica en Oaxaca (Alicia M.Barabas \& Miguel A.Bartolomé eds.): 173-211. INAH, Mexico.

. 2000. La Dinastía de Añute. Historia, literatura e ideología de un reino mixteco. CNWS, Leiden. 2003. El Vocabulario del Dzaha Dzavui (Mixteco Antiguo), hecho por los padres de la Orden de Predicadores y acabado por Fray Francisco de Alvarado (1593). Edición Analítica. Online publication www.archeologie .leidenuniv.nl.

- 2005. Codex Bodley. A Painted Chronicle from the Mixtec Highlands, Mexico. Bodleian Library, Oxford.

. 2007a. Encounter with the Plumed Serpent. Drama and Power in the Heart of Mesoamerica. University of Colorado Press, Boulder.

— 2007b. Historia, literatura e ideología de Ñuu Dzaui. El Códice Añute y su contexto histórico-cultural. Instituto Estatal de Educación Pública, Oaxaca. [Second edition of Jansen \& Pérez Jiménez 2000, with facsimile edition of Codex Añute (Selden)] 
2009a. Voces del Dzaha Dzavui (mixteco clásico). Análisis y Conversión del Vocabulario de fray Francisco de Alvarado (1593). Gobierno del Estado de Oaxaca \& Colegio Superior para la Educación Integral Intercultural de Oaxaca \&Yuu Núú A.C., Mexico.

—_. 2009b. La Lengua Señorial de Ñu Dzaui. Cultura literaria de los antiguos reinos y transformación colonial. Gobierno del Estado de Oaxaca \& Colegio Superior para la Educación Integral Intercultural de Oaxaca \& Yuu Núú A.C., Mexico.

Jansen, Maarten \& Luis Reyes García (eds.). 1997. Códices, Caciques y Comunidades. Cuadernos de Historia Latinoamericana 5, AHILA (Asociación de Historiadores Latinoamericanistas Europeos), Ridderkerk.

Jansen, Maarten E.R.G.N. \& Laura N.K. van Broekhoven (eds.). 2008. Mixtec Writing and Society / Escritura de Nuu Dzaui. Royal Netherlands Academy of Arts and Sciences, Amsterdam.

Jansen, Maarten \& Marcus C. Winter. 1980. Un relieve de Tilantongo, Oaxaca, del año 13 Buho. Antropología e Historia 30: 3-19. Mexico.

Jaulin, Robert (ed.). 1976. El etnocidio através de las Américas. Siglo XXI Editores, Mexico.

Jaulin, Robert. 1979. La des-civilización. Política y práctica del etnocidio. Editorial Nueva Imagen, Mexico.

Jiménez Moreno, Wigberto. 1974. 'Primeros Memoriales' de Fray Bernardino de Sahagún. INAH, Mexico.

Jiménez Moreno, Wigberto \& Salvador Mateos Higuera. 1940. Códice de Yanhuitlan. Mexico.

Jiménez Muñoz, Victor \& Rogelio González Medina . 2009. Inquisición y Arquitectura. La "evangelización" y el ex-obispado de Oaxaca. Editorial RM, México.

Johansson, Patrick. 2007. La palabra, la imagen y el manuscrito. Lecturas indígenas de un texto pictórico en el siglo XVI. Universidad Nacional Autónoma de México, Mexico.

Johnsen, Harald \& Bjørnar Olsen. 1992. Hermeneutics and Archaeology: on the Philosophy of Contextual Archaeology. American Antiquity 57 (3): 419-436.

Johnson, Nicholas. 1997. The Route from the Mixteca Alta into Southern Puebla on the Lienzo of Tlapiltepec. In: Códices y Documentos sobre México, Segundo Simposio (Salvador Rueda Smithers, Constanza Vega Sosa, Rodrigo Martínez Baracs, eds.) vol I: 233-268. Instituto Nacional de Antropología e Historia, Mexico.

Jones, Lindsay. 1995. Twin City Tales. A hermeneutical reassessment of Tula and Chichén Itzá. University Press of Colorado, Boulder.

Josserand J. Kathryn. 1983. Mixtec dialect history. Ph.D. dissertation, Tulane University, New Orleans.

Joyce, Arthur A. 2010. Mixtecs, Zapotecs and Chatinos. Ancient Peoples of Southern Mexico. Wiley-Blackwell, Malden \& Oxford.

Joyce, Arthur A. \& Andrew G. Workinger \& Byron Hamann \& Peter Kroefges \& Maxine Oland \& Stacie M. King. 2004. Lord 8 Deer "Jaguar Claw" and the Land of the Sky: The Archaeology and History of Tututepec. Latin American Antiquity, Vol. 15 (3): 273-297.

Joyce, Rosemary A. 2000. Girling the Girl and Boying the Boy; the production of adulthood in Ancient Mesoamerica. World Archaeology 31 (3): 473-483.

- 2001. Gender and Power in Prehispanic Mesoamerica. University of Texas Press, Austin. 
Joyce, Rosemary A. \& Susan D. Gillespie. 2000. Beyond Kinship: Social and material reproduction in house societies. University of Pennsylvania Press, Philadelphia.

Joyce, Rosemary A. et al. 2002. The Languages of Archaeology. Blackwell Publishers, Oxford.

Julián Caballero, Juan. 2002. Educación y cultura, Formación comunitaria en Tlazoyaltepec y Huitepec, Oaxaca. CIESAS, Mexico.

- 2009. Nuu Davi, Yuku Yata. Comunidad, Identidad y Educación en la Mixteca (Mexico). Ph.D. dissertation, Leiden University (www.openaccess.leidenuniv.nl).

Kaemmerling, E. (ed.). 1979. Ikonographie und Ikonologie. Dumont, Cologne.

Kardulias, P. Nick (ed.). 1999. World-Systems Theory in Practice: Leadership, Production and Exchange. Rowman \& Littlefield Publishers, Lanham.

Katz, Esther. 1996. Recovering after Childbirth in the Mixtec Highlands (Mexico). In: Médicaments et Aliments: l'approche ethnopharmacologique, Actes du 2e Colloque Européen d'Ethnopharmacologie et de la 11e Conférance d'Ethnomédecine, Heidelberg (E. Schröder, G. Balansart, P. Caballon, J. Fleurentin, \& G. Mazars, eds.): 99-111. ORSTOM Editions \& Société Française d'Ethnopharmacologie, Paris.

- 2008. Vapor, aves, y serpientes. Meteorología en la 'Tierra de la Lluvia' (Mixteca alta, Oaxaca). In: Aires y Lluvias. Antropología del Clima en México (Annemaría Lammel \& Marina Goloubinoff \& Esther Katz eds.): 283-322. Centro de Investigaciones y Estudios Superiores en Antropología Social, Mexico.

Keen, Benjamin. 1971. The Aztec Image in Western Thought. Rutgers University Press, New Brunswick.

Kelley, David H. 1992. Yucatán y el imperio tolteca. Arqueología 8: 113-119.

King, Marc. 1988. Mixtec Political Ideology: Historical metaphors and the poetics of political symbolism. Ph.D. dissertation, University of Michigan, Ann Arbor.

1990. Poetics and Metaphor in Mixtec Writing. Ancient Mesoamerica 1(1): 141-151.

King, Stacie M. 2002. Social Practices and Social organization in Ancient Coastal Oaxacan Houselholds. Ph.D. dissertation, University of California, Berkeley.

Kiracofe, James B. 1995. Architectural Fusion and Indigenous Ideology in Early Colonial Teposcolula. The Casa de la Cacica: a Building at the Edge of Oblivion. Anales del Instituto de Investigaciones Estéticas 66: 45-84. Mexico.

Kirchhoff, Paul \& Lina Odena Güemes \& Luis Reyes García . 1976. Historia Tolteca Chichimeca. CISINAH \& INAH, Mexico.

Klein, Cecilia \& Eulogio Guzmán \& Elisa C. Mandell \& Maya Stanfield-Mazzi. 2002. The Role of Shamanism in Mesoamerican Art. A reassessment. Cultural Anthropology 43 (3): 383-419.

Köhler, Ulrich. 1979. In Memoriam Karl Anton Nowotny. Zeitschrift für Ethnologie 104 (1): 7-16.

Kohl, Karl-Heinz (ed.) 1982 Mythen der Neuen Welt, Zur Entdeckungsgeschichte Lateinamerikas. Frölich und Kaufmann, Berlin.

König, Viola. 1979. Inhaltliche Analyse und Interpretaction von Codex Egerton. Beiträge zur mittelamerikanischen Völkerkunde XV. Hamburg.

- 1984. Der Lienzo Seler II und seine Stellung innerhalb der Coixtlahuaca Gruppe. Baessler Archiv N.F. 32 (2): 229-320.

- 1993. Die Schlacht bei Sieben Blume. Konquistadoren, Kaziken und Konflikte auf alten Landkarten der Indianer Südmexikos. Edition Temmen, Bremen.

- 1998. Die Mixtekische Schrift. In: Die Bücher der Maya, Mixteken und Azteken (Carmen Arellano Hoffmann \& Peer Schmidt eds.): 103-147. Vervuert Verlag, Frankfurt am Main. 
Kowalewski, Stephen A. \& Andrew K. Balkansky \& Laura R. Stiver Walsh \& Thomas J. Pluckhahn \& John F. Chamblee \& Verónica Pérez Rodríguez \& Verenice Y. Heredia Espinoza \& Charlotte A. Smith. 2009. Origins of the Nuu. Archaeology in the Mixteca Alta, Mexico. University Press of Colorado, Boulder.

Kreichgauer, Damian. 1915-1916 Die Astronomie des Kodex Nuttall. Anthropos 10/11: 1-23. Vienna.

- 1917. Die Astronomie in der grossen Wiener Handschrift aus Mexiko. Sitzungsberichte der Akademie der Wissenschaften in Wien. Phil. hist. Klasse 182, Band 5.

Krumbach, Helmut. 1982. Schwitzbaddarstellungen und deren Symbolen in Bilderhandschriften. Zeitschrift für Ethnologie 107: 95-128. Braunschweig.

Kubler, George. 1961. On the Colonial Extinction of the Motifs of Pre-Columbian Art. In: Essays in Precolumbian Art and Archaeology (S.K. Lothrop, ed.): 14-34. Cambridge Mass.

Kuper, Adam. 1988. The invention of primitive society. Transformations of an illusion. Routledge, London/New York.

Kuschick, Ingrid. 1995. Medicina Popular en España. Siglo XXI editores, Mexico.

Lafaye, Jacques. 1976. Quetzalcóatl and Guadalupe. The formation of Mexican national consciousness 1531-1813. University of Chicago Press, Chicago / London.

Lamas, Marta. 1996. Las reglas de matrimonio entre los mixtecos. El caso de 8 Venado, "Garra de Tigre", rey de las dos Mixtecas. In; Cultura y Comunicación. Edmund Leach in memoriam (Jesús Jáuregui, María Eugenia Olavarría, Victor M. Franco Pellotier eds.): 121-127. CIESAS, Mexico.

Laurencich Minelli, Laura. 1999. A note on the Mesoamerican Codex Cospi. Journal de la Société des Américanistes 85: 375-386. Paris.

Lawn, Chris. 2006. Gadamer : A Guide for the Perplexed. Continuum, London \& New York.

Leclerq, Gerard. n.d. Antropología y Colonialismo. ENAH, Mexico.

Lehmann, Walter. 1938. Die Geschichte der Königreiche von Colhuacan und Mexico. W. Kohlhammer, Stuttgart \& Berlin.

Lehmann, Walter \& Ottokar Smital. 1929. Codex Vindobonensis Mexic. 1. Faksimileausgabe der mexikanischen Bilderhandschrift der Nationalbibliothek in Wien. Verlag von Anton Schroll \& Co, Vienna.

Lemaire, Ton. 1986. De Indiaan in ons bewustzijn. De ontmoeting van de Oude met de Nieuwe Wereld. Ambo, Baarn.

Lenz, Hans. 1948. El Papel Indígena Mexicano. Historia y Supervivencia. Editorial Cultura, Mexico. (reprint: SEP, Mexico 1973).

León, Nicolás. 1982 (1906). Códice Sierra. Reprint. Editorial Innovación, Mexico.

León-Portilla, Miguel. 1973. Alfonso Caso 1896-1970. American Anthropologist NS 75 (3): 877-885.

—_. 1974. La Filosofía Náhuatl estudiada en sus fuentes. Universidad Nacional Autónoma de México, Mexico.

—. 1996. Códice Alfonso Caso. La vida de 8-Venado, Gara de Tigre (ColombinoBecker I). Patronato Indígena, Mexico.

—. 1997a. El binomio oralidad y códices en Mesoamérica. Estudios de Cultura Náhuatl 27: 135-154. UNAM, México.

- 1997b. Los códices mesoamericanos. Grandes momentos en su investigación. In: Códices y Documentos sobre México. Segundo Simposio (Salvador Rueda Smithers, Constanza Vega Sosa y Rodrigo Martínez Baracs, eds.), I: 13-61. Consejo Nacional para la Cultura y las Artes \& Instituto Nacional de Antropología e Historia, México.

—. 2003. Códices. Los antiguos libros del nuevo mundo. Aguilar, Mexico. 
Lévi-Strauss, Claude. 1982. The Way of the Masks. University of Washington Press, Seattle.

Levin, Danna \& Federico Navarrete (eds.). 2007. Indios, mestizos y españoles. Interculturalidad e historiografía en la Nueva España. Biblioteca de Ciencias Sociales y Humanidades, Universidad Autónoma Metropolitana, Azcapotzalco.

Leyenaar, Ted. J.J. 1978. Ulama. The perpetuation in Mexico of the pre-Spanish ballgame ullamaliztli. Mededelingen Rijksmuseum voor Volkenkunde XXIII, Leiden.

Lienzos:

Lienzo of Otla, see Ruiz Ortiz \& Jansen 2009.

Lienzo of Tlapiltepec (= Lienzo Antonio de León), see Caso 1961.

Lienzo of Yucu Satuta (= Lienzo of Zacatepec), see Smith 1973a.

Lind, Michael. 1987. The Sociocultural Dimensions of Mixtec Ceramics. Vanderbilt University Publications in Anthropology, Nashville.

Lipschutz, Alejandro. 1975. El problema racial en la conquista de América. Siglo XXI Editores, Mexico.

Lockhart, James. 1992. The Nahuas after the Conquest. Stanford University Press, Stanford.

Long, Richard C.R. 1926. The Zouche Codex. Journal of the Royal Anthropological Institute LVI: 239-258.

Loo, Peter L. van der. 1987. Códices, Costumbres y Continuidad. Ph.D. dissertation, Leiden University.

Loomba, Ania. 1998. Colonialism / Postcolonialism. Routledge, London / New York. López Austin, Alfredo. 1973. Hombre-Dios. Religión y política en el mundo náhuatl. UNAM, Mexico.

- 1980. Cuerpo humano e ideología. UNAM, Mexico.

1994. Tamoanchan y Tlalocan. Fondo de Cultura Económica, Mexico.

López García, Ubaldo. 1991. Sa Taxisa'a Ñuyi, xi’in tse kuna’nu Ñuu Davi. CIESAS / Gobierno del Estado, Oaxaca.

- 1997. La presencia de Apoala en los códices mixtecos. In: Historia de Arte de Oaxaca (Margarita Dalton Palomo \& Verónica Loera y Chávez, eds.) I: 269-285. Gobierno del Estado de Oaxaca.

_. 1998. El uso cotidiano y ceremonial del mixteco de Apoala, Oaxaca. Tesis, CIESAS, Mexico.

—. 2001. Los Símbolos en la Cosmovisión de los Mixtecos. In: Presencias de la Cultura Mixteca (Reina Ortiz Escamilla \& Ignacio Ortiz Castro, eds.): 53-70. Universidad Tecnológica de la Mixteca, Huajuapan.

- 2007. Sa'vi. Discursos ceremoniales de Yutsa To'on (Apoala). PhD dissertation, Leiden University. (www.openaccess.leidenuniv.nl).

López García, Ubaldo (coord.). 1993. Tutu Ñu Na'a. Códice Muro. Instituto Oaxaqueño de las Culturas \& CIESAS, Oaxaca.

López Ruiz, Mariano. 1898. Estudio cronológico sobre la dinastía mixteca. Memorias de la Sociedad Científica 'Antonio Alzate' XI: 437-448.

Macaulay, Monica. 1996. A Grammar of Chalcatongo Mixtec. University of California Press. Berkeley/Los Angeles/London.

Machuca Gallegos, Laura. 2008. "Haremos Tehuantepec". Una historia colonial (siglos XVI-XVIII). Colección Diálogos, Oaxaca.

Magallón Anaya, Mario. 2006. De Abraham Castellanos a la educación alternativa de hoy. In: Ñuu Savi, la patria mixteca (Reina Ortíz Escamilla \& Ignacio Ortíz Castro, eds.): 157-201. Universidad Tecnológica de la Mixteca, Huajuapan.

Maldonado Alvarado, Benjamín. 2002. Auronomía y Comunalidad India. Enfoques y propuestas desde Oaxaca. CONACULTA-INAH / Secretaría de Asuntos Indígenas 
/ Coalición de Maestros y Promotores Indígenas de Oaxaca / Centro de Encuentros y Diálogos Interculturales, Oaxaca.

Maldonado Alvarado, Mauricio. 2009. Análisis macroscópico de las pieles de dos códices mixtecos. Educación Comunal 2: 171-190. Oaxaca.

Maldonado Alvarado, Mauricio \& Benjamín Maldonado Alvarado. 2004. La Sabiduría de las Pieles. De las técnicas de curtición de los códices a la curtiduría tradicional actual en Oaxaca. Instituto de Investigaciones en Humanidades de la Universidad Autónoma Benito Juárez de Oaxaca / Secretaría de Asuntos Indígenas del Gobierno del Estado / Centro INAH, Oaxaca.

Manning, Roswitha A.G.F.M. 1993. Vrouwen met goddelijke kracht. Godinnen en vroedvrouwen bij de Maya's. Ph.D. thesis, Leiden University.

Map of Chiyo Cahnu (= Map of Teozacualco), see Caso 1949, Acuña 1984 (II) and Anders \& Jansen 1988.

Marcus, Joyce. 1992. Mesoamerican Writing Systems: propaganda, myth and history in four ancient civilizations. Princeton University Press.

Marcus, Joyce \& Judith F. Zeitlin (eds.). 1994. Caciques and their People. A Volume in Honor of Ronald Spores. Anthropological Papers, Museum of Anthropology, University of Michigan 89, Ann Arbor.

Martin, Simon \& Nikolai Grube. 2000. Chronicle of the Maya Kings and Queens. Deciphering the Dynasties of the Ancient Maya. Thames \& Hudson, London.

Martínez Gracida, Manuel. 1883. Colección de Cuadros sinópticos de los pueblos, haciendas y ranchos del Estado libre y soberano de Oaxaca. Oaxaca.

- 1986. Los Indios Oaxaqueños y sus monumentos arqueológicos. Gobierno del Estado de Oaxaca.

Martínez Gracida, Manuel \& Mariano López Ruiz. 1906. Ita Andehui. Leyenda Mixteca. Talleres tipográficos de J.S. Soto, Oaxaca.

Mason, Peter. 1990. Deconstructing America. Representations of the Other. Routledge, London/New York.

Matadamas Díaz, Raúl. 1997. Pictografías de San Pedro Jaltepetongo, Cuicatlan. In: Historia del Arte de Oaxaca (Margarita Dalton Palomo \& Verónica Loera y Chávez eds.) I: 201-209. Oaxaca.

- 2001. Pictografías del norte de Oaxaca ¿escritura periférica zapoteca? In: Procesos de cambio y conceptualización del tiempo. Memoria de la Primera Mesa Redonda de Monte Albán. (Nelly Robles García, ed.): 185-201. INAH, México.

- 2005. Jaltepetongo, Tumba 1. In: La Pintura Mural Prehispánica en México. Oaxaca, tomo II Catálogo (Beatriz de la Fuente and Bernd Fahmel Beber, eds.): 392-409. Instituto de Investigaciones Estéticas, Universidad Nacional Autónoma de México. Mexico.

Matute, Alvaro. 1976. Lorenzo Boturini y el pensamiento histórico de Vico. UNAM, Mexico.

McAnany, Patricia A. 1995. Living with the Ancestors. Kinship and Kingship in Ancient Maya Society. University of Texas Press, Austin.

McCafferty, Sharisse D. \& Geoffrey G. McCafferty. 1994. Engendering Tomb 7 at Monte Albán. Respinning an Old Yarn. Current Anthropology 35: 2, pp. 143-166. Chicago.

- 2006. Weaving Space: Textile Imagery and Landscape in the Mixtec Codices. In: Space and Spatial Analysis in Archaeology (Elizabeth C. Robertson, Jeffrey D. Seibert, Deepica C. Fernandez, Marc U. Zender, eds.): 334-341. University of Calgary Press.

Melgarejo Vivanco, José Luis. 1980. El Códice Vindobonensis. Instituto de Antropología, Universidad Veracruzana, Xalapa. 1991. Códice Nuttall. Tres historias medievales. Gobierno del Estado de Veracruz, Xalapa. 
Méndez Martínez, Enrique \& Enrique Méndez Torres

—. 2007a. Historia de Zaachila, Cuilapan y Xoxocotlan. Tres pueblos unidos por sus orígenes. Instituto Cultural Oaxaqueño, Oaxaca.

— 2007b. Origen del pueblo Montaña que escupe y sus gobernantes. In: Raíces mixtecas (Reina Ortíz Escamilla \& Ignacio Ortíz Castro, eds.): 65-92. Universidad Tecnológica de la Mixteca, Huajuapan.

- 2008. Historia de Yya Dzehe (Princesa) Nu Nuu (6 Mono) "Quechquemitl de Serpiente”. In: Caminos de la Historia Mixteca (Reina Ortíz Escamilla, ed.): 43-60. Universidad Tecnológica de la Mixteca, Huajuapan.

Mikulska-Dąbrowska, Katarzyna. 2008. El Lenguaje Enmascarado. Un acercamiento a las representaciones gráficas de deidades nahuas. Instituto de Investigaciones Antropológicas, Universidad Nacional Autónoma de México/Sociedad Polaca de Estudios Latinoamericanos/Instituto de Estudios Ibéricos e Iberoamericanos, Universidad de Varsovia, Mexico.

Miller, Arthur G. 1975. Codex Nuttall. Dover Publications, New York.

Mitchell, W.J.T. 1994. Picture Theory. University of Chicago Press, Chicago/London.

Mohar Betancourt, Luz María \& Rita Fernández Díaz. 2006. El Estudio de los Códices. Desacatos 22: 9-36. CIESAS, Mexico.

Molina, Fray Alonso de. 1970. Vocabulario en Lengua Castellana y Mexicana. Editorial Porrúa, México.

Molloy, John P. 1983. Dynasts and Revolutionists. A synthesis of Toltec chronology and history. Ph.D. dissertation. University of Arizona, Tucson.

Monaghan, John. 1990a. Performance and the Structure of the Mixtec Codices. Ancient Mesoamerica 1: 133-140.

- 1990b. Sacrifice, Death, and the Origins of Agriculture in the Codex Vienna. American Antiquity 55: 559-569.

- 1995. The Covenants with Earth and Rain. Exchange, sacrifice, and revelation in Mixtec sociality. University of Oklahoma Press, Norman.

. 1997. Mixtec caciques in the nineteenth and twentieth centuries. In: Códices, Caciques y Comunidades. (Maarten Jansen \& Luis Reyes García eds.): 265-281. Cuadernos de Historia Latinoamericana 5, AHILA (Asociación de Historiadores Latinoamericanistas Europeos).

Monaghan, John \& Arthur Joyce \& Ronald Spores. 2003. Transformations of the indigenous cacicazgo in the nineteenth century. Ethnohistory 50 (1): 131-150.

Moser, Christopher L. 1977. Nuiñe Writing and Iconography of the Mixteca Baja. Vanderbilt University Publications in Anthropology 19, Nashville.

Motolinia, Fray Toribio de Benavente . 1969. Historia de los Indios de la Nueva España (edited by Edmundo O' Gorman). Editorial Porrúa, Mexico.

Müller, Frank G.J.M. 1994a. The So-called Peleus and Thetis Sarcophagus in the Villa Albani. J.C. Gieben Publisher, Amsterdam.

- 1994b. The Wall paintings from the Oecus of the Villa of Publius Fannius Synistor in Boscoreale. J.C. Gieben Publisher, Amsterdam.

. 1994c. The Aldobrandini Wedding. J.C. Gieben Publisher, Amsterdam.

Mullen, Robert J. 1995. The Architecture and Sculpture of Oaxaca, 1530s-1980s. Arizona State University, Tempe.

Mundy, Barbara E. 1996. The Mapping of New Spain. Indigenous cartography and the maps of the Relaciones Geográficas. University of Chicago Press, Chicago / London.

Musiro, Stichting voor Indiaanse Cultuur (ed.)

. 1989. La Visión India: tierra, cultura, lengua y derechos humanos. Archeologisch Centrum, Leiden.

Myers, J.N.L., et al. 1951. The Bodleian Library in the Seventeenth Century. Guide to an Exhibition held during the Festival of Britain 1951. Bodleian Library, Oxford. 
Navarrete Linares, Federico. 2000. Nahualismo y Poder: un Viejo binomio mesoamericano. In: El Héroe entre el Mito y la Historia (Federico Navarrete \& Guilhem Olivier, eds.): 155-179. Universidad Nacional Autónoma de México, Mexico.

Nicholson, H.B. 1978. The deity 9 Wind 'Ehecatl-Quetzalcoatl' in the Mixteca Pictorials. Journal of Latin American Lore 4 (1): 61-92.

- 2001. Topiltzin Quetzalcoatl. The once and future lord of the Toltecs. Boulder: University Press of Colorado.

Nielsen, Jesper. 2009. Worms Mexicanske Hieroglypher om en Kopi af et Mixtekisk Håndskrift i det Kongelige Bibliotek. Fund og Forsking i det Kongelige Biblioteks Samlinger 48: 109-125. Copenhagen.

Nora, Pierre. 1989. Between Memory and History: les Lieux de mémoire. Representations 26: 7-24.

Nowotny, Karl Anton. 1948. Erläuterungen zum Codex Vindobonensis (Vorderseite). Archiv für Völkerkunde III: 156-200.

—. 1959a. Ueber Aufgaben der mexikanistik, Erschließung neuer Geschichtsquellen, religionswissenschaftliche Probleme. Archiv für Völkerkunde XIV: 119131. Vienna.

— 1959b. Die Hieroglyphen des Codex Mendoza: der Bau einer mittelamerikanischen Wortschrift. Mitteilungen Museum für Völkerkunde und Vorgeschichte Hamburg, XXV: 97-113.

. 1959c. Die Bilderfolge der Codex Vindobonensis und verwandter Handschriften. Archiv für Völkerkunde XIII: 210-221.

-1960. Mexikanische Kostbarkeiten aus Kunstkammern der Renaissance. Museum für Völkerkunde, Vienna.

- 1961a. Tlacuilolli, die mexikanischen Bilderhandschriften, Stil und Inhalt, mit einem Katalog der Codex Borgia Gruppe. Monumenta Americana. Gebr. Mann, Berlin. English translation: Tlacuilolli: Style and Contents of the Mexican Pictorial Manuscripts with a Catalog of the Borgia Group, University of Oklahoma Press, Norman 2005.

—. 1961b. Codices Becker I/II. ADEVA, Graz.

—. 1967. Die Mexikanische Bilderschrift. Studium Generale XX (9): 584-594. Berlin.

- 1975. El Fragmento de Nochistlan. Beiträge zur mittelamerikanischen Völkerkunde XIII. Hamburg.

- 1976. Codex Borgia. ADEVA, Graz.

- 1980. Die Krise der Völkerkunde. Zeitschrift für Ethnologie 105: 113-124.

Nuttall, Zelia. 1902. Codex Nuttall. Peabody Museum of American Archaeology and Ethnology, Harvard University, Cambridge Mass.

Offner, Jerome A. 1983. Law and politics in Aztec Texcoco. Cambridge University Press.

Ojeda Díaz, María de los Angeles. 2002. Una Yakua, señor 8 venado. La historia de un hombre-dios en el códice colombino. In: La Tierra del Sol y de la Lluvia (Reina Ortiz Escamilla \& Ignacio Ortiz Castro, eds.): 35-98. Universidad Tecnológica de la Mixteca, Huajuapan.

—. 2005. Iya Si I Huidzu, "Ñuu Dzavui Ñuu Ñuhu” Señor 11 jaguar "Dios de la lluvia friso de fuego" y la fundación de Yucu Sa Tuta en el Lienzo de Zacatepec. In: Pasado y presente de la Cultura Mixteca (Reina Ortiz Escamilla \& Ignacio Ortiz Castro, eds.): 15-76. Universidad Tecnológica de la Mixteca, Huajuapan.

Olivier, Guilhem. 2007. Sacred Bundles, Arrows, and New Fire. Foundation and Power in the Mapa de Cuauhtinchan No.2. In: Cave, City, and Eagle's Nest. An Interpretive Journey through the Mapa de Cuauhtinchan No. 2 (David Carrasco \& Scott Sessions, eds.): 281-313. University of New Mexico Press, Albuquerque. 
Olivier, Guilhem (ed.). 2008. Símbolos de poder en Mesoamérica. Universidad Nacional Autónoma de México, Mexico.

Olko, Justyna . 2005. Turquoise Diadems and Staffs of Office. Elite costume and insignia of power in Aztec and Early Colonial Mexico. Sowa, Warsaw.

Ong, Walter J. 1982. Orality and Literacy. The Technologizing of the Word. Methuen \& Co, London.

Ordahl Kupperman, Karen (ed.) . 1995. America in European Consciousness, 14931750. University of North Carolina Press, Chapel Hill / London.

Orlandi, Stefano. 1952. La Biblioteca di S. Maria Novela in Firenze dal sec. XIV al sec. XIX. Florence.

Ortiz Lajous, Jaime. 1994. Oaxaca: Tesoros de la Alta Mixteca. Mosaico Mexicano, Mexico.

Ortiz Castro, Ignacio. 2006. Acercamiento a la filosofía y la ética del mundo mixteco. Secretaría de Cultura del Gobierno del Estado de Oaxaca, Oaxaca.

Otte, Enrique. 1970. La Nueva España en 1529. In: Historia y Sociedad en el Mundo de Habla Española. Homenaje a José Miranda (Bernardo Garcia Martínez, ed.): 95-111. El Colegio de México, Mexico.

Oudijk, Michel R. 2000. Historiography of the Bènizàa. The Postclassic and Early Colonial Periods (1000-1600 AD). CNWS, Leiden.

- 2002. La toma de posesión: un tema mesoamericano para la legitimización del poder. Relaciones 23 (91): 95-132. Zamora. 2008. De tradiciones y métodos: investigaciones pictográficas. Desacatos 27: 123-138.

Oudijk, Michel R. \& Maarten Jansen.2000. Changing Histories in the Lienzos of Guevea and Santo Domingo Petapa. Ethnohistory 47 (2): 281-332. Duke University Press.

Oudijk, Michel R. \& Sebastián van Doesburg. 2007. A New Pictorial from Tilantongo. Mexicon XXIX : 45-49.

Ouweneel, Arij \& Simon Miller (eds.). 1990. The Indian Community of Colonial Mexico. Fifteen Essays on Land Tenure, Corporate Organizations, Ideology and Village Politics. Latin American Studies 58, CEDLA, Amsterdam.

Paddock, John (ed.). 1966. Ancient Oaxaca. Discoveries in Mexican Archaelogy and History. Stanford University Press, Stanford.

Paddock, John. 1983. Lord 5 Flower's Family. Rulers of Zaachila and Cuilapan. Vanderbilt University Publications in Anthropology 29. Nashville.

Paillés Hernández, María de la Cruz. 1993a. Documentos del archivo del doctor Alfonso Caso para el estudio de la Mixteca (Ramo Tierras). INAH, Mexico.

Paillés Hernández, María de la Cruz. 1993b. Documentos del archivo del doctor Alfonso Caso para el estudio de la Mixteca (Ramo Civil). INAH, Mexico.

Palmer, Richard E. 1969. Hermeneutics. Northwestern University Press, Evanston, Illinois.

Parmenter, Ross. 1966. Break-through on the 'Lienzo de Filadelfia'. Expedition 8 (2): $14-22$.

1982. Four Lienzos of the Coixtlahuaca Valley. Dumbarton Oaks, Washington.

1993. The Lienzo of Tulancingo, Oaxaca: an introductory study of a ninth painted sheet from the Coixtlahuaca Valley. Transactions of the American Philosophical Society 83, part 7.

- 1997. A Nativitas Ruler List on Lienzo A. In: Códices y Documentos sobre México, Segundo Simposio (Salvador Rueda Smithers, Constanza Vega Sosa, Rodrigo Martínez Baracs, eds.) vol I: 269-303. Instituto Nacional de Antropología e Historia, Mexico.

Pastor, Rodolfo. 1987. Campesinos y Reformas: La Mixteca, 1700-1856. El Colegio de México, México. 
Paulat Legorreta, Jorge . 1969. Una leyenda mixteca. Anales del INAH, séptima época, I: $181-184$.

- 1972. Una Crónica de la Condición Humana: La historia de la discriminación del indio. Academia Nacional de Ciencias, Mexico.

Pels, Peter. 1997. The Anthropology of Colonialism: Culture, History and the Emergence of Western Governmentality. Annual Review of Anthropology 26: 163-183.

Pérez Jiménez, Gabina Aurora. 1982. La imagen mutilada de los Indígenas. In: Los Indígenas de México en la época precolombina y en la actualidad (Maarten Jansen \& Ted Leyenaar eds.): 23-28. Leiden.

- 1984. Mexico: bilingual-bicultural education, a synthesis of documents of APIBAC. In: IWGIA Newsletter 38: 90-103. Copenhagen.

— 1989. Somos víctimas de una ciencia colonialista y de un indigenismo internacional. In: La Visión India: tierra, cultura, lengua y derechos humanos (Musiro ed.): 421-426. Centro Arqueológico, Universidad de Leiden.

- 1990. Intimidazione, inganno e violenza nel territorio mixteco (Messico). In: Natura e Ambiente. Lo Sguardo Indio (Antonella Camarrota ed.): 25-40. Armando Siciliano Editore, Messina.

—. 1991. I Diritti Umani e i Popoli Indigeni in Messico. In: Diritti Umani, Diritti dei popoli: le popolazioni indigene del Centro America (Antonella Cammarota ed.): 97-110. Armando Siciliano Editore, Messina.

- 1999. Popoli indigeni: gioco coloniale e cultura della povertà. In: I Colori degli Indios. Le culture indigene: in Nord impara dal Sud (Antonella Cammarota ed.): 16-33. Coordinamento delle Organizzazioni non governative per la Cooperazione Internazionale allo Sviluppo, Roma.

—. 2008. Sahìn Sàu. Curso de Lengua Mixteca (variante de Nuù Ndéyá) con notas históricas y culturales. Colegio Superior para la Educación Integral Intercultural de Oaxaca, Oaxaca.

Pérez Jiménez, G. Aurora \& Maarten Jansen

. 1979. Los códices y la conciencia de ser indígena. Revista Mexicana de Ciencias Políticas y Sociales 97: 83-104. Mexico.

- 2006. Native Culture and Colonial Structure. In: The Social and Linguistic Heritage of Native Peoples in the Americas. The struggle to maintain cultural particularity (Laura van Broekhoven, ed.): 177-219. Edwin Mellen Press, Lewiston / Queenston / Lampeter.

Pérez Ortiz, Alfonzo. 2003. Tierra de Brumas. Conflictos en la Mixteca Alta, 15231550. Plaza y Valdés Editores, Mexico.

Pérez Reyes, Tomás. 2008. La Genealogía de Tlazultepec, una pictografía mixteca del siglo XVI. In: Caminos de la Historia Mixteca (Reina Ortíz Escamilla, ed.): 61-115. Universidad Tecnológica de la Mixteca, Huajuapan.

Pérez-Rocha, Emma \& Rafael Tena. 2000. La Nobleza Indígena del Centro de México después de la Conquista. Instituto Nacional de Antropología e Historia, Mexico.

Pérez Rodríguez, Verónica. 2006. States and households: the social organization of terrace agriculture in Postclassic Mixteca Alta, Oaxaca, Mexico. Latin American Antiquity 17 (1): 3-22.

Philip, Ian. 1984. The Bodleian Library in the Seventeenth and Eighteenth Centuries. Clarendon Press, Oxford.

Pohl, John M.D. 1994. The Politics of Symbolism in the Mixtec Codices. Vanderbilt University Publications in Anthropology 46, Nashville.

— 2005. The Griffin Fragment: a Mixtec Drinking Vessel portraying the place sign for 'Hill of the Turkey'. Record of the Art Museum, Princeton University 64: $80-90$. 
2007. Narrative Mixtec Ceramics of Ancient Mexico. Princeton University Program in Latin American Studies.

Pohl, John M. D. \& Bruce E. Byland. 1996. Identification of the Xipe Bundle- Red and White Bundle place sign in the Mixtec codices. Journal of Latin American Lore 19(1-2):3-29

Pohl, John M. D. \& John Monaghan \& Laura R. Stiver. 1997. Religion, Economy and Factionalism in Mixtec Boundary Zones. In: Códices y Documentos sobre México. Segundo Simposio (Salvador Rueda Smithers \& Constanza Vega Sosa \& Rodrigo Martínez Baracs, eds.) vol I: 205-232. Instituto Nacional de Antropología e Historia, Mexico.

Prem, Hanns J. 1974. Matrícula de Huexotzingo. ADEVA, Graz.

Preucel, Robert W. 2006. Archaeological Semiotics. Blackwell Publishing, Oxford.

Preucel, Robert W. \& Ian Hodder (eds.). 1996. Contemporary Archaeology in Theory: a Reader. Blackwell Publishers, Oxford.

Quiñones Keber, Eloise. 1995. Codex Telleriano-Remensis. Ritual, Divination, and History in a Pictorial Aztec Manuscript. University of Texas Press, Austin.

Rabin, Emily. 1974. Some problems of chronology in the Mixtec historical manuscripts, Part I. Paper presented at the XLI International Congress of Americanists, Mexico.

- 1976. Some problems of chronology in the Mixtec historical manuscripts, Part II. Paper presented at the second Cambridge symposium on recent research in Mesoamerican archaeology, University of Cambridge.

- 1979. The War of Heaven in Codices Zouche-Nuttall and Bodley. A preliminary study. Actes du XLII Congrès International des Américanistes VII: 171-182. Paris.

- 1981. Chronology of the Mixtec Historical Codices: an overview. Paper, Annual Meeting American Society for Ethnohistory, Colorado Springs.

- 2004. Toward a Unified Chronology of the Historical Codices and Pictorial Manuscripts of the Mixteca Alta, Costa and Baja: an Overview. In: Homenaje a John Paddock (Patricia Plunket, ed.): 101-136. UDLA, Puebla.

Ramírez Zarza, Javier. 2004. Educación y Revolución, por el alma nacional. Semblanza biográfica del maestro Abraham Castellanos. Oaxaca.

Rappaport, Roy A. 1999. Ritual and Religion in the Making of Humanity. Cambridge University Press.

Ravicz, Robert. 1961. La Mixteca en el estudio comparativo del hongo alucinante. Anales del INAH XIII: 73-92.

- 1965. Organización Social de los Mixtecos. Instituto Nacional Indigenista, Mexico.

Redmond, Elsa M. 1998. Chiefdoms and Chieftaincy in the Americas. University Press of Florida.

Renfrew, Colin \& Paul Bahn. 1996. Archaeology: Theories, Methods and Practice. Thames \& Hudson, London.

Renfrew, Colin \& John F. Cherry (eds.). 1986. Peer Polity Interaction and Socio-Political Change. Cambridge University Press, Cambridge.

Resines Llorente, Luis. 2007. Diccionario de los Catecismos Pictográficos. Simancas Ediciones S.A., Diputación de Valladolid.

Restall, Matthew. 2003. A History of the New Philology and the New Philology in History. Latin American Research Review 38 (1): 113-134/

Reyes, Fray Antonio de los. 1593. Arte en Lengua Mixteca. Casa de Pedro Bailli, Mexico.

- 1976. Arte en Lengua Mixteca. Vanderbilt University Publications in Anthropology 14, Nashville. 
Reyes García, Luis (ed.). 1993. La escritura pictográfica en Tlaxcala. Universidad Autónoma de Tlaxcala, Tlaxcala.

Reyes García, Luis, con una contribución de Remco Jansen. 1997. Matrícula de Tributos o Códice de Moctezuma. Fondo de Cultura Económica, México.

Reyes Hernández, Zoila. 2005. Sólo soy una mujer. Universidad Autónoma Benito Juárez de Oaxaca / MC editores, Mexico.

Ricoeur, Paul. 1976. Interpretation Theory. Discourse and the surplus of meaning. Texas Christian University Press, Fort Worth.

- 1984-1988. Time and Narrative. University of Chicago Press, Chicago \& London.

Rincón Mautner, Carlos . 1999. Man and the Environment in the Coixtlahuaca Basin of Northwestern Oaxaca. Two Thousand Years of Historical Ecology. Ph.D. thesis, University of Texas, Austin.

- 2007. A study of the Lienzo de San Jeronimo Otla from the Coixtlahuaca Basin of Oaxaca, Mexico. Latin American Indian Literatures Journal 23 (1): 74-95.

Ringle, William \& Tomas Gallerta \& George Bey. 1999. The Return of Quetzalcoatl. Evidence for the Spread of a World Religion during the Epiclassic Period. Ancient Mesoamerica 9: 183-232.

Rivera Guzmán, Ángel Iván. 2000. La iconografía del poder durante el Clásico en la Mixteca Baja de Oaxaca. Evidencia iconográfica y arqueológica. Cuadernos del Sur 15: 5-36.

- 2002. La iconografía del poder en los grabados del cerro de La Caja, Mixteca Baja de Oaxaca. In: Iconografía mexicana IV: Iconografía del poder (Beatriz Barba de Piña Chan, ed.): 49-74. Instituto Nacional de Antropología e Historia, Mexico.

- 2004. Gobernantes mixtecos: sus imágenes en piedra. In: Personajes e Instituciones del Pueblo Mixteco (Reina Ortíz Escamilla \& Ignacio Ortíz Castro, eds.): 9-17. Universidad Tecnológica de la Mixteca, Huajuapan.

- 2008. La iconografía de la pintura mural de la tumba de Ixcaquixtla, sureste de Puebla, México. In: Caminos de la Historia Mixteca (Reina Ortíz Escamilla, ed.): 15-41. Universidad Tecnológica de la Mixteca, Huajuapan.

Robertson, Donald. 1959. Mexican Manuscript Painting of the Early Colonial Period: the Metropolitan Schools. New Haven.

. 1970. The Tulum Murals: the International Style of the Late Postclassic. Actas del XXXVIII Congreso Internacional de Americanistas (Stuttgart-München) II: $77-88$.

- 1982. Some Comments on Mixtec Historical Manuscripts. In: Aspects of the Mixteca-Puebla Style (Doris Stone, ed.) MARI Occasional Papers 4. Tulane University, New Orleans.

Robles García, Nelly M. (ed.). 2004. Estructuras Políticas en el Oaxaca Antiguo. Memoria de la Tercera Mesa Redonda de Monte Albán. CONACULTA-INAH, Mexico.

Robles García, Nelly M. \& Alberto Juárez Osnaya . 2004. Historia de la Arqueología en Oaxaca. Instituto Oaxaqueño de Culturas / Gobierno del Estado de Oaxaca / CONACULTA-INAH, Oaxaca.

Röck, Fritz. 1935. Ein altindianisches Bilderbuch. Frohes Schaffen XI, pp. 193-204. Vienna.

- 1937. Getarnte Himmelskunde in altmexikanischen Bilderhandschriften. Forschungen und Fortschritte 13, pp. 356-57. Berlin.

Rodríguez Cano, Laura. 1996. El sistema de escritura ñuiñe: análisis del corpus de piedras grabadas de la zona de la Cañada en la Mixteca Baja, Oaxaca. Tesis ENAH, Mexico. 
2006. Códices de la Mixteca Baja de la Época Colonial. In: Ñuu Savi, la patria mixteca (Reina Ortíz Escamilla \& Ignacio Ortíz Castro, eds.): 37-86. Universidad Tecnológica de la Mixteca, Huajuapan.

- 2007. Geografía histórica de la Mixteca Baja a través de su toponimia. In: Raíces mixtecas (Reina Ortíz Escamilla \& Ignacio Ortíz Castro, eds.): 177-242. Universidad Tecnológica de la Mixteca, Huajuapan.

- 2008. Toponymic Analysis of Three Lienzos from the Mixtec Lowlands, Oaxaca. www.famsi.org/reports

Rodríguez Cano, Laura \& Ángel Iván Rivera Guzmán \& Júpiter Martínez Ramírez

1996-1999 Piedras Grabadas de la Mixteca Baja, Oaxaca. Anales de Antropología 33: 165-205. UNAM, Mexico.

Rogers, David. 1991. The Bodleian Library and its Treasures, 1340-1700. Aidan Ellis, Oxford.

Romero Frizzi, Ma. de los Angeles. 1996. El sol y la cruz. Los pueblos indios de Oaxaca colonial. CIESAS \& INI, Mexico.

Romero Frizzi, Ma. de los Angeles (ed.). 2003a. Escribir para Dos Mundos. Testimonios y Experiencias de los Escritores Mixtecos. Voces del Fondo, IEEPO, Oaxaca.

. 2003b. Escritura zapoteca: 2,500 años de historia. CIESAS / CONACULTAINAH, Mexico.

Romney, Kimball \& Romaine Romney. 1966. The Mixtecans of Juxtlahuaca, Mexico. Wiley, New York / London / Sydney.

Roskamp, Hans 1999. La Historiografía Indígena de Michoacán: El Lienzo de Jucutácato y los Títulos de Carapan. CNWS, Leiden.

Rossell, Cecilia \& María de los Ángeles Ojeda Díaz. 2003. Las mujeres y sus diosas en los códices prehispánicos de Oaxaca. CIESAS / Grupo Editorial Miguel Ángel Porrúa, Mexico.

Ruiz Cervantes, Francisco José \& Carlos Sánchez Silva. 1997. La Ciudad de Oaxaca a través de sus Planos. Instituto Oaxaqueño de las Culturas, Oaxaca.

Ruiz de Alarcón, Hernando et al.1953 (1629) Tratado de las idolatrías, supersticiones, dioses, ritos, hechicerías y otras costumbres gentílicas de las razas aborígenes de México. Ediciones Fuente Cultural, Mexico.

Ruiz Gallut, María Elena (ed.). 2002. Ideología y política a través de materiales, imágenes y símbolos. Memoria de la Primera Mesa Redonda de Teotihuacan. CONACULTA-INAH / UNAM, Mexico.

Ruiz Ortiz, Victor Hugo \& Maarten E.R.G.N. Jansen. 2009. El Lienzo de Otla. Memoria de un Paisaje Sagrado. Gobierno del Estado de Oaxaca \& Yuu Núú A.C., Mexico.

Sahagún, Fray Bernardino de. 1975. Historia General de las cosas de Nueva España (edited by Angel María Garibay). Editorial Porrúa, Mexico.

- 1950-1978 Florentine Codex, General History of the Things of New Spain (edited and translated by Arthur J.O. Anderson and Charles E. Dibble). The School of American Research/University of Utah, Santa Fe.

Sánchez Sánchez, Ernesto L. 2007. Kuentu, jnuhun vii ti ja jini jnuni jiin san sau ñuu Yosondúa, Oaxaca. Instituto Nacional de Lenguas Indígenas, Mexico.

Sandstrom, Alan R. . 1991. Corn is our Blood. University of Oklahoma Press, Norman.

Santiago López, Félix Arturo (coord.). 2006. Memoria Histórica de Santa María Yucuhiti-Ocotepeque, Tlaxiaco, Oaxaca. Colegio de Investigadores en Educación, Oaxaca.

Santos Gómez, Hugo \& Yanga Villagómez Velázquez. 1998. En señal de verdadera posesión. Mitos y ritos agrarios del Oaxaca colonial. Acervos 8/9: 33-37. Oaxaca.

Saussure, Henri de . 1891. Antiquités mexicaines. Geneva.

Schele, Linda and Jeffrey Miller. 1983. The Mirror, the Rabbit and the Bundle. Dumbarton Oaks, Washington. 
Scholes, France V. \& Eleanor Adams. 1961. Cartas del Licenciado Jerónimo Valderrama y otros documentos sobre su visita al gobierno de Nueva España 1563-1565. José Porrúe e Hijos, Sucs, Mexico.

Schultze Jena, Leonhard. 1933-1938 Indiana (3 vols). Gustav Fischer, Jena.

Séjourné, Laurette. 1987. El Pensamiento Náhuatl cifrado por los calendarios. Siglo XXI, Mexico.

Seler, Eduard. 1904-1909. Codex Borgia. Eine altmexikanische Bilderschrift der Bibliothek der Congregatio de Propaganda Fide (3 tomos). Berlin.

-1960-1961(02/23) Gesammelte Abhandlungen zur Amerikanishen Sprach- und Alterthumskunde (I-V). ADEVA, Graz.

—. 1963. Comentarios al Códice Borgia. (traducción española de Seler 19041909). Fondo de Cultura Económica, México. Reprint 1988.

Sepúlveda y Herrera, María Teresa. 1994. Códice de Yanhuitlan. INAH \& Benemérita Universidad de Puebla, Mexico.

- 1999. Procesos por idolatría al cacique, gobernadores y sacerdotes de Yanhuitlan, 1544-1546. INAH, Mexico.

Simonin, Martine. 1998. Manuscrit Aubin No. 20. Presses Universitaires du Septentrion, Villeneuve d'Ascq.

Simons, Bente Bittmann. 1963. Hieroglyphica Mexicana, a manuscript in the Royal Library at Copenhagen. Tlalocan IV (2): 169-172.

Smith, Linda Tuhiwai. 1999. Decolonizing Methodologies. Research and Indigenous Peoples. Zed Books, London/New York.

Smith, Mary Elizabeth. 1973a. Picture Writing from Ancient Southern Mexico, Mixtec Place Signs and Maps. University of Oklahoma Press, Norman.

- 1973b. The Relationship between Mixtec manuscript painting and the Mixtec language. In: Meso-american Writing Systems (Elizabeth P. Benson ed.): 47-98. Dumbarton Oaks, Washington.

- 1979. Codex Becker II: a manuscript from the Mixteca baja? Archiv für Völkerkunde 33, pp. 29-43.

1983. Codex Selden: a manuscript from the Valley of Nochixtlan. In: The Cloud People: Divergent Evolution of the Zapotec and Mixtec Civilizations (Kent V. Flannery \& Joyce Marcus eds.): 248-255. Academic Press, New York.

- 1988. It Doesn't Amount to a Hill of Beans: the frijol motif in Mixtec Place Signs. In: Smoke and Mist: Mesoamerican Studies in Memory of Thelma D Sullivan (J. Kathryn Josserand \& Karen Daken, eds.) II: 696-710. BAR International Series 402-II, Oxford.

- 1994. Why the second Codex Selden was painted. In: Caciques and their people. A volume in honor of Ronald Spores (Joyce Marcus \& Judith Francis Zeitlin eds.): 111-141. Anthropological Papers, Museum of Anthropology, University of Michigan 89. Ann Arbor.

- 1998. The Codex López Ruiz. A lost Mixtec pictorial manuscript. Vanderbilt University Publications in Anthropology 51. Nashville.

- 2000. The home town of the rulers of the Codex Muro. In: In Chalchiuitl in Quetzalli, Precious Greenstone Precious Quetzal Feather (Eloise Quiñones Keber, ed.): 103-114. Labyrinthos, Lancaster CA.

Smith, Mary Elizabeth \& Ross Parmenter. 1991. The Codex Tulane. Akademische Druck- und Verlagsanstalt, Graz \& Middle American Research Institute, Tulane University, New Orleans.

Smith, Michael E. \& Frances Berdan (eds.). 2003. The Postclassic Mesoamerican World. University of Utah Press, Salt Lake City.

Smith, Michael E. \& K.J. Schreiber. 2006. New World States and Empires: Politics, Religion and Urbanism. Journal of Archaeological Research 14(1) 1- 52. 
Smith, Michael E. \& Cyntia M. Smith. 1980. Waves of Influence in Postclassic Mesoamerica? A Critique of the Mixteca-Puebla Concept. Anthropology IV (2): 15-50.

Spinden, Herbert J. 1935. Indian Manuscripts of Southern Mexico. Annual Report of the Smithsonian Institution 1933: 429-451. Washington.

- 1940. Diffusion of Maya Astronomy. In: The Maya and their Neighbours (Clarence L. Hay et al. eds.): 162-178. D. Appleton-Century Company, New Work (Reprint Dover Publications 1977).

Spores, Ronald. 1964. The Genealogy of Tlazultepec: a sixteenth-century Mixtec manuscript. Southwestern Journal of Anthropology 20: 15-31.

- 1967. The Mixtec Kings and their People. University of Oklahoma Press, Norman.

- 1972. An Archaeological Settlement Survey of the Nochixtlan Valley, Oaxaca. Vanderbilt University Publications in Anthropology 1, Nashville.

- 1974. Marital Alliance in the Political Integration of Mixtec Kingdoms. American Anthropologist 76: 297-311.

- 1976. La estratificación social en la antigua sociedad mixteca. In: Estratificación social en la Mesoamérica prehispánica (Pedro Carrasco \& Johanna Broda, et al.): 207-220. SEP-INAH, Mexico.

-1992. Colección de documentos del Archivo General de la Nación para la etnohistoria de la Mixteca de Oaxaca en el siblo XVI. Vanderbilt University Publications in Anthropology 41, Nashville.

- 1997. Arte Antiguo en la Mixteca. In: Historia del Arte de Oaxaca. Volumen I. Arte prehispánico (Margarita Dalton Palomo y Verónica Loera y Chávez, eds.): 61-77. Oaxaca: Gobierno del Estado de Oaxaca \& Instituto Oaxaqueño de las Culturas.

—. 2007. Nuu Nudzahui. La Mixteca de Oaxaca. La evolución de la cultura mixteca desde los primeros pueblos preclásicos hasta la Independencia. Instituto Estatal de Educación Pública de Oaxaca, Oaxaca.

- 2008. La Mixteca y los mixtecos: 3000 años de adaptación cultural. Arqueología Mexicana XV, Núm. 90: 28-33.

Stenzel, Werner. 1972. The Sacred Bundles in Mesaoamerican Religion. Acts of the XXXVIII International Congress of Americanists, II: 347-352. Stuttgart.

-1980. Quetzalcoatl von Tula. Die Mythogenese einer postkortesischen Legende. Zeitschrift für Lateinamerika - Wien, 18. Vienna.

Stiver, Laura R. 2001. Prehispanic Mixtec Settlement and State in the Teposcolula Valley of Oaxaca, Mexico. Ph.D. dissertation, Vanderbilt University, Nashville.

Stokes, Phil. 1997. Una nueva evaluación de la cronología en los códices históricos mixtecos. In: Códices y Documentos sobre México. Segundo Simposio (Salvador Rueda Smithers \& Constanza Vega Sosa \& Rodrigo Martínez Baracs, eds.), vol. I: 189-203. CONACULTA-INAH, Mexico.

Stone, Linda. 1997. Kinship and gender. An Introduction. Westview Press, Boulder / Oxford.

Suárez de Peralta, Juan . 1949. Tratado del Descubrimiento de las Indias. Secretaría de Educación Pública, Mexico.

Suma de Visitas. In: Papeles de Nueva España (Francisco del Paso y Troncoso, ed.), vol. I. Madrid 1905.

Tak, Herman. 1990. Longing for local identity: intervillage relations in an Italian town. Anthropological Quarterly 63: 90-100.

Terraciano, Kevin. 2001. The Mixtecs of Colonial Oaxaca. Ñudzavui History Sixteenth through Eightteenth Centuries. Stanford University Press.

Tezozomoc, Hernando Alvarado. 1975. Crónica Mexicana. Editorial Porrúa, Mexico. 
Tilley, Christopher. 1994. A Phenomenology of Landscape: Places, Paths and Monuments. Berg, Oxford.

1999. Metaphor and Material Culture. Blackwell, Oxford

Toorians, Lauran. 1983. Some Light in the dark century of Codex Vindobonensis Mexicanus 1. Codices Manuscripti IX: 26-29. Vienna.

- 1984. Codex Vindobonensis Mexicanus 1, its history completed. Codices Manuscripti X: 87-97. Vienna.

Torquemada, Fray Juan de. 1975-1979. Monarquía Indiana (I-VI). UNAM, Mexico.

Tozzer, Alfred M. 1941. Landa's Relación de las Cosas de Yucatan. Papers of the Peabody Museum of American Archaeology and Ethnology, Harvard University, vol. XVIII (Kraus reprint, 1975).

Trigger, Bruce G.995 A History of Archaeological Thought. Cambridge University Press, Cambridge.

Troike, Nancy. 1974a. Notes on the possible source of the Codex Zouche-Nuttall and the Codex Colombino-Becker. Paper presented at the XLI International Congress of Americanists, Mexico.

— 1974b. The Codex Colombino-Becker. Ph.D. dissertation, University of London.

- 1978. Fundamental Changes in the Interpretation of the Mixtec Codices. American Antiquity 43 (4): 553-568.

- 1979. Preliminary Notes on Stylistic Patterns in the Codex Bodley. Actes $d u$ XLII Congrès International des Américanistes, VII:183-192. Paris.

- 1980. The Identification of Individuals in the Codex Colombino-Becker. Tlalocan VIII, pp. 397-418.

-1982a. Studying Style in the Mixtec Codices: an Analysis of Variations in the Codex Colombino-Becker. In: Pre-Columbian Art History (Alana Cordy-Collins ed.), pp. 119-151, Peek Publications, Palo Alto.

-1982b. The interpretation of Postures and gestures in the Mixtec Codices. In: The Art and Iconography of Late Post-Classic Central Mexico (Elizabeth H. Boone ed.): 175-206. Dumbarton Oaks, Washington.

Troike, Nancy (with preface by Ferdinand Anders198. Codex Zouche-Nuttall. ADEVA, Graz.

Udeani, Chibueze C. \& Veerachart Nimanong \& Zou Shipeng \& Moustafa malik (eds.). 2008. Communication across cultures: the hermeneutics of cultures and religions in a global age. Series: Cultural heritage and contemporary change, Volume 26. Washington D.C.

Urcid Serrano, Javier. 2001. Zapotec Hieroglyphic Writing. Dumbarton Oaks, Washington D.C..

. 2004. Lecciones de una Urna Ñuiñe. In: Homenaje a John Paddock (Patricia Plunket, ed.): 85-99. UDLA, Puebla.

Urueta Flores, Cecilia. 2004. Los penates mixtecos. La trasfiguración de los antepasados. In: Iconografía mexicana V: Vida, muerte y transfiguración (Beatriz Barba de Piña Chan, ed.): 69-85. Instituto Nacional de Antropología e Historia, Mexico.

Van Alphen, Ernst. 2005. Art in Mind. How contemporary images shape thought. University of Chicago Press.

Van Broekhoven, Laura N.K. (ed.). 2006. The Social and Linguistic Heritage of Native Peoples in the Americas: The Struggle to Maintain Cultural Particularity. Lampeter: The Edwin Mellen Press.

Van Doesburg, Sebastián. 1996. La herencia del Señor Tico: Fundación y desintegración de un cacicazgo cuicateco. Ph.D. dissertation, Leiden University. Published with reproduction of the manuscripts in colour photographs as Códices Cuicatecos 
Porfirio Díaz y Fernández Leal, Grupo Editorial Miguel Angel Porrúa, Mexico 2001.

- 2000. Origin of the Lienzo de Tulancingo. Ancient Mesoamerica 11 (1): 169183.

2001. De Linderos y Lugares: territorio y asentamiento en el Lienzo de Santa María Nativitas. Relaciones vol. 22, número 86: 15-82.

. 2003. El Siglo XVI en los lienzo de Coixtlahuaca. Journal de la Société des Américanistes 89 (2): 67-95.

.2008a. Los documentos pictográficos de la Mixteca Baja. Arqueología Mexicana XV, Núm. 90: 53-57.

. 2008b. Documentos pictográficos de la Mixteca Baja de Oaxaca: el Lienzo de San Vicente el Palmar, el Mapa núm. 36 y el Lienzo Mixteca III. Desacatos 27: 95-122. Centro de Investigaciones y Estudios Superiores en Antropología Social, Mexico.

Van Doesburg, Sebastián (ed.). 2008. Pictografía y escritura alfabética en Oaxaca. Fondo Editorial del Instituto Estatal de Educación Pública de Oaxaca, Oaxaca.

Van Doesburg, Sebastián \& Olivier Van Buren. 1997. The prehispanic history of the Valley of Coixtlahuaca, Oaxaca. Códices, Caciques y Comunidades. (Maarten Jansen \& Luis Reyes García eds.): 103-160. Cuadernos de Historia Latinoamericana 5, AHILA (Asociación de Historiadores Latinoamericanistas Europeos).

Van Zantwijk, Rudolph A.M. 1985. The Aztec arrangement : the social history of preSpanish Mexico. University of Oklahoma Press, Norman.

Vander Meeren, Marie. 1997. El papel amate, origen y supervivencia. Arqueología Mexicana vol. IV, núm. 23: 70-73.

Vázquez León, Luis. 1996. El Leviatán Arqueológico. Antropología de una tradición científica en México. CNWS, Leiden.

Villavicencio Rojas, Josué Mario \& Rogerio Montesinos Maldonado (comps.). 2004. Donde se canta y se baila. H. Ayuntamiento Constitucional de Coicoyán de las Flores \& Fondo Editorial del Instituto Estatal de Educación Pública de Oaxaca, Oaxaca.

Villoro, Luis. 1979. Los grandes momentos del indigenismo en México. Ed. Casa Chata, Mexico.

Von Hanffstengel, Renata \& Cecilia Tercero Vasconcelos. 2003. Eduard y Caecilie Seler: Sistematización de los estudios americanistas y sus repercusiones. UNAM / INAH / Instituto de Investigaciones Interculturales germano-Mexicanas / Ediciones y Gráficos Eón, Mexico.

Watkins, Joe. 2000. Indigenous Archaeology. American Indian values and scientific practice. Altamira press, Walnut Creek.

Weitlaner Johnson, Irmgard. 1966. Análisis Textil del Lienzo de Ocotepec. In: Summa Anthropologica en homenaje a Roberto J. Weitlaner: 139-144. Instituto Nacional de Antropología e Historia, Mexico.

Whitecotton, Joseph W. 1990. Zapotec Elite Pictorial-Genealogies: new evidence for Zapotec-Mixtec interactions in Postclassic Oaxaca. Mexicon XII (4): 66-73.

Whitecotton, Joseph W. \& Judith Bradley Whitecotton, eds. 1982. Native American Ethnohistory. University of Oklahoma Papers in Ethnohistory 23 (2). Norman.

Willey, Gordon R. 1981. Recent Researches and Perspectives in Mesoamerican Archaeology: an introductory commentary. In: Supplement to the Handbook of Middle American Indians, I: Archaeology (Jeremy Sabloff, ed.): 3-27. University of Texas Press, Austin.

Williams, Robert Lloyd. 2009. Lord Eight Wind and the Heroes of Ancient Oaxaca. Reading History in the Codex Zouche-Nuttall. University of Texas Press, Austin. 
Wolf, Eric R. . 1982. Europe and the Peoples without History. University of California Press, Berkeley/Los Angeles/London.

Wood, Stephanie. 1998. Gender and Town Guardianship in Mesoamerica: Directions for future research. In: Journal de la Société des Américanistes 84-2: 243-276.

. 2003. Transcending Conquest. Nahua views of Spanish Colonial Mexico. University of Oklahoma Press, Norman.

Yoneda, Keiko. 1991. Los mapas de Cuauhtinchan y la historia cartográfica prehispánica. CIESAS/Estado de Puebla/Fondo de Cultura Económica, Mexico.

Zavala, Silvio. 1991. Repaso Histórico de la Bula Sublimis Deus de Paulo III, en Defensa de los Indios. Mexico: Universidad Iberoamericana / Colegio Mexiquense.

Zeitlin, Judith Francis. 2005. Cultural Politics in Colonial Tehuantepec. Community and State among the Isthmus Zapotec 1500-1750. Stanford University Press.

Zetina, S \& J.L. Ruvalcaba \& M. López Céceres \& T. Falcón \& E. Hernández \& C. González \& E. Arroyo. 2009. Non destructive in situ study of Mexican codexes: methodology and first results of materials analysis for the Colombino and Azoyu codices. http://www.museoamparo.com/2009/Diplomado/LECTURAS/Zetina3 .pdf (consulted January 12, 2010).

Zijlmans, Kitty \& Wilfried van Damme. 2008. World Art Studies: Exploring Concepts and Approaches. Valiz, Amsterdam.

Zourabichvilli, François. 2004. Deleuze. Una filosofía del acontecimiento. Amorrortu Editores, Buenos Aires \& Madrid. 


\section{INDEX}

Acatepec 323-324, 347

Acatlan xiv, 90-91, 141, 163, 330-331, 336-337, 406, 427, 535

Achiutla ix, xiii, 9, 52-53, 303-305, 307-308, 318, 357, 388, 406, 416, 458, $462,507,509$

Acuchi 308, 419

Adeques 86, 443

Adzeque 443

Agency 172, 192, 236, 261, 352, 496, 508-509, 512

Ambassador 31, 56, 58-59, 130, 242, $359,377,385,390,392,456,461,472$, 492,514

Amoltepec 55, 88, 399

Ancestor xii, 46, 277, 293, 359

Andua xviii, 39, 297, 299, 331, 442$443,453-454,459,483$

Aniñe $16,31-32,52,85,226,327,359$, 363, 365, 443, 462, 467-468, 494, 496, 521,523

Añute $74,80,82-84,123,152-153$, $155,228,292-293,302,304,322,343$, $359,364,371-374,377,399,432,435$, $437,439,444-446,453-455,458-459$, 464,506

Apoala x-xii, 12, 42, 55-56, 66, 128$131,143,148,167,169-170,174$, 253, 277-279, 288-291, 307-309, $318,321-322,327,339,352,357,359$, 369-370, 503, 507, 542, 547

Astraldeutung 104-105, 107, 109, 125, 274

Atonal xvi, 380-381, 452

Aztec 4-5, 14, 86, 116-117, 121, 125, $141,143,163,171,175,231,463,467$, $470,474,476,535,537,541,545,550-$ $551,553,559$

Ballcourt xiv, 37, 302, 334-335, 431

Ball game $120,247,366,368$

Belching Mountain 79, 123, 292

Bell 87, 488, 492, 496, 522-523

Beni Zaa 4, 48, 72, 97, 141-142, 149, $217,260,318-319,324,326,353,359$,
$371-372,413,420,426,435,439-440$, 450,510

Cacicazgo 39-43, 47, 52-53, 76-77, 82, $84-85,118,243,465,474,479,496$, $516,518,524$

Cacique xiii, 27, 88, 135, 137, 155, 293, $295,324,346,381,387,509$

Calci 469-470, 473, 486-488, 493, 496

Calendar 6, 14, 22-23, 26-28, 109, $112,150,166,264,380,435,474,476$, 526-527

Casa de la Cacica ix, 15, 31, 52, 299, $462,467,545$

Cave xv, 74, 128, 153, 155, 271, 291, $315,333,339,348-349,351,359,508$, 550

Ceiba 276, 357, 359, 463

Cerro de los Cervatillos xiii, 312, 314315,317

Cerro Verde xiv, 300, 342, 345, 353, 380 ,

Chalcatongo xiv-xv, 11, 20, 35, 47, 89, $91,127-128,130,143,150,163,172$, $195,235,238,259,264-265,272,309$, $312,314-316,318,346-347,367-368$, $374,385,431,504,508,519,547$

Chicomoztoc 349

Chila 31, 91, 141, 331, 336, 338-339

Chiyo Cahnu 43-52, 72-73, 76, 86, 88, $113,130,132,287,323,385,390-391$, 397, 402, 405-406, 408, 410-411, 413-417, 421, 426-428, 430-431, 436, $439,441,444,453,458,509-510$

Chiyo Yuhu xiii, xvii, xix, 53, 86, 298$299,370-372,412,442-446,454$, 457-459, 483, 506

Cholula xv-xvi, 4, 116, 140, 348-349, $377-379,381-383,387,512$

Chronology xxv, 107, 113, 123, $131 \mathrm{ff}$, $151,159-161,176,404,413,447$

Cihuacoatl $64,171,245,255,264-265$, $375,508,536,543$

Classic ix, 4-6, 15, 17, 21, 23, 27, 41, $96,133,166-167,174,202,207,217$, 
224, 284, 299, 314, 319, 322-324, 357, 370, 379, 395-396, 506-507, 527, 539, 541-542, 558

Coanacoch 385, 390-392

Coatepec 427-428

Coat of Arms of Saha Yucu 87, 141142, $\mathrm{x}$

Cocijopij 440, 450

Codex Añute ix-x, xii-xiii, $x v-x v i$, xviii-xix, xxvi, 32, 38, 67, 75, 79-84, $107,123,136,140,144,149,160,166$, $187,228-229,231,236,253,257-258$, 266, 286, 292-293, 297, 299, 304-305, $308,312,314,317,323,325,327,330$, $333-334,338,354,361,363-365$, 371-373, 377, 399, 432-433, 435, 437, 445-446, 453, 455, 458-459, 463, 495, $498,536,543$

Codex Azcatitlan 149

Codex Becker II see Codex Iya Cochi

Codex Bodley see Codex Nuu TnooNdisi Nuu

Codex Borbonicus see Codex Cihuacoatl

Codex Borgia see Codex Yoalli Ehecatl

Codex Cihuacoatl 64, 171, 245, 255, 264, 536

Codex Colombino-Becker see Codex Iya Nacuaa

Codex Cospi see Codex Tlamanalli

Codex Egerton see Codex Ñuu Naña

Codex Fejérvàry-Mayer see Codex Tezcatlipoca

Codex Fonds Mexicain 20 see Codex Yecu

Codex Iya Cochi $\quad$ x, 90-91, 334

Codex Iya Nacuaa $\quad \mathrm{x}, \mathrm{xv}-\mathrm{xvi}, 71,74-77$, $79,91,100,106,113,122,149,154-$ $156,159-160,176,221,229,248,288$, $302,347,350,353,366,378-379,386$, 390, 401, 528, 536, 558

Codex Laud see Codex Mictlan

Codex Mendoza ix, 6, 17-20, 58, 80, $108,244,292,299,302-303,363,390$, 458, 467, 536, 550

Codex Mictlan 64, 107, 536

Codex Muro see Codex Nuu Naha

Codex Nuttall see Codex Tonindeye

Codex Nuu Naha xvii, xix, xxi, xxvi, 34, $37-38,86,89,119,121,132-133,140$, $149,164,283,286,288,297,308,405$,
410-412, 443-444, 454, 457, 459, 536, 534, 536, 542, 545

Codex Ñuu Ñaña $34,37,89,91,121$, 140, 149, 286, 329-330, 333, 337, 385, 391, 536

Codex Ñuu Tnoo-Ndisi Nuu xxi, xxvi, $38,54-55,65,67-70,73-74,80,97$, $113-115,119,133-139,149,154-155$, $242,250,257,264,283,299,300,303-$ $304,307-308,312-313,318-320$, $325,332,334,337,350,368-374,379$, $388-389$, 394-405, 408-411, 414$449,452-454,458-460,471,535-536$, 543, 558

Codex of Yanhuitlan xxiv, 112, 463, 469, 493, 536

Codex Porfirio Díaz see Codex Yada

Codex Selden see Codex Añute

Codex Tezcatlipoca 61, 96, 108, 229, $257,263,536$

Codex Tlamanalli $12,61,536$

Codex Tonalpouhqui 61,536

Codex Tonindeye ix-xiv, xvi-xviii, xxvi, $33,35-39$, 55-56, 70-74, 76, 97, 103$107,119,128,132,138,140,142,148$, 154-156, 165-166, 225, 228, 233, 236, 248, 254, 263, 277-281, 283-286, 290, 296-298, 301, 309, 320-321, 323-327, $329,331,334,347,353,369-371,374$, $376,382,391-393,395-396,402$, $405-406,411-414,416,426,430$, $433-434,436,438-440,444,509$, 532, 536, 541-542, 546, 548-550, 553, 558-559

Codex Tulane see Roll of Toavui-Yucu Yusi

Codex Vaticanus A 96, 366

Codex Vaticanus B see Codex Tonalpouhqui

Codex Vindobonensis see Codex Yuta Tnoho

Codex Yada 64, 108, 308, 536

Codex of Yanhuitlan see Codex of Yodzo Cahi

Codex Yecu ix, 59-63, 108, 308-309, 311, 316, 536

Codex Yoalli Ehecatl 60-61, 96, 104, $108-109,116,143,147,159,161,173$, $191,255,257,260-261,265,280-282$, 526, 532, 536, 550, 556

Codex Yodzo Cahi 31, 85, 118, 187, 245, 299, 463-499, 522, 536 
Codex Yodzo Yaha 89, 91, 149, 226227, 245, 518, 536

Codex Yuta Tnoho ix-xviii, xxvi, 21, $22,32,35,37,53,55-56,60,65,67$, $80,94,105,107-108,113-114,120$, $122,125,127-128,130,142,147-149$, 154, 156-157, 169-170, 174, 193, 195, $228,237,248-250,257,259-262$, 264-266, 272-276, 283-284, 286, 292-294, 296, 301-302, 306-311, 313, $315-317,320,322,327-328,330-332$, 334-343, 348-349, 352, 354, 357-366, 368-369, 371, 384, 387, 395-396, 398, $401,408,411,415,421,424,426,428-$ $431,433,435,448,461,468,470,476$, $495,507,512,536$

Coixtlahuaca xiv-xvi, $\quad 18, \quad 47, \quad 58$, 94-95, 140, 149, 288, 296, 300, 334$335,340-341,351,353,380-381,428$, $431,433,452-453,455,457,545,551$, 554,559

Community viii, 206, 253, 501, 551, 560

Copal 247, 280, 282, 452

Cosijoeza 435

Costa $3,8,143,148,344,508,537-538$, 553

Council x, 139, 245-246, 371, 401-402

Cuauhtinchan xv, xviii, 95, 140, 310, $351-352,431-433,510,550,560$

Cuauhtitlan 380-381, 453

Cucharilla 367

Cuilapan $\mathrm{x}, 87,141-142,318,324,413$, 439-441, 450-451, 476, 549, 551

Cult 277, 359

Curandero 109, 120, 250, 525

Cutha 427-428, 535

Cuyotepeji $89,385,390$

Dark Speckled Mountain $\quad 419-420$

Difrasismo 10, 14, 22, 28, 38, 57, 116, $171,174,175,220,230-231,235-236$, $248,250,254,258,277,282,364,365$, $409,422,515$

Dominican ix, xix, 4, 9, 42, 70, 86, 118 , $222,299,305,312,462,464,466,481$, 484-485, 490-491, 493, 497-498

Doña Catalina Cuetzpalin 89

Doña Catalina de Peralta 52

Doña Francisca de Mendoza 49-50

Doña Inés de Zárate 52

Doña Isabel de Rojas $52-53$
Doña María Coquahu 243, 486

Doña María de Estrada 49

Doña María de Saavedra 53

Doña María de Zárate 52

Don Angel de Villafañe $\quad 84,463$

Don Carlos de Villafañe $83-84,463$

Don Diego de Mendoza 52, 490

Don Diego de Orozco 490

Don Diego Ñuqh 243

Don Domingo de Guzmán xix, 50, 458, 469, 473, 486-488, 493

Don Felipe de Austria 46, 51-53, 68, 99, 503

Don Felipe de Saavedra 53, 304

Don Felipe de Santiago 43, 46, 49-51

Don Francisco de Mendoza 43, 49-50, 52-53, 89

Don Francisco Pimentel y Guzmán 465

Don Gabriel de Guzmán 52-53, 68, 467, 485-486, 491, 493

Don Juan Cortés 440

Don Juan de Aguilar 51-52

Don Juan de Mendoza 49-51

Don Miguel de Guzmán 53

Don Pedro Osorio 52

Durán 4, 85, 249, 380, 455, 537

Dzandaya 312-313, 318

Dzico xi-xiii, xvi, 34-36, 225, 228, 261, $263,298,369-370,436,473$

Dzini Titi 347

Elotepec 48,50

Ethno-archeology 210

Etla xiii, 319, 445, 458

Feast $22,64,86,127,174,228,245,246$, $247,249,255,269-272,276,314,476$, 497, 504-505, 513

Fejérvàry-Mayer 61,96

Fire Serpent ix-x, xii-xiii, 32, 37, 88, 136, 155, 281, 287, 298, 319, 339, 388, $411,414-415,417,419-420,422$, $433-435,437,441-442,445,449$, $458-459,473$

Foundation vii, 14, 64, 68, 95, 131, 173-174, 222, 237, 247, 257, 273, 276, $280,305,334,352,363,380,421,485$, 494-495, 503, 507-508, 512, 550

Gender 236, 533, 544, 560

Genealogy of Tixii xiii, 94, 300 
Gesture 223, 226-229, 280, 367, 371372,483

Goddess $64,83,245,257,261-263,266$, $280,376,395-396,476$

God xi, 7, 22-23, 25, 27, 42, 49, 57, 61, $72,83,101,105,116-117,141,161$, $171,174,225,235,245,250,253-254$, 256-260, 267, 280, 285, 298-299, 305, $321,323-324,354,359,369,381-382$, $461,474,476,496,508,527,529$

Grandmother of the River xiii, 83, 261, $282,311,396$

Guaxolotitlan xiv, 334-335

Hallucinogenic 170, 247-249, 265, 361, 363

Hermeneutics 151, 182, 184, 198, 201, 203, 213

Herrera $9,31,39,82,85,137,194,231$, 242, 245-246, 249, 409, 453-454, 465-467, 469-470, 476, 481, 486-487, 489-490, 497, 536, 542, 556

Historia Tolteca Chichimeca $7,95,135$, 140, 350, 432-433, 435, 542, 545

Huachino $153-155$

Huahi Cahi xiii, 264-265, 308, 311, $313,317,347,422,508$

Huajuapan xiv, 177, 337-338, 402, 531, 534, 537, 539, 541, 547, 549-550, 552, 554-555

Huamelulpan $\quad \mathrm{x}, 91,131,140,330,336$, 406, 427

Huauclilla 297

Huitzo 87, 297, 435, 458

Iconology xxiv, 5, 17, 148, 151, 161, 181-182, 185, 193, 197, 204, 213

Icxitlan 329-330, 337

Identity xxiv, 28, 96, 144, 185, 195, 205, 208-209, 212-214, 244, 254, 276, 353-354, 463, 503, 506, 508, 512, 515, $519,521-524,527-528$

Ideology 202, 205, 536-538, 545, 551

Incense $29,31,158,247,266,280,282$, $422,451-452$

Intercultural 182, 184, 199, 200-201, 209, 213, 216

Itzpapalotl 261, 395, 508, 542

Ixtayutla 345

Iztaccihuatl 349
Jaltepec xii, 21, 80, 84, 123, 134-136, $152,292-293,302,304,318,322,328$, $343,359,371,374,453,458,463-464$, 506

Jicayán 121-122, 344

Juxtlahuaca $\quad x, 34,90-91,261,334,555$

Kaua Kaandiui $\quad 55,128,291,321,352$, 369

Kinship 28, 40, 228, 232-235, 240-241, $244,386,460,487,504-505,513-515$, $545,548,557$

Koo Sau 259, 272

Kukulkan 382

Lady 1 Death xiv-xv, 114, 321, 325, 369-370, 372

Lady 1 Deer $\quad 55,57,128,358$

Lady 1 Eagle xii, 132, 261, 263-264, 266, 282, 311, 396-397, 411, 413-414

Lady 1 Flower xiii, 243, 298-299, 399$400,458,471,473,487-488$

Lady 1 Grass 394-397, 401-402

Lady 1 Jaguar 442

Lady 1 Monkey $411,418,420,422$

Lady 1 Rabbit 395

Lady 1 Reed xviii, 438-440

Lady 1 Serpent $434-435,437,455$

Lady 1 Vulture xi, 36, 225, 369

Lady 2 Death 417

Lady 2 Eagle 424

Lady 2 Flint 437

Lady 2 Flower xviii-xix, 442-444, 454, 459

Lady 2 Grass 400

Lady 2 House 419, 482

Lady 2 Jaguar 413

Lady 2 Rain 399, 409

Lady 2 Serpent $371-372$

Lady 2 Vulture 403, 416-417, 419, 435, $439,442,444$

Lady 3 Alligator xviii, 439, 441-442, 444, 449-450

Lady 3 Flint $\quad x i-x i i, 35,233,236,280-$ $282,327,409,533$

Lady 3 Jaguar $\quad$ xvii ,410, 418-420

Lady 3 Rabbit xviii, 38, 429, 431, 433, $435-436,438,441,448$

Lady 3 Serpent 394

Lady 3 Water $\quad 410-411$

Lady 4 Alligator 458 
Lady 4 Death 391

Lady 4 Eagle 408

Lady 4 Grass 437

Lady 4 Monkey 414

Lady 4 Rabbit $\quad x, 73,413-414,510,540$

Lady 4 Serpent $421,431,436$

Lady 4 Water 446

Lady 5 Eagle 434, 436, 438

Lady 5 Flint $\quad$ xviii, 437-438, 440

Lady 5 Flower xix, 449-450

Lady 5 Grass 418

Lady 5 House $419-421$

Lady 5 Lizard $\quad 388,395$

Lady 5 Monkey $113,446,458$

Lady 5 Rabbit xvii, 387, 399, 408-409

Lady 5 Reed $\quad$ xvi, 124, 369-371

Lady 5 Serpent $\quad$ xviii, 442-443, 454, 459

Lady 5 Wind $36,388,394,417,446,458$

Lady 6 Alligator $\quad x v i i, 387,398-400$

Lady 6 Eagle xvi, 384-386, 389-390, 399

Lady 6 Grass $132,410-411,415$

Lady 6 Monkey $\mathrm{x}$, xiii, xvi, xxii, 34, $74-75,82,107,144,177,193,195$, 228-229, 236, 317, 372-377, 383, 386, $407,508,510,517$

Lady 6 Rabbit $\quad 415,423-424,426,436$

Lady 6 Reed xviii, 409, 414-416, 419, $426,428-431,433-434$

Lady 6 Water $\quad$ xviii, 414-415, 426, 429431

Lady 6 Wind xvii, 385, 387, 390-393, 437

Lady 7 Death 417

Lady 7 Flint $\quad 83,428-430,436-437$

Lady 7 Flower 414

Lady 7 Grass 265, 454

Lady 7 House $x, 90$

Lady 7 Lizard 399

Lady 7 Rabbit 437

Lady 7 Rain 437, 445

Lady 7 Reed 372

Lady 7 Vulture xiii, $319,445,455$

Lady 7 Water 446

Lady 8 Alligator 449

Lady 8 Deer $332,446,449-451$

Lady 8 Flint $\quad 414,423,431$

Lady 8 House 485

Lady 8 Jaguar $\quad 394,449$

Lady 8 Lizard 395

Lady 8 Rabbit xii, 293

Lady 8 Reed 405
Lady 8 Serpent $\quad 408,411,418,420,422$

Lady 8 Wind 441

Lady 9 Alligator $x, 130,359$

Lady 9 Deer ix, xix, 66-67, 113, 446, $452,455,459,461$

Lady 9 Dog 399

Lady 9 Eagle $371-372,442$

Lady 9 Flint 372

Lady 9 Grass xi-xiii, 228, 231, 264-266, $268,317,375,508$

Lady 9 Monkey 421

Lady 9 Movement $\quad$ xvii, 387, 389

Lady 9 Reed xii, xviii, 261, 263, 334, $337,367,376,403,422-423,508$

Lady 9 Vulture xviii, 425, 437

Lady 9 Water 420

Lady 9 Wind $x v i, 228,373$

Lady 10 Deer xi, xiii, 225, 298, 371372, 434

Lady 10 Dog 420, 423, 425

Lady 10 Eagle 408

Lady 10 Flower ix, xvii, 32, 88, 346, 388-389

Lady 10 Grass 418

Lady 10 Jaguar 409

Lady 10 Reed xvii, 387, 398-400

Lady 10 Serpent 83

Lady 10 Vulture xvii, 373, 385, 387, 399, 408, 446

Lady 10 Water 431

Lady 10 Wind 399

Lady 11 Alligator $411,413,415-417$

Lady 11 Deer 395, 397-398

Lady 11 Lizard 420, 423, 445

Lady 11 Monkey 445,458

Lady 11 Movement 451

Lady 11 Rabbit xviii, 424-426, 428430, 437-438

Lady 11 Reed 441

Lady 11 Serpent xvi, xix, 67, 384-385, $389,434,436,459-460$

Lady 11 Water 372

Lady 12 Death 437, 449

Lady 12 Flint 409, 446

Lady 12 Flower 442,444

Lady 12 Vulture 325,459

Lady 12 Water 418

Lady 12 Wind 417

Lady 13 Flint 434

Lady 13 Flower $\quad x, 130,388-389,394-$ $397,410,418$

Lady 13 Grass xiii, 296-297, 395 
Lady 13 House 455

Lady 13 Lizard 411

Lady 13 Reed $x, 90$

Lady 13 Serpent ix, xvi, 33, 383-384, 388-390, 439

Lady 13 Wind 444-445 Laguna de Términos 381-382

Landscape vii, 55-57, 60, 131, 154-157, $167,173,271,276,283,285,308,352-$ $353,511,527-528,534,548,558$

Lienzo of Otla xiv, 94-95, 342-345, 353,547

Lienzo of Tlapiltepec xiii, $\mathrm{xv}-\mathrm{xvi}, 94-$ $95,108,140,286,295-296,300-302$, $339,343,351,353,380-381,403,428$, 452, 544, 547

Lienzo of Yucu Satuta xiv, 88, 121, 344-346, 547

Liminal 184, 259, 374, 508-509, 522, 527

Lord 1 Alligator 395

Lord 1 Death xii, 57, 257-258, 305, 389

Lord 1 Deer $55,57,128,358,385,390$ 392,418

Lord 1 Dog 437

Lord 1 Eagle 396, 401-402

Lord 1 Flower 130, x

Lord 1 Grass 396-397, 440

Lord 1 House 132, 134, 411

Lord 1 Lizard xvii, 399, 408-410

Lord 1 Monkey xviii, 313, 318, 437440,446

Lord 1 Movement xii, 257-258, 408, 419

Lord 1 Reed 258, 388

Lord 2 Dog xi, xviii, 170, 414-416, 426, $428,430,434-436,441$

Lord 2 Eagle 408, 471

Lord 2 Flower xiii, 295-296

Lord 2 Grass xii-xiii, 293, 296-297, $359,420-421$

Lord 2 Jaguar 435-437

Lord 2 Movement xvii, 408-409, 417, 419

Lord 2 Rabbit $\quad \mathrm{x}, 90$

Lord 2 Rain xiii, 305, 354, 371-372, 426

Lord 2 Vulture 402, 436, 438, 455

Lord 2 Water ix, xviii, 38-39, 429, 433-436, 439, 441-442, 444, 447-449, 453-454

Lord 2 Wind 416-418
Lord 3 Alligator 414, 435

Lord 3 Dog xviii-xix, 418-420, 422423, 427-428, 454, 457

Lord 3 Lizard xvi, 376

Lord 3 Monkey $\quad$ x, xviii-xix, 39, 90-91, 442-443, 446, 453-455, 459

Lord 3 Reed 438, 440, 450

Lord 3 Serpent $417-418,449-451$

Lord 3 Vulture 395

Lord 3 Water 420-421

Lord 3 Wind xvii, 393

Lord 4 Alligator ix, xv, 33, 42, 54, 66, $114,283,368-369,372,389,394-395$

Lord 4 Death $\quad 426,430,445,458$

Lord 4 Deer $\quad$ xix, 392, 447, 458-460

Lord 4 Dog ix, xvi, xvii, 33, 384-385, 390-394, 437

Lord 4 Flower xiii, 133, 319, 399, 445, 447-448, 455

Lord 4 House 419-420

Lord 4 Jaguar 228, 390, 394, 396, 398, 410, 508

Lord 4 Lizard 402

Lord 4 Movement 424

Lord 4 Rabbit 90, 369

Lord 4 Reed 73, 89

Lord 4 Serpent 260, 458

Lord 4 Water 394-396, 414, 426, 429

Lord 4 Wind $\mathrm{ix}-\mathrm{x}, \mathrm{xiii}, \mathrm{xvii}, 32,66$, 88, 135-136, 155, 163, 293-295, 346, $350,381,383,386-390,394-395,397$, 399-400, 402-403, 406-408, 416, 419, $426,469,508-509$

Lord 5 Alligator $\mathrm{x}$-xii, 137, 152, 225, 246, 248-251, 371-372, 389

Lord 5 Dog 390-393

Lord 5 Flower x, xii, 73, 141, 280-282, 413-414, 510, 540, 551

Lord 5 Movement 371

Lord 5 Rain x, xix, 90, 130, 411, 441, 449-450, 452

Lord 5 Reed xviii, 422, 434, 441-442

Lord 5 Water xvii, 387, 390, 398-399, 437, 444

Lord 5 Wind 332, 452

Lord 6 Death xviii-xix, 425, 442-444, 454,457

Lord 6 Deer xix, 133, 442, 444-445, $447-448,454$

Lord 6 House xvi-xvii, 384-385, 387, 389-390, 398-399 
Lord 6 Movement 482

Lord 6 Vulture 436

Lord 6 Water xviii, 435, 438-441, 452

Lord 7 Alligator 83

Lord 7 Deer 88, 336, 485, 491

Lord 7 Eagle 394, 397

Lord 7 Flower 257, 400

Lord 7 Grass 431, 436

Lord 7 House 435

Lord 7 Lizard 399, 409

Lord 7 Monkey 490-491

Lord 7 Movement $410-411,437,449$

Lord 7 Rain xii, xviii, 77, 260, 414, 421, $426-428,438$

Lord 7 Reed 398, 402, 446, 458

Lord 7 Serpent xii, xviii, 56, 77, 260, $262,418-421,485$

Lord 7 Vulture 436

Lord 7 Water xvi-xvii, 380-381, 391, 393, 402

Lord 7 Wind 332

Lord 8 Death xiii, 68, 86, 243, 298-299, $458,471,473-474$

Lord 8 Deer ix-x, xvi-xvii, xxii, 33, $42,66,71-72,74-76,82,106,124$, 131-133, 149, 151, 154-156, 161, 163, $165,167,177,193,195,221,228,246$, 249-250, 293, 302, 307, 347, 350, 353, $372-378,381-391,393-394,398,400$, $406-407,419-420,423,425-426$, 449-451, 503, 508-510, 517, 542, 544

Lord 8 Grass ix, xvii, xix, 66-67, 113, $139,302,408-410,446,449-453,455$, $457,459-461$

Lord 8 Jaguar $402-405,410,416-417$, 419

Lord 8 Monkey 446

Lord 8 Rabbit $\quad$ xvii, 132, 134, 405, 410412,415

Lord 8 Reed xvii, 387, 399-400, 408409

Lord 8 Vulture 441

Lord 8 Wind xi-xii, 225, 277-279, 297-298, 353, 370-372, 430

Lord 9 Alligator 429

Lord 9 House xviii, 85, 416, 426-429, 431-433, 435-436, 438, 441, 448, 469-474

Lord 9 Lizard 432, 435

Lord 9 Movement 88, 336, 413

Lord 9 Rabbit 50
Lord 9 Rain $\quad 426,428-430,436-437$

Lord 9 Reed 437

Lord 9 Serpent $414-416,423,426,429$

Lord 9 Wind $\mathrm{x}$-xii, $\mathrm{xv}-\mathrm{xvi}, 55-56,58$, $125,130,170,220,258-259,272-273$, 281-282, 308, 352, 354, 357-361, 369-371, 401, 449, 507

Lord 10 Alligator 416-417, 449-450

Lord 10 Eagle 228, 372, 418

Lord 10 Flint 359

Lord 10 Flower $371-372,419$

Lord 10 Grass $80,83,280,463$

Lord 10 Lizard 359

Lord 10 Monkey 437, 445, 485, 491

Lord 10 Movement xiv, 322, 441

Lord 10 Rabbit xviii, 399, 408, 424-426, 429-430, 437-438

Lord 10 Rain xix, 133, 280, 445-448, 458,471

Lord 10 Reed 280, 282

Lord 10 Serpent 430

Lord 10 Vulture 280

Lord 10 Water 445

Lord 10 Wind 282

Lord 11 Flint $x, 90$

Lord 11 Flower 278, 388, 394, 417

Lord 11 Jaguar 88,446

Lord 11 Rain 442, 446

Lord 11 Reed 50

Lord 11 Serpent 422, 431

Lord 11 Water 435, 439-440

Lord 11 Wind xvi, xviii, 228, 375, 377, $383,386,436-437$

Lord 12 Alligator 277-278

Lord 12 Deer xviii, 415, 420, 422-428, 430

Lord 12 Dog 413

Lord 12 House xii, xvii, 287, 411-415

Lord 12 Lizard 325, 371

Lord 12 Movement 442

Lord 12 Rain 411, 418, 420-423

Lord 12 Reed xvii, 410, 415, 418

Lord 12 Wind 236, 321, 327

Lord 13 Death 372

Lord 13 Dog xi, xvii, 225, 391, 393-394

Lord 13 Eagle xvii-xviii, 391, 393, 402, 404-405, 410, 416-417, 419, 438, 442, 444,449

Lord 13 Grass xi, 83, 225, 446, 459

Lord 13 Jaguar $431,437,442$

Lord 13 Lizard 431 
Lord 13 Serpent xvii, 395, 397-400, $402,418,422$

Lord 13 Wind 411, 413-414, 437

Maguey 302, 310, 359, 361, 367

Maize xi, xiii, 48, 156, 170, 257, 267, $317,342,402,527,536$

Malinaltzin ix, xix, 66-67, 113, 451453

Map of Chiyo Cahnu ix, xxi, xxvi, 43-45, 49-51, 65, 72, 283, 287-288, $390,414,444,515,522,548$

Map of Macuilxochitl 141

Map of Tuhu x, 92-94, 288

Map of Xochitepec 94, 336

Map of Xoxocotlan xiv, 88, 323-324

Market 100, 168-172, 240, 276, 315, $505,511,513$

Martínez Gracida x, xix, xxvi, 37, 85, 87, 97-99, 101, 104, 106, 142, 150, $164,267,286,316,332,336,451$, 465-467, 4841, 486, 488, 548

Matlalcueye 349,379

Maya 3-4, 15, 41, 58, 119, 125, 150, $165,184,202,211-212,224,253$, 255, 262, 381-383, 526, 531-532, 538, 541-542, 545, 548, 557

Memory vii, xxiii-xxiv, 157, 185, 208$213,219,223,226,271,325,352-354$, 463, 506-508, 517, 519, 522, 526

Metaphor $10,25,31,61,125,158,189$, $191,195,197,202,219,221,224,232$, 239-242, 260, 274, 303, 368, 381, 456, 496, 506, 545, 558

Mexica ix, 4-5, 9, 13-14, 17, 20-21, 23, $38-39,41-43,58,64,66,82,103,110$, $112,125,147,150,202,245,252,254-$ $255,257,261,263-265,267,269,302$, $312,353,377,380,407,434,446,451-$ $455,457-461,464,510,516,519-520$

Milky Way 265

Miltepec 331, 337, 433

Mitlatongo $163,312-313,318$

Mixteca Alta ix, xiv, 5, 7, 11-12, 15, $18-19,46,48,53,58,73,76,80,86$, $91,104,118,127,130,140,143,150$, $152-153,167,237,262,283,286,288$, 299, 307, 309, 311, 315, 318, 331, 333, 346, 349-350, 375, 390, 399, 402, 406, $415,426,428,435-436,458,469$, 507-508, 531, 533, 539-541, 544, 546, 552-553
Mixteca Baja xiv, 8, 77, 89, 91, 94, 140, $143,217,254,261,286,327-336,351$, $379,406,427,549,554-555,559$

Moctezuma / Motecuhzoma 59, 451457,520

Mogote del Cacique xiii, 27, 88, 135, $137,155,293,295,324,346,381,387$, 509

Monte Albán xiv, xvi, xxvi, 4, 17, 27, 87-88, 104, 106, 112, 165-166, 172, $217,238,244,246,319,323-325,327$, $343,353,369-371,375,377,395-396$, $408,440,506,508,522,532-533,535$, $543,548,554$

Monte Negro 154, 248, 285-286, 318, $325,353,370,428$

Mountain of the Mask xviii, 316, 427

Mountain of the Precious Mask 414$415,421,423,426-428,432,436,438$

Mountain that is Opened xiv, 142, 320, 322,343

Mushroom 170, 248, 361, 363

Nacxitl 379-382, 385, 387, 390, 393, 396, 407, 508-509, 542

Nahual $36-37,100,169,171,206,250$ 251, 259, 281-283, 464, 497, 517

Narrative xxiii, 14, 72, 74, 83, 144, 148, $185,192-193,200,223,256,276,494$, $508,522,528$

Ndaa Nduvua $331,337,433$

Ndisi Nuu 38, 48-49, 52-53, 66-67, 88, $113,139,163,302-304,346,402-406$, $411,415-431,436-441,444-447$, 449-453, 455, 457-461, 509

Nejapa $309,311,397$

Network 203, 207, 244, 271, 406, 504$505,511-512,515,525$

New Fire ceremony xiii, 130, 247, 310, 316, 401

Ngigua 95, 150, 310, 340, 342

Noble house $14,16,82,196,207,244$, 426, 431, 505-506, 509, 513, 518

North ix, xiii, xv, 8, 47, 62, 91, 153, 196, $200,255,268,308-310,318,334,351$, $366,377,427-428,431,540,551$

Nuhu vii, $x$-xii, xiv-xv, 1, 7, 12, 38, 46, $48,84,88,130-131,163,170,246-$ 247, 252-256, 283, 316, 335, 338-339, $361,375,390,399,405,408,410,414$, $421,424-425,430-431,433-434,436$, $441-442,444,449,510,523,550$ 
Ñuu Caa 345, 435

Ñuu Cohyo 307, 349-350, 377, 379

Ñuu Dzai xiv, 337-338, 402

Ñuu Huiyo 402

Ñuu Naha 132-133，411，442-444, 454-455

Ñuu Ñaña $\quad 89,385,390-392$

Nuu Ndaa $\quad 8,52,301,307,331,458$

Ñuu Ndaya xiii-xiv, 21, 90, 130, 163, 264-266, 312, 314, 317, 346-347, 374, $385,422,431,508$

Ñuu Ndecu xiii, xv, xviii, 52-53, 303$305,307-308,316,357,359,363,388$, $394,406,416-417,420,423,425,437$, 449-452, 455, 458, 462-463, 507, 509

Ñuu Ndoco 90

Ñuu Ndodzo 87, 297

Ñuu Nduchi xiii, 319, 445

Ñuu Nduyu xiv, 332

Ñuu Niñe xii, xiv, 8, 90, 217, 261, 263, 332-333, 340, 399, 508

Ñuu Saha 329-330, 337

Ñuu Sii Quaha 344

Nuu Siya 336-337

Ñuu Tiyaha 68,338

Ñuu Tnoo $10,42-43,46,48-57,65-68$, $71-73,80,86,90,98-99,106,113-$ $114,119,124,130,139,152-155$, $228,243,245,249-251,260,283-288$, 292-293, 296, 300, 311, 319-320, 322, $353,359,368-373,376,383-385,387$, $389-390, \quad 397-400,406,408-415$, $418,420-421,424,426,428-431$, 433, 435-436, 439, 441, 444-445, 447, 453-455, 457-461, 471, 503-504, 506, 509

Nuu Yoo xiv, 88, 163, 237, 239, 259, $265,314,316,346,504$

Ñuu Yuchi ix, xiii, xvii, 32, 88, 155156, 293-295, 324, 346, 381, 387-388, 394, 397, 401-402, 405-406, 426, 509

Ñu Yucu 90

Oaxaca xxvi, 5, 7-8, 17, 40, 64, 72-73, $80,82,85,91,94,97-98,104,113$, $118,127,135,140-141,144,148-150$, $152,164-167,177,204,213,218,222$, 234, 236, 247, 250, 267, 292, 318-319, 323-324, 352, 379, 413, 458, 465, 483, $485,510-511,524-525,531-535$, $537-541,543-545,547-549,551-$ $555,557,559$
Ocoñaña xiii, xviii, 51, 73, 99, 141, 305, $354,371,426,434,441-442$

Opossum 367

Otla xiv, 94-95, 342-345, 353, 547, 554-555

Piaztla xiv, 340-341

Piciete 247, 248, 250, 265

Place-date combination $273,276,495$

Plumed Serpent xi, xii, xviii, xxii, 35, $74,193,220,233,272,280-284,293$, $303,308,318,340,354,357,359,370$, $372,414,429,434,436,439,442,453$, $507,519,543$

Pochote 357, 369

Popocatepetl 349, 379

Popol Vuh 109, 120, 253, 255, 258, 264, $361,379,383$

Postclassic xxi-xxii, xxiv, 5, 12, 15, $22,37,53,57,64-65,72,75,96,116$, $118,133,141,167,174,189,207,217$, 261, 284-285, 298, 303, 314, 318-319, 324-326, 357, 361, 379, 407-408, 441, $471,504,507,512,516,519,527,543$, 551-552, 554, 556-557, 559

Postcolonial 4, 151, 177, 184, 201, 212-214

Power xii, 193, 225, 228, 245, 261, 263, $266,436,510,538,540,543-544,550$, xi

Preclassic ix, 5-6, 96, 255, 512

Priest $249-250,327,359,371,373,382$, 401

Proceso Inquisitorial 466, 469-470, 487, 497

Puebla xxii, 5, 7, 76, 85, 94, 120, 140 $141,150,166-167,174,217,244,257$, $310,330,349-350,352,379,428,464$, $497,535-536,538,541,544,553-554$, $556-558,560$

Pulque xiv, 265, 342-343, 388-389

Putla 345, 404

Quechquemitl xi, xiii, 34-35, 49, 225, $233,261,298,408,410-411,418-419$, $434,436,458,473,549$

Quetzalcoatl xii, 55-56, 58, 101, 125, $250,258-259,272,281,340,352,357$, $369,379,381-383,385,387,390,393$, $396,407,461,508-509,520,535,538$, $540,550,554,557$ 
Rain God xi, 7, 22, 25, 49, 83, 225, 245, 256, 260, 267, 285, 298-299, 321, 323-324, 354, 359, 369, 461, 476, 527

Reciprocity 29, 40, 215, 511, 513, 521

Red and White Bundle $\mathrm{x}, 153-156,254$, 336, 553

Relaciones Geográficas 4, 9, 94, 118, $141,194,319,440,531,549$

Relación Geográfica 31, 34, 42-43, 46, $48-51,54,56,88,113-114,138,242$, $245,254,261,283,285,297,310,313$, $318,329,336,339,349,368,399,413$, $420,439-441,447,457,459$

Religion 28, 56, 60, 85, 108, 143, 200, 204, 209, 250-252, 269, 462, 488, 507, $522,536-538,542,553-554,556-557$

Ritual 28-29, 37, 55-61, 94, 108-109, $120,125,152,157,171-174,197$, 205, 208, 224-225, 230, 235-237, 242, 245-250, 255, 269-270, 273, 276, 282, $285,349,352,361,363,380,396,400$, $422,433,476,505,508,511-514,522$, 526

Road 43, 48, 265, 419, 421-423, 428, 470-471, 476, 515

Roll of the New Fire 94-95, 108, 359, 534

Roll of Toavui-Yucu Yusi 91, 94, 140, $288,427,556$

Sacred Arrow 396

Sacred Bundle xi, xvi, 29, 82, 84, 202, $248,252-253,255,281-282,303,308$, $318,327,373,408,463-464,507,523$

Sacrifice 38, 66, 144, 171, 229-232, 247, 261, 269-270, 367, 372, 421-422, 427-428, 457, 470, 514, 519, 537, 549

Sahagún $4,226,255,265,269-270,344$, $374,381,456,470,534,544,555$

Saha Nuu Quu 340

Saha Yucu 87, 141-142, 316, 413, 439$441,451, \mathrm{x}$

Sahu / parangón $57,148,221,223,235$, $272,279,364,404$

San Agustín Tlacotepec 94, 300

San Andrés Huaxpaltepec 347

San Andrés Sabanillos 337

San Jerónimo Sosola $\quad 308,419$

San Juan Sosola 94, 307

San Martín Duraznos 90

San Miguel Achiutla ix, 9, 303, 305, 318,357
San Miguel Cuevas 90

San Pablo Tequixtepec 90, 329

San Pedro Cántaros 86, 164, 286, 442, 536

Sayultepec 297, 323-324

Selden Roll see Roll of the New Fire

Shield 37, 221, 230, 231, 365, 399, 471, $480,483,479$

Sigüenza Map 150

Silacayoapan xiv, 332,

Sosola x, 92-94, 297, 307-308, 419

Spanish conquest $\mathrm{xxi}, 5,76,91,106$, $124,208,312,462-463,509-510$

Spanish invasion $4-5,17,42,66,106$, $113,131-132,195,407,441$

Staff $49-50,52,277,280,483$

Stone Men xiv, 327-330, 335, 506, 508

Suchixtlan 53, 86, 298, 370-371, 443, $446,483,506$

Suma de Visitas $\quad 48,304,557$

Sun God 42, 57, 83, 105, 257, 280, 305, $381-382,476,508$

Sunrise $48,55,257,276,325,337,357$, 361,367

Sweatbath xiv, 90, 332-333

Taix $\quad 222-223,249,251,337,543$

Tamazola xiii, 243, 296-297, 482

Tecamachalco 352,431

Tecomatlan 68, 338, 469

Tecomaxtlahuaca $\mathrm{x}, 89-91,226,245$, 536

Tecpan $31,467-468$

Tejupan $27,52,301-302,307,379,458$

Temazcal xiv, xvi, 263, 332-333, 385

Temple of Heaven xi, 46, 54, 56, 61, $137,152,248,283,285,347,353,371$, 408

Tenochtitlan $4,17,85,87,379,457$, $470,512,520$

Teoamoxtli $64-65,119,147,161,173$, 191,526

Teotihuacan $4-5,21,32,152,231,255$, $325,379,512,538,541,555$

Teozacualco ix, xii, xxi, 43-45, 47, 51, $72,86,88,112-113,130,134,283$, $287,319,323,385,390,402,406,408$, $411,414,421,427,444,460,509,522$, $532,541,548$

Tepeaca $\quad \mathrm{xv}, 140,351-352,431$

Tepeji xv, 309-311, 351 
Tepozcolula ix, xiii, 9, 11, 15, 20, 31, 42, 52, 167, 299-302, 331, 409, 458, 462, $465,467,482,490$

Texupan 331, 478, 488, 492, 536

Tezoatlan 51-52, 254-255, 336-337

Tilantongo $\mathrm{x}$-xii, 10, 42-43, 46, 49-51, $56,67,86,90,113-114,130,134-139$, $143,152,167,225,245,283-286$, 292-293, 301, 311, 318-319, 322, 324-325, 352-353, 373, 381, 385, 401, 406, 408, 458-459, 471, 473, 503, 506, $534,539,541,544,551$

Time xxiii, 22, 27, 48, 60, 66, 101, 182, 192-193, 260, 271, 276, 325, 352-353, $357,451,459,467,470,494-498,516$, $523,525-527,533,538,541,554$

Tira xi, 89, 149, 226-227, 245, 518, 536

Tixii xiii, 94, 300

Tiyusi 337

Tlaxiaco ix, 38, 48-49, 53, 66-67, 88, $91,113,139,163-164,302,304,346$, 402-403, 405-406, 411, 416, 425-426, $430,451,456,458,460,509,531,555$

Tlazultepec $94,300,552,557$

Toavui xiv, 91, 94, 141, 288, 331, 336, $338-340,427$

Tobacco 224, 242, 247, 265, 279, 336, 389

Tocuisi $\mathrm{x}, \mathrm{xiv}, \mathrm{xvi}, 72,141,144,324$, $327,339,377,439$

Tollan 4, 121-122, 139-140, 307, 332, $340,349-350,377,399,508,540$

Toltec xv-xvi, 61, 106, 140, 228, 293, 307, 311, 332, 335-336, 340, 349-350, $353,377,379,381-382,385,387,391$, 396-397, 399, 407, 451, 508-509, 520, 549

Tonalá xii, xiv, xvi, 8, 90, 261, 263, 332334, 340-341, 376, 385, 508

Topiltzin $379,381-382,385,390,393$, $396,407,508-509,542,550$

Torquemada $4,139,218,220,379,381$, $451,453,455-457,558$

Trade $168,207,237,319,406,505,510$, $511,513,515$

Tree of Origin $\quad 274,291,304,357,363$, 370

Tribute 4, 7, 17-18, 66, 86, 89, 207, 226-227, 243-245, 386, 431, 455, 466, 474, 476, 480, 484, 493, 497, 505, 511, 521

Tuctla 402
Tuhu x, 92-94, 288, 307

Tula xvi, 307, 349, 377-379, 544, 557

Tututepec xv, xix, 8, 74-76, 150, 152, $167,346-347,353,376,385,458,465$, 486,544

Umbilical cord $\quad 232,528$

Vehe Kihin xiii, xvi, 265, 311-312, 314, 374-376

Venus xii, xviii, 105, 107, 136-137, $257-258,277,280,336,379,391$, $410-411,416,418,420,422-423,426$, 430, 437, 445, 449, 451, 458, 526

Village-state $15,32,42,133,205,207$, $271,325,495,504-507,513,515,519$

Vision $36-37,170,202,246-250,255$, 261, 281-282, 359, 374, 383-384, 408, 514

War 37-38, 49, 51, 58, 89, 103, 116, $229,394,398-399,410,414-415$, 418-420, 422-423, 426, 430-431, 434, 437, 441-442, 445, 458, 508, 541, 553

West ix, xiii, 7, 62, 83, 168, 197, 199, $261,263,268,282,285,308-309,311$, 314, 318, 396-397, 402, 422, 528

Worldview $65,111,116,144,171,190$, 192, 205, 207, 241, 256, 498, 503, 515

Xicalango $381-382$

Xicolli 36-37, 170, 202, 246-250, 255, 261, 281-282, 359, 374, 383-384, 408, 514

Xipe Bundle xvi, 153, 254, 277, 364, 370, 375, 377, 383, 399, 436, 445, 553

Xipe $\quad x, x i v, x v i, 72-73,141,153,245$, 254, 260, 277, 280-281, 325-326, 364, $370,375,377,383,399,413,436,445$, 474, 553

Xochitepec 94, 336, 535

Yaa Yuta 261, 282, 308, 311, 396

Yahui ix, xiii, 32, 37, 48, 169, 298, 422, $433,449,473$

Yanhuitlan xiii, xix, xxii, xxiv, 7, 18, 31, $39,52-53,68,82,85,112,118,177$, $187,243,245,261,286,297-299,329$, $331,334,363,370,442,453-454,458$, $462-467,469,473,476,478,480-483$, $485,488,490-491,493-494,497,506$, $522,533,536,538,544,556$ 
Year bearer $\quad 27-28,112,447$

Yodzo Cahi 7, 39, 52-53, 68, 82, 243, $261,286,299,370,442,453,455,458-$ $459,462-463,469,471-473,480-481$, 483-485, 488-490 492-497, 506

Yodzo Coo 340, 431, 433

Yodzo Cuiya $\quad \mathrm{x}, 34,90-91,261,334$

Yodzo Yaha 89-91, 226

Yucu Cuii 300, 342-343

Yucu Dzaa xv, 8, 75-77, 167, 346-347, $375-376,385,390,406,458$

Yucu Ita 10, 331, 335, 414, 431, 446

Yucu Ita Ino 335

Yucu Iti 88, 316, 346, 404

Yucu Naa 91, 308-309

Yucu Nama 47, 55, 88, 399

Yucu Ndaa ix, xiii, 9, 11, 15, 31, 42, 52, 90, 167, 299-302, 329, 337, 343, 409, $458,462,490-492$

Yucu Ndaa Yee 90, 329, 337

Yucu Ndedzi 48, 50

Yucu Ndeq 297

Yucu Nindavua 91, 94, 140, 330, 336

Yucuñudahui 279-280, 298, 329, 353, 370, xii

Yucu Quimi 336, 422

Yucu Satuta xiv, 88, 121, 162, 312, 344$346,403,406,509,547$

Yucu Tiyuqh 323-324

Yucu Yoo 323-324, 327, 347

Yucu Yusi xiv, 90-91, 94, 141, 288, 330, 336-337, 406, 427
Yuhua Cuchi xiv, 334-335

Yuta Ndeyoho 350, 379

Yuta Nee 345

Yuta Tnoho 21, ix-xviii, xxi, xxvi, 22, $32,35-37,42,53,55-56,60,65-67$, 80, 94, 97, 105, 107-108, 113-114, 119-120, 122, 125, 127-128, 130-131, $142,147-149,154,156-157,169-170$, $174,193,195,228,237,248-250,257$, 259-262, 264-266, 272-276, 283284, 286, 288, 290-294, 296, 301-302, $306-311,313,315-317,320-322$, $327-328, \quad 330-332, \quad 334-343, \quad 348-$ $349,352,354,357-366,368-371,384$, $387,390,395-396,398,401,408,411$, $415,421,424,426,428-431,433,435$, $448,461,468,470,476,495,503,507-$ $508,512,536$

Yuvui tayu 10, 14-16, 219, 224, 232, 242-243, 363, 462, 496, 505, 515

Zaachila $\quad x$, xiv, xvi, 37, 72-73, 87, 141$142,144,260,319,324,326-327,375$, 377, 413-414, 426, 435-436, 438-441, $450-451,510,532,542-543,549,551$

Zacatepec $88,121,162,288,312,344-$ $345,403,406,509,538,547,550$

Zapotec $4,106,142,203,319,324,379$, $413,510,538,556,558-560$

Zapotitlan 90 